-THE.BOOK.OF.THE. A.NIIMAIKINGDOM
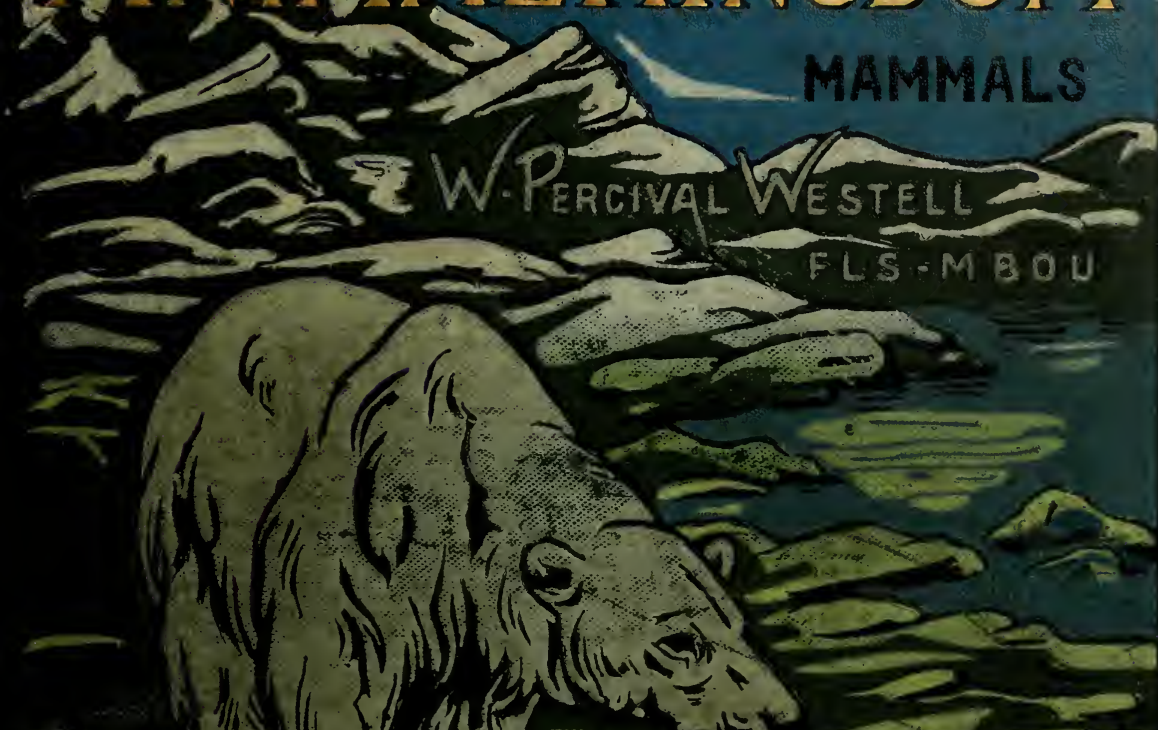
$\leq+1)(1,2=$

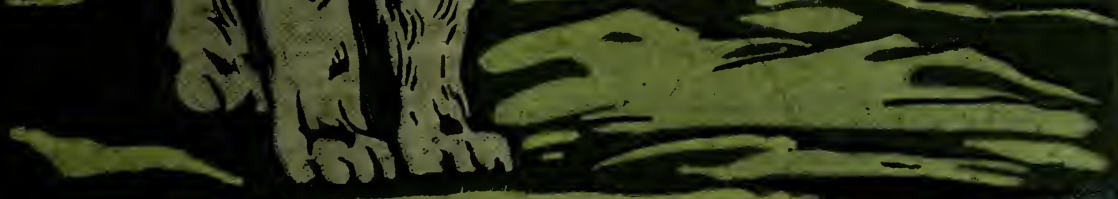




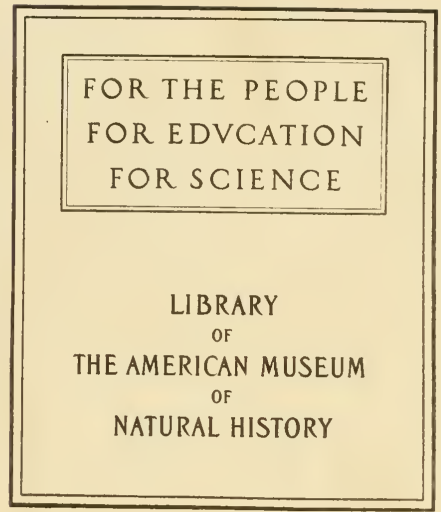





\section{THE BOOK \\ OF THE}

ANIMAL KINGDOM 
All rights reserved. 
n 
Plate 1.

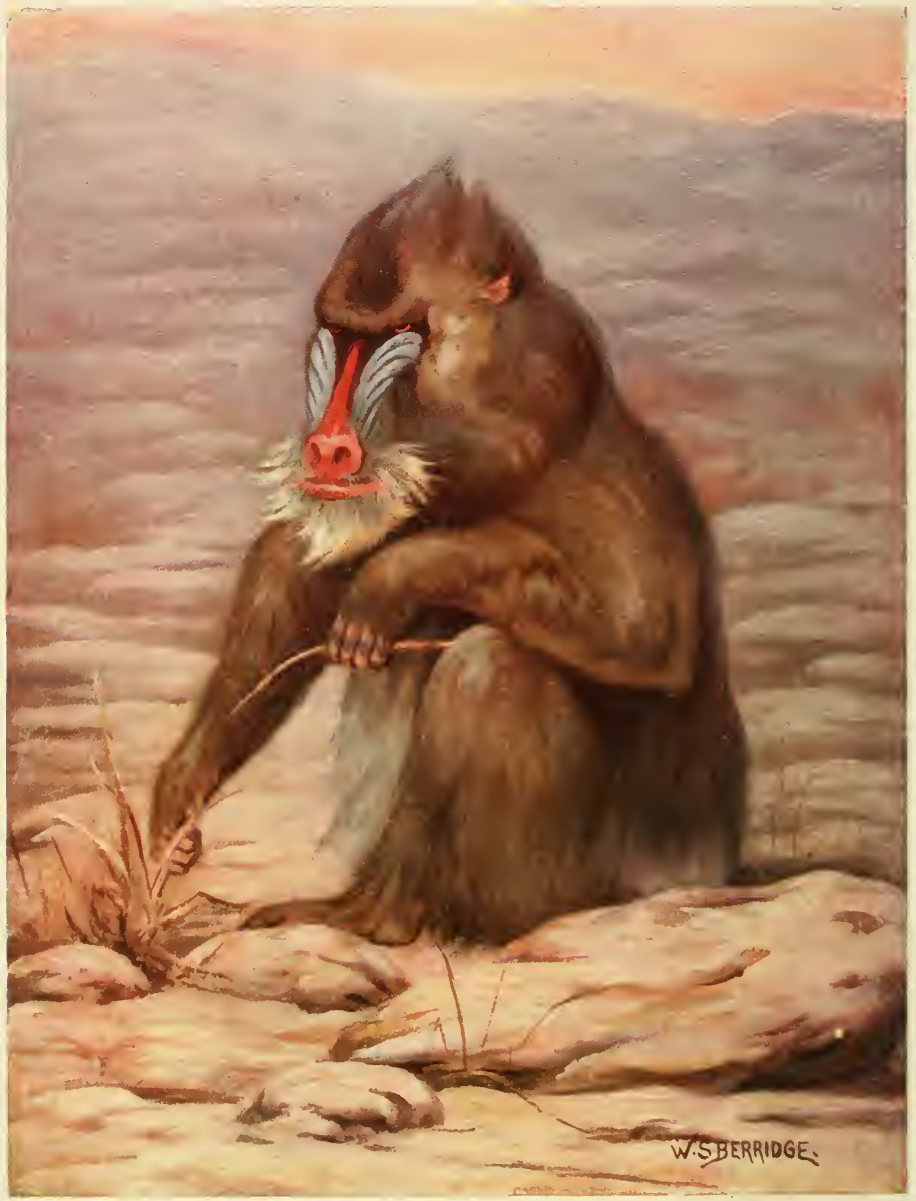

THE, MANDRILL. 


\section{THE BOOK \\ OF THE}

\section{A N I M A K I NGDOM}

MAMMALS

BY

W. PERCIVAL WESTELL F.L.S.

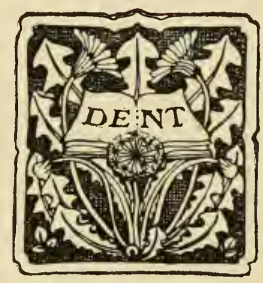

14 COLOURED \& 260 PLAIN PLATES

CHIEFLY FROM PHOTOGRAPHS

OF THE LIVING ANIMALS BY

W. S. BERRIDGE, F.Z.S.

LONDON: J. M. DENT \& SONS, LTD.

NEW YORK : E. P. DUTTON \& CO.

MCMX 
in in I

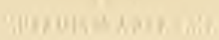

Richard Clay \& Sons, limited, DREAD STREET HILL, E.C., AND BUNGAY, SUFFOLK.

in AA An 3. MC de 8 


\section{PREFACE}

I HAVE endeavoured in this book to present a general survey of a large number of the mammals of the world, which will, it is hoped, aided by the comprehensive collection of coloured pictures and photographs, not only appeal to our young folks in the Homeland, the United States, and in Britain beyond the seas, but also to grown-up people who are desirous of acquiring a knowledge of animals without having to resort to bulky and expensive tomes. The story I have told in these pages is set out in a popular, and I hope understandable way, and whilst scientific accuracy has not been sacrificed, it has been my constant aim to eschew dry and uninviting definitions, and to attract all those who read this volume to the fascinating study of animal life. Each section deals more or less with a distinct set of mammals, but some amount of overlapping occurs which it was neither possible nor policy to obviate. Should my work meet with sufficient encouragement, it is intended to follow up this volume with a further one devoted to a careful selection of the Birds of the World whose animate forms and winning ways will make them peculiarly suited for inclusion in The Book of the Animal Kingdom.

I have several important acknowledgments to make. I am greatly indebted to Mr. Henry R. Knipe for permission to use six plates of Extinct Animals which appeared in his remarkable book, Nebula to Man, and to the Rev. H. N. Hutchinson for help accorded in identifying and titling some of the huge creatures of other days. For the loan of books I am under obligation to the Hon. Walter Rothschild, whilst for permission to include quotations from books published by them, I am indebted to Messrs. A. \& C. Black (Textbook of Zoology, by Dr. Otto Schmeil); Messrs. Macmillan \& Co., Ltd. (The Life of Animals, by Ernest Ingersoll ; A Hunter's Wanderings in Africa, by F. C. Selous, and Curiosities of Natural History, by 
Frank Buckland); Mr. John Grant (Thirteen Years Among the Wild Beasts of India, by G. P. Sanderson); Mr. H. Wingfield ("Allen's Naturalists' Library"), and Mr. Edward G. Fairholme, Secretary of the Royal Society for the Prevention of Cruelty to Animals, for permission to make extracts from various articles which appeared in The Animal World.

I also wish to acknowledge my indebtedness to the writings of Mr. Frank Finn, Dr. Henry O. Forbes, Mr. R. Lydekker, and Mr. Ernest Protheroe.

To Mr. C. S. Cooper, F.R.H.S., and Mr. W. S. Berridge, F.Z.S., I wish to convey grateful thanks for assistance in reading the proofs, and especially to Mr. Charles Barrett, M.A.O.U., of Melbourne, for his chapter on the Mammals of Australia, and to the Rev. Charles A. Hall of Paisley, who very kindly contributed the section entitled "Animals of Long Ago."

Lastly, to the intrepid big-game hunter, Mr. F. C. Selous, I am under an obligation for permission to make free use of the works written by him which have done so much to enrich our knowledge of the fauna of the great African Continent.

iV. Percival IVestell.

Letchworth, Hertfordshire,

England,

Autumn, Igro. 


\title{
CONTENTS
}

\author{
CHAPTER I \\ ANIMAL GIANTS
}

African and Indian Elephants-Hippopotamus-Rhinoceroses-GiraffePAGE

Dwarf Buffalo-American Bison-Eland-Wapiti Stag .

\section{CHAPTER II}

DOMESTIC AND SEMI-DOMESTIC ANIMALS

Domestic Asses-Domestic Sheep-Aurochs and Domestic Oxen-Gayal -Banting, or Javan Ox-Domesticated Rabbits-Cavies, or Guinea Pigs-Foster Parents-Ferret . . . . . . .

\section{CHAPTER III}

ANIMAL PETS, IN AND OUT OF DOORS

On Keeping Pets-Chimpanzee and Orang-Utan-Lemurs-KinkajouCoati-Marmosets-Suricate, or Meerkat-Mongoose-RaccoonAmerican and British Squirrels-Spix's Cavy-Carpincho-Common Seal-Dingo-Hare-Egyptian Jerboa . . . . .

\section{CHAPTER IV}

LOVERS OF THE CHASE AND SOME OTHERS

Wolf-Timber Wolf-Coyote, or Prairie Wolf-Black-Backed Jackal-Cape Hunting Dog-Dholes, or Indian and Siberian Wild Dogs-Brown Hyæna-Spotted Hyæna-Common Badger-Sand Badger . .

\section{CHAPTER V \\ SACRED ANIMALS}

Humped Cattle-Life History of the Ox-Hanuman Monkey-Fettered, Egyptian, or Caffre Cat vii 


\section{CHAPTER VI \\ ANIMALS WITH ARMOUR}

Hairy Armadillo-Giant Armadillo-Tatouay Armadillo-PichiciagoPangolin-Common Porcupine-Brush-Tailed Porcupine-Canadian Porcupine-Common Hedgehog-Tenrecs

CHAPTER VII

ANTELOPES AND DEER

Addax Antelope-Beatrix Antelope-Dik-Dik Antelope-Nagor Antelope Nilgai-Prong-Horned Antelope-Sable Antelope-Duikers-Marsh Bucks-Sing Sing Water Buck-Springbok-Brindled and WhiteTailed Gnus-Four-Horned Antelope-Indian Antelope-Red and Fallow Deer-Axis, Chital, or Spotted Deer-Barasingha-Eld's Deer -'Muntjac - Sika-Altai-Musk Deer-Red Brocket-Indian Chevrotain, or Mouse Deer . . . . . . . . 108

CHAPTER VIII

CATS-GREAT AND SMALL

Lion-Tiger-Leopard-Puma-Ocelot-Caracal-Northern Lynx-IVild Cat-Leopard Cat-Margay-Servaline Cat . . . . . 134

CHAPTER IX

MONKEYS, APES AND THEIR KINDRED

Mandrill - Gorilla - Chimpanzee - Orang-Utan - Hoolock Gibbon Vervet, Brazza's and Moustache Monkeys-Patas Monkey-RedEared and Schmidt's Monkeys-Roloway Monkey-MangabeysJapanese Macaque-Moor Macaque-Pig-Tailed Macaque-Other Macaques-Dusky Gelada Baboon-Guinea Baboon-Ibean Baboon -Variegated Spider Monkey-Black Lemur-Dwarf Lemurs-Grey Slow Loris-Slender Loris-Galagos and Mouse Lemurs-Douroucolis

\section{CHAPTER $\mathrm{X}$}

\section{MAMMALS OF AUSTRALIA}

Introduction-Dingo-Jerboa Rat-Kangaroos-Great Red KangarooGreat Grey Kangaroo-IVallaroo-Bridled Wallaby-Black-Gloved Vallaby-Pademelon Wallaby-Dama Wallaby-Tree KangaroosLumholtz's Tree Kangaroo-Bennett's Tree Kangaroo-Rat Kangaroos -Common Rat Kangaroo-Prehensile-Tailed Rat Kangaroo-BrushTailed Rat Kangaroo-Lesueur's Rat Kangaroo-Phalangers-Koala 
-Spotted Cuscus-Common Opossum-Short-Eared Opossum-

Ring-Tailed Opossum-Greater Flying Opossum-Yellow-Bellied Flying Opossum-Squirrel-Like Flying Opossum-Lesser Flying Opossum-Long-Snouted Opossum-Common Wombat-Tasmanian Wombat-Hairy-Nosed Wombat-Marsupial Mole-Brush-Tailed Pouched Mouse-Narrow-Footed Pouched Mice-Tasmanian TigerTasmanian Devil-Native Cats-Bandicoots-Monotremes-Platypus -Echidna

\section{CHAPTER XI}

RATS AND MICE

Brown Rat-Black Rat-Cane Rat-Dormouse-Canadian JumpingMouse-Jerboa, or Kangaroo Rat-Fat Mouse, and Fat-Tailed Desert Mouse-Spiny Mice

\section{CHAPTER XII \\ WILD SHEEP AND GOATS}

Urial, or Punjab Wild Sheep-Barbary Sheep-Burrhel Wild SheepHimalayan Goral - Tahr - Chamois - Rocky Mountain Goat Markhor-Himalayan Serow, or Goat-Antelope . . .

\section{CHAPTER XIII}

WILD PIGS

European Wild Pig, and Wild Pigs Generally-Indian Wild Pig-Other Wild Pigs-Babirusa-Wart Hogs-Giant Bush-Pig-Peccaries

\section{CHAPTER XIV}

\section{WOOL- AND FUR-BEARING ANIMALS}

Bactrian and Arabian Camels-Huanaco, or Guanaco-Vicuna-LlamaAlpaca-Polar Bear-Brown Bear-Japanese Bear-Malay BearSloth Bear-Common Red Fox-Arctic Fox-Fennec Fox-Indian Fox-Silver Fox-Coypu Rat-Chinchilla-Skunks-Marmots-Seals -Beaver-Otters

\section{CHAPTER XV}

\section{ZEBRAS AND ASSES}

Burchell's Zebra-Grévy's Zebra-Mountain Zebra-Quagga-Asiatic Wild Ass-African Wild Ass-Legends concerning the Domestic Donkey . 


\section{CHAPTER XVI}

RARE AND UNFAMILIAR ANIMALS

White-Headed Saki-White-Thighed Guereza-Sloths-Bhutan TakinDomestic Horses-Prejevalski's Wild Horse-Bontebok-BlessbokAard Wolf-Cape Ant Bear, or Aard Vark-Great Ant-Eater-Ratel, or Honey Badger - Brazilian Tapir - Malayan Tapir - Walrus Viscacha-Paca - Agutis - Crab-Eating Dog-Black-Footed Cat Civet Cat-Malaccan Civet, or Rasse-Pallas's Cat-Palm CivetsGenets-Cape Hyrax, or Klip-Das-Common Polecat-Zorilla, or Cape Polecat-Orkney Vole-Gerbils-Crab-Eating Opossum. .

\section{CHAPTER XVII}

\section{GIANTS OF THE DEEP}

Greenland Whale, and Whales in General-Pigmy Whale-Grey WhaleHumpback Whale-Fin-Whales, or Rorquals-Lesser Fin-WhaleEden's and Rudolphi's Fin-Whales-Common Fin-Whale, or Rorqual -Sibbald's Fin-Whale-Sperm Whale-Bottlenose Whale-Sowerby's Whale-Layard's Whale-Armux's Whale-Fresh-Water DolphinsNarwhal-White Whale, or Beluga-Common Porpoise-Indian Porpoise, and Others-Killer, or Grampus-Common Dolphin .

\section{CHAPTER XVIII}

MAMMALS OF THE AIR

Chief Features of Bats-Kalong-Vampire Bat-Long-Eared BatPipistrelle

\section{CHAPTER XIX \\ ANIMALS OF LONG AGO}

The Story of the Earth-The Four Great Epochs-Creatures of the Past -Plesiosaurs-Teleosaurus-Pterodactyle-Deinosaurs-Stegosaurus - Brontosaurus-Other Deinosaurs-The First Birds-Dodo-Moa - The Age of Mammals-Palæotherium-Animals of Eocene Days - Brontops-Evolution of the Horse-Sabre-Toothed Tiger-Giant Sloth, or Megatherium-Mylodon-Scelidotherium-ArmadillosAncestors of the Elephant-Mastodon-Mammoth-Conclusion 


\section{LIST OF ILLUSTRATIONS}

\section{COLOURED AND FULL-PAGE PLATES}

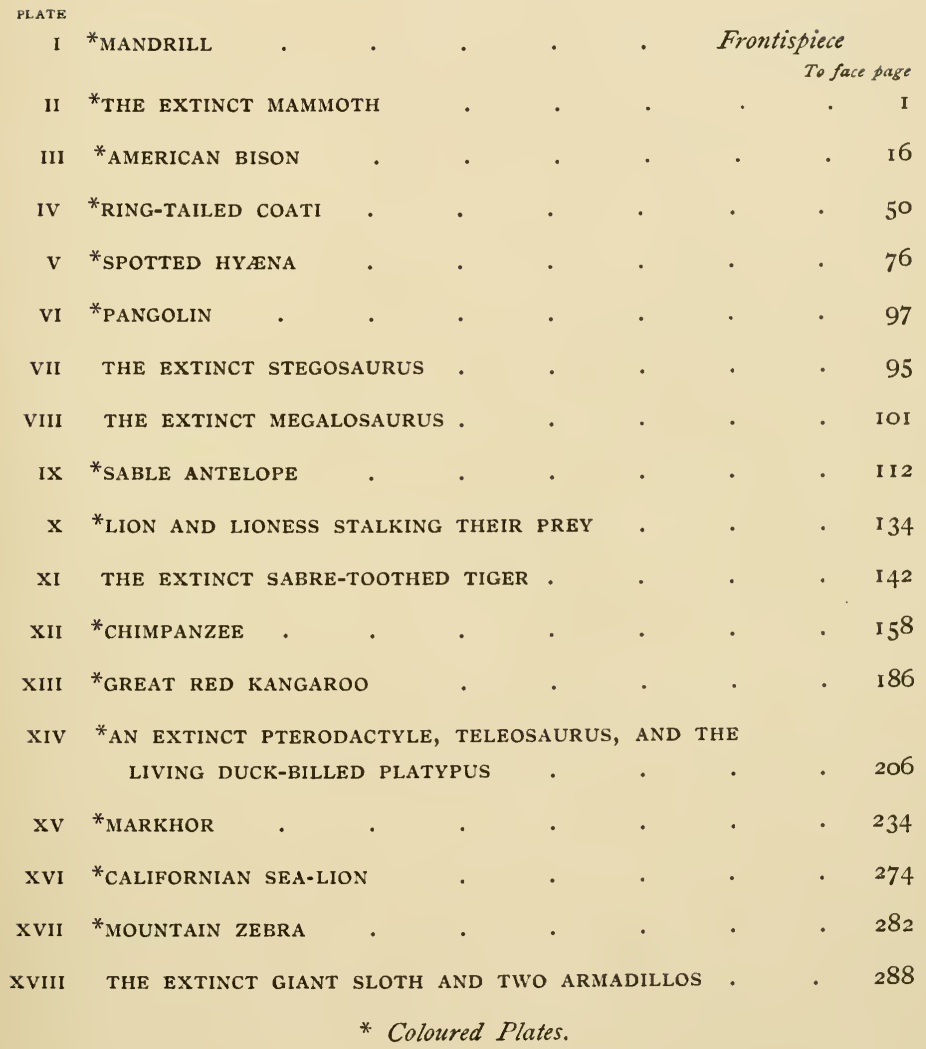




\section{PHOTOGRAPHS}

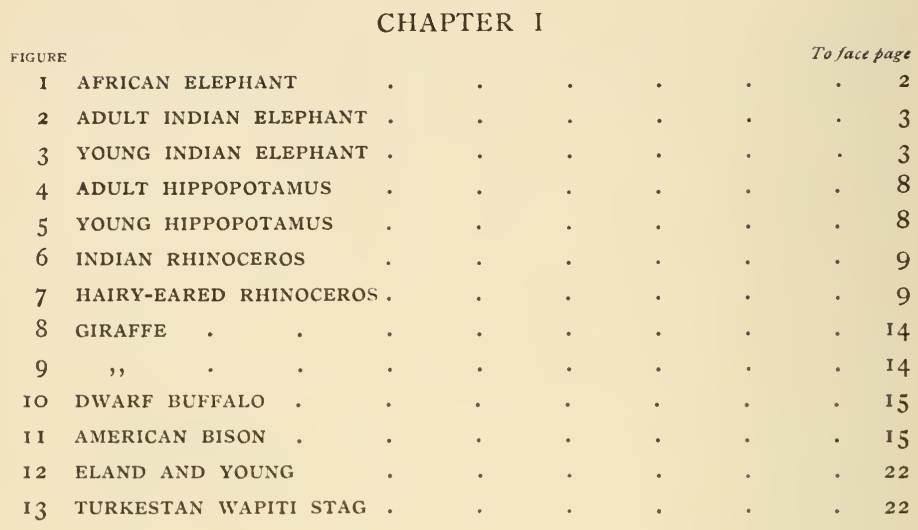

CHAPTER II

I4 SPANISH DOMESTIC ASS $4 \quad$. $\quad . \quad$. $\quad$. 23

I5 SPANISH AND ENGLISH DOMESTIC ASSES • . $\quad 23$

I6 HYBRID ZEBRA AND PONY . . . . . 26

17 HYBRID SOMALI AND DOMESTIC ASS . . . . 26

I8 HAUSSA SHEEP (RAM) . . . . . . . $\quad$. 27

$19 \quad, \quad$, (EWE AND LAMB) . . . . 27

20 HUNIA (FIGHTING RAM) . . . . . . 32

$2 \mathrm{I}$ ONE-HORNED INDIAN DOMESTIC SHEEP * * * 32

22 DUMBA SHEEP, OR FAT-RUMPED SHEEP • . . 33

23 ENGLISH WILD BULL

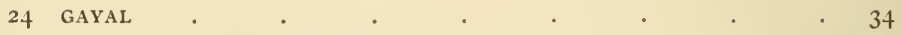

25 Gayal (VARILTY) . . . . . . . . . 34

26 JAVAN OX . . . . . . . . . 35

27 ENGLISH RABBIT . $\quad$. $\quad$. $\quad$. 35

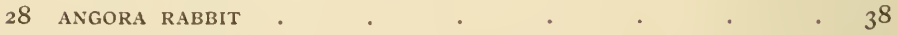

29 DUTCH RABBIT . $\quad$. $\quad . \quad$. $\quad . \quad 38$

30 SHORT-HAIRED GUINEA-PIG * . . . 39 
FIGURE

3 I LONG-HAIRED GUINEA-PIG .

32 CAT REARING SQUIRRELS.

42

33 YOUNG WOLVES AND FOSTER MOTHER

34 FERRET

CHAPTER III

35 CHIMPANZEE

36 ORANG-UTAN

37 RING-TAILED LEMUR

$3^{8}$ KINKajou .

39 KINKAJOU HANGING BY TAIL

40 RING-TAILED COATI

41 BLACK-EARED MARMOSET .

42 LION MARMOSET .

43 PINCHÉ MARMOSET .

44 SURICATE .

45 GREY INDIAN MONGOOSE

46 COMMON RACCOON .

47 AMERICAN GREY SQUIRREL

48 SPIX's CAVY

49 CARPINCHOS

50 COMMON SEAL

5 I DINGO PUPS

52 COMMON HARE

53 EGYPTIAN JERBOA .

\section{CHAPTER IV}

54 SIBERIAN WOLF

55 ALBINO SIBERIAN WOLF

56 TIMBER WOLF

57 PRAIRIE WOLF, OR COYOTE

58 BLACK-BACKED JACKAL

59 CAPE HUNTING DOG

6 INDIAN WILD DOGS

6 I SIBERIAN WILD DOG

62 BROWN HYENAS

$$
\begin{array}{ll}
\text {. } & 65 \\
. & 65 \\
. & 70 \\
. & 70 \\
. & 71 \\
. & 71 \\
. & 74 \\
. & 74 \\
. & 75
\end{array}
$$


FIGURR

63 COMMON BADGER.

\section{CHAPTER V}

65 HISSAR BULL

66 GUZERAT BULL

67 GYNEE CATTLE

68 MYSORE COW

69 CEYLONESE LANGUR

70 FETTERED, EGYPTIAN, OR CAFFRE CAT

80

CHAPTER VI

7 I HAIRY ARMADILLO.

72 TATOUAY ARMADILLO

73 CRESTED PORCUPINE

74 BRUSH-TAILED PORCUPINE .

75 CANADIAN PORCUPINE

76 COMMON HEDGEHOG

77 ,

78 ALGERIAN HEDGEHOG

79 COMMON TENREC .

CHAPTER VII

80 ADDAX ANTELOPE .

8I BEATRIX ANTELOPE

82 DIK-DIK ANTELOPE

83 NAGOR ANTELOPE .

84 NILGAI ANTELOPE .

$8_{5}$ PRONG-HORNED ANTELOPES

86 SABLE ANTELOPE .

87 ABISSINIAN DUIKER

88 CONGO MARSH BUCK

89 ,

(DOE AND YOUNG)

90 SING SING WATER BUCK

9 I SPIRINGBOK 
FIGURE

92 BRINDLED GNU

93 FOUR-HORNED ANTELOPE

94 INDIAN ANTELOPE .

95 RED DEER .

96 AXIS, CHITAL, OR SPOTTED DEER .

97 BARASINGHA, OR SWAMP DEER

98 PANOLIA, OR ELD'S DEER .

99 MUNTJAC, OR BARKING DEER (ALBINO)

IOO SIKA, OR JAPANESE DEER .

IOI ALTAI DEER (WITH FAWN).

102 MUSK DEER

IO3 RED BROCKET

IO4 INDIAN CHEVROTAIN, OR MOUSE DEER
To face page

- 117

- 117

- 124

- 124

- 124

- 125

- 125

- 125

- 130

I 30

- I3I

- I 31

- I 3 I

CHAPTER VIII

$$
\begin{aligned}
& \text { I } 3^{8} \\
& \text { I } 39 \\
& \text { I } 39 \\
& 143 \\
& \text { - } 143 \\
& \text {. } 144 \\
& \text {. } 144 \\
& \text { - } \mathbf{I} 44 \\
& \text { - } 145 \\
& \text { - } 145 \\
& \text { - } 145 \\
& \text { - } 152 \\
& \text { - } 152 \\
& \text { - }{ }^{1} 5^{2}
\end{aligned}
$$

CHAPTER IX

I I9 CHIMPANZEES AT PLAY

I 20 ORANG-UTAN

I 2 HOOLOCK GIBBON.

I 22 VERVET MONKEY 
FIGURE

To face page

I 23 BRAZZA'S MONKEY .

124 MOUSTACHE MONKEY

I 25 PATAS MONKEY

I 26 RED-EARED AND SCHMIDT'S MONKEYS

127 ROLOWAY MONKEY

I 28 HAMLYN'S MANGABEY

I 29 JAMRACH'S MANGABEY

I3O JAPANESE MACAQUES AND YOUNG .

I3I MOOR MACAQUE .

I32 PIG-TAILED MACAQUE

I 33 DUSKY GELADA BABOON

I 34 GUINEA BABOONS .

I35 IBEAN BABOONS .

I36 VARIEGATED SPIDER MONKEY

I 37 BLACK LEMURS (MALE AND FEMALE)

I $3^{8}$ DWARF LEMURS

I 39 GREY SLOW LORIS

I 4 O SLENDER LORIS

I 4 I MAHOLI GALAGO

I42 DOUROUCOLI

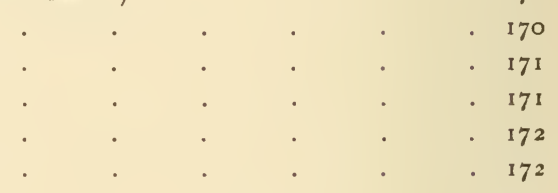

CHAPTER $\mathrm{X}$

I 43 DINGO

I 44 AUSTRALIAN DESERT JERBOA-RAT .

I45 GREAT RED KANGAROO .

146 GREAT GREY KANGAROO .

I 47 GREAT GREY KANGAROO (ALBINO).

148 GREAT WALLAROO.

149 BRIDLED WALLABY

I5O BLACK-GLOVED WALLABY

I 5 I URSINE TREE KANGAROOS .

I52 RUFOUS RAT KANGAROO.

I53 SPOTTED CUSCUS.

I54 A PET SHORT-EARED OPOSSUM

I55 RING-TAILED OPOSSUM

I 56 SQUIRREL-LIKE FLYING OPOSSUM

173

173

I 80

- 180

I 81

188

I 88

- 189

- 189

- 192

- 192

- 193

- 193

- 196 
YIGURE

To face page

I57 SHORT-HEADED FLYING OPOSSUM .

- 196

I 58 WOMBAT .

I 59 TASMANIAN WOLF, OR TIGER

I6O SKULL OF TASMANIAN WOLF

I6I TASMANIAN DEVIL . .

I62 DASYURE, OR NATIVE CAT OF AUSTRALIA

I63 RABBIT-EARED BANDICOOT.

164 PLATYPUS.

I65 ECHIDNA .

\section{CHAPTER XI}

I66 BLACK RAT

I67 TAME RAT .

I68 WHITE RAT

I69 CANE RAT

I7O DORMICE .

I I CANADIAN JUMPING MOUSE

172 FAT MOUSE

I73 FAT-TAILED DESERT MOUSE

I74 CAIRO SPINY MOUSE

I75 STRIPED MICE

I76 FANCY MICE

I77 URIAL, OR PUNJAB WILD SHEEP .

I 78 BLANFORD'S SHEEP

I79 BARBARY SHEEP .

I8O BURRHEL WILD SHEEP

I8I HIMALAYAN GORAL

I82 TAHR

I 83 LONG-TAILED GORAL

- 197

- 197

- 204

- 204

- 205

- 205

- 208

- 208

184 CHAMOIS.

I85 ROCKY MOUNTAIN GOAT

186 MARKHOR (MALE)

I87 , (FEMALE) WITH YOUNG

- 224

- 224

- 225

- 225

- 226

. 226

- 227

- 227

- 228

- 228

I 88 HIMALAYAN SEROW, OR GOAT-ANTELOPE

- 229

- ${ }^{2} 36$ 


\section{CHAPTER XIII}

FIGURE

I89 ALBANIAN, OR EUROPEAN, WILD PIG

I9O BABY INDIAN WILD PIG

236

I9I BABIRUSA .

237

192 WHITE-WHISKERED SWINE .

237

I93 EAST AFRICAN RIVER HOG

194 WART HOG

195 RED RIVER HOG

I96 COLLARED PECCARY

CHAPTER XIV

197 BACTRIAN CAMEL AND YOUNG

I 98 HUANACO, OR GUANACO

199 VICUNA

200 POLAR BEARS

201 ISABELLINE BEAR

$2 \mathrm{O} 2$ JAPANESE BEAR

203 MALAY BEAR

204 SLOTH BEAR

205 ARCTIC FOX IN WINTER COAT

206 FENNEC FOX

207 INDIAN FOX.

208 SILVER-BACKED FOX

209 VIRGINIAN FOX

210 COYPU RAT.

211 CHINCHILLA.

212 CANADIAN SKUNK

2 I 3 PRAIRIE MARMOT

214 ALPINE MARMOT

215 CALIFORNIAN SEA-LION

216 CANADIAN BEAVER.

2 I7 COMMON OTTER

218 BURCHELL'S ZEBRAS . 
22 I MOUNTAIN ZEBRA

222 KIANG

223 AFRICAN WILD ASS.

276

- 276

277

277

CHAPTER XVI

\begin{tabular}{|c|c|c|c|c|c|c|c|}
\hline 224 & WHITE-HEADED SAKI & - & - & $\cdot$ & - & · & - \\
\hline 225 & WHITE-THIGHED GUEREZA & $\cdot$ & - & . & - & - & - \\
\hline 226 & HOFFMANN'S SLOTH. & . & · & . & • & - & - \\
\hline 227 & BHUTAN TAKIN & • & - & $\cdot$ & • & · & - \\
\hline 228 & PREJEVALSKI'S WILD HORSE & & • & $\cdot$ & , & • & $\cdot$ \\
\hline 229 & BONTEBOKS & - & - & - & - & - & • \\
\hline 230 & AARD WOLF & $\cdot$ & $\cdot$ & $\cdot$ & - & • & - \\
\hline 231 & CAPE ANT BEAR, OR AARD & VARK & $\cdot$ & $\cdot$ & $\cdot$ & . & - \\
\hline $23^{2}$ & GREAT ANT-EATER & $\cdot$ & · & · & · & · & - \\
\hline 233 & RATEL, OR HONEY BADGER & & · & $\cdot$ & · & $\cdot$ & - \\
\hline 234 & BRAZILIAN TAPIR & $\cdot$ & · & • & $\cdot$ & • & - \\
\hline 235 & MALAYAN TAPIR & . & · & $\cdot$ & $\cdot$ & - & $\cdot$ \\
\hline 236 & WALRUS • & $\cdot$ & · & - & - & - & $\cdot$ \\
\hline 237 & VISCACHA & . & $\cdot$ & . & - & - & • \\
\hline $23^{8}$ & PACA & - & • & $\cdot$ & - & - & • \\
\hline 239 & WEST INDIAN AGUTI & $\cdot$ & $\cdot$ & - & • & · & . \\
\hline 240 & PUNCTATED AGUTI • & . & - & - & $\cdot$ & $\cdot$ & . \\
\hline 24 I & CRAB-EATING DOG . & - & $\cdot$ & · & - & - & - \\
\hline 242 & BLACK-FOOTED CAT & . & . & $\cdot$ & $\cdot$ & $\cdot$ & - \\
\hline 243 & CIVET CAT & · & - & $\cdot$ & . & - & - \\
\hline 244 & MALACCAN CIVET, OR RASSE & & . & - & - & - & . \\
\hline 245 & PALLAS'S CAT & - & • & · & - & · & . \\
\hline 246 & AFRICAN PALM CIVET & $\cdot$ & $\cdot$ & $\cdot$ & $\cdot$ & $\cdot$ & . \\
\hline 247 & RUSTY-SPOTTED GENET & - & $\cdot$ & - & - & - & • \\
\hline 248 & CAPE HYRAX, OR KLIP-DAS & & • & · & . & . & · \\
\hline 249 & COMMON POLECAT & $\cdot$ & - & $\cdot$ & • & - & · \\
\hline 250 & ZORILLA, OR CAPE POLECAT & & $\cdot$ & · & - & . & . \\
\hline $25^{I}$ & ORKNEY VOLE & · & - & • & • & • & · \\
\hline $25^{2}$ & CAPE GERBIL & • & • & - & · & . & s \\
\hline 253 & CRAB-EATING OPOSSUM & - & - & · & - & - & 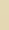 \\
\hline
\end{tabular}




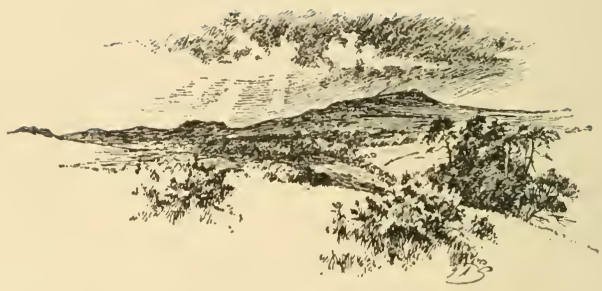





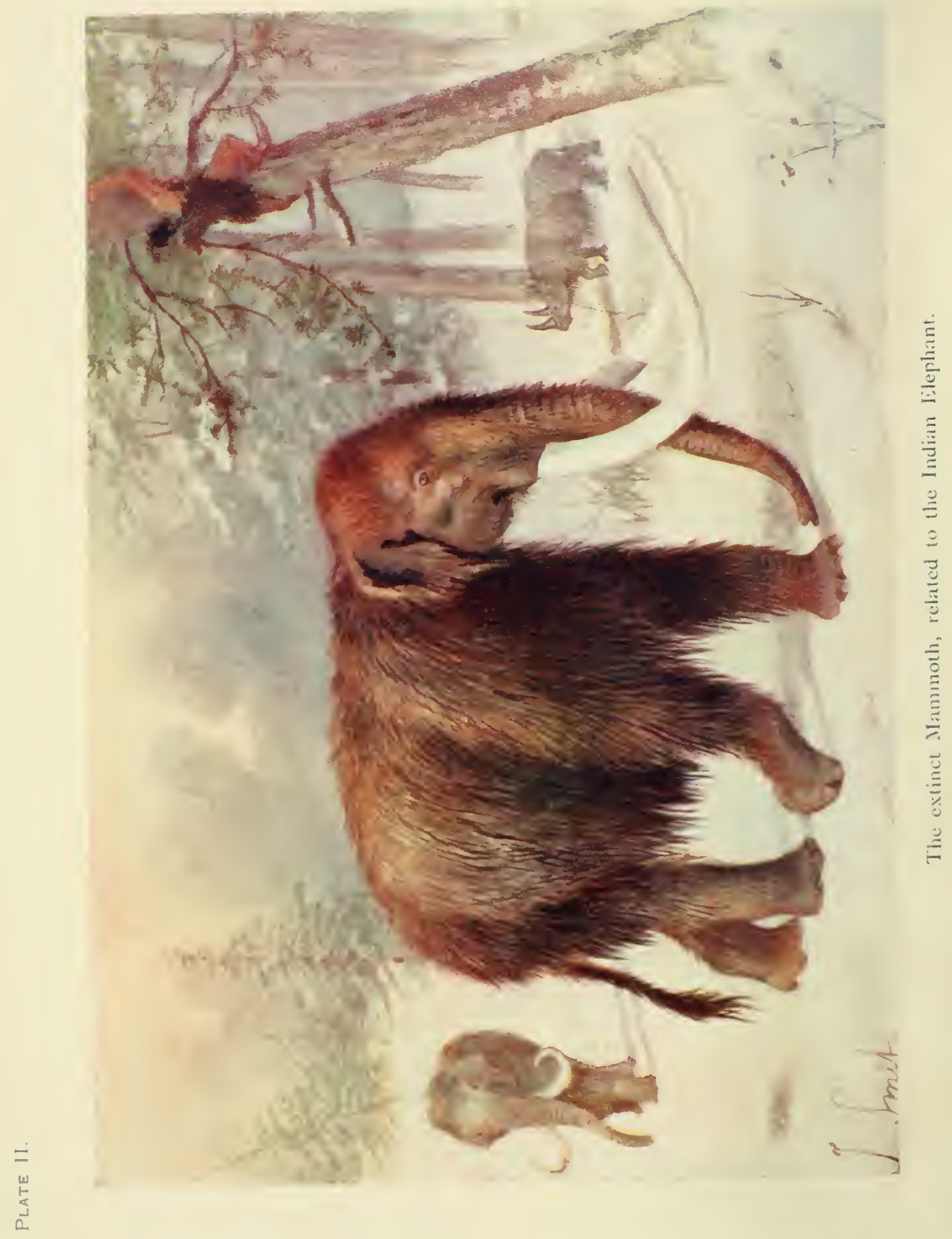




\section{THE BOOK OF}

\section{THE ANIMAL KINGDOM}

\section{CHAPTER I}

A N I M A G I A N T S

AFRICAN AND INDIAN ELEPHANTS.-In a survey of the animal kingdom mapped out according to the sections herein included it is particularly appropriate that pride of place should be accorded to the Elephant, that huge beast-the largest living animal of the world-of whom Pliny wrote, "We find in him qualities which are rare enough amongst men-honesty, prudence, equity." This, to say the least, is bestowing upon the Elephant lavish, but by no means ill-deserved, praise, for all those who have been brought into contact with the huge beast under review are aware of how, when it is kindly treated, it evinces considerable powers of intelligence, will obey orders, show much regard for its owner or keeper, and maintain in many ways the reputation which Pliny accorded to it.

It is not intended in this popular book devoted to a representative selection of the world's mammals, to introduce any long and dry scientific words, but it will be as well to point out here that the Ungulata, or hoofed animals, are split up by scientists into several sub-orders, to one of which, the Proboscidea, or proboscis bearers, the Elephant belongs.

Acquaintance will be made with many other representatives of this important order Ungulata as our study progresses, and for the present, therefore, it is sufficient to indicate the place occupied by the Elephant in the scale of animal life. 
It is pleasant to recognize, too, that it is not alone from the point of view of size that the huge monster under consideration should be given a foremost position among the mammalian members of the animal kingdom of whom such a number of pictorial representations are here given and whose life-histories are accorded attention.

Possessing, as the philosopher Pliny has well and truly said, at least three vastly important qualities which are worthy of imitation by human kind-honesty, prudence and equity-and an ancestry which is deserving of more than passing notice, the Elephant is a patriarch among animal folk upon whom much attention has been devoted right away from the $\operatorname{dim}$ and misty past until the present day.

To-day, when the mammalian fauna is in many instances becoming so scantily represented in several parts of the world, for reasons which at this juncture it is not necessary to dilate upon, it seems difficult to realize that the old-time ancestor of the Elephant was a huge Mammoth with a hairy coat, and large, curiously curved tusks, the points of which were turned towards each other instead of outward, as in many Elephants who roamed about in Siberia and other parts of Asia, as well as in England.

Tusks and teeth of this Mammoth are being frequently found, and in the Natural History Museum at South Kensington, London, there is exhibited a whole skull with enormous tusks, a curious epitaph of a past mammalian giant which was discovered in a brickfield at Ilford in Essex. Sir Ray Lankester gives this interesting information in his valuable work on Extinct Animals, and states that when a boy he used to obtain many remains of Mammoth, Rhinoceros and Hippopotamus from this same brick-field. This statement illustrates how important it is for the student of animals to pay attention to all parts of the country, for underneath the soilas well as upon it-wonderful secrets remain hidden which are only waiting to be revealed.

I have before now been in the company of a party of field naturalists who did not deem it expedient to explore the neighbourhood of a disused clay-pit. Who knows but that some hidden Mammoth lay below the surface? These and others might with advantage take note of Sir Ray Lankester's discovery in the brickfield to which allusion has been made, and profit accordingly.

Before passing on to a consideration of the life-history of the African and Indian Elephants, it should be stated that in the United 


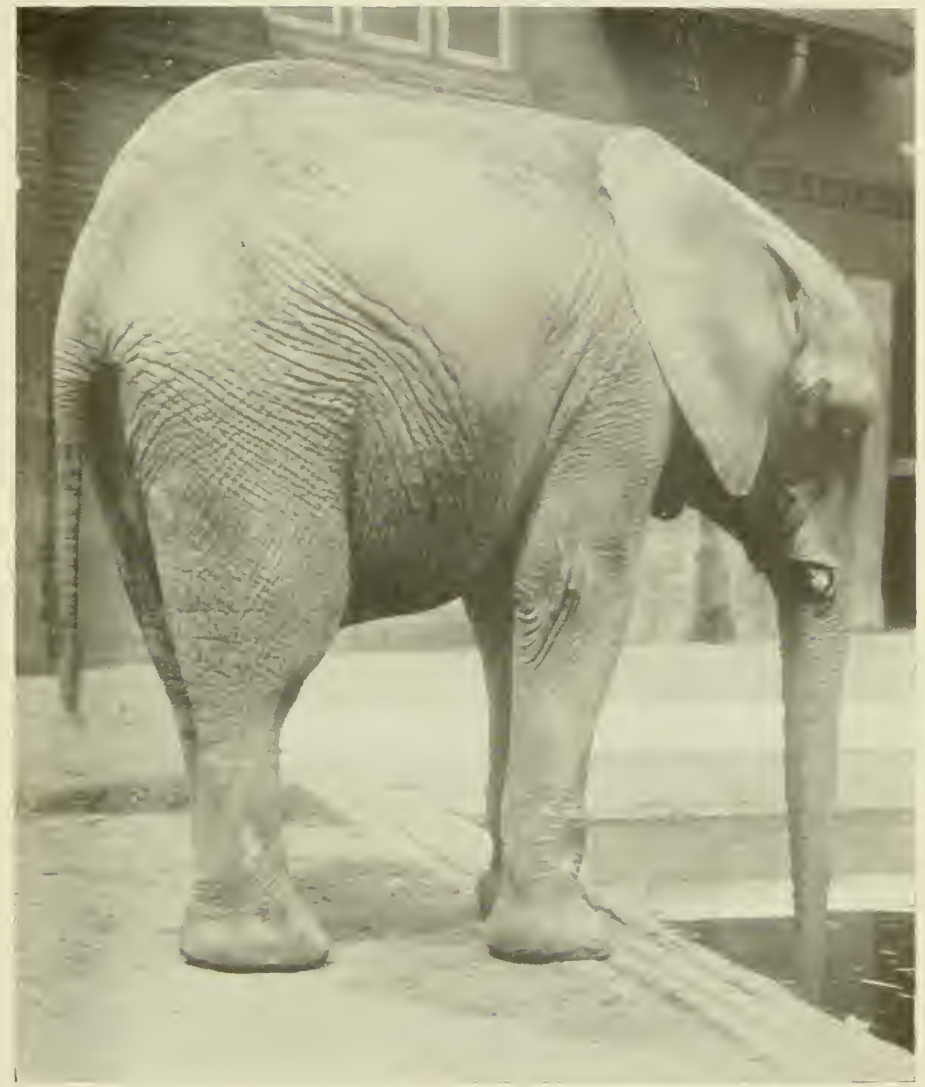

FIG. I. AFRICAN ELEPHANT 


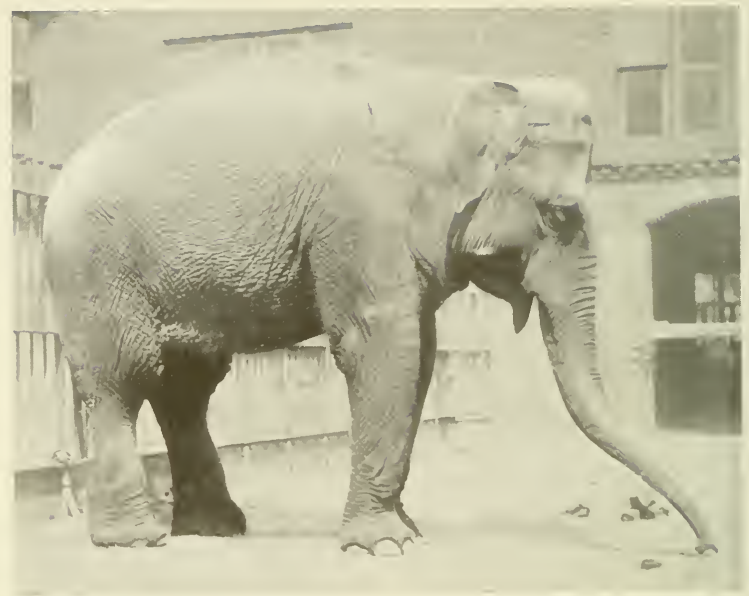

FIG. 2. ADELT INDIAN ELEPHANT

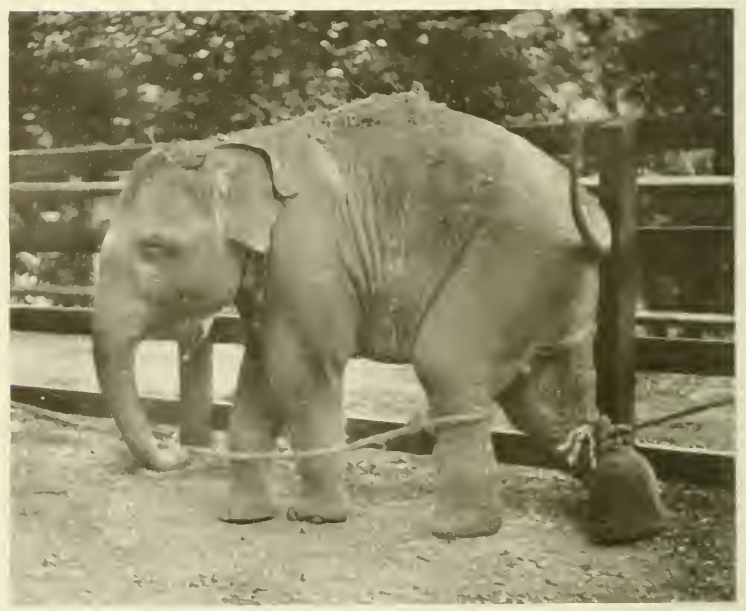

FIG. 3. TOL. INI ININ EIEPHA.T 
States remains have been discovered of a creature known as the American Mastodon. This animal was to all appearances very similar to the true Elephant, but careful examination of its remains reveals that its teeth were different, and the head and jaw were more elongated than in the present living animals.

Sir Ray Lankester states that in Ohio and other localities in the United States "very complete remains of this enormous creature have been found in bogs and morasses which are probably not more ancient than the peat-bogs of Ireland in which the great Irish Stag is found. Man was certainly contemporary with some of the American species of Mastodon. But in Europe no Mastodons survived to so late a period. Other and older species of Mastodon seem to have preceded the Elephants in Europe, Africa and Asia, and, in fact, to have been the ancestors from which Elephants were derived."

The Mammoth, it is interesting to note, more nearly resembled the Indian Elephant than the latter's African cousin, but its coarse hairy felt and tremendous tusks would distinguish it from either of the living animals of to-day. In size the Mammoth was somewhat larger than a big Indian Elephant, and that evidence of parentage is still forthcoming is shown by the fact that the new-born young of both the Asiatic and African Elephants have a complete covering of fairly long hair, but this coat is lost a few weeks after birth.

As will be seen by comparing the African Elephant (Fig. I) with the adult Indian Elephant (Fig. 2), the former possesses a more elongated head and much larger ears than the Indian species, the comparatively small ear and the high forehead of the latter being shown very distinctly in Fig. 2.

The ancestral history of Elephants tempts one to enlarge upon the fascinating story-a veritable romance of animal life-but in a popular book dealing with so many mammals of the world this is not possible, and the reader must be referred to the various exhaustive works on the subject if he is desirous of following up the story on his own account.

One need not watch even a captive Elephant very long without becoming convinced of the great use of the trunk, for by means of it the animal procures its living, and its importance is such that although the heavy and gigantic body and massive limbs cannot fail to attract notice, the chief part of the huge animal to which attention is directed is the proboscis. How wonderfully flexible and 
sensitive this important organ is; to what remarkable uses it is put. Without it eating and drinking would be difficult, and even if most of us have only been able to satisfy Jumbo's appetite by delivering a bun or a crust guaranteed to cause indigestion in a smaller animal, as the large beast has thrust its trunk over the bars of its den, or craftily on one side as a happy freight of children were being taken for a ride round the Zoological Gardens, our acquaintance has been intimate enough to realize that the animal places food in its mouth through the agency of the indispensable trunk, and when watching the animal taking up water and blowing it into the stomach through its living water-hose, it is evident that without the aid of the trunk in placing food in the mouth, great difficulty would be experienced when feeding.

Who, excepting those who study animals, would imagine that the well-known tusks-so valuable as articles of commerce-are simply two enormously developed teeth situate in the upper jaw?

The Elephant does not possess any canine teeth, and the incisors, as has been shown, are limited to two in the top jaw. Swainson says that "the more perfect quadrupeds have three sorts of teeth, termed incisors, canines and molars. .. The canines follow the incisors, and occupy an intermediate station between them and the molars; they are only employed in tearing or holding; hence they are chiefly confined to quadrupeds who live upon animal matter, and are wanting in the herbivorous ruminants, to whom, in fact, they are unnecessary." The molar teeth are of enormous size; there are twenty-four of these cheek teeth in all, six on either side of both upper and lower jaws. Never more than two of these teeth are in use at once.

Viewing the general form of the Elephant, the next important feature to recognize after the trunk, the pouchy skin and the enormous body, is the straightness of the massive legs. Pedestal-like and to all appearances jointless, they are admirably calculated to support the weight of the body, but those who have witnessed a troupe of performing elephants must have noticed how active the legs are, and that Shakespeare was woefully at fault when he believed that the animal possessed no joints in its legs and thus could not lie down! Although it does not come within the scope of this work to deal at length with performing animals, much information may be obtained by a careful watch being kept when one is attending such performances. Too many people perchance pay no 
heed to the animals themselves, restricting attention to the actual performance, but if intelligent observation be displayed one can gain some idea of the use of the limbs and the general structure of an animal thus exhibited.

I was recently watching a well-known troupe of performing Elephants, and although I am not desirous on this occasion of entering into the question of the rights or wrongs of the treatment meted out to these remarkable creatures before they are capable of going through such extraordinary evolutions, the fact remains that much time and patience must have been displayed in training the animals to such a high state of proficiency. When they are moving about in imitation of a dance, or sitting down, standing on a tub, lifting one or more legs, or even standing bolt upright on the head, the mobility of the limbs, in spite of the absence of angulation at the joints, is very marked.

Hunted very largely for the sake of its valuable ivory tusks, the Elephant-and the African species in particular-has disappeared from many of its former haunts, and in several districts is now as extinct as its venerable ancestors already mentioned earlier in this chapter.

When first captured great strategy has to be adopted in dealing with the animal under review, even though it may have celebrated only its first birthday, as in the case of the twelve-months-old baby shown in Fig. 3. This is a photograph of a young Indian Elephant belonging to King George $V$. When it stood for its portrait it had been roped because it had just arrived from India, and had only been out of its packing-case a few minutes.

How different the surroundings of the pure, unfettered wild from the dark recesses of the Elephant-house, and yet, on reflection, the huge beasts appear for the most part to take very kindly to their transported state, and evince remarkable traits most interesting to notice.

They have keen memories, and although they will after a time develop much regard for those responsible for their charge, they never forgive cruel treatment, and sooner or later, as many instances show, will have revenge in no uncertain manner.

Utilized by mankind in foreign climes for transport, sporting and other purposes, the Elephant is, as a result, sought after, not only for the valuable ivory tusks to be obtained from it, but for the help it may render in the living state. In time of both peace and 
war it has proved of inestimable service, and in districts where transport has been associated with almost impossible obstacles, this huge lord of the wild kingdom has been trained to come to the rescue. It is not a quickly-moving animal, but being endowed with tremendous staying powers, is a magnificent plodder, shuffling along for miles at a stretch without any apparent effort.

During the Roman era these beasts were chiefly used for sport, and we are told that the great Pompey on one occasion had as many as five hundred Lions and eighteen Elephants engaged in the arena at one time!

In those far-off days Elephants were found in plenty in Northern Africa, and so common were they that we learn the native tribes bordering upon Ethiopia used their tusks for doorposts and for palisades to enclose their corn-fields! Alas! how have the mighty fallen.

Beyond being serviceable as a beast of burden and for its valuable ivory tusks, there are other parts of the body that are utilized in various ways, for the tongue is said to be very good eating, the foot is converted into soup, the bones make good manure, the teeth are sawn into plates from which such articles as card-racks, knifehandles and paper-presses are manufactured, and celluloid owes part of its composition to ivory-dust.

Although reports are sometimes circulated as to vast Elephant herds that are still come across in the wild fastnesses, Mr. Selous and other experienced explorers relate that a company of four hundred is a very large one. He himself shot seventy-eight Elephants during his hunting trip in the years $1873^{-1} 875$, but even although he formed one of a party of four who shot twenty-one Elephants in a day, and once three of the same men killed nineteen out of a herd of twenty-one, Mr. Protheroe states that, "huge bags as these were, they could not compare with the feat accomplished by three Boers. Coming up with a troop of a hundred and four Elephants, they caused the animals to stampede into a marsh, where their heavy bodies became helplessly bogged. During the day every animal was slain, a piece of wanton destruction in which neither females nor calves were spared."

Small herds of from twenty to fifty individuals are the usual rule, and these huge beasts, in spite of their size, are evidently believers in the motto that "union is strength." They rarely attack unless a single ferocious individual has become ostracized from the rest of 
the herd, and if this happens to be a solitary bull it exhibits fierce and quarrelsome tactics which may prove the reverse of pleasant. These solitary animals, too, perpetrate a good deal of harm by trampling down crops during their protracted wanderings.

The smallness of its eye has doubtless attracted the reader's attention when standing before an Elephant, and in comparison with the animal's mammoth proportions the brain it possesses is also of small dimensions. Yet, as has been shown, the Elephant evinces considerable powers of intelligence when it comes under the influence of man, and this in spite of the fact that young animals are rarely captured.

Generally speaking, the African species exceeds in size its Asiatic relative, but in both kinds the male is the larger of the two sexes.

Dear old Jumbo, beloved by many both in England and America, was a huge African Elephant, and I well remember how he carried his happy juvenile passengers upon his broad back at the London Zoo. Young England parted regretfully with this favourite occupant of Regent's Park, but it is interesting to recall its memory and to remember that it weighed no less than six and a half tons . and measured eleven and a half feet in height.

These are long-lived beasts, and although it is difficult to accurately determine the life-span of a great many kinds of wild animals, careful records of those kept in confinement enable us to acquire some amount of useful information. Thus an Elephant has been known to live in captivity for over one hundred years, and it is reasonable to suppose that in a natural state, surrounded by all the regal splendour and virgin fastness of its forest home, the animal probably celebrates many more birthdays beyond the century before its life is brought to a close. But how and where does the forest monarch expire? Its body would of necessity attract attention, and yet we are told on unimpeachable authority that the remains of a dead Elephant are rarely met with even in its most favourite haunts!

This opens up the interesting question as to how and where many kinds of far commoner and better-known animals die, and why it is that we so seldom locale them. Do they betake themselves to some secluded spot and there pass away in solitude? Are their dead bodies then preyed upon by various carnivorous animals (including insects) and thus got rid of? The Burying Beetles, as we well know, are the grave-diggers of the insect world, for these persever- 


\section{THE BOOK OF THE ANIMAL KINGDOM}

ing creatures carefully inter the bodies of small animals, but the fact remains that, however much one may wander in a wood, along a lane, upon a common and elsewhere, it is rare to come across the body of a wild creature that has died a natural death.

Those who study Nature aright are, of course, aware of how remarkably well her sanitary inspectors do their work, and how admirable are her laws of cleanliness and sanitation, but, exceptions as there are to every rule, one would imagine that, during their country pilgrimages, the bodies of several wild animals would be located by field naturalists and others whose avocation takes them out of doors, and whose eyes have been trained to observe all kinds of natural phenomena.

Before leaving the subject of the Elephant's demise, and the age attained in a natural condition, it should be pointed out that, whether in India or Africa, the Elephant is found to be a lover of the forest. The largest land animal now roaming the face of the earth, it is a true denizen of the forest, and there finds a congenial home. The roots, twigs, leaves, young shoots and fruits of trees are greatly relished, as well as grass and other plants. By means of the trunk the leaves are stripped from the branches, and if some unforbidden fruit is beyond reach, and there is no tap-root to give stability, the forest monarch makes small work of uprooting the whole tree.

Both sexes of the African Elephant bear tusks, but those of the male are the finer of the two. In the Indian species, however, the tusks of the female rarely protrude beyond the jaws, and even among the males instances are frequently forthcoming of their not possessing tusks worthy of the name.

From one to nine or ten feet may be mentioned as the length of a tusk. The girth may be given as about twenty-four inches at the base, and the weight attains as much as $230 \mathrm{lb}$.

HIPPOPOTAMUS.-The second kind of animal giant that is entitled to occupy a foremost place in this section is the Hippopotamus.

This huge, and, when on land, somewhat ungainly monster always attracts considerable attention when on exhibition, and when England was far less sparsely populated than it is to-day the Hippopotamus roamed about in a wild state on the banks of the Thames. IVe have indeed lost several mammalian giants, and whilst to-day our largest living British mammal is the Badger, it is as well to 


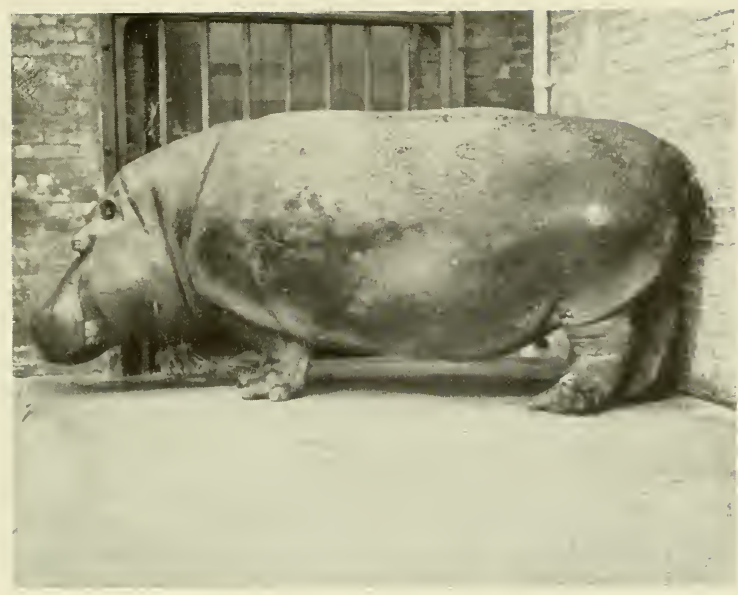

FIG. 4. ADULT HIPPOPOTAMUS

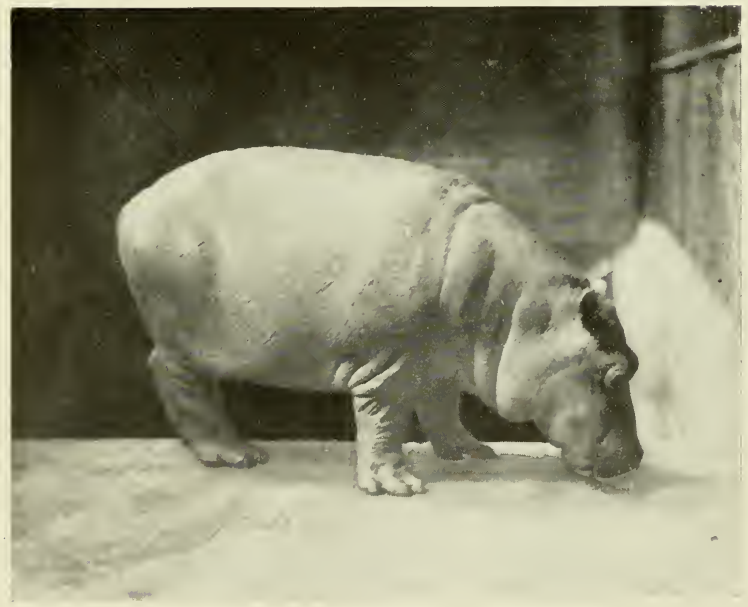

FIG. 5.-YOUNG HIPPOPOTAMUS 


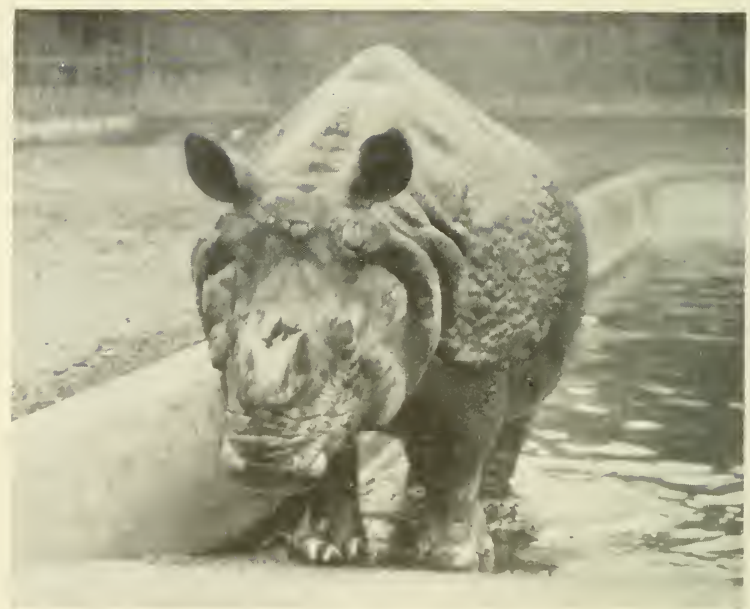

FIG. 6.-INDIAN RHINOCEROS

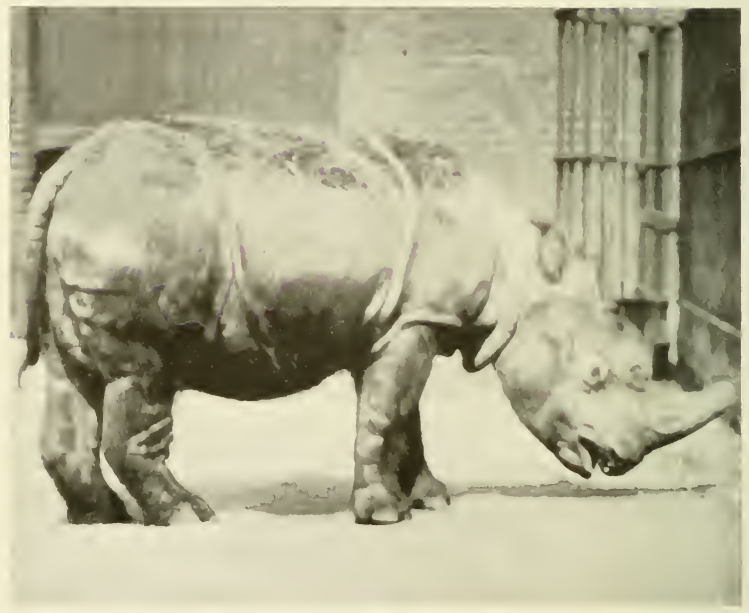

FIG. 7.-HAIRY-EARED RHINOCEROS 
remember that at one period in our remarkable history, the huge creature now under review occupied a place in the fauna of our country.

The particular specimen shown in Fig. 4 has died since its photograph was taken, and I handled its enormous skull at a soirée of the Selborne Society in 1909. An old favourite at the Zoo-it had been an inhabitant of the Gardens for over thirty-five yearsthere was a touch of remorse in handling the skull of a once living animal, whom it was always interesting to watch and feed. It is pleasant, however, to have one of the last photographs taken of our old friend, and his place is now occupied by a comparatively young Hippopotamus which, as Fig. 5 portrays, is making very rapid progress.

The baby shown has already become very tame, and quite recently I helped to appease her prodigious appetite by shovelling dead leaves into her capacious mouth! Still she clamoured for more, and in spite of a cargo of leaves, sugar, monkey-nuts and other tit-bits, she refused to close her mouth until she realized that her human friends were of opinion she had had a good meal and was sufficiently "full inside"!

There are two kinds of Hippopotamus known to science, one small and rare species hailing from West Africa, known as the Pigmy or Liberian, and the common and larger species coming from other parts of Africa, and particularly from the upper tributaries of the Nile.

Next to the Elephants, Hippos are the largest living terrestrial animals. They belong, however, to a different sub-order, claiming kinship with the even-toed Ungulates, and are not very distantly related to the Pigs.

The reader will, on first acquaintance, probably be attracted by the huge barrel-shaped body, large head and mouth, short and thick legs and small eyes. Although the latter are not of large dimensions, they project prominently from the forehead and thus aid the animal in locating anything, especially when lying almost immersed in water, the top part of the head alone being visible.

The Hippo seems for the most part to take life very soberly, and when walking down to its water-tank does not make any commotion or splashing, but approaches the water quietly and then slowly immerses its huge body. After a short time spent underneath-some two or three minutes is the usual limitation- 
the giant makes its appearance above water, the flat part of the head, and perhaps a portion of the broad shoulders, alone being projected.

At such time a good view may be obtained of the small rounded ears, and the closeness of the slit-like nostrils, which are placed high on the broad muzzle. This is an important point to recognize, because when the animal is in the water the nostrils may be raised above the surface for breathing purposes without more than a few

- inches of the head appearing above the level. This is, of course, of service to the animal in hiding its body, and so escaping detection.

So tame have these huge beasts become at the London Zoo that a gentleman of my acquaintance has made fast friends with these and many other animals, about which more will be said when we come to the chapter devoted to "Cats-Great and Small." They have learned to recognize his voice; they come towards him as a result of a welcome summons, for the temptation to be fed with a delicacy of some kind is more than they can resist.

Being vegetarian in its natural haunts, it is small wonder that the specimen I helped to feed not long since showed such a liking for leaves. In a wild state the animal grazes at nightfall, dozing during the daytime, or immersing its body in the water and remaining motionless. Where the water is sluggish, there this River Horse, or River Swine as the Egyptians called it, should be sought for, as when the water is fast running the animal must use all its wits to battle with the swift running current. In fact, being a lethargic creature during the day, the Hippo cannot bear its nap to be interfered with, and so chooses those waters where it may hope to rest without let or hindrance.

Where the monster is found it is still common to-day, and although specimens in Zoological Gardens may become friendly with those whom they learn to recognize, a ferocious, wild specimen is not a pleasant customer to deal with. Much damage is often perpetrated by the Hippos charging at boats and digging holes in the bottom by means of their strong tusks.

A new innovation at the time of writing is now in vogue at the London Zoo, namely, measurement tables have been placed near several of the animals, enabling the visitor to ascertain for himself the height or length of any inhabitant he may be watching. When taking note of one of the Hippopotami in Regent's Park recently, 
I noticed with interest that it was about four feet high at the shoulder. This height is exceeded in some instances, but five feet may be mentioned as the limit.

The species attains a length of from twelve to fourteen feet, and in weight is a close rival of the Elephant, turning the scale at as much as four tons. The hide, too, is very thick and heavy; indeed this alone will weigh five hundredweights when freshly taken off. It is dense and tough, as well as rough and warty. Close examination will show that it is almost naked with the exception of some short bristles near the end of the tail.

The male Hippo is dark brown, whilst his consort is of a yellowish colour.

As those who have fed this creature will know, the mouth is of large dimensions, and, says Mr. Selous, "the lower canine teeth or tusks grow to a great size, and in bulls may weigh from four to seven pounds each. They are curved in shape, and when extracted from the jaw form a complete half-circle, and have been known to measure upwards of thirty inches over the curve. In life, however, not more than a third of their length protrudes beyond the gums."

The lower incisors, as may be imagined, aid the creature in cutting, as with a scythe, various aquatic herbage upon which it feeds. The massive jaws are extremely powerful, and, aided by these and the formidable teeth, it is small wonder that the animal has been known to sever a man's body asunder at one stroke!

Although awkward on land, it can, if needs be, travel fairly fast for a restricted distance. The water, however, is undoubtedly its home, and there it swims with ease and facility and can walk on the bed of the river with comparative comfort.

The hide and tusks are both valuable, hence we find that this mammalian monarch is much sought after, and is often secured by the natives by means of a levered-trap and a poisoned spear which is heavily weighted. The natives find the spoor of the Hippo and then set their trap in his path, and sooner or later secure him.

In spite of his huge body we learn that this animal is not particularly tenacious of life, and-although it is cold-blooded slaughter hardly worth chronicling- "Mr. Neumann once killed four in four consecutive shots."

RHINOCEROSES. - There are two kinds of Rhinoceroses illustrated in Figs. 6 and 7, and these are easily distinguished one 


\section{THE BOOK OF THE ANIMAL KINGDOM}

from the other. The Indian species is a big, heavy animal which bears a thick plated coat of mail, and the Hairy-Eared species is much less distinguished in this way, and is a variety of the Sumatran Rhinoceros. In Mr. Walter Rothschild's well-known collection at Tring I have also seen the famous so-called "White" Rhinoceros, which is characterized by its square mouth. It is also known as the Mochuco, or Burchell's Rhinoceros.

This is a really magnificent specimen and was the first to reach England, the animal having been shot for Mr. Rothschild by Mr. Coryndon. In former days the species inhabited the South African steppes in great numbers, but it is now confined to British East Africa and the Eastern Soudan.

Whilst the Hippopotamus belongs to the even-toed Ungulates, the Rhinoceros owns alliance with the odd-toed set of Ungulates, having three digits on the fore and hind limbs, each ending in a strong hoof. The central digit is much longer and stronger than the remaining ones, and corresponds to the middle finger or third toe of Man, and to the well-known single digit of the Horse.

Four kinds of Rhinoceroses may be mentioned, namely, the three Asiatic species known as the Indian, Sumatran and Javan, and the African. The Indian and Javan species have only one horn, whereas the Sumatran and the Common African species have two, one situated behind the other.

The Asiatic Rhinoceroses are noted for their large erect ears, the massive folds of skin which give the body the appearance of armoured plates, and the horn, or horns, which, it is interesting to note, are composed of stout hairs firmly matted together.

As mentioned earlier in this chapter, fossil remains of these animals have been discovered in England, and, like the Hippopotamus already dealt with, in former days species of Rhinoceros were to be reckoned in our own fauna.

Hog-like, of sulky temperament, possessing a large body and small eyes, short, stout legs and a tremendous head, such, shortly stated, is a description of the animal giant with whom we are now concerned. As with the Hippo, it is during the silent nightwatches that it awakes from its lethargy, feeding upon vegetable food.

Although the skin is thick, and when dried becomes exceedingly hard, it is, nevertheless, very sensitive to the touch, and is not nearly so bullet-proof as some people might imagine. When dried 
and hardened, an excellent weapon of defence is provided, and the natives of India use it as a shield.

Although one might suppose that such an ungainly and slovenly creature would be slow of movement, the Rhino can, as a matter of fact, move very quickly, and requires a fast horse and an experienced hunter to overtake and capture it.

In swampy jungles, rank with vegetation, the Rhinoceros finds a congenial home. It loves to wallow in mud, and thus ease its body of insect parasites that tickle and annoy it. Amid the regal splendour of its jungle haunts the Rhino gives very little evidence of its presence, for a number of the beasts will use regular runs like our better known rodents, the Rabbit and Hare, and to stalk them successfully is not by any means an easy task.

Hunted like the Hippo for the sake of its hide and tusks, the African Black Rhinoceros was, says Mr. Ernest Protheroe, shot in thousands between the years 1840 and 1880 . He states that "two men bagged no less than fifty upon one occasion in a single excursion; Oswell and a companion captured eighty-nine in a season; and in the same short period sixty fell to C. J. Andersonn's gun alone."

Mr. F. C. Selous, the intrepid big-game hunter, who has given us so much first-hand information concerning different kinds of animals which those of us, less fortunate, perhaps, have only been able to study in Zoological Gardens, gives an interesting account in his Hunter's Wanderings in Africa of the capture of a Rhinoceros calf, and before passing on to the next animal giant on our list $\mathrm{Mr}$. Selous's graphic description of his encounter will be read with interest. He writes :-

"One morning Wood and myself, taking advantage of a few hours of clear weather, rode out to look for game, and after shooting a Roan Antelope bull were returning home, when, in a small patch of bush, we rode right on to a Black Rhinoceros, that we at once saluted with two bullets. As the wounded animal galloped off, we saw for the first time that it was followed by a small calf, which could not have been more than a day or two old, for it seemed unable to keep up with its mother, and upon our approach ran under the legs of Wood's horse, who, calling to me to go on and kill the cow, pulled in, in order to secure it. With another bullet I dispatched the cow accordingly, and returning to my friend, found him sitting under a shady tree, and the little Rhinoceros 


\section{I4 THE BOOK OF THE ANIMAL KINGDOM}

standing close beside his horse, which did not manifest the slightest alarm at the near proximity of the uncouth-looking and, no doubt to him, strangely-smelling little beast. The young Rhinoceros, too, that was scarcely larger than a half-grown pig, did not seem at all frightened when either Wood or myself, or any of the Kaffirs, approached it, but stood quite still when we went up to it and passed our hands down its back. It was, of course, too young to have any sign of horns, but two round patches on the nose showed where they would in time have grown; in other respects, with its prehensile lip, large ears, and little twinkling eyes, it was a perfect miniature of an adult Black Rhinoceros. One circumstance, I remember, that struck me at the time, was that it sweated most profusely all over the back, which I never remember to have seen an adult animal do. As we found that it followed Wood's horse as closely as if it had been its own mother, we determined to try and get it to the wagons, which were about six miles distant, and endeavour to rear it on thin gruel, for, unfortunately, we had no milch cows with us; so, leaving the Kaffirs to cut up the old cow, we rode home, the little Rhinoceros following us like a dog the whole way. The heat of the sun seemed to give it great inconvenience, for it halted and remained behind beneath every shady tree; but, as soon as the horse was about twenty yards ahead, it would twist up its little tail, give a squeal, and come trotting up alongside of it again. At last we reached the wagons, when of a sudden the nature of the hitherto quiet little beast seemed changed; whether it was the sight of the dogs, that came barking around it, or of the wagons, or the tout ensemble of sights and smells with which its eyes and nostrils were assailed, I know not, but it was now transformed into a perfect little demon, charging people, dogs, and even the wagon-wheel, with great fury. I now passed an ox-rein round its neck and behind one shoulder, when it rushed alternately to the length of its tether, springing from the ground in its fury, and then back again at me, when it would inflict several bumps on my knees with its nose. Its modus cperandi was to lower its head between its legs, and then, by throwing it up perpendicularly, strike several blows in quick succession with its nose. Small and weak as the poor little creature was, it still battered my knees with considerable violence. After being secured to the wagon-wheel it presently became quieter, though it still charged out to the full length of its tether at any dog 

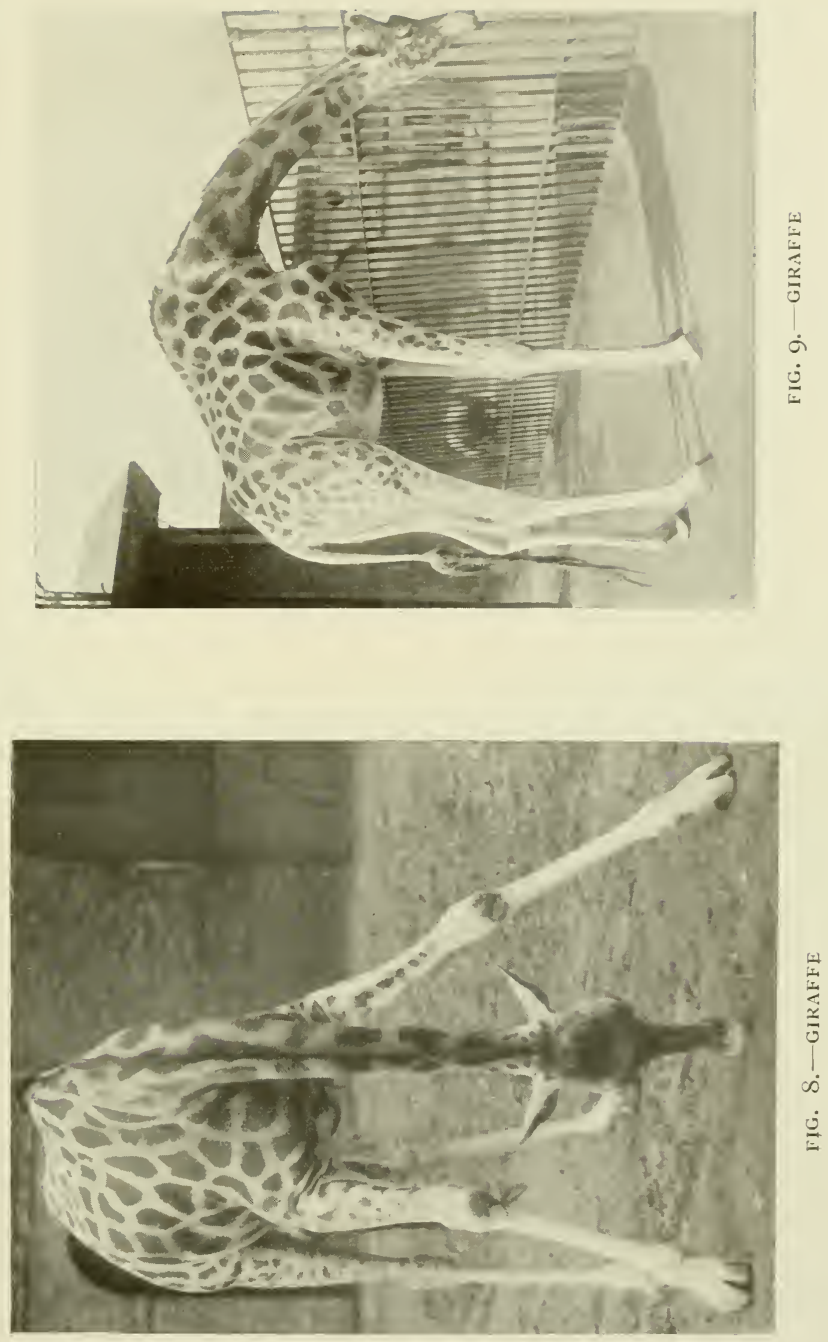


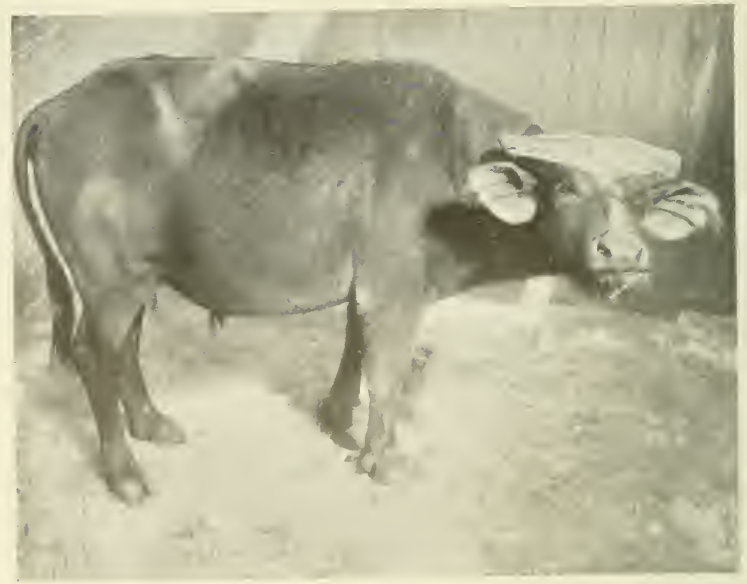

FIC. IO.- DIIARF BLFFIIO

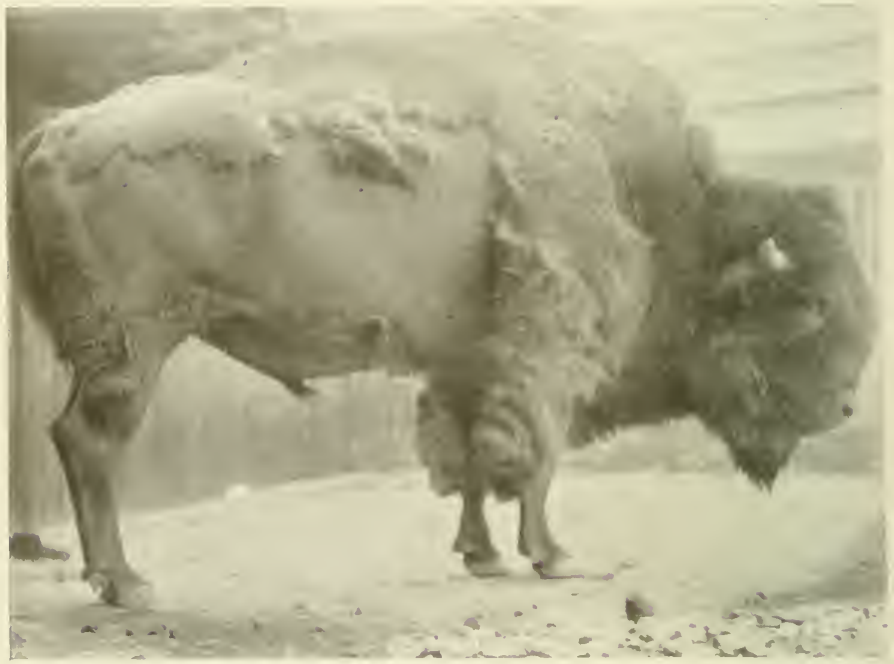

FIG. I I. M.MERICAN BISON 
or person that approached it. It, however, as I feared, obstinately refused all food, though I have no doubt it would have drunk milk had we had a cow with us; so, knowing that to let it run loose would be merely to condemn it to a lingering death from starvation, or an equally painful one by the fangs of Lions or Hyænas, I judged it most merciful to put a bullet through its head, which I did, though not without regret, for I should much have liked to rear it."

GIRAFFE. - If the animals we have met with so far are distinguished by their enormous bulk, the next species of giant with which we propose to make acquaintance, the Giraffe, is characterized by its long neck and legs, small head and body. It must be a fine sight to observe a herd of these beautiful African beasts in their native wilds, and it is not at all difficult to imagine the enthusiasm with which Mr. Selous writes of his first experience with them.

That first experience, however, nearly cost the big-game hunter his life, for, becoming separated from the rest of the party through an unfortunate collision with the trunk of a tree, and losing his horse, he was stranded upon the veldt without food or shelter. He tells how in Africa the burning heat of the day is succeeded by Arctic cold at night, and how vainly he tried to close his eyes as he lay upon a hastily-made bed of cut grass. Hungry, and perishing with cold, it must have been no joke to lie on the veldt homeless and alone, with the moon and the stars in the vault above, and prowling Hyænas passing close by and uttering cries that made night hideous.

Looking at the creatures shown in Figs. 8 and 9, one exhibiting a specimen at the Zoo with body raised and neck outstretched, and the other showing the beast straddling, one can faintly realize the charm of watching a small herd in the pure unfettered wilds.

They can travel at a remarkable speed, and it requires a good horse to overtake them. Their tails are twisted over their backs like corkscrews, and when seen from the rear, we are told, the animals appear to be gliding or sailing along without any apparent movement. Their mode of locomotion is a kind of gallop, for the hind legs are straddled out at each step, and come (one on either side) in front of the forelegs.

The dappled hide of the Giraffe will naturally attract notice, for the animal is beautifully marked and always appears wonderfully well groomed. It is, in many ways, one of the most striking 


\section{I6 THE BOOK OF THE ANIMAL KINGDOM}

of living creatures, and it was not until 1827 that the first specimen reached England alive. This only lived a few months, but others being imported later thrived amazingly, breeding freely, and so stocking the collection of the Zoological Society for some time. The last of the original stock succumbed in 1892 , and when the Soudan was closed to the outside world because of the rise of Mahdism, Zoological collectors found it difficult to secure several kinds of animals which the great African continent yields.

Eventually other specimens reached the Gardens mentioned, and there are to-day four fine examples to be seen there. This in itself shows the strides we have made since Pennant's time, for he observes that had he not seen a dried skin of the Camelopard, he should have been almost inclined to entertain doubts as to the existence of so extraordinary an ánimal!

That Giraffes are not such sweet-tempered creatures as some people who admire their pretty hide and attractive presentment imagine, may be ascertained by any one visiting the Giraffe house in Regent's Park, for a note in my diary reminds me of a plate that is to be seen on the wall there commemorating a charge made at his keeper by one of the beasts which, fortunately for the former, missed its mark!

This, the tallest of all known animals, strikes one as a strange mixture of parts, for, although the name Giraffe is a corruption of the Arabic zirafah, meaning "graceful," it has been recorded that "a careful study of its features will discover in the Giraffe a likeness to the Camel, the Ox, the Deer, the Antelope, the Goat and the Ostrich"!

There are two distinct species recognized, one being found in the North and the other in the South of Africa, whilst numerous varieties are known to occur which have been accorded much attention by reason of the colouring varying so much in animals procured from different localities. The male attains a height of nineteen or twenty feet, but the female is shorter. The long thin legs; long, but strong neck; the deception in the length of the front and hind legs by reason of the greater elevation of the withers; the remarkably well-poised head, narrow muzzle, and long tongue; the large, pointed ears, and prominent eyes which give a wide range of vision, are all distinguishing features worthy of note when taking stock of the animal giant now under review.

Whilst the species inhabiting Northern Africa possesses, as a 
Plate ili.

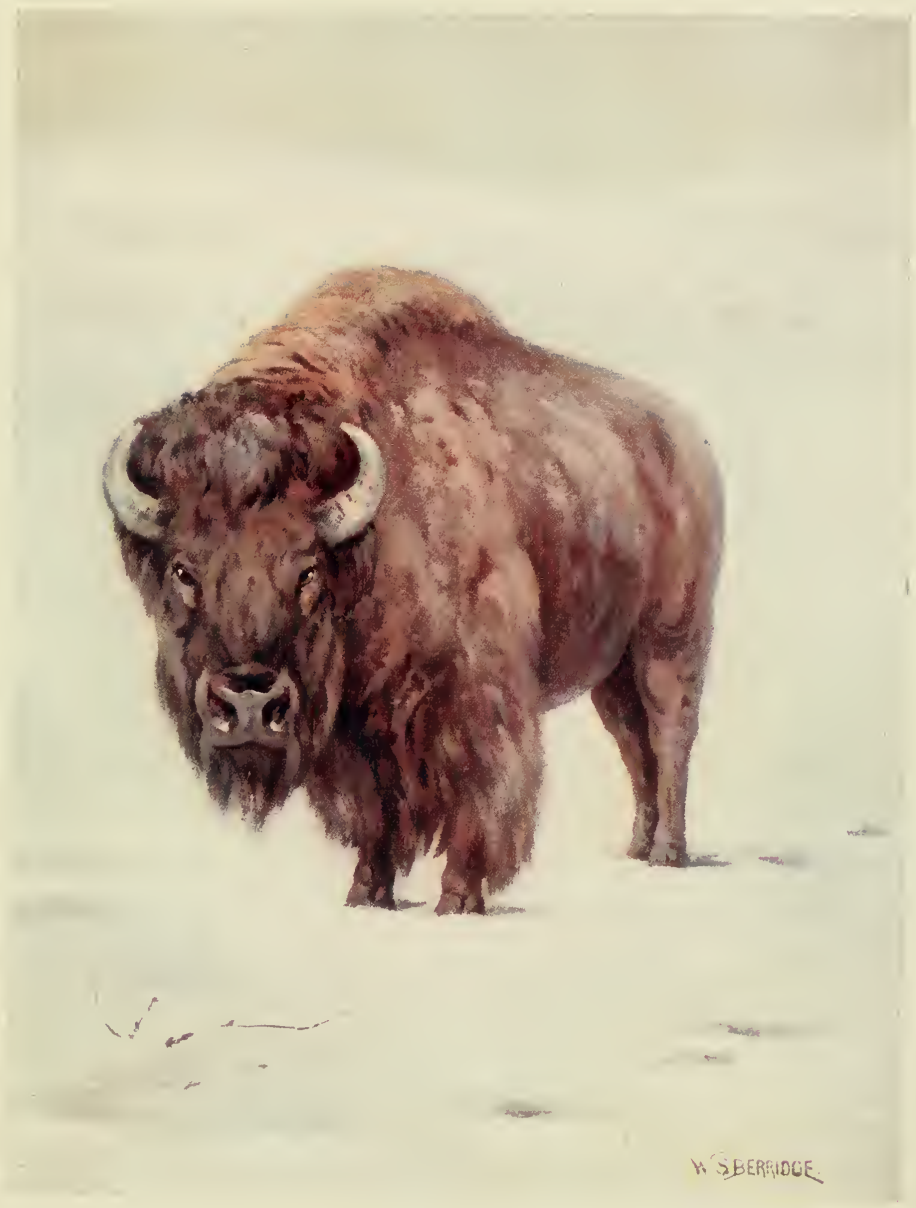

AMERICAN BISON. 

rule, three horns, the Southern species has a pair only. Both male and female bear these so-called horns, for, unlike horns possessed by other animals, those of the Giraffe are only bony excrescences tipped with a tuft of black hair and do not, as one might suppose, acquire the proportions of the appendages borne by other hornbearing beasts.

The great length of neck permits the Giraffe to reach the succulent leaves of trees, and the long and prehensile upper lip and long tongue greatly assist in the feeding process.

In the dry regions of the arid desert, where this fine tall giant makes its home, water is at a discount, and hence it comes about that the Giraffe must perforce go without it for a great length of time. Having located a welcome oasis in the desert, some such attitude as that shown in Fig. 9 has to be adopted before the animal can satisfy its thirst. The creamy-fawn ground-colour of the South African species is marked with patches of lemon-fawn to brownishblack of various sizes, whilst the Northern kind is generally light reddish-chestnut, marked with tawny lines which are extremely regular in design.

Although this interesting creature is not nearly so plentiful to-day as in the by-gone, and those who would pursue it must go into the wilds of Africa where civilization has not yet penetrated, there is no immediate cause for alarm concerning its numbers. The discovery by Sir Harry Johnstone a few years ago of that remarkable animal, the Okapi, supplied a sort of connecting-link between the Giraffe and the Antelope, and goes to prove that secrets are yet to be discovered in the great African continent which has thus far proved so abundantly rich in faunal life.

DWARF BUFFAL0. - This fine animal belongs to a dwarf race of the African Buffalo, and, as Fig. io shows, it possesses horns which are more like a heavy two-sided crown, or two large plates. These horns almost meet in the middle of the forehead (having the appearance of being fused together), and so low do they lie that the large ears when brought forward only just steer clear of the lower part of the heavy appendages mentioned.

It is a strong, powerful-looking Buffalo and claims relationship with the Oxen.

The Cape Buffalo is a formidable beast, and this is heightened by the horny helmet with which the head is adorned, and which in the bull is flattened out in the manner shown in Fig. Io. 
A dangerous beast to encounter in its native wilds (the Lion is a veritable coward when compared with it), the intrepid hunter has to exhibit considerable pluck, coolness and daring in successfully withstanding the fierce onslaught of a Cape Buffalo, more especially if a wounded animal is being dealt with. The beast can charge with no uncertain aim, and is, of course, largely aided by the strong horns with which it is supplied.

Bold, fearless, courageous, we see here a wild monarch which many a hunter has just cause to remember, and although Mr. Selous has related many instances of almost certain death from starvation, fever and the attacks of wild animals, he never came nearer to being launched into eternity than when he came face to face with a ferocious bull of this species.

It is stated that two powerful Lions are required to pull down an adult male, and at night the cows resort to the method of "Union is strength," and contrive between them to ward off the attacks of night prowlers, and so shield their calves.

In an analysis of game shot by Mr. Selous in Africa in the years $1877-1880$, one hundred head of Buffaloes are included, and, excluding 304 various kinds of Antelopes shot in the same period and under the same auspices, the list given in A Hunter's Wanderings is as under-

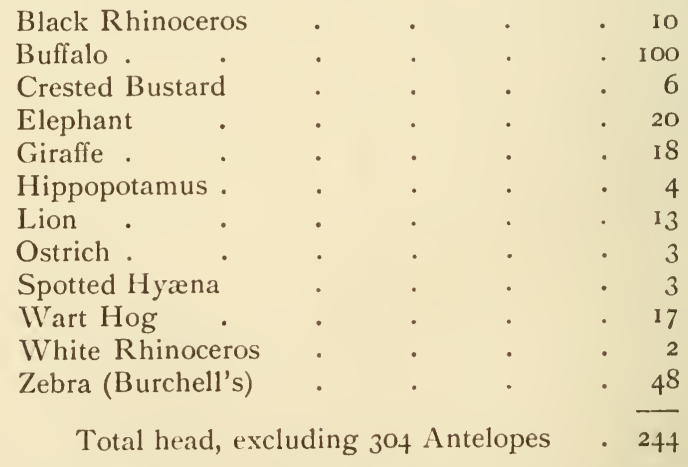

These figures will, in a way, give some idea of the animals encountered and their comparative distribution, but it is only fair to state, in view of Mr. Selous's own words, that "some people may consider it a dreadful record of slaughter," the figures given do not 
represent all the game that might have been obtained, and it must be borne in mind that upon his expedition various animals had of recessity to be procured for the purposes of both food and barter.

AMERICAN BISON. - It seems difficult to imagine that a fine, noble animal such as this, which only a few years ago was to be counted in vast herds consisting of millions of individuals, is, as a pure wild beast of to-day, reduced to comparatively small numbers.

That it has not been totally abolished from the face of the habitable globe is due to the praiseworthy efforts made by both the American and Canadian Governments, and although in confinement the Bison is ill-tempered and ferocious-and the bull shown in Fig. I I particularly so-it is far too interesting an animal to be swept from the world without, so to speak, any warning.

The year I 867 seems to have been the time when this, the largest of the North American hoofed animals, became doomed, for the immense herd that roamed the prairies at the date named was cut in two by the construction of the first trans-continental railway line. This having been done, it only took a few years to exterminate the two portions of the original herd, for in I 884 the deed was practically accomplished. Whilst there are said to be a few survivors in a wild condition to-day, there is little doubt that but for timely Government assistance the American Bison would have been lost to us ere this. This would have been more regretable in view of the fact that its European brother is also very rare, being now confined to the preserved forests of Lithuania and in the Caucasus.

Covered with a thick, warm coat of shaggy hair, which is well shown in the coloured plate of this fine beast, the Bison is in many respects a remarkable giant of the animal kingdom, but our photograph depicts the bull with his winter coat peeling off, and giving him somewhat the appearance of a large French poodle!

More bulky and formidable than the European species, our American friend has a more prominent head, and its coat is longer, being composed of much shaggier hair. When the thick covering is shed, as partly shown in Fig. I I, the Bison does not look nearly so big nor so bulky as when he possesses his full coat. At such time he is indeed a noble creature, possessing, as has been well said, "a grandeur and nobility of presence which are beyond all comparison among ruminants."

For all that, the keeper of the cow, bull and calf now housed at the London Zoo told me recently that he would not trust himself C 2 
in the yard with them, and from what I saw of the damage done to one of the fences by the animals charging, I can well imagine why the keeper is not anxious to become on too intimate terms of acquaintance with his formidable captives. In days gone by, when the prairies of North America were literally blackened with the huge herds of these monarchs of the wild, the Bison was much sought after by the Red Indians. They found it an extremely useful animal, as it provided them with food, clothing, covering for so-called houses, weapons of defence, and other articles. It appears, too, that man was not alone to blame in the vast toll taken from these animal hordes of the by-gone, for when a troupe of Bisons stampeded they became frenzied with rage and excitement. So much so, indeed, that, with huge heads lowered and tails whisked in the air, they would rush madly on, apparently caring little what became of them. Thus many an animal perished by tumbling headlong into some abyss from which there was no return, and even trampling one another underfoot in the mad scamper of retreat.

It is hardly possible to conjecture what a spectacle such a gathering of these noble animal giants must have presented. It is no idle fairy-tale to write of them as literally blackening the environs they frequented, as it is only about forty years ago that a train "on the Kansas Pacific Railway passed through a herd for a distance of over a hundred miles"! The white man, too, has helped in the work of destruction, as now, when it is almost too late, he is doing his best to save the mere remnant remaining.

In its gregariousness and its immense numbers, the American Bison must assuredly be considered one of the most remarkable animals of the world-living or dead-and in its almost total extinction from its former haunts we have an apt illustration of how soon the work of destruction may be carried out when once begun in real earnest, and the rapid annihilation of this creature will certainly be handed down to posterity as one of the most extraordinary animal episodes of the nineteenth century.

ELAND. - But, we may well ask, what are we doing of real practical service to-day to save many other creatures from extermination? If we leave the great American continent and betake ourselves to Africa, whither we have already in our pilgrimages been in quest of some monster we have set out to survey, somewhat the same harrowing tale must perforce be told. Let us take the case of the Eland, of whom we have examples in Fig. I2. 
This really magnificent creature is the largest of all the Antelopes. It is now practically extinct in Cape Colony, and owing to civilization penetrating elsewhere into the great African continent, it is safe to assert that the day is not far distant when, as a wild animal, the Eland will be no more. And this is to be regretted all the more because if it had been domesticated by man there is every likelihood that it would have been spared to us for generations to come.

Attempts have, it is true, been made to acclimatize it in England, but it is a thousand pities that some preserves have not been mapped out in its own native land where it would have remained in safe keeping. The tender flesh being in days gone by highly esteemed for food has, as a natural consequence, helped very largely to reduce its numbers, whilst the skin is valuable in many ways.

A good specimen will weigh from $\mathrm{I}, 500$ to $2,000 \mathrm{lb}$, , and attain a height of nineteen hands at the withers, and a length of nine feet. The young one shown in the photograph was only four days old when it stood for its picture, but the adult is distinguished by the strong twisted horns and a dewlap which bears a fringe of black hair like the mane. There are two varieties of Elands in Africa, which vary in colour. The species in Central Africa is pale fawn, whilst the species in the South is bright yellow tan. The thinness of the hair, however, often gives the old bulls a bluish cast.

Elands are found in dry, sandy, and yet thickly wooded country, and that they sometimes associate with other inhabitants of the wilds is shown by Mr. Selous entering in his diary a note to the effect that he saw on one occasion a large herd of Zebras, headed by two fine Elands, standing in the open flat. The bull, according to the same observer, is, when encountered in a wild state, a grand-looking beast, "with his heavy though shapely body, low-hanging dewlap, fine, clean-cut limbs and small, game-looking head. He is one of those stately creatures that few reflecting men can slay without regret, and fewer still, I hope, would kill for sport alone, leaving the carcase to rot in the wilderness or fatten the Wolves ${ }^{1}$ and Vultures; but, at the same time, it is as necessary for the hunter, upon whose rifle, perhaps, a score of hungry savages are dependent for food from day to day, to shoot many beautiful and harmless animals, as it is for a butcher in a civilized land to poleaxe an Ox."

WAPITI STAG. - The Turkestan Wapiti Stag is the Asiatic

1 Doubtless Mr. Selous here refers to the Jackals, no true species of Wolves being found in Africa.-W. P. W. 
representative of the handsome Wapiti of North America, and visitors to the Zoological Gardens in London have an opportunity of comparing the two animals, and thus ascertaining for themselves how difficult it is to separate them. On my last visit to the Zoo I very carefully examined both kinds of Deer, and the only external distinguishing features that I considered worthy of note were the darker collar, broad muzzle and fine Roman nose of the Turkestan Wapiti. He, poor old chap, was at the time of my visit in a sad state, evidently being in a decline, and quickly qualifying as an inmate of the newly-erected dead-house hard by his den.

One hears some very funny remarks at the Zoo from persons who go there sight-seeing rather than to study and note the characteristics of the animal inhabitants. Thus a friend of mine who was with me on the day in question was feeding some of the foreign birds in the aviaries. The keeper had ready for him a tin of mealworms, and for these tasty tit-bits the feathered creatures evinced keen delight. A woman standing by me, her curiosity evidently aroused to the utmost of its capacity, remarked to her companion : "Oh! look at that gentleman feeding those birds on shrimps!"

With the exception, then, of the Moose, the Wapiti Stag is the largest Deer in existence. It has a somewhat shaggy coat of yellowish-brown, and its fine symmetry and graceful bearing is well shown off by the large antlers, which are nicely portrayed in the accompanying picture. Antlers have been shed in the Gardens weighing between thirty and forty pounds the pair.

In former times the Wapiti had a wide range in North America, but civilization has made its mark with this as with other animals, and to-day it is decreasing everywhere, and in many districts has been entirely eliminated. How America came to possess the Wapiti is only a matter of conjecture, but the probability is that it migrated into the New World in former days by way of Behring Straits, and there are in Asia a number of Stags which, from west to east, approach the true Wapiti more and more closely.

Known also as the Elk, the animal under review is much larger than our own Red Deer, and those who have seen large specimens of this handsome species-to which the IVapiti is closely relatedwill be able to form some idea of its magnificence. Fearless fighters, when two males meet the combat is a fierce one to witness, and when the rutting season is in full swing it must be a wonderful sight to observe the Stags fighting desperately and challenging all comers 


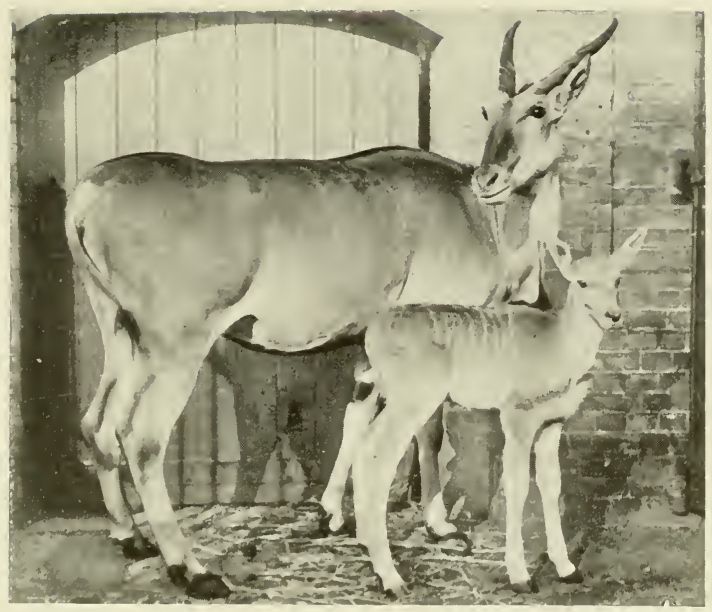

FIG. I 2.-ELAND AND YOUNG

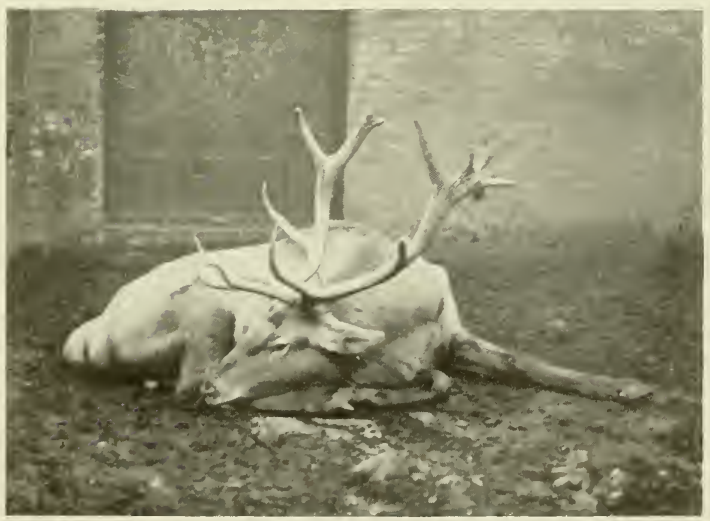

FIG. I3.-TURKESTAN WAPITI STAG 


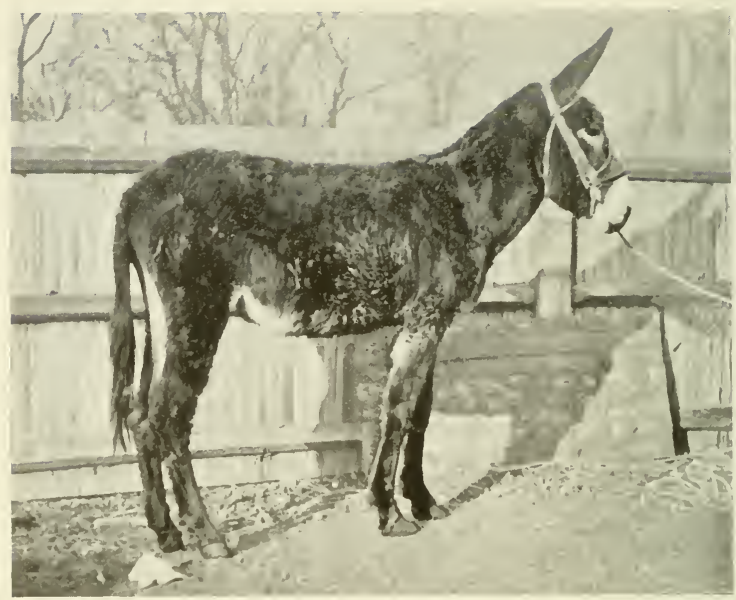

FIG, If.-SPANISH DOMESTIC ASS

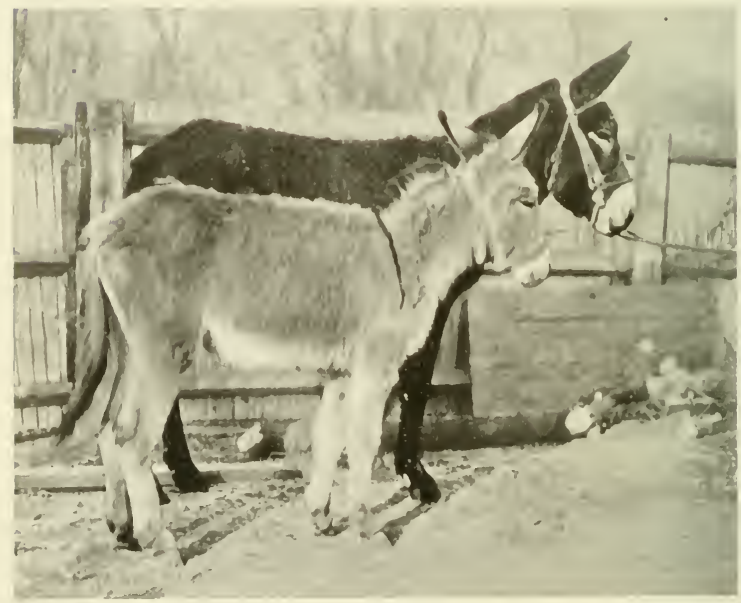

FIG. 15.-SPANISH AND EXGLISH DOMESTIC ASSES 
to battle. Thus, whether on sentinel-guard or engaged in stern conflict, we see here a monarch of the wild who, even in captivity, cannot withstand the unfailing instinct which it possesses during the rutting season, but charges the bars of its yard, banging its head and antlers heavily, and causing very often ugly wounds piteous to see. Compare this with the solicitude and courage evinced by the hind-or female-in defence of her fawn, and the wonderful death-feigning of the little one as it lies in some embowered retreat, and one must of necessity admire the fine beast whose life-history may well conclude our tour among a few of the animal giants of the world.

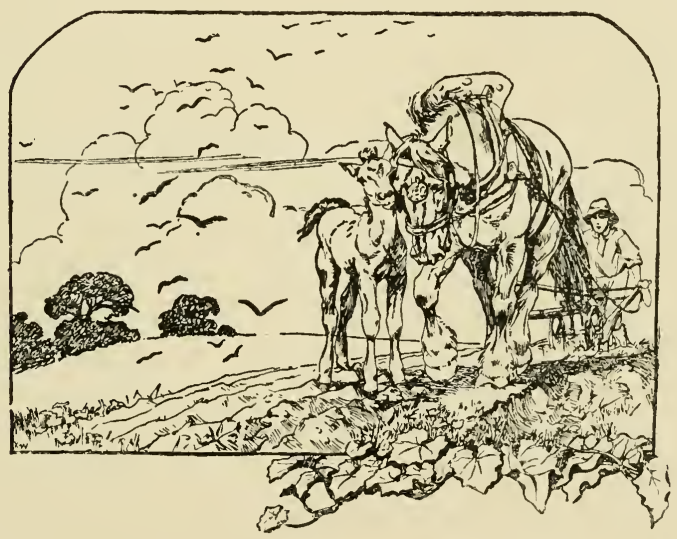




\section{CHAPTER II \\ DOMESTIC AND SEMI-DOMESTIC ANIMALS}

DOMESTIC ASSES. - Whilst we shall make acquaintance with some examples of Wild Asses and Zebras at a later stage, it is appropriate that in this section there should be found representatives of this highly useful family of beasts. Horses, Asses and Zebras belong to the Equidæ, and these animals have, as is well known, long been domesticated by mankind, and have played nounimportant part in the world's history and progress.

Their ancestors have long since become extinct, for our presentday Horses and Asses are descended from creatures which at an earlier period possessed on all four legs extremities containing five fingers or toes, the complete hand or foot being placed flat on the ground in walking. A careful study of geology reveals the fact that the ancestors of the Horse came by degrees to walk on the ends of the fingers and toes, and during the long ages that intervened the middle toe or finger became gradually larger until the nail eventually formed the hoof, whilst the remaining digits entirely disappeared. Our own domesticated Horses are to be distinguished from the Asses and Zebras by the comparatively small ears, a greater profusion of hair upon the tail, and the appearance of what are called "chestnuts," or bare warty patches, situate on the inner side of each hind-leg as well as the fore-legs. These, it is believed, are the remains of recognition, or scent glands, which are also found to exist in other kinds of quadrupeds.

Prejevalski's Wild Horse-which lives in the deserts of Mongolia -is a most interesting species because it represents in many ways the intermediate form between the Domestic Horse and the Wild Asiatic Asses. It is true that the ears of the Asses of Asia are shorter and the tails are more hairy, but, unlike the former, Prejevalski's Horse is distinguished by the presence of these bare warty patches, or "callosities," as they are also called, on both the hind and the fore limbs. 


\section{DOMESTIC AND SEMI-DOMESTIC ANIMALS 25}

The photographs depict several interesting examples of Asses such as the Spanish Domestic Ass (Fig. I4), the Spanish and English Domestic Asses for comparison of size (Fig. I5), a Hybrid Zebra and Pony (Fig. 16) in which the stripes on the legs are plainly to be seen, and a Hybrid Somali and Domestic Ass (Fig I 7).

The Wild Ass has been domesticated since a very remote period in the world's history, and whilst to-day it is difficult to locate the pure wild animal of the unfettered fastness, there are several places where the fleet-footed wild beast is still found. The Asiatic representatives of the IVild Ass (Equus hemionus) are the Kiang, or Kulan, of Tibet and Mongolia, the Ghorkhar, or Onager, of Western India and Baluchistan; a third variety inhabits Syria and Persia, whilst in Africa the Wild Ass (Equus asinus) ranges through Abyssinia, Somaliland and various parts of the Sudan.

It appears to be generally recognized that the Domestic Donkey is a near descendant of the African Wild Ass, being, as a matter of fact, the African species domesticated. Doubtless it was first tamed to be of service to mankind hard by the River Nile, and as its usefulness was made manifest and appreciated and civilization advanced, the habits of the beast rapidly became known in other Eastern countries. With the civilizing influence that came about as a result of the discovery of the Western passage, the fame of the Donkey as a beast of burden became still better known. It spread rapidly throughout the countries adjacent, and yet it seems to have taken quite a long time before it was introduced into Europe. In our own land its introduction was indeed fairly recent. That it did not for some time find favour here is evidenced by the comparatively low price at which the animal was valued, and it was not until the remarkable Elizabethan era that its true worth was recognized and its obstinacy tolerated.

Although, as perhaps the reader may be aware, the ordinary Domestic Donkey which one meets with at the seaside is characterized by its unwillingness to traverse a single step farther than is necessary, and the general obstinacy which it exhibits, there can be little doubt that this trait in its character is largely due to the ill-treatment it receives. This is more apparent when one becomes intimate with other individuals whose claims to be treated kindly and humanely are recognized, and who are well and properly fed and housed, for it is seen that such treatment results in goodtempered and willing servants being forthcoming, and it is always 
pleasant to recognize a good Donkey when one is seen, for it undoubtedly proclaims by its very movements the kind of treatment that is meted out to it. Generally regarded as a somewhat spiritless, stubborn and obstinate creature, I have long since formed the opinion that the Domestic Ass has been a good deal misjudged, for in several instances I have noted its willingness to obey orders, and have also been much struck with certain individuals whose powers of intelligence were very remarkable.

The Donkey seems to be one of those creatures which keenly resents unkind and unfair handling, and those who have watched the animals owned by the London costers and noted how well groomed they are, and how excellently they trot along, will have had ample evidence of what a change may be wrought when so-called dumb animals are treated with the respect and devotion that is their due.

An examination of the Spanish Domestic Ass and our own domestic animal will reveal a striking difference in both size and appearance, and whilst we in England are very fond of advertising our claims to humanity and preaching about the wrongs of others, it would be as well perhaps if at any rate in some instances we set our own house in order first. It is a recognized fact that in Eastern countries, such as Egypt, Persia, Syria and India, and also in Southern European lands, such as Spain and Italy, the Ass is a larger animal, better fed and more carefully tended than elsewhere. As a result the owner obtains more willingness from his beast, receiving, as Mr. Protheroe well says, "a corresponding good return for the trouble and expenditure incurred. It is capable of a good day's journey at a moderate pace, with a man on its back, and it has a spirited demeanour and wide-awake manner which render it a pleasant quadruped to deal with."

In foreign lands, of course, the Ass is a much more valuable creature as a beast of burden than in England, for it is wonderfully sure-footed in districts which it is difficult for any other animal to traverse, and where railways and motors are unknown. It is in many instances the only domesticated animal that is of any lasting service to those whose business it is to travel over a wide extent of rough untrammelled country. In America, too, Asses are much larger creatures than those found in our own land, those on the Western Continent standing from fourteen to sixteen hands high.

In Figs. I6 and 17 we have examples of the results of crossing a Zebra with a Pony, and a Somali IVild Ass with a Domestic Ass. 


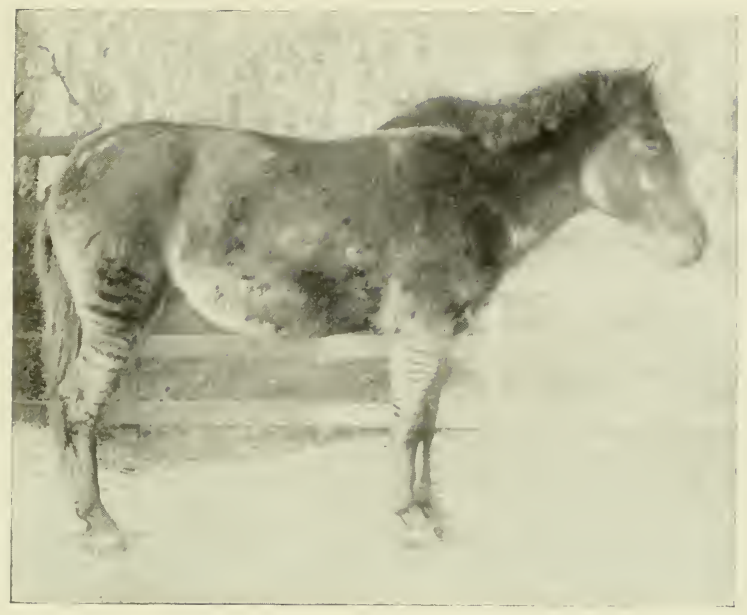

FIG. I6. - HYBRID ZEBRA AND PONY

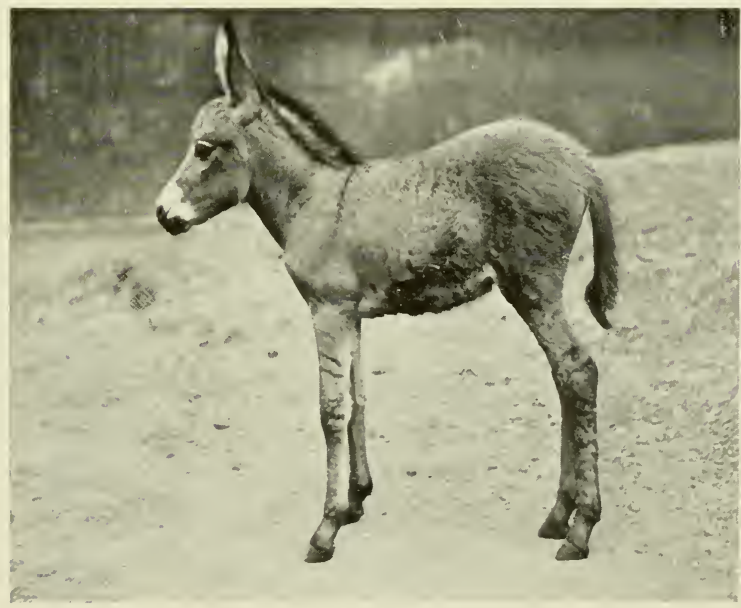

FIG. 17.-HYBRID SOMALI AND DOMESTIC ASS 


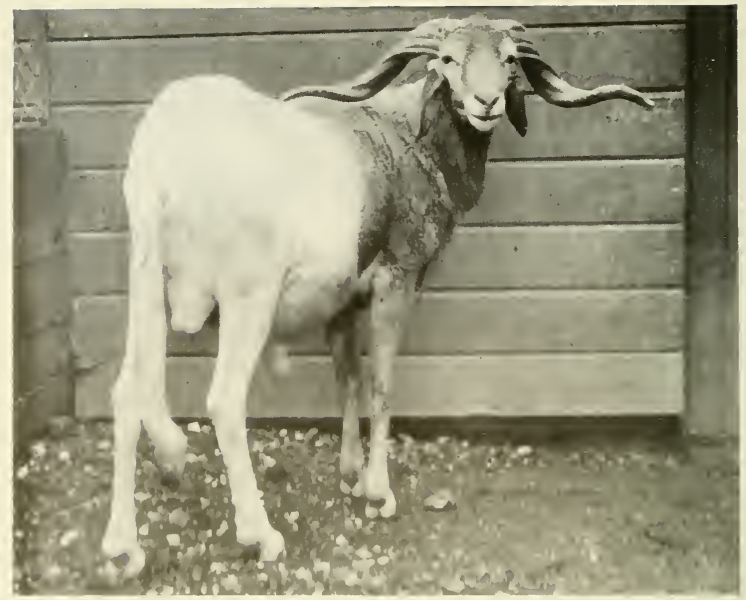

FIC. IS. HIISSA SHEEP (RAM)

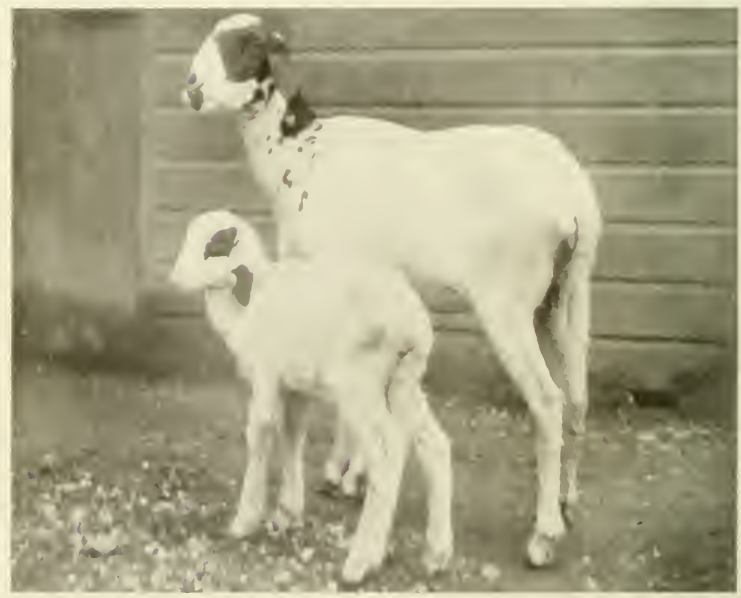

FIG. 19.- HAUSSA SHEEP (EWF ANH LAMB) 
A large male Ass when mated with a female Horse produces a fine Mule, and these latter are well known for their remarkable surefooted powers as well as their endurance. In consequence of this, they are much sought after, for they are able to make protracted journeyings over rocky country where it would be almost impossible for a Horse to travel. Whilst on occasion Mules exhibit even more obstinacy and stubbornness than the Ass, when once these curious habits are overcome their value is undoubted, and it is interesting to observe before passing on to the next species which claims our attention, that there do not appear to be any authentic instances of Mules breeding among themselves, although now and again a female Mule will produce offspring with the male Horse or Ass. And it is certainly worth noticing that, so far as has been ascertained, it does not seem that "the hybrids between any other members of the equine family are mutually fertile."

We shall have more to say regarding Wild Asses in Chapter XV, so that we may now leave our present subject and pay attention to other animals whose claims for inclusion in our second section must not be overlooked. Among these we may include a few kinds of Sheep which are entitled to be considered, and which do not come under the heading of Wild Sheep, to be dealt with later on.

DOMESTIC SHEEP.-Foremost among the domestic kinds is the striking form of the Haussa, of which we have examples among our pictures (Figs. 18 and 19) of the Ram, Ewe and Lamb. This beautiful animal comes from Africa, and whilst the ram is chiefly noticeable for his larger and bulkier build and the handsome pair of gracefully curved horns which adorn his head, the ewe, as will be seen by a reference being made to Fig. 19, does not possess these crown appendages. She, as a matter of fact, does not strike one as very Sheep-like in general outward form, and the dark markings on the head and ears stand out conspicuously from the otherwise lightcoloured coat. The long tail and legs possessed by this animal are also worthy of note. Other breeds represented in our pictures and to which attention may be directed before we consider a few interesting points concerning various kinds of Domestic Sheep, are the Hunia (Fighting Ram) (Fig. 20), One-Horned Indian Domestic Sheep (Fig. 2I), in which the horns are fused into one, and the Dumba, or Fat-Rumped Sheep (Fig. 22). All these, as their pictures clearly show, vary a good deal in general build and also in the character of the horns. 


\section{THE BOOK OF THE ANIMAL KINGDOM}

Of the antiquity of our Domestic Sheep it is impossible to write with any degree of certainty, for these useful animals, which have been, and still are, so largely used for food and clothing, have from time immemorial been inseparably connected with mankind. The Domestic Sheep is undoubtedly one of man's most cherished possessions, and to-day when one so continually hears the cry of "back to the land," and new countries are being opened up by settlers from the homeland, Sheep are to be reckoned in countless numbers, for their wool is greatly sought after for the purpose of making into clothing, and so ministering to the wants and comforts of the human race. We in England do not possess any adequate idea of the enormous flocks of Sheep which are found in the great continent of Australia, in South America, Canada and elsewhere, and we regard their being kept in such numbers as one of the surest signs that mankind-at least those races which live in temperate climates where clothing is a necessity-owes a great deal to the usefulness of the Sheep, to say nothing of its flesh being still largely used in spite of the active propaganda of vegetarians and others.

We are as a nation great meat-eaters, and the colonist has not been slow to note this, owing to his knowledge of the old country. Having become the possessor of a tract of land which he may have almost for the asking, in view of the amount of tillage it requires before becoming remunerative, he has in course of time seen the result of his labours rewarded by the soil giving forth abundant fruit and his herd of cattle gradually assuming respectable proportions. In some instances flock owners have become the possessors of such immense herds of Sheep and other animals that on large areas of sparsely populated land it is often impossible to accurately determine, except on rare occasions, the number constituting the flock. This gives an idea of the vastness of those countries which have been opened up of recent years, and the demand which exists to supply the home and other markets with produce that we in England are unable to supply for ourselves. Some relatives of the writer emigrated to Australia about forty years ago, and by dint of hard work-the very necessary essential which every successful colonizer must undergo-they have succeeded in procuring rich crops from land which, at first sight, hardly looked worth the tilling, and reared huge flocks of Sheep whose exact numbers it is often difficult to determine.

These animals are permitted to roam over a vast extent of 


\section{DOMESTIC AND SEMI-DOMESTIC ANIMALS 29}

country, feeding as they go, and out there on the almost unlimited ground that is occupied it must be a remarkable sight to witness hill and valley tenanted by the whitened flocks in peaceful security. It aptly illustrates, this advent of the great herdsman, flock owner, or agriculturist, the progress of the world and the custom of nations, and brings back to mind the days when a pastoral life was the chief occupation of mankind. All was not gold that glittered in what we are so fond of referring to as "the good old days," but in olden time the shepherd occupied a prominent position in the world's history. A peaceful and perhaps uneventful occupation it may have been, but one that by degrees has largely regulated the modes and manners of many countries where Sheep have become domesticated and reared in large companies. Sheep are, it should be noted, the first animals which occupy pride of place in the Holy Word, and all are familiar with the references made to them in the Bible and the sacrifices that were made of the firstlings of the flock. Poets, painters, historians and others have referred to the shepherd and his flock both by brush and pen, and the scene of peaceful serenity has become engrained, as it were, in our national history.

Recognizing then the important position which Sheep have held since the dawn of day, and still hold, we may pass on to remark that although there is just reason to believe that our domestic breeds are descended from such wild species as the Mouflon, the Armenian Wild Sheep and the Urial, there is nevertheless a good deal of information yet to be gained as to their exact origin. It is, for instance, far from being decided at present whether the various domesticated breeds so well known to every one have been derived from a single, or from several, original wild stocks.

Shortly stated, Domestic Sheep differ from their wild associates in having a coat of shaggy wool instead of hair, and in regard to the length of the tail. No species of Wild Sheep, excepting the Barbary, has a long tail, and Mr. Lydekker notes that "it has been suggested that the long tails of the domestic breeds are due to a kind of degeneracy, although it must be confessed that this does not much advance matters. Unfortunately, geology does not help us much in this investigation; although it is ascertained that the inhabitants of the ancient Swiss lake-like villages were possessed of a breed of Sheep characterized by their small size, long, thin legs and Goat-like horns."

In regard to the horns Domestic Sheep vary a good deal, for in 
many kinds these appendages are so little developed that they are almost absent. Whilst, for example, Figs. 18 and 20 show animals possessing strong and prominent horns of a curved and heavy kind, Fig. 2 I displays the curious fused horn of the One-Horned Indian Domestic Sheep which, to say the least, gives the animal a very uncommon appearance, especially with regard to the head.

And whilst, as has been mentioned, in some breeds of Domestic Sheep the horns may be said to be almost absent, in others they are found to be comparatively large in the male, taking a sharp curve downwards and not uncommonly up again.

The various domestic breeds of Sheep need not be enumerated, for whether we pay attention to such of our own country as the Shetland breed, the Scotch, Welsh or Irish, the Heath breeds, the Cheviots, Norfolk or Moor breeds, the Southdowns or Dorsets, the Merino or the Long-Woolled breeds, we find some distinguishing characteristic that cannot fail to be observed, and when we come to the domestic breeds of Sheep in other parts of the world, every country more or less presents some peculiar modifications which need not be detailed.

Naturally enough sheep-breeders make it their aim to produce animals that will yield either good, or superior, meat, or profitable wool, whilst in some of the commoner kinds both these essential features are found.

Mention may be made of the Merino Sheep found in Spain, because of all breeds this animal is most noted for the excellence of the wool it yields. The climate of Britain is unsuited to this profitable breed, but in other parts of the world it has been introduced with most encouraging results. British Sheep, however, have many distinct characteristics worthy of note, for they vary a great deal both in size and the length and quality of their wool. The Shetland and Orkney breeds bear a fine soft wool which is profusely intermixed with hair. They are small in size, of a hardy disposition, and horns are often found in both sexes. The Scotch Sheep come from older stock, have small horns, short wool and lank bodies. Both races of Welsh Sheep are of small stature, those which resort to the mountains having horns in both sexes, a dark coloration, and hair largely intermixed with the soft wool. Those of the second race have no horns; they possess soft wool "which is deficient in the property of felting"; they are hardy animals, and are highly esteemed by reason of the excellence of their flesh. 
Sheep do not thrive in the Emerald Isle, the humid climate not suiting them, but the breed known as the Irish Wicklow are very similar to the Welsh Mountain breed, and among other Irish kinds the Kerry Sheep alone claim mention. Of all British Sheep the Black-Faced Heaths which resort to the mountains and moors north of Derbyshire may be justly regarded as the hardiest and boldest. The ram and ewe both have hornis, the face and limbs are dark-coloured and the coat is coarse and shaggy.

The Cheviot Sheep are not numerous. They are heavier but not so hardy as the last-named; both sexes are hornless, have white faces and limbs, and yield a moderately fine wool. Strong in body and active in disposition, the Norfolk Sheep have horns in both male and female, which, in the former, assume a thick and spiral form. On Dartmoor and Exmoor in the west of our island home the Sheep there found may, says one writer of repute, "be taken as samples of the breeds of the older forests, commons and chases." They may, or may not, possess horns, the wool is of moderate length, and the animals are of small size.

High up on the famous chalk hills of Sussex where such healthy, invigorating conditions prevail-for Richard Jefferies facetiously remarked that it was a good plan to discover some excuse to be up there always, if only to search after stray mushrooms-it is small wonder that we find a breed of Sheep, known as the Southdown, which is much sought after. The Southdown does not bear any horns, but may be recognized by the dark-brown face, ears and limbs, and the short felted wool. The large head, well-woolled space between the ears, and the large proportion of meat that this breed produce are also deserving of mention. Going westward again in search of the Dorset and pink-nosed Somerset Sheep, we find that these animals are characterized by the length of the white limbs, the white face and frequently flesh-coloured muzzle, as well as by the presence of horns in both sexes. The wool is medium in length, and the lambs are brought forth very early in the season. There is another variety of the Dorset Sheep which flourishes on poor soil and which resorts to Dean Forest and the Mendip Hills, whilst the Portland Sheep is a near relative which is still smaller than the last-named. Of the Merino we have already written, and it only remains for us to notice the Long-IVoolled Sheep, "under which heading," says Mr. Lydekker, "are comprised the new Leicester and the varieties more or less intermixed with it in blood, 


\section{2 \\ THE BOOK OF THE ANIMAL KINGDOM}

such as the Lincolnshire, the Romney Marsh, the Cotswold, the Devonshire, the Notts and the Long-Woolled Irish breeds. They are all of large size, destitute of horns in both sexes, and bear long wool, which, while unsuitable for felting, is eminently adapted for the manufacture of worsted yarn."

Before finally leaving the subject now under review it is useful to notice that from the latest statistics before us we learn that thers are now in Australia over sixty million Sheep; in New Zealand (which only received its first one as recently as i 840 ) there are twenty millions; in the Argentine Republic there are over seventy million Sheep, whilst on the great Continents of America and Africa the number must be very large, and of those bred the Merino appears to be the general favourite. Truly, as one writer says, "it can readily be seen how wool and mutton form no inconsiderable share of the wealth of our kindred across the seas, wealth more assured and enduring than even the gold that has been mined under the Southern Cross."

THE AUROCHS AND DOMESTIC OXEN-Like the Sheep, the so-called Wild White Cattle of to-day-represented in our photographs by the English Wild Bull (Fig. 23)-are descended from animals whose pedigree is shrouded in the mist of ages. The Wild $\mathrm{Ox}$ of Europe no longer holds a place in our fauna. This massive beast, which the all-conquering Cæsar described as being little inferior to the Elephant in size, is extinct, and although our present herds are no doubt very indirectly descended from the great beast which roamed about in Julius Casar's time, the half-wild cattle found in herds in a few British parks to-day have degenerated a good deal as the result of comparative confinement and in-breeding.

Yet the few herds that are preserved by the Duke of Bedford, and at Chillingham Park, Northumberland, and elsewhere, enable us to comprehend to better advantage the immensity of the pure wild creature of former times, and also supply us with an interesting link as to the ancestry of our own domestic cattle.

As our photograph of an English Wild Bull depicts, the beast has a pair of horns which occupy a prominent position on the summit of the forehead, and whilst those possessed by the specimen shown are fairly straight, the Aurochs was, and the semi-wild and domesticated cattle of Europe are, noticeable for the circular horns on the top of the skull. The Wild Ox still left to us presents several interesting features of note, for it varies in many ways from the more domesti- 


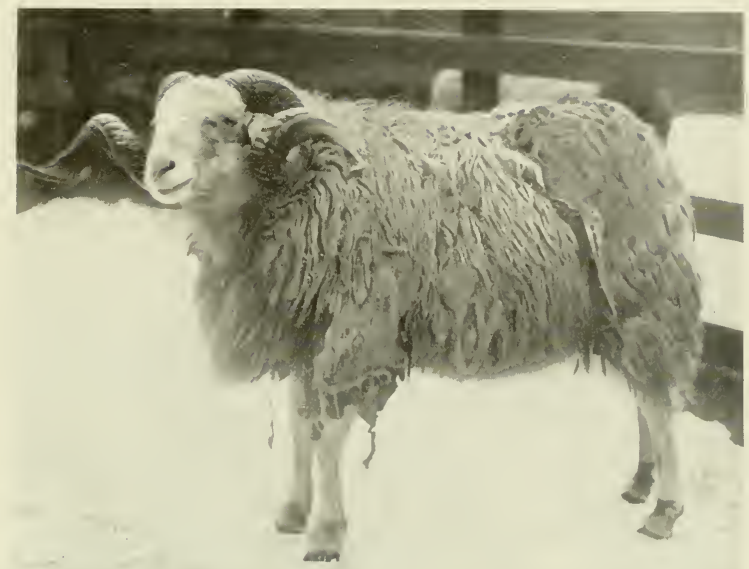

FIG. 2O.-HUNIA (FIGHTING RAM)

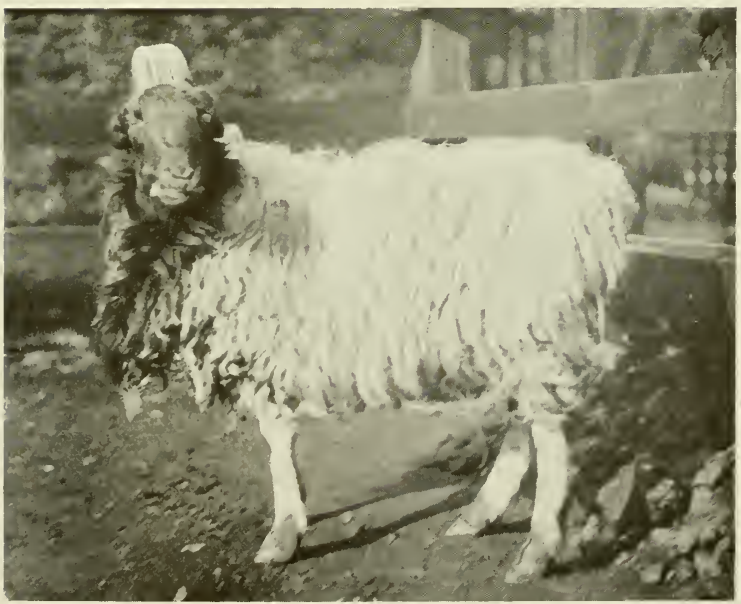

FIG. 21.-CNE-HORNED INDIAN DOMESTIC SHELP 


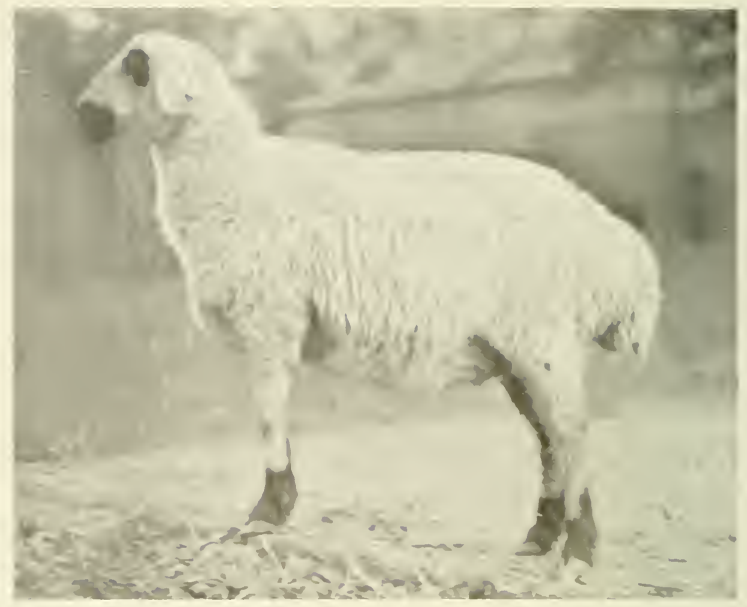

FI\%. 22. - bIMIPA SHEEP. CR F:T-RLMPED SHEEP

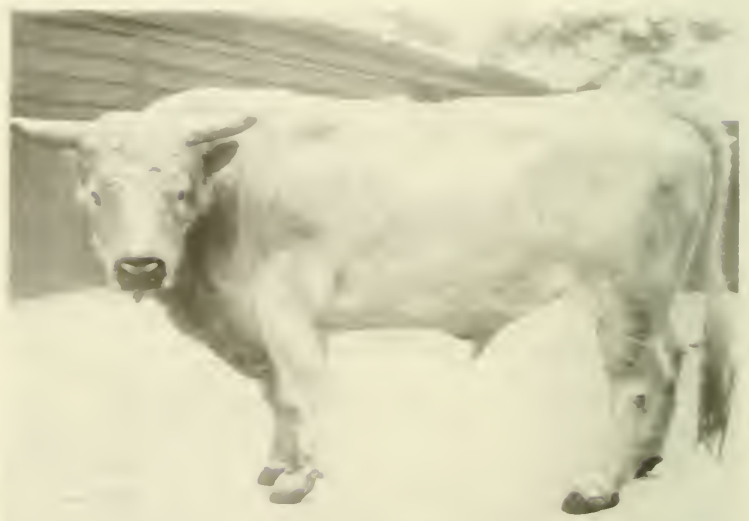

FIG. $23 .-E N G L I S H$ WILU BLLL 
cated breeds known to every one. It grazes for the most part during the silent watches of the night, resorts to the habit of hiding its young, and when unduly interfered with, or alarmed, exhibits a fierce disposition which enables one to conjure up some idea of the habits of its ancient relatives.

That the historic IVild Ox of Europe, known as the Urus as well as Aurochs, was a bold, courageous beast during the Roman era is evidenced by the data handed down to us by the indomitable Julius Cæsar, for he records that a man's prowess was recognized by the number of horns he had managed to secure in the chase.

The bull shown in Fig. 23 came from the Chartley herd in Staffordshire, and the Zoological Society state that it is believed to be as nearly genuine as any, as "it is known that these cattle are the direct descendants of the wild cattle which roamed at large in the Forest of Needwood in I 248 ," whilst the cow that is exhibited in the Regent's Park collection came from the fine beasts located at Vaynol Park, Bangor. These two animals have mated successfully, producing calves which are, of course, of mixed blood.

From remains that have been discovered in various parts of England and the Continent, it is evident that the great Cæsar was no mere adventurer or romancer when he described the Aurochs of old as being little less than the Elephant in size. A skull that came under the notice of the writer, for example, bore upon it horns which in their original condition must have measured at least four feet from tip to tip, whilst other specimens that have been discovered from time to time have considerably exceeded these dimensions, if not in the span occupied by the horns, then certainly by the immensity of the skull.

These intensely interesting epitaphs that have been preserved for us reveal many features which enable us to piece the fascinating story together, for we are able to ascertain some idea of the size, shape and structure of the ancient originators of the English WVild Cattle of to-day, and also the place they occupied in the life of the mighty hunters of olden time. That the huge beast was sought after by the hunter in prehistoric days is not only revealed to us by Cæsar's own words, but the skulls unearthed have been found to be pierced by flint hatchets.

The exact date when this monarch of the wild disappeared from our own country is difficult to determine with any degree of certainty, but it seems agreed that the latest examples were found in Scotland 
and not in England. It does not appear to have occurred in Ireland, but flourished in Germany, Switzerland, France, Italy, Greece, Austria, Scandinavia, Russia and elsewhere.

Accurate data concerning the Aurochs seem to end somewhere about the twelfth century, when we are told by Mr. Lydekker that four individuals are mentioned as having been slaughtered in the neighbourhood of Worms. The coloration of the original wild animal is even more speculative than its size, but from old records preserved to us it may be assumed that it was white, intermixed with dun-red. In view of this coloration it is certainly interesting to note that we may observe the prevalence of these colours in a large number of our domestic cattle of to-day.

As to our British Park Cattle-the half-wild, even although very distant, representatives of the extinct monster whose claims we have so far considered-these are almost white in colour when pure bred, the ears and muzzle being either black or red, as also on occasions is the front of the legs. They are not large animals, but what they lack in stature they make up for in their general symmetry, the short, strong legs, straight back, small head and long tail being characteristics worth noticing. It should be noted that the bestknown herd of these Park Cattle in England is that at Chillingham, whose numbers Mr. Harting and others have enumerated in a most interesting way. Then we have the Cadzow Cattle, which differ from the last-named in various ways, as well as the Chartley herd already referred to. There are other herds of these fine beasts that need not be detailed, and we may conclude this part of our story by relating "that all these various herds of White Cattle are doubtless derived from the half-wild cattle which, as we learn from the writings of Fitz Stephen, dating from about the year 1174 , were common in the forests around London, and probably therefore in other parts of England. When the various parks were enclosed a certain number of these cattle were driven in, and the herds thus obtained have been preserved with more or less care by their subsequent owners" (vide The Royal Natural History).

Of the various breeds of domestic Cattle little need be written excepting to mention a few of their names, such as the small Shetland Cattle found in Shetland, the Orkneys and Iceland; the Highland Cattle so characteristic of the higher parts of Scotland; the somewhat larger WVelsh Cattle, which are noted milk-givers; the hardy Kerry breed, which thrive upon the mountains; the Polled 


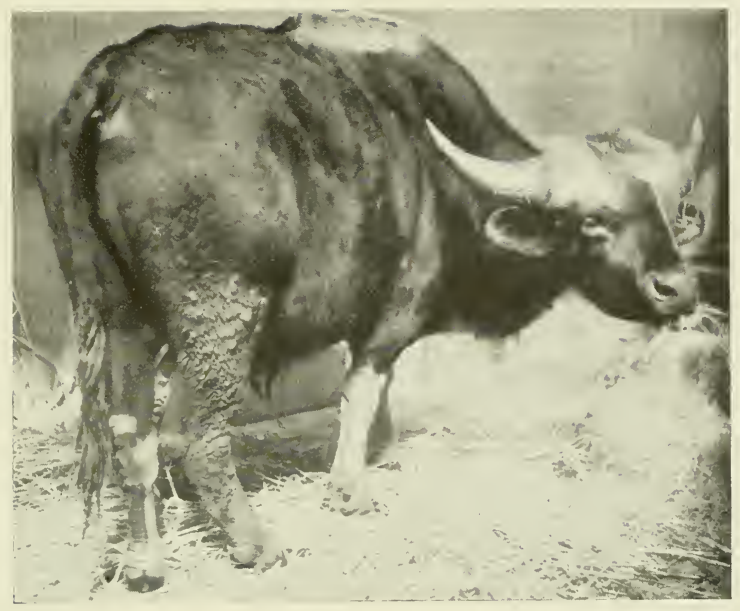

FIG. 24. -GAYAL

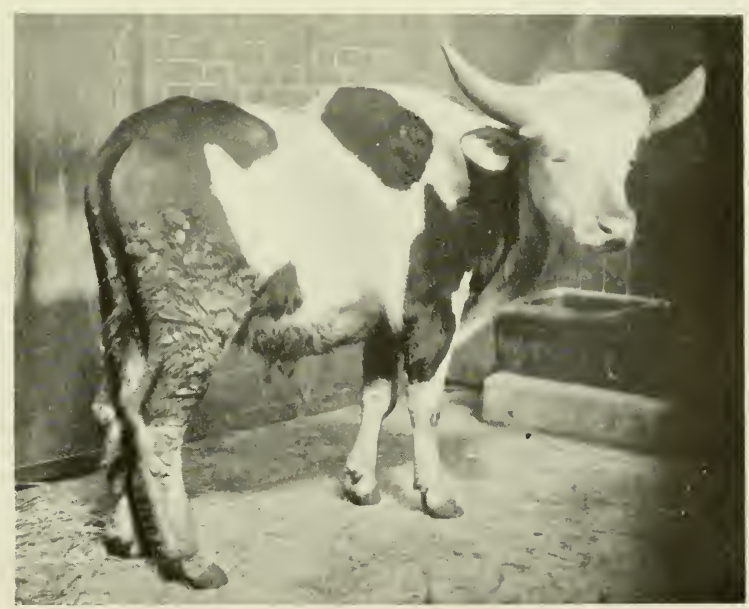

FIG. 25. C.MYAL (VARIETY) 


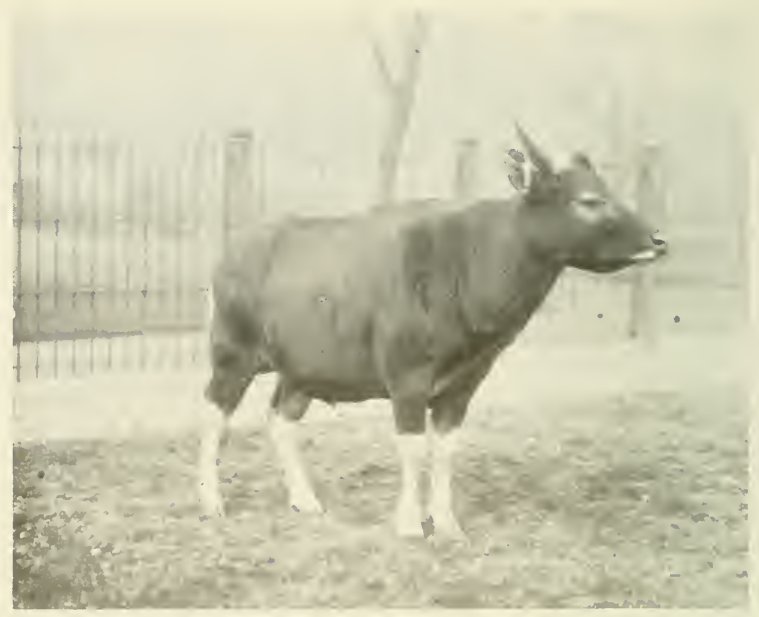

FIG. 26. - JIVAN OX

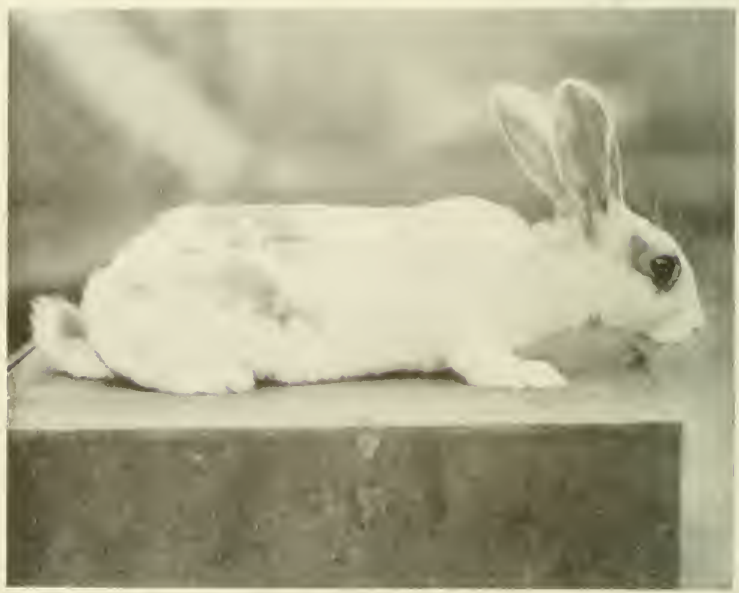

FIG. 27. ENGLISII R.IBBIT 
Angus and Aberdeen breeds, which are distinguished by the absence of horns in both sexes; the hornless Galloways, which are descended from relatives of ancient origin; the Polled Suffolk, which are also hornless and found in Eastern England; the three closely related Alderney, Jersey and Guernsey breeds of the Channel Islands, which are so chaste in appearance and give such beautiful butter and cream; the Ayrshires, which have now become represented in several places outside the county after which they acquired their name; the Devons, Herefords, Longhorns and Shorthorns. These various breeds fairly well represent our British domestic Cattle, whilst on the Continent we find, among others, the Friburg breed, which appear to be almost first cousins to the English Shorthorns; the Dutch breed, which originated in Holland, but have now made their way into Germany; the large Hungarian Cattle, which range through Hungary into Turkey and Western Asia; the Podolian Cattle; the breeds of Domestic Cattle in India and Africa, and last, but by no means least, the vast herds of different kinds of Cattle found in Australia, America, the Argentine, New Zealand and elsewhere.

Thus from the time of Cæsar, when the wild Aurochs monarch roamed at large in the forests of by-gone days, all through the ages we see a gradual process of selection, until at the present time the number of different breeds is extraordinary. Several of these we have mentioned in passing, and even if we only recognize their intrinsic value and usefulness to the human race of to-day, and do not stay to consider the many interesting features connected with their production, we cannot fail to recognize that Cattle, though they be unintelligent creatures, as the boy wrote in his essay, have played no unimportant part in the history of nations.

GAYAL-A peep at two foreign kinds of Cattle, one, the Gayal, from India (Fig. 24) and the other, the Banting or Javan Ox (Fig. 26), may now be taken, and then we pass on to consider the claims of some smaller animals with which the reader will doubtless be more familiar.

Whilst the normal colour of the Gayal is blackish-brown in both the cow and the bull, with the lower portion of the limbs white or yellowish, Fig. 25 displays an interesting variety to which attention may be directed. Here it will be seen that the head and body are whitish, the latter having a dappled effect pleasant to notice. At a meeting of the Zoological Society of London held in 
November 1909, Dr. F. D. Welch, F.Z.S., exhibited photographs of a male Gayal living in the Society's Gardens, in which the lower halves of both fore- and hind-legs were almost entirely black, instead of pure white as in the normal adult.

The Gayal may be regarded as a semi-domestic animal which is found in the hilly parts of North-Eastern India, but of late years some interesting data have come to light concerning it, and we now learn that it is also a perfectly wild beast. Its life and habits as such are at present imperfectly understood, and there is no doubt much of interest to learn concerning it from this point of view.

A somewhat heavy-looking creature, the broad head and flat forehead are distinctly attractive, and whilst it resembles somewhat the handsome Gaur, or mis-named Bison, it is smaller in stature, has shorter limbs, and a lesser development of the ridge along the back, but a more prominent dewlap on the throat, as shown in the picture of the bull in Fig. 24.

The Gayal is one of the three most remarkable members of the genus to which it belongs, and, like the magnificent Gaur, it possesses thick, massive horns which are, however, not nearly so curved, and where they do curve it is outwards and upwards rather than inwards. Thus the horns have a wider stretch than in the case of the Gaur. These appendages are blackish in colour throughout.

As has been shown, some kinds of domestic Gayals (see Fig. 25) are parti-coloured, or even white, and the cow is considerably smaller than her mate. In a wild state it is an inhabitant of hilly country, of wild forests where it can roam about at will, whilst it is as well to notice that difficult rocky places are surmounted with ease, an interesting trait in an animal built on such bulky lines.

IIigh up on the Indian hills, and also on the hillsides below, the Gayal is a favourite animal among the tribes there found, whilst the Gaur is an established favourite as well, so much so indeed that from careful examinations that have been made there seems reason to suppose that the two animals sometimes interbreed.

Also known as the Mithan, the Gayal is most useful to the Indians for the purposes of food, and this apparently is all, for, as Mr. Blanford points out, the Indo-Chinese tribes who keep Gayals never drink milk, and so far as has been ascertained, the animals are not used as beasts of burden, nor are they employed in agricultural labour.

Mr. Protheroe mentions that "the Kukis of the Chittagong 
region, in capturing the animal, trade upon its liking for salt and a particular kind of earth. Balls of these mixed substances are thrown down in some jungle area that is known to be frequented by a wild herd. The animals will not leave the district so long as there are balls to be consumed, and the hunter spreads them about for a period of five or six weeks. During this time he sends out his tame Gayals to mix with their wild brethren, and then proceeds to familiarize the Wild Oxen with himself. Presently he can go among the mixed animals and stroke the tame ones without affrighting the wild ones, who in due course allow themselves to be caressed. Thus it comes about that at the end of the fifth or sixth week the Kuki villager is able to drive home the mixed herd, there to complete the subjection of the latest additions to his stock."

BANTING, OR JAVAN 0X.-We now come to the Banting or Javan Ox shown in Fig. 26. As will be observed from even a cursory inspection, this beast differs a good deal from the animal last under consideration. It is not, for instance, such a heavily built creature, the head is less massive and the horns are smaller. On the hind-quarters the Banting is distinguished by the prominent patch of white, the beginning of which can just be discerned in the picture.

The white buttocks and legs possessed by the bull are also well shown in Fig 26, and whereas he has a black coat, the cow resembles her calf in having reddish-brown or chestnut.

This Ox, a sort of connecting link with the typical Oxen, does not enjoy a wide range. It is found in the Malay Peninsula, Burma, Java, Bali, Borneo, Siam and perhaps Sumatra.

The Malays keep big herds in Java-from whence it obtained one of its names-and in Bali the cattle are replenished by individuals imported from the first-named island.

In writing of the now extinct Aurochs, it will be remembered, reference was made to the white and reddish-brown coloration of the ancestral animal, and, this being so, it is deserving of notice that the calves of the Gaur, Gayal and Banting are reddish-brown in colour, a somewhat significant fact which should not be overlooked.

It needs but a passing glance to observe that the Banting stands upon longer legs than the Gayal, and, as a consequence, we find that it is less adapted for climbing among rocky and precipitous situations, restricting its attention to the lowlands where the luxurious plains suit it admirably. 


\section{8 THE BOOK OF THE ANIMAL KINGDOM}

DOMESTICATED RABBITS.-Of the smaller kinds of domestic and semi-domestic animals deserving of attention in this section we may mention the Rabbit, the Cavy, or Guinea Pig, and the Ferret. We will take them in the order written, and this brings us to the Rabbit.

The illustrations depict three kinds of these favourite pets, namely, English Rabbit, showing approximate markings (Fig. 27), Angora Rabbit (Fig. 28) and Dutch Rabbit (Fig. 29). An examination of the pictures of these three kinds will be sufficient to reveal the differences that exist both in colour and texture. The number of persons who now keep and breed Rabbits is extraordinary, and the popularity of the animals is unbounded. I recollect with vivid interest how, as a boy, I used to keep both Rabbits and Cavies, and there is hardly any one who has not at some time or other kept these favourite pets.

The remarkable varieties of Rabbits that have been produced by fanciers show the rapid strides that have been made in popular favour of late years, and although it does not come within the province of this book to dilate at length upon the merits, or otherwise, of the various breeds now obtainable, a few notes as to some of the more important of them will not be out of place. Whilst the variety known as the Lop does not appear so popular as in days gone by, the Belgian Hare-which in colour, size and shape resembles very closely the British Wild Hare-has many admirers, both on account of its pleasing appearance and its excellence for the table.

The Silvers are a nice group of Rabbits in which animals possessing grey, fawn, cream or brown coats are found, whilst the Dutch (Fig. 29) is popular, although a small kind. The latter makes a good foster-mother and has also the advantage of showing at an early age whether a good specimen has been obtained.

From the small Dutch we come to the large Flemish Giants, which are heavy pets and invariably secure prizes where awards are offered for the heaviest Rabbits. The Himalayan are probably so called because they are of Eastern origin, but this breed, and also the pure white Polish, do not now appear in special favour.

The Angora (Fig. 28) is to be regarded as one of the most beautiful Rabbits known to us, and is a great favourite among both fanciers and others. It is the longest haired variety met with, the fleecy white coat giving the creature a magnificent appearance. As may be imagined, this coat-which in a good specimen looks like 


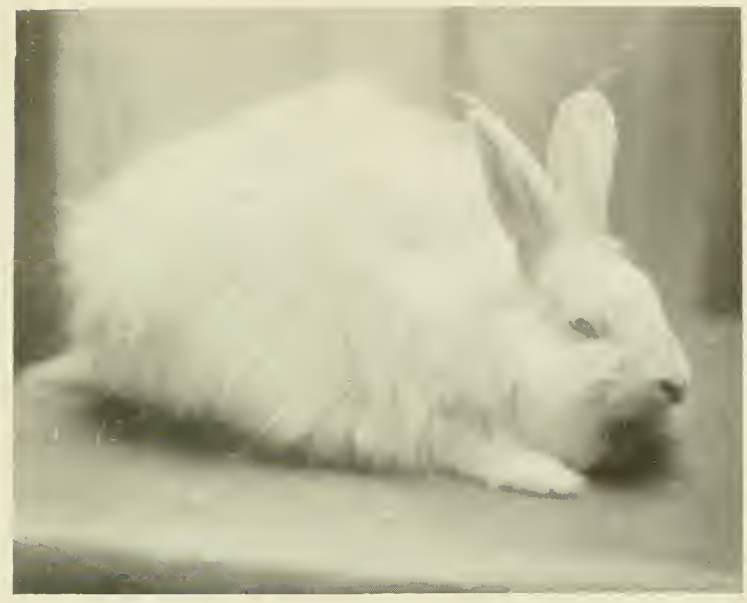

FIG. 28.-ANGORA RABBIT

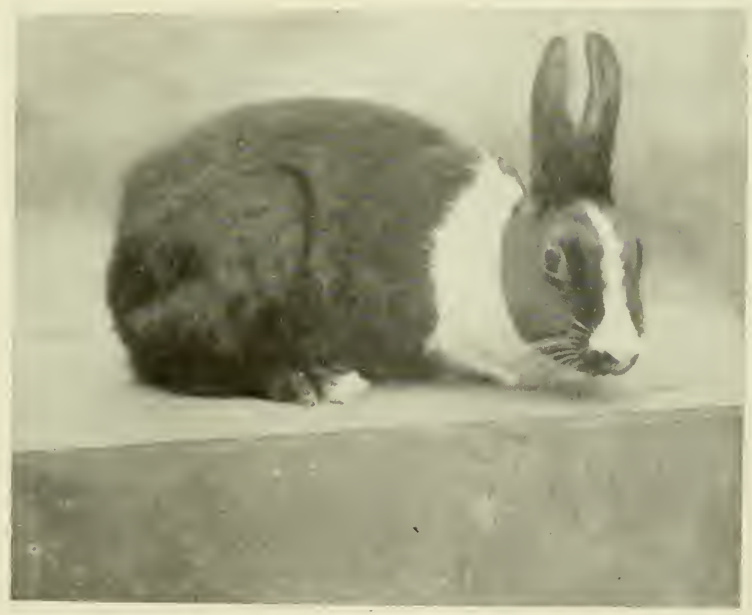

FIG. 29.-DUTCH RABBIT 


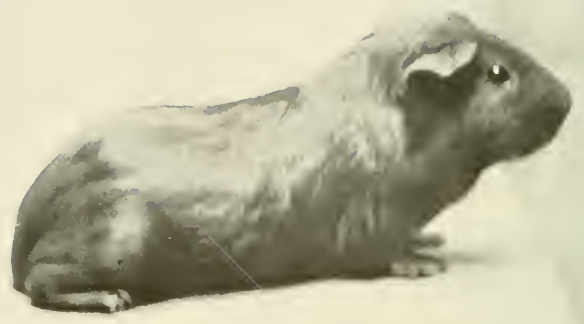

FIG. 3O.-SHORT-HIIREI) GLINEA PIG

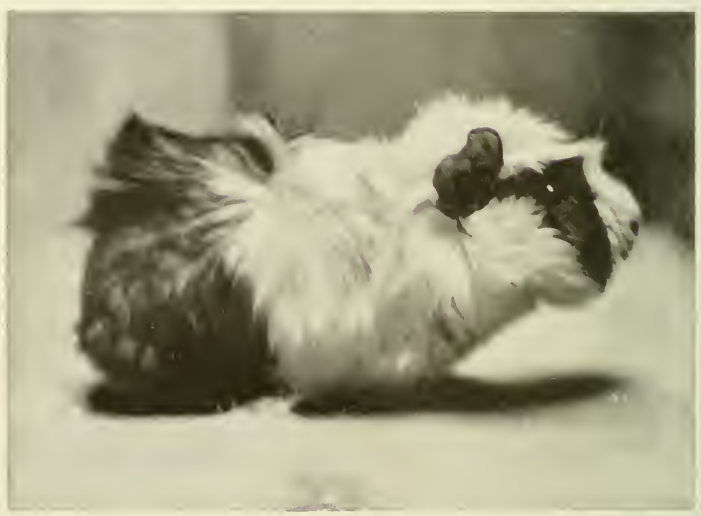

FIG. 3I- LONG-HAREI) G(INEI PIG; 
a mass of soft, silky hair-requires a great deal of attention, especially if the owner desires to keep his pet in good trim for show purposes.

Another favourite to-day is the English Rabbit, which appears to be a new name for an old variety that used to be known as the Spotted Butterfly. Mr. Lane says that after the Wild Rabbit and the Lop, it is probably the oldest variety of the family with a strictly British origin. This Rabbit is of medium size, white in colour, with prescribed black markings, "comprising a mark much like a Butterfly on the nose, hence its old name, a trace down the back and chains of spots from sides of neck, connecting with markings on sides and back markings, forming a sort of saddle." Another kind of Rabbit known as the Patagonian does not appear to have any relation with that far-off country more associated with the Sloth, for we find that most of those imported into England hail from the Continent. It resembles the Flemish Giant already mentioned. Then there is the Siberian Rabbit, which is in no way connected with Russia, the opinion among fanciers being that it is a cross between the Angora and the Himalayan.

The Japanese is somewhat like the Dutch Rabbit, a variety to which more attention might be devoted by fanciers, and it only remains to mention two more varieties, namely, the Black and Tan, and the Blue and Tan, to complete our list of those kinds on which "the fancy" mostly concentrate their attention at the present day.

Before passing to the Cavies, it is interesting to note that the pure Wild Rabbit makes a nice pet. if obtained when quite young, and the same may be said of a Leveret, or young Hare. I kept one of the first-named for some time and endeavoured to write its autobiography in my book Animals at Home, to which the reader is referred for fuller details. One point that struck me particularly with regard to this Rabbit-which was permitted to run about at will in the garden and became very tame-was its preference, among greenstuff grown in the garden, for the leaves of the Golden Rod (Solidago). If the leaves of this showy garden plant were mixed up with others the little IVild Rabbit would invariably pick them out from the rest and make short work of them.

As the little stranger from the woods came to grow up he suddenly evinced habits which seemed to be a sort of call from the wild, and so it came about that one fine evening I carried my pet to a spinney where Brer Rabbit holds undisputed sway and set him free. 
But a pang of regret stole into my heart and I felt as if parting with a real friend.

CAVIES, OR GUINEA PIGS.-In Figs. 30 and 3 I we have excellent representatives of the Cavies, or Guinea Pigs, in the Short-Haired and Long-Haired respectively. Known to us in childhood by the name of Guinea Pig, the humble Cavy, as it is now called, seems to be very popular again. There are three important sections of these interesting little animals, and these may be divided thus: (I) those having long hair (Fig. $3 \mathrm{I}$ ) are known as Peruvians; (2) those with short, smooth hair are styled Bolivian, English or Smooth Cavies; (3) those with rough, short hair are called Abyssinians.

Among the Peruvians one often finds delightful little animals worthy of an artist's brush, the length and shading of their warm coats making them particularly attractive; the Bolivian is more abundant than either the Peruvian or the Abyssinian, and this for two reasons, $i . c$. there is a greater variety of colour and they are easier to produce and keep. The Rough-Haired, or Abyssinians, have curious coats, the hair apparently lying the wrong way, with tiny rosettes of hair which one writer states are "somewhat the size and shape of a dandelion flower."

FOSTER-PARENTS.-Instances of curious foster-parents are continually occurring, and two worth recording pictorially are shown in Figs. 32 and 33. In the one an example is given of a Cat rearing some young Squirrels-gay woodsprites about which I shall have more to say later on-and in the other a Curly-Coated Retriever bitch acting as foster-mother to some young Wolves.

These strange friendships in the world of animal life are often amusing and always interesting, and they certainly display a pleasing trait in the character of a so-called dumb creature which is too little recognized in an age which rushes along at such a pace that these chivalrous deeds of the brute creation are very often overlooked.

FERRET.-The last animal in our present section to which it is proposed to direct attention is the Ferret. The specimen shown in the photograph (Fig. 34) is pure white in colour, but this is not the true natural colour, as, after a great deal of controversy among zoologists, it is now generally recognized that this animal is a domesticated variety of the handsome Polecat. The Ferret has, through being made captive, suffered accordingly, until we find that, generally speaking, it is inferior in size to the wild animal from 


\section{DOMESTIC AND SEMI-DOMESTIC ANIMALS 4I}

which it is descended. I remember, however, seeing some specimens of Ferrets possessed by my gamekeeper friends that have equalled in bulk the Polecat of the unfettered wilds, and $I$ also remember on one occasion meeting an almost tame Ferret in a country lane which, at the time of my interview with it, I certainly took to be a Polecat, so large was it, and so similarly coloured. I have always had a warm place in my affections for the Ferret ever since that fatal day when I stupidly killed an inoffensive semi-domestic animal which, instead of boding me harm as I interpreted, was, as a matter of fact, doing its best to make friends with me !

It appears that a well-known ferreter had visited a village barber's, and whilst there one of his best Ferrets had escaped from his bulky pocket. It was making its way homewards when I encountered it in a quiet country lane, and I did not learn until I returned to the village that instead of possessing a wild Polecat, I had been the victim of misfortune (or stupidity!) and had slain the missing Ferret that had escaped from the barber's shop!

The Ferret is usually smaller and more slender than the Polecat, and although the general colour is stated to be yellowish-white, those which I have seen have mostly been brown or brownish. These are known, it is true, as Polecat-Ferrets.

Those who do not know how to handle such animals as these should hesitate before doing so, for they are hardly to be trusted, except by those whom they come to recognize. Some individuals never seem to become thoroughly trustworthy, whilst others I have seen which have appeared as gentle as the proverbial kitten! They are largely used for ratting and rabbiting, the Ferret being put into a hole. The precaution is usually taken of either muzzling the Ferret or attaching a string to it, as otherwise the animal would probably find the occupants inside so attractive and enticing as to render its recovery a very difficult matter. Naturally enough such an enemy appearing upon the scene frightens Brer Rabbit to distraction, and the wary creature bolts for his very life! Out he comes, only to find himself a prisoner in a small bag-like net placed over the entrances to the burrows, or he is shot as he comes out.

When ferreting, as in almost all other occupations where the ways of wild folk are concerned, it is essential that absolute quiet should be preserved, as otherwise the Rabbits will remain in the interior and "prefer to be eaten alive by the Ferret in their holes rather than attempt to escape." 


\section{2 THE BOOK OF THE ANIMAL KINGDOM}

The Polecat is the first species of the most interesting genus known as the Mustela, and this genus numbers among its members the Polecats, Weasels, Stoats and Minks.

The first-named is now a rare British species, and I remember how, as a boy, I with pride released a magnificent specimen from a keeper's trap, the cruel teeth of which held it fast.

The agonizing and piercing screams of the tortured beast attracted my attention to the spot where the captive was located, and I remember well how I called forth the ire of the keeper who came hastily and unexpectedly upon the scene (as keepers are so wont to do!) when I informed him of what I had done. Cats which have strayed into game preserves, and become veritable poachers, I have endeavoured to release in a like manner, but of all the savage creatures imaginable a semi-wild stray Cat firmly held in a toothed trap is one of the most difficult animals I have ever had to deal with.

Rabbits whose piteous squealings could not fail to attract attention, I have released from their prisons many times, and I once, and only once, tried my powers on a captive Stoat. I have never repeated the operation, for I well recollect how the magnificent creature reared up (it was caught by the hind-legs in some way) to the full extent of the chain which held the trap down, and swore at me in such a terrible way, and assumed such a threatening attitude, that 1 left the sickening scene until the keeper returned to put the animal out of its misery. And such, curious to relate, is the reward one receives when desirous of being merciful to a creature of the wilds. Man is its remorseless enemy, and the animal has become so accustomed to persecution that it fails to recognize when a deliverer comes!

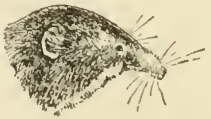




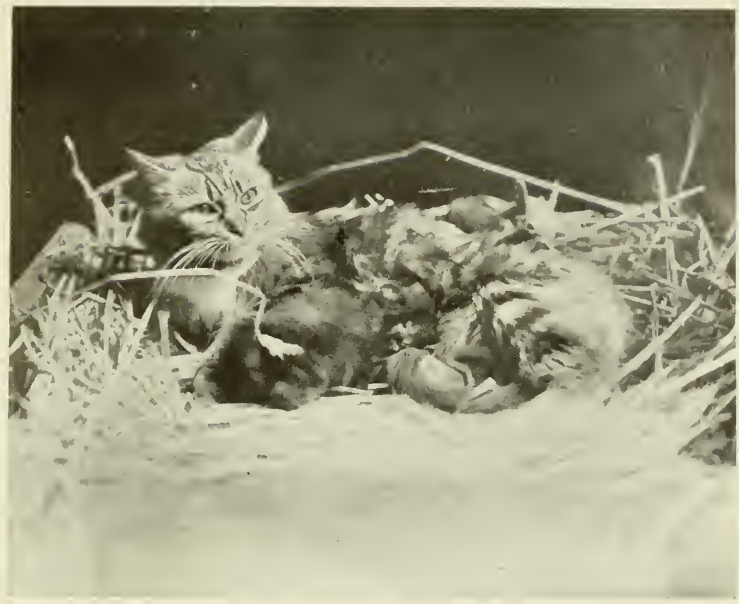

FIG. 32, CAT REARING SQUIRRELS

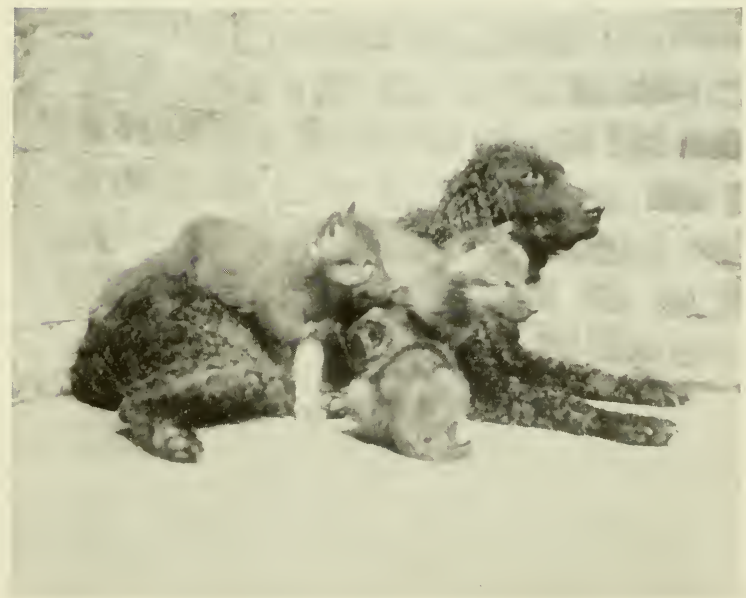

FIG. 33. - YOLNG WOLVES AND FOSTER MOTHER 


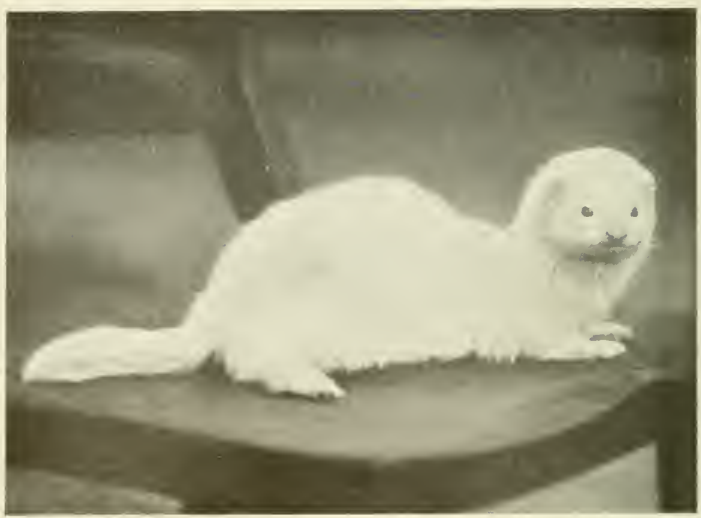

FIG. 34.-FERRET

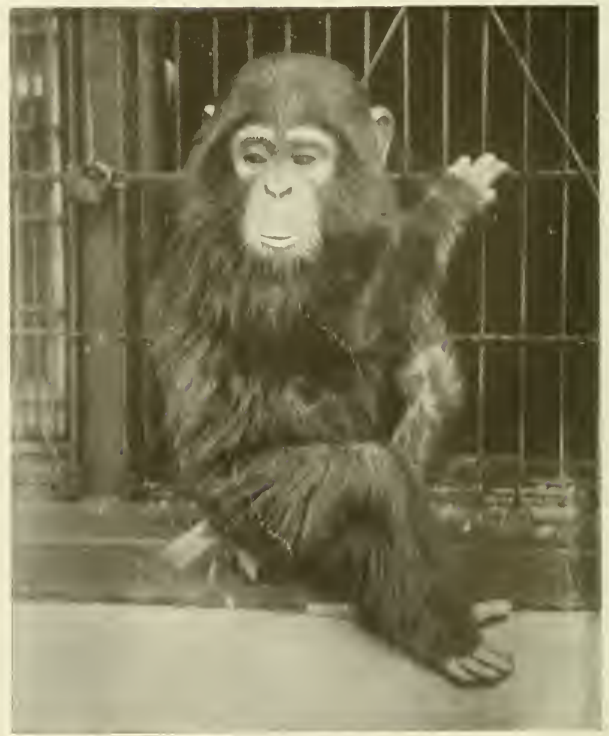

FIG. 35-CHIMPANZEE 


\section{CHAPTER III}

ANIMAL PETS, IN AND OUT OF DOORS

ON KEEPING PETS. - It is interesting to notice the different kinds of animals that are now kept as pets, and not the least feature of interest that affords pleasure to the lover of the wild beasts of the world who is desirous of seeing animals whom it is not possible to observe in their own native fastnesses, is the comparative freedom that is afforded to several species which have been proved to be on their best behaviour when not incarcerated in a wretched little cage, unfit for habitation by either beast or body, as they say in Scotland.

Almost every boy, I suppose, has at some time or other had a pet of some kind, from the humble Guinea Pig or tame Mouse to the pet Teddy Bear. Boys have an innate love and strong passion for the possession of a pet, and so long as the animal is treated kindly and humanely and is well housed and cared for, it is a trait in the boy's character which, in my opinion, is worthy of cultivation. Better still, it is true, if boys would more often express a desire to become field-naturalists, or observers of the wild folk in the great arena of Nature, but we must not lose sight of the fact that there is a period in all our lives when the spirit of intellectual inquiry, of intelligent observation and perception, is dormant, so to speak, and one's outlook on life is far different at such time to the aspect which comes to one after maturer years. Boys will be boys the whole world over, and the sooner we can realize-those of us who have reached manhood-that it is unfair to expect the average boy in his teens to have a man's head on his shoulders, the better it will be for all concerned.

Do we not, as a general rule, expect too much from our young people, who, if they do not see as we see and think as we think, are apt, as a result, to be described as dullards, and to be relegated to the dunce's class? Let us each put himself, as it were, in the boy's shoes, and be a boy again. Then, looking at the subject 


\section{THE BOOK OF THE ANIMAL KINGDOM}

from the boy's point of view, we shall be better able to interest and amuse, bring home to the young people a correct understanding, and get into clearer focus that distant horizon which the average boy only dimly perceives.

Having agreed, then, that it is good for boys to have petsprovided always that their acquaintances are treated with every care and consideration-we will shortly consider some of the world's animals that make a special appeal. Is it not interesting to notice how boys' tastes differ in regard to pets?

Some boys I know utter exclamations of disgust at the sight of a Rat, Lizard, or Snake; others, less timorous, perhaps, than their fellows, simply revel in handling these creatures, and possess a real love for their captive friends; while birds they all seem to love, and rightly so. I met a boy in a railway train not long ago who was caressing in a most delightful way a warty old Toad which he had captured as the result of a half-day spent in the country. All other sights and sounds paled into insignificance in that boy's estimation. The tea he had was good-he remembered that-and the ride in the brake was enjoyable. The flowers, birds and insects appealed to him in a way, and he had a distinct recollection of some tall trees in which some sable Rooks had built their nursery homes, and he longed to climb the dizzy heights. There was also a waterfall which attracted attention, and other features of which he had a dim recollection, but all these were meaningless to him, and his chief delight was centred in the capture of an old Toad.

It was good to see this urchin from Slumland fondling one of our most useful and interesting British animals, although probably a death from starvation came eventually to the little stranger. Advice as to the best methods of keeping it proved in all probability of little or no avail; the boy seemed to realize that the Toad belonged exclusively to him. It had, as it were, been made for him, and his love for it was so inherent that he could not believe that in the immediate future the inanimate form of the Batrachian would be his sole possession.

These little incidents are cram-full of interest to those who look at them aright, and by making comparisons as to the pets which appeal to boys, and why and how, one is able to come to some interesting conclusions, the importance of which all those who are engaged in the upbringing of our children cannot fail to recognize. Agreeing, then, that for some unaccountable reason a pet which 


\section{ANIMAL PETS, IN AND OUT OF DOORS}

appeals to one boy makes a poor impression on another, indeed, in some instances results in actual repulsion, let us have a peep at a few animal pets suitable for keeping both in and out of doors.

CHIMPANZEE AND ORANG-UTAN.-I suppose if a vote were taken among juveniles as to the most popular feature at the London Zoo, the inmates of the Monkey-house would receive a triumphant majority. Their inquisitiveness, curious facial expressions, agility and keen sense of intelligence make a strong appeal to the young visitors, and I have been interested, too, in observing the patronage bestowed on the Monkeys by grown-up persons.

The Chimpanzees in Regent's Park now have an excellent new house all to themselves, although our rough old friend, the OrangUtan, is also permitted to live under the same roof. Visiting the new home of these remarkable creatures not long since, I had an example of how well they recognize any one who has accorded them a share of attention. I accompanied a well-known Fellow of the Society on his rounds of the animals-and shall have more to say regarding his interview with the King of Beasts hereafter-and the moment he entered the doors of the new Ape-house the Chimpanzees became terribly excited, and more so when this devout lover of the brute creation played bo-peep with them from behind a pillar in front of the cage.

Food plays an important part in the friendliness of many kinds of animal pets-so dependent are they upon their owners for the bread of life-but they also exhibit many other important traits which are apt to be overlooked by those who do not regard their pets as anything more than mere dumb, senseless beings.

The little game between the Chims and their human prototype continued, and not the least interesting of the little company was Micky, whose portrait is shown in Fig. 35, and the Orang-Utan portrayed in Fig. 36 .

The latter, rough-coated fellow that he is, seemed much perturbed at the attention devoted to his Chim relatives next door, but a friendly word encouraged and solaced him.

Whilst Monkeys are in some respects undesirable pets, and it is in their life-histories as wild creatures that we are more interested, there can be no doubt that, difficult as they are to study in their home surroundings, they are a never-failing source of interest and genuine amusement.

We shall meet with them again at a later stage, and then have 


\section{THE BOOK OF THE ANIMAL KINGDOM}

something to say regarding their life-stories, and it is at present sufficient to point out that many species exist, and all exhibit some characteristics worthy of note. Pride of place must, however, be given to the two subjects shown in our illustrations (Figs. 35 and 36 ), which in themselves demonstrate the general outward differences which exist between them.

Of the remarkable Man-like Ape, Consul, and his successor, Consul II, passing mention need only be made, for the escapades of these wonderful animals have been witnessed and read of by many. Whilst there may be, and probably is, some tangible objection raised as to the desirability of exhibiting wild animals under certain conditions in which cruelty is unmistakably involved, there can be no doubt that when their training is carried out with kindness and consideration-if that be possible-most delightful instances of sagacity, devotion, intelligence and cleverness are displayed.

Any who read the delightful reminiscences of Frank Buckland will find much that is entertaining, as he was a devout lover of pets, a great naturalist, and the worthy son of a naturalist, Dr. Buckland, Dean of Westminster. One incident concerning his Monkey Jacko may here be told. Says Buckland: "Jacko once got loose again. Remembering his previous adventure with the schoolboys, he ventured not beyond the premises, but quietly sneaked into the knife-house, and tried his hand at cleaning the knives. In this attempt he was evidently not successful, inasmuch as the handles were the parts he attempted to polish on the brick-board, and a cut was found in the middle of his hand the next day. Resolved, however, not to be defeated, he set to work to clean the shoes, in imitation of the man IVilliam, his kind and indulgent custos here. Again he had not distinctly recollected the various steps necessary for the right performance of the operation, for he covered an unfortunate shoe all over, sole and all, with the blacking which he got out of the blacking-bottle, and then he emptied what was left of the precious Day and Martin into the hollow of the shoe, nearly filling it; his coat was in a nice mess for some days afterwards. One morning, again, when the servants returned from the parlour into the kitchen, they found Jacko had taken all the kitchen candlesticks out of the cupboard and arranged them on the fender before the fire, as he had seen done before. Finding the black-lead in the same place, he took it to a bowl of water which was at hand, 


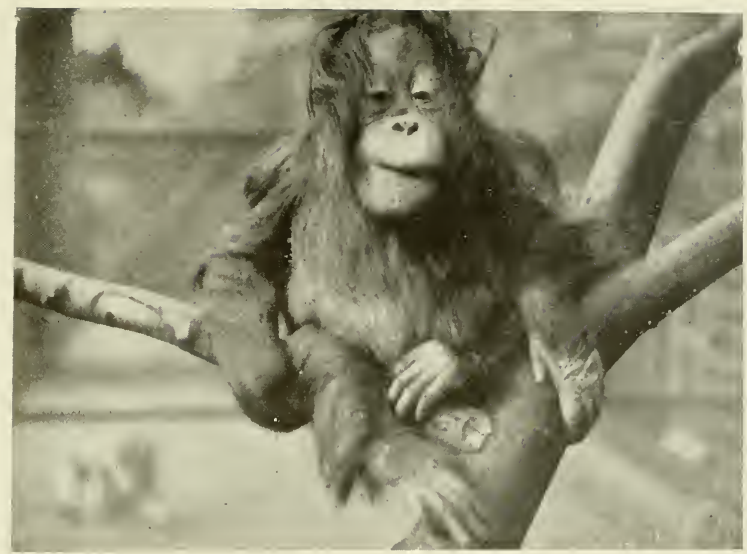

FIG. 36. ORANG-UTAN

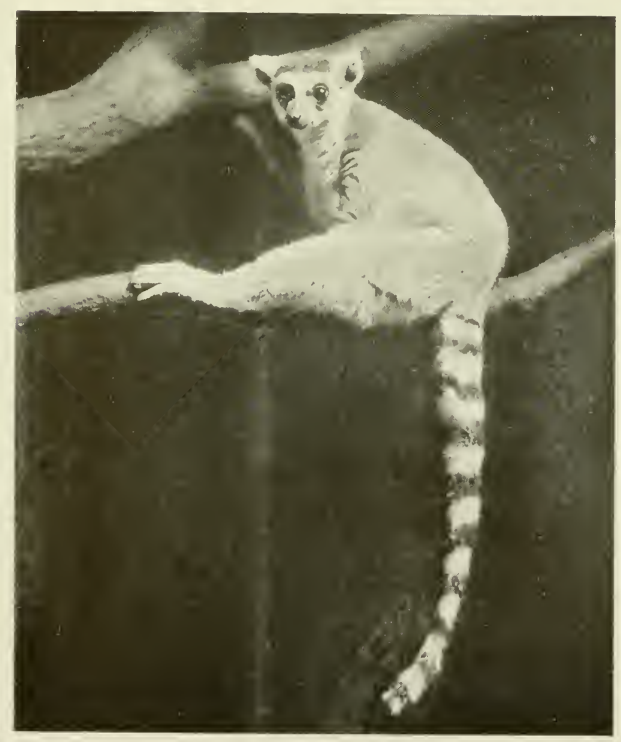

FIG. 37.-RING-TAILED LEMUR 

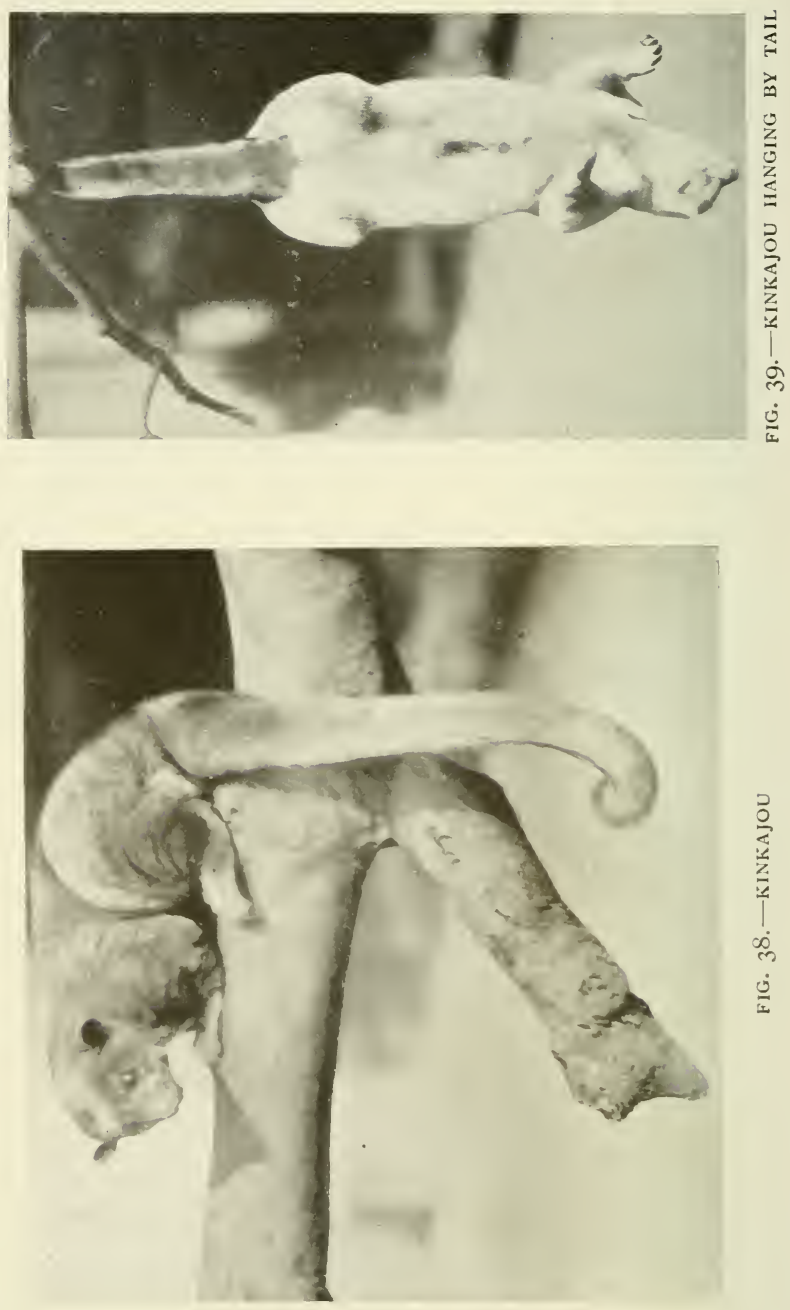


\section{ANIMAL PETS, IN AND OUT OF DOORS}

wetted it, and was diligently rubbing the table all over with it, when he was caught in the act. On the entrance of the servants, he immediately retreated to his basket in the corner, and tried to look as though nothing had happened. A great treat to this would-be kitchen-maid was to have a large bowl of warm water given him. He would first of all cunningly test the temperature with his hand, and then gradually step into the bath, first one foot and then the other, finally completely sitting down in it. Comfortably placed, he would then take the soap in his hands or feet, as the case might be, and rub himself all over. Having made a dreadful mess on the table, and finding the water becoming cold, the next part of the play was to get out and run as quickly as he could to the fire, where his coat soon became dry. If anybody laughed at him during this performance, he would chatter and grin at them, and frequently even splash water out of the bath towards and sometimes over them."

This is one of the many interesting episodes connected with Buckland's Monkey, Jacko, which was his constant friend and companion. He took the pet up to Oxford with him, and it there nearly caused Buckland a disaster, for on the day of an examination he found, to his horror, that Jacko had torn his notes into a thousand pieces. "Jacko," exclaimed Buckland, "we are both ruined!" and Jacko did not seem to mind in the least--but fortunately for both of them the naturalist's prognostications were not realized, for the tutor was satisfied with his pupil's explanation as to how he came to present his notes in fragments. "So great was my glee," Buckland says, "that I had mercy on Jacko, and did not shake him well-the greatest punishment I could inflict on him-but merely shut him up in his bag, and for three hours hung him up for penance on a hat-peg."

LEMURS.-Closely allied to the Monkeys, and a really delightful pet, the Ring-Tailed Lemur is deserving of notice here. That the animal is well named may be ascertained by a reference to Fig. 37, in which the beautifully ringed tail is nicely shown, as well as the pretty face. Lemurs are a sort of connecting-link between the Monkeys and the genuine quadrupeds, and these interesting creatures are not found away from Madagascar and the adjacent Comoro Islands. They are nocturnal in their habits, and the English name is derived from the Latin lemure, a ghost.

These are engaging pets, active in disposition, but less intelligent than the creatures last under consideration. Sometimes they are referred to as Madagascar Cats, and the appellation is not at all 
misapplied. The woolly fur and toes are well displayed in the specimen depicted in Fig. 37 ; so also are the long muzzle, prominent eyes and raised ears.

Those who keep Lemurs as pets must be careful not to annoy their charges, as a bite from them is something to be remembered. Whilst we cannot hope in this book to deal at length with the best methods of keeping animals in captivity, it may be pointed out with regard to this species that although fed in confinement upon bread and fruit, the Lemurs in their wild state also vary their fruitarian dietary by partaking of small birds and lizards.

There are ten species of Lemurs found in Madagascar, the RingTailed Lemur being characterized by a well-marked appendage after which it has been named. Perhaps the Ruffled species is the handsomest of them all, the ruff round the neck and the large tail being especially striking. When sleeping these animals take the precaution to roll into a ball and curl the tail round the body, for the purpose of warmth, and when a number are thus seen close together the effect is very delightful to notice.

KINKAJOU.-Another pet distinguished at once by its tail is the Kinkajou (Fig. $3^{8}$ ) from South America. It is a heavier-looking creature than the Lemur, and belongs to a very different family, claiming kinship with the Raccoons, one of which we shall meet with presently. The older naturalists, however, placed it among the Lemurs.

That the Kinkajou deserves its name may be evidenced by an examination of the use to which it puts its tail. Better by far to watch the living animal if possible, but, failing that, the photographs (Figs. 38 and 39 ) both show the flexible appendage to advantage. It is from two Greek and Latin words that the Kinkajou has derived its name, which, being translated, mean "twisted tail." It possesses the habit when it goes to sleep of rolling into a ball, like the Lemurs, but, unlike them, has a foot webbed almost to the claws. In captivity it is interesting to observe the animal holding its food in one "hand" and preparing it for reception with the other, and the long tongue aids the creature in licking out insects from their hidingplaces. In a wild state it feeds on birds and their eggs, small mammals, honey and fruits.

The rounded and broad head, low body and short muzzle are worth noticing, as compared with the Lemur. The fur is short and soft, and in colour pale yellowish-brown. Like the Lemur, it is a 


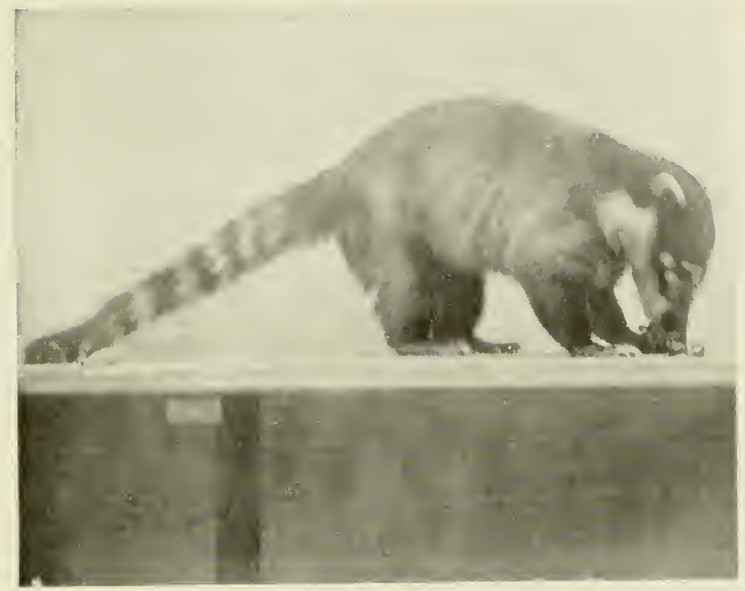

FIG. fO. RING-TAILED COATI

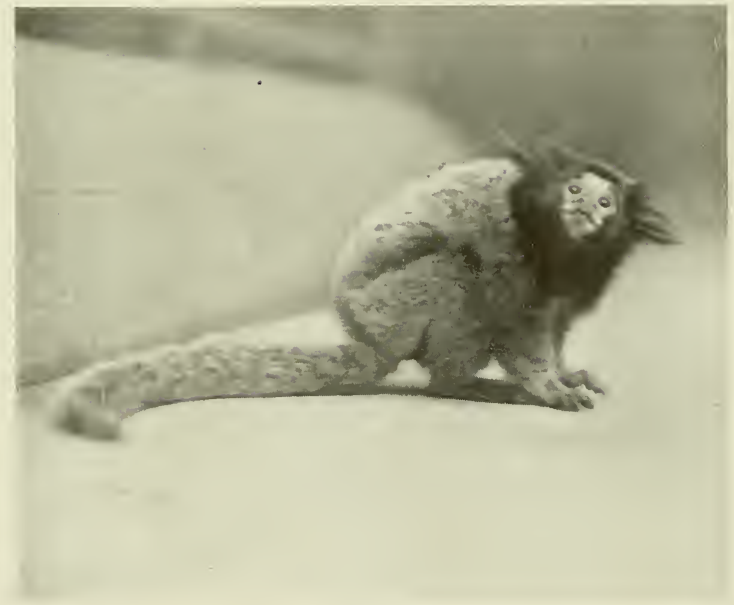

FIG. 4I.-BLACK-EARED MARMOSET 


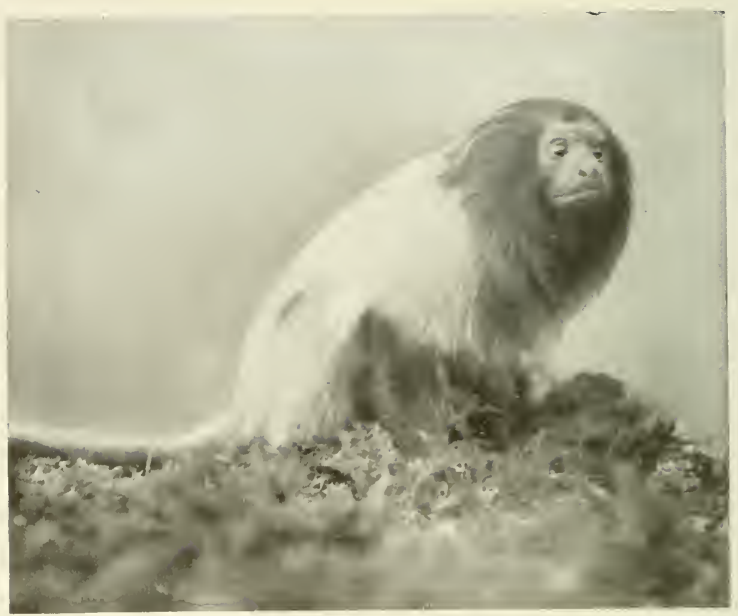

FIG. +2. LION MARMOSET

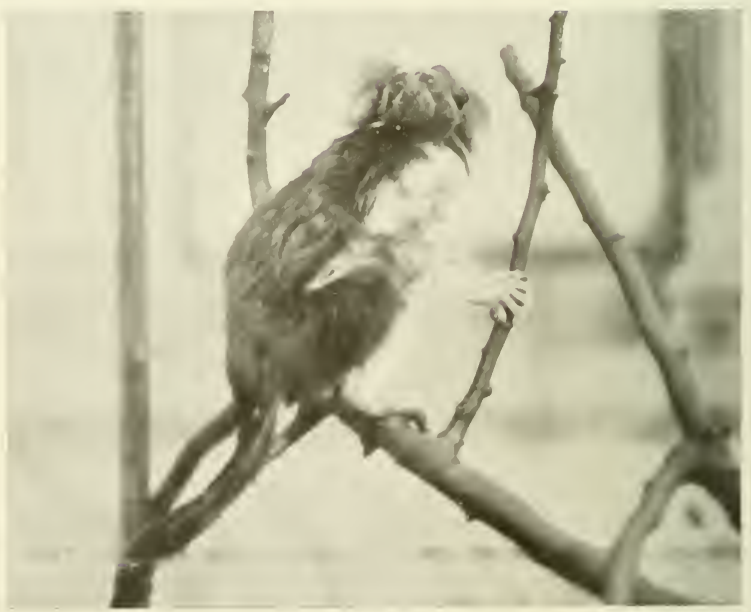

FIG. +3. PINCHÉ MARMOSET 


\section{ANIMAL PETS, IN AND OUT OF DOORS}

night animal, concealing itself during the day in holes of trees and similar places. Whilst amenable to those to whom it has become attached, the Kinkajou is of uncertain temper, and does not take kindly to strangers.

Mr. Lydekker says that "it is found in wooded districts from Central Mexico to the Rio Negro in Brazil," and that "in Guatemala, where it is far from rare, it ranges to elevations of four thousand and five thousand feet above the sea."

One can imagine how excellently the tail serves the animal in procuring food in those wooded retreats, and Bates mentions an instance of how he came on intimate terms of acquaintance with some of them when he spent a night in the forest. He tells of how at midnight he lay down and listened to the "impish hosts of Vampire-Bats crowding round the cajes-trees," and how "a rustle commenced from the side of the woods, and a troop of slender, longtailed animals were seen against the clear, moonlit sky, taking flying leaps from branch to branch through the grove." These night creatures proved to be Kinkajous, or Jupuras, as they are also called, and one can imagine how in the stillness of a night in the forest "the hustling, twittering and screaming, with the sounds of falling fruits, showed how they were employed."

COATI. - Another ring-tailed creature which hails from Brazil, and is first cousin to the Kinkajou, is known as the Coati. This is exclusively a South American species, and although the picture (Fig. 40) does not show to advantage the long snout, owing to the specimen depicted being engaged in a meal, the great length of the snout and its mobility are features of interest. By their snouts you may know them, and they have, comparatively speaking, a long and narrow skull.

The long body bears at its extremity a tapering and elongated tail, as Fig. 40 portrays. There are two species of Coatis, or Coatimundis, as they are also called, one being an inhabitant of Mexico and Central America, and the other being found in South America. Both kinds vary a good deal in coloration, but are easily domesticated, and make interesting pets. Mr. Berridge has well displayed one of these Ring-Tailed Coatis in his coloured picture.

These creatures have been long resident in the countries named, as is proved by the remains which have been discovered from time to time, whilst at a still earlier epoch in the world's history another species was an inhabitant of the Argentine Republic. 


\section{THE BOOK OF THE ANIMAL KINGDOM}

Firm believers in the motto that "Union is strength," Coatis travel about in companies-an interesting trait in animals to which we have already drawn attention-and may be found for the most part among the trees, in which they so dearly love to pass the time, feeding on a similar diet to that of the Kinkajou, and going through various acrobatic exercises with which one cannot help associating these arboreal tenants of the forest.

That these are wary wood-folk goes without saying, for we are told by an observer that when hunting for food the troop divides into two companies, one devoting their energies to the higher branches of the trees, and the second section concentrating their efforts upon the ground. It is no easy matter to capture the Coati in its own domain-easily tamed though it may afterwards become -for it is a desperate fighter, and the double-edged canine teeth will give the hunter just cause to remember the encounter, if the battle is fought at too close quarters!

MARMOSETS.-Closely allied to the Monkeys as well as the Lemurs, the Marmosets (see Figs. 4I, 42 and 43) make very gentle and affectionate pets, but are delicate creatures, and difficult to keep in captivity. As will be observed from the photographs, these are somewhat peculiar-looking animals, but, in spite of this, they are well worth keeping, many of them being small in size. They are restricted to South and Central America, and the curious facial expression in each individual which posed for its photograph is worthy of note.

One most interesting feature concerning the Marmosets is the number of their teeth, for whereas the Monkeys of the Old World have thirty-two teeth, American Monkeys possess thirty-six. Yet, curious to relate, we find that the Marmosets differ from their American Monkey relatives by having thirty-two teeth only, like the Old World Monkeys, although it is true that they are disposed differently, there being three pre-molars and two molars. It is interesting to carry this analysis a little further, for although the Marmosets resemble the Old World Monkeys in having thirty-two teeth, a careful examination reveals the fact that in the number of pre-molars the Marmosets agree with their American cousins, the Monkeys.

Mr. Lydekker puts the matter nicely when he states that a Marmoset "differs by the comparatively unimportant feature of the loss of the last molar in each jaw. A Marmoset may, indeed, be 
Plate IV.

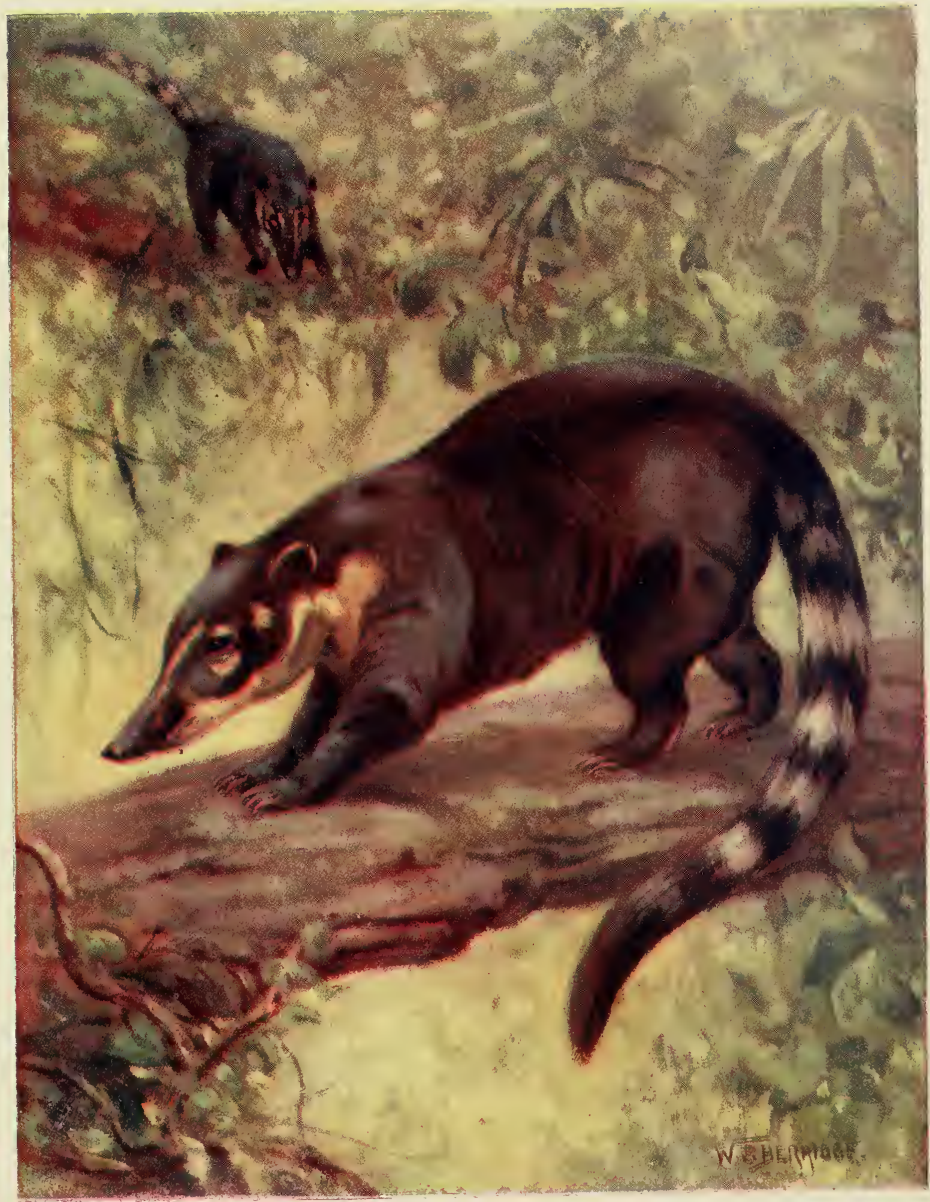

RING-TAILED COATI. 



\section{ANIMAL PETS, IN AND OUT OF DOORS 5I}

defined as a small American Monkey which has lost its wisdom teeth."

Another distinguishing feature which it is important to recognize is one concerning the fingers and toes, for, with the exception of the so-called great toe, the Marmoset possesses pointed claws in place of somewhat flattened nails. Among the Marmosets, too, we meet with animals having a ringed tail as in the Lemurs and others whose characteristics we have already considered. In scientific sequence the Marmosets come before the Lemurs, and it is in the former group that we make acquaintance for the first time in the great tree of animal life with creatures which are the possessors of caudal appendages ringed with alternate dark and light bands. Another characteristic feature is the wealth of hair which flourishes in the region of the ears of all three kinds illustrated.

Squirrel-like in many of their ways, Marmosets have longer and stronger limbs behind than in front. They travel about in small troops, being arboreal in their habits, and feed upon insects and fruit. In their breeding habits these creatures also differ from their Monkey cousins, giving birth to two or three young ones instead of a single individual.

The Black-eared species (Fig. 4I) well deserves the name, as the picture depicts, the hairy black ears being particularly noticeable. This Marmoset comes from South-Eastern Brazil, and it will be noticed that the head and neck, as well as the tufts of long hair on the ears, are quite black. There are a number of different species of Marmosets as well as varieties whose exact pedigree it is often difficult to determine, but attention may be drawn, before passing on, to the beautiful coat with which the Lion Marmoset (Fig. 42) is clothed, and also to the Pinché Marmoset (Fig. 43). This latter animal is quite a small species, measuring, exclusive of the black tail, some seven inches only in length. It has small ears, which, as will be seen by referring to Fig. 42 , are hidden by the mass of silky fur with which the sides of the face and the crown of the head are clothed. The general body colour is brownish-tawny, with red and black variations on the back. On the under parts the coloration is lighter, the neck, breast and lower parts being yellowish, standing out in strong contrast from the otherwise dark coat. It will be noticed, too, that the hands and feet are yellowish-brown.

The Marmosets, it should be noted, are split into two groups, those in the Short-tusked section having tusks which are not longer 


\section{THE BOOK OF THE ANIMAL KINGDOM}

than the incisors situate in the lower jaw, and those claiming kinship with the Long-tusked section, or Tamarins, as they are called, have tusks, or canine teeth, in the lower jaw much longer than the front, or incisor teeth. Thus the lower teeth of the animals in the second group do not present that regularity so characteristic of the Shorttusked group, and may thus be distinguished.

From the foregoing it will be observed what interesting tenants of the South American forests these Marmosets are, and those who keep them as pets will find that they are fully entitled to claim a prominent place among the more favourite kinds of animal pets.

SURICATE, OR MEERKAT.-The Suricate, or Meerkat, next claims attention; it is a near relative of the Mongoose next to be described. Whilst a general resemblance is discernible, it differs from the Mongoose in possessing only four toes on each foot. It has not the groove below the nose, but is the owner of thirty-six teeth. This South African beast has a long and soft fur, grizzledgrey in colour, and, as our photograph shows (Fig. 44), black transverse stripes across the hinder part of the back. The under parts are rufous, the white head has a black mark round the eyes, the ears are black, and the yellowish tail has a black tip.

The long nose and black ears at once distinguish this African mammal from any others related to it, and that it has a distinct characteristic appearance those who have a knowledge of animals and will examine the photograph must at once agree.

The Meerkat makes a desirable pet, becoming very tame and companionable. One word of warning, however, is necessary: it is an inveterate thief!

In its natural condition it resembles the Rabbit by living in colonies. It constructs deep burrows in the sandy soil, and is very fond of the sun, coming out from its underground home at the rising of King Sol and basking in the warm sunlight. It evinces little fear of mankind, inquisitive creature that it is, but to catch one is easier said than done, for it scuttles off when approached too closely, and disappears into its fastness below ground.

Bulbs seem to be the chief food, and these the animal dislodges by means of the long, curved black claws on the fore-feet.

In captivity, too, this delightful pet-if its thieving propensities are overlooked-evinces considerable impudence and curiosity. Its whole little body seems full of fun and mischief, and its bravado is 
nothing short of remarkable, for it will approach with impunity an animal large enough to swallow it.

MONG00SE.-The Mongoose (Fig. 45), which in days gone by was known as the Ichneumon, represents a group of animals that are divided into several genera. Our photograph depicts the Grey Indian Mongoose, and to this representative species our attention may be given. This animal is, as its name implies, an inhabitant of India, and although it is of fierce disposition, it is regarded in its own country as a desirable pet because of its useful habit of preying, among other things, upon Snakes and Rats. It belongs to the Civet family, and in size may be about half as large as a domestic Cat.

The loose, coarse fur is grizzled-grey in colour, but this varies in different localities, some being rusty-red instead of grey.

Although a native of India and Ceylon, the species under review has increased its range, through the agency of man, to other parts of the world because of its repute as a slayer of vermin. It was, for example, introduced into Jamaica at a time when the sugar plantations there were subjected to the ravages of Rats. Although only a few Mongooses were turned out, their numbers soon increased, until eventually the depredations of one of the worst pests on the face of the earth were kept under control. But there is always an element of danger attached to the introduction of an animal into a foreign country, and this held good in the case in question, for the Mongooses, having performed good work in ridding the plantations of Rats, turned their attention to more desirable creatures, and commenced pillaging hen-roosts. As one writer well says, however, "it is easier to keep a Mongoose out of enclosed premises than it is to keep Rats out of open plantations." It is computed that the good deeds of the Mongoose in Jamaica alone saved the colony $\mathscr{E}_{\mathrm{I}} \mathrm{oo}, 000$ to $£_{150}$,ooo per annum; but one can have too much of a good thing, as it were, and eventually it was claimed that the Mongooses did more harm than the rodents which preceded them!

A deadly enemy to Snakes, and therefore a boon in a country where these venomous reptiles are found in large numbers, it is rare that the mammal comes to grief in an encounter. It is ably protected by means of its harsh hair and thick skin, added to which is the fact that the Mongoose possesses great adroitness when dealing with its reptilian adversary. That it is quite regardless of the effects of poison is proved by the animal having been known to "eat a Cobra's head, poison-glands and all" ! 


\section{THE BOOK OF THE ANIMAL KINGDOM}

It is, unlike many other animals of a similar nature, a day-hunter. Thus it comes about that it may often be observed and its habits closely studied. All its deeds, as has been mentioned in passing, are not beneficial, for, as Mr. Frank Finn observes, "it is particularly omnivorous, feeding on almost any animal which its great courage and activity enable it to master, and also eating various kinds of fruit. Birds, beasts, reptiles and insects contribute to its fare, and it is doubtful whether it does more good by destroying Rats, Snakes and such-like vermin, or harm by its raids on poultry and its destruction of birds and eggs generally, and harmless and useful reptiles such as Lizards."

The voice is described as "a sharp yapping bark or yelp, but when irritated, as when disturbed while feeding, it utters a growl remarkably loud for so small an animal. The young of the Mongoose are produced three or four at a time, and lodged in a burrow, which may be dug by the animal itself."

At least eight species of Mongooses claim relationship with the typical genus in Africa, whilst a similar number are accounted for in India, Ceylon and Burma. One Indian kind is noted for the fact that it feeds upon Crabs and Frogs, but further observation of this Crab-eating Mongoose is invited.

The Egyptian Mongoose deserves mention before we strike up an acquaintance with our next pet. This species is an inhabitant of the northern parts of Africa, as well as Palestine, Asia Minor and the southern parts of Spain. It is a large animal, measuring about twenty inches exclusive of the tail, and is said to have a liking for the eggs of Crocodiles.

That this is a patriarch among Mongooses is proved by the frescoes of the ancient Egyptians, which often contain pictorial references to it.

RACC00N.-The Raccoon (Fig. 46), although a somewhat shy pet, improves on acquaintance, and does well when kept in captivity. It exhibits considerable powers of intelligence and sagacity, and is remarkable for its cleanly virtues with regard to its food, washing the same in water before eating it. There are many points such as this which may be made a note of both by those who keep animals as pets and also as a result of studying wild creatures' ways out of doors. Even the cleanliness of a domestic Cat is worth noticing, for, as the reader will doubtless have observed of his own accord, Pussy goes to infinite pains not only to keep her fur spick and span, 


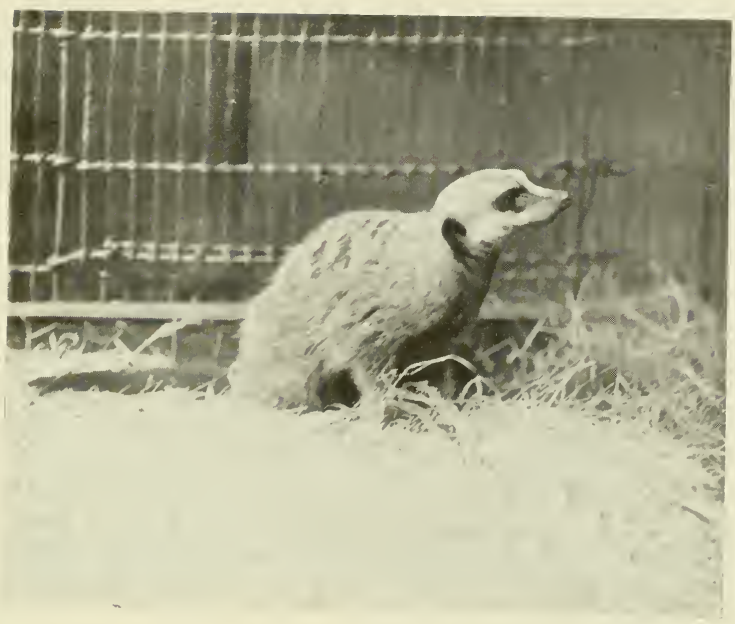

FIG. +4 - SURICATE

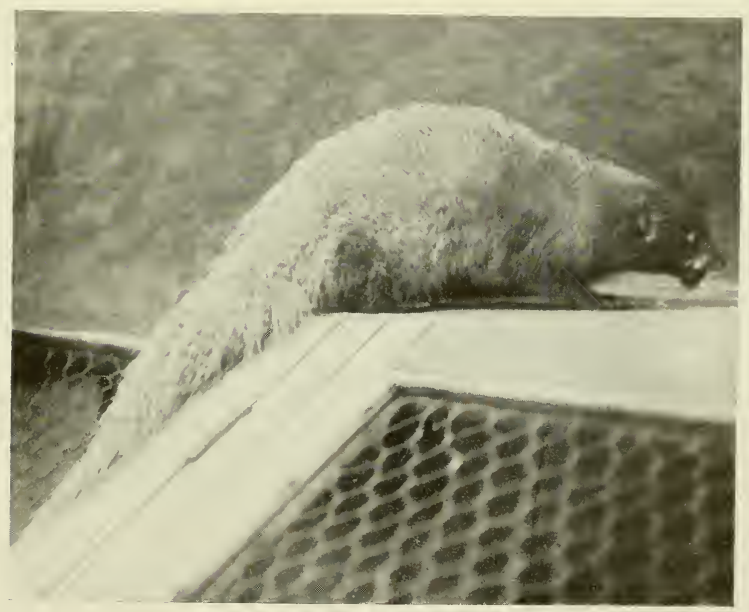

FIG. 45.-GREY INDIAN MONGOOSE 


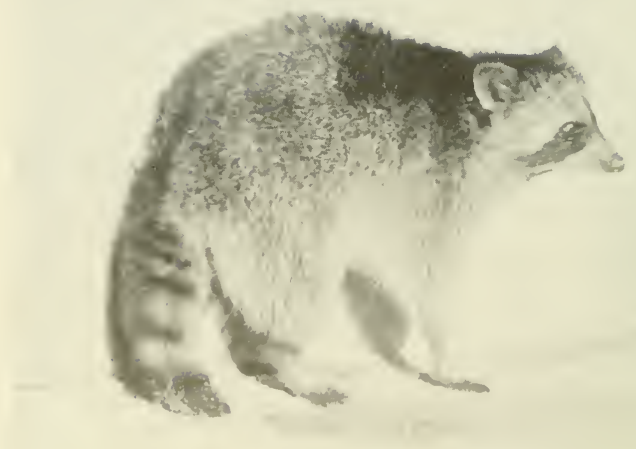

FIG. 46. - COMMON R.ACCOON

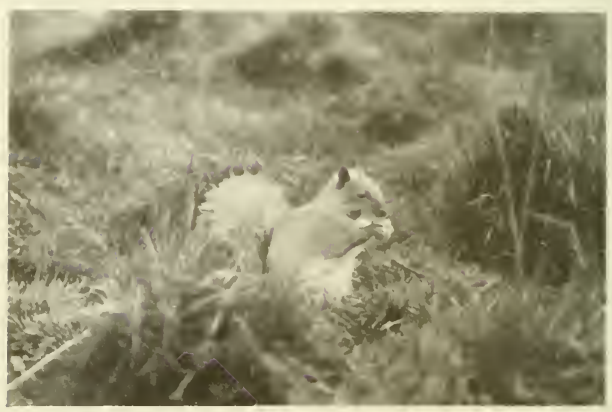

FIC. +7.- MMERICAN GREY SQTIRREL 


\section{ANIMAL PETS, IN AND OUT OF DOORS}

but exhibits a keen desire to scratch out a little pit in which to deposit and bury her own excrement.

Animals, it should be noted with emphasis, are not the dull, uncomely and unclean creatures that some people imagine them to be, and I know of many of the lower creation which can give some human beings a good start regarding their laws of morality, sanitation and home influences.

To return to the Raccoon after this digression-for in a careful and intelligent study of the world of animal life one is bound to take little journeys along some inviting by-path-there are two species. One is found in North America and the other in the South, the Crab-Eating Raccoon inhabiting the South being chiefly distinguished from its Northern relation by the short coat.

It is the Southern form that is represented in Fig. 46, and from this excellent likeness the reader can gain an adequate idea of the splendid long fur in which this Raccoon is clothed, as well as the black- and yellow-ringed tail. The handsome grizzled fur is largely used for rugs. Does not the general form of this denizen of South America strike the reader as somewhat Fox-like, more particularly as reyards the face, upon which, as will be noticed, there is a prominent black patch near the eye?

Although the tail is fairly bushy and prettily marked, it does not bear successful comparison with that possessed by Reynard, whilst there are other characteristics which amply distinguish it from the Dogs, these being the arched back (nicely shown in Fig. 46), and the habit the Raccoon has of walking on the soles of its feet instead ci on its toes. Beyond these differences, our present pet has the five toes more fully developed, and when walking spreads them out in a very singular way. Similar to the Fox, however, it is nocturnal in its habits, resorting to some congenial hiding-place during the day. There, snugly tucked up in a hole or the fork of a tree, it rests until the gloaming hour approaches and the hunger-call summons it from lethargy. Out the wary creature goes on its foraging expedition, and little comes amiss to it, both animal and vegetable food being relished. Like some prowling Reynards known to me, the Raccoon is fond of raiding a hen-roost, and we are also told that it has the habit of visiting streams and fishing out the finny tribe by means of one of its active paws.

When the rigour of Winter drives various kinds of wild folk to securer quarters, the Raccoon is to be numbered among them, for 
at such time it hibernates, several individuals frequently taking advantage of one hiding-place, evidently helping to keep one another warm in this way. Having passed the lone Winter days, the Spring sunshine tempts the creature to awake to activity, and home cares soon engage attention, as many as six young ones sometimes being born.

Although hunted a good deal, both for the sake of its fur and flesh, and also by reason of occasional depredations, the Raccoon appears to hold its own, as it were, and that it may long enjoy its wild, unfettered life is the hope of every lover of the world's fauna.

\section{AMERICAN AND BRITISH SQUIRRELS.-That the American} Grey Squirrel will soon become a familiar woodland rover in England those who visit Regent's Park and other spots where these attractive creatures have been let out may ascertain for themselves, and the amount of pleasure and entertainment that the nimble little mammal affords to passers-by is very considerable. I have witnessed some amusing episodes with regard to these out-of-doors pets in the London Parks, and often been highly interested in the remarks made by those who were unaware that the animals had really not escaped from the Zoo. Several of the adroit little rascals are at large in the Zoological Society's grounds, and more than one keeper has received a report from a vigilant and timorous visitor that there was a small animal at large! These American animals are becoming quite used to their surroundings. They are now tame and confiding, and in the tree-tops among the busy hum of the great metropolis take the place of the red-coated little gentleman of our own wild woodlands. True the grey fur of the American species is not so attractive as the rich chestnut of the British Squirrel, and there is some danger in introducing a foreign animal in our midst by reason of the damage that may be done if it be allowed to increase to any undue proportions, yet nothing but good can result from putting out a few of these pert and engaging creatures, whose ways make such a strong appeal to all those who can appreciate the delightful scampers of these arboreal rovers.

Our photograph (Fig. 47) depicts the American Grey Squirrel, and if his more sombre coloration is excepted, the differences between him and his English relative are very slight. They need not, at any rate, detain us here, but I should like to put on record what I consider is a distasteful practice, viz. keeping a Squirrel caged up in a wretched dark prison. It is obviously an out-of-doors 


\section{ANIMAL PETS, IN AND OUT OF DOORS}

pet, and one can only appreciate its habits to the full by observing it in enjoyment of the wild woodland or park where it has chosen to make its home.

Had our present section not included animals suitable for keeping or observing out of doors, the Squirrel would assuredly not have been accorded a place, as if any creature is to be recognized by having unfettered liberty it is the sly little animal now under review.

How pleasant my own pilgrimages in the woods have been made on many occasions by seeking an interview with a British Squirrel, and how many happy games at hide-and-seek I have played with the frolicsome creature as he has gambolled in the tree-tops to his heart's content.

I came across one not long since as he was engaged sitting on the ground on his haunches, with his back perched against the bole of a tall tree. He held a fir-cone in his fore-paws, much after the manner of the American species shown in Fig. 47, and I was attracted to the spot by the loud tumult made by some Missel-Thrushes, which were evidently much perturbed at Master Squirrel forsaking his home among the leafy mansions above. Their harsh scolding notes sounded strange in the peaceful retreat in which I found myself, and I knew from my experience of woodcraft that something was amiss. Careful stalking revealed the little incident I have so imperfectly described, but some satisfaction was obtained which, to those who study wild Nature's ways, is so acceptable. It is a good thing to make a point of becoming acquainted with the why and wherefore of rural sounds, for by this means a good deal of useful and interesting information is elicited, and an intimate insight obtained as to the home life of furred and feathered creatures.

The "drey," or nest, of the Squirrel always attracts attention from the young folks who may accompany me on Natural History excursions, but even to-day there are persons who ask whether the Bat or the Squirrel lays eggs! Of course both creatures, being mammals, produce their young alive, and there is every indication that the ways of wild animals will be far better appreciated and understood in the immediate future in view of the introduction into our schools of a system of real Nature Study. No more need be said here of these popular fallacies that still exist, but one or two anecdotes of Unnatural History at the Zoo related to me by $\mathrm{Mr}$. W.S. Berridge, F.Z.S., may fittingly conclude our reference to the animals recently considered. 


\section{THE BOOK OF THE ANIMAL KINGDOM}

A youth, looking at a Snake protruding its tongue, exclaimed: "Oh, look at its stinging nettle!"-A navvy and family were looking at a Lion, and the former was heard to exclaim: "Fancy him being able to kill a man with a blow of his tail!"-Old lady (to keeper of Eagles): "What do you feed them on, keeper?" Keeper : "Flesh, madam." Old lady: "Oh, how savage!"-Party in Antelope house, observing the Mice running about: "Are they put there on purpose?"

SPIX'S CAVY.--In view of the domesticated Cavies, or Guinea Pigs, which were dealt with in the last chapter, it is as well to find a place in our present section for a further representative of this interesting family of animals. Spix's Cavy (Fig. 48) is an inhabitant of Brazil, whilst the whole of its wild congeners are resident throughout South America. These true Cavies, as we may call them, are uniformly coloured, and, with the exception of the Carpincho-which is the largest of living rodents, and belongs to a different genusthey are small creatures whose tails, as is so well known, are very insignificant.

As to the ancestor of the domestic Guinea Pig some speculation still exists, but the nearest present solution of the problem is that it is descended from Cutler's Cavy, which is a Peruvian species having black fur, with the flanks and underneath parts brownish. Another well-known wild species is the Restless Cavy, which hails from Uruguay and Brazil, and is fond of inhabiting damp places. Its fur is greyish-brown in colour.

CARPINCH0. - The Carpincho Cavy (Fig. 49) attains a length of about four feet, and is thoroughly aquatic in its habits. It has bristly reddish-brown hair and a grunting voice. It is a splendid swimmer and diver, is gregarious in disposition, and, in a wild state, is very conscious of protection. It is, like its congeners the true Cavies, a vegetarian in diet, and the two individuals in the photograph are busily engaged feeding upon cabbage.

Young Cavies born in captivity are remarkably well advanced at birth, for their eyes are open, their milk-teeth have been lost, and in a few hours' time the fresh arrivals are well able to take care of themselves.

Although lacking in intelligence, the small Cavies are really good pets for young children, as they are easy to keep-if a nice dry, warm place is given to them-and are perfectly harmless.

COMMON SEAL.-Leaving these small pets, we come to a much 


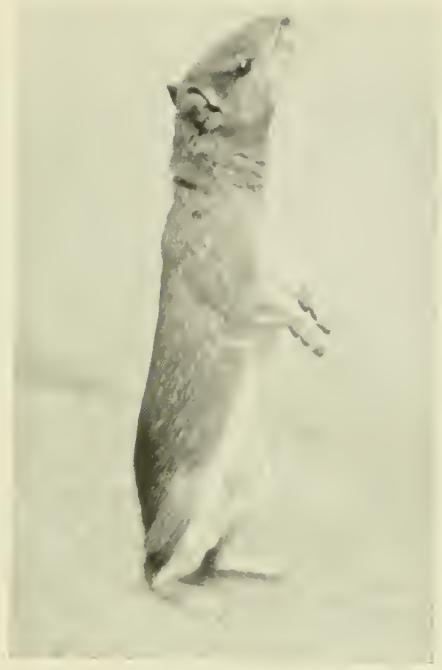

FIG. 48.-SPIX's CAVY

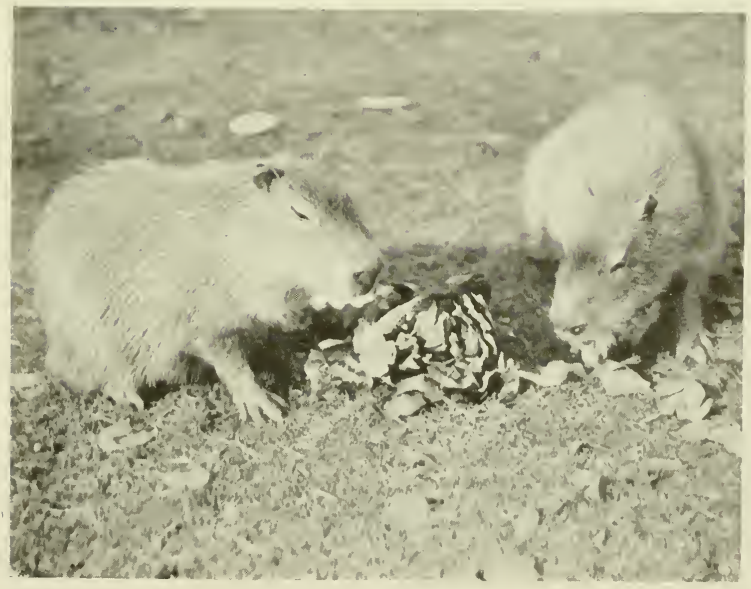

FIG. 49.-CARPINCHOS 


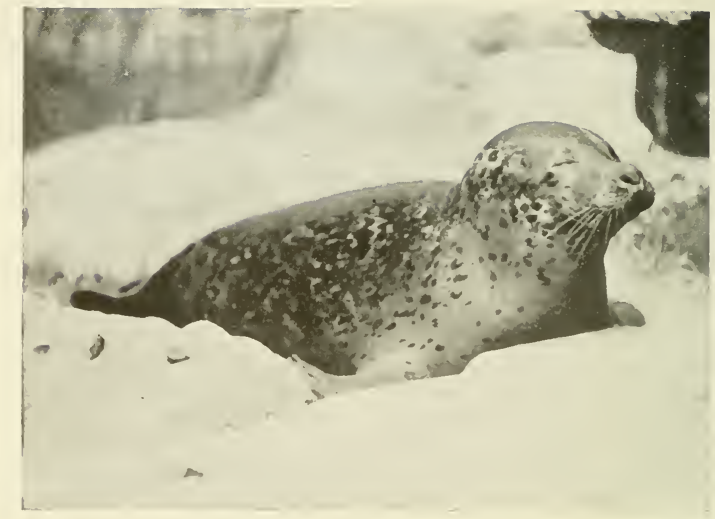

FIG. 5O.-COMMION SE.ML

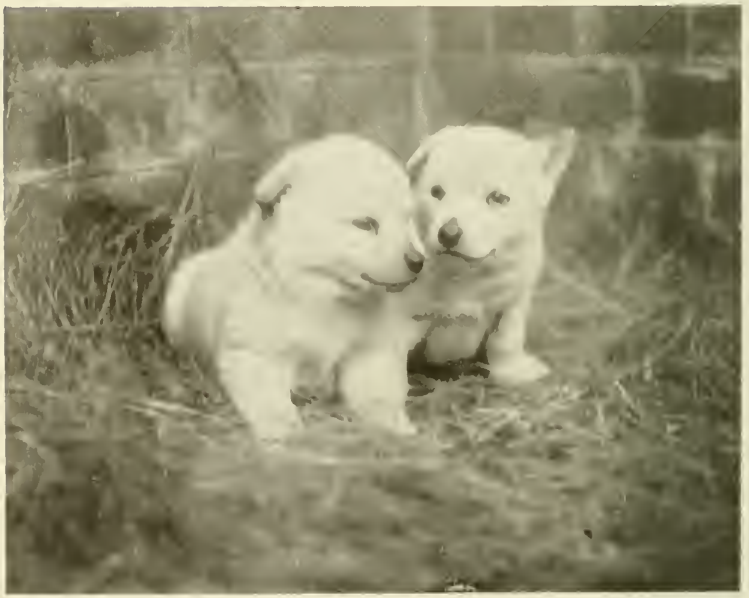

FIG. 51.-DINGO PUPS 
larger one in the person of the Seal shown in Fig. 50. Here we see the animal enjoying forty winks. Nobody should keep a Seal as a pet unless living near the sea, where a good supply of fish is guaranteed. I have on more than one occasion known the poor creature to be literally starved to death through failure to procure proper food, and this practice of keeping an animal which it is not possible to feed properly cannot be too strongly condemned.

There are a number of different kinds of Seals, both real and so-called, which, shortly stated, may be placed in three different families, such as Eared Seals, Walruses and Earless Seals. Among the first family are included the valuable fur-bearing Seals, whose pelage is of such commercial value, and these fur-bearers are naturally more highly regarded from the commercial point of view than their cousins the hair-bearers. We shall meet with the wellknown Californian Sea-Lion-which is also a hair-bearer-in a subsequent chapter, and we need only concern ourselves here with a few particulars as to Seals in general and the Common Seal shown in Fig. 50.

The Northern and the Southern Sea-Lions are worthy representatives of the Eared family, although both species are hair-bearers, whilst the Northern Sea-Bear, the South American Fur-Seal, the Cape Fur-Seal and the New Zealand Fur-Seal adequately represent the true fur-bearing species.

The Walrus is placed in a family of its own, and although there may be two species-both exclusively inhabitants of the Polar regions of the Northern and Southern Hemispheres-many naturalists are of opinion that they are so closely allied that they belong to one and the same species.

This brings us, then, to the third family we mentioned, and of these true, or Earless Seals, the Grey, Common (Fig. 50), Greenland, Ringed and Bearded need only be mentioned by name.

The Common Seal is the species mostly met with on the British coast, and it seems a thousand pities that such an interesting visitor should so frequently receive a most undesirable welcome from some hooligan with a gun or stick. The young Seals are difficult to distinguish-that is, so far as concerns the Common, Ringed and Greenland species-but there is no mistaking the first-named if an examination of its teeth is made. It has broad and thick cheek-teeth, which are characterized by being set close together; it has shorter 
limbs, a broader nose, larger head, and is altogether a more heavilybuilt animal than either of the two other species referred to.

The usual colour of the adult animal is yellowish-grey above and yellowish-white below. As the photograph well shows, the coat is marked with irregular dark-brown or blackish spots. The young ones are yellowish-white at birth, but soon get rid of their initial coat, shedding the same within a few hours of being brought into the world. Mr. Lydekker observes that this Seal possesses a wider geographical range than its cousin, the Grey Seal, "occurring not only in the North Atlantic, but also in the North Pacific, and extending on the shores of both oceans to the Arctic regions, and thus being doubtless circumpolar. In the Atlantic it is found, though rarely, as far southwards as the Mediterranean, and on the American side as far as New Jersey. In the Pacific its southern limits appear to be marked on the Asiatic side of Kamschatka, and on the American by Southern California. It is, moreover, by no means confined to the coasts, but ascends some of the larger tidal rivers to a considerable distance from their mouths; and it has been known to pass up the St. Lawrence to the Great Lakes."

Where the water is shallow and the haunt is sheltered, there one may expect to find this animal, for it sticks to the same haunts, like our bird friend the Robin, and does not, so far as is known, undertake any seasonal migratory movements.

It is not exclusively aquatic in its habits, for as each tide recedes and leaves rocks and shore exposed, the Seal rests until the incoming tide summons it to the water again. It feeds exclusively upon fish.

In the early days of Summer the young are produced, and very soon engage in graceful evolutions in the sea. This species makes a very affectionate pet if properly treated, evincing much regard for its owner, and following him about after the manner of a Dog. It has, like its relatives, a curious love for music; it is a most solicitous creature in regard to the welfare of its progeny, and is in many respects an intelligent inhabitant of our shallow seas with a lifehistory as interesting as its winning ways are entertaining.

DING0. - We shall learn more of the Dingo at a later stage in our story (see Chapter X), and it is only included here as a pet. Fig. 5 I portrays a couple of Dingo pups which are sure to make an irresistible appeal to young people. There is such an innocent playfulness and desire for fun and mischief about puppies that it is small wonder 


\section{ANIMAL PETS, IN AND OUT OF DOORS 6I}

they are such genuine favourites; indeed, it is interesting to observe how baby animals of many different kinds always attract attention. It is much the same with young birds, and I have noticed over and over again that photographs of young birds, when shown at my lectures, invariably appeal to an audience more than pictures of adult birds and representations of nests and eggs. The moment that one lets his hearers into a few of the secrets of baby birds, such as the early life of the young Cuckoo as a worthy example, greater interest is displayed. Truly the ways of all young creatures, including human beings, are vastly interesting, and attract considerable attention from those who can appreciate their winsomeness.

As regards the Dingo, although the Australian Government have not encouraged it because of the depredations it carries out among sheep and poultry, it is a favourite animal among the native tribes, but has never really become properly domesticated. It is treated well, but in spite of this frequently runs away from its owner, and does not return.

We cannot, of course, accord a place in this book to the many kinds of domestic Dogs, even if we dismiss them by referring to a few of the more important among them, but mention should be made of the wonderful pets, guardians and companions that may be found among our domestic breeds of to-day.

That the Dog has for long occupied a prominent position in the world of animal life is ably demonstrated by the pictures from facile brush and pen that have been contributed by eminent artists and writers. A more faithful animal than a trustworthy Dog probably does not exist, and Man has not been slow to so train his canine friend as to make it of service in many directions. True enough, there are Dogs and Dogs. Many of the poor little miserable outcasts one finds stranded must have possessed owners whose love for the brute creation was of the basest kind, but the finest thoroughbred, or the most perplexing mongrel, evinces commendable traits in its character if treated aright, and will learn to become a faithful hound worthy to occupy an honoured place in any household.

On the other hand, we have met people who are just a trifle too doggy, as it were! IVe are not writing of those who go in for showing Dogs, breeding them, and so on, but certain curious individuals who do not seem able to discriminate between a Dog and a human being. I have some strong ideas on the subject of our relationship with the lower animals, and have already expressed a 


\section{THE BOOK OF THE ANIMAL KINGDOM}

few of them in these pages, but I do not hold with those people whose love for animals is so blinded that in keeping them under unnatural conditions they prejudice their own health, and become a nuisance to their neighbours. Well-conducted homes exist for the reception of stray Dogs cast upon the streets, and whilst these exist, and should receive the adequate support of all those animal-lovers able and willing to give, it is not for private individuals in a hampered and restricted environment to house a whole regiment of howling Dogs, which, however companionable and faithful individually, become, when unnaturally congested, a nuisance to every one with whom they are brought into contact.

As is well known, perhaps, the Wolf-which is the largest living wild representative of the Dog family-the Coyote, the Kabern, or Abyssinian Wolf, the Fox, and the different species of Jackals all belong to the Dog tribe. Whilst there is some doubt as to the exact status of the Dingo of Australia as a wild animal, there can be little doubt that it has become an indigenous species now, and it possesses an ancient pedigree which is shrouded in the mist of ages.

HARE. - It has already been noticed in the last chapter that the Common Hare, which is such a typical animal of wild England, makes a really delightful pet when taken young, and a few further notes upon this species may be accorded. Fig. 52 depicts an adult specimen, and an old writer sums up the history of this animal very tersely as under-

"Hare, a small four-footed animal, with long ears and a short tail, that moves by leaps and is remarkable for its timidity, vigilance and fruitfulness. The first year it is called a Leveret, the second a Hare, and the third a Great Hare. Her ears lead the way in the chase, for with the one of them she listens to the cry of the Dogs, while the other is stretched, like a sail, to promote her flight."

I must candidly confess that it is as a wild animal I most appreciate the Hare, for I always associate the curious, impetuous creature with wild England of to-day. Living as it does a solitary life amid surroundings that appeal to the quiet lover of the countryside, there is something connected with this species that is entirely lacking in the case of its first cousin the IVild Rabbit. I love both, indeed all, animals, but of the two I like better to watch the antics of the Hare.

Its movements are less restricted, its plan of campaign seems more comprehensive, its wanderings across country are more ex- 


\section{ANIMAL, PETS, IN AND OUT OF DOORS $6_{3}$}

tended and power of continuous locomotion greater, whilst its love of the free, unfettered wild and a terrestrial rather than an underground citadel, make a strong appeal to my innate love for all things that live out of doors.

It is a question very largely of one's environment, as it were, and the associations that are linked up with the same. Ever since I was a boy I have regarded the Hare as a typical representative of the wild countryside; it has always been indelibly associated in my mind with wide-spreading fields across which the wind of heaven finds neither barrier nor anchorage. I could even to-day make a pet of a Leveret (a young Hare), and it would afford me considerable amusement and charm me by its winning ways; but in confined quarters I feel sure the animal which I have for so long associated with fields and meadows would not make such an irresistible appeal to me.

It is a good thing we do not all see or think alike. What appeals to one makes a poor impression upon another, and whilst some people I know regard the Wild Hare as a creature devoid of understanding and possessed of madness-especially during March -it is its weird nature and protracted wanderings that have for so long made an impression upon me. My country pilgrimages would be considerably lessened in both pleasure and interest if my wild companion did not entertain me with his mad scampers and engaging frolics, and my stalking adventures in the country would be far from complete if the subject of this eulogium did not invariably become associated in my mind with a good deal of mystery. I love and appreciate his roving disposition and his positive enjoyment of a wild, untended solitary life. There is a fascination in watching him because observation of his home life is so difficult, and there is always a craving on the part of the enthusiastic field-naturalist to get on more intimate terms of acquaintance with him.

There are some animals around us which we have come to learn about and recognize as part and parcel of our existence, as it were. These cold wintry days, as I write, would be peculiarly dismal without the jocund note of defiance uttered by a Blue Tit, or the bugle-call of a Hedge Sparrow as the well-groomed bird searches for food in the naked hedgerow.

There are still other familiar wild friends with whom a close acquaintance is more difficult, common though they may be. Their life and habits are such that nought but the free, unfettered wild 


\section{THE BOOK OF THE ANIMAL KINGDOM}

suits them, and one invariably associates them with unrestrained liberty and unlimited freedom. I am thinking in this respect of the Skylark on the one hand, and the Hare on the other, for both bird and beast love a wide range, one of space and the other of earth. Thus may they enjoy their little day.

It may not generally be known that whereas the young of the Rabbit are born blind, young Hares are brought into the world with their eyes wide open, and thus resemble the Cavies of whom we have already written. There is just reason for this, as the young Rabbit is born in a snug nest below ground, and is thus more protected from its numerous enemies, whilst the young Hares are born above ground, and are surrounded by foes both on the earth and above it. So it comes about that we find the Leveret soon able to run about and take care of himself.

EGYPTIAN JERB0A.-The last animal pet included in our present section is one of the most delightful little creatures known to us. The Egyptian Jerboa (Fig. 53)-for such is its name-is just that kind of pet to give to a young boy fond of animals. It is such an engaging little being that it cannot fail to arrest attention and create interest in an intelligent youth having a love for pets. As will be observed, the Jerboa is at once distinguished by its long tail and very long hind-legs. It reminds one in a measure of the Kangaroo, especially so far as concerns its mode of progression.

The Jerboas, and their relatives the Jumping Mice, are terrestrial creatures, and are mostly found in Asia and Africa, although there is one species in North America and a few others in Southern Europe.

The Jerboas proper are split up into two groups, the first consisting of species possessing three toes on the hind-feet, and the second of those which have five toes on the hind-feet. The Egyptian species figured in the illustration belongs to the three-toed section, the two small lateral toes on the hind-limbs having been completely lost. It measures about six and three-quarter inches exclusive of the tail. the total length over all being about fifteen inches. It is sandy-grey on the upper parts, with white below, and a wide stripe down the hind-limbs. The long tail is yellowish-brown on top and whitish underneath, tipped with black and white, a characteristic feature.

It is upon the dry desert that this little mammal makes its home in company with its fellows. The arid nature of its surroundings makes one wonder what the animal finds to eat. It is largely a 


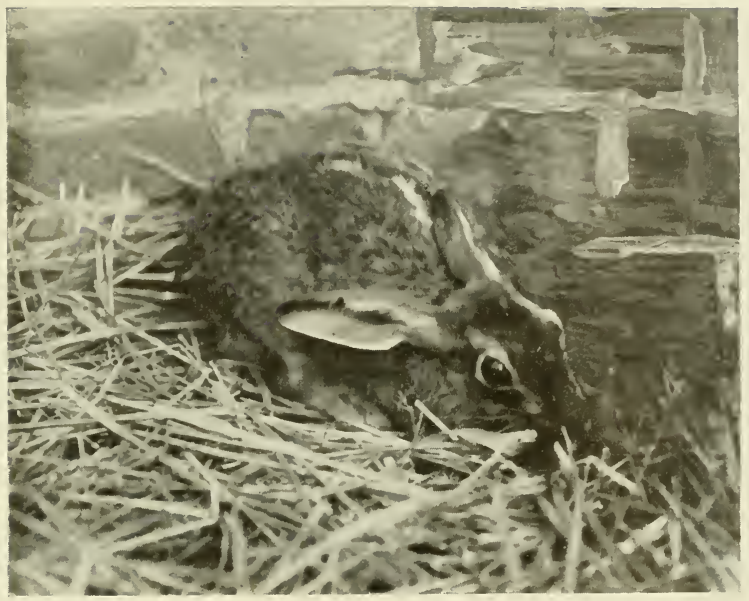

FIG. 52.- COMMON HARE

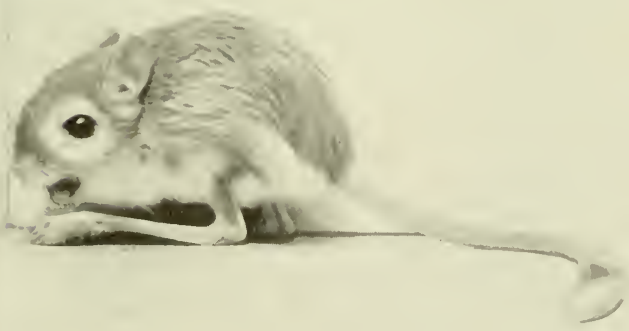

FIG. 53.--EGYPTIAN JERBOA 


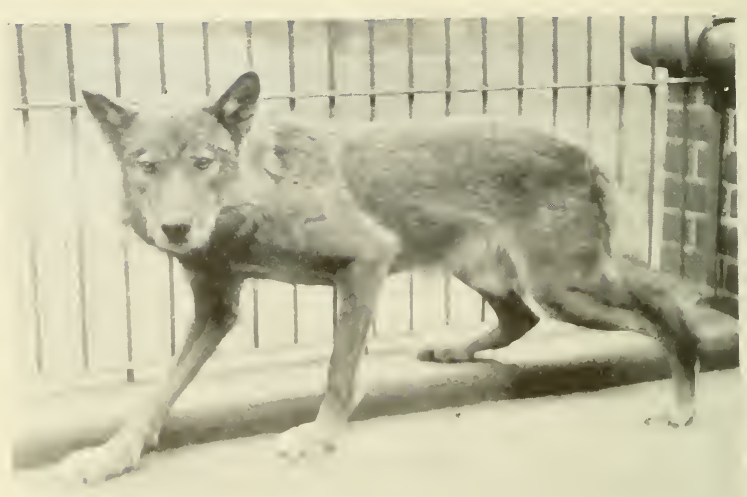

FIG. 54- SIBERIII WOLF

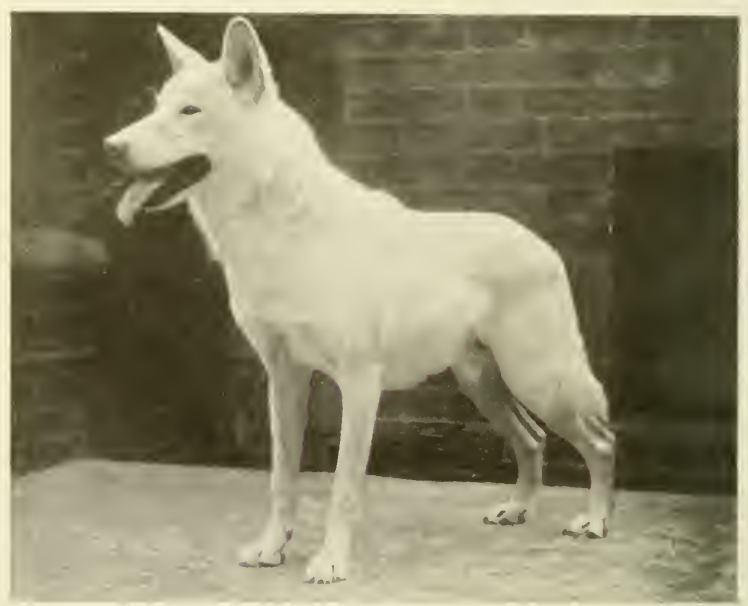

FIG. 55.-ALBINO SIBERIAN WOLF 


\section{ANIMAL PETS, IN AND OUT OF DOORS 65}

vegetarian, but will also eat, in a wild state, insects and carrion. It comes from its burrow in the sandy soil at nightfall, and is very rarely seen, being of an extremely shy disposition. Beyond this, its colour harmonizes with its surroundings in a remarkable way. When first disturbed it moves slowly, but as it quickens the pace it proceeds to leap in a wonderful manner, the tail being carried straight out behind. Its movements become very rapid at last, so much so, indeed, that they have been confused with the flight of a bird.

Easily tamed, a beautifully groomed and engaging little creature, it seems strange the Egyptian Jerboa is not a more general favourite, while those who have kept it are lavish in their praise.

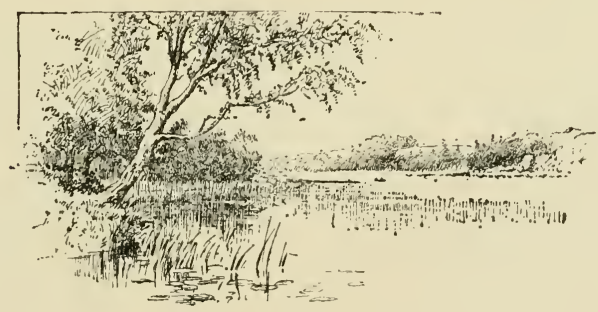




\section{CHAPTER IV}

\section{LOVERS OF THE CHASE AND SOME OTHERS}

WOLF. - IVe shall make acquaintance during the progress of our present expedition with several members of the Dog tribe, and towards the conclusion one or two other kinds of animals. Whilst it must be admitted that all perhaps are not strictly entitled to inclusion as lovers of the chase, there is bound to be some amount of overlapping in a work of this description, and a certain amount of licence must be allowed.

The Wolf is rightly entitled to premier honours in this chapter, and in Figs. $5+$ and 55 we have presentments of two specimens from far-away Siberia, showing, in Fig. 5t, the normal type, and in Fig. 55 a magnificent albino.

Both photographs depict the animal in excellent poses, the first showing the large head, long body, massive limbs and skulking gait, and the second portraying a far happier-looking individual with body erect and standing at attention as it were.

The general Dog-like form of the Wolf shown in Fig. 55 is particularly striking, and it is small wonder perhaps that interesting associations are inseparably connected with these wild denizens when one remembers the many kinds of their domestic brethren whom man has for so long made his companions. There can be no confusion in the animals constituting the Dog tribe. They possess strong characteristics which cannot be mistaken, and all of them, except the curious Cape Hunting Dog which we shall meet with shortly, are clothed in a somewhat sombre coat.

That we are only able to make acquaintance with a small selection of the Dog tribe will be apparent when it is stated that there are probably about forty distinct species. Although, as has been hinted in passing, the general colour of their coats presents a remarkable uniformity, it should also be mentioned that in these IVild Dogs there is a noticeable tendency for "either individual or seasonal variation, both in respect of colour, and also as regards the length of their 
fur." This is especially exemplified during the Winter, when the general effect is a lighter coat among those species inhabiting the Arctic Circle, and a corresponding increase in the length of the fur. A further interesting feature that is worth mention before passing on is that, unlike the Cats, many Wild Dogs hunt in packs. They are, it appears, largely guided during their hunting expeditions by a keen sense of smell, but it has also to be noted that their power of seeing and hearing are remarkably acute.

The Wolf is an apt illustration of a pack-hunting species, and the reader will be acquainted with accounts of the daring movements of these animals in countries where the weather is of such severity that the creatures inhabiting lonely solitudes are often hard put to it to obtain a living. Hard weather predicts hard hunting, and union being strength, the Wolf puts these things to the test with no small measure of success. At such time its fierce disposition knows no bounds, and its strong, wiry form and powerful teeth are such that its deeds may at times indeed bewilder the least timorous among us.

There is a species of IVolf in the Falkland Islands, but with that exception the genuine animal is not found outside the Northern Hemisphere. It is quite unknown in both Africa and South America. It nevertheless has a very extensive range, being not only an inhabitant of certain parts of Europe, but also of the greater part of Asia north of the Himalayas, penetrating as far East as Japan, and it also roams over nearly the whole of North America, as we shall presently see.

In Britain it appears that the last WVolf disappeared towards the close of the eighteenth century, but its remains are often discovered, and not long since a well-known Irish naturalist came across a quantity of bones in the Emerald Isle, where, we are told, this animal was very common in the time of Oliver Cromwell.

It is during the hard weather that the Wolf travels about in packs. At other times it is either solitary in disposition or is joined by a mate. Open country and the regal splendour of the forest equally appeal to this four-footed hunter. It is a typical haunter of the silences. Its hunting excursions are carried out both by day and night, and although not very plucky when encountered singly, at night, when reinforced by its comrades, or when the pangs of hunger are keen, it exhibits a change of front and is a dangerous beast to encounter. So much so, indeed, that not many years ago over one hundred and sixty people were killed by Wolves in Russia. 
The prey is a differential one. Birds are of course largely sought after, but larger game, such as Deer, Sheep and Cattle, are also preyed upon. The greatest damage is done when the animals stalk the country in packs, for it is at such a time deeds of daring are perpetrated which would not be risked under less forceful conditions.

The food of this bold adventurer, however, is not restricted to the animals mentioned, for, when hunger is upon it and food has to be obtained at all costs, it will partake of carrion and offal as well as smaller fry such as mice, frogs and some kinds of plants.

Like the sagacious Fox, the Wolf appears on occasions to kill far more food than it can possibly eat, seeming to kill for killing sake. By pursuing this unenviable habit it perpetrates, like the Fox, more harm than it otherwise would do, and thus adds to its depredations a series of misdeeds which, for some unaccountable reason, it is unable to withhold.

Where the ground is rocky, in the thick undergrowth of the forest, beneath the shelter of a fallen monarch, or sometimes in a hole in the ground, such are a few of the chief places chosen by the Wolf as a suitable lair. Here the six to ten cubs are born during the Spring, and these keep company with their parents for some considerable time.

This is, as might be expected, a very tenacious beast, its speed and endurance being on occasions quite phenomenal. In a similar way to the wary Fox, it is an adept at avoiding traps, and when it does happen to fall a prey to the cunning ingenuity of man, it often evinces much strategy by feigning death in a most realistic manner and eventually making good its escape.

We are told that its loud and prolonged howl, when listened to during the shadowy stillness of night, is something to be remembered, for the cry of one animal is sufficient to lead the inexperienced traveller to suppose that a pack of hungry Wolves may be close upon him.

TIMBER WOLF.-The Timber Wolf shown in Fig. 56 was born at the Zoological Gardens in London. It was reared by a Retriever bitch, has become extremely tame and docile, and has for a companion its foster-brother.

This species is found in North America, and is a beast of the wooded mountains, hence its popular name of "Timber" Wolf. It is also known as the Great Grey Wolf, for it measures in its largest form some three and a half feet long, exclusive of the bushy tail. 


\section{LOVERS OF THE CHASE AND O'THERS 69}

The under-fur is slate-grey in colour, and this is not found in the animals which inhabit more southerly regions. It is rufous or yellowish-grey above, underneath it is whitish, and the tail frequently has a tip of black.

Mr. Ernest Ingersoll, in his Life of Mammals, gives a delightful account of this animal, in which he says that "as the Summer closes and the whelps grow, the parents take them out with them and show them what is good to eat and how to hunt for it. With the onset of Winter times become harder, the small creatures disappear, and then the Wolves must arouse their strength and intelligence to outwit and overcome the larger animals-the Wild Cattle, Deer, Antelopes and the like upon which they prey.

"The peaceable disposition of Summer changes as the snow fills the forests, the cold gales moan through the trees, and the long, dark nights enshroud an almost dead world, into hungry ferocity and a force of craft and caution born of the direst need, breeding a daring which at last makes the animal formidable to man himself. . . . In is in Winter, mainly, when the larger animals must be depended upon, that the Wolves form themselves into 'packs' and assist one another. To this class of animals hunting is truly 'the chase,' for their method is, having found their quarry (in which the good nose for a trail and the keen hearing assist them), to keep it in sight and run it down.

"The endurance of their gallop is astonishing, yet most Deer, Antelopes and Horses can outspeed and outswim them, and would usually escape a single Wolf. Therefore, two, or sometimes many, unite, and by relieving one another, cutting across corners, surrounding a pond in which some fleeing victim has sought safety, or otherwise acting in concert, will exhaust and pull down an animal large enough to furnish a meal for all-if the later ones are not too slow in arriving! A band of Arctic Wolves will depopulate a district of Reindeer in one Winter; only the Polar Bear and the Musk Ox can hold their own against them... . Dwellers on the frontier, or in thinly settled and mountainous districts, suffer much from the depredations of the bigger Wolves, which maim more than they kill and eat, when famine, or the lesson learned from some previous success, leads them to attack domestic animals. . . . This destructiveness, and the value of their pelts, have led to their extermination throughout the more thickly settled parts of both the United States and Canada, and even in the Far IVest they have 
become scarce since the disappearance of Bison, Elk and Blacktail. .. A black variety still haunts the recesses of the Florida ever. glades. . . .

"In the ranching districts, however, Cattle and Sheep keep many bands alive wherever there are rocky fastnesses to which they may retire, in spite of the traps, poisons and guns which they understand so much better than did their forefathers; but they are not as adaptable, clever and safe as the Coyotes."

COYOTE, OR PRAIRIE WOLF.-It will be as well to introduce the Coyote, or Prairie IVolf, here in view of the mention made of it by Mr. Ingersoll. Unlike the animal last under review, the present inhabitant of North America and Southern Canada is specifically distinct from the Common Wolf. The Coyote is smaller in stature and possesses a much more prominent tail in thickness, length of fur and bushiness.

Fig. 57 will give a general idea of the form of this inhabitant of the prairie. The thick fur in which it is clothed gives it a bulkier appearance than it really possesses, the legs seeming to be short and stumpy. It reminds one somewhat of a shaggy-coated Collie Dog, but it varies a good deal in colour according to the season.

In Summer it is bright fulvous-brown, in Winter it is grey or greyish, and in both instances there is a black shading on top of the ground-colour which has the effect of forming stripes down the back and elsewhere.

Although the Common Wolf will on occasion burrow in the ground of its own accord (a habit which, so far as my experience goes, the sly Fox never exhibits), the Coyote is much more fond of carrying out excavation work, and is to be regarded as not nearly so savage in general disposition. In consequence it is not found to be so destructive, and makes quite a solicitous pet in captivity.

In many of its ways it is, of course, very distinctly Wolf-like, sometimes hunting in packs and offering, when attacked, a fierce defence. Out on the lone wastes of the vast prairie the voice of the Coyote gives that touch of weirdness and wildness to the environment which has a peculiar fascination for the stalker. Although a different howl from that of the Common Wolf, it is quite as loud.

In the matter of diet the Coyote is by no means a particular beast, feeding upon various small mammals and birds as well as wild fruits of various kinds. In keeping down such creatures as Rats and Rabbits there seems little doubt that the Coyote acts as 


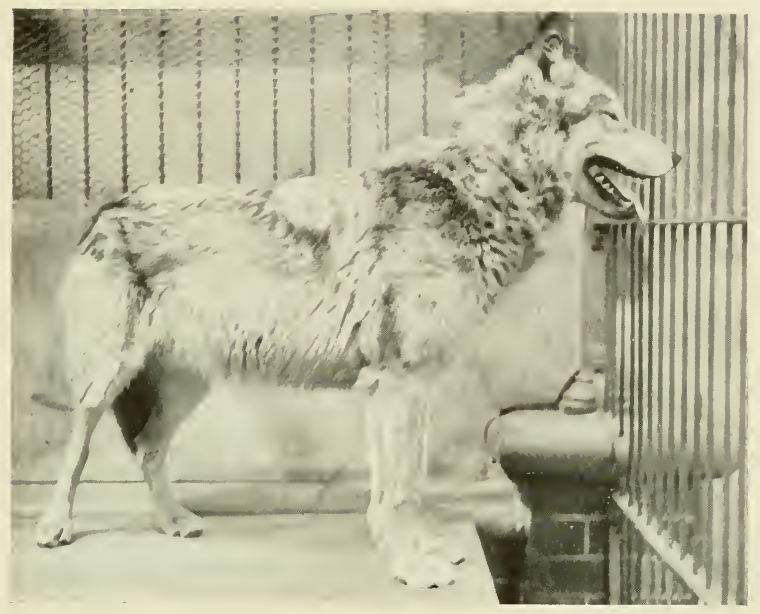

FIG. 56. - TIMBER WOLF

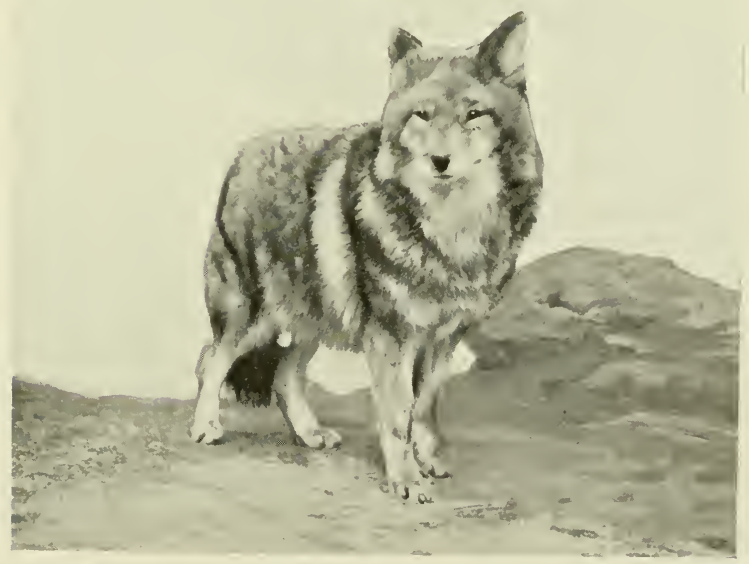

FIG. 5\%-PRAIRIE WOLF, OR COYOTE 


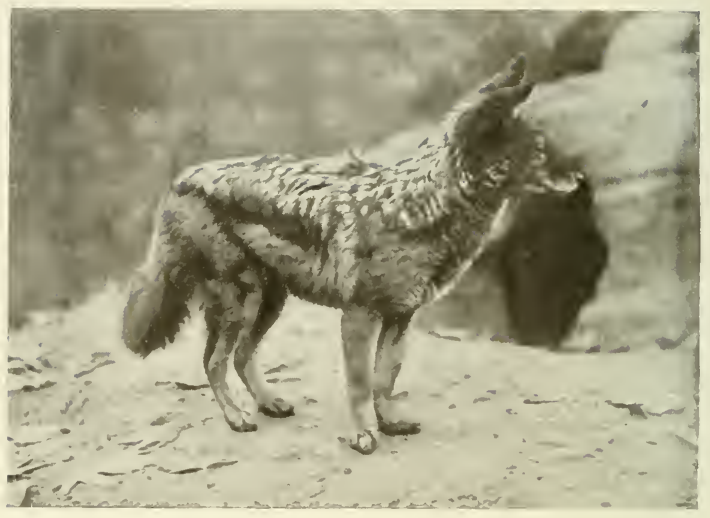

FIG. รో.-BL.ICK-BACKED JACKAL

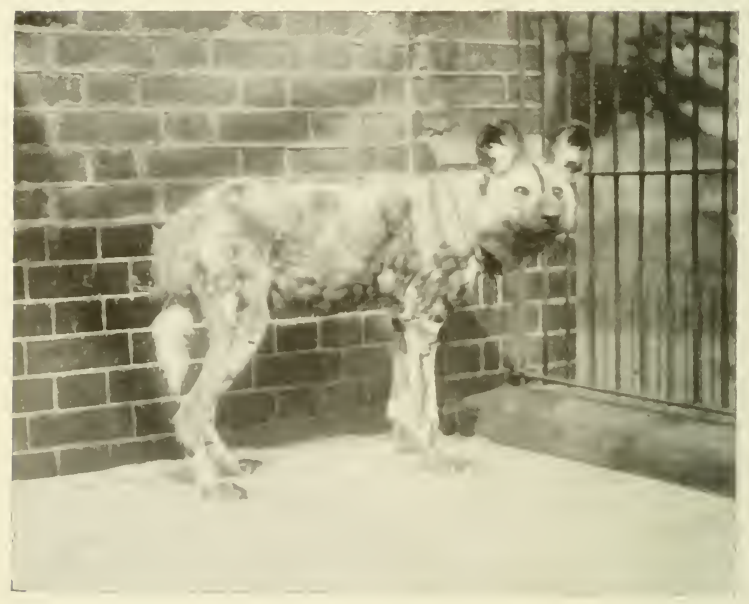

Fli. 59. C.NP HLNTING DOG; 
one of Nature's balance-keepers, and the amount of good performed by any given animal in this respect is very often overlooked. It certainly does not appear to attack the large prey which the hungry Wolf makes raid upon, one reason probably being that its speed is much less than that of its dangerous relative, but it does make serious attacks at times upon poultry-yards, pigsties and lamb-folds. From five to ten cubs are born in early Summer.

BLACK-BACKED JACKAL.-If the great Continent of Africa does not possess a Wolf, it numbers at any rate among its many other remarkable animals the Black-Backed Jackal, and also the most interesting Cape Hunting Dog which we shall meet with shortly. The Jackal is shown in Fig. 58, and this species is justly entitled to early mention because it has been well described as "the handsomest and most distinct of the group of wild canines known as Jackals, which, although presenting some points of resemblance to Foxes, come nearer to the Wolves. Indeed, as far as size goes, there is little to choose between the large dull-coloured Jackal of Egypt (Canis anthus) and the undersized Wolf of the Indian Peninsula."

Jackals may be compared in size to that of a large Fox, but the Black-Backed species under consideration has a more prominent tail than its congeners. The appendage is not so brush-like as that of the Fox, but that the animal affords sport is testified by the fact that in South Africa it has been regularly hunted for a long time after the same method as applied to the Fox in England.

It perpetrates much damage among flocks, and adds to the Jackal's reputation of cowardice. Like the Coyote, its diet is omnivorous, for it will hunt and kill any animal inferior to it in size, such as Hares and Poultry; it readily devours carrion, and thus acts as a scavenger, and Mr. Finn remarks that "even a Water-Tortoise has been found in the stomach of one."

Unlike the three animals we recently met with, the Black-Backed Jackal is of a much more solitary nature. At nightfall several may perhaps be observed together on occasions, but the gregarious instincts of the race are absent in the case of this species. Even the parents do not reside with their cubs, the latter (which number about six) passing their time in an "earth," or burrow, and the dog and vixen housing themselves in some cover in the vicinity.

Unlike the industrious Badger, or even the Rabbit, the Jackal does not aspire to much as a burrowing animal, preferring to take 


\section{THE BOOK OF THE ANIMAL KINGDOM}

advantage of the labours of others, and rarely excavating an earth on its own account. One important point deserves mention in connection with the homestead, and that is the burrow has a sort of emergency exit in case of necessity.

The Black-Backed Jackal is not only an inhabitant of South Africa, but is found as far north as Abyssinia. The note is described as a wailing laugh, and has been likened to "wa-ah-wah, wah, wah." That the beast does well in captivity is shown by the specimen illustrated, the same being a tenant of the London Zoo.

CAPE HUNTING DOG.--So far as the scientific classification of animals goes, we have for the time being left in the rear the Wolves, Jackals and other members of the Dog tribe, and have reached an animal which is not included among them and which has been assigned to a different genus. Although IVolf-like in parts, the Cape Hunting Dog is a more lanky beast, it has four toes on each foot, instead of five on the fore-feet, and is characterized by being spotted in an irregular way.

Fig. 59 shows the broad, flat head; somewhat large, raised ears; long limbs; skimpy fur and prominent black mark on the forehead. This latter, however, is not always present. The fur is variously coloured, being a mixture of grey, white, yellowish and black, with blotches or patches on each side of the body.

This IVild Dog is an inhabitant of that part of Africa which is situate "southwards and eastwards of the Sahara." One of the most interesting points concerning it is the similarity which exists between it and the Spotted Iyana which inhabits the same country. The resemblance, however, is merely superficial, and there is no close relationship between the two beasts. The resemblance is most noticeable in those Dogs which have a more ochreous tint about them and in which the dark parts are spotted. Naturally enough this curious resemblance has given rise to much speculation among Zoologists, but no definite conclusion has yet been reached as to exactly how the Cape Hunting Dog gains anything by "mimicking" the Hyæna in the manner referred to.

It is, like the Iyyana, a prowler of the night for the most part, but hunts in organized packs. When thus engaged, the movements carried out are well worth noticing, extreme strategy and cleverness being displayed, the animals possessing remarkable powers of endurance and relieving one another in the chase in a very delightful way. 
This is a bold, courageous hound; for mankind it cares but little, evincing, as a matter of fact, considerable curiosity at the latter's approach, and merely steering clear for fear of anything untoward happening. When disturbed with young, however, we are told that they do not seek shelter in the large holes on the desolate open plains which they frequent at such times, but retreat hastily across the waste land accompanied by their young.

Gordon Cumming, the big game hunter, writing about 1845, remarks that "the devastation occasioned by them among the flocks of the Dutch Boers is inconceivable. It constantly happens that when the careless shepherds leave their charge, in quest of honey or other amusement, a pack of these marauders comes across the defenceless flock. A sanguinary massacre in such cases invariably ensues, and incredible numbers of Sheep are killed and wounded. The voracious pack, not content with killing as many as they can eat, follow resolutely on, tearing and mangling all that come within their reach."

Among other vastly interesting things the same observer also notes that the "voice consists of three different kinds of cry, each being used on special occasions. One of these cries is a short angry bark, usually uttered when they behold an object which they cannot make out. Another resembles a number of Monkeys chattering together, or men conversing together when their teeth are chattering violently from cold. This cry is emitted at night, when large numbers of them are together, and they are excited by any particular occurrence, such as being barked at by domestic dogs." But the third and last cry is the most curious, I think, of all, for it "resembles the second note uttered by the Cuckoo which visits our islands during the Summer months, and, when heard in a calm morning echoing through the distant woodlands, has a very pleasing effect."

Truly this is a wonderful adept animal so far as concerns its hunting proclivities. There is no other beast exactly like it, and in spite of the depredations enacted it would be a thousand pities if we lost it from the African fauna. Since Gordon Cumming's day the beast has become less conspicuous, but it is to be hoped that it will remain a typical inhabitant of open dry country in Africa for many years to come. Among Cattle and Sheep it commits, it is true, sad havoc, but to the naturalist the manner in which it hunts for its prey is bound to make a strong appeal, and not the least interesting 


\section{THE BOOK OF THE ANIMAL KINGDOM}

feature that may be mentioned is the skill displayed "in driving their game towards the home of the nursing bitches, so as to kill it conveniently near to them. In short, they seem to know all about hunting that an animal could learn, their tactics being nearly perfect."

DHOLES, OR INDIAN AND SIBERIAN WILD DOGS.-Leaving the African continent, let us in imagination take a trip to India, for there we may observe the Dhole, Indian, or Red Dog. The specimens exhibited in Fig. 6o came over to England with our present King's collection in 1906, and were the first of their kind exhibited at the Zoological Gardens in Regent's Park.

The Red Dog is a resident of the forest in its native land, and possesses a wide range in spite of its being an inveterate enemy of game.

For purpose of comparison it is interesting to take notice of the Dhole of Siberia, or, as we may call it, the Siberian Wild Dog. This latter, as will be observed after examining the specimen depicted in Fig. 6r, has a prolific Winter coat and a large brush-like tail. It is lighter in colour than its Indian relative.

Strictly speaking, these Dholes, as some naturalists prefér to call them, are distinguished from Dogs, Wolves and Foxes by being the possessors of a less number of teeth. There are two teeth missing in the lower jaw, and to this divergence must also be added the long hair which is situate between the pads of the feet, and further the greater number of teats. These distinguishing differences dispel the idea that the many breeds of domestic dogs are descended from these so-called wild kinds, and hence, as Mr. Finn rightly remarks, "the term Dhole is preferable to that of Wild Dog."

A lover of the chase, the Indian Dhole hunts in packs, and its courage at such times is nothing short of remarkable when it is remembered that it is no larger than a Collie Dog, and that even such a large beast as the Gaur, an Indian IVild Ox, may fall a prey to its cunning. In the forest, too, the game stand a poor chance when a hungry pack of these Indian Dholes decide on a night's slaughter. Deer are persistently pursued, and once the Dholes get on the track of likely prey their pertinacity knows no bounds. Having come up with their larger cousin of the wilds, it is he or they who are destined to prove conquerors, for one or other must assuredly give in. The Dholes in their strongly organized pack bait their prey until they prove successful combatants. 


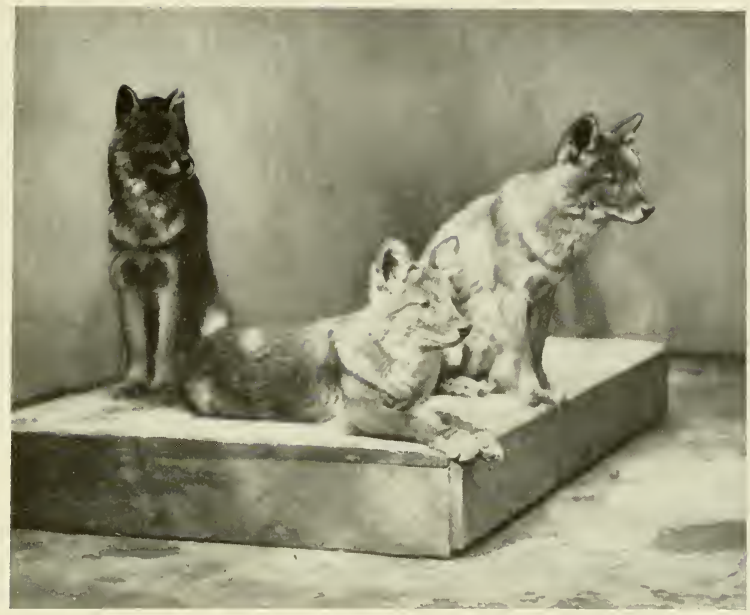

FIG. 60.-INDIAN WILD DOGS

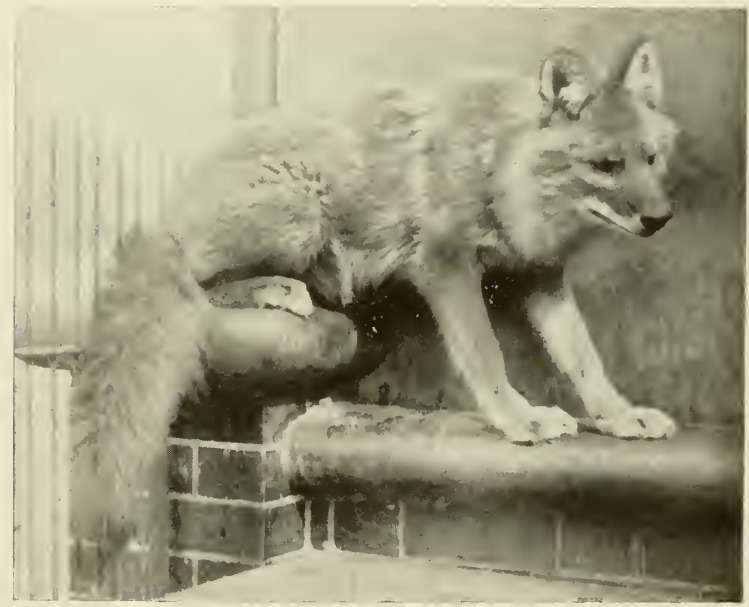

FIG. 6I.- SIBERIAN WILD DOG 


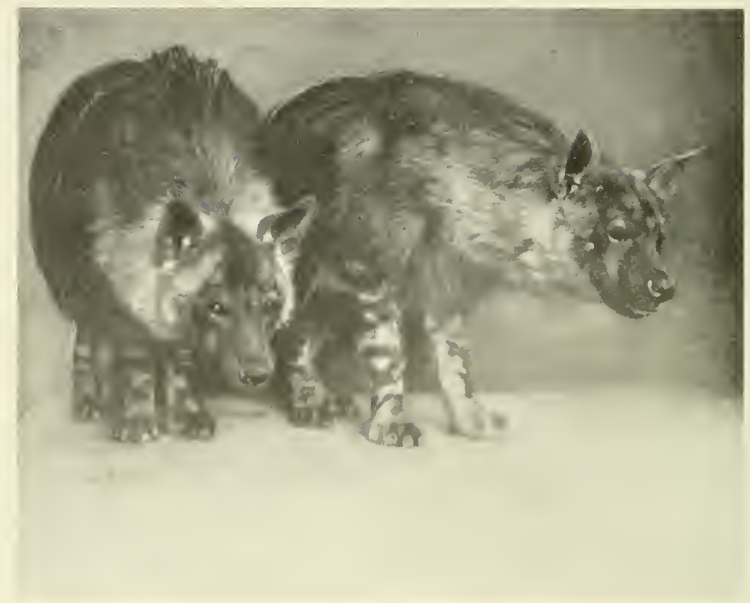

FIG. 62.-BROWN HY.ENAS

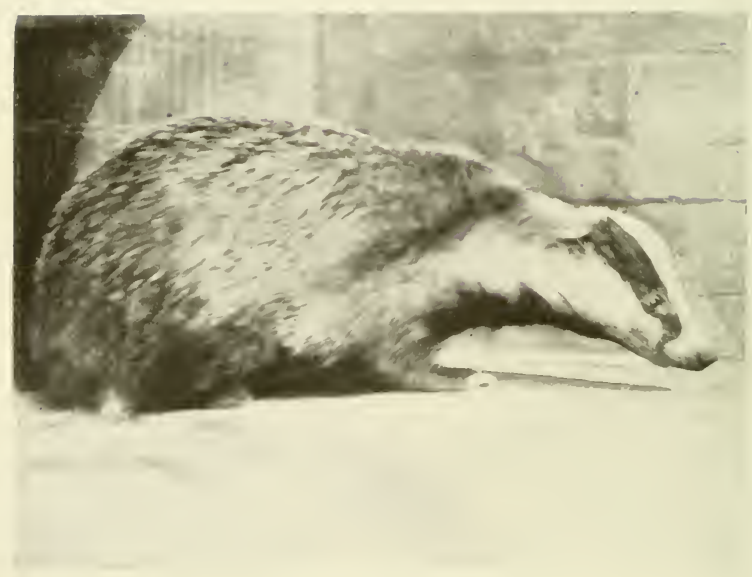

FIG. 63. - COMMON B.IDGER 


\section{LOVERS OF THE CHASE AND OTHERS 75}

It seems remarkable that such a small animal as this should be capable of accomplishing such wonderful deeds of daring, but union in their case indeed is strength. To reflect upon the fact that an animal no larger than an ordinary Collie can successfully attack a large beast like the Gaur, which even the redoubtable Tiger usually fights shy of, is extraordinary. Indeed we are told by a highly competent authority that "even the Tiger himself is believed occasionally to be killed by the red pack, and in any case their operations so terrify his prey that he may be forced to leave the depleted district."

The Dhole is not a graceful animal by any means, but what it lacks in this respect it makes amends for in others. Its bite is of a terribly severe nature, and when the pangs of hunger are severely felt one can imagine what an onslaught must be made against the foe. On one occasion only has the Indian Dhole been known to attack man, but hunters consider the Siberian beast a nasty nut to crack, and it is distinctly dreaded. We are told that if the Indian species acquires in time dangerous habits it will become a much worse enemy to the natives than the Wolf or even the man-eating Tiger!

Most of the animals we have so far considered eat carrion as well as being great hunters and lovers of the chase, but with the Dhole this is not so.

The breeding operations are carried out in an earth which is excavated by the adults, and, like the Rabbit, "in some cases, at all events, they form quite a colony." The young ones, instead of being red like their parents, are sooty-brown and much resemble young Fox-cubs.

BROWN HYÆNA. - I have noted how most people who visit collections of wild animals in which Hyænas are included, purposely fight shy of these nocturnal wanderers. Why is this? True enough they evince considerable restlessness in their dark, ill-suited cages, and their cry is ear-splitting, but exactly why they should be such poor favourites among the general public I have long failed to understand. Probably it is because of their "skulking, cowardly, treacherous and cruel" habits, but to my mind the most hideous animal living - the Tasmanian Devil, if you like-has some interesting trait in its character deserving of notice, and it is only as a result of a comprehensive knowledge of wild creatures that one can gain any adequate idea of their relative differences in form, structure, 


\section{THE BOOK OF THE ANIMAL KINGDOM}

habits, etc. Taking it for granted, then, that the reader of this book at any rate sees nothing repulsive in the Hyæna, let us endeavour to learn something of interest concerning it.

In view of the inclusion in this chapter of the Cape Hunting Dog and the superficial resemblance between it and the present species, it is particularly appropriate that the Brown Hyæna should be accorded a place. It will be observed from the two animals depicted in Fig. 62, that the general markings upon the Brown Hyæna are self-coloured, and although it bears a resemblance to the Striped species, it is more particularly noticeable in this respect because of the markings on the short-haired legs.

We are fortunate in having a photograph of this wild prowler, because its numbers have now become so diminished that it is believed to be on the verge of extinction. Its resemblance to the Wolf is exemplified in several ways, but it is as well to bear in mind that true Wolves do not inhabit South Africa, their place being taken by the animals now under review.

When it roamed over the African plains in days gone by this must have been a formidable beast to encounter, as we are told by early colonists that it was a ferocious and dangerous foe to comè in contact with.

Mr. Selous, in describing one of his many exciting adventures in Africa, relates that on one occasion a Hottentot murdered a Kaffir boy in cold blood, and eventually suffered the penalty of death for his dastardly deed. He states that the Kaffirs assembled and "at once knocked his brains out with their knobkerries." The point of the story, however, which concerns us is the information given regarding the fate of the murderer's body, for the intrepid hunter remarks that "his body was dragged just over a little ridge not three hundred yards from the wagons. In the night Hyænas came and laughed and howled round the corpse for hours, but never touched it. The second night the same thing happened, but on the third day they ate him up. Now, as these Hyænas were beasts belonging to an uninhabited country, they were unused to human remains, and had not, I think, lost their instinctive dread of the smell of man; for in the Matabele country, where the bodies of people killed for witchcraft are always 'given to the Hyænas,' a corpse is invariably dragged off even from the very gates of a kraal before the first night is many hours old."

SPOTTED HYANA.--Besides the Brown and Striped Hyænas, 
Plate V.

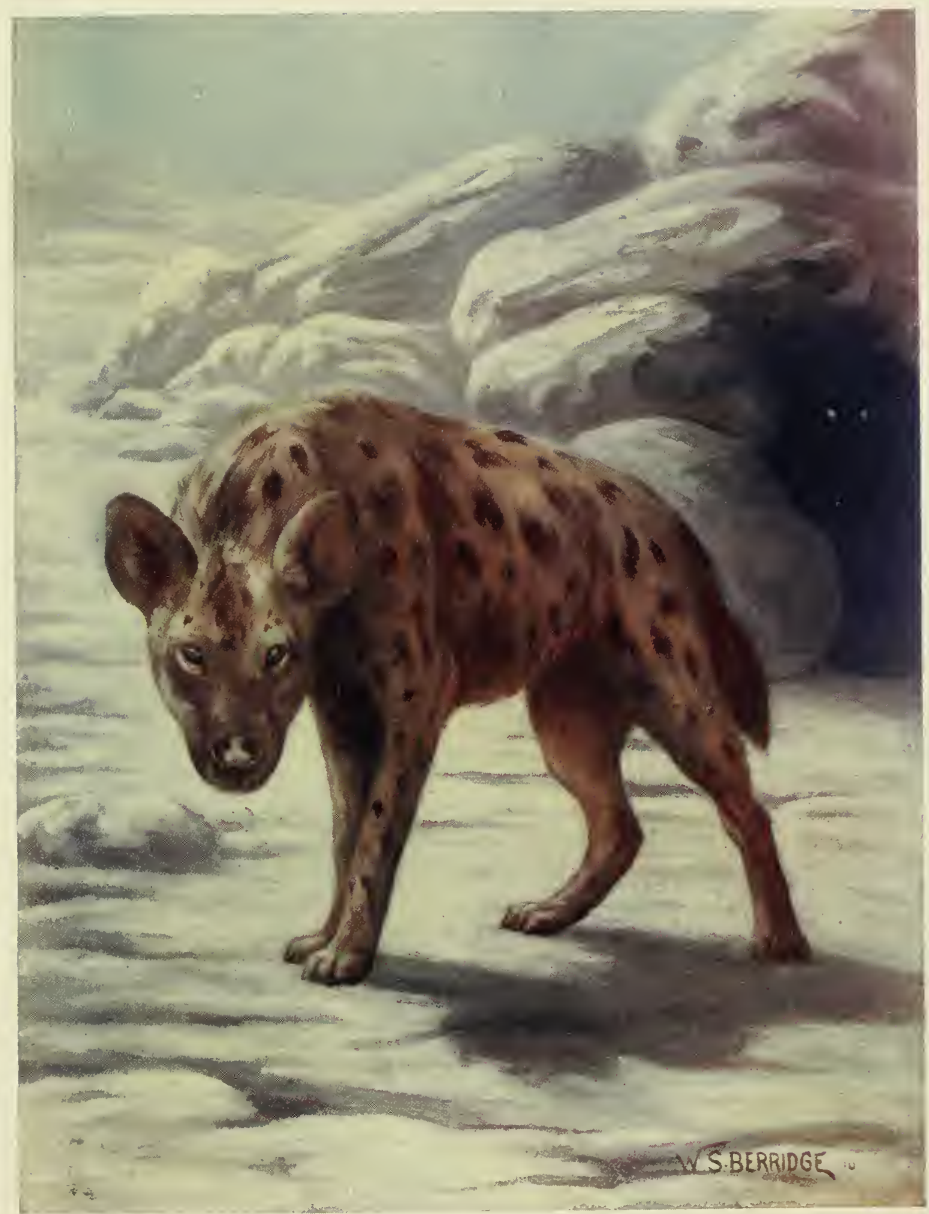

SPOTTED HYENA. 

the Spotted species may also be mentioned, and our artist has accorded attention to this animal in one of his coloured plates. Some of these beasts were once resident in Europe, but to-day sees them restricted to Africa, Asia Minor, Persia and India. The Spotted and Brown Hyænas are, however, inhabitants of Africa, and it is only the Striped species which is found outside the African continent.

The Spotted Hyæna differs from its Striped relative by hunting in packs, but as a rule prefers to pick up food already killed. It is a more powerful beast, larger, fiercer and very voracious. Truly an animal scavenger, the Hyæna occupies a curious place in Nature, for it is a cowardly creature and will only show fight when it is driven to bay. It has been aptly termed "the veriest pariah of the animal world," but it is as well to remember, in view of the hatred most people evince for it; that it is a veritable scavenger, that it forms a sort of connecting-link between the Cats and Dogs (having a Cat-like skull and Dog-like claws), and that its massive jaws, powerful muscles and strong teeth can pulverize the thigh-bone of a Buffalo and can crush bones that no other living animal would attempt. It will be observed that the Hyæna is very strongly developed in the front part of the body, and that the general form falls away towards the hind-quarters. This doubtless accounts for the skulking, or slinking, gait.

COMMON BADGER.-That this animal is more common in England than is usually supposed seems generally agreed, but, being a nocturnal creature, it is rarely seen except by gamekeepers and others occupied in the open air.

Beyond this, it spends most of its time, when not engaged foraging for food, below the ground in its remarkable fortress. It is quite a wonderful citadel, this subterranean home of Brock, as he is sometimes called, and I vividly remember seeing an "earth" which was opened in Hertfordshire which was of tremendous dimensions, there being a succession of ingenious chambers disclosed as excavations proceeded.

It is a shy, timid animal and has a distinct hatred of being watched. The only real way to get a good sight of it, once having found out the favourite home and haunts, is to sit up in a tree for some hours at night. Even then the vigil may be a long and unprofitable one, as Brock soon passes by, and the light is insufficient to obtain more than a passing glimpse of the old warrior. 


\section{THE BOOK OF THE ANIMAL KINGDOM}

Search should be made for the "earth," or burrow, on the sunny side of a wooded hill, and if the inside of the home could be examined it would be found to consist of a sort of general livingroom, with vertical passages leading upwards for the purpose of ventilation, and several tubular passages from twenty-five to thirty feet long. The central chamber is snugly lined with moss and leaves, and the whole homestead is a model of neatness. Indeed, the Badger is not only a tidy animal, but is also exceedingly clean in its habits, setting a brilliant example to the Fox in this respect. It will even search for parasites on the body of its children.

The structure of the creature at once reveals its adaptability for the life it leads, for the legs are short and powerful (Fig. 63), the sharp broad claws of the fore-feet serve as shovels, whilst the hindlegs enable the soil which has been excavated to be thrown backwards. The sturdy body also comes into action when a large heap of soil requires removal, for Brock contrives to get his back against it, obtains a firm hold on the ground by means of the powerful feet, and then all is plain sailing. The whole build of the beast is worth noticing, for the short bristly hairs with which the body is clothed lie flat on the skin so that no dirt can adhere to, or accumulate between, them.

These hairs are earthy-grey in colour on the back, and very often harmonize in a remarkable way with the environment, whilst the black and white markings on the head and elsewhere, although well displayed in Fig. 63 , are very inconspicuous at nightfall. The tail is very short, there being no necessity for the beast to possess a long appendage.

That this is not a particularly active animal will soon be apparent, but it can, if occasion demands it, amble along at a tremendous speed. It is not adapted for jumping or leaping, and, as a consequence, we find that it is not able to prey to any extent upon quickmoving creatures like many of its relatives. If we examine the teeth this fact will be plainly shown, for the molars have broad crowns and blunt tubercles, and are thus more adapted for crushing than tearing. The food is made up of fruit, roots, various kinds of insects, earthworms, snails, small rodents, lizards, toads and snakes. It will also eat birds' eggs, young rabbits and leverets.

In its search for food it is largely aided by its long, broad and sharp claws, which enable it to dig for larve and worms; by the tapered snout which assists it in foraging under leaves, and by the 


\section{LOVERS OF THE CHASE AND OTHERS}

short and muscular neck which enables the animal to exert great force in both burrowing and rummaging operations.

The Common Badger and the Sand Badger (Fig. 64) cannot be included specifically as lovers of the chase, coming under the heading of "some others." The former is very largely an energetic vermin-hunter, and, such being the case, it should be protected. It cannot be said that man is in any way adversely affected by this interesting underground dweller, and it is to be hoped that it will remain a member of our British fauna for many years to come.

During the Summer Brock pursues a busy life, for, although it rests in the heat of the day, at nightfall it undertakes protracted wanderings in search of food, and when the first chill days of Autumn arrive its body is well nourished and very fat. So much so, indeed, that Brock retires from business, as it were, the fat accumulated enabling the beast to exist through its long Winter fast. It does not resort to fasting in real earnest until King Frost rules the land with his ice-bound grip, living meanwhile on such things as turnips and other vegetables which it has put by for hard times.

The outer coat not proving sufficiently impervious to the cold, the inner layer of fat beneath the skin protects the body like warm underclothing, and then, when Winter has arrived with all its severity, Brock rolls itself up, "in order to offer the least possible cooling surface to the air, and falls into a deep sleep." Thus it remains until signs of Spring awaken the land from slumber, but it is only a temporary resurrection, for, after having a drink at the nearest spring, the animal returns again to its citadel and once more goes to sleep. The next time it awakes to find bird and beast making joyous at the triumphant uprising of all things that live out of doors, and who share with ourselves the beneficence of the sunshine and the glorious breathing of the air.

The Badger is an inhabitant of the whole of Europe and Northern Asia, and in England it is interesting to notice the names of places which are indelibly associated with it. In olden time it was called Brock, and thus we have Brockenhurst, Brockley, Brockett, etc.

The cubs usually number three or four, and these are born during the Summer. They are blind, and do not open their eyes until they are about ten days old. When taken young it is said that the cub makes a desirable pet, being easily tamed.

When the cubs are able to take care of themselves and leave 


\section{8n THE BOOK OF THE ANIMAL KINGDOM}

the "earth," it must be an engaging sight to watch the family party during the silent watches of the night, as secrets such as those revealed in the home life of the Badger are rarely told. The senses of smell and hearing are very acute, and he must be a lucky stalker who, without exerting much strategy, would successfully make acquaintance with Brock and its bairns above ground. I have heard with disgust a good deal about Badger-baiting at fairs and elsewhere, but it is pleasant to reflect that this so-called "sport" has almost died out in rural England. In a few districts even to-day Dogs are turned upon a Badger after the latter has been cowardly dug out of its natural hiding-place so as "to give the Dogs a chance." I have no sympathy whatever with this detestable practice, and when I was recently informed of some Terrier Dogs being badly mauled by a Badger as a result of their being set upon it by people of high position who could surely have found something better to occupy their time, I must candidly confess that whilst I felt sympathetically disposed towards both Brock and the Dogs, my feelings with regard to the human beings who engaged them in battle may be better imagined than described.

Brock was eventually battered to death with spades and forks, and the brutes who took such a delight in unfairly attacking an innocent and inoffensive animal would, if I had my way, be made to undergo a heavy penalty for perpetrating an outrage which cannot be tolerated to-day.

SAND BADGER. - The Sand Badger (Fig. 64) belongs to a different genus from the species recently under review, and is placed by Zoologists as the last representative of the Weasel family. It is an inhabitant of India, being found in the Eastern Himalayas "through Assam and the neighbouring regions to Tenasserim and Lower Burma."

Whilst the shortness of the tail of the Common Badger has already been mentioned as a salient feature of that species, it is the length of tail possessed by the present animal that is worthy of note. This appendage measures from a quarter to a third the length of the head and body.

The soles of the feet are naked, and only a portion of these is put on to the ground when the beast is walking, so that the Sand Badgers "may be described as digitigrade rather than plantigrade when in motion."

The Indian Sand Badger is mostly dirty grey in colour all over, 


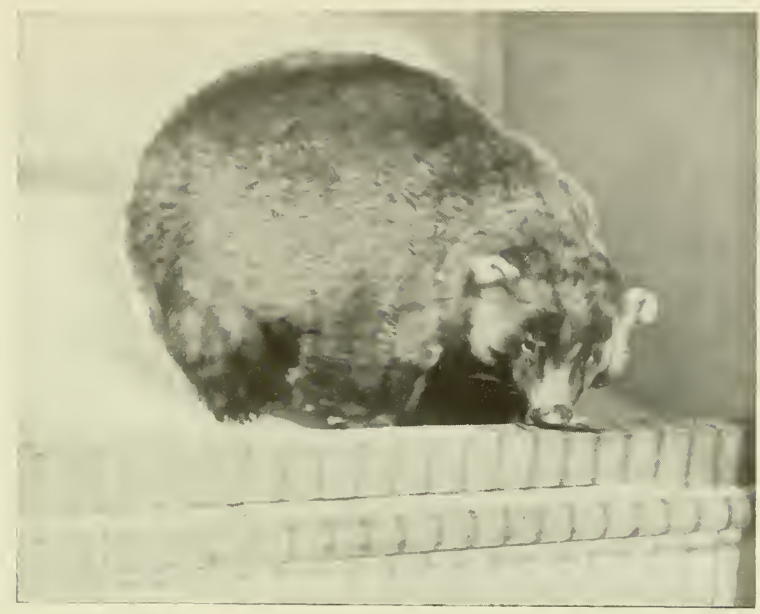

FIG. 64. SAND BADGER

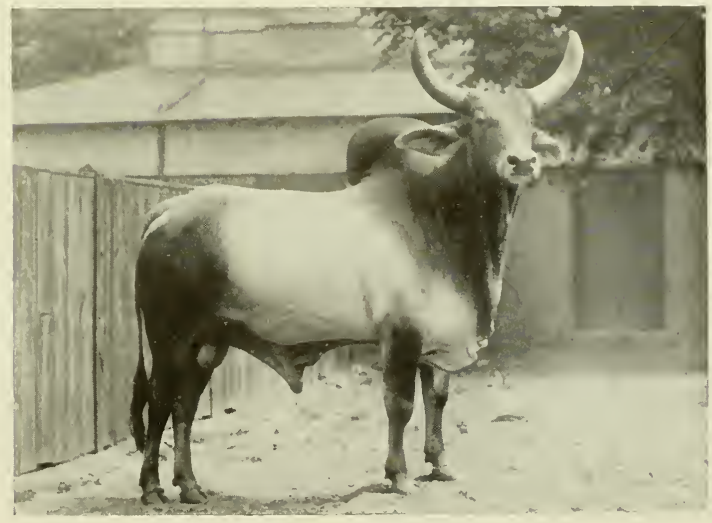

FIG. 65.-HISSAR BULL 


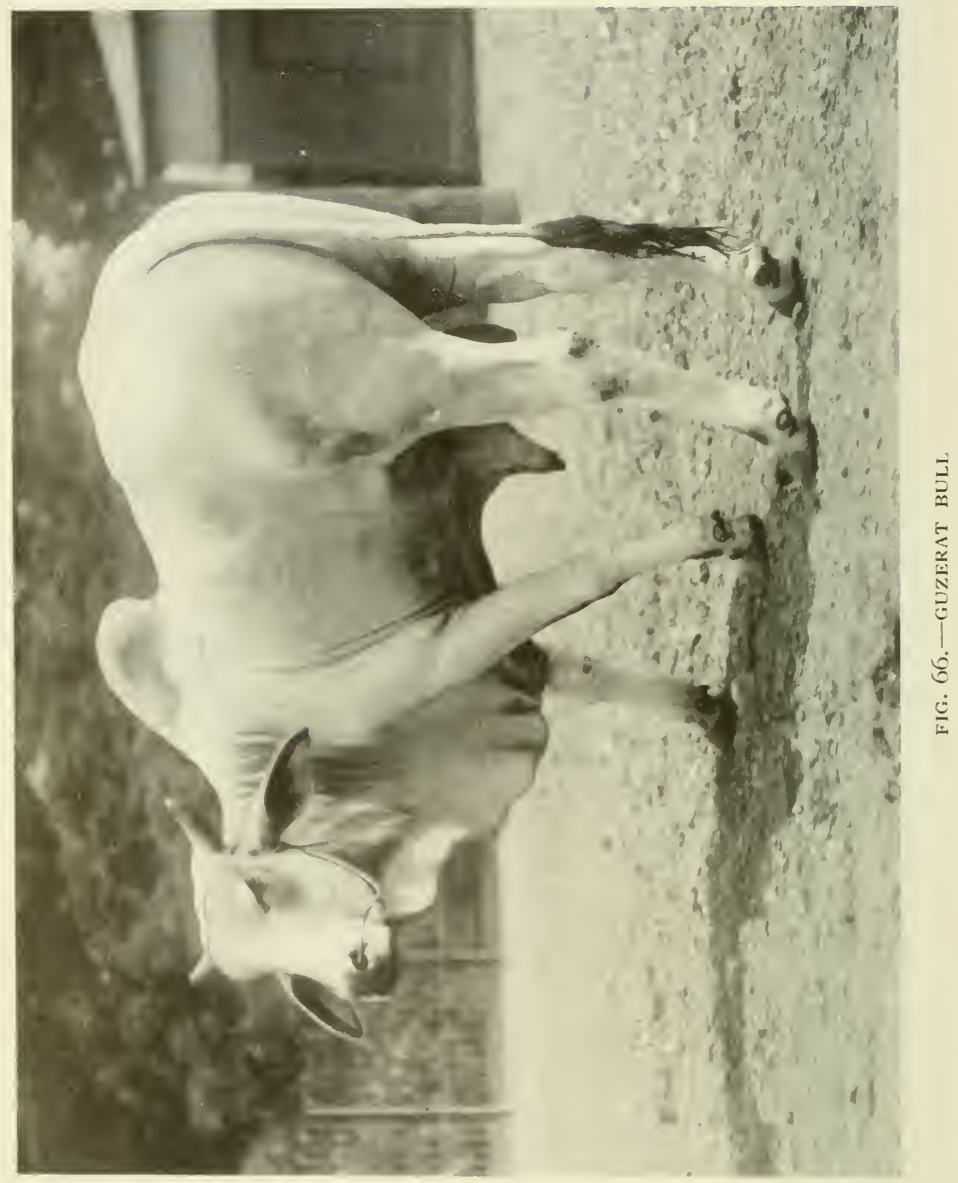




\section{LOVERS OF THE CHASE AND OTHERS 81}

marked with a tinge of blackish on the back. The white head is banded with black, whilst the underparts are dusky coloured as the photograph depicts. The length of the body is about thirty inches, exclusive of the tail. This latter measures some eleven inches.

In the structure of the skull, and also in regard to the teeth (structurally, not numerically), the Sand Badgers differ from the Common species; indeed the skull is different to that possessed by any other kinds of mammals, with the exception of some of the Edentates and Dolphins.

The Indian species-for there are two smaller kinds "inhabiting Assam and Arakan, and possibly China, while there is probably a third in Eastern Tibet "-frequents undulating stony ground or small hills among the jungle, and lives in fissures of the rocks or holes which are excavated by the animal itself.

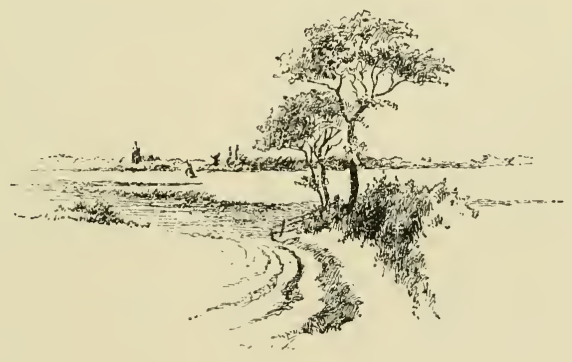




\section{CHAPTER V}

\section{SACRED ANIMALS}

HUMPED CATTLE. - In India there are several breeds, or varieties, of Humped Cattle. Of these the Indian Ox, Zebu, or Brahmin Bull may be specially mentioned, more particularly as this beast is also found in East Africa and Madagascar. Humped Cattle are also inhabitants of the Chinese Empire.

There are stated to be at least fifty million cattle in India, and of the different varieties of the Zebu (a name which is only heard in Europe and is never used in India) attention may be directed to those represented in Figs. 65, 66, 67 and 68. Fig. 65 is a Hissar Bull, the largest and finest variety of the Zebu; Fig. 66 shows a Guzerat Bull; Fig. 67 represents the interesting Gynee Cattle, which are the smallest of all, being very little larger than a Newfoundland Dog; and Fig. 68 portrays a Cow of the Mysore, or Trotting, Cattle, which is remarkable for the manner in which the horns slope backwards.

These beasts are much kept as pets, and this prompts one to write of the place occupied by Cattle generally in the affection of the Indian people. Whilst for riding and performing labours of various kinds, these Humped, or Sacred, Cattle are highly esteemed, they are also valuable on account of their flesh and milk. But many of them are of gentle disposition, and for these animals the Indians evince the greatest regard. Mr. Protheroe says that many of the finer Zebu Bulls are dedicated to the God Siva, but he goes on to say that "these sacred Bulls are nearly as intolerable a nuisance as the venerated Monkeys. . . . They wander just where they like in the streets and market-places, block up the traffic, and no one dares to drive them away. They help themselves to the choicest vegetables and fruit, and the aggrieved owners may not even check their depredations. They behave generally like spoiled children or dogs, rendered selfish and offensive by the weakness of those who ought to have taught them better." 


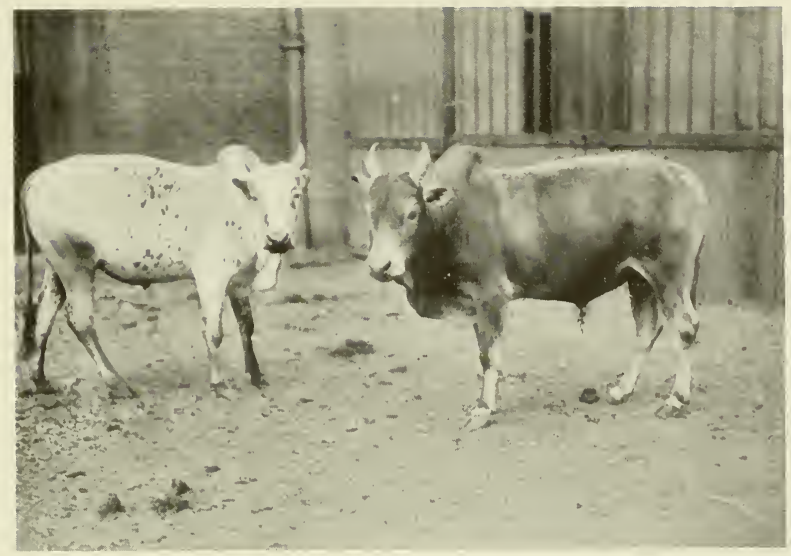

FIG. 67. GYNEE CATTLE

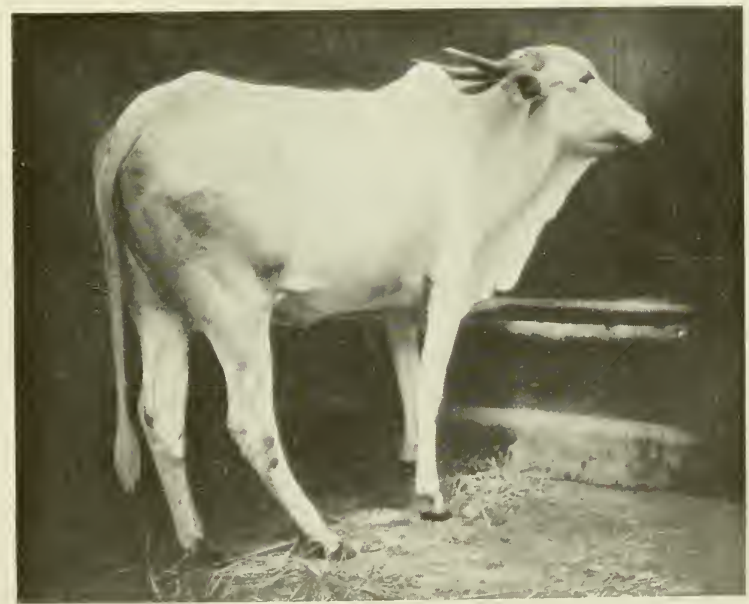

FIG. 68. - MYSORE COW 


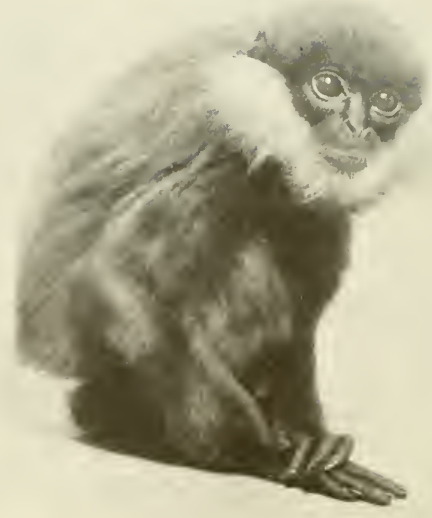

FIG. 69.-CEYLONESE LANGUR

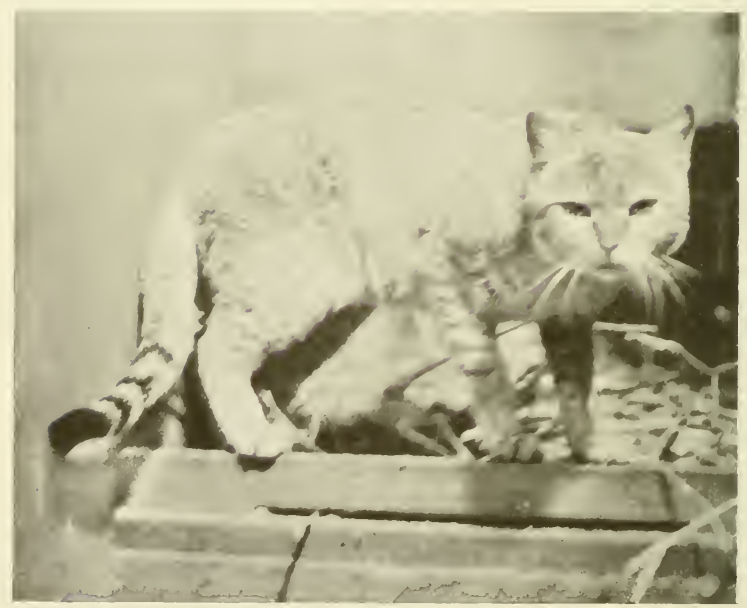

FIG. 7O. -FETTERED, EGYPTIAX, OR C.IFFRE CAT 
As an instance of the extraordinary regard in which these creatures are held, the same writer states that, "in the early days of the railway in India a Brahmin Bull charged a locomotive, with somewhat disastrous results to the holy animal. It was feared that the natives would view the railway as a menace to their religion. To the great satisfaction of the authorities, the people did not take offence; they simply accepted the Engine as a superior divinity, and decorated it with flowers."

Before passing on to consider the salient features inseparably connected with these Humped Cattle, it will be as well to give some particulars regarding Oxen in general, that is so far as concerns their structure and mode of life, for, being so accustomed to see Domestic Cattle, we are somewhat apt to overlook many interesting points concerning them.

Dr. Otto Schmeil, in his excellent Text Book of Zoology, sets out in a concise way a vast array of details connected with animals, treating of his subject from a biological standpoint, and in getting out the following summary respecting the Ox, I am much indebted to the work in question.

The origin of the Ox has already been treated of in a previous section (Chapter I), and little need be added here, excepting to state that the Urus survived in Poland until the sixteenth century, that in Germany it has been extinct since the year I Ioo, "but in the form of our Domestic Ox, which naturalists have recognized as a descendant of that primeval giant, it survives to the present day, and will probably prolong its existence far into future ages. The Urus was domesticated long before the beginning of history. By the constant selection for propagation of individuals most useful for his purpose (compare Dog), Man, in the course of thousands of years, has succeeded in transforming the Urus into the Domestic Ox, numerous varieties of which are now spread, as the most important of domestic animals, over a great portion of our Earth."

A comparison between the eyes of the Wild Oxen and our Domestic Cattle reveals the fact that the first-named have, as a rule, bright, brilliant eyes, "evidently endowed with such visual powers as are required for a life in a state of Nature," whilst the latter have large and dull eyes, which indicate feeble sight.

That these wild beasts are possessed of keen powers of scent is proved by the widely-opened and constantly-moistened nostrils of their domestic brethren. The wild beasts are, according to one

G 2 


\section{THE BOOK OF THE ANIMAL KINGDOM}

traveller, "as light-footed as Antelopes," and whilst the reader will agree that a mad Bull rushing across an open field can move at an alarming speed, it is obvious that a changed life has resulted in the Domestic $\mathrm{Ox}$ of to-day being far more lethargic than it otherwise would be, for great speed of locomotion is no longer an indispensable condition of the animal's life. It is ably protected by the large size, great strength, and the possession of special organs of defence, namely, the horns.

The horns are worthy of close study in themselves, and whilst we cannot enlarge on the subject here, attention may be directed to the various examples of these appendages shown in Figs. 65 to 68 , and to the fact that the presence of these organs largely conditions the great breadth and height of the forehead. "The cranial bones, too, are of unusual thickness and are capable of enduring the hardest blows. The force employed in the use of the horns as thrusting or butting weapons, is supplied in the powerful musculature of the nape of the neck. Through the presence of these muscles and a loose-hanging cutaneous fold, the dewlap, the neck appears shorter than it really is." In the neck the strength of the Ox chiefly lies, and, this being so, one can realize why it is that when made to draw a cart or a plough, the yoke is attached to the animal's forehead.

It is as well to remember, too, that IVild Oxen live in herds, and this renders them better able to defend themselves than if they lived in a solitary state. In considering the general characteristics of our Domestic Cattle, a comparison between them and their wild relations is essential, and in this connection it is interesting to observe that Dr. Schmeil states: "The body of every animal must be so constructed that it may be able to obtain the necessary food for its own maintenance and that of its young, and also may be capable of protecting itself against its enemies and the influences of weather and climate; for unless these conditions are fulfilled, it is doomed soon to disappear from the Earth. Man, however, hy taking the $\mathrm{Ox}$ under his protection, has relieved this animal from either of the above-named functions, and in order to understand its structure in reference to them, we must consider only such animals of the species as still live under natural conditions, or, at least, such surroundings as deviate but slightly from a state of Nature." In our consideration thus far this method has been adopted, and it is important to bear this in mind. 
We may now consider (I) the $\mathrm{Ox}$ as a herbivorous animal and endeavour to learn something of interest as a result, and after that a few points may be referred to concerning (2) the Ox as a domestic animal.

I. The $O x$ as a Herbivorous Animal.-Vegetarians may not agree with the statement, but it is generally recognized that "meat furnishes a more lasting nourishment than an equivalent amount of bread or any other vegetable product (e.g. fruit or vegetables). Vegetable substances are, therefore, less nutritious than animal products (flesh, milk, blood, etc.)." As a result, the Ox, having a large body to support, is bound to partake of large quantities of food.

The animal would not be able, for example, to appease its hunger by eating a single blade of grass at a time, and, this being so, the Ox pulls up its food in bunches. How is this task accomplished? The long and very rough tongue is an efficient organ in this respect, for by means of it food is secured and conveyed to the teeth. The latter are excellently arranged, for a long row of incisors is essential. There are accordingly six broad incisor teeth in the lower jaw, and the lower canine teeth have the same form as the incisors. "By these teeth the bunch of fodder is pressed against the edge of the upper jaw, which is toothless and cartilaginous. The tufts of grass are detached by an upward push of the head. The incisors are very long and large, and directed obliquely forwards, so that the animal is able to cut off quite short grass; but in this case no assistance is rendered by the tongue."

The Ox spends the best part of the day in the act of feeding, and this necessitates that it must continue to be always on the move. Thus we find that it possesses strong legs and feet, which terminate in stout hoofs. It is interesting to notice also that the wild animals must undertake prolonged wanderings in order to find fresh pastures.

Having watched an Ox feeding in a pasture field for some considerable length of time, has it ever occurred to the reader how well adapted is the beast for the life it leads? The strong musculature of the neck, for example, enables the animal while engaged in feeding to keep its head depressed for several hours.

Let us follow this analysis of the Ox a little further, and to enable us to do this the concise method adopted by Dr. Schmeil may be followed thus- 


\section{THE BOOK OF THE ANIMAL KINGDOM}

a. The large quantity of food taken in calls into requisition a large stomach for its reception and digestion, as well as a long intestine which offers a large surface of absorption for the nutritious particles of the food which are only sparingly scattered throughout the whole digestive mass. (Compare, on the contrary, the Carnivora.)

$b$. The nutritious elements of vegetable substances (starch, sugar, albumin, etc.) are enclosed within what are called hard coats of cellulose, and these are not dissolved by the digestive juices. In order, therefore, that the contents may be digested, these cellulose envelopes must of necessity be destroyed, and to bring about this desirable result the vegetable substances taken in as food must be crushed and ground up as finely as possible. An interesting comparison may thus be made with the Dog, which bolts, or swallows, a piece of meat without making any attempt to masticate it.

The Ox, then, grinds up its food by means of a lateral grinding movement of the lower jaw. This movement is effected by reason of the situation and the construction of the teeth in both the upper and lower jaws, details of which need not be given, but in order that the food may be efficiently pulverized a large grinding surface is necessary. Hence we find that the molars are both large and numerous, there being six on each side above and below.

A number of large teeth naturally means that they must be located in large jaws, and in consequence of these the elongated head of the $\mathrm{Ox}$ is the result.

Dr. Schmeil concludes this part of his analysis with the remarks that "the longer a man moves, and the more energetic his movements, the more food is he obliged to take, in order to replace used-up force; the longer he remains at rest, the less force is used up, and consequently the less food required to replace it. The same law applies equally to animals. (Compare with Bat and Mole.) Applying this principle to the $\mathrm{Ox}$, it is easily seen that if this animal were at once to grind up its food, while in the act of feeding, to the necessary fineness, it would be obliged to stand or slowly walk about on the pastures for an even longer time than it actually does. In consequence, however, of the division of the stomach into four compartments and the act of rumination, the animal is able to carry on the greater part of the act of mastication while at rest. It is evident that in this matter much 
force is saved, and the animal is consequently able to do with less food than it otherwise would."

We now come to the last point we set ourselves out to consider in regard to the Ox, namely-

2. The $O x$ as a Domestic Animal.-Having agreed that rumination-or, as it is better known, perhaps, to the average individual, the act of chewing the cud-undoubtedly implies a saving of force and also, as a result, of food, we find that this capacity is not only of immense service to the animal, but also to Man. The eminent German zoologist, to whose work we are already indebted for almost the whole of this section of our book, thus concludes his observations: "The $\mathrm{Ox}$, in fact, in virtue of this ruminating capacity, from a certain amount of food unfit for human consumption (grass, flowers of the field, etc.), produces a larger quantity of food suitable for human nourishment (meat, fat, milk) than it otherwise would, and, if supplied with an abundance of fodder, is more rapidly and easily fattened.

"All mammals produce milk only as a nourishment for their young. When these are capable of finding their own food, the parents refuse them further access to the teat, and the nourishing spring dries up. With his domestic cattle, however (Cow, Goat, Reindeer, Camel and in some parts even Horses), Man does not allow matters to proceed so far. He assumes to himself the part played by the young, for by constant removal of the milk (milking) he stimulates the milk-glands so that they continue to secrete for a long period. The Cow, having but one or at most two calves at a time, is provided with only four teats. (Compare, on the contrary, the large number of teats in the Pig, Dog, Cat, etc., in relation to the large number of their young.) The value of Cow's milk to Man (as a source of butter and cheese), and the further uses of this animal by reason of its flesh, fat, hide, hair, horns and bodily strength, are too well known to need further discussion."

We may now return to the Humped Cattle after this somewhat protracted but important consideration, which affects them equally well.

The common domesticated cattle of India and the humped beasts of Africa and China are distinguished from the breeds of cattle in Europe by the characteristic hump, which is so well shown in the animals illustrated in Figs. $65,66,67$ and 68 . Beyond this hump on the withers, they also possess further distinguishing 
features, such as the nature of the voice, habits, general coloration and other structural characteristics that need not be detailed.

As a result of these important features, there is no doubt that Humped Cattle are specifically distinct from our own domestic breeds, although the former are not known in a strictly wild state.

The large drooping ears possessed by these animals are well exhibited in Figs. 65 and 66 , where it will be seen that the Hissar Bull and the Guzerat Bull are worth examination in this respect. The enormous dewlap which hangs in folds along the whole length of the neck is also particularly characteristic of these Humped Cattle, and is excellently shown in the case of the Guzerat Bull in Fig. 66.

As has been mentioned earlier in this chapter, the size of these beasts varies from the large Hissar in Fig. 65, which is a tremendous beast standing as high as a Buffalo, to the small Gynee Cattle (Fig. 67), which are not much larger than a Newfoundland Dog. The usual colour appears to be light ashy-grey, and this may be found in various gradations and passes off into cream-colour, milkwhite, etc. It must not be assumed, however, that these tints are inevitable, as red and brown are two more common colours, whilst melanic varieties are sometimes met with.

These Humped Cattle grunt rather than low like our own beasts, and a further interesting comparison is that the former rarely take advantage of the shade during the hot weather, as our own cattle are so fond of doing, and, unlike them, the Indian kinds do not evince any desire to stand knee-deep in water when the scorching sun demands something cooling.

Although it has been mentioned that no Humped Cattle are found in a perfectly wild condition, it is stated that "in certain parts of India Humped Cattle have run wild; those found on the sea coast near Nellore, in the Carnatic, have been in this state for a long period, and Jerdon describes them as being extremely shy and wild, their size being large and their horns long."

The Galla $\mathrm{Ox}$ is the African representative of the Humped Cattle, and in this beast the thickness of the horns is especially noteworthy. It is also known as the Sunga, and it is worth mentioning that "the forehead of the skull lacks the convexity characteristic of the Indian Humped Cattle; and as the curvature of the horns is somewhat similar, Professor Rütimeyer believes that the Galla $\mathrm{Ox}$ is most nearly related to the Asiatic Banting. . . ." 
Before passing on to the two remaining sacred animals on our list, namely, the Hanuman Monkey and the Fettered, Egyptian, or Caffre Cat, it is as well to notice that in India several fossils of Oxen have been found. The handsome Narbada $\mathrm{Ox}$ which roamed about in the Narbada valley in days long since gone by was one of these Indian Oxen, and it is worthy of special mention if for no other reason because it was as large as the Aurochs (see page 32). The typical Narbada Ox had cylindrical horns, but there existed a second race whose members possessed more flattened appendages, and thus resembled more closely those of the Indian Wild Cattle existing at the present day. Then again, from still earlier deposits there have been rescued the remains of the Sharp-Fronted Ox, a tremendous beast which possessed horns of great length "which swept upwards and outwards in a bold curve, and were probably but little short of ten feet in span."

HANUMAN MONKEY.-Beyond the Sacred or Humped Cattle already treated of in this section, the Hanuman Monkey is entitled to inclusion. Although unrepresented in the illustrations, Fig. 69 gives an example of the Ceylonese Langur and serves to show the kind of Monkey with which we are now concerned. This species, true Wanderoo as we may call it, is a rare animal from Ceylon, but, strictly speaking, it is the Hanuman Monkey that may be regarded as the sacred beast.

As will be observed from the species shown in the photograph, the Langurs are an interesting genus. There are four different kinds in India, and of these the Hanuman is the best known. The chief outward characteristic is the hair-covering on the crown of the head, for this radiates in all directions from a central point situated on the forehead.

Langurs have for long been regarded as sacred animals by the Hindus, but whilst one writer states that the species now under review takes its name from the God Hanumán to whom it is sacred, another authority says that "the Hanuman Monkey is supposed by the Hindus to be a visible incarnation of the God Vishnu, and consequently the temples dedicated to the God are happy havens for the particular species. They simply swarm about the cities and villages where Vishnu is worshipped. The beautiful carvings of the temples and even the holiest idol shrines are defiled by the jabbering creatures, who, not content with the offerings of the faithful, rob orchards, pilfer from fruit stalls, and even enter shops 


\section{THE BOOK OF THE ANIMAL KINGDOM}

in search of delicacies. No native would dream of taking active, offensive measures against the four-handed robbers."

There is no doubt that in considering the history of mankind, which is, in parts, as entertaining as a romance, the love evinced for certain kinds of animals should not be overlooked, even though, as is the case with some of the creatures treated of in this section, the regard shown towards them is not altogether of an uninspired character. Nations a good deal less Christianized than we are have shown a peculiar affection for the brute creation, and although to-day, with the civilizing influences which follow in the train of the world's progress, it is perhaps essential that obsolete manners and customs should be eradicated, there is, nevertheless, some amount of real charm in this old-time love for the animal world.

Therefore, although we may on occasions write disparagingly of some kinds of animals which in these modern days have, through being succoured during the ages, become so engrafted with the history and customs of nations as to be difficult to stamp out, it is pleasant to recognize that the lower animals of the Earth have not been forgotten by mankind, even if we exclude those beasts which man has paid attention to for selfish reasons.

The Hanuman is not a heavily-built Monkey. It has a tail longer than the body, and this latter measures about two feet. The greyish-brown fur is darker along the back, but as the animal grows older the coat becomes considerably more darkened. A good description of the appearance of the Langur has been given by one writer as under: "The tout ensemble of the Langur is so peculiar that no one who has once been told of a long, loose-limbed, slender Monkey, with a prodigious tail, black face and overhanging brows of long, stiff, black hair, projecting like a penthouse, ${ }^{1}$ would fail to recognize the animal."

FETTERED, EGYPTIAN, OR CAFFRE CAT. - The last sacred animal upon our list is the Caffre Cat, which is worthy of mention because it is recognized by many authorities as "the parent stock from which the Domestic Cat of Europe has sprung." In size it resembles a large specimen of one of our own pussies, and in colour is yellowish-grey, striped and banded, and having a blackringed tail. As will be observed from Fig. 70 , the tail is quite long.

This Cat ranges throughout Africa and penetrates also into 1 A shed standing aslope from the main building. 
South-Western Asia. Beyond this, it is interesting to note that in days gone by the Caffre Cat was also found in South-eastern Europe, and its fossilized remains have been found at Gibraltar.

Long, long ago the Caffre was held to be a sacred animal by the Egyptians, and their love for the creature is depicted in many of the remarkable epitaphs that they have left behind.

Their bodies were embalmed and preserved in tombs and other places, two famous cities that may be mentioned in this respect being Beni-Hassan and Bubastis. It is interesting to notice that the mummified remains of these pets of the Egyptians are identical with the Wild Caffre Cat, and there seems good reason to suppose that the animals which found so much favour with the Egyptians were tamed individuals of the wild species shown in Fig. 7o. These Cats were doubtless great hunters, and were of assistance to the inhabitants of Egypt in the long ago in helping then to procure food, for even to-day many of us are aware that the docile pussy purring before the fire can, if occasion demands it, become one of the keenest poachers among four-footed beasts.

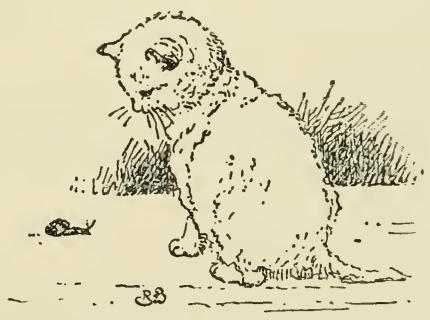




\section{CHAPTER VI}

\section{ANIMALS WITH ARMOUR}

ArMoured animals are at all times interesting creatures to study, although some of them must of necessity be observed at a safe distance and under conditions which bode no ill to the onlooker. Indeed, the clothing of animals generally provides a wealth of information worthy of note, and helps one to ascertain some idea of the surroundings frequented and the life that is led.

When, added to the skin of an animal, an armoured coat is supplied, or the outer covering consists exclusively of weapons of either offence, defence, or both, the interest increases. We find these armoured animals to consist of various kinds, some almost microscopic in size, others of large dimensions.

There is, for example, the familiar Wood Louse, known by sight to almost every one. It is far better known in the country as the Sow Bug. It is an interesting little creature in many ways, for when its jointed steel-grey coat of mail is rolled up into a ball, the IVood Louse is ably protected from its enemies.

Then, again, this small member of the Crustacea is a land representative of a number of aquatic IVood Lice, and claims kinship with the Lobsters, Crabs and Shrimps.

Many kinds of insects are also armoured, and especially the larvæ, which bear spines and hairs, and are thus ably protected from their numerous enemies. Some Fish, the common FreshWater Perch, of our British waters, for instance, have prickly fins, which have a nasty way of puncturing the skin when handled, and doubtless act as protective designs against natural enemies, whilst other animals-including Mammals and Birds-have sharp claws and other armoured devices which stand them in good stead.

If the subject be pursued further and attention devoted to. 
animals which are not, correctly speaking, clothed in a coat of mail which protects them, but possess other means of defence for their protection, then many instances will be forthcoming of how wonderfully the creatures of earth and sea are provided with devices whereby their survival is maintained.

In this section of the Book of the Animal Kingdom, it is not proposed to deal at length with these various subjects, for a selection of animals have been chosen to illustrate this chapter which will not permit of such treatment. The Armadillos, the Porcupines, the Pangolin and the common British Hedgehog admirably represent some armoured animals, and it is with the life-histories of these that we may now concern ourselves.

HAIRY ARMADILLO. - The skin of the back of an Armadillo (see Figs. $7 \mathrm{I}$ and 72 ) is modified into movable rings, or girdles, consisting of plate-like shields, each containing a plate of bone, as present in some Reptiles. The teeth are numerous, but are not strong, and beyond being ably protected by the formidable plated armour, the Armadillos further protect themselves by burrowing into the ground by means of their powerful claws. In this way, too, food is sometimes procured, for they feed largely upon insects and earthworms, which are secured as a result of this burrowing. Mice, snakes, eggs and young birds, as well as carrion, are also eaten.

The Hairy Armadillo (Fig. 7I) is probably the best known member of its family, as it is usually this species that is exhibited in captivity. The jointed bony plates situate upon the fore-parts and hind-quarters of the present species form two large shields, and, as will be observed, between each section of plates a number of hairs are present, which fact gives the animal the first part of its name. These hairs are also scantily found upon the lower parts of the body.

The body is broad and flat; the legs are short and stumpy; the claws very strong, and, as Mr. Frank Finn has well remarked, "the whole effect is rather Tortoise-like." The tongue is long and can be protruded some distance from the mouth, reminding one of the lengthy, flexible organ of the Ant-Eater.

Although it only measures some twenty-four inches long, the Hairy Armadillo is a heavy beast, and is "surprisingly solidly built for its size."

Like its relatives, it is an inhabitant of the Argentine Republic, 


\section{THE BOOK OF THE ANIMAL KINGDOM}

and although it is not accorded a high position in the scale of animal life, being a slow and lowly organized creature, it has proved itself capable of survival where other higher organized animals have failed. This remarkable achievement has been accomplished by the Hedgehog at home, and that in spite of the fact that the last-named is mercilessly persecuted by the gamekeeper and its numbers considerably thinned out each season.

The Armadillo is not particular as to the nature of its food, being easily satisfied with whatever is easiest to procure, and it is said that a particularly tasteful banquet is found to be the carcase of a Horse, "for he" (the Armadillo) "will drive a shaft under it and live in luxury, eating away at the carcase from beneath. If his more natural animal food should fail, he will make shift with herbage, and even maize has been found in his stomach."

Although clumsily built, this animal can, if occasion demands it, move over the ground at a good pace; it possesses great strength, and is also further protected from enemies by its rapid burrowing powers underground.

"Armadillo" upon a bill of fare would look strangely out of place, but the flesh is said to be good eating and to be not unlike roast Pig! The animal is, however, very fat.

Although used to a warm climate, these animals appear to be hardy and tenacious, and succeed well in captivity, even outdoors, during the rigours of an English Winter. That it is also a longlived creature is reasonable to suppose, as it has been known to exist for twenty years in a Zoological Garden out of England.

GIANT ARMADILLO. - There are other species of Armadillos that may be mentioned, but these mostly resemble the hairy kind, excepting as regards size and the hairs on the carapace, which are so characteristic of the latter. Few of them exceed the Hairy Armadillo in point of size, although the Giant Armadillo is its successful rival in this respect. The Giant species is more than thirty-six inches in length, whilst the armour bands are more pronounced and numerous. It is a resident of Brazil, and has acquired a bad character by reason of its habit of burrowing after the contents of graves, in which nefarious work it is largely aided by the enormous claws.

TATOUAY ARMADILL0. - The Tatouay, or Broad-Banded Armadillo (Fig. 72), comes from Surinam, Brazil, and Paraguay, and its name sufficiently indicates its salient feature, the broad armoured 


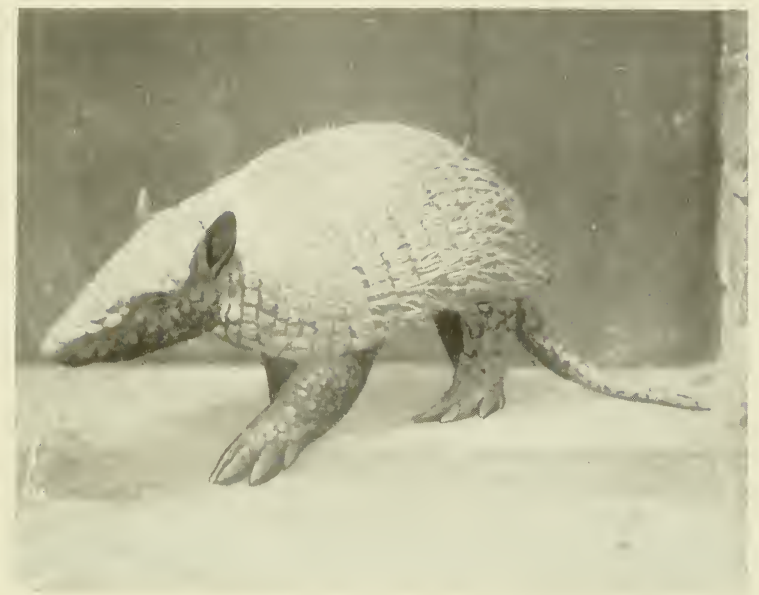

FIG. 7I. - HAIRY ARMADILLO

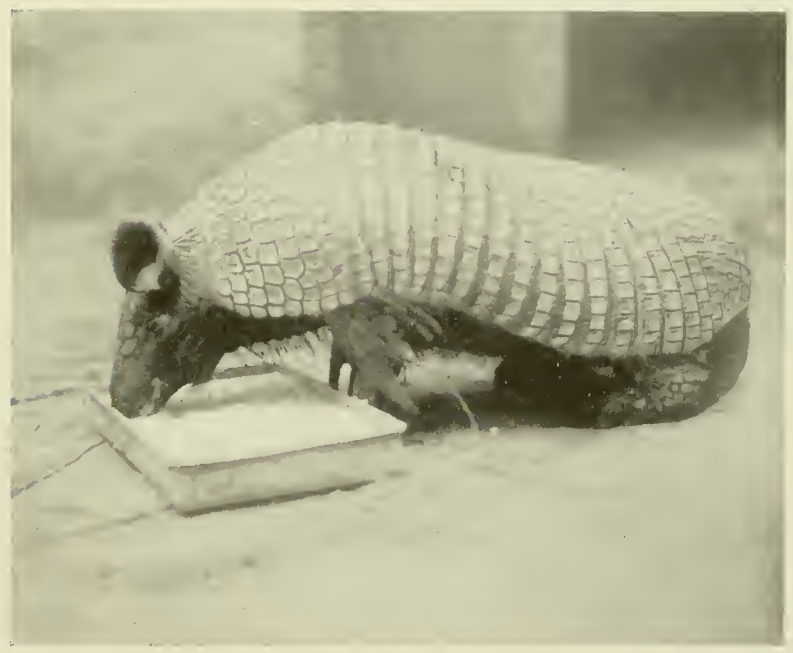

FIG. 72.-TATOUAY ARMADILLO 


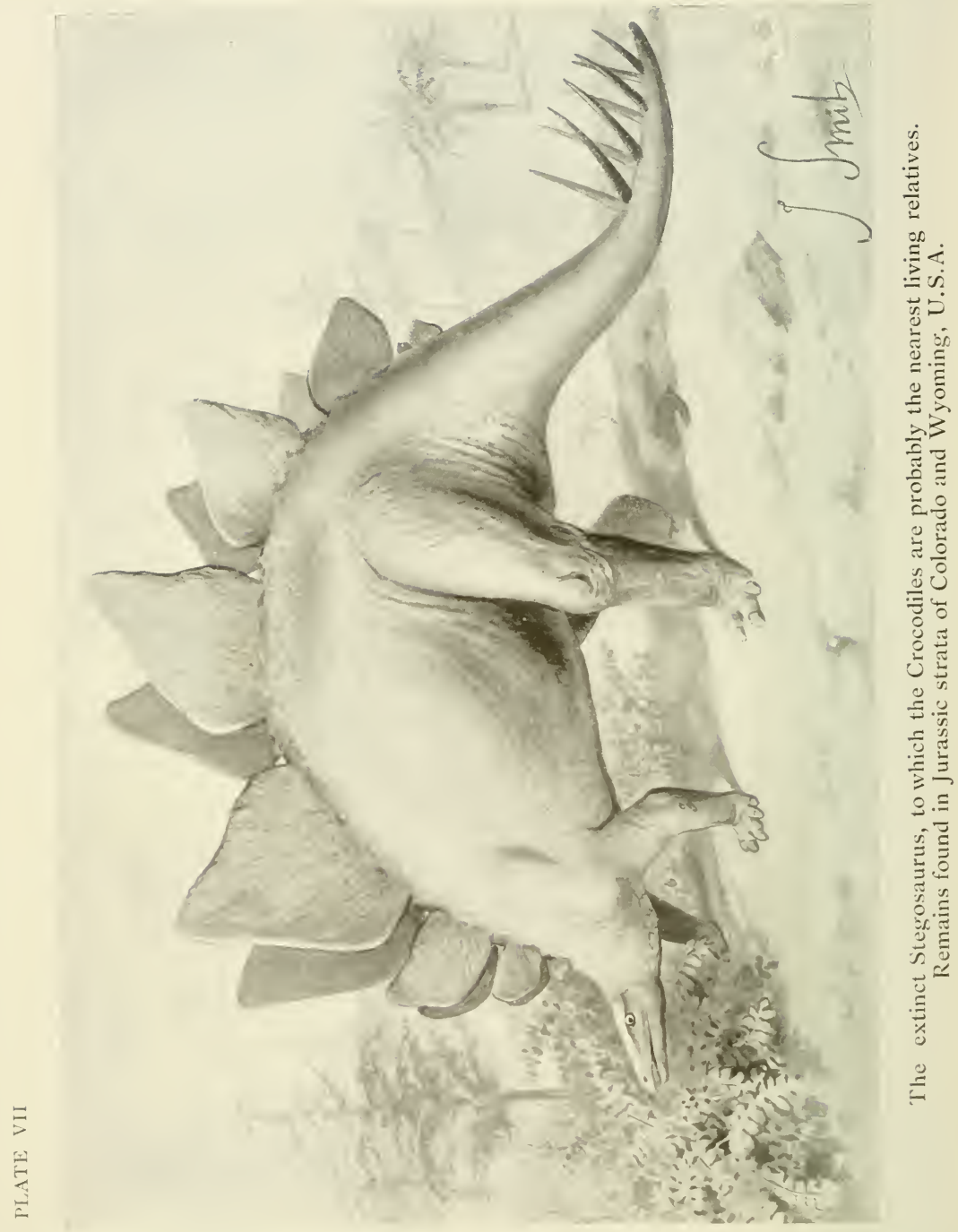


bands being well exemplified in the photograph, as well as the general effect of the body when stretched out. The hairs underneath the body of this species are also shown in Fig. 72.

In the carapace of the Tatouay there are twelve or thirteen movable bands; the slender tail is almost naked, but in point of size this species is the largest of the group next to the Giant Armadillo last under review.

PICHICIAG0.-The Pichiciago, or Pink Fairy Armadillo, also deserves mention before passing on, as although only a few inches in length this animal is of such importance zoologically that it has been relegated to a subfamily of its own.

It was not discovered until as recently as 1824 , when Harlan, an American naturalist, found it at Mendoza, which is not a great distance from Santiago.

The armour is pink in colour and the fur snowy-white, whilst there are structural features of interest to the anatomist, but which need not be detailed here. The Pichiciago is quite a rare species and is not found outside the western portion of the Argentine, but in the neighbourhood of Mendoza it is, curious to relate, the least uncommon. It inhabits "open, sandy dunes, or their proximity, the vegetation in such spots consisting of thorny brushwood and cacti."

It appears that this species-which is really not a true Armadillo-is, unlike those already treated of, very susceptible to cold, so much, indeed, that one observer has stated that a specimen he captured shivered violently under a Mendozan midday sun. Whether this was through chill or fear, queries the same observer, it is difficult to say, but if the action of some Bank Voles, which are at present in my possession, is any comparison, I am strongly of opinion that fear and not cold often accounts for the "shivering" above referred to.

The Pichiciago is much more fond of burrowing than the other Armadillos, and has been aptly referred to as "a sort of armourplated Mole." It has one relative that is deserving of mention, but this species, an inhabitant of Bolivia, although diminutive in stature, is not of such small dimensions as the species from Western Argentina.

PANGOLIN.-This interesting animal is represented in the coloured plate, and, as may be surmised, is not very distantly related to the Armadillos. As a matter of fact, it has been placed 


\section{THE BOOK OF THE ANIMAL KINGDOM}

in a separate family immediately preceding the last-named beasts, and coming between them and the Ant-Eaters. Instead of being armoured with bony plates, the Pangolin bears upon its body overlapping scales, which can best be compared to tiles upon the roof of a house, and in this way we are reminded of the large overlapping scales borne by some kinds of Fishes, the Carp and the Rudd being two common British fresh-water species that occur as apt examples.

The present animal is not known outside Africa and Asia, but in the New World it is distantly represented by the Ant-Eaters. The Pangolin resembles the latter in its mode of walking, namely, by doubling under the forepart of the foot so as to protect the formidable claws which are used for digging, and, like the AntEater, it has a long tongue which is admirably suited for procuring Ants as food, and it does not possess any teeth.

In many ways this is a remarkable creature, and is quite unlike any other living animal. It resembles, in some features, as has been shown, the Ant-Eater and the Armadillo, but although belonging to the same order of Edentates is relegated to a distinct family. 'The broad horny scales are found not only upon the back, but these characteristic structures are borne also on the long, broad tail and the outsides of the limbs. These scales are deepochre in colour. There are no external ears, as in the case of the Armadillo and the Ant-Eater, and, as Mr. Protheroe points out, "were it not for the scanty hairs that are found on the undersurface, these creatures might reasonably be taken for some curious sort of Lizard rather than for beasts of any kind."

The scales have acute edges, and when the Pangolin resorts to the device of rolling his body into a ball, the protection is complete. So invulnerable is the armoured coat that an instance is recorded of the Phatagin-a West African species-having shots fired at it with a revolver which failed to make the slightest impression. The beast was knocked over, but rolled itself into a ball. Thereupon a second shot was fired, but this time the shot "recoiled upon the firer and bruised him. Eventually he dispatched the animal by inserting a dagger between the scales and driving it home with a mallet." This, to say the least, seems to me a repulsive method of meting out death to one of the lower animals, and some more humane way would better commend itself, but it is only fair to state that the reason the beast had to be killed was because its 



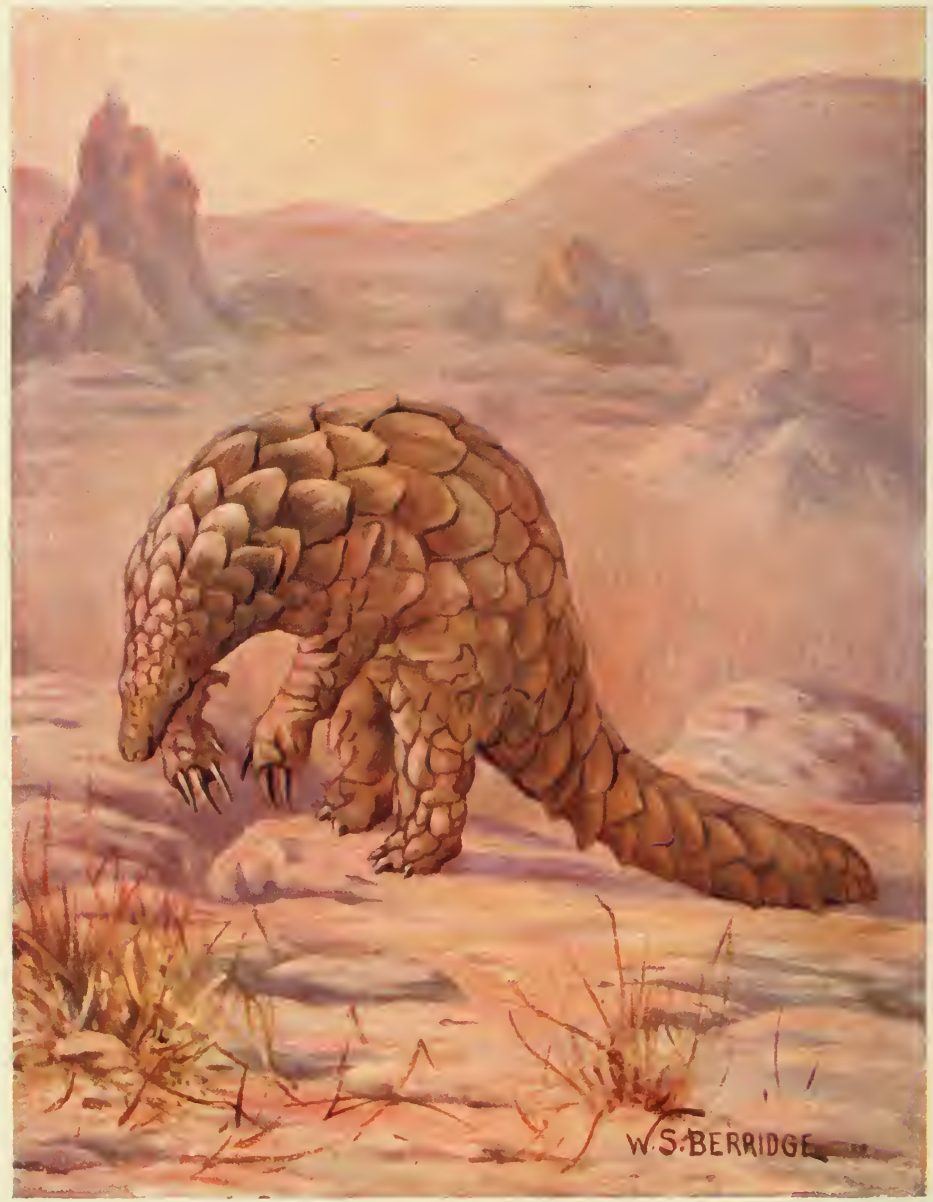

PANGOLIN. 
constant burrowing endangered the foundations of the house where it was kept as a pet. But if I had found it necessary to do away with a pet, I should have been hard put to it to have had recourse to the cruel proceedings above described.

The Pangolin of India has a short tail, and the Phatagin of West Africa a long one. Both animals resemble one another in general habits and are nocturnal beasts. Some species of Pangolins, however, are terrestrial and others partly arboreal, but all are alike in regard to their breeding, only one or two young ones being produced at a time. Mr. Finn says that in the case of the Burmese species, the youngster rides on the base of the mother's tail, clinging with its powerful claws.

These scaly Ant-Eaters, as they may be called, vary in size, the largest species being found in Africa. This attains a length of six feet, so that it easily outvies the Armadillos in point of size. The Indian species, however, is only about two feet in length.

The burrows of the latter animal are constructed to a depth of from "eight to twelve feet below the surface, and terminating in a large chamber, which may be as much as six feet in diameter. Here a pair of these animals take up their abode, and in the Winter or early Spring give birth to their young."

When first born the young ones are covered with soft scales, but, although born underground, and it is reasonable to suppose that such is the case, it does not appear to have yet been ascertained whether the youngsters are born blind. This opens up an interesting branch of natural science that has not received as much attention as the subject deserves. It has already been pointed out that the young of the Rabbit are born blind, and that this prolific rodent constructs a nest below the surface, but that the young of the Hare are born above ground and with their eyes wide open.

Attention might be devoted by the young naturalist to this phase in the life-history of other mammals, for the results could not fail to be of interest and service, whilst further information on the subject among our bird and other animal friends would also be of advantage.

COMMON PORCUPINE-The Porcupines are well entitled to inclusion among animals with armour. They have a wide geographical range, and are at once distinguished by the quill-like spines in the skin. They are mostly stoutly-built animals, with short, broad faces, and the grunting Pig-like cry accounts for the 


\section{THE BOOK OF THE ANIMAL KINGDOM}

name, which is derived from the old French porc éspin, meaning Spiny-Pig. The modern French is porc-éfic, probably derived from the Latin porcus, a pig, spina, a spine.

Porcupines are inhabitants of both the Old and New World, and whilst some are terrestrial, others are arboreal in their habits.

The three photographs (Figs. 73, 74 and 75) represent the Crested, Brush-Tailed and Canadian Porcupines respectively, and whilst a few notes respecting these species will be given, attention may chiefly be devoted to the Common Porcupine. This is what is known as a true Porcupine, and claims kinship with a family all the members of which are residents of the Old World. It differs from its American cousins in being entirely nocturnal and terrestrial; the tail, as a result, is not prehensile; the soles of the feet are quite smooth; there is a small thumb on each fore-foot, and the female has six teats. The Common species is a large beast; it bears upon its bulky body long quills, has a short, spiny tail, upon the end of which there are a number of short quills on slender stalks, and has a greatly elevated and convex skull. The short, slender-stalked quills, which are found in a cluster on the tail, are hollow, and it is these tail quills which are responsible for the curious rattling noise which is made when the animal is moving about.

The species now under consideration measures from twenty-six to twenty-eight inches in length without the tail, and, if the Beaver be excepted, the Porcupines may be regarded as the largest Rodents of the Old IVorld.

The brownish-black colour of the Common Porcupine is banded with white across the front of the neck and also on part of the sides. There is a crest of long bristles on the neck, which are brown below and white above.

The well-known quills on the body are of two kinds, one of these being slender, flexible, and very long, whereas the second kind is almost hidden by the great length of the last-named and is stouter and shorter. There are prominent black and white rings on all these quills, and the extremities of both kinds are tipped with white. The quills situate upon the rump are, however, mostly black in colour, but those at the tail end and elsewhere are white. Southern Europe and both the northern and western parts of Africa are the habitats of this Porcupine.

It used to be believed that this creature had the power of 


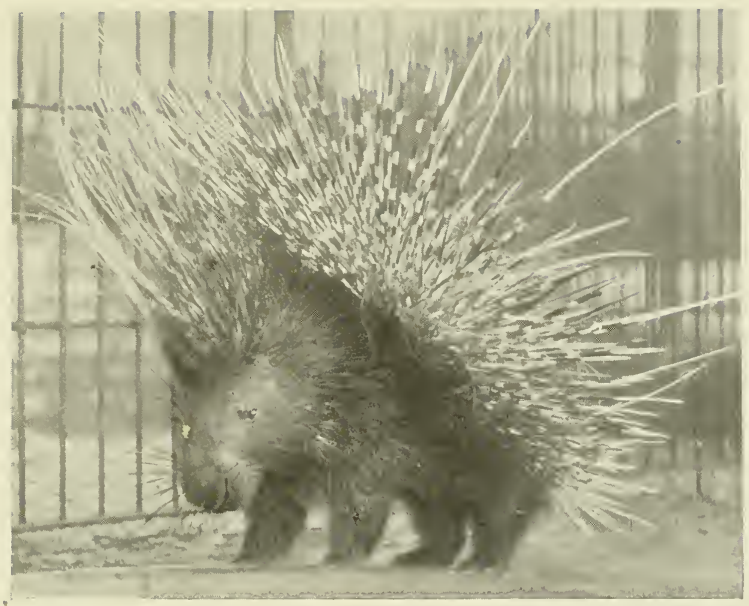

FIG. 73.-CRESTED PORCUPINE

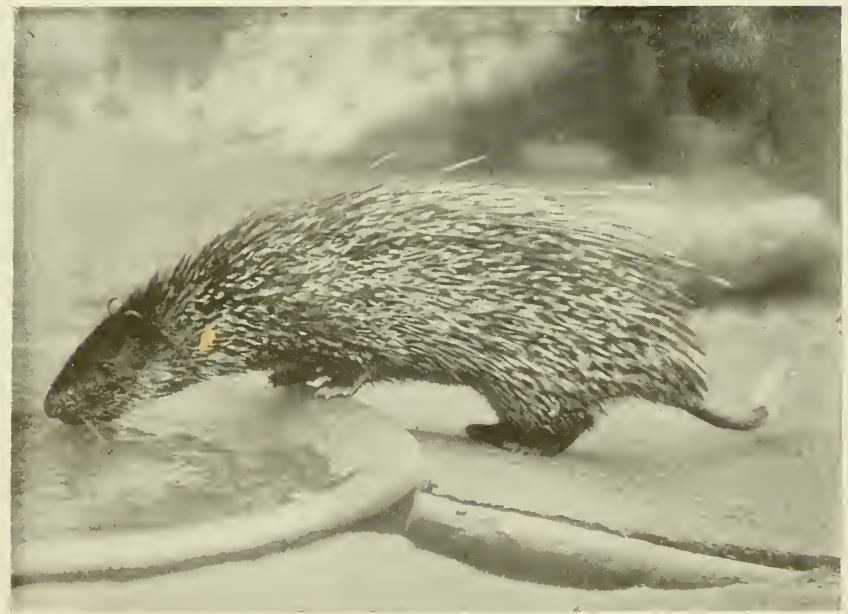

FIG. 74. - BRUSH-TAILED PORCUPINE 


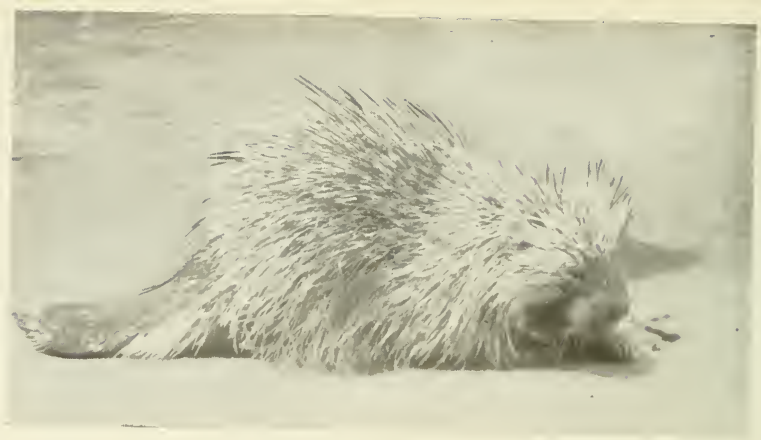

FIG. 75.- CANADIAN PORCUPINE

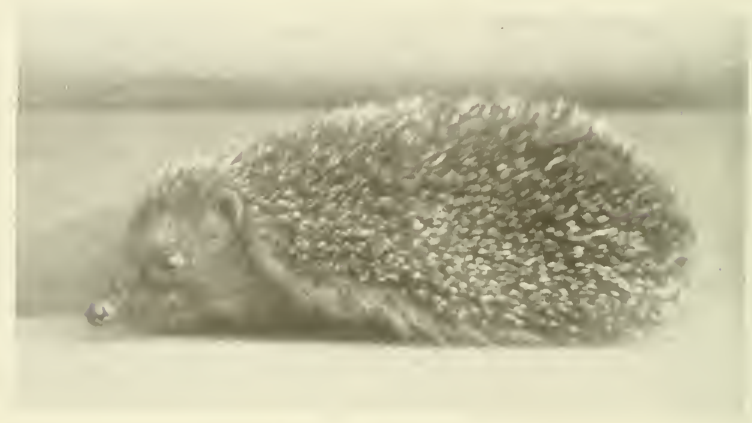

FIG. T6.-COMMON HEDGEHOG

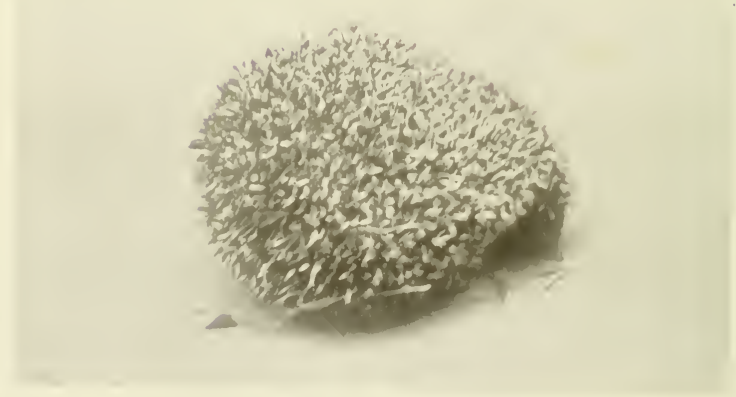

FHC. TT.-COMMON HEDGEHOG ROLLED UP 
"flinging its dart-like quills at an antagonist," but this is undoubtedly pure imagination. Remembering that these beasts are nocturnal, remaining hidden in burrows, caves, or clefts of rocks, it is unlikely that this provision is provided, more especially when it is borne in mind that to have any effect the "shot" would have to be made with considerable force. On the other hand, it appears well authenticated that wild denizens of the jungle, such as Tigers and Leopards, have been found dead with the quills of the Porcupine "piercing their nostrils and muzzles," and, so far as I can ascertain, no reason is forthcoming as to how the quills became thus embedded, unless the Porcupine had been attacked at close quarters. The explanation may be that normally the quills lie smoothly along the back, but when excited, or challenged to battle, the Porcupine raises its quills of defence and then runs backwards and makes a charge at its adversary. Therefore, those wild beasts that have been discovered with the quills adhering to their heads were attacked in this way, or their attacks upon the Porcupine were warded off by the latter in the manner indicated. Some of the quills are always somewhat loose, and it would not be a big task to dislodge them, beyond which the curious appendages are also shed periodically.

It is stated that the quill is armed with projections or barbs, which, once inserted in the skin of another animal, make the task of getting rid of them almost impossible. As a result, it is stated that inflammation is set up-and the result is aggravated by the efforts of the animal to dislodge its dart-and eventually the Leopard or Tiger, or other assaulted beast, dies of starvation.

I should like to state, however, that all the quills I have examined have not possessed any projections or barbs, and I do not quite see how this idea has originated.

The food of this Porcupine largely consists of roots, but, like the Common Hedgehog, shortly to be described, it resorts to sleep during the Winter, and has no necessity to bother itself as to provisions. For such a clumsily built animal it is quick-footed and possesses a keen eye. The quills, as is well known, are used for fishing floats, pen-holders, etc.

The litter is produced during the Spring or early Summer, and consists of from two to four. These interesting babies of the wild are snugly ensconced in a nest which is built of grass, leaves and fibrous roots. The youngsters are well advanced even when first born,

H 2 


\section{0 \\ THE BOOK OF THE ANIMAL KINGDOM}

having their eyes open. The spines are soft at first, but soon harden when exposed to the air.

It is a powerful gnawing rodent, the large size of the teeth and jaws aiding it in this respect, and in some districts a good deal of harm is perpetrated among growing crops in the fields and gardens.

BRUSH-TAILED PORCUPINE.-This is another species restricted to the Old World and, like its congeners, is terrestrial in its habits. It is, as Fig. 74 shows, considerably smaller than the species exhibited in Fig. 73, and is described as more Rat-like than the true Porcupines, "from which it is distinguished at a glance by the long and scaly tail terminating in a tuft of bristles." The spines are flattened and grooved, and of about the same length all over the back, shoulders and hind-quarters.

There are two species of Brush-Tailed Porcupines, one inhabiting Western and Central Africa, whilst the second is restricted to Burma and the Malay States. The Indian species measures up to twenty-two inches over head and body, and in colour is darkbrown above and whitish underneath. The longer quills on the back portion of the body are white for the most part, whilst the tips of the remaining quills and the bristles on the extremity of the tail are white. The Crested Porcupine (Fig. 73) need only be mentioned as possessing a crest of hairs on the shoulders which, when raised, give the beast a very pleasant effect.

CANADIAN PORCUPINE (Fig. 75).-This is a Porcupine of the New World, and although lacking the long prehensile tail of the Tree Porcupines, it is a good climber, arboreal in its habits, and strips trees of their leaves in no uncertain manner. It is also known as the Urson and Cawquaw, and is an inhabitant of Canada and almost the whole of the United States in spite of the first part of its name. It may be further distinguished by the possession of only three teats in the female, "the absence of a cleft in the upper lip, by the naked soles of the feet being covered by a number of tubercles," and "by the want of the first toe in the fore-foot." There are other structural differences as compared with the species previously dealt with, but these need not be detailed. The body is clothed with long brown hair, which almost hides the stumpy barbed spines; these latter are white, tipped with brownish. For an animal measuring only twenty-four inches in length, this species is heavy-looking and clumsy. It weighs from fifteen to twenty 


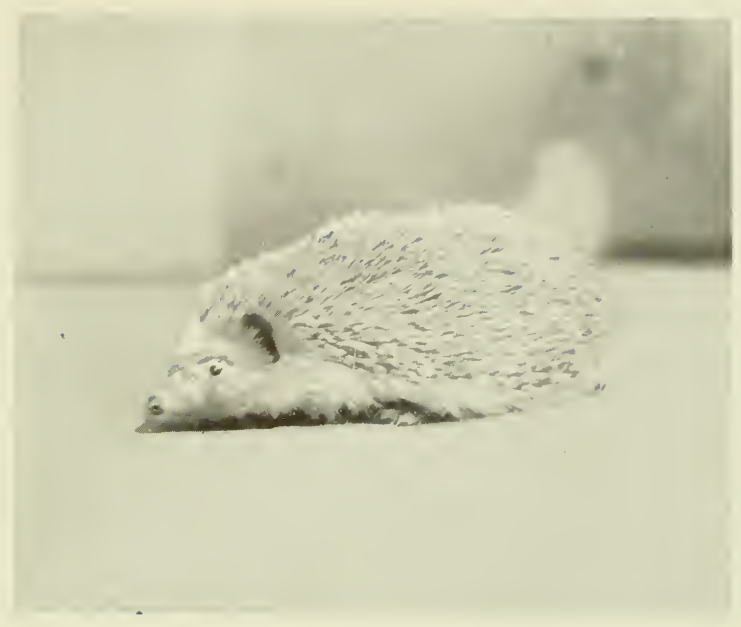

FIG. 78. -ALGERIAN HEDGEHOG

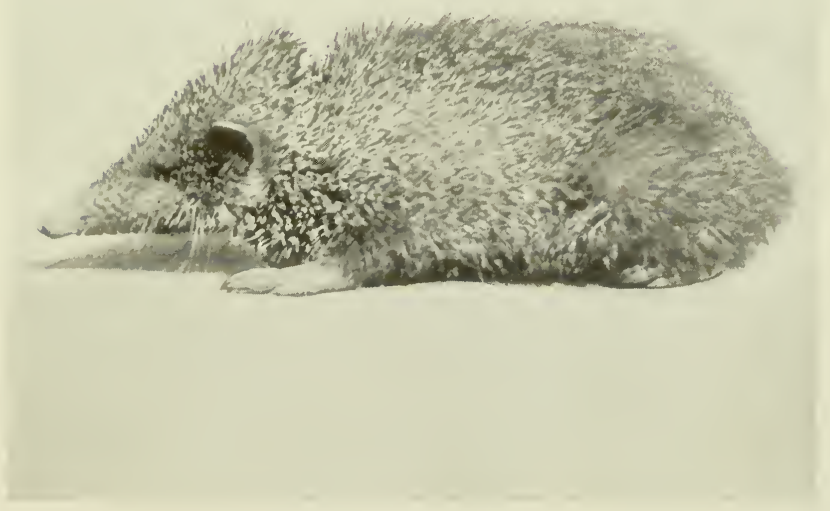

FIG. 79.-COMMON TENREC 


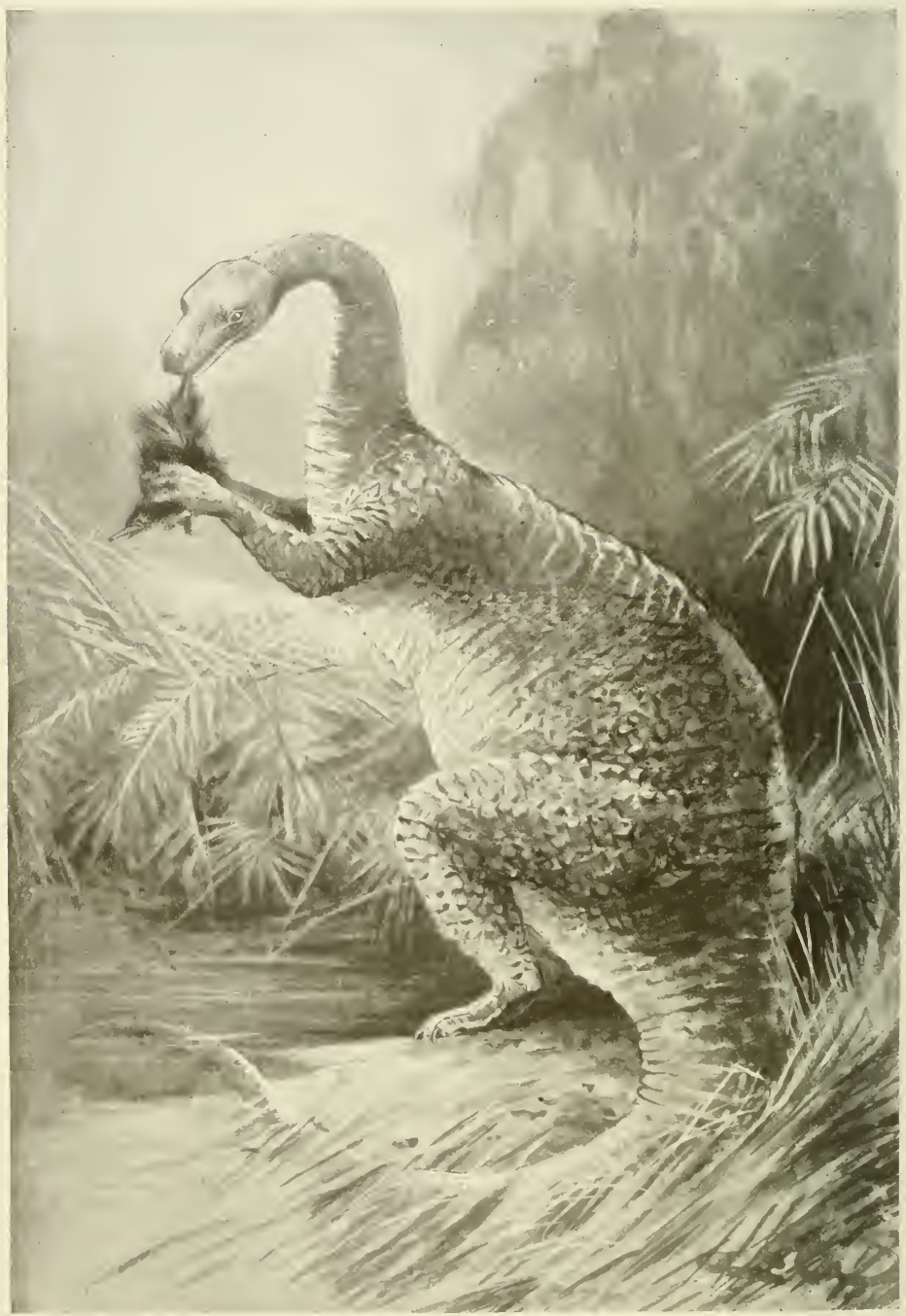

The extinct Megalosaurus, whose nearest living relatives are probably Crocodiles. Remains found in England and America. 
pounds. The long, powerful claws and large but only partly prehensile tail are also worthy of mention.

When in a normal condition the quills lie flat over the surface of the body, but when the animal stands at attention these are raised "by the aid of a sheet of muscle underlying the skin." These quills are only loosely inserted in the skin of the Porcupine, and can thus be easily detached.

This is the most northern form of Porcupine found in Canada, its range extending as far north as trees are found, whilst in the United States it is resident in the East, "as far south as Virginia, and on the Western Coast from Alaska to Arizona and New Mexico."

In spite of its heaviness and only partly prehensile tail, this species is a first-rate climber, and most of its time is spent in the tree-tops. It is largely nocturnal in its habits, but may also be observed during the daytime. Having become comfortably located in a tree and hunger requiring appeasement, the Urson makes short work of the surrounding foliage, stripping the tree of its leaves, and leaving the same quite bare. Succulent twigs as well as leaves are eaten, and the amount of harm perpetrated when the beast is thus engaged may well be imagined. It is astonishing to notice how so cumbersome a creature contrives to not only spend its time disporting among the tree-tops, but to reach with ease the leaves on the outside branches. One would have thought that the weight and general bulky build would have made this impossible, but this arboreal wanderer is no fool, for, by clever strategy, he manages to distribute his weight "by bringing several branches together, and then, with his powerful paws, bends back their ends and passes them through his mouth. When high in the tree-tops he is often passed unnoticed, mistaken, if seen at all, for the nest of a Crow or a Hawk." Beechmast, as well as the leaves, twigs and bark of trees are partaken of, whilst it is stated that the creature has a partiality for salt and is also fond of the pods of water-lilies.

The lair of this interesting American animal may be come across in a hollow tree, in bushes, or among the clefts of rocks. It is here that the nest is constructed and the one or two young ones produced during early Summer. Dr. Merriam, who studied these animals closely, states that the young are very large for the size of the beast, "being actually larger, and proportionately more than thirty times the size of the cubs of the Black Bear." 


\section{IO2 THE BOOK OF THE ANIMAL KINGDOM}

HEDGEHOG.-Few animals have survived in Britain better than the Hedgehog, for, in spite of persecution, it is still a common species in many districts. Being, however, largely nocturnal in habits, it is rarely seen except by gamekeepers and others whose work takes them continually out of doors, and, this being the case, the Hedgepig, as it is sometimes called, is considered by many to be comparatively rare.

I have found that in game-preserving country it is quite a common inhabitant of the woodland and hedgerow, and during one season alone on a small estate known to me over three hundred were trapped in a few weeks. Let it be stated straight away, this wild creature is an inveterate enemy to game birds, and my sympathy is always extended to the keeper who loses, through its pilferings, whole nests full of eggs either of Partridge or Pheasant.

One day during my country wanderings, the keeper and I kept careful watch over a Pheasant's nest. We had had suspicions that some unwarrantable intruder had purloined some of the eggs, several having been missed. The clutch was made up by us with spare eggs from time to time, but still some were missing on each occasion the nest was visited. We suspected a Stoat or Rat as the culprit, but one day our vigilance was rewarded, for, as we approached the Pheasant's nest, we espied a Hedgehog busily engaged scooping out the contents of an egg! The little beast was sitting, Squirrel-like almost, on its haunches, holding the egg between its fore-paws.

The small black eyes twinkled as the luscious feast proceeded, the whole form of the animal was agitated as if something were being enacted that ought not to be, and the reader can well imagine the ire of my keeper friend at this loss of the Pheasant's eggs. His first impulse was to rush forward and slay his foe, but on second thoughts we decided to wait further developments.

Such developments were not long in coming, as, having sucked one egg dry and discarded the shell, the Hedgehog trotted back to the nest, took out another egg, and made short work of the interior. This operation was carried out again and again, until eventually every egg in the nest was sucked dry and the whole clutch was destroyed. What happened afterwards is not for me to tell, for the keeper carried out measures which, humanitarian as I am, did not appeal to me. It would be a painful story to relate, and must be left unwritten. This little incident, however, goes to prove how 


\section{ANIMALS WITH ARMOUR}

harmful the Hedgehog may be in a district where game-preserving is indulged in, but it is most essential in considering the good or bad deeds of a wild animal that the whole, and not a part, should be taken into account.

What, then, does the Hedgehog feed upon in addition to the eggs of Partridge and Pheasant, and does it perform any good in preserving the balance of Nature? It attacks young wild birds, has been accused (and I believe not without good reason) of making raid upon the inmates of a fowl-house; it partakes of various kinds of insects as well as snails, slugs, toads, frogs, earthworms, etc.

Thus, it will be seen that the despised Hedgepig is not altogether harmful, indeed, putting game-preservation aside as a sport which affords pleasure to a very small percentage of our population, it may be stated that the animal has its uses and probably does more good than harm. Many people condemn the Jay and Magpie because of their pilferings among eggs and young birds, but it is important to recognize that a check of some kind is most essential, and if these natural balance keepers did not exist, certain species of animals would unduly increase over the normal, with results which in some instances would prove disastrous to agriculturists and others.

A note upon the subject of the value of animals of prey in the Field may be quoted. "It is generally admitted," says the Field, "as an abstract proposition, that predaceous animals perform an important function in the economy of Nature by preventing undue increase of the hordes that feed on herbage, seeds, fruits, and other vegetable life. But often when it comes to particular cases man looks askance at every mammal or bird that molests his poultry or game. The recent report of Mr. A. K. Fisher, the officer of the United States Department of Agriculture, who is in charge of the economic investigations, deals with this subject at some length. In his opinion, most of the predatory mammals of the United States confer great benefits on the agriculturist by keeping down the number of rodents. Thus in the fruit-growing districts of the West Prairie Wolves and Lynxes have freed ranches and fruit farms from Rabbits and other crop or tree destroyers, and at times the Prairie Wolf feeds entirely on large insects, such as May beetles-closely allied to the cockchafer, and equally destructive-crickets and grasshoppers. He has a good word to say for the Mink, the Weasel, the Skunk, the Badger, and the Raccoon, and considers 


\section{I04 THE BOOK OF THE ANIMAL KINGDOM}

that the Fox is often unjustly blamed for ravaging poultry yards when the responsibility lies on the farmer for not keeping his birds safely housed at night. Where this precaution is taken the Fox necessarily turns his attention to Field Mice, Rabbits, Ground Squirrels and insects, to the great benefit of the farmer. Of course, cases arise in which it is necessary to keep down the number of predaceous mammals in certain localities, but judicious thinning out is advocated rather than extermination."

That the Hedgehog has more than a passing liking for the eggs of Partridges and Pheasants has been conclusively proved to me by the large number I have seen caught in traps which have been set close by the nests of these two birds, but it must be remembered that the eggs of these game birds are only to be obtained during a few weeks of Spring and Summer, and some other food must then be sought for. Thus we may leave the dietary of this member of the Insectivora, and give consideration to other parts of its story.

As Figs. 76 and 77 show, this is a well-armoured beast and entitled to inclusion in the present section. It is only a small animal, attaining a length of some ten inches. The legs and feet are short and stumpy, and it is remarkable to notice, in view of the bulky spine-covered body, that the Hedgehog can travel at a rapid rate when it is once on the move. Having found one in a hedgerow bottom snugly tucked up, secure from frost-bite and cold, pick it up, if you can! It is more easily said than done, for the spines are exceedingly sharp, and to handle the creature successfully is almost impossible. At least such is my experience.

You may be tempted to carry the interesting beast home in a pocket-handkerchief, but if you do, and are at all particular as to the abundance of live stock you may harbour, my advice is, leave the animal in its own wild fastness. It is simply alive with black parasites, and I remember on one occasion my handkerchief was a perfect sight, peopled as it was with thousands of small parasites, which seem to leave the Hedgehog's body in a swarm. I have had somewhat similar experience with IVild Rabbits, for they, too, are largely infested with parasites during life. I have noticed with interest, however, that as soon as the body of the dead Rabbit becomes cold, the parasites make haste to leave it and seek the body of a living rodent upon which they may again pay attention.

Parasites are worthy of study, and have not been accorded 
that share of attention that they deserve. People who know little of such creatures shudder at the thought of them, let alone the sight. Not long since I saw four distinct kinds of parasites taken from the body of a Mole, and when I display these and other subjects at my lectures, I notice time and time again the general repulsion that is felt at the sight of these creatures, many of whose life-histories are far too important and even useful to be passed by.

If you do not decide, then, to carry the Hedgehog home, but wait until it unrolls its body, just watch it run and then try to catch it. I have been amazed at the speed it can attain.

It seems a shy creature and hates being watched. So soon as encountered it promptly rolls itself into a ball, as shown in Fig. 77. It has a Pig-like face, and although timid in a natural state, it learns, when in captivity, to become docile and trustful in a short time. The worst case against it as a pet when given its liberty, even in a securely walled-in garden, is its remarkable habit of making good its escape in a most unaccountable way.

Ably protected by its spiny coat, the Hedgehog has existed where other animals have gone under, and has changed very little from its earlier form. Its nocturnal habits have also afforded assistance to it. It is one of the oldest animals we have; it is well guarded from the attacks of other predaceous beasts, and itself encounters an Adder with inevitably fatal results to the last-named.

The Hedgehog angers the Adder until the latter is thoroughly roused. The Snake prepares to attack its mammalian adversary, and darts at it with unerring aim. The Snake, however, has reckoned without its host, for the Hedgehog, quick as thought, curls into a ball before the impact, and the reptile finds itself impaled in the spines, to meet certain death. Then the Hedgehog, satisfied with the result of its strategy, unrolls its body and feeds upon its prey!

If the animal now under review is sought for during the day, search should be made along a hedge-bottom, where it may be found snugly tucked up among dead leaves or grasses. During the Winter it hibernates, making a cosy nesting-place of leaves at the base of a tree where there is a convenient hollow, in a wood, thicket, hedgerow or other environment. Nc food is taken during this Winter fasting, and thus with the advent of Spring the beast possesses a keen appetite, which is not easily appeased.

The two to four young ones are born during the early days of 


\section{I06 THE BOOK OF THE ANIMAL KINGDOM}

Summer. They are at first blind, and the spines are soft and white. The latter, however, soon harden as the little ones come to run about and secure provender on their own account. To see a mother Hedgehog with her young is one of the most delightful sights in the whole realm of nature.

Outside Britain the range of the Hedgehog includes China, Amurland, Scandinavia, Italy, Asia Minor and Syria. Its range is not restricted to the low-lying portions of the regions inhabited, for it is found at as high an altitude as six thousand feet in the Alps, and still higher in the Caucasus, where it ascends to an elevation of more than eight thousand feet.

Mention need only be made by name of the Algerian Hedgehog (Fig. 78), which represents one of the African species found both in the North and South of the great continent. One species there is interesting, because it has lost the inner toe of the hind-foot. There are in all almost twenty known species of Hedgehogs.

TENRECS. -- At first sight this animal (Fig. 79) might pass muster for a Hedgehog, but it is relegated to a different genus of the Insectivores. As a matter of fact, the Common Tenrec of Madagascar is stated to be the nearest living relative of the Marsupials of Australia and America. This curious relationship is brought about by reason of the teeth of both the Common Tenrec and the carnivorous Marsupials being somewhat identical; the skulls are very similar, and the number of young also resemble the Marsupials and go to enhance the kinship. The Common Tenrec-which is much less Hedgehog-like than the Hedgehog-Tenrec, which bears short particoloured bristles-often has as many as fifteen or sixteen young ones at a birth, whilst twenty-one have been recorded.

It should be stated with emphasis here the great importance in the classification of animals which is attached to the number, position and structure of the teeth. The young zoologist will find very often when pursuing his studies that the teeth of an animal at once identify it and go to prove the position it occupies in the scale of animal life. This book does not pretend to be a dry scientific discourse upon anatomy, and it does not come within the province of the writer to enlarge upon this subject. He merely makes the suggestion that the young student should follow up the matter on his own account if, by reading this volume, he has been sufficiently attracted to pay attention to some of the living mammals of the world. 
The Common Tenrec and its allies are entirely confined to Madagascar and a few of the neighbouring islands. As Fig. 79 shows, they have long snouts and a body somewhat akin to that of the animal last under review. Whilst the common species does not possess a tail, the Hedgehog-Tenrecs have a short appendage as in the European animal.

These Hedgehog-Tenrecs cannot, however, roll their body into a complete ball in the same way as the Common Hedgehog, for it is found that the powers of muscular contraction are far less developed, and whilst the animals are not related, it is most interesting to observe that both possess spines of a similar nature, which are used as weapons of defence in a similar way, that the food is somewhat similar and that they are nocturnal.

The Madagascan animals are smaller than the Common Hedgehog, one species being about six inches in length, whilst another of these Hedgehog-Tenrecs is still smaller.

Besides the foregoing, there are the Streaked Tenrecs, the LongTailed Tenrecs and the Rice-Tenrecs. None of these possess spines, and cannot therefore be justly included as armoured animals, and the mere mention of them must suffice, as the reader can, if he so desires, follow up the subject on his own account, for these comparisons cannot fail at all times to prove of interest to the zealous and painstaking student of animal life.

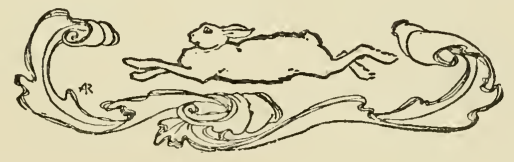




\section{CHAPTER VII \\ ANTELOPES AND DEER}

ADDAX ANTELOPE.-This, the first of the Antelopes chosen as worthy of inclusion in this section, is an inhabitant of Northern Africa and Arabia. It belongs to the genus Addax, the members of which are characterized by the possession of long cylindrical horns in both male and female. In the Addax (Fig. 8o) the horns "attain a length of from twenty to twenty-eight inches in a straight line, and from twenty-six to thirty-five and three-quarters along the spiral." The curious open spiral shape of the horns may be seen to advantage in the photograph.

For the most part this Antelope is covered with short and thick hair of a yellowish-white colour, but on the head, neck and mane it is brown. As Fig. So depicts, there is a prominent transverse band of white below the eyes; the lips and a spot on the outside of the ears are also white. The male is more thickly clothed than the female, the colour of the hair is darker, and during the Winter the yellowish-white merges into grey.

The Addax stands over thirty-six inches high, and inhabits sandy and waterless wastes. Shy in disposition and wary, few observers seem to have had any opportunity of studying this animal to any extent. Its flesh is highly regarded, and for this and other reasons the Addax is sought after by the Bedouins, who organize protracted expeditions among the barren, sandy deserts which it frequents.

BEATRIX ANTELOPE. - Still less appears to be known of the Beatrix Antelope (Fig. 8I) of Western Arabia, but it will at once be seen that the spiral horns are absent in this species, and it is a smaller animal than the last named, standing about thirty-two inches high. It is whitish in colour, with a dark spot on the face, and, as the photograph clearly indicates, a large dark patch on each cheek. These patches meet underneath the throat. The legs are also dark coloured and the tail is tipped with black. 


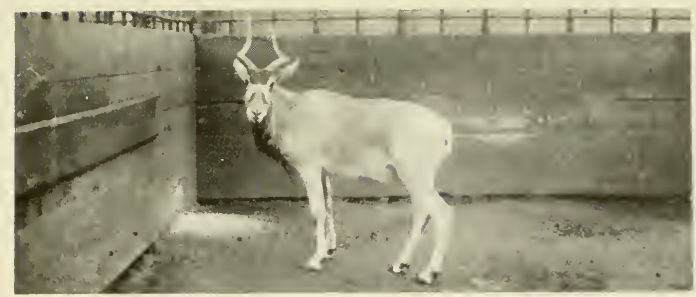

FIG. SO.-ADDAX ANTELOPE

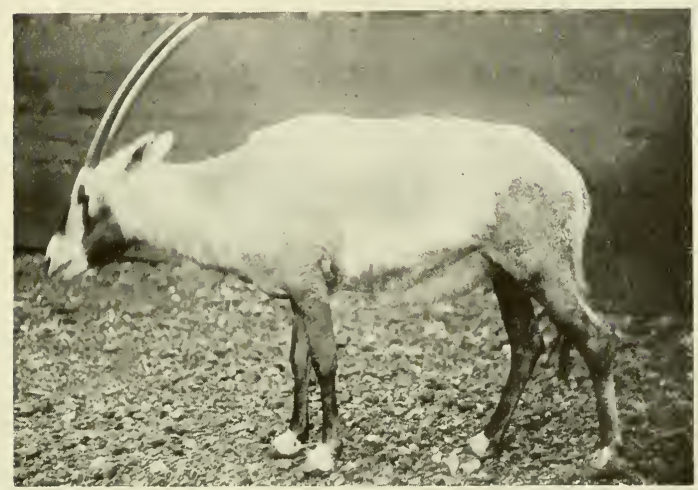

FIG. 8I.-BEATRIX ANTELOPE

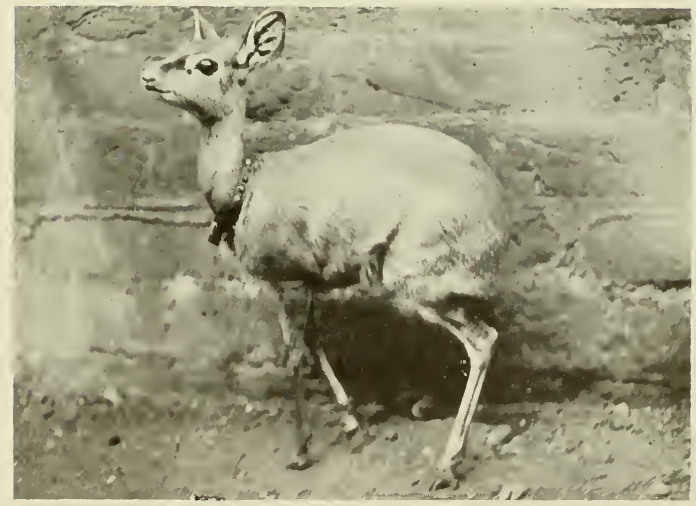

FIG. 82,-DIK-DIK ANTELOPE 


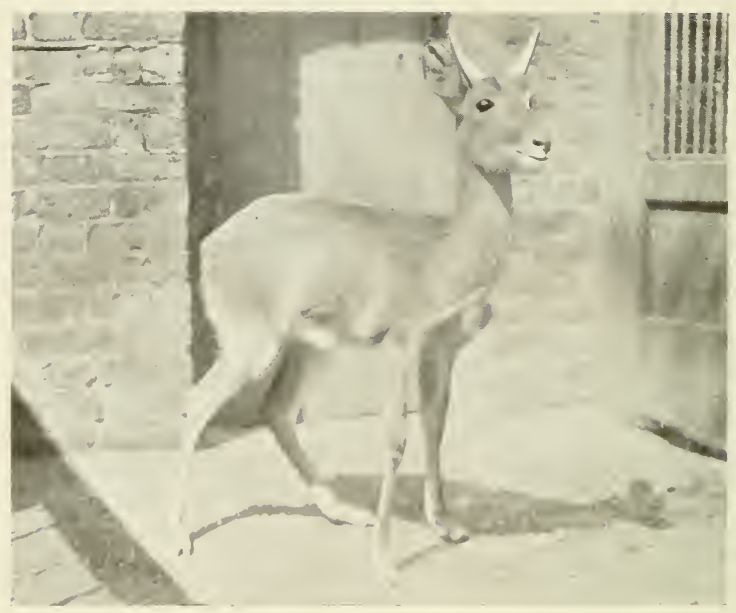

FIG. 83 - NAGOR ANTELOPE

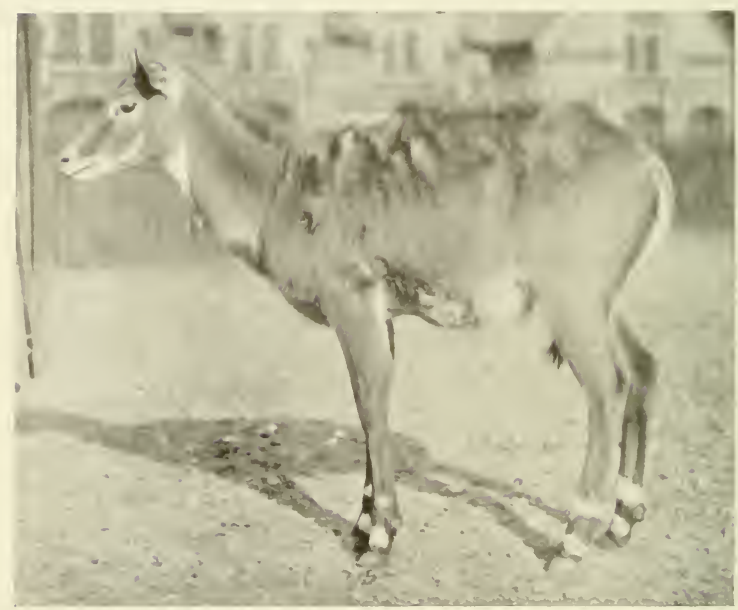

FIG. 8+.-NILGAI ANTELOPE 
DIK-DIK ANTELOPE.-This small Antelope (Fig. 82) has a short tail and a tuft of hair on the crown of the head. It haunts the bush in the east and north-east parts of Africa, but more than two or three are rarely seen together. There are several species, but all may be regarded as rare in captivity.

NAGOR ANTELOPE.-This is another small Antelope (Fig. 83) with horns seldom longer than six inches. It is a West African beast and is closely allied, if not identical with, the South African Antelope known as the Roi Rhebok. The long, coarse hair is reddish-brown on the upper parts, the under parts being white. Only the male has horns, and the small, upright pair possessed by the animal are well shown in Fig. 83 .

NILGAI.-Leaving the great African continent for the present, we now make acquaintance with the Nilgai (Fig. 84). 'This is the largest Antelope of Asia, having short, untwisted horns, and these are possessed only by the male. The latter is iron-grey in colour, but the cow is quite different, being light fawn or yellow generally, but with white markings as in the bull. The reader will probably be struck with the fact that the Nilgai is very unlike an Antelope. Such is the case, for in size it about equals a Pony, and there is, as Mr. Finn says, "something very Horse-like about its general appearance, although the kind of Horse it suggests is a very badlyshaped one."

This Antelope is an inhabitant of India, and whilst it does not resort to the dense forest it is usually found where there is some amount of cover. It travels about in small companies, feeding upon leaves, grass, wild fruits, etc., and is said to be very destructive to the crops of the natives. Mr. Finn says that among the Hindoos "it is a sacred animal, simply because its name means 'Blue Cow,' so that the sanctity of the bovine race has been absurdly transferred to it. Mohammedans, of course, will eat its flesh readily enough, but it is not much hunted by European sportsmen, because no one cares much about possessing a head with such insignificant horns. It thus comes about that the Nilgai is probably less hunted than any other animal of the size; but, of course, it has natural enemies to reckon with in the shape of Tigers, Dholes and other carnivores." The cow is the swifter traveller of the two sexes, and whilst she will gallop straight away from her pursuers, the bull can be ridden down if he is pressed hard at the commencement of the chase. 


\section{IIo THE BOOK OF THE ANIMAL KINGDOM}

In captivity the animal now under review does very well, and had it not been for the uncertain temperament of the bulls, it might lave been introduced among British park animals, although, to say the best, its value from an ornamental standpoint is not great. Either one or two young ones are produced at a birth.

PRONG-HORNED ANTELOPE.-This Antelope (Fig. 85) is one of the very few species which are found in the New World, being a resident of North America. The photograph shows a male and $\mathrm{f} \in \mathrm{male}$, the lower figure being that of the male, with horns just growing. As the name implies, the horns are branched and these are shed annually. This is interesting to observe, because by reason of these two characteristics it is distinguished from the whole of the remaining Hollow-Horned Ruminants.

The Prongbuck, as it is also called, attains a height of about thirty-six inches at the shoulder. It stands erect (as the female in Fig. 85 displays), is pleasing in appearance, and has a chestnut coat with white on the under parts and the hind-quarters. The darkbrownish face is topped with white, as are also the ears, cheeks and chin. Three bars of russet-yellow across the throat complete the dress. Although an Antelope-and it is often thus designated in America-the structure of its horns remind one strikingly of those possessed by the Sheep and Goats. They measure about twelve inches in length, are flattened from side to side, and bend backwards at the tips. There is a short branch thrown out from about the middle of the horn, and this is directed outwards.

The Prongbuck is a fast runner but a bad jumper, the result, as Mr. Protheroe states, of its life on the prairies, where obstacles are few and far between. It is shy and timid in its habits, and it needs a practised stalker to successfully get within gunshot of it. It is very keen-sighted, and yet in spite of these credentials we learn with regret that it is "rapidly approaching the point of extinction, and it is now only found in the more remote western regions."

Mr. Ernest Ingersoll says that in years gone by "nowhere were they originally more abundant than upon the high, dry plains of the Arkansas valley, IVestern Texas and thence out to California."

It is curious to notice that it was not until 1865 that the fact of the shedding of the horns, which had long before been asserted as taking place by Indians and plainsmen, was admitted by the 


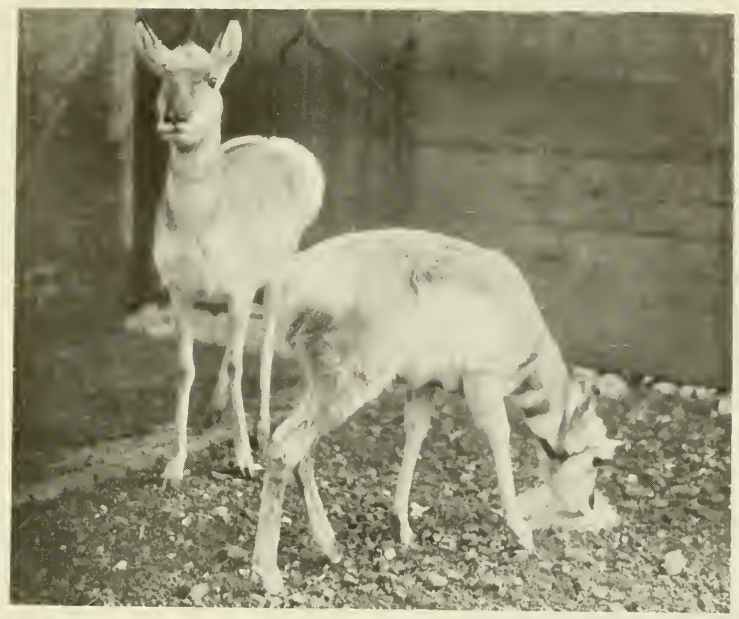

FIG. 85.-PRONG-HORNED ANTELOPES

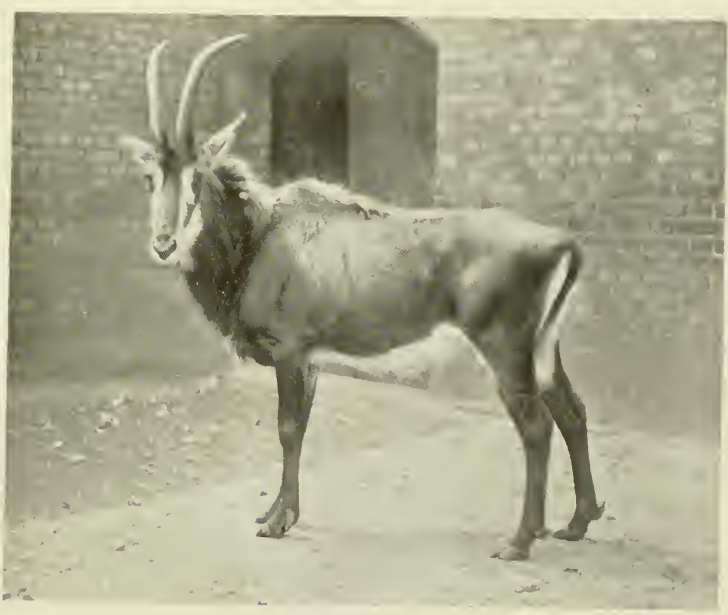

FIG. 86. - SABLE ANTELOPE 


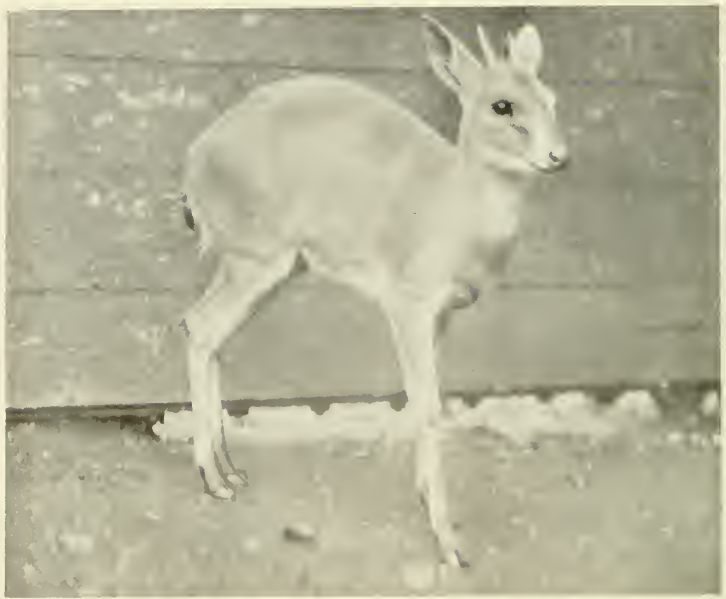

FIG. 87.-ABYSSINIAN DUIKER

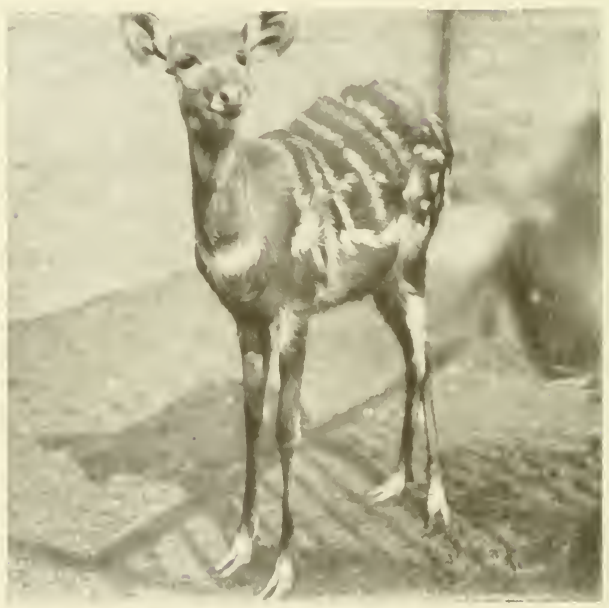

FIG. SS.-CONGO MARSI BLCK 
scientific world, and Audubon declared he had "proved to the contrary." Although hunters had frequently asserted that the animal shed its horns every year, it remained for some years a matter of doubt until a specimen in confinement afforded actual and visible proof of the peculiarity.

It is worth noticing also that the white stern of the Prongbuck acts as a sort of danger signal in the same way as the upturned tail of the Rabbit. When it is necessary for this danger signal to be increased in area, the animal "cocks" its tail and thus displays the white under side. Thompson Seton has described it as "a great double disk or chrysanthemum of white that shines afar like a patch of snow."

Mr. Ernest Ingersoll gives a full account of this beast in his Life of Mammals. He says that "the life of our Antelope is very simple. It is the genius of the dry, gravelly, bunch-grass plains, where it finds in the sun-cured nutritious herbage, relieved each Spring by a juicy new growth, all the sustenance it craves. Wooded spaces it naturally avoids, not only because it has no appetite for leaves and twigs, but because thickets shelter Wolves and Wild Cats; yet now and then a solitary buck will make a grove his hermitage, or a heavy doe retire to some bushy glade to be delivered of her fawn. Of late, however, under the changed conditions in its home, the Pronghorn seeks cover more than formerly. It has no Goat-like fondness for rocks, and rarely climbs the rough slopes of even the foothills.

"The young, usually two, are dropped in May or early June, when the mothers have stolen away separately to secret places, and the bucks are wandering alone or in small gay parties by themselves; these fawns are not spotted, but plain dun miniatures of the mother, and for the first few days lie motionless whatever happens, trusting to be overlooked; but soon they get upon their legs and begin to accompany the doe. From the start they show an instinctive intelligence in meeting the dangers that beset them, clinging, as if bound by a short tether, to the heels of the mother, when, as so often happens, a Coyote does its best to get past the valiant doe's defence of lowered horns (which are short, sharp and unforked) and striking feet, to seize the tender youngling. I have told at length elsewhere of such a battle which I once witnessed on the Wyoming plains. Rattlesnakes are another ever present peril, but these the Antelope, if not first fatally struck, cuts to 


\section{2 THE BOOK OF THE ANIMAL KINGDOM}

pieces by stamping upon them with quickly repeated bounds, all four hoofs alighting together on the reptile's coils.

"A Pronghorn's javelin-like fore-feet are its best weapons, though the bucks-furious in their rivalry when forming their haremspush one another about with their forked horns. Nowhere is to be read a more discerning, intimate and delightful account of the Prongbuck than in Ex-President Roosevelt's chapter on it in The Deer Family, and on this point he notes: 'All the Deer are fond of skulking; the Whitetail pre-eminently so. The Prongbuck, on the contrary, never endeavours to elude observation. Its sole aim is to be able to see its enemies, and it cares nothing whatever about its enemies seeing it.

'Its colouring is very conspicuous, and is rendered still more so by its habit of erecting the white hair on its rump.

'It has a very erect carriage, and when it thinks itself in danger it always endeavours to get on some crest or low hill from which it can look all about.

'The great bulging eyes, situated at the base of the horns, scan the horizon far and near like twin telescopes. They pick out an object at such a distance that it would entirely escape the notice of a Deer. When suspicious, they have a habit of barking, uttering a sound something like 'kau,' and repeating it again and again as they walk up and down, endeavouring to find out if danger lurks in the unusual object. They are extremely curious, and in the old days it was often possible to lure them towards the hunter by waving a red handkerchief to and fro on a stick, or even by lying on one's back and kicking the legs.'

"Yet in Summer, when small scattered parties dot the plainsor used to - a band would lie down during the midday hours in some open valley and rest in negligent ease. More than once have I ridden quietly over a ridge and thrown such a resting band into a momentary paralysis. Surprised, yet hardly knowing what to fear, they would spring to their feet, then, suddenly panic-stricken, start off in high, stiff 'buck jumps,' making no progress and the picture of wild terror. An instant later, however, gathering its faculties, the band would skim away in flight, then, if not followed, halt a few hundred yards off to look back. This curiosity is a strong trait, and often brings Antelopes close to camp, or into a band of Horses or Mules, and their liability to panic leads them now and then to run right into danger. Audubon pictures their contradic- 


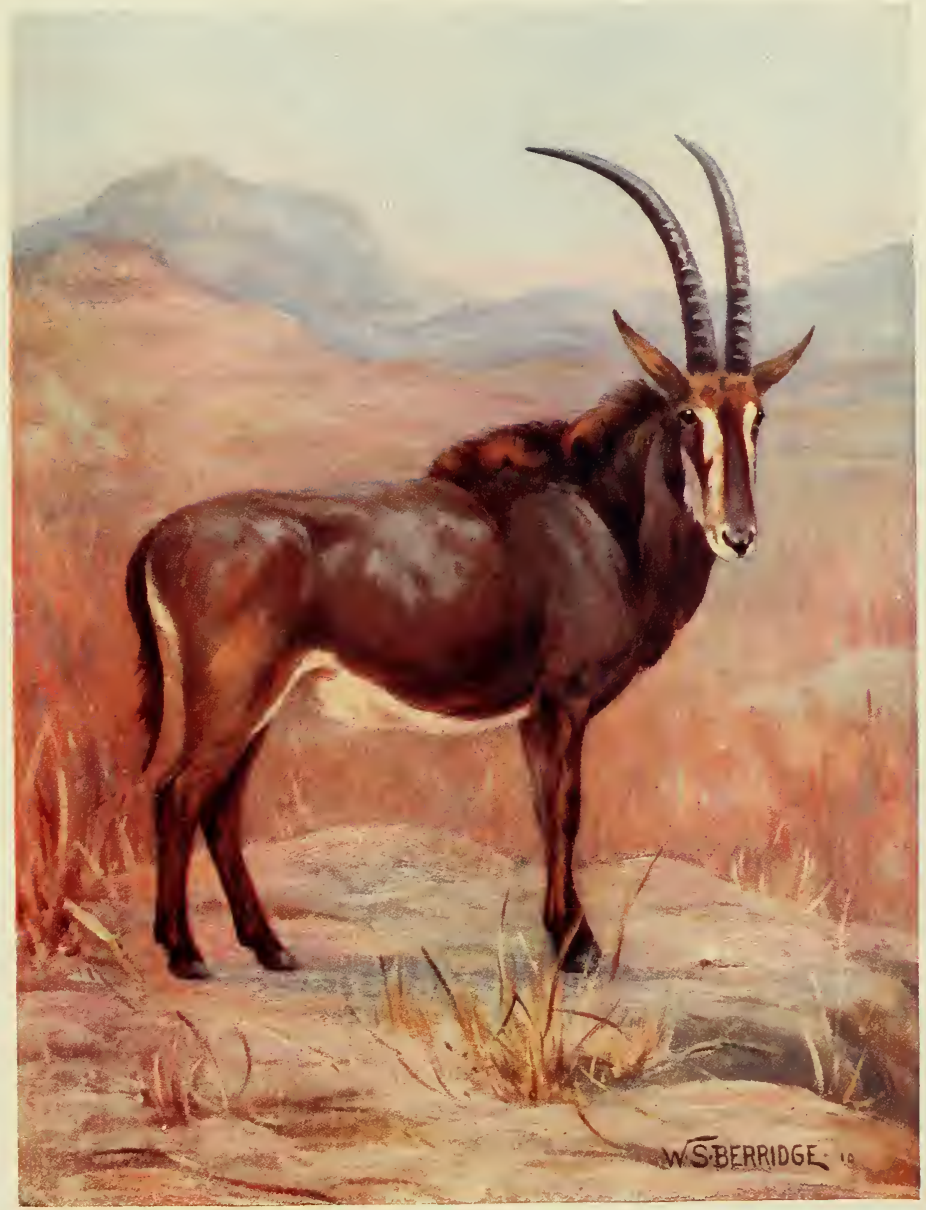

SABLE ANTELOPE. 

tory behaviour excellently in that long account of the animal as he saw it on the Upper Missouri in 1843 , which so enriches his great work on American quadrupeds.

"This disposition is a mark of the high intelligence of the animal, whose wits have been sharpened by generations of life in the midst of danger. Judge Caton came to have a very high idea of their brain power after keeping them in his park. "When taken young,' he says, 'it soon acquires the attachment of a child for the human species, and when captured adult in a short time becomes so tame that it will take food from the hand and follow one by the hour, walking through the grounds. One that was in the constant habit of following me soon became disgusted with the Elk which chased him, so that whenever he saw me going toward the gate which opened into the Elk park, he would place himself in front of me and try to push me back.' Thornaday warns us, however, from his experience in zoological gardens, that as the bucks grow older they become dangerously rough in their play."

SABLE ANTELOPE.-This fine Antelope (Fig. 86) is an African animal, and although a prominent resident of South Africa is also an inhabitant of other parts of the great continent. It was first found in the Transvaal by Harris, and although it has now become extinct in that colony, the name of the discoverer is perpetuated by some of our own kith and kin, the animal being sometimes called the "Harrisbuck." Its general coloration may be presumed from the fact that the Boers call the beast "Zwart-wit-pens," meaning black-white-belly.

The Sable Antelope is considered by many as the finest Antelope of all, and it has been chosen as the subject for the coloured plate to represent this section. Its size is equivalent to that of a fullgrown Pony; it possesses an elegant and pleasing carriage, and its general form and colour cannot fail to commend it to those who take an interest in these wild creatures.

Whilst the female (or cow) is not so dark-coloured as the male (or bull), she may be distinguished by the shorter, more slender and less strongly-curved horns. The horns of the bull attain a length of more than thirty-six inches. The light markings on the face are well shown in both the photograph (Fig. 86) and the coloured plate, but the young ones are characterized by the absence of these face-marks and are light-brown in colour. It is of sociable disposition and inhabits open country well above sea-level and where 


\section{THE BOOK OF THE ANIMAL KINGDOM}

there is some amount of cover. The cows and calves keep together, but only one bull accompanies them, as keen rivalry exists between the males; indeed, the bull "may be aggressive to other Antelopes, as it has an unscrupulous habit of turning out Lichtenstein's Hartebeest from beds or lairs which this animal is fond of making for itself."

The Sable Antelope is a quick traveller, is a dangerous beast at close quarters when hard-pressed, exhibits indomitable courage and makes every use of its horns. Mr. Finn says that like the Gemsbok it fights lying down, and is very dangerous to hounds.

Mr. Selous, in his Hunter's Wanderings, gives an interesting incident which is worth relating here. He says that one day he and his party "witnessed a very pretty sight, as we were riding across a wide, open down between the Zweswe and Umfule rivers. We had a short time previously noticed a solitary old Sable Antelope bull feeding on the edge of a small strip of bush that intersected the plain. Suddenly this Antelope, which was 600 or 700 yards distant, came running out into the flat straight towards us, on perceiving which we reined in our horses and looked around for the cause of its alarm. This was soon apparent, for before long we saw that an animal was running on its tracks, and though still distant, overhauling it fast, for the Sable Antelope, not being pressed, was not yet doing its best, so that when it was about 200 yards from us, its pursuer, which we now saw was a Wild Dog, was not more than fifty yards behind it. The noble-looking Antelope must just then have seen us, for it halted, looked towards us, then turning its head glanced at its insignificant pursuer. That glance, however, at the open-mouthed Dog thirsting for its lifeblood must have called up unpleasant reminiscences, for instead of showing fight, as I should have expected it to have done, it threw out its limbs convulsively, and came dashing past us at its utmost speed. It was, however, to no purpose, for the Wild Dog, lying flat to the ground as a Greyhound, its bushy tail stretched straight behind it, covered two yards to its one, and came up to it in no time. It just gave it one bite in the flanks, and letting go its hold instantly, fell a few yards behind; at the bite the Sable Antelope swerved towards us, and upon receiving a second, in exactly the same place, turned still more, so that taking the point on which we stood for a centre, both pursuer and pursued had described about a half-circle round us, always within 200 yards, since the Sable Antelope had 
first halted. As the Wild Dog was just going up the third time it got our wind, and instead of again inflicting a bite, stopped dead and looked towards us, whilst about Ioo yards from it the Sable Antelope also came to a stand. The baffled hound then turned round, and, pursued by Clarkson, made off one way, whilst the Sable Antelope, delivered from its tormentor, cantered off in another."

DUIKERS.-There are many species of these small Antelopes, and they all belong to the bush and forest districts of Africa. Fig. 87 represents the Abyssinian Duiker, which is an allied species from East Africa, and which may be identified from the Common Duiker by its grizzled greyish-brown colour.

The Duikers form the genus Cephalophus and are distinguished by the short, conical horns, rounded backs, pointed heads and short legs. Although the Yellow-Backed Duiker and two or three other kinds stand nearly thirty-six inches high at the shoulder, the remaining ones do not attain a greater height than about twenty-four inches. A feature of interest respecting these animals is the tuft of hair which grows on the head between the horns. When these horns are very insignificant the hair-tuft entirely covers them. In some species both sexes possess horns, in others the males only.

Duikers generally are grey or brown in colour, having a sober and unobtrusive dress, but exception must be made in the case of Jentink's Duiker, in which the head and neck are black and the body light-grey, and the Banded Duiker, in which, as the name implies, there are prominent black stripes on the back.

These little African Antelopes inhabit the bush; they are active beasts, and have derived their name from their habit of diving into cover.

MARSH BUCKS.-The Sitatungors, or Marsh Bucks, are closely related to the Harnessed Antelopes, or Bush Bucks. They are African beasts and there are three species. The Congo Marsh Buck (Fig. 88) is a large animal, and a doe and young are shown in Fig. 89. This animal breeds freely at the London Zoological Gardens. In view of the nature of its wild environment the yards are floored with peat, and the visitor would do well to notice the long, pointed toes which, when placed on the ground, are spread out, as may be observed in the case of the specimen illustrated in Fig. 88 .

It is interesting to narrate that although closely allied to the 12 


\section{II6 THE BOOK OF THE ANIMAL KINGDOM}

Bush Bucks, the Marsh Bucks may be distinguished by the very long hoofs, "and in the fact of the back of the pasterns being bare and horny." This enables the Marsh Buck to inhabit marshes, an unusual environment in which to find an Antelope.

Swamps and marshy surroundings are the favourite haunts of these beasts. They are fond of immersing the body in water although, as Mr. Finn points out, they are waders rather than swimmers. It has been recorded, however, that they can dive and even sleep under the water, the nostrils only being exposed.

The Sitatunga stands about three and a half feet high in the male, and in the swamps of Central, South Central and East Africa makes its home. They go about in pairs in a similar way to their relatives. They are uniform greyish-brown in colour, the hair is long and silky, the horns are smooth, slender and strongly ridged, and the young are faintly striped and spotted. The markings on the Congo Marsh Buck are sufficiently indicated in Figs. 88 and 89.

SING SING WATER BUCK.-This animal (Fig. 90) belongs to a different genus from the Marsh Bucks but, like them, is an aquatic beast found in Western and Central Africa. Unlike the species last under review, however, the Water Bucks move about in small herds; they inhabit precipitous hills, are wonderfully sure-footed for such heavy-looking Antelopes, and although on occasions found some distance from water they invariably make for it when harassed.

The Sing Sing stands something over three and a half feet at the shoulder, and may be distinguished from the Water Buck (Cobus ellipsiprymnus) by the less coarse hair, the presence of a whitish patch on the buttocks, and the absence of a white gorget. The horns measure a little over two feet, and the general appearance of these may be seen in Fig. 90.

There are several other species of Water Bucks from the large C. ellipsiprymnus, which stands over four feet at the withers, to the Puku, the Lichi and the still smaller West and East African Equitum. To one of these smaller kinds, Mr. Lydekker points out, the species of Cobus found in the Pliocene rocks of Northern India is probably allied.

SPRINGBOK. - This active little South African animal (Fig. 9I) is another member of the Antelope family worthy of mention. It has acquired its name by reason of its habit of leaping several feet in the air when it is engaged in running at top speed. It was formerly distributed over a wider area than it now obtains, the chief 


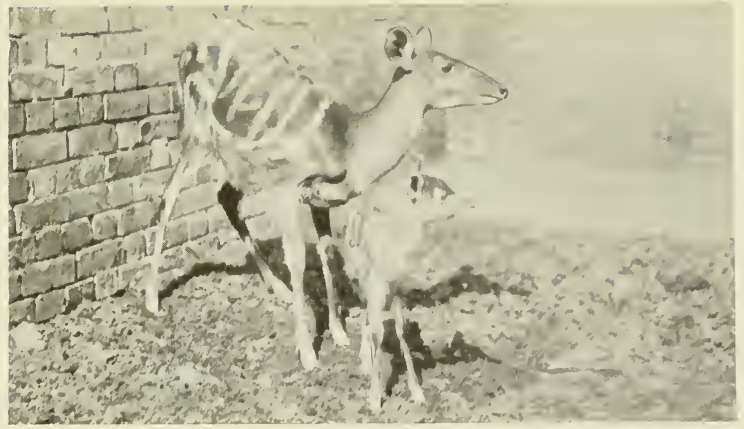

FIG. 89.-CONGO MARSH BUCK (DOE AND YOUNG)

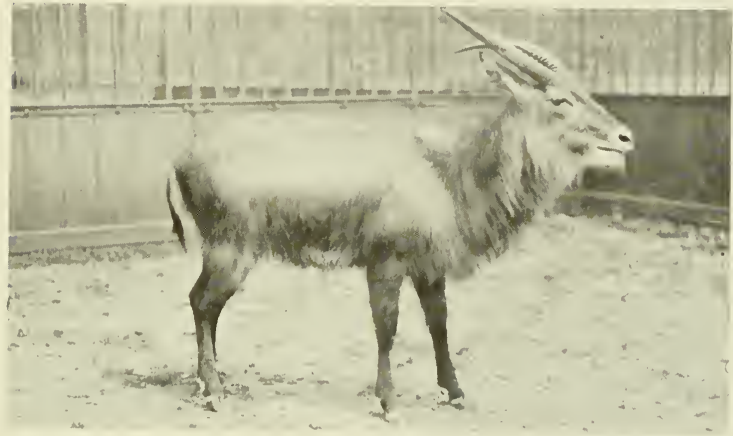

FIG. 9O.- SING SING WATER BUCK

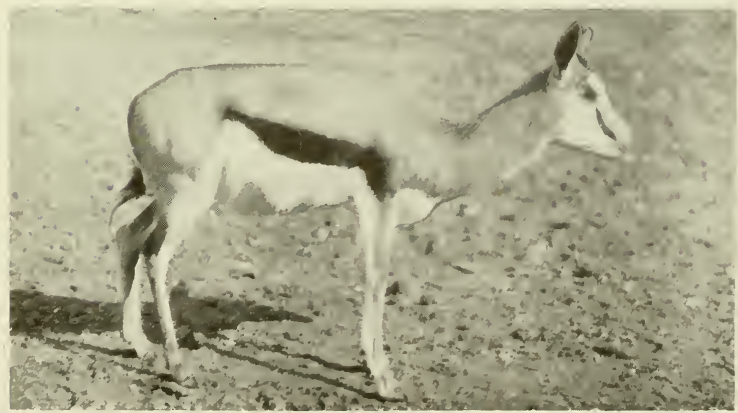

FIG, 9I.-SPRINGBOK 


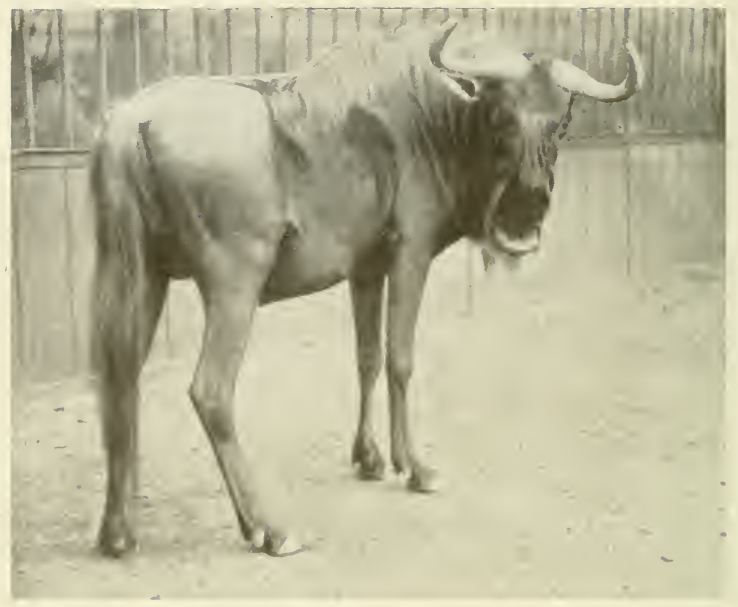

FIG. 92.-BRINDLED GNL

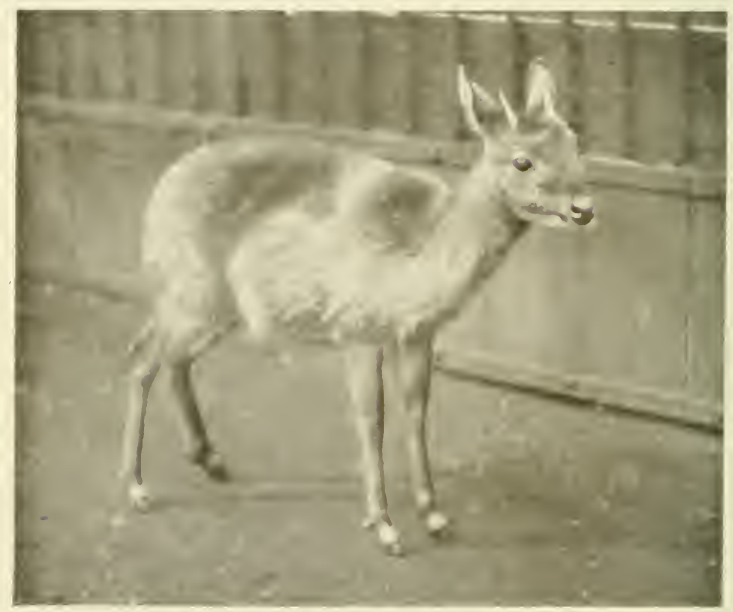

FIG. 93.-FOUR-HORNED ANTELOPE 
habitat now being the Kalahari Desert, and that it once inhabited the North-western portion of Cape Colony is evidenced by the town in Namaqua Land known by the animal's name, and its familiarity was brought home to us when the famous colonial footballers visited England.

The Springbok is somewhat like a Gazelle, but it stands some inches higher than that animal. A distinguishing feature is the curious white patch which is displayed on the rump when the beast is moving, and especially when leaping. This long white stripe is only very little seen when the animal is at rest, a double fold of skin along the middle of the back practically hiding it from view. When suddenly appearing the effect is very peculiar, but distinctly interesting.

Another salient feature concerning the Springbok which is worthy of attention is its migratory movements. Many people seem to imagine that birds are the only animals which exhibit migratory babits, and although with regard to the movements of our bird friends much yet remains to be ascertained, there is no doubt that other animals, including mammals, fishes, amphibians and insects, do undertake protracted wanderings, whilst many animals temporarily shift their quarters to a far greater extent than is generally understood.

This sudden onrush of a migrating army of wild beasts is inseparably associated in the minds of those who study animals with one of the most interesting phases of natural phenomena, and whilst it seems to be largely a question of food supply, we have yet to learn a good deal as to the why and wherefore of the marches of animals of various kinds. The four-footed beasts are naturally restricted in their movements, but whilst these do on occasions traverse a great extent of country, fishes and birds are, of course, better able to pursue their operations with less restriction.

As to what rules regulate and guide these children of the wild it is not for us to discuss in this volume, but the whole subject of migration is one which is still shrouded in mystery, and even if attention be devoted to a few of our commoner bird visitors, a whole vista is opened up which will be found as fascinating as a fairy tale and full of the fragrance of the most delightful romance.

To return, then, to the wanderings of the Springbok, it occasionally migrates from its more usual habitat of the semi-desert when there has been a prolonged drought and the scorching rays 


\section{8 THE BOOK OF THE ANIMAL KINGDOM}

of the sun have withered plants, as the hot July days welter the common Dog's Mercury of English woodlands.

Both drink and food having disappeared, small wonder the Springbok should decide upon fresh pastures and start off on a foraging expedition in new country.

It must have been an engaging sight before civilization had penetrated South Africa to the extent we see it to-day, to witness an army of Springboks bounding across a barren, desolate plain in anxious search of some fertile territory where hunger and thirst might be appeased and the young fawns reared in comparative luxury.

Some idea may be gained of the immense companies that were to be seen years ago, for Gordon Cumming has graphically recorded the first herd he saw. He says that for two hours he watched an army of Springboks which were in a solid mass, and which measured at least half-a-mile in width. Mr. Protheroe states that "these moving herds are called 'trekbokken,' and they are of such vast dimensions that a Lion, which has tried to snatch a Springbok out of a herd, has been unable to extricate himself, and in the most humiliating manner has been obliged to march with the herd, unable even to feed upon any of the animals which pressed him on every side. A flock of Sheep has also been enveloped in one of these 'trekbokken' and carried off."

Migration movements of animals-including birds, fishes and insects-are accompanied by perilous adventures of many kinds. Storms, winds, hard weather, various enemies (including man), the necessity for keeping up with the onward "trek," all these have to be encountered, and unknown perils hover over these wild creatures during their protracted wanderings.

The Springbok usually migrates eastwards, but, curious to relate, at intervals of some twenty years an exactly opposite direction is chosen. Not long since, says the writer just quoted, "there was a great 'trek' to the sea, where the creatures drank greedily and then died in tens of thousands. For many miles the dead bodies lay along the shore, presently to putrefy and drive the few inhabitants of the region far inland for fear of pestilence." Such is the penalty involved by a sudden decision to overcome a terrible thirst, and this incident shows one of the dangers to which these migratory beasts are exposed.

In size the Springbok stands about two and a half feet at the 
shoulder, whilst the young are duller in colour than the adults, being yellowish-grey, and having indistinct side-stripes. The buck and doe both possess horns; those of the first-named attain a length of about fifteen inches, but those of the doe are not so large.

Whilst once regarded as a serious pest because of the harm perpetrated among growing crops by countless thousands of these beasts when on their famous "treks," the animal has so far been reduced in numbers that it is now afforded protection. It is a quick traveller, an active little animal at all times, courageous to a degree, needs careful stalking, and its flesh is highly regarded in South Africa.

BRINDLED AND WHITE-TAILED GNUS-The casual observer might be excused if he considered the Brindled Gnu (Fig. 92) anything but an Antelope. Such, however, it is. The Antelopes form, indeed, a rich group in both species and varieties, and are a great adornment to the steppes and deserts of the African continent. Also known as Wildebeests, it is evident from the big game hunting expedition recently carried out in Africa by ex-President Roosevelt that these curious-looking animals are still found there in considerable numbers, for in his interesting series of letters contributed to a London paper, Mr. Roosevelt frequently refers to large numbers of these beasts coming under his notice.

Gnus belong to the last group of the Antelopes and are placed in a genus of their own, being followed only by the Hartebeests, Blessbok and Bontebok, to which they are closely allied. Of large size, curious facial expression, with a prominent mane, long tail and large, lyrate horns, the Gnu cannot fail to arrest attention. Some may regard it as an uncouth-looking beast, but the two species which inhabit South and East Africa-the White-Tailed and the Brindled, or Blue $\mathrm{Gnu}$, are both worthy of notice. Whereas the former is exclusively confined to South Africa, the Brindled species shown in Fig. 92 is not found south of the Orange River.

The White-Tailed Gnu stands about four and a half feet at the shoulder, has a fringe of long hair on the chest, a long white tail and a uniformly coloured body. The Brindled Gnu, however, is distinguished by the absence of the long hair on the chest, the shorter tail is white instead of black, the sides of the withers have dark transverse stripes, and the hair on the face is not so ruffled. Both male and female possess horns, those of the first-named having a spread of from twenty-four to twenty-six inches. 


\section{I20 THE BOOK OF THE ANIMAL KINGDOM}

Open country not far from the neighbourhood of water is the typical haunt of these Wildebeests; they are fast runners and endowed with remarkable powers of endurance. Their habits are distinctly entertaining, for we are told that they whisk their tails in a very eccentric way, utter loud snorts and short, sharp cries, spring into the air, prance and caper and chase one another in circles at an amazing pace. Gordon Cumming in describing these manœuvres, says that they suddenly "all pull up together to overhaul the intruder" (the hunter), "when the bulls will commence fighting in the most violent manner, dropping on their heels at every shock; then, quickly wheeling about, they kick up their heels, whirl their tails with a fantastic flourish, and scour across the plain enveloped in a cloud of dust."

FOUR-HORNED ANTELOPE.-Also known as the Chousingha, the Four-Horned Antelope (Fig. 93) is an Indian animal, and the male is distinguished from all other ruminants by possessing as a rule two pairs of horns. There are a pair of small ones just above the eyes (and these may be discerned in Fig. 93), whilst the second and larger pair are situated farther back on the head. These horns are short and smooth, and the front pair may either be very rudimentary or entirely absent.

The male of this Antelope stands a little over two feet high at the withers and has a thin, short and harsh fur. It is dull palebrown in colour, tinged with rufous on the upper parts with white below. On each leg there is a dark streak, but this is more noticeable on the hind-limbs.

It inhabits wooded and hilly country, but does not dwell in thick cover, thin forest and bush on hilly ground being its favourite retreat. It is a solitary and shy Antelope; is mostly found not far from water, and has a jerky action when moving. Among long grass or dwarf bushes the Chousingha conceals itself, only rousing when it is closely approached and then running away at breakneck speed. The one or two young ones are born in the first or second month of the year.

INDIAN ANTELOPE-Another Indian animal is presented in the Black Buck or Indian Antelope (Fig.94), a well-groomed and handsomely coloured species which is placed in a genus entirely its own. The buck is blackish-brown above with a rufous patch on the nape of the neck and a white ring around each eye. The under parts, as in the doe, are white. The last-named, however, as also 
the young bucks, are yellowish fawn-colour on the upper parts instead of the darker dress of the adult buck. The tail is short, the lateral hoofs are small, and the fine horns cylindrical, V-shaped and ridged throughout. As Fig. 94 shows, the horns have a number of "turns in the spiral," and these may be from three to five.

This Antelope is found in greatest quantities in the north-west, and in grassy or cultivated districts may be located in small and large herds numbering as few as ten to thirty, or sometimes as many as thousands of individuals. It is akin to the Springbols of South Africa in regard to the habit of springing into the air when running, and is a splendid traveller when well under weigh on good ground.

In the pairing season battles wage fast and furious between the males, and when alarmed the latter utter a short grunt and the does give vent to a hissing sound. The does hide their fawns among long grass, for they do not resort to forests or bushes, and although on occasions these Antelopes appear to be fond of drinking, some individuals inhabit districts where water is only procurable in deep wells.

RED AND FALLOW DEER.-The first representative of the second group of animals in our present section is rightly the handsome Red Deer (Fig. 95), and it is accorded pride of place because it is a British species. Mention may also be made of the Fallow Deer, and the following account of these two animals is taken from my book, Nature Stalking for Boys. This gives a fairly comprehensive sketch of the life and habits of these two species, and it need only be added here that outside the British Isles the Red Deer is widely distributed in the temperate regions of Europe and Asia, whilst what is regarded as a variety only is found in Morocco and Algiers. The Fallow Deer "is a native of Northern Africa and the countries bordering the Mediterranean, and in a wild state is still abundant in Sardinia, Spain and some of the islands of the Grecian Archipelago." From these countries it was introduced into Central Europe.

Although there are over three hundred parks in England that contain Deer, besides a few spots where they are still found in a wild state, it is surprising how little information there is to be found in the many books on natural history and sport concerning their habits. In only about eighty of these parks Red Deer are kept, the two species living quite peacefully together. 


\section{I22 THE BOOK OF THE ANIMAL KINGDOM}

Fallow Deer are the most common in England; therefore we will deal with that species first.

Some writers tell us these animals were brought to England by the Romans, but this may be because we have no mention of them at an earlier period. It has been repeatedly stated that the dark variety of Fallow Deer was brought from Norway by James I. to improve those already in our parks, but Mr. Harting has shown clearly that this variety existed in English parks long before James's day! Equally erroneous is the statement that the spotted variety, known formerly as Menil, was brought from Manilla.

Outside park fences Fallow Deer have been found in a wild state in the New Forest, Epping Forest, Rockingham Forest, and one or two other places, where a few still exist.

The food of Fallow Deer consists chiefly of grass, acorns, beechmast, chestnuts, berries of the white thorn, young tender shonts of beech, hazel, ash, bark, roots, and corn of all kinds, in fact little comes amiss to them in the vegetable world. They will even chew up shed horns and bones! I have often seen them eating scraps of cooked meat and other refuse that has been thrown away after clearing out ashpits, and have also known clothes that have been hung out to dry to be eaten by them!

Fallow Deer shed their coats in the early Spring. If they have had good IVinter feeding and the weather comes mild they begin to disrobe about the middle of March and get their new coats complete about the end of April. The greater part of the old coat is pulled out by the Deer themselves and may be seen on the ground in mouthfuls. Jackdaws use the hair for lining their nests, and are often seen on a Deer's back helping themselves !

A change of coat means a change of colour too. The dark variety of Deer becomes much darker in the Summer, and the lighter coloured ones become paler. Just before the last of the old coat is off they shed their horns, the older bucks being the first to lose these appendages, and the younger ones, according to age, a little later.

The shedding of old horns is caused through the new growth pushing the old ones off, exactly in the same way as the teeth of an infant have to make room for permanent ones. The whole of the new growth takes place in about fifteen weeks. After the horns have done growing they begin to harden, the blood-ressels dry up, and the velvet is pealed off by being rubbed against trees, fences, or 
other hard material. As soon as the horns are free from velvet a change of disposition takes place with the bucks, for instead of herding peacefully together as they have done since shedding the old horns, they become quarrelsome, and by the middle of September their necks increase in size and strength, a provision Nature has made fitting them for the fierce fights about to take place with their fellows for the ownership of, and mating with, the does.

It is the finest and fittest bucks that take possession of the does ; one buck will often take all the does in a small park and keep other bucks at a distance for a time; however, as the rutting season advances and his strength decreases, another will probably soon take his place. So fierce are the fights at this time that it is not unusual for bucks to get killed by being gored to death, and when one gets badly disabled he is sure to be killed by others perhaps not in the first quarrel. I have frequently known a buck that has been killed in this way to have his lungs pierced through, although it is seldom that the tough hide is punctured, the points of the horns only being pushed through the vital parts. As the rutting season advances the fine condition so rapidly gained is as quickly lost, and by the end of October the Deer are in their Winter coats, presenting quite a different appearance from what they did six weeks previous !

The period of gestation with Fallow Deer is about eight months, and one is born at a birth. Although some naturalists tell us that two and three are sometimes born, this may have happened, but my friends, who have had long experience with Deer, have never seen it, although some of them have had charge of Deer for twentyfive years and have killed from twenty to seventy does each year. The does are usually killed about two months after the rutting is over, therefore there is always an opportunity of knowing if a doe was likely to become the mother of more than one fawn. The father and grandfather of a noted Deer-keeper whom I know had charge of a big herd for nearly one hundred years, and never knew more than one at a birth. I have spoken to many old park-keepers on this interesting subject, but never could find one who could tell me he had actually seen it, although one or two keepers of considerable experience have told me they believed it had happened. This may have been because they saw two fawns sucking one doe, an unusual occurrence, but one which I have seen, and each time I was able to find out that they were the fawns of two does.

Fawns are born about the first and second weeks of June. I 


\section{I24 THE BOOK OF THE ANIMAL KINGDOM}

have known one as early as May 25, and as late as October 20, but both these dates may be taken as extremes. They are on their feet and quite active a few hours after birth. When a doe is about to give birth to a fawn she goes from the herd and selects a quiet spot, where she leaves her fawn for some hours before returning to feed it. This takes place in the evening. The next morning the fawn will probably be found some distance from where it was seen the previous evening.

The first fortnight of its life is spent in sleep during the day and feeding and play at night. When about fourteen days old it follows the mother, and is seldom seen from her side mixing with the herd. If the weather is warm when fawns are born, in about three days afterwards they are strong enough to make their escape from most enemies, unless it be a very fast dog. The following incident will show the strength and activity of fawns even at birth. I once knew of a doe which gave birth to a fawn. A friend of mine rode up to it for the purpose of earmarking (a custom for keeping up the stock), when up it got and went over the sea cliff, swimming out to sea about two hundred yards and returning to the same spot! He marked it, and carried it into the park none the worse for its adventure. Seven years afterwards he killed it, and it was then a fat buck weighing $140 \mathrm{lb}$. clear.

Some does have their first fawn at two years old, while others do not breed until the third year. They usually breed until about fourteen years of age, and may live a few years longer. Bucks are not so long-lived as does, for nine years is a good age for the former, although much depends on the park. On a rich pasture Deer do not live so long as on poorer land. A buck is at his best when seven years of age; after this his horns deteriorate each year, and if left the chances are that he will get killed by stronger animals during the rutting season or die in the Winter through being unable to get sufficient food for an already weak body. In the buck the horns increase in size annually till he is six or seven years old.

Deer vary in different parks both in size of body and horn growth. In some parks I have known some remarkably heavy animals with very poor heads, and in others good heads on very small bodies. This variation is due to the soil, although no doubt in-breeding has often something to do with poor heads. Inbreeding always shows more in the horn than body. Mr. T. Bamford, head-keeper to the Earl of Clarendon, tells me that he has 


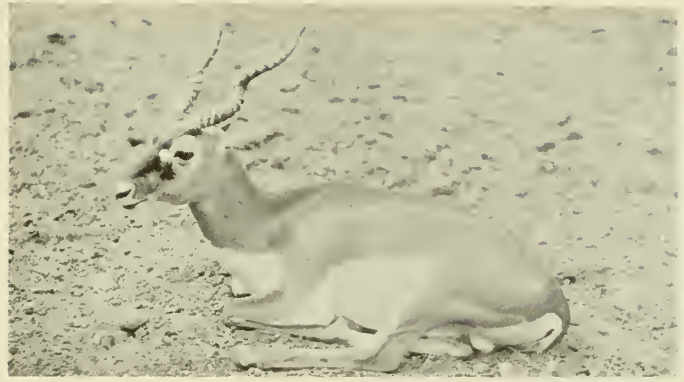

FIG. 94- - INDIAN ANTELOPE

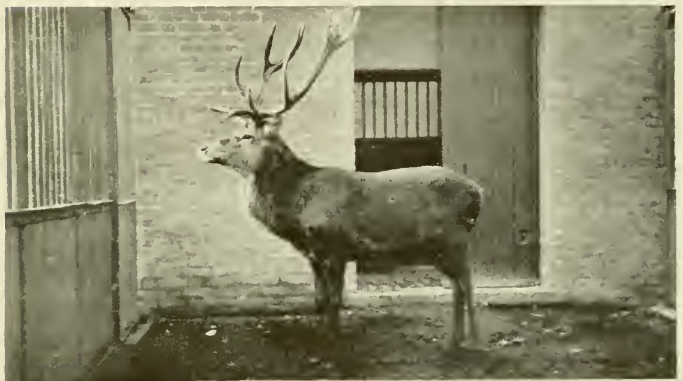

FIG. 95.-RED DEER

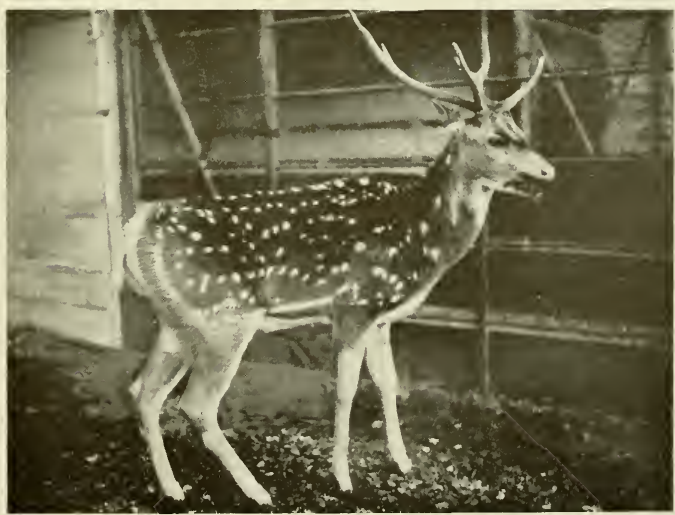

FIG. 96. - AXIS, CHITAL, OR SPOTTED DEER 


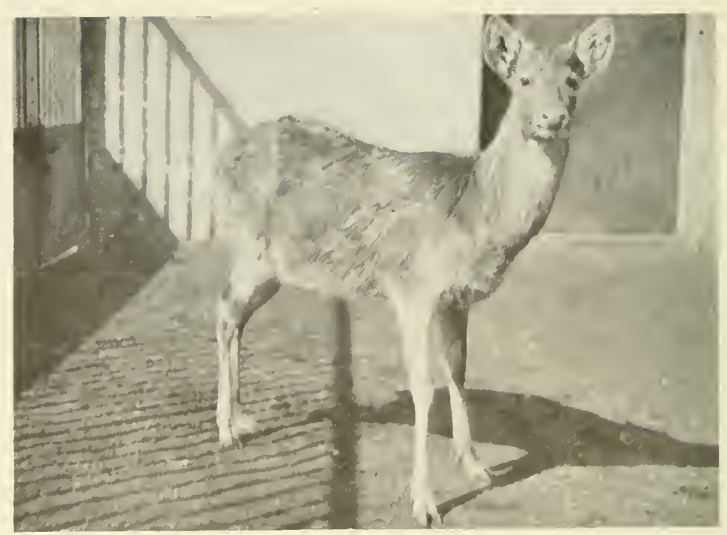

FIG. 97.-BARISINGHA, OR SIIAMP DEER

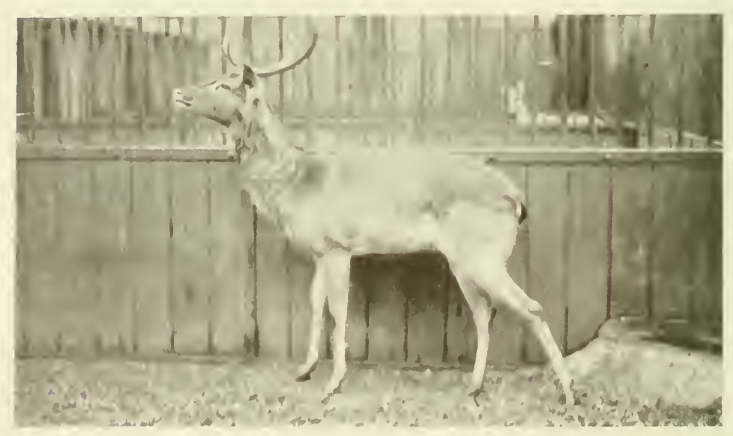

FIG. 98. - PANOLIA, OR ELD'S DEER

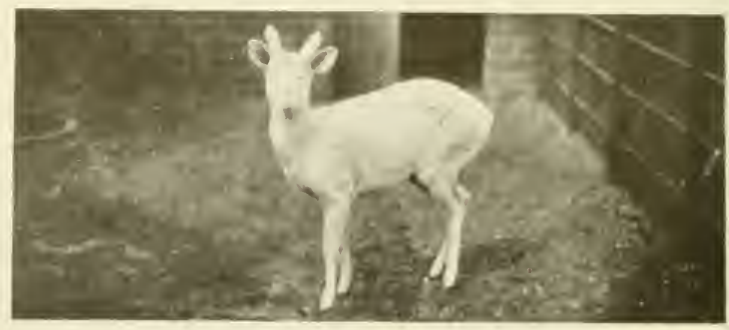

FIG 99. - MLNTJAC, OR BARKING DEER (ILBINO) 
recently been killing Deer in two parks situated only about two miles apart; the soil in both is rich and about the same; in one frequent changes of blood have been made from time to time, and here the heads are very fine, while in the other no change has been made in the memory of man, yet the bodies are exceptionally good but the heads very poor indeed. In both these parks bucks have been killed weighing $150 \mathrm{lb}$. clear. This is very heavy, considering that in many parks the bucks do not average more than $90 \mathrm{lb}$.

The habits of Deer vary according to season and food supply. In parks where there is plenty of keep during the Summer they spend most of the day resting. From May till the end of September they rest from 9 a.m. until 2 p.m. in the shade when the sun is hot. During the period of rest they occasionally get up to stretch themselves; after licking or scratching their sides with hoof and horn they lie down again, but always on the other side.

They pass the time in brushing flies off, chewing the cud, and sleeping. From 2 p.m. they feed and wander about until 4 p.m., when they again lie down. Starting again at 7 p.m. they feed till io p.m., and then probably rest till 5 o'clock the next morning. In the Winter, when they have to work harder for food, they take their rest at midday and night, three hours at a time, but much, of course, depends on food supply.

Snow and frost have no bad effect on Deer if plenty of good food is put down for them; the best is good hay and beans, although they are particularly fond of maize, locust beans and oil-cake.

During the Winter the bucks are in the lowest condition and the does at their best, especially those that may have lost their fawns in the Summer. Does suckle their young to within a month of the next birth, and I have known cases where, the doe having lost her fawn in the Summer, the fawn of the previous year has suckled on through the following Winter.

There are several ways of catching Deer. In some parks they are ridden down, but this is the worst plan I know of, for if a Deer gets thoroughly blown, as he must do by this means, he more often than not dies after being secured, especially if his legs are strapped. Another way in which Deer may be caught is by using Deerhounds trained for the purpose and run by sight. This answers very well for old bucks that have to be caught for stall feeding and are not 


\section{I26 THE BOOK OF THE ANIMAL KINGDOM}

strong enough to run too great a distance, but for younger and stronger animals it is not a good plan. Undoubtedly the best, most humane, and safest way of catching Deer is by netting them. This is done with long lengths of rope-netting made for the purpose and set in enclosures or other places where the Deer can be driven, and escape made impossible without going into the nets. Deer caught in nets naturally struggle very violently to get free, but if too many are not driven in at one time, and they are secured at once, little or no damage is likely to be done.

It is surprising what fences Deer will get over when cornered. Anything under six feet is of little use, and I once knew a buck get over a fence nine feet high. This he did by jumping sufficiently high enough to get his fore-legs over the top, and then throwing his body over. It is very rare to see a Deer jump clear over any obstacle that is more than five feet six inches high, for the animal nearly always settles on the top and clambers over.

Fallow bucks, although quite harmless when at large, are by no means so when brought in close quarters with man or dog, for a buck will savagely use his horns in self-defence to the bitter end. I have known many who have received ugly wounds when catching bucks. Deerhounds are often stabbed through by a buck at bay, and few people who have never handled a live Deer have any idea of the great strength they possess for their size.

Deer suffer from diseases of various kinds, but much less so than domestic animals, and even less than most of our wild animals. On heavy land Fallow Deer often suffer from liver fluke; this is a very troublesome disease and one that frequently ends fatally. For cure many park-keepers have great faith in strewing Scotch and Spruce Fir boughs about for the Deer to eat the bark, which contains turpentine and is said to kill the fluke, but unless the weather becomes severe the Deer will not eat enough fir bark to do much good, so that the remedy is not to be depended upon. Rock salt is, no doubt, a fine tonic for Deer.

Footrot is another disease from which Deer suffer in some parks; in others it is unknown. Where Sheep are suffering from the disease the Deer often get it, more especially the older bucks. Does, curious to relate, rarely get it! The bucks suffer most, owing to being more liable to get the points of their hoofs broken through fighting and other causes, leaving the foot exposed to take the disease. I am of the opinion that the disease only attacks after the 
hoof has been broken. It usually comes on after the rutting season and gets better the following Spring.

Red Deer are very similar to Fallow Deer, both in structure, habits and food, and are probably as numerous now in England and Scotland as at any period. The late IV. Shirley tells us that in 1867 Red Deer were then kept in thirty-one Deer parks in England; now they may be found in at least eighty-six. The Scotch forests, too, are now more heavily stocked than formerly, owing to the demand for stalking.

There are still a few Red Deer in England that may be said to be wild or that are not enclosed by fences. In the New Forest, as well as in Devon, Somerset and Westmoreland a few are found.

The period of gestation is about a fortnight longer than that of the Fallow Deer. The young are born about the middle of May or early in June. The hind isolates herself from the herd and has her young, leaving it in much the same way as a doe will do, although she never gets too far away. Should any person or stray dog turn up she is always ready to fight in its defence, and this she is very capable of doing by getting up on her hind-legs and striking with her fore-feet. I have on several occasions seen a hind kill dogs in this way, and a friend of mine was once severely punished by a hind's fore-feet when attempting to earmark a fawn. The young are born spotted and remain so until the coat changes in the Autumn.

Red Deer when in anger have a way of giving warning by grinding their teeth, which can be plainly heard for some distance.

The shifting of coat, shedding of horns, rutting and breeding seasons are each similar to that of the Fallow Deer, only all are a little earlier.

The first growth of horn starts in the Spring, when the young one is a year old or a little more. One single spike from twelve to eighteen inches is grown the first year, and this increases in size and points each year until the stag is eight years old.

The life of a Red Deer is longer than that of a Fallow Deer. A stag is at his best from eight to twelve years of age, for after twelve years he deteriorates in horn and body. Hinds live much longer, and I have known several well over twenty years of age, and have heard of some over thirty.

The weight of Red Deer, as in Fallow Deer, varies according to richness of pasture. A good average for English Deer parks is 


\section{THE BOOK OF THE ANIMAL KINGDOM}

twenty stones for stags and fourteen for hinds. In the Highlands of Scotland the Deer do not often get so heavy.

Much has been said of late years about the deterioration of heads in the Highlands. No doubt the chief cause of this is overstocking on poor soil and killing the best stags without due respect to future stock. Owners of Scotch forests have introduced stags from English parks, nearly always selecting Deer from parks where the heads are exceptionally fine in hopes of breeding animals with fine heads; but this is usually disappointing, for big heads are produced on good land, and to take Deer from a rich feeding park to a povertystricken Scotch forest is sure to fail in the desired result unless artificial feeding is resorted to, and even this is not often a success. Change of blood is a step in the right direction, but to get the greatest success Deer must be brought from poor land to better. Good Winter feeding is, no doubt, an aid to the production of fine heads, but the soil has most to do with it.

Strange to say the span of life with Deer of both species on poor land is longer than on rich soil.

In some parks there may be seen a white or cream-coloured variety of Red Deer. They are quite as heavy and carry as fine heads as those of normal colour. Whence this variety was derived is uncertain; some say they are German and others call them Danish. They are not so common as the white variety of Fallow Deer, in fact I never knew a white Red Deer from other than white parents or one of that colour. Such is not the case with Fallow Deer, for it sometimes happens that a white fawn is born of parents of the dark variety. The white variety of Fallow Deer as fawns are a cream colour, but afterwards become white.

The largest parks in England are Savernake 4,000 acres, Windsor 3,000, Knowsley 2,600, Gredge 2,500 (this latter is the oldest Deer park in England, and the only one mentioned in Doomsday Book as containing Deer then, as now), Duncombe 2,240 acres, Buckhurst 2,100, and Thoresby 2,000 acres.

Deer parks were formed after the Norman Conquest, and increased until Cromwell's time, when they were probably more numerous than now. During the Civil War many of the park fences were broken down and the Deer driven out or killed. Many Deer parks date no farther back than Charles II.'s time, when owners settled down again to restore the mischief caused by the war.

Old-world legends associated with animals are at all times 
interesting, even if most of them are mythical in their origin, and a writer in The Animal World says that-

"A hind appears in the arms of the City of Edinburgh in memory of the animal which was said to have preserved the patron saint of the city, St. Giles, or Ægidius, from dying of hunger and thirst when he retired as a hermit to a forest near Nismes, and the animal came day by day that he might refresh himself with her milk. His retreat was finally discovered by the King of that region in starting the 'milk-white doe' as he was out hunting and following her till she took refuge at the feet of the pious anchorite, who was often depicted with the head of the hind resting on his knees.

"An Irish legend tells how St. Benin, or Berichert, a noble Saxon, who came and settled in Munster, and was a disciple of St. Patrick's, began to build a church at Tullylease, near Charleville, in Co. Cork. To manifest God's pleasure at the work a beautiful snow-white hind came every morning before sunrise and shed milk into a rough stone trough in a neighbouring field, the quantity being each time sufficient for the need of all the persons employed on the building for the day, but they were warned not to be curious, and strictly forbidden to go near the stone while the hind was there. However, one of the masons could not restrain his curiosity, but hid himself in a furze-bush to watch and alarmed the animal, who kicked a hole in the stone, so that all the milk ran through, and darted away, never returning to the spot, and the workmen were obliged to seek elsewhere for milk. A rude stone trough still stands in a field near 'St. Ben's well' at Tullylease, and there is a hole to be seen in it to this day. It is known as 'Cloc na Eilit' (the hind's stone). People suffering from headaches, who come to pay their rounds at the two holy wells here, end by saying a ' round' of their rosary at Cloc na Eilit, and then, stooping, rub their heads around the bowl; this is done thrice in the names of the Holy Trinity, and is thought a certain cure for headaches."

AXIS, CHITAL, OR SPOTTED DEER.-This Deer (Fig. 96) strikingly reminds one of the Fallow Deer last under consideration. It is an inhabitant of India and Ceylon, is about the same size as the Fallow Deer, and is characterized by the large white spots which are admirably shown in the photograph. It is stated that the spotted coat acts as a sort of protection to this species, "the covering harmonizing with dead vegetation and the flecks of sunlight passing through the dense foliage."

$\mathrm{K}$ 


\section{I30 THE BOOK OF THE ANIMAL KINGDOM}

The Axis Deer has been introduced into some of our English parks, and it is most interesting to notice that whereas in a wild state the young are not born until October, the acclimatized beasts produce their young in June, thus affording an apt example of change of front according to circumstances and the environment frequented. It is obvious that fawns born in England in chill October would stand less chance of survival than in leafy June.

BARASINGHA, OR SWAMP DEER.-The Barasingha, or Swamp Deer (Fig. 97), is also an Indian animal. It resorts to the outskirts of woods, open forests and grass-lands in the neighbourhood of trees. Although closely related to the handsome Sambar Deer, the Barasingha is not nearly so nocturnal in its habits. It is gregarious during Winter, travelling about in herds of from thirty to fifty individuals.

The name of Barasingha indicates the distinctive character of this Deer, meaning "twelve-tined," the antlers, unlike those of most other Indian Deer, having more than three tines. The buck stands from three feet eight inches to three feet ten inches high at the withers, and large specimens have been known to turn the scale at anything between thirty-two and forty stones.

ELD'S DEER.-The Panolia, or Eld's Deer (Fig. 98), inhabits India, the Malay Peninsula, Cambodia, and the Island of Hainan. The distinguishing feature is the curious downward and then upward sweep of the horns. It is about the same size as the species last under review; the coat is dark in Winter with pale-brown below, and fawn-coloured in Summer with white underneath.

Eld's Deer appears to frequent similar haunts to the Barasingha, but seems to prefer an open plain often far from water. In the swamps it procures wild rice and other plants. A short, barking grunt is uttered by the hind, whilst the stag gives vent to a more lengthy call of a similar kind.

MUNTJAC, OR BARKING DEER.-Fig. 99 illustrates an albino Muntjac, or Barking Deer, an elegant little species which is found in India, Burma, the Malay Peninsula and elsewhere. The Barking Deer is so called because of its peculiar cry, and of the fine species included in the Muntjac group it is the most familiar.

This is a beautiful creature, the dark-reddish fawn-coloured hair being close and shiny; it has slim limbs, diminutive and simple antlers and large, brilliant eyes. It is a dweller upon the hills, is very agile and swift-footed, and is no mean antagonist when closely 


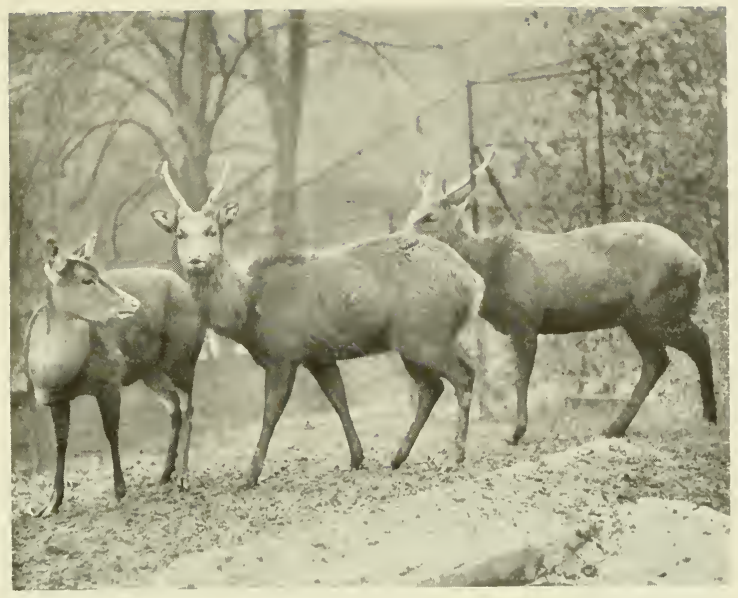

FIG. IOO.-SIKA, OR JAPANESE DEER

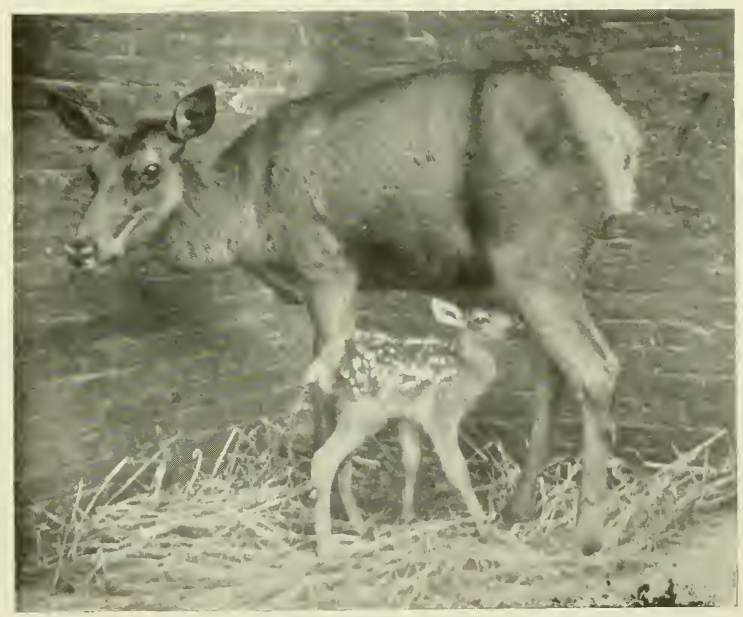

FIG. IOI.-ALTAF DEER (WITH FAWN) 


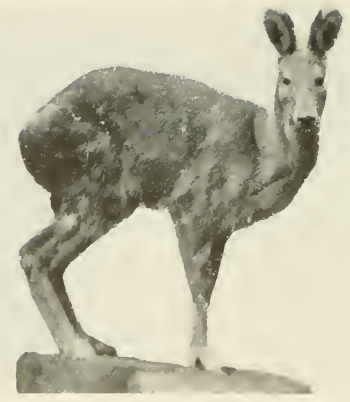

FIG, IO2. MILSK DEER

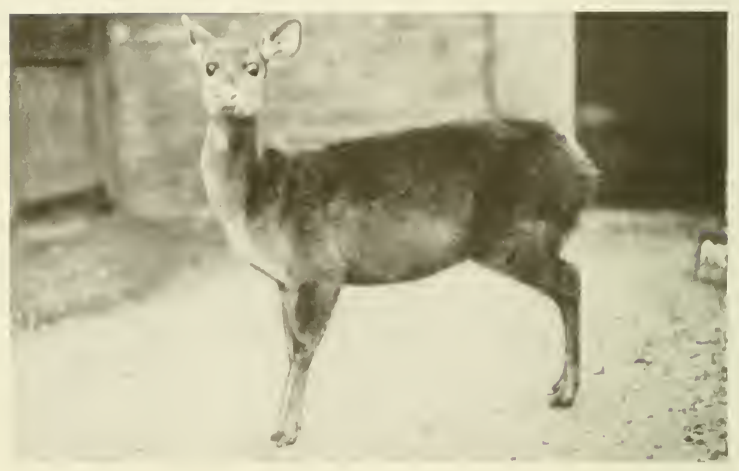

FIG. IO3. - RED BROLKET

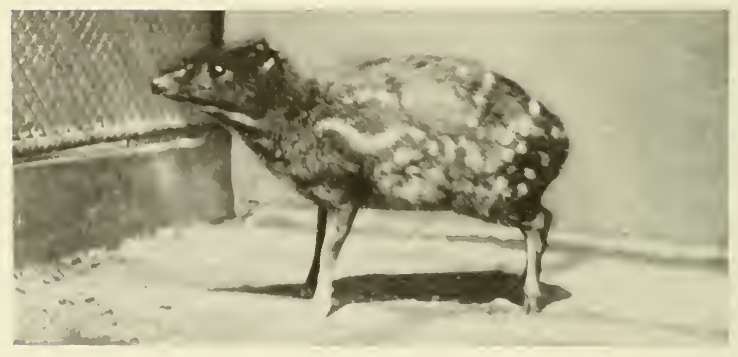

FIG. IOf. - INIIAN CHEVROTAIX, OR MOLSE DEER 
pursued, having some fairly long tusks in the upper jaw which it uses to advantage.

SIKA, OR JAPANESE DEER.-A small group of these interesting beasts are shown in Fig. Ioo. This is a common Deer in Japan and Northern China; it is of handsome attire, being brilliant chestnut, profusely spotted with white. When the bucks have the antlers in the velvet they are still more attractive, for these are bright chestnut-red in colour tipped with black. The Sika has been introduced into several English Deer parks, and although the male is of small stature he is a powerful beast and will, says Mr. Protheroe, "often carry off the hinds of the Red Deer in face of the bigger red bucks." This is evidence of a wild animal keeping up the plucky traditions of the wily little Japs whose country has, during the last decade, made such remarkable strides in the progress of civilization.

ALTAI.-The Altai (Fig. Ior) is a tenant of Central Asia and is the Asiatic representative of the handsome Wapiti Deer. It is smaller in size than the last-named, although the male has larger horns. Presumably its habits are similar to those of the Wapiti already described. The photograph (Fig. 10I) shows a doe with her two-days-old fawn.

MUSK DEER-Of similar distribution to the Altai, the Musk Deer (Fig. IO2) is chiefly remarkable because of the absence of antlers in both sexes; it is the only species of Deer that has no gall-bladder to the liver; it possesses the simplest form of brain of any of the Deer, and has an abdominal pouch or pod in which the brownish musk is secreted. This, although it is exceedingly strong when first taken away, makes a pleasing scent when diluted, and is also usefully employed as a medicine.

There are structural details concerning the canine teeth of the upper jaw which should also be mentioned, for these are so large that they give the animal a curious appearance, and they have been aptly compared to the tusks of the young IValrus.

In other ways this Deer is unique, for the feet are quite distinctive; it is sure-footed, an inhabitant of precipitous rocks and mountains, where, among the pine woods, it finds a congenial home.

The long, coarse coat of hollow hair admirably protects the Musk Deer in IVinter, and it varies in colour from rich dark-brown to brown and yellowish-white. The beast stands about two feet high, is somewhat clumsy in appearance, yet is wonderfully active 


\section{I32 THE BOOK OF THE ANIMAL KINGDOM}

and watchful. It feeds on leaves for the most part, but is credited by natives with a fondness for snakes.

RED BROCKET.-The Red Brocket (Fig. I03) is a South American animal, which, like its relatives included in the same group, is distinguished by its unbranched spike-like antlers. It is also noticeable for the hair on the middle portion of the face "radiating in all directions from two points, one of which is situated on the crown of the head, and the other just below the eyes." A considerable part of the muzzle is naked; the tail is not of great length; the fawns have spotted coats, whilst the adults are uniform reddishbrown.

The Red Brocket comes from North-Eastern Brazil and Guiana; it is not a particularly attractive-looking animal, but is interesting in many ways, not the least of which is its habit of probably pairing for life. It is not at all gregarious, being found either alone or in pairs.

The young one is born in December or January, and in a few days after birth it is able to follow its parents.

INDIAN CHEVROTAIN, OR MOUSE DEER.-The last representative with which we are now concerned is the Indian Chevrotain, or Mouse Deer (Fig. I04), which, as its first name implies, is a resident of India.

There are two genera of Chevrotains, one being Asiatic and the second African. The species illustrated in Fig. 104 is, of course, one of the Asiatic kinds, and although closely related to the Deer, the Chevrotains are placed in a separate group between them and the Camels. That they are small Deer-like animals cannot be gainsaid, but external appearances often count for nothing in the world of science. Hence we find that internally the Chevrotains differ from the Deer and are rightly relegated to a family of their own.

These Asiatic Chevrotains are almost the smallest living Ungulates. The Indian species is different in dress from its four Asiatic relatives, for it has the body spotted with white and the chin and throat are uniformly covered with hair. The upper parts are brown with small yellow specks.

It stands only about one foot high at the withers, and weighs about five and a half pounds. The range is Southern India and Ceylon, grass or jungle being the environment frequented. It appears to be largely nocturnal in habits, feeding either during 
the night or early morning. It is a shy, timid little beast in a native state, but in captivity quickly becomes docile and makes a nice pet.

One peculiarity that may be noticed in conclusion is the habit the Chevrotain has of walking on the tips of the hoofs. This gives the legs a stiff and rigid appearance, which may be well seen by examining the specimen depicted in the illustration. Strictly speaking, of course, the Chevrotains are not entitled to inclusion in the present section, but as they rightly come after the Deer in scientific sequence they are not altogether out of place in the position given them.

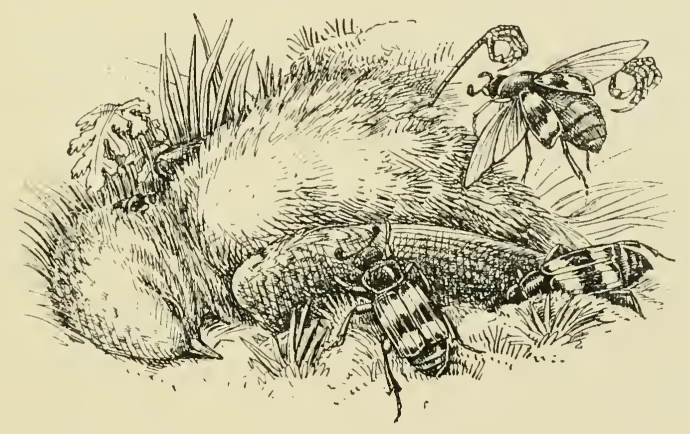




\section{CHAPTER VIII \\ CATS-GREAT AND SMALL}

LION. - Although generally known as the King of Wild Beasts, and accorded the foremost position in this section of our work, it is as well to recognize straight away that the Lion (Fig. I05) is really not entitled to all the wonderful deeds accredited to it.

That the male with his flowing mane is a handsome and at all times interesting animal, goes without saying, but that he should occupy such a prominent position as a so-called ling by reason of his pluck or daring is somewhat ill-deserved. Let it be said at once that the Lion is in many respects a coward, and if strength counts for anything in the title bestowed upon this wild monarch, then the Tiger is probably his successful rival.

Not only is the Lion found in reedy swamps and upon the plains, but, as the coloured plate exhibits, its range extends into mountainous country. The animal undoubtedly roams about for considerable distances during its peregrinations after food, and in the picture the artist has imagined a Lion and Lioness coming over hilly, rocky ground which led into a fertile valley with a possible favourite drinking-place for wild beasts. The animals are peering over the edge to see if any game awaits them in the distance.

The ambition of most big-game hunters who go forth to slay the denizens of the forest and jungle is to add one or more of these beasts to their bag, but it is pleasant to observe that during recent years there are those-such as the intrepid Mr. Selous and Mr. Radclyffe Dugmore-who have thought fit to substitute a camera for a gun. Fresh from his triumphs with Mr. Roosevelt's African Expedition, Mr. Dugmore has brought back some remarkable studies of bloodless snapshots of animal folk in their native wilds. He says that although at one time a big-game hunter himself, the idea of killing for the sake of killing has lost its fascination for him, and he abandoned the gun in favour of the camera because "unquestionably the excite- 


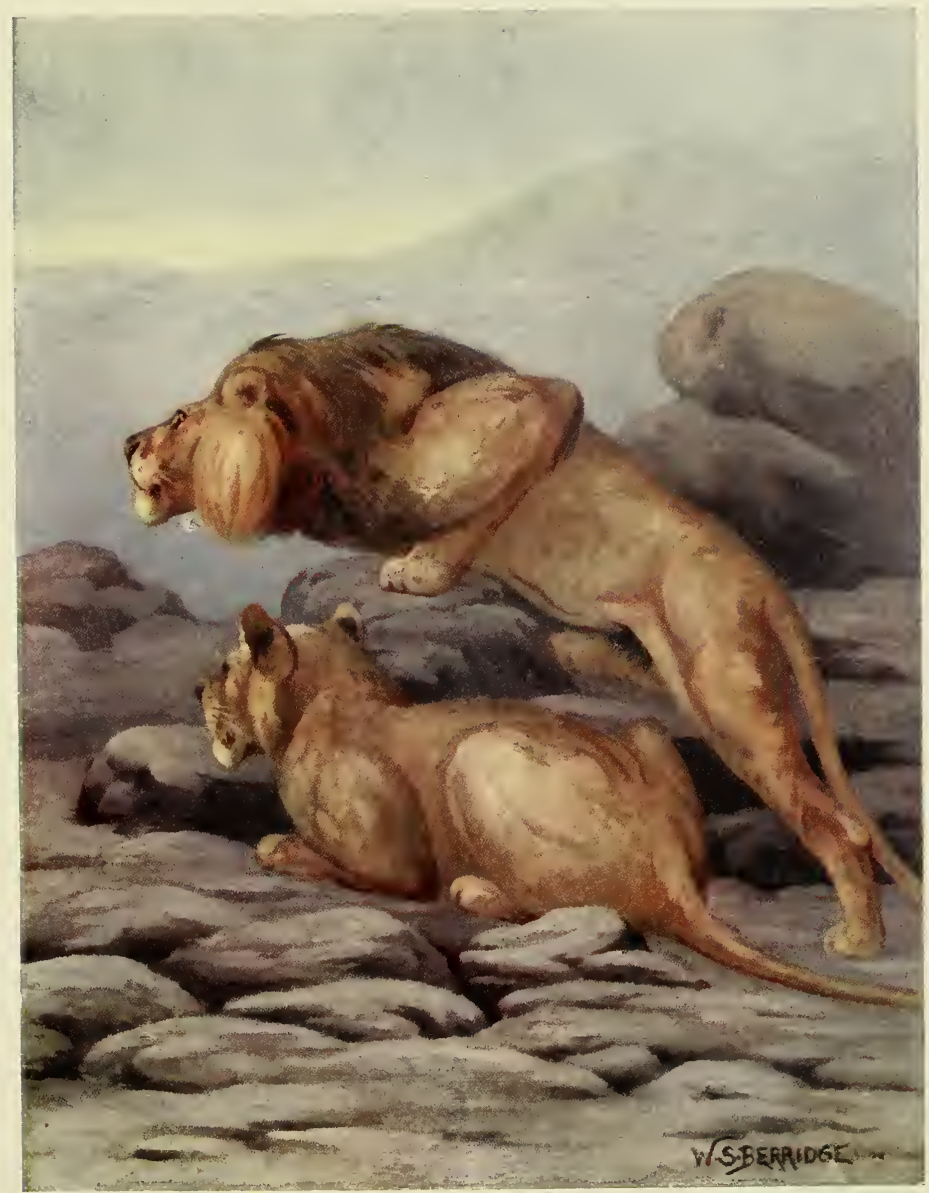

LION AND LIONESS STALKING THEIR PREY. 

ment is greater, and a comparison of the difficulties makes shooting in most cases appear as a boy's sport. The efficiency of the modern rifle greatly reduces the chance of failure, and consequently places the balance of chance too much in the sportsman's hands, while the difficulties of photography are lessened almost yearly by the invention of better and more simple devices, with the result that pictures which hitherto were practically unobtainable are to-day becoming common. It will be but a few years before we shall see clubs and societies formed for the advancement of natural history photography; in fact, an important and wide-spreading one is now being organized, and before the year is past it will probably be an accomplished fact."

It is obvious, as a writer in Country Life remarks, that "the photographer of big game must acquire a more patient and detailed knowledge than the ordinary hunter. He must get much nearer, as photography at the outside range of a modern gun would be out of question. It is in the struggle to get close that the danger arises."

In his Camera Adventures in the African Wilds Mr. Dugmore has pictured for us wild beasts of many kinds in their own homes, leading their own remarkable lives, snapped, as it were, whilst in the full enjoyment of unfettered liberty.

One cannot but admire the enthusiasm and stalking of this clever American naturalist, and I must candidly admit I have a much warmer appreciation for his bloodless records of the chase than valuable trophies which at best only testify to the sacrifice of life. It is apparent both from Mr. Dugmore's work, and also the graphic accounts sent home by the ex-President of the United States, that there still exists in Africa a tremendous population of wild beasts. It must not be overlooked, however, in giving consideration to this matter of hunting, that we owe practically all our knowledge of big game to men like Gordon Cumming, Selous, Gambier Bolton and others, and it is only fair to recognize the interesting narratives they have given us of the wild creatures they have encountered during their protracted and oftentimes perilous wanderings.

Perhaps the greatest adventure chronicled by Mr. Dugmore was the photographing of Lions at night by flashlight. The intrepid photographer was hidden inside a thorn boma with a dead Zebra laid as a bait for the forest monarch just outside. Inside the hidingplace Mr. Dugmore waited for the King of Wild Beasts to approach. 


\section{I36 THE BOOK OF THE ANIMAL KINGDOM}

At last he came within twelve feet of the camera, and a flashlight photo was then taken.

"No one," says Mr. Dugmore, "who has not gone through the experience can imagine what is the sensation of being at such very close quarters with so powerful and determined a creature as $a_{1}$ Lion. It would be exciting enough in the day, but in the awe-inspiring darkness of night it is even worse, as one knows that for the Lion there is no night, his eyes being as good then as in the clear sunshine."

La Fontaine in his Fables gives an amusing account of a Lion and the hunting Ass to which attention may be directed.

One day the King of Beasts took it into his head to go a-hunting. Now, when the Lion goes a-hunting he does not look for Sparrows, but for fine Boars and handsome Stags. In order to have a good day's sport he called to his aid the Ass of the stentorian voice. King Lion's Ass took his office seriously. He was placed somewhere in ambush and ordered to bray his best, for the King was sure that at the sound even the least timid would fly to their lairs. And this indeed did happen. The beasts, unaccustomed to the tempestuous voice of the Ass, were seized with terror at the awful noise, and fled in wild confusion, inevitably falling a prey to the Lion.

"Have I not served thee well?" the Ass, with a great show of self-satisfaction, inquired of the Lion. "Yes," replied the Lion, "thou hast made a brave noise. If I did not know thy manner and thy kith and kin, I myself should have been scared."

The Lion inhabits the whole of Africa as well as a good portion of Western and Southern Asia. We learn that ages ago it existed in Palestine and Greece. It stands some three and a quarter feet high at the shoulders, and is of splendid proportions and stately bearing.

The powerful head, broad chest, slender body and the strength of the paws and teeth are salient characteristics worthy of note. Thick, short hair from a light-yellow to dark-brown in colour clothes the body, and it is said that in native wilds this colour assimilates to the environment frequented. The male bears a dark-coloured mane which hangs over the breast and shoulders, and the tail has a tuft of hair at the tip. This mane is well exemplified in Fig. I05, whilst in the next illustration (Fig. I06) a Lion cub is shown. For some considerable time after birth, cubs produced in captivity are tame and docile. Sometimes they are fed with a bottle during infancy, but in time it becomes necessary to dispense with them as 
pets and safely house them behind iron bars. Yet it is remarkable to notice how, during illness especially, the adult beast will permit a human being to attend to it. Instances of this kind have been given by Bostock, Hagenbach, Sanger and others who have been brought into contact with these fine beasts. Mr. H. Lincoln Tangye gives an account in his book, In the Torrid Soudan, of a pet Lion kept by a friend of his at Omdurman. As a youngster this pet Lion was exceedingly tractable, and exhibited from its infancy upwards a great respect for its master's fist. Mr. Tangye writes-

"As a youngster the blow used to hurt, and Leo would put back his ears, shut his eyes, and brace his nerves for the shock. Not realizing that the strength of his master did not increase proportionately with his own growth, he was as scared of the fist when threequarters grown as when he was a baby." This somewhat embarrassing pet resorted to a playful habit of waiting behind doors and pouncing out upon unwary guests who happened to pass, "merely in fun." Most Lions are unable to climb, but this one learnt the difficult art, and was once surprised by his master at the top of a telegraph pole, resting his chin on the summit. Panic seized him when he found himself discovered. At the thought of the fist, losing his presence of mind, "he missed grip, and slid with his legs grasping the pole and an expression of agony on his face, from the top to the bottom, landing on his tail with a terrible bump."

During the daytime the Lion snugly ensconces himself among cover of some kind. Here he reposes until the heat of the day has departed. When the heavens twinkle with millions of stars then Leo rouses himself to action and sets out on his hunting expeditions. One writer has graphically described the nocturnal wanderings as under: "With a thunderous roar he announces his setting out for the nightly hunt; all the other Lions who hear the sound from afar reply in concert, but all other animals are seized with fear. The howling Hyæna grows dumb; the Leopard ceases its growling; the Monkeys begin to utter gurgling sounds, and fly terror-stricken into the highest branches; the lowing herd becomes silent as death; the Antelopes in mad flight burst through the bushes; the Camel trembles under its load, and, ceasing to obey its driver's voice, throws load and rider off and seeks safety in speedy flight; the Horse rears and snorts, and with inflated nostrils rushes away; the Dog, fawning, seeks protection with his master; and even the man on whose ears falls for the first time the voice of the Lion in the 


\section{I38 THE BOOK OF THE ANIMAL KINGDOM}

aboriginal forests, questions whether he be bold enough to meet the creature that sends forth such thunderous tones."

We cannot many of us visit the King of Beasts in his own domain, and few of us, I guess, would do so if we could, but some idea may be gained of the awe-inspiring spectacle created by one or more of these beasts, and the din set up by several of them, by visiting the Lion-house at some Zoological Gardens. Yet even here one may see on occasions pleasant episodes such as I promised to tell of in a former chapter.

A well-known Fellow of the Zoological Society of London has made great friends with many inhabitants in the fine collection housed in Regent's Park. Among these the Lion is to be numbered, and not long since I accompanied this modern Orpheus, as we may appropriately call him, upon one of his rounds. Placing his hand through the Lion's cage he caressed the animal without the slightest umbrage on the part of the King of Beasts. He fondled the lordly monarch much as one caresses the domestic Cat, much to the astonishment of a bevy of visitors, who apparently wondered what magnetic influence was possessed by this devout lover of the brute creation.

A little hair taken from the mane of one of the Lions at the London Zoo by this modern Orpheus lies before me on the study table, reminding me of a pleasant hour in company with him not long since. Many other animals have become his fast friends. The knowing little Chimpanzees play hide-and-seek as he enters their house; the Capybara awaits his coming with feverish anxiety; the IVolves watch his approach as that of a true friend, and birds fly to him from all parts of the aviaries.

What is the real secret of this remarkable exhibition of animal friendship? Tasty titbits, it is almost needless to state, have a very alluring influence, but one must of necessity recognize that some influence other than that mentioned is possessed by this splendid type of English gentleman who is so modest about his deeds that I am forbidden to mention his name.

It must not be supposed from what has been written earlier in this chapter that the Lion is altogether undeserving of the title that has for so long been bestowed upon it. Every one must admit its majestic appearance-although it does not in a wild state carry its head high as would befit a King-whilst the immense muscles of the jaws, shoulders and fore-legs give the animal enormous strength. 


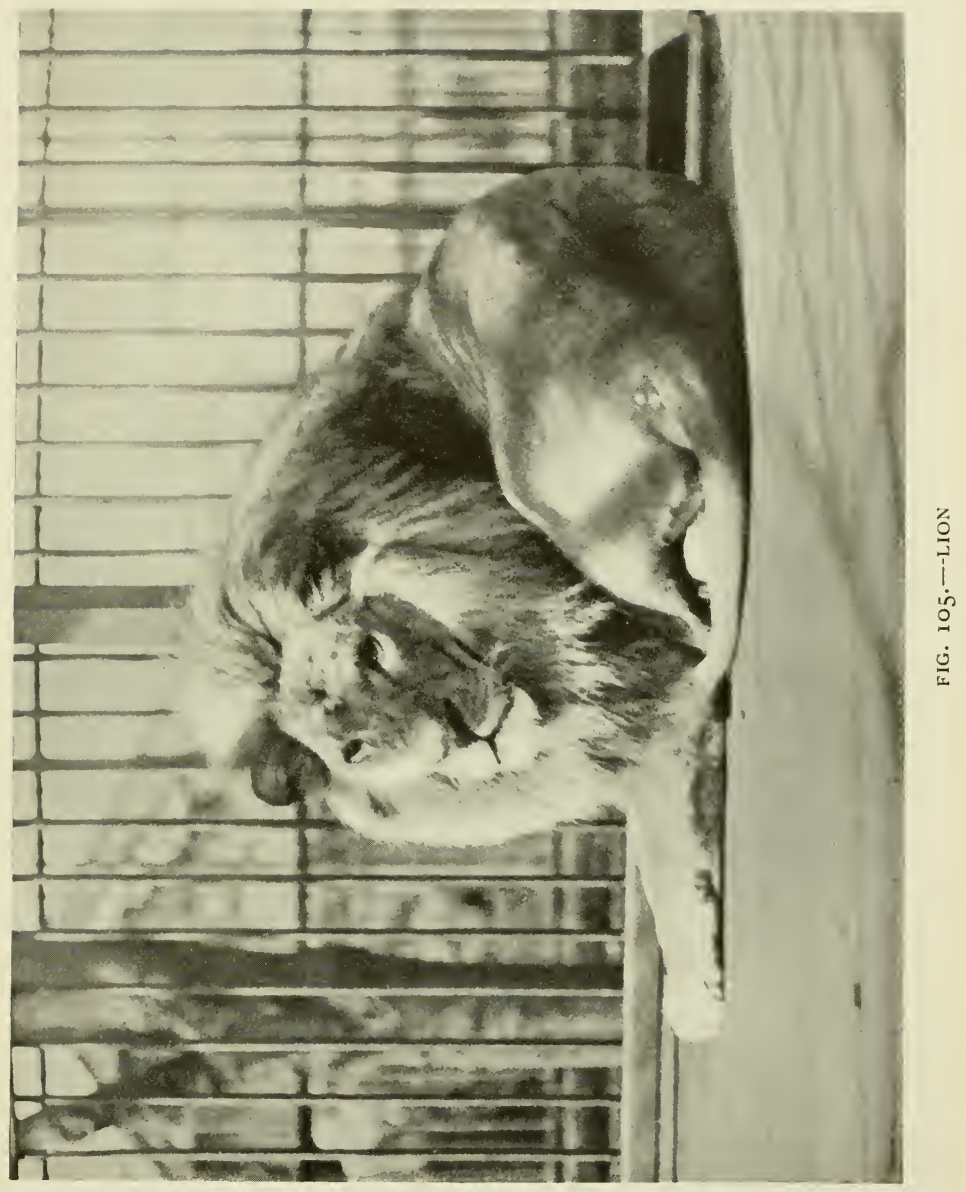




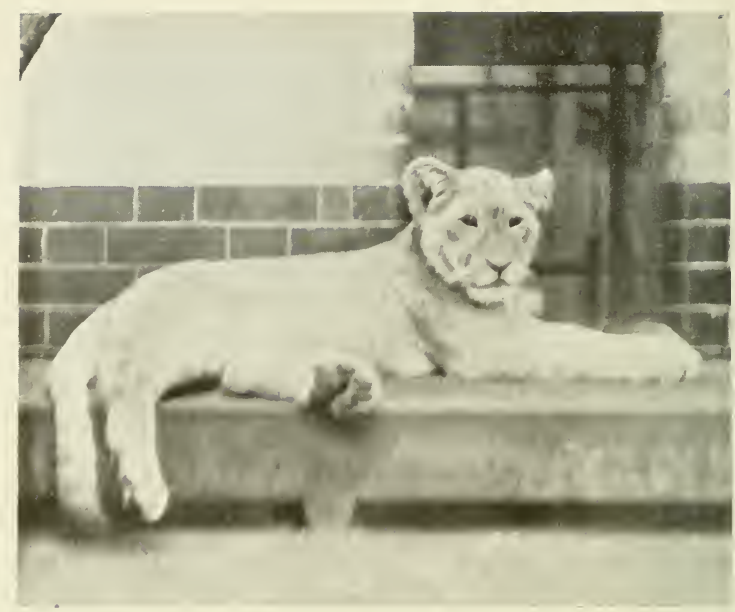

FIC. IO6.- LION CLB

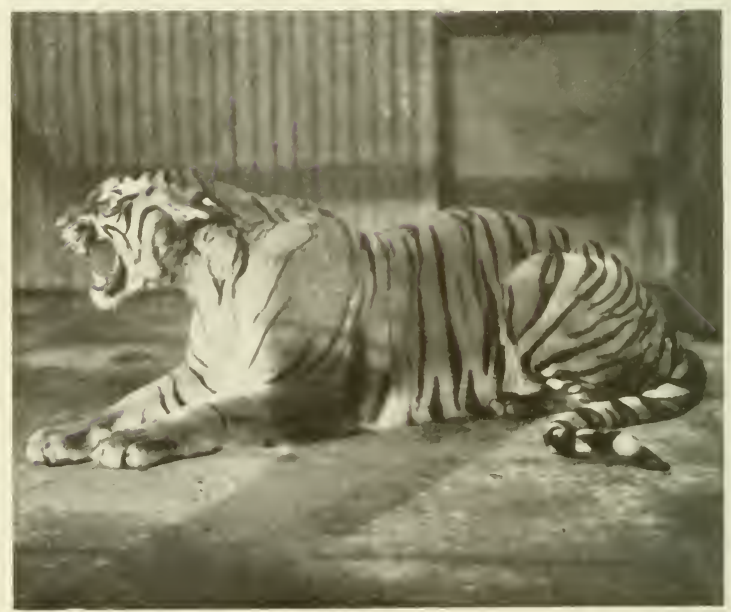

FIG. IO-, TIGRESS 
It can drag a Buffalo or Ox for a considerable distance, but cannot lift its prey off the ground. It prefers, however, to eat it where killed if undisturbed.

It can spring and leap, gallop at a tremendous pace, and overtake a horse going at its fastest speed. It does an enormous amount of damage when found in the neighbourhood of Cattle and Horses, but when far removed from these and haunting the silences it has to content itself with such beasts as Gazelles, Antelopes, Giraffes and Zebras, lying in ambush and waiting the close approach of its prey.

It may lie in wait near some meandering brook whither some other wild beast comes to quench its thirst, and then, when the fatal moment arrives, it dashes out and soon all is over.

In India the range of this powerful beast is much restricted to-day, for "the sport-loving Briton has made relentless war upon the larger Carnivores, one cavalry officer alone, early in the last century. bagging no fewer than eighty Lions within three years."

Two Lions have been known to kill twenty-eight Indian coolies, and as many, if not more, native workmen. The Lioness is the most to be feared, and if she has her cubs near at hand will make a formidable attack upon the intruder. One Lioness in Mashonaland has been known to kill one hundred Pigs during a single night Whilst this powerful adventurer has been known to kill natives to an alarming extent, as well as white men, for the last-named it appears to have a distinct dread. One writer has said that "Man, however, by his lofty bearing and especially by a sure and steady look, inspires even the Lion with respect. With shy mien the ' King of the Desert ' makes way for the 'Lord of the Earth.' On the other hand, after he has once discovered man's real physical weakness, he prefers human flesh to any other food; in the words of the Kaffirs, he becomes a 'man-eater.',

Much has been written from time to time of the experiences of those who have been seized by wild beasts, and we may conclude this account of the Lion by relating an incident in the life of Dr. Livingstone. He says: "I saw the Lion just in the act of springing upon me. Grunting horribly close to my ear, he shook me as a Terrier does a Rat. The shock produced a stupor similar to that which seems to be felt by a Mouse after the first shake of the Cat. It caused a sort of dreaminess, in which there was no sense of pain or feeling of terror, though I was quite conscious of all that was 


\section{I4O THE BOOK OF THE ANIMAL KINGDOM}

happening. The shake annihilated fear, and allowed no sense of horror at looking round the beast. This peculiar state is probably produced in all animals killed by the Carnivora, and, if so, is a merciful provision by our benevolent Creator for lessening the pains of death."

TIGER. - Of all the Cat tribe the Tiger (Figs. I07 and I08) is the most brilliantly coloured, the magnificently striped coat being well known to almost every one.

The two animals shown in the illustrations are both females, and were presented to the London Zoo by King George $\mathrm{V}$ after his Indian tour.

The male and female are both very much alike, the latter being somewhat smaller and the cheek frills are less pronounced than in the old male. The young also resemble their parents, being striped at birth.

The Tiger is a resident of all Asiatic countries, and visitors to Zoological Gardens where Siberian specimens are on view will have ocular demonstration of the thickness of the coat and larger size of those beasts found in the north of Asia, the extra thickness, of course, affording better protection in those parts where the cold is intense. Many people seem to inseparably associate the Tiger with a tropical country, living in regal splendour amid the luxuriance of its jungle home, but from its wide distribution throughout Asia it will at once be apparent that its haunts are often far from the swampy districts of the tropical zone.

The favourite habitat is, however, the latter, where, in a thickly overgrown bamboo swamp, it lurks in wait for prey. Although the protective coloration of this and other wild beasts has perhaps been somewhat exaggerated, there seems little doubt that the magnificent colour and stripes of the Tiger's coat closely assimilate to its environment, for the light and shade cast by upright stems, such as bamboos, fall in stripes or streaks, and thus blend with the Tiger's striped coat under the influence of the same rays of light.

It is a larger animal than the Lion, attaining a length of some ten feet, and certainly more powerful and courageous than the so-called King of WTild Beasts. Its ferociousness has frequently been chronicled, and even to-day the loss of thousands of human lives every year may be attributed to it. The man-eating Tiger haunts villages, ever on the prowl for some human prey, and whole districts have become depopulated as a result of its daring deeds. 
Although it does not possess the remarkable tusk-like teeth of its extinct ancestor, the Sabre-Toothed Tiger shown in Plate XI., it is not difficult to realize, even when looking at a living specimen kept in captivity, the poor chance of escape when man happens to get within striking distance of this handsome monarch of the jungle. The strong jaws, powerful limbs and remarkable paws are worthy of note, whilst the quiet movements and general lissome appearance are also of interest.

In its native wilds the Tiger manages to choose a haunt which is not far removed from water, and it is a good swimmer. In India it is more common to-day than in times gone by, and evidence points to the fact that it reached the Indian Empire from other parts of Asia. Whilst the Lion has diminished its range in India, the Tiger has increased, yet it has not managed to reach Ceylon, and although frequenting such cold climates outside India, it does not appear to have penetrated the Himalaya Mountains notwithstanding its power of enduring cold.

It is a lover of the forest, of nocturnal habits, and usually of a solitary disposition. When attacking its prey it makes for the neck in the same way as the Lion, and afterwards commences to feed upon the hind-quarters. Large beasts are as a rule attacked, including Cattle, but the Tiger, when driven to hard straits, is not at all particular as to its diet, and will condescend to eat even frogs and locusts. So long as it restricts its attention to wild animals all is well, for these themselves are very destructive to growing crops, but the moment it attacks cattle or becomes a man-eater, it is a terrible scourge which must be got rid of at all costs.

Authentic records are forthcoming of Tigers eating one another; of attacking such prey as Elephants and Bears, and its own cubs are on occasions devoured. Being more solitary than the Lion, it is naturally enough less sociable. It does not make its presence known by roaring to the same extent as its rival among the great Cats, but when it does give vent to its feelings the voice is not unlike that of the King of Beasts.

Tiger-hunting is carried out either by the sportsman being mounted on an Elephant, or secreted in a tree-top near the animal's lair, where he waits an opportunity for a shot as the monarch approaches a bait put out for it, such as a young Buffalo or Bullock.

Mr. G. P. Sanderson, in his Thirteen Years Among the Wild Beasts of India, gives many graphic accounts of adventures with 


\section{I42 THE BOOK OF THE ANIMAL. KINGDOM}

Elephants, Tigers and other animals, and one of these may here be given. He says: ". . When watching for a Tiger by moonlight I was entertained until his arrival by the proceedings of three Jackals.

"Two arrived before sunset, and their elaborate care in approaching the carcase of the bullock the Tiger had killed, though it lay in open ground, and they might have known the Tiger could not be secreted in very close proximity, was highly amusing.

"When close to it they would suddenly scamper off, apparently with the object of drawing some movement from the Tiger if it were anywhere near.

"Having at last plucked up courage to begin, one fell to voraciously, tugging away at the skin and making a great noise, whilst the other watched assiduously, never essaying to taste the tempting flesh. Presently the sentry raised every hair on its body and tail, lowered its head into the attitude of a dog in vomiting, tucked in its tail, and made a quick shuffling movement forward, ludicrously like an aggressive turkey.

“' Here comes the Tiger,' thought I; but presently I descried the cause in the shape of a third Jackal.

"The jealous sentry-the first-comers were evidently a pairwould not permit its approach, and the new-comer at last lay down with an assumed air of unconcern to await its turn.

"The Jackal had been tugging away at the dead bullock for about half-an-hour, the sentry not having had its turn yet, when both started away from the carcase and looked fixedly in a direction almost under my tree. They then commenced to make a peculiar sniffing noise, and changed places restlessly, running first a few paces to one side, then to the other, but never taking their eyes off the object that had attracted them. I knew they had viewed the Tiger.

"I had never seen a Tiger's reception by Jackals before; but their demeanour was so marked that I felt certain to what to attribute it. It was a moment of intense excitement, as I could not turn to look in the direction from which I felt sure the Tiger was approaching. Presently the Jackals, after changing their note to a sort of sharp twittering, evidently intended to conciliate their lord and master, retired to some little distance, and I shortly heard the quiet, measured footfall of the Tiger almost below me. I had the wind in my favour. Presently the striped head and shoulders came into sight, and after one or two pauses their owner marched to the tail of the bullock and stood looking in the direction of the Jackals. 


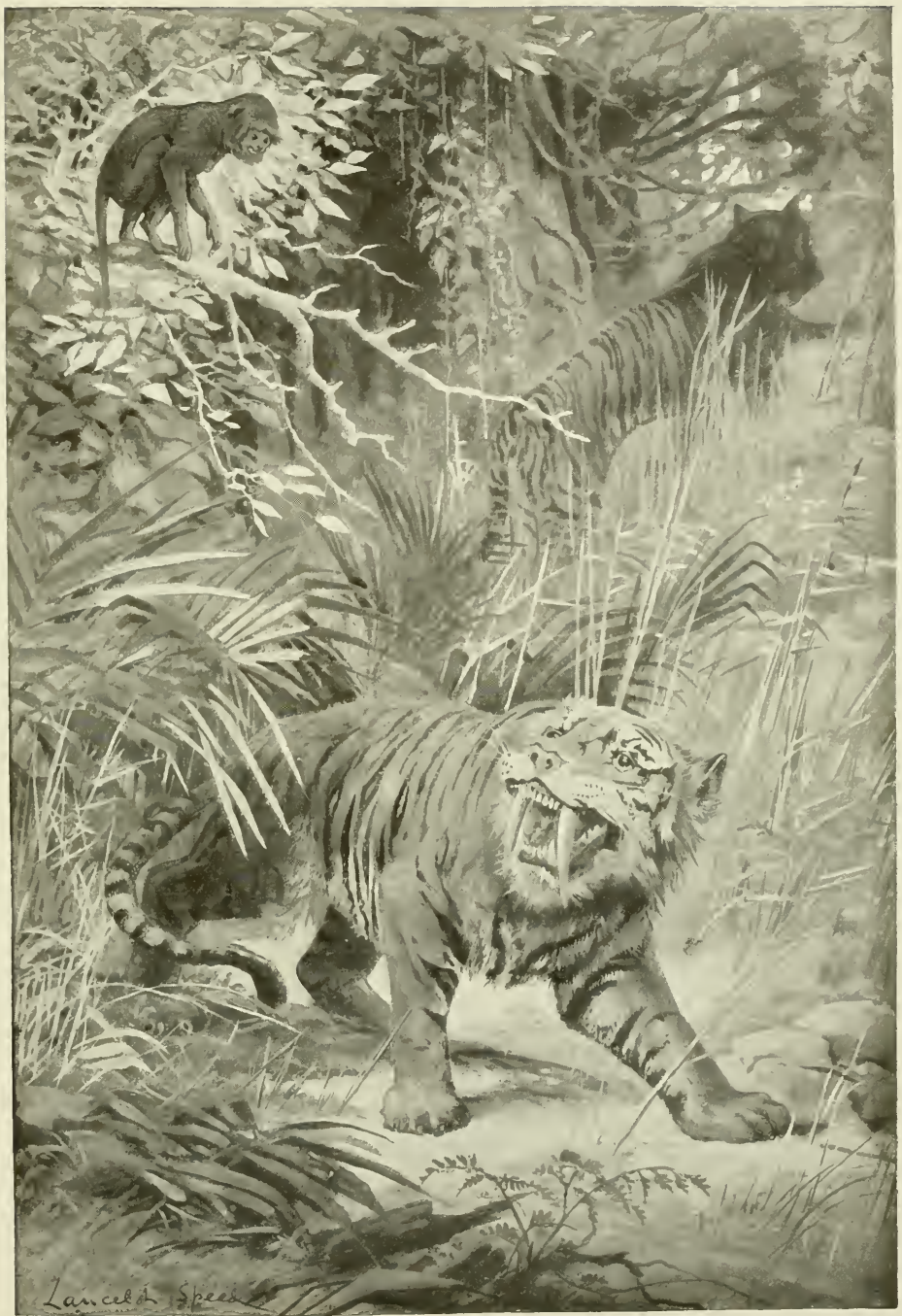

The extinct Sabre-Toothed Tiger, and ancestor of the living animal 


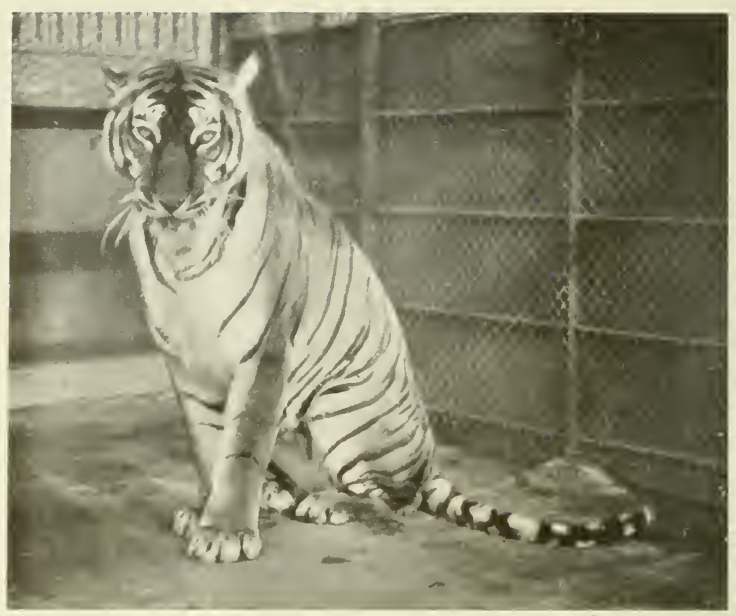

FIG. IOS.-TIGRESS

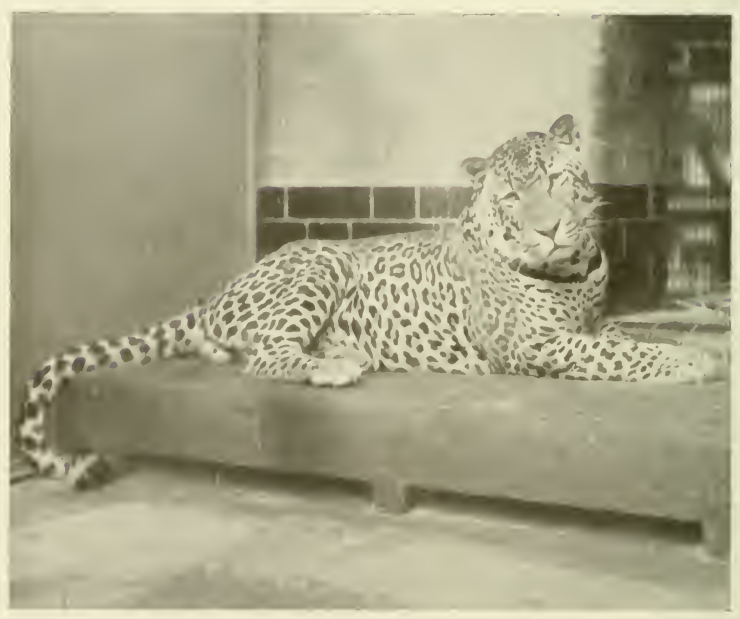

FIG. IOO. I.EOI'IRI) 
"He exposed his full broadside towards me, and looked very large in the moonlight. I knew if he lay down he would offer a more difficult mark, so I lost no time in firing. With a loud ' wough, wough,' the stricken brute galloped heavily away, but I felt sure I heard him fall when about sixty yards distant. I listened -there was a low groan. Again the sound was repeated-the peculiar sobbing groan of a dying animal.

"I waited for twenty minutes and then signalled to the trackers, who were in a tree at some distance, in a direction in which we previously knew their presence would not interfere with the Tiger's approach. I had been amused by their answering some Spotted Deer which began to bark soon after my shot, and not far from me, and which they mistook for my signal. The five naked and odoriferous, but simple and attached fellows, were soon safe with me in the tree. We agreed to wait for half-an-hour and then to look the Tiger up. We considered that there was no necessity to wait till morning, as the moonlight was very bright and there were only a few trees dotted about in the otherwise open ground, and we were sure of one point-namely, that if the Tiger had any strength remaining he would have used it ere this to put as great a distance as possible between himself and us. We decided only to look as far as the spot where I was of opinion he had fallen.

"If he were not there we would defer further search till morning. On getting down the tree we found the trail was very distinct. The grass was about eighteen inches high, quite dry, and almost white, as it had seeded and withered. The bent blades, upon which the moonlight glinted brightly, showed a glistening path where the Tiger had passed. When we had got to about the spot where I supposed the Tiger to be, one tracker pointed silently to a dark object lying where the silvery path ended abruptly, and beyond which the grass stood undisturbed. 'It looks like a log,' whispered one. 'A log with stripes and a tail, then,' said the quicker-sighted Murga. It was the Tiger, quite dead."

LEOPARD.-It is as well to point out here that the range of the Tiger is often misunderstood, and many people seem of opinion that it is found also in Africa and America. This, however, is not so, as it is the Leopard (Fig. I09) which is found in Africa and the Jaguar that inhabits America. The Leopard, of course, is a citizen of other parts of the world besides Africa, being a resident also of a large portion of Asia, including Ceylon and the Himalayas. 


\section{I44 THE BOOK OF THE ANIMAL KINGDOM}

Of the Old-world Cats the Leopard comes next in point of size to the Lion and Tiger, and its beautiful spotted coat is well known. It is a deceitful beast in captivity, and is not to be trusted, the Lion, curious to relate, being the best in this respect of the three species just mentioned.

For a long time it was thought that the "Panther" of India was a distinct animal, but it is now regarded as "a big, finely-developed Leopard ... such animals being naturally more inclined to attack large prey than the smaller and more Cat-like individuals which are the typical Leopards."

The ochre-yellow skin of this animal is richly ornamented with small and large black annular spots, and it is said that when the beast is reposing in the jungle its coat resembles the play of the sunbeams and the circular shadows of the leaves. The Leopard, however, varies both in size and colour. Sometimes the spots are fawn-colour instead of black, and almost wholly black varieties are met with. These so-called Black Leopards are almost entirely absent from Africa, and seem to occur for the most part in the Malay Peninsula and the surrounding islands.

The Leopard is an easily satisfied beast. It frequents both the forest and rocky ground; unlike the Tiger it is a splendid climber, and does not care for water to anything like the same extent. Its diet is a differential one, such animals as Birds, Monkeys, Cattle, Dogs, Bush Pigs, Antelopes, etc., falling a prey to its daring. It is a bolder beast even than the Tiger, and when it does attack man the results are appalling, one famous Leopard in India having been known to kill no less than two hundred human beings before it was dispatched!

Like its near relative, the Tiger, the animal under review is of solitary disposition, and is commoner, more cunning and versatile. Mr. Frank Finn says that it "has a most peculiar call, very like the sound produced by cutting wood with a coarse saw."

It will be remembered that mention was made earlier in this chapter of the method adopted by both the Lion and Tiger as to the commencement of a meal. The Leopard differs from its first-cousins by seizing its prey by the throat and beginning to feed at the fore instead of the hind-quarters; in this way the slayer of the prey may be identified.

Mention may be made of the Ounce, or Snow Leopard, of Central Isia, whose long fur is white, clouded with grey, and having irregu- 


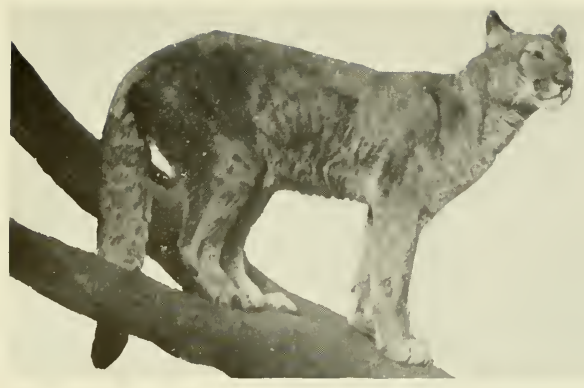

FIG. I IO.-PUMA.

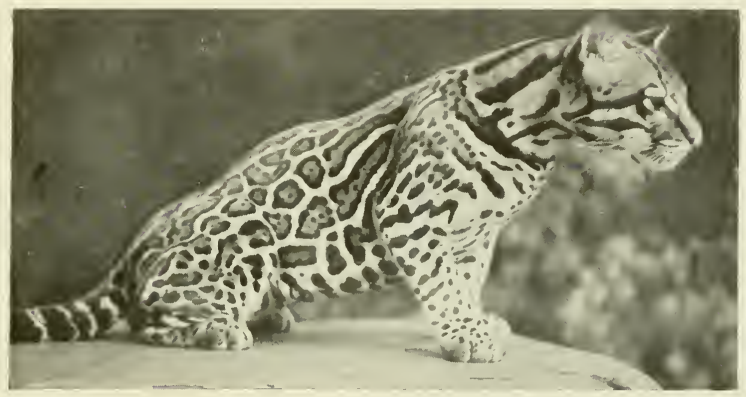

FIG. I I I . - OCELOT

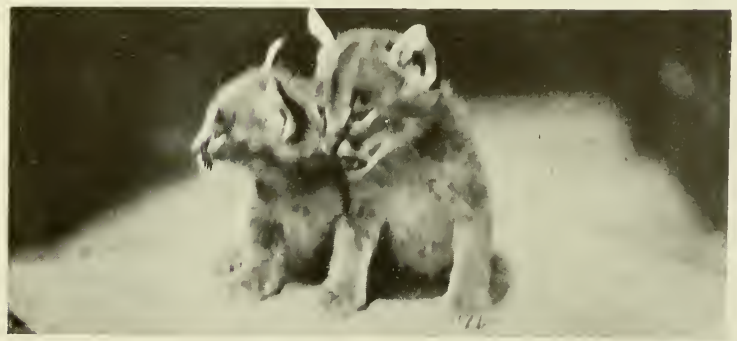

FIG. I I 2. CARACAL CUBS 


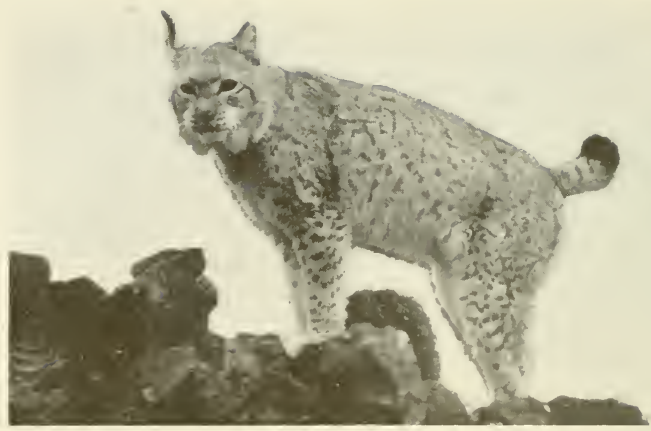

FIG. I I - NORTHERN LYNX

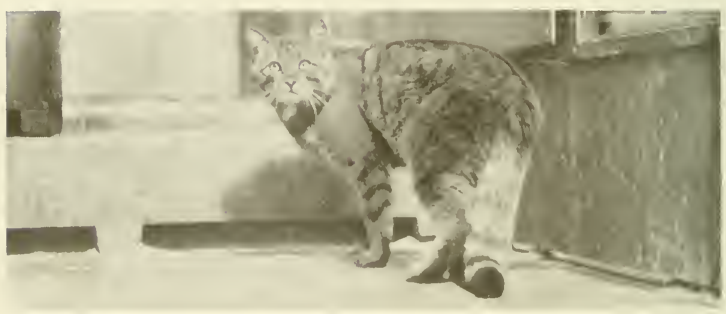

FIG. II I WILD C.IT

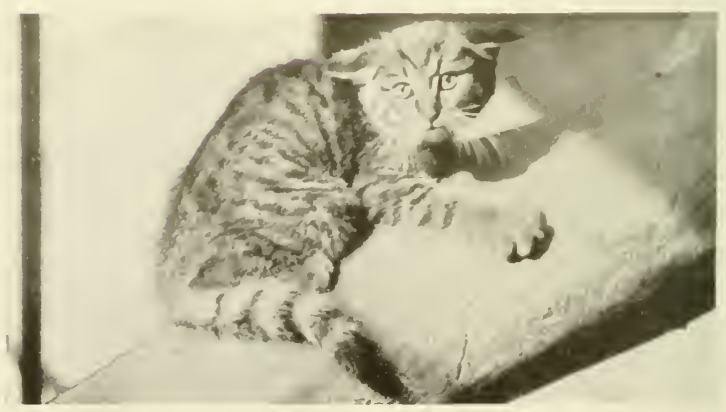

FIC, II 5, WILI) KITTEN 


\section{CATS-GREAT AND SMALL}

lar black rosettes. It has a long, bushy tail which is equally thick throughout almost the entire length. The long thick fur admirably protects this beautiful species during the rigours of Winter, and at such time the fur is particularly lovely. Resorting to treeless wastes, observations of this Leopard are infrequent, and whilst its food probably resembles that of its better known relative, the Ounce does not apparently climb trees nor attack mankind.

PUMA.-The Puma (Fig. I Io), or Mountain Lion, as it is also called, is a splendid American example of the great Cats. Mr. Ingersoll has well said of this animal that "until the invasion of his domain by civilization, he possessed the whole continent from near Hudson Bay to the Strait of Magellan. No other land animal whatever has so great a north and south range; and when one thinks of the wide contrasts in climate and conditions generally to which it must accommodate itself, one would expect to find a bewildering variety of forms. On the contrary, it would be hard to find a species so uniform as this. There is little or nothing by which any man might say whether a certain skin came from the Orinoco jungles, or the Patagonian pampas, or from some old canyon in the Rockies. The earliest visitors to this continent (America) mistook the skins they saw in the hands of the Indians for those of true Lions, or rather of Lionesses, for they missed the mane. Our 'Mountain Lion ' is a survival of this, strengthened by the fact that the Spanishspeaking people from California to Cape Horn still say Leon. In New England, however, a worse error took its place, giving it the name Panther, or 'Painter,' as Natty Bumppo and his tribe pronounced it. 'Puma' is Peruvian, and the best name, because, in addition to its being a native and an easy word, it alone appears to refer to this very animal; for 'Cougar' is a made word, coined or borrowed by Buffon."

Whilst, then, the Lion and Tiger are both absent from the New World, the Puma is a worthy representative of this splendid feline race. The adult is unspotted and differs widely in this respect from the Jaguar of the South, "the biggest, handsomest and most formidable of American Cats." To quote the same writer again : "Since it" (the Jaguar) "exactly takes the place in our tropical forests of the 'Tiger of Southern Asia, it is named 'el tigre' throughout Spanish America, or 'onea' (in Spanish, onza) among the Portuguese of Brazil. 'Jaguar,' 'Juarite' and the like are derived from Guaranese Indian words explained at length by Azara. But the term 


\section{46 THE BOOK OF THE ANIMAL KINGDOM}

'Tiger' is as carelessly wrong as is 'Lion' for the Puma, since the Jaguar is not striped but spotted, so that it closely resembles a Leopard."

The Puma is uniform pale fox-red to slaty-blue in general colour; it has black lips, a white patch on each side of the muzzle, and white on the throat, belly and inside of legs. The largest adult attains a length of about eight feet and a weight of some two hundred pounds. The head is full (see Fig. IIO) and gives an expression to the beast which is lacking in most of its foreign relatives. There are more females than males, but the latter, in a district where the former are scarce, will travel long distances in search of a partner. Sometimes it appears they pair for life, but at others the union is only a temporary one.

The female selects an isolated cave or quiet environment in some rocky fastness for the production of her family, but in a country where these secret silences are unavailable she resorts to a dense thicket, or a cane brake, as a suitable lair. The "nest" is made up of herbage of various kinds.

In the tropical south of the great continent the young are produced about February, but in the north the breeding season is later. Four or five young ones constitute the litter, but frequently less, and, curious to relate, only two seem to survive. During their infancy, it should be noted, young Pumas are spotted and the tail is ringed, but in a few months these markings disappear.

The cubs keep company with the female, watching the hunt and learning to procure food on their own account, but the rigours of oncoming Winter drive the beasts from the higher altitudes, and at such time the cattle-owner suffers acutely from their ravages. ExPresident Roosevelt, in his Outdoor Pastimes of an American Hunter, says that "in its essential habits and traits the big, slinking, nearly unicoloured Cat seems to be much the same everywhere, whether living in mountain, open plain, or forest, under arctic cold or tropic heat. When the settlements become thick it retires to dense forest, dark swamp or inaccessible mountain gorge, and moves about only at night. In wilder regions it not infrequently roams during the day and ventures freely into the open. Deer are its customary prey when they are plentiful, bucks, does and fawns being killed indifferently. Usually the Deer is killed almost instantaneously, but occasionally there is quite a scuffle, in which the Cougar may get bruised, though, as far as I know, never seriously. It is also a 
dreaded enemy of Sheep, Pigs, Calves, and especially Colts, and when pressed by hunger a big male Cougar will kill a full-grown Horse or Cow, Moose or Wapiti. It is the special enemy of Mountain Sheep. In 1886, while hunting White Goats north of Clark's Fork of the Columbia, I found them preying as freely on the Goats as on the Deer. It rarely catches Antelope, but is quick to seize Rabbits, other small beàsts, and even Porcupines."

OCELOT. - The Ocelot (Fig. III) is an inhabitant of tropical America, one of many small Cats there found, and of great interest. It has several names, such as "Tiger Cat," "Manigordo" and "Leopard Cat," but these are somewhat misleading in view of the two other animals treated of towards the end of this chapter. Julius Barras says that "from Oklahoma to southern Brazil it is always found in the woods and especially in thickets." It is an active and, as the photograph depicts, a beautiful animal; it readily takes to trees and there procures most of its food. It is a bloodthirsty beast, of great daring, but the specimen in Fig. II I, which was housed at the London Zoo and died in Igo8, became very tame and confiding. It measures about two and a half to three feet in length, exclusive of the tail, which is a foot long. The general coloration is grey, prominently marked with small and large fawn-coloured spots having black edges. Individuals vary a great deal, so much so, indeed, that one observer has remarked that it exhibits a distinct pattern on each of its sides.

The coat is soft and long, and the beautiful irregular mottling accounts for the demand that exists for it, enormous numbers of these Cats being trapped every year. It is of stout and heavy build, and has dark eyes and a pink nose.

CARACAL.-Fig. I 2 shows a pair of Caracal cubs, the first ever born at the London Zoo, this interesting event having taken place in the Spring of 1908. It is probable that this is the first time the Caracal has ever produced young in captivity. It is an active member of the Cat tribe and is found inhabiting open country throughout the whole of Africa and through Western Asia into India. In colour it is uniform bright reddish-fawn; it does not possess a ruff, but has sharp ears penciled with black, and a long tail which bears a black tip. It is, like the Ocelot, a good tree-climber, and can leap with amazing adroitness. It preys upon game birds, rabbits and other animals, but although trained by Eastern princes for sporting purposes, it is a fierce little beast, yet elegant in shape, 


\section{I48 THE BOOK OF THE ANIMAL KINGDOM}

and "the handsomest of the Lynx tribe." It is not so large as the Common Lynx, but exceeds most of the other smaller Cats.

Where there is bush and grass-covered jungle, there the Caracal makes its home, stalking its prey with immense cleverness and leaping into the air and securing ground-dwelling birds in less time than it takes to tell the story. It travels very swiftly when once under way, and runs down such prey as small Antelopes, Hares and large birds like Cranes, Bustards and Peafowl. Mr. Finn states that "one curious use of the animal is worth mention; the fur is in any case a handsome one, and the Boers in South Africa are firmly convinced that a rug of Caracal skins is a preventive of rheumatism, and Messrs. Nicholls and Eglington, who mention this, state that the fur even of the dead animal is highly electrical, as that of the living tame Cat is so well known to be."

NORTHERN LYNX.-The Lynxes are less Cat-like than any of the great and small Cats with which we have already made acquaintance, and an examination of Fig. I I3 of a specimen of the Common, or European, species from the Caucasus will reveal the short, thick tail, the long legs and pointed ears. It will be observed also that the Lynx is a heavily-built animal and does not exhibit that remarkably active appearance so characteristic of the beasts we have recently had under consideration. The Northern Lynx is found in Europe and Asia; it can exist in both hot and cold countries, and, in consequence, much variety is exhibited in the colour of its dress. The Northern species under notice has a soft, thick, greyish or reddiș fur, generally spotted with black; the Southern form is of a redder hue, whilst the beast found in Central $\Lambda$ sia is more regular in colour, and paler. It attains a length of three to four feet exclusive of the short tail, and has powerful paws and fore-arms.

A nocturnal animal, the Lynx dwells in forest regions, and, as might be supposed, climbs trees in pursuit of its prey, this consisting of various kinds of small mammals and birds. It is said to be "the most destructive of the Carnivores now left to plague Europe," and will kill Goats and Sheep with impunity. Like the Fox it kills more than it can eat, partaking of a portion of its prey and leaving the rest. Its ravages are, like those of the Fox, often extraordinary, for one individual has been known to kill no less than forty Sheep in a few weeks.

It is difficult to attack because its wanderings are restricted to the silent midnight watches, but is hunted whenever opportunity offers, 
as it is considered a worse enemy to flocks than the Wolf. It is not a fast-moving animal, but possesses indomitable patience, and its powers of stalking are unapproachable. It has been well said of him that although he is "more patient than the Fox, he is less cunning; less hardy than the Wolf, he leaps better and can resist famine longer. He is not so strong as the Bear, but keeps a better look out and has sharper sight. . . Every animal he can reach with one of his bounds is lost and devoured; if he misses he allows the animal to escape, and returns to crouch in his post of observation, without showing his disappointment. He is not voracious, but he loves warm blood, and this habit makes him imprudent. . . . If he comes upon a flock of Goats or Sheep, he approaches, dragging his belly along the ground like a Snake, then raises himself with a bound, falls on the back of his victim, breaks its neck, or cuts its carotids with his teeth, and kills it instantly."

The Canadian Lynx is not a common animal to-day, for its skin has long been sought after, and except in Eastern Quebec and the adjoining forests of Maine and New Brunswick, it is rarely seen south of Lake Superior, but on the Pacific side it traverses well south in the high mountains.

It spends the Summer in tangled thickets, and it is there that the young are reared and given their early lessons in hunting. By Winter-time the "ill-natured kittens" are able to procure food on their own account, and whilst at times this is difficult to obtain through long, cold nights in Northern forests, when Spring comes round again, bringing in its train hosts of returning birds, the Lynxes find food in plenty, and make ample amends for the lack of provender which was forbidden them during lone Winter days.

WILD CAT. - In Great Britain Wild Cats, real and so called, are many, but the pure wild animal (Fig. II4) is a rare creature restricted to the north of Scotland. Such a number of domestic Cats are turned from home and become wanderers, and others so frequently evince a desire to hunt, that it is small wonder there are chronicled in the papers captures of so-called Wild Cats south of the land of the thistle. During my own country pilgrimages I have very frequently come across a domestic Cat poaching in some secluded wood or along an unfrequented hedgerow miles from a habitation of any kind, and my gamekeeper friends have shown me numbers of undesirable feline marauders which have been shot or 


\section{I5O THE BOOK OF THE, ANIMAL KINGDOM}

trapped because of their fondness for young Pheasants. I remember being in a wood very early one Spring morning, long before the keeper had made the round of his traps set overnight, and my experience then was of such a distasteful kind that I made a vow never to be out and about before a keeper again. As I approached the snug little wood in which I have spent many pleasant and, I hope, profitable hours animal stalking and bird watching, I heard heartrending screams as of many wild animals evidently in great distress. The noise, I felt convinced, was not the squeal of a Rabbit in a trap, and in the quietude of the morning air I was considerably perturbed at such an unusual occurrence. Diving into the heart of the woodland fastness I hardly knew which way to go first, for I distinctly heard loud unearthly screams coming from several parts of the wood. Whilst I was thus meditating, I was suddenly surprised by an animal half springing at me, for I had unconsciously almost trodden upon a large black and white domestic Cat caught in the clutches of a heavily-toothed trap. Never as long as I live shall I forget the sickening scene; I can still bring vividly to mind the fierce maniacal expression of the Cat's face; the bulging, fiery eyes, agitated form and wild, uncanny look. A strong chain held the trap fast, and this in turn was firmly riveted to the ground. The Cat had dragged the chain to its extreme length, and had it not been for the weight of trap and chain combined, I guess the consequences would have been far more serious for me than they were. To approach the furious beast so as either to release it or kill it was out of the question, and I passed on, obtaining some relief from the love-songs of migrating birds just arrived from over-sea, and countless blossoms of pale dew-spattered primroses which were kissing the first sunbeams.

More screams penetrated the woodland fastness, and a hurried exploration in the direction from which they proceeded revealed two more traps, both containing domestic Cats. One of these was a large creature, marked very much like the true wild species, and I have been led to give an account of this little experience because an ordinary observer seeing this Wild Cat-like specimen might easily have concluded that a wild, not a domestic, beast had been trapped. The third captive was a big sandy Cat, and I have noticed many times that sandy-coloured Cats seem especially fond of poaching, especially around farmyards.

The Wild Cat, then, is in Great Britain to-day restricted to the 
north of Scotland, one of the last authentic records of its appearance further south being about $S_{40}$ in Yorkshire. Another example was seen somewhere about the same time in North Wales, and a few years afterwards one was said to have been secured in Oxfordshire. Outside the British Islands, the Wild Cat is found in many parts of Europe and Asia, whilst, of course, there are various other species "of small felines known as 'Wild Cats' found almost all over the world where Cats are found at all-i.e. except in Madagascar and the Australian region."

It is small wonder that in such a game-preserving and stockrearing country, the IVild Cat should have become almost exterminated in Britain, for there can be no question as to its misdeeds among various furred and feathered creatures, and also lambs. Whilst it should be emphasized that genuine IVild Cats are now few and far between in the old country, it should be pointed out that the wild and domesticated Cats are known to interbreed, whilst in Fig. II5 an example is given of a wild kitten, a cross between a IVild Cat from Scotland and the Egyptian or Fettered Cat.

Lynx-like in general appearance, the wild species is a strikinglooking animal, having a body which at once gives one the impression of a remarkable combination of strength and activity. The large, bushy tail is seen to advantage in Fig. I I4. The coloration varies, but generally the thick, close fur may be stated to be yellow, banded with darker shades, with black rings on the tail and a black line along the back. It is also black on the soles of the feet.

The litter is produced during early Summer, five or six kittens being born either in the forsaken "earth" of our old friend the Badger, or in the seclusion of a hollow tree.

It is ferocious, savage and untamable, and although at one time it was considered to be the ancestor of our own domestic pussy, it is now agreed that the Egyptian Cat is more nearly related to the well-known pet animals which, when properly looked after, make such desirable companions. The Wild Cat of Europe has an ancient history in Britain, being one of the oldest mammalian inhabitants we have, but, curious to relate, it has not been known to occur in Ireland. Few writers appear to be able to say a good word for this ferocious Carnivore, and Mr. Pennant has stated that it "may be called the British Tiger; it is the fiercest and most destructive beast we have, making dreadful havoc amongst our poultry, 


\section{I52 THE BOOK OF THE ANIMAL KINGDOM}

lambs and kids. It inhabits the most mountainous and woody parts of these islands, living mostly in trees and feeding only by night."

In the course of a most informative and interesting article in The Animal World, Mr. Harwood Brierley gives a delightful sketch of his feline majesty at home. He says--

"Of nocturnal habits, like the Badger, Otter and Fox, this most ferocious beast can rarely be seen except by daybreak or evening twilight, and may for a long time frequent a mountain district unknown to its sparse population until certain tell-tale marks are left in the Winter snow, thus making his presence felt at last by a series of misdeeds. After going on prowl he habitually uses a different route on returning to his lair, where he sleeps during the daytime with, apparently, a quite easy conscience. Sanguinary always, both sexes kill more than twice as much game as they can devour, rarely returning to finish the remains of a previous meal. In an ordinary way the beast prefers to feed where he has killed his prey, leaving behind either fur or feather. . . .

"Judging by the story of the mediæval Yorkshire knight, Sir Perceval Cresacre, whose effigy may be seen in Barnborough Church, and who was killed by a IVild Cat in the church porch after a fight lasting some hours, discretion remains the better part of valour when a warrior huntsman, gamekeeper, or ranger not well armed comes into the vicinity of a Wild Cat's lair, for the chances are that she will hazard anything in defence of her kittens. The Cat-a-mount, as this beast used to be called, has not only a double set of keen, retractile claws, but she has 'nine lives' at least, and will not be humiliated into submission by flogging with the cat-o'nine-tails. . . .

"The question arises: is the indigenous Wild Cat of Europe to be allowed to multiply with or without restraint in some of its Highland fastnesses, or is it to be trapped and shot wherever seen in such a manner as to make its death as speedy and painless as possible? There are the interests of landowners, sportsmen, farmers, crofters, shepherds, naturalists, and humanitarians to consider.

"I hold the opinion that if the much-discussed schemes for the reafforestation of Scotland takse a substantial form it will be possible to offer even this wild beast a few sanctuaries wherein to dwell at peace with mankind." 


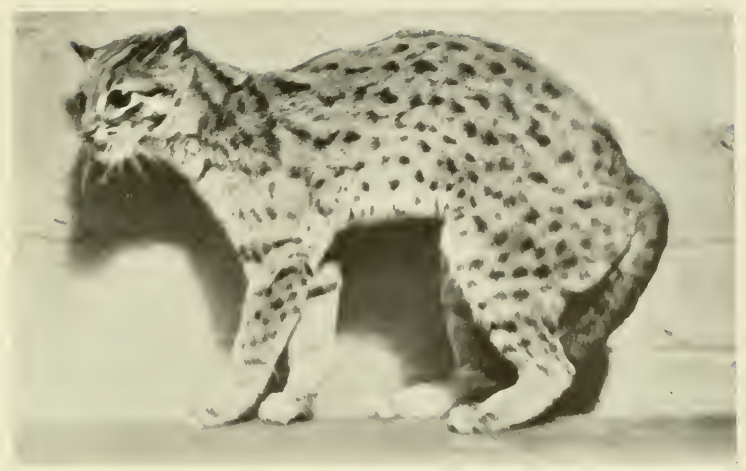

FIG. I I6.-LEOPARD CAT

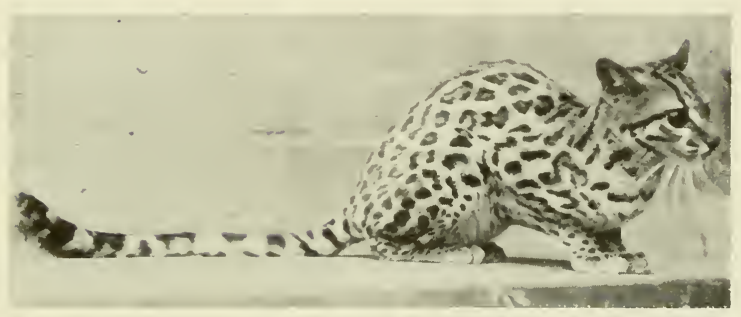

FIG. 117 - MARGAY

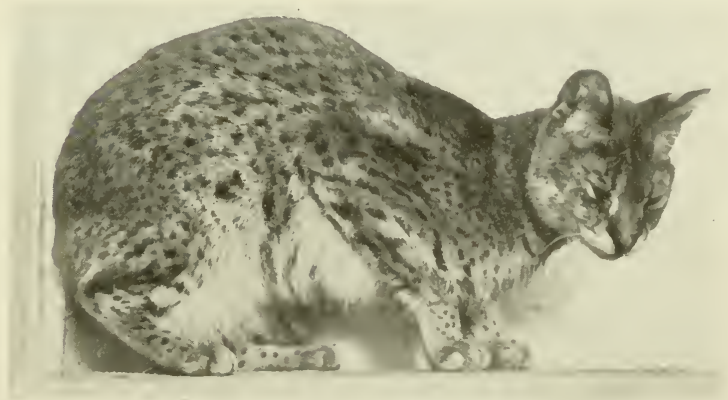

FIG. IIS.-SERVALINE CAT 


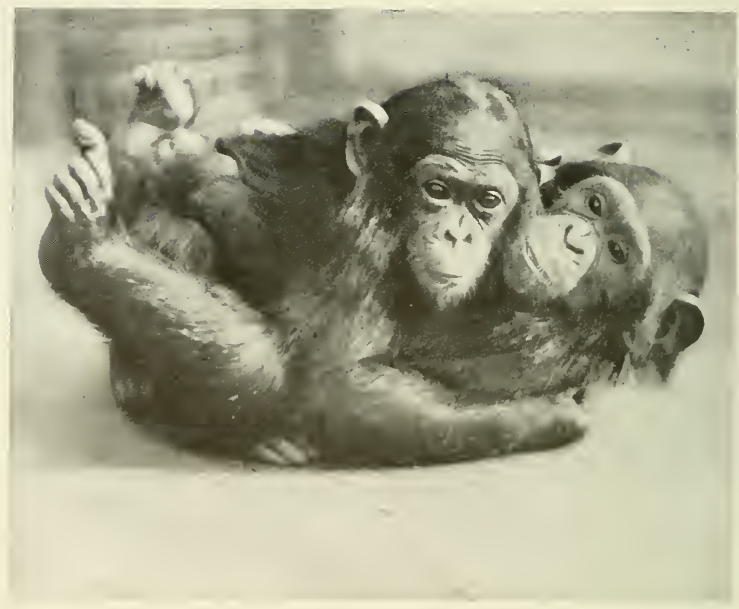

FIG. I I9. CHIMPANZEES AT PLAY

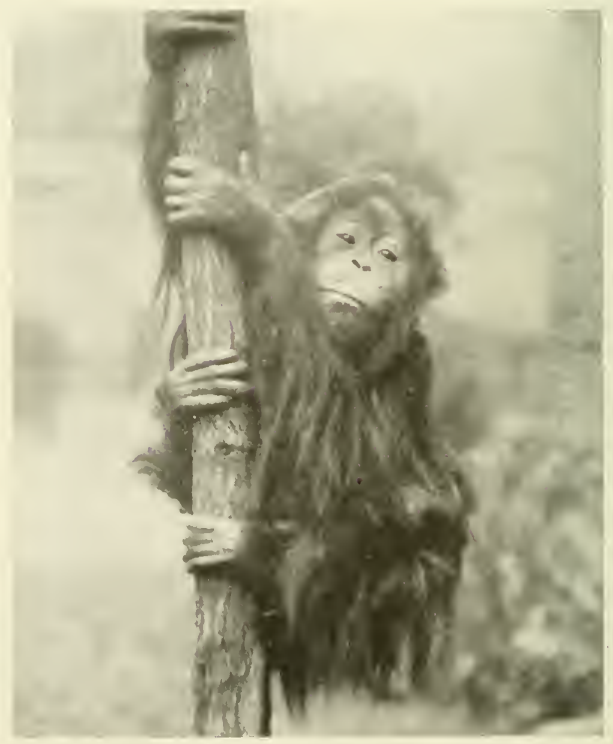

FIG. I 2O. ORANG-UTAN 
LEOPARD CAT.-The Leopard Cat (Fig. I16) is found in South-Eastern Asia, and is known by a great many different names. This is doubtless to be accounted for by reason of the variation in colour and markings to which this pretty species is subject.

It is about the size of the ordinary domestic Cat, but has longer ears. A general description of the coat must suffice, as the variation is so great that a comprehensive account is impossible.

The upper parts are usually pale tawny of some kind, "varying," says one writer, "from rufous to greyish; while the spots, which have a more or less marked tendency to form longitudinal lines, may be either wholly black, or partly black and partly brown. The spots extend over the under-parts and limbs and the upper part of the tail; although the tip of the tail is barred. Four distinct longitudinal stripes on the forchead give a characteristic physiognomy to the head, these stripes being generally continued in a more or less distinct manner along the back."

The Leopard Cat is to be numbered among the dwellers of the forest, and occurs both in the Highlands and Lowlands of India and other parts of South-Eastern Asia. The litter consists of three or four young ones, and these are born during the early Spring, the lair selected being a cliff or cave far from the haunt of man.

It feeds on small mammals and birds, although it has been known to seize a fowl almost as large as itself. It is a ferocious and untamable little beast, and I have many times noticed how the specimen depicted in Fig. I 16 displays its temper when I have vainly endeavoured to coax it into the open at the London Zoo.

MARGAY.-The Margay (Fig. I I 7 ) brings us almost to the end of the small Cats included in this section. Like the Leopard Cat it is an inhabitant of forest regions, but is of American parentage, the specimen shown in the photograph having come from Northern Brazil. Its range extends from Mexico to Paraguay. It is a beautiful species so far as concerns its dress, being similarly striped and spotted to the Ocelot already described.

Individuals vary to a great extent, a fact to be particularly noted with regard to several of the Cats recently under review, and different names have in consequence been accorded to these varieties, including that of the "Cauzel" of Costa Rica.

Like many, if not most of its relatives, it is nocturnal in its habits, feeding for the most part on birds, which, before being eaten, are shorn of their feathers. 


\section{I54 THE BOOK OF THE ANIMAL KINGDOM}

SERVALINE CAT.-The last representative of the Cats-great and small-is the Servaline Cat (Fig. II $)$, which has more spots than the Serval, and these are smaller. With the exception of these markings there does not appear to be any great difference between the two beasts, but it should be mentioned that whereas the Serval inhabits the whole of the African continent, its namesake seems to be restricted to the neighbourhood of Sierra Leone.

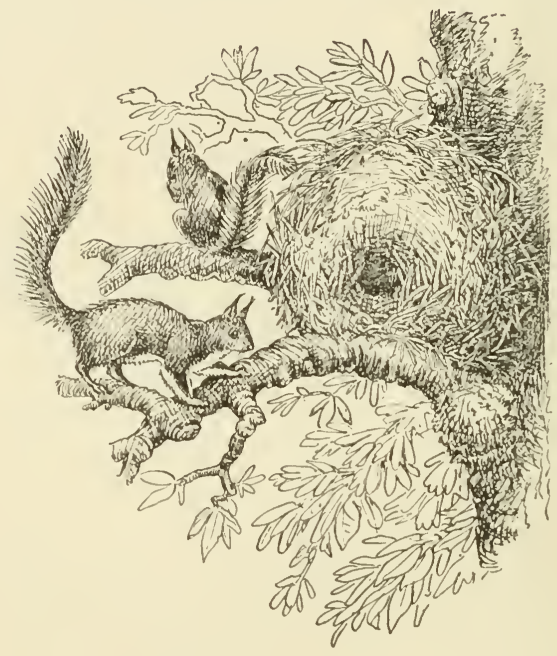




\section{CHAPTER IX}

\section{MONKEYS, APES AND THEIR KINDRED}

IF a vote were taken, among young people at any rate, as to the most popular kind of animal exhibited in zoological collections, there is little doubt that the Monkeys, Apes and their kindred would almost, if not quite, head the list. Among mammals, Monkeys undoubtedly hold a very high place, so far as concerns their general appeal to the human race, and perhaps, remembering our close relationship to them, this is as it should be.

Their comical faces, curious ways, active habits and at times remarkable attachment to their owners, and attainments as tricksters, cannot fail to interest the student of animal life, and whilst in other ways, such as the point of view of real beauty, few Monkeys have much to commend them, there is little doubt that taken all round they are a very popular class of mammals deserving of attention.

The family is a pretty extensive one in regard to numbers, whilst in size they range from the huge Gorilla to tiny mites not much larger than a Squirrel. It is these smaller kinds which appear to possess such bright, intelligent little faces which appeal more to the writer than the larger species, although the rough old OrangUtan and, of course, the Chimpanzees are always worth paying attention to.

MANDRILL.-Another great friend of the writer's is Georgie, the handsome Mandrill Baboon, which, in view of a lengthy and delightful acquaintance, has been given pride of place in this volume in the for $\mathrm{n}$ of a coloured frontispiece, a remarkable likeness painted from life. Strictly speaking, the Gorilla should be first treated of among the Monkey tribe, but a few notes may be given concerning the Mandrill, then we can follow on with the first-named, and afterwards make acquaintance with the Chims, Orang-Utan and many other kinds of less known Monkey-folk.

Our friend Georgie Mandrill, as we will call him, must never on any account be missed by visitors to the London Zoo, for he is 


\section{I56 THE BOOK OF THE ANIMAL KINGDOM}

far too important a person to be overlooked. Not that Georgie will thrust himself upon one's attention, so to speak, for he is far too sedate and retiring for that, and he nearly always requires a deal of persuasive coaxing before he can be tempted from his snug indoor apartment from whence he surveys his visitors with a critical eye. He is a Baboon, this big fellow, and has been called "extraordinarily hideous." It is not proposed to apply this somewhat unkind appellation to Georgie, for although, compared with a beautiful bird, he may not strike one as particularly attractive, there is something about him that appeals to the devout lover of animals which makes it impossible to correctly apply the title quoted to this handsome beast. A wag at the Zoo more correctly referred to it as an animal of East and IVest, showing a sunrise in front and a sunset behind!

The coloured frontispiece will convey a far better idea than any written description of the general appearance of the Mandrill. $\mathrm{He}$ is about three feet in height, of bulky build and possessed of great powers of strength. In colour he is mostly olive-brown, with silvery-grey below, but the most striking parts are the brilliant blue ridges and scarlet on the front of the face; the purplish-red of the hinder portions of the body, the tuft of hair on the head, and the deep setting of the eyes arched with overhanging eyebrows.

Georgie at the Zoo must look to his laurels, for another Mandrill has recently arrived which shows a friendliness for visitors which may make him eventually a general favourite, and on a recent occasion this smaller specimen evidently enjoyed a brief interview with the writer, in the course of which the sagacious creature uttered curious sounds as if endeavouring to articulate some of its secrets to the interested onlooker. Yet, we are told, it must not be trusted, for, on the least provocation, it bursts into a temper and endeavours to frighten a person by wild gestures calculated to inspire fear in the more timorous visitors. Notwithstanding this, in a wild state the Mandrill is a coward, for, when attacked, he will beat a hasty retreat, and, like some boys I used to know at school, will take to hurling missiles from a safe cover rather than have a straight, stand-up fight in the open.

The Mandrill's native home is in West Africa, where, like other Baboons, he travels about in troops, and is closely related to a second species in which the prefix Man is dropped, the animal being known as the Drill. 
GORILIA.-Although no pictorial representation appears in this volume of the Gorilla, the huge giant being so extremely rare and difficult of capture that it is not often seen alive, a few notes concerning it must perforce be given. It is the largest and most powerful of the Man-like Apes, and like the Mandrill it lives in West Africa, especially where there are damp, impenetrable forests.

Its habitat is restricted even on the great African continent, but it has long been known by name, for we read of its being christened by Hanno as long ago as 350 в.c. It is stated, however, that the Carthaginian mentioned did not in all probability encounter the Gorilla during his African wanderings, for although be brought back some stuffed specimens of so-called Gorillas, "it is far more likely that his captures were only large Baboons." It was not until ages afterwards, as recently as 1847 , that further light was thrown upon this gigantic beast, for in that year Sir Richard Owen, to whom we owe so much for our knowledge of extinct and living animals, procured a skull from an American missionary which set all doubts at rest as to the strange creature which Hanno, the Carthaginian, had named so long previously. Then, a few years afterwards, in 1852 , a large number of Gorillas migrated to the African Coast and were captured, and in I 853 the eminent Professor astounded an audience at the Royal Institution with particulars of the habits, etc., of the formidable beast under review.

General characteristics that may be noted are the muscular powers of the limbs and jaws; massive shoulders; large head on a short, thick-set neck; large brawny arms and hands; short, thick fingers; great spreading feet; intense black skin, clothed with short, coarse dark-grey hair tipped with whitish; reddish-brown hair on face and head; ruff under the chin; small ears; deeply sunken eyes which give a horrid expression; wide, gaping mouth; powerful jaws and tusklike teeth.

One would hardly imagine when looking at the huge form of this mammalian giant that it should be capable of activity, more especially among trees. Such, however, is the case, for we are told by $\mathrm{Du}$ Chaillu, the famous French explorer, that it spends most of its time in trees, and can spring and leap with remarkable adroitness. For the most part the Gorilla is a vegetarian, partaking of various kinds of fruit, and is especially fond of sugar-cane. It will also feed upon insects, birds' eggs and honey.

It is a shy creature, and in the dark recesses of the forest makes 


\section{THE BOOK OF THE ANIMAL KINGDOM}

its home. Rarely encountered even by those who live near its haunts, it is a formidable opponent, for it can easily overcome a Leopard in a fair, straightforward fight, and Man would doubtless stand a poor chance if brought face to face with it. It is courageous, all-powerful, Man-like in form in many ways, but from all accounts quite lacking in intelligence. True, it builds a home in the tree-tops, but, as Mr. Protheroe says, "he has not the wit to add a roof," and "from time immemorial the animals have lived in communities something like Men, but during countless ages they have learnt nothing; they remain as brutish as ever were their ancestors."

CHIMPANZEE.-The Chimpanzee (Coloured Plate XII, and also Fig. I 19, showing two of these animals at play) is also an inhabitant of the aboriginal forests of IVest Africa, and both this species and the Orang-Utan resemble the Gorilla in their general structure and mode of life.

At the same time, neither the Chim nor the Orang are so repulsive-looking as the more formidable beast last considered; indeed, the Chims especially are very popular, and among the most intelligent of the anthropoid Apes. We have already met both the Chim and the Orang among Animal Pets in a former chapter, but a few further particulars may be added concerning both species. The Chimpanzee has been well known much longer than the Gorilla, for, being much smaller and more reconcilable, the natives of Africa have for long caught them and made pets of them. The first appearance of one in London appears to have been about 1740 .

It is a resident of Equatorial Africa, but is much more widely distributed than the Gorilla. An adult male attains a height of some five feet, the female being perhaps a trifle less in stature. It is quite unlike its powerful rival in general appearance, lacking many of the characteristic features recently enumerated. The Chim is not nearly so tall nor so massive in build, and whilst the head and ears are large, there is an intelligent expression upon the face which is wanting in the rarer beast. The muddy, flesh-coloured skin is adorned with coarse black hair, and this is plentiful on the back and shoulders, whilst one writer facetiously remarks that "there are very passable whiskers on the sides of the cheeks." The flat nose may be noted, also the less massive jaws and canine teeth, whilst the writer just quoted states that "the hair on the forehead is parted with an accuracy almost suggestive of the services of a hairdresser."

It travels about in companies, but is not so strictly arboreal as 
Plate XII.

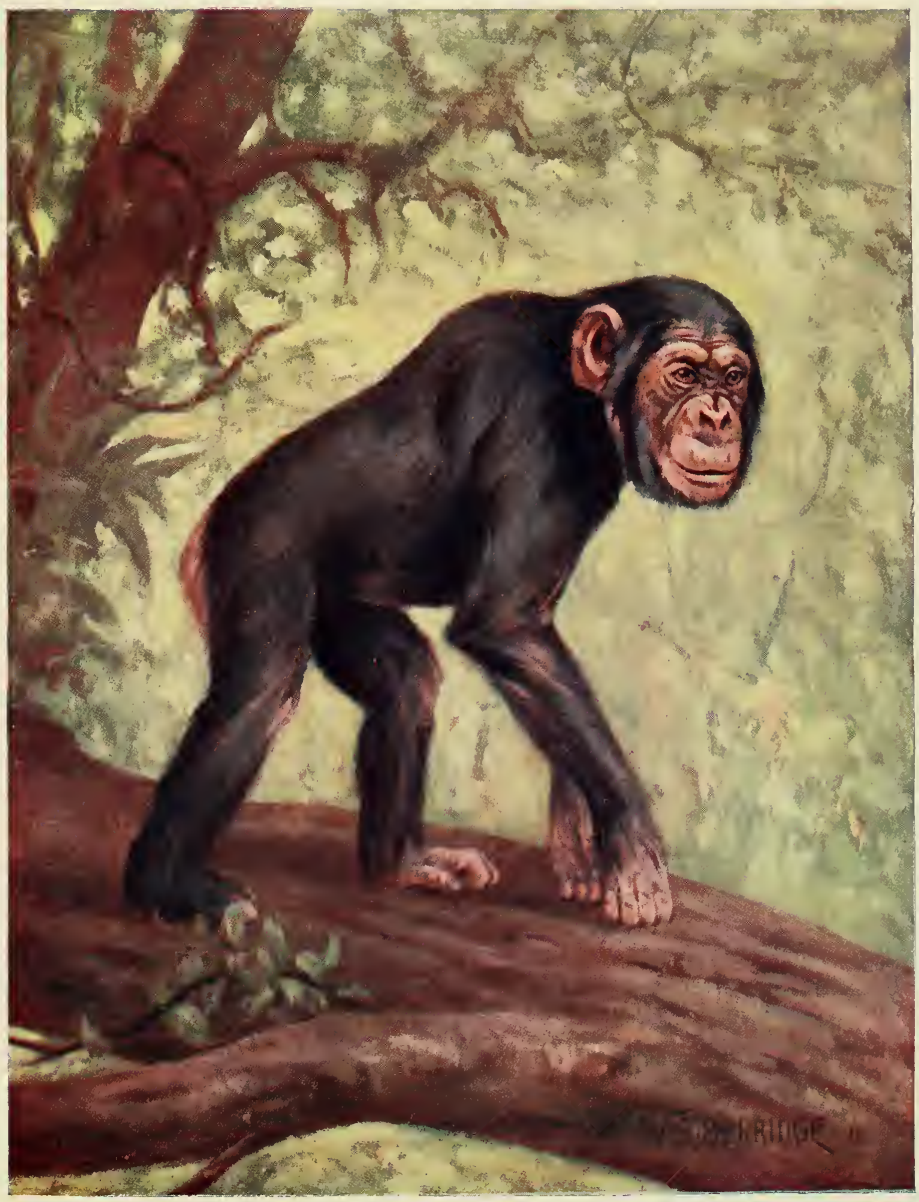

CHIMPANZEE. 

some of its relatives, and is a wary beast, difficult to stalk in its wild fastness. Its food consists of soft fruit, but it will not disdain such delicacies as honey, larvæ, and even birds. Where the beasts frequent a tract of country upon which agriculture is practised, the crops often suffer from their ravages, the animals banding together and making a raid upon corn, banana, and other plantations, and as they are mostly nocturnal, it is difficult on this account, and also because of their watchfulness, to effect a capture.

It is very sensitive to cold, and great care has to be exercised in keeping it in captivity, although it is true that it endures the changeable English climate better than its other anthropoid relations. It is at all times an interesting animal to make friends with, and visitors to our and other Zoological Gardens will have made acquaintance with such famous Chims as Sally, Micky, Consul, and others. Whilst Chims exhibit a certain intelligence, there is a decided limit to their powers, which at once cuts them off from the keen perception and intellectual capabilities of mankind, and although they go through various tricks with a cleverness which is bound to attract attention, there seems little doubt that the author of The Handy Nalural History is right when he states that "these show animals have little claim to real intelligence. They only go through what at best are their tricks while under the watchful eye of a trainer. The cleverest Ape would no more dream of using a knife and fork of its own initiative when feeding, than a caged Lion would of its own free-will amuse an audience by leaping through blazing hoops."

ORANG-UTAN.-The Orang-Utan (Fig. I 20) stands about four and a half feet in height, and makes its home in the densely wooded and well-watered districts of Borneo and Sumatra. Possessing a facial resemblance to the Chimpanzee, it is distinguished from it by being clothed in a rougher coat of shaggy hair, and is much more arboreal in its habits. It is, as its Malayan name of Orang-Utan implies, a man-of-the-woods, frequenting the tops of the tallest trees of the aboriginal forests.

In colour the shaggy coat is reddish-brown, and this is stated to harmonize with the bark of the trees the animal frequents, thus affording excellent protection to the defenceless young ones. The profusion of hair with which the body is clothed, and especially the back, ably protects the Orang from tropical rains, as, in consequence of its habit of assuming a semi-erect posture, it exposes its back parts 


\section{THE BOOK OF THE ANIMAL KINGDOM}

to the rain, and thus the necessity for greater protection than on other portions of the body.

Like other Apes, the Orang also has the habit of holding its hand over its head to ward off rain. Some of the hairs are very long, those on the shoulders and upper arm attaining a length of sixteen to twenty inches.

In the giant tree-tops this animal is at its best, revelling in its arboreal home, and performing wonderful feats difficult of accomplishment. It can swing its way through the thick, impenetrable forest with remarkable adroitness and ease, and its mobility has often been commented upon by those who have had the good fortune to watch it at work and play in its own native fastness.

Fig. I 20 shows the hands to advantage, and these, it will be noticed, are very similar to those of the reader, excepting that the

- fingers are longer and the thumb shorter. It is by means of these long fingers that the Orang is able to secure a firm hold of the treebranches among which it lives. The feet are also of great assistance in climbing, as the large toe is comparable to the thumb of the human hand, and can be much distended, so that the beast can obtain a sure grip of the trees among which it is traversing.

The feet are decidedly hand-like in general form, and are of immense aid to the Orang, not only in its progressive movements in the tree-tops, but also in procuring food, for, having anchored its body by means of them, it has its hands free, and can thus secure fruit and leaves from pliant branches which it could not otherwise reach, even although the arms are of great length. It is the enormous arm-stretch which is of such assistance to this typical arboreal mammal, for it is thus able to walk down branches in a slanting direction. This would not be possible if its arms were no longer than those of a man, for, "in consequence of the forward displacement of the centre of gravity, it would be exposed to the danger of falling like a Hare running downhill."

Ungainly when upon the ground, it will at once be seen that much exertion is necessary to proceed from tree to tree and to travel any distance through the forest, and this means that the Orang must be possessed of enormous strength. Thus we find that the arms are the chief organs whereby locomotion is carried out, and that they bear more powerful muscles than the hind-limbs. And although this animal is only an adept in the tree-tops, and makes such a sorry show when upon the ground, it is interesting to observe that Man 


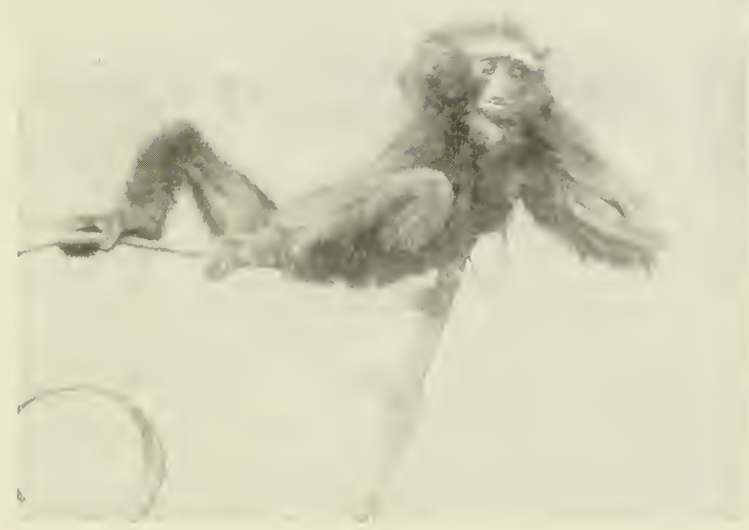

FIG. I 2 I.--HOOLOCK GIBBON

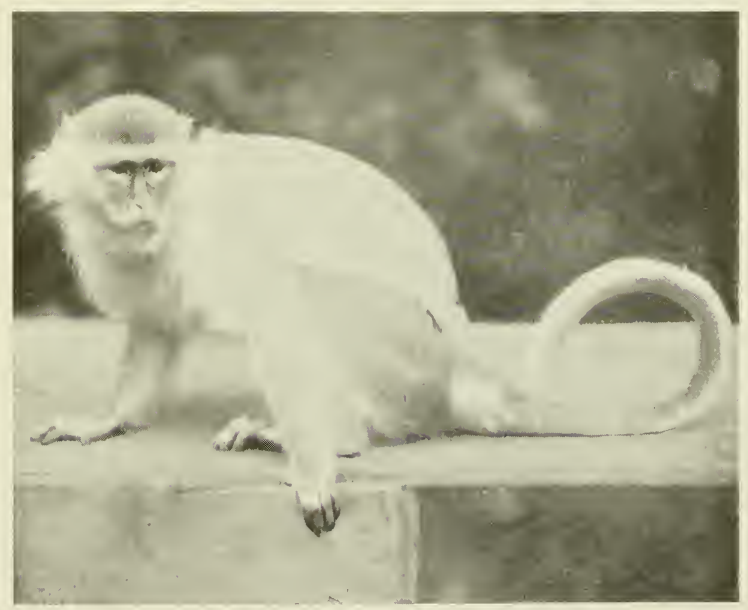

FIG. 122.-VERVET MONKEY 


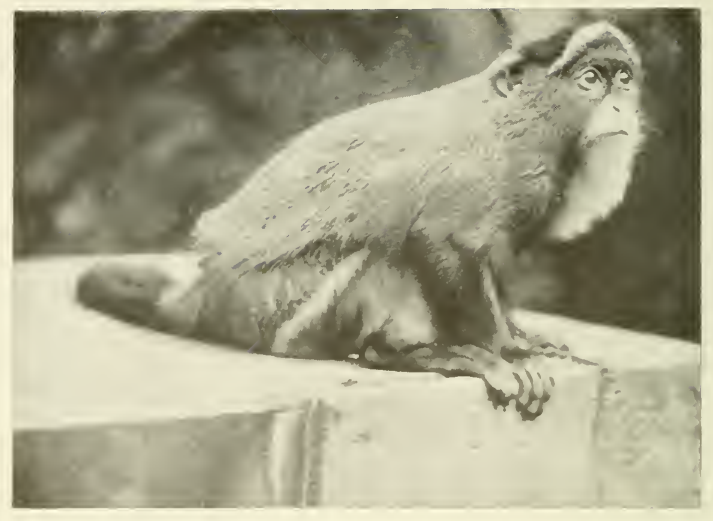

FIG. I23.--BR.AZZA'S MONKEY

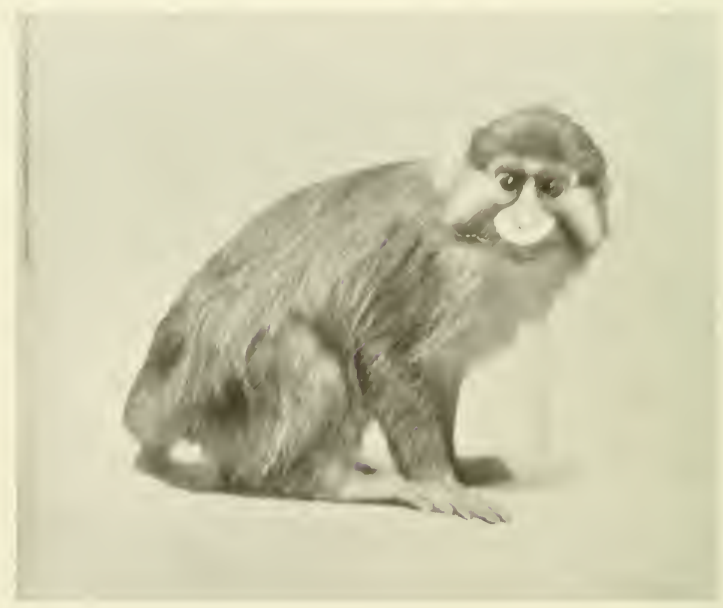

FIG. 124 - MOLSTACHE MONKEY 
-the nearest living relative, and the highest of all known animalsis, on the other hand, remarkably adapted for a many-sided existence, of which examples need not, of course, be detailed.

Feeding for the most part upon young leaves, juicy fruits and buds, the Orang spends a pleasant time in its forest home; it rarely needs to come to the ground for water, as the moisture of its tropical environment supplies it with the necessary sustenance by means of the succulence of its food, and the rain which descends from above. Then, living high up out of reach, what enemies has this inhabitant of the aboriginal forest to contend with? The Python appears to be its chief aggressor in the forest, and when its foodsupply does fail it in the tree-tops, the Ape comes to ground, proceeds to some luscious river-bank, and there encounters the Crocodile. Both these enemies are, it appears, more often than not successfully overcome. The huge Snake is pounced upon, held securely by the powerful hands, and bitten to death, whilst the Crocodile is beaten both with the hands and feet, the flesh is torn from the body, and the animal killed, or, as sometimes happens, the jaws and throat are torn asunder, which, of course, means instant death.

It has a strong voice, for it is one of the chief sentinels of the jungle, and Man is rarely able to emerge successfully from a close contact with such a powerful adversary.

The female is a solicitous mother, and produces one young one every year. That this is not a lazy beast is proved by the fact that "every evening the Orang-Utan builds a nest out of branches and leaves in the fork of a tree, in which it passes the night."

HOOLOCK GIBBON.-The Gibbons represent the last genus of the Man-like Apes, but they are to be distinguished from the species so far considered by reason of their smaller stature-the largest of all only attains a length of about three feet-less powerful build, and longer arms. They are also able to walk on the ground in an upright position, either with or without the aid of their long arms.

Gibbons are inhabitants of the warmer parts of South-Eastern Asia, and whilst there are several species, it will be sufficient for our present purpose to deal with the Hoolock Gibbon (Fig. I2I).

This, like its other relatives, is an arboreal Ape, and is also known as the White-Browed Gibbon, from the prominent band of white or grey on the forehead. The specimen figured came from India, and it is the only Gibbon there found. The general colour 


\section{I62 THE BOOK OF THE ANIMAL KINGDOM}

is anything from light yellowish-grey to black, the males being, as a rule, the darker of the two sexes.

It is an active little beast and of docile habits, allowing itself to be tamed and kept as a pet in a very short time after capture. When the climate of Southern Europe was far more tropical than it is to-day, some species of Gibbons undoubtedly lived in the dense forests of a by-gone age, for fossil remains have been found which prove the existence of these animals in tropical times, and it is interesting to notice that there is no evidence of the existence of any Gibbons in Europe after the middle or miocene division of the Tertiary period (see page $34 \mathrm{I}$ ), although it should be pointed out that many different kinds of Monkeys existed until much later than the period mentioned.

VERVET, BRAZZA'S AND MOUSTACHE MONKEYS.-The Vervet Monkey (Fig. I22) and Brazza's Monkey (Fig. I23) are both African species, and need only be mentioned in passing, although the somewhat striking appearance of Brazza's Monkey is worthy of note. The native name for this Monkey in the Cameroons is "Avut" or "Fum." The Vervet, or Malbrouck, is at once distinguished by the very distinctive red root and black tip of the tail and the black of the chin.

This brings us to the Moustache Monkey (Fig. 124), which also belongs to the Guenons group. The members of this group are all African species, and are distinguished by the possession of cheek pouches, simple stomachs, and arms and legs of almost the same length.

These Guenons travel about in troops; they are strictly arboreal, and are famous for the continuous chattering which they keep up. That these are Monkeys of ancient origin is proved by the fact that the sculptures of the Egyptians bear the likeness of either Guenons or Mangabeys upon them, the last-named being the next group of Monkeys with which we shall make acquaintance.

The Moustache Monkey, an apt representative of this important group, is characterized by the yellow whiskers and a triangular blue mark upon the nose. In general colour it is olive-green, speckled with yellow; it is grey upon the throat and under-parts, black on the face and temples, with blackish feet and hands.

PATAS MONKEY.-The Patas Monkey (Fig. I25) also belongs to the Guenons, the specimen shown in the photograph having been obtained from its only home in Senegambia. It is also known as 
the Red Monkey, and in this lies the distinguishing difference between it and most of the other members of the Guenons, the species now under consideration having red fur on most of the body, with a blackish nose, and the same colour on the forehead and the outer surface of the arms. The large blackish ears bear beneath them shaggy patches of light-grey hair, as Fig. 125 depicts, and these bushy tufts, extending on to the cheeks and lower jaw, almost hide the naked parts of the face. The under-parts of the body, as also the inner sides of the limbs, are greyish, whilst the hands are dusky brown, and bear short fingers, the thumb being quite rudimentary.

RED-EARED AND SCHMIDT'S MONKEYS.-A happy snapshot at the London Zoo of the Red-Eared and Schmidt's Monkeys is shown in Fig. 126, the first-named being on the left and the latter on the right.

The Red-Eared Monkey comes from IVest Africa, and has a red patch on the nose; red ear-fringe; greyish-black legs and a red tail, except on the upper part of the base. These are the distinguishing features.

Schmidt's Monkey (of which there appear to be two or three sub-species) is an inhabitant of the Congo region. It is peculiar in having a white tip to the nose, and animal dealers term some, if not all, of the members of this group "Putty-Nosed Monkeys"!

The Red-Eared and Schmidt's Monkeys shown in Fig. I 26 lived together at the London Zoo, and were great friends. Whenever they were taken out of their cage they invariably cuddled one another, as exhibited in the picture.

ROLOWAY MONKEY.-The Roloway Monkey (Fig. I27) is often mistaken for the handsome Diana, to which it is very similar, and a few particulars of which will not be out of place at this juncture. The Diana, it is as well to notice, also claims kinship with the Guenons, and is mostly prominent because of the long, pointed white beard, which, it will be observed, is also very characteristic of the Roloway shown in Fig. 127. On the Gold Coast the Diana Monkey is more generally known by the name of Roloway in the districts it frequents, but on the Congo it is called the Exquima. It is an inoffensive and docile animal and becomes easily reconciled when kept in captivity. It makes an affectionate pet, but has been proved to possess a better temper during its youth than when it attains a greater age, and appeals to one much more during its early career than when it has become adult. 


\section{I64 THE BOOK OF THE ANIMAL KINGDOM}

MANGABEYS. - The Mangabeys, or White-Eyed Monkeys, as they are also called, acquired the first name mentioned because the great French naturalist, Buffon, was of opinion that they came from the Manongabe or Mangabe district of Madagascar, whereas, as a matter of fact, they consist of a small group of West African species. They are represented in the illustrations by Hamlyn's Mangabey (Fig. 128) and Jamrach's Mangabey (Fig. I 29). They are closely related to the Guenons, but are separated from that large group of Monkeys by reason of the structure of the teeth, which resemble the Macaques in this respect. Beyond this, the prominent white eyelids at once serve to distinguish them, as well as the oval-shaped head, long muzzle, and hairs not ringed with various colours as in the Guenons.

Other species that may be mentioned in addition to the two already referred to are the Sooty Mangabey, which is deep, dull black in colour, with the chin and under-parts ashy, the face being livid and blotched with dark-brown. The hair on the top of the head is not carried in the form of a crest. The IVhite-Collared Mangabey is blackish-grey, with a white collar round the neck, and the same colour on the cheeks, throat and chest. The WhiteCrowned Mangabey derives its name from a white-spotted crown, and also has a streak of white along the centre of the back, whilst the Grey-Cheeked Mangabey is at once identified from its relatives by having the hair on the crown elongated into a crest. It is blackish for the most part, acquiring its name from the greyish colour of the throat-sides and cheeks. Thus we see that the four species last mentioned have all been accorded English names because of the colour of, or markings upon, the body, whilst the two remaining species (Figs. I $2 S$ and I29) have been named after the well-known animal dealers, Messrs. Hamlyn and Jamrach. Both these species are interesting because they are recently discovered Monkeys. Both kinds are white, and Hamlyn's Mangabey has a curious freckled face. The two appear to be doing well at the London Zoo, and share the same cage. Hamlyn's Mangabey came from the Upper Congo, and Jamrach's Mangabey from Central Africa. All these Monkeys are of arboreal habits, living in troops in the forest, and feeding chiefly upon various fruits. They appear to be of active disposition, and in captivity become docile and entertaining.

JAPANESE MACAQUE.-This species (Fig. 130) introduces us to the Macaque Monkeys, which are Isiatic species. They are more 


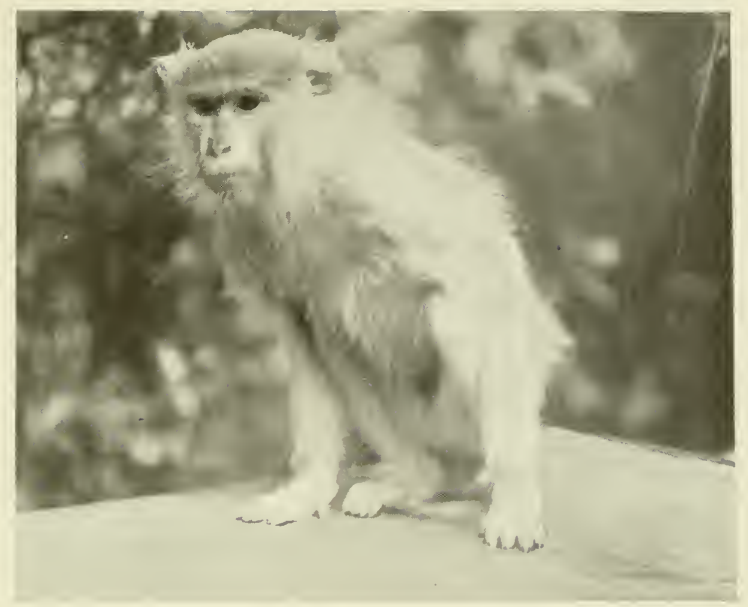

FIG. 125.-PATAS MONKEY

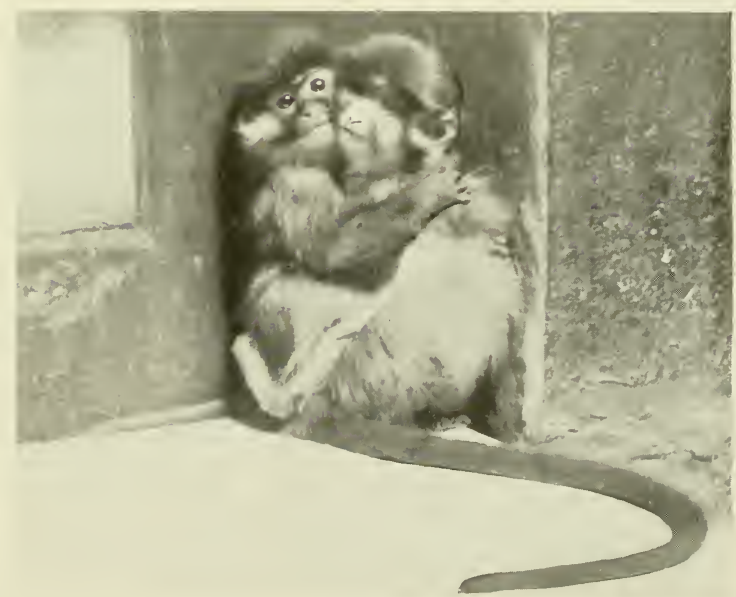

FIG. I 26. -RED-EARED (LEFT) AND SCHMIDT'S (RIGHT) MONKEIS 


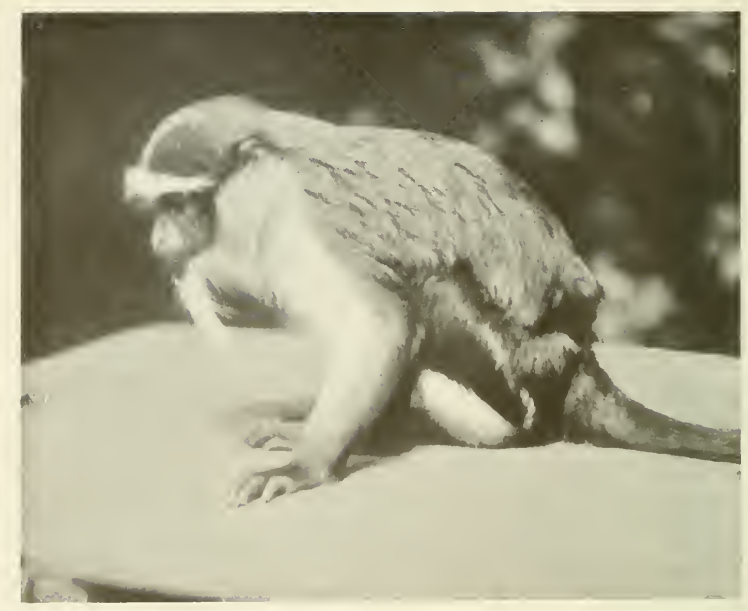

FIG. I 27.- ROLOWAX MONKEY

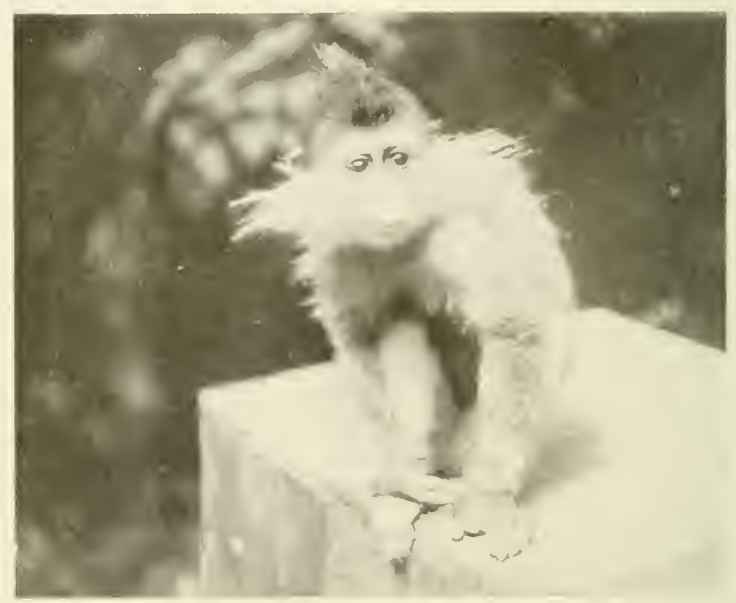

FIG. 1 28 H.MHIN'S MANGMBEY 


\section{MONKEYS, APES AND THEIR KINDRED I65}

stoutly built than the Mangabeys, but in many respects are closely allied to them. The body is thick-set, the limbs short and stout, and the thumb is set backward. The tail is worth mentioning because it is either short or long, or a mere apology for an appendage of any kind! Some species have long hairs on the head, from which they radiate in various directions, whilst others have the face almost covered by a sort of mane. It is interesting to observe also that in some kinds inhabiting northern countries the fur covers the whole of the body, as an able protection against the cold. Dr. H. O. Forbes says that "the Macaques are among the commonest Monkeys of India and the East Indian islands. They occur also in Northern Africa (Morocco) and in Gibraltar, across the Straits. Eastwards they extend into Tibet and Northern China. They are also found in Sumatra, Java, Borneo, Celebes, and in Timor."

They move about in companies, and resemble each other in habits. They are active in disposition, and feed not only on fruits, but also insects, and one species lives on crustacea. They have also been known to partake of Lizards and, it is stated, Frogs.

Only one young one is, as a rule, produced at a birth, and this reaches the adult stage in the course of four or five years' time.

The male and female Japanese Macaques (Fig. I30) are shown, together with the single young one, one of the parents being engaged in an operation which does not need any explanation. The interested look of the youngster is worthy of attention. It is sitting on the top of its father for warmth, having been born at the Zoo in an outdoor cage during cold and frosty weather. This species is found, as its name implies, all over Japan, and it is interesting to note that it has "a further northern habitat than any other existing Monkey." The general colour of the fur is dark-brown, yellowishbrown, or olive, the hairs being ringed with either brown and yellow, or brown and black; the sides of the head, breast and underparts are greyish, and the beard is yellowish-brown. The living animal has a naked purplish-red face, with a prominent muzzle, whilst that of the young is pale-pink.

MOOR MACAQUE.-This Macaque (Fig. I3I) is only found in the Southern Peninsula of Celebes, but in the photograph looks perfectly at home in confinement, being busily occupied eating a carrot. The Celebes Islands are in the East Indies, to the east of Borneo, and although it was conjectured for a long time that the home of the Moor Macaque was in Borneo, this has now been proved incorrect. 


\section{I66 THE BOOK OF THE ANIMAL KINGDOM}

It has, as Fig. I3 I shows, a narrow, elongated and naked face, with a flat nose and prominent round ears. The general coloration is sooty-black above and grey below. The length of the body is about twenty-one inches, and the short tail measures only one inch. The black face distinguishes this species from the Brown and Japanese Macaques, the faces of those beasts being bright red.

PIG-TAILED MACAQUE.-This excellently-named Macaque (Fig. I32) is found in Tenasserim, Southern Burma, the Malay Peninsula, Bangka, Sumatra, Java and Borneo. It is so called, of course, because of the pointed tail, which is eight inches in length and carried in an erect position, the length of the body being about eighteen inches. It is thus a good-sized Monkey, and, as Fig. 132 displays, it has a broad head, a long muzzle, powerful limbs, short fur, that on the head standing erect, and giving it the appearance of the head of a close-cropped school-boy. The fur is mostly olive in colour, with the hairs grey at the base, and ringed alternately with yellow and black; the deep-brown or blackish-brown head is relieved by the blackish-grey sides of the face, whilst the under-parts of the body are greyish-white.

The Pig-tail is an inhabitant of low-lying countries, and goes about in large troops, feeding upon fruits, seeds and insects. It is recorded that this is an easily tamed Monkey when taken young, and has been used for climbing coconnut-trees to throw down the nuts, and it is specially worth noticing that we are told it is only the ripe fruit that the Macaque is taught to handle.

OTHER MACAQUES.-Mention may here be made of other prominent members of this interesting and large group of Monkeys, such as the Bonnet Monkey, which has a prominent crest of hair on the crown of the head; the Crab-Eating Nacaque, which feeds largely on crabs; the Lion-Tailed Monkey of Western India, which has an enormous grey beard and ruff almost surrounding the black face; the Bengal, or Rhesus, Monkey, which, unlike the last-named, does not possess any trace of either a beard or ruff, and is distinguished by the erectness of its hair, and being probably the best known of all the Macaques; the Brown Stump-Tailed Monkey, which, as the name indicates, has quite a rudimentary caudal appendage, and the Magot, or Barbary, Macaque, which does not possess a tail at all! Thus, from the lengthy tail of the Bonnet Macaque, measuring almost, if not quite, the length of the whole body, one can trace in an interesting way the gradual disappearance of the tail, 


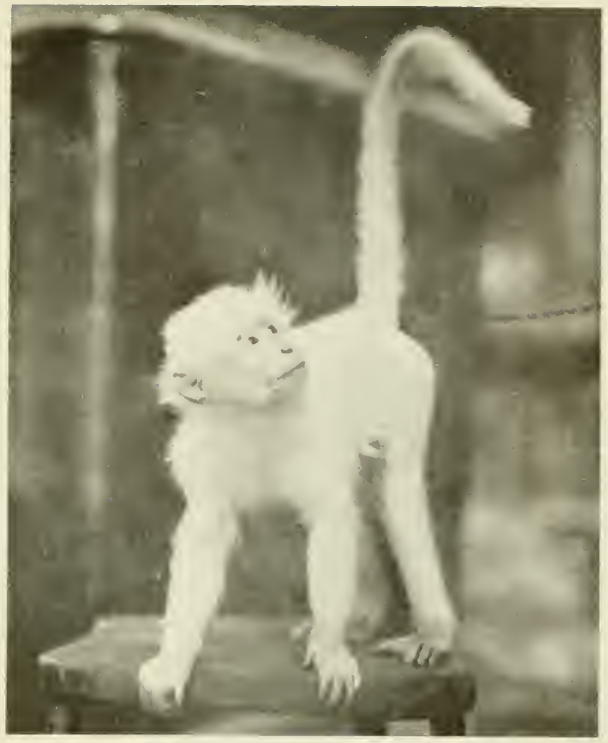

FIG. I 29. - JAMRACH'S MANGABEY

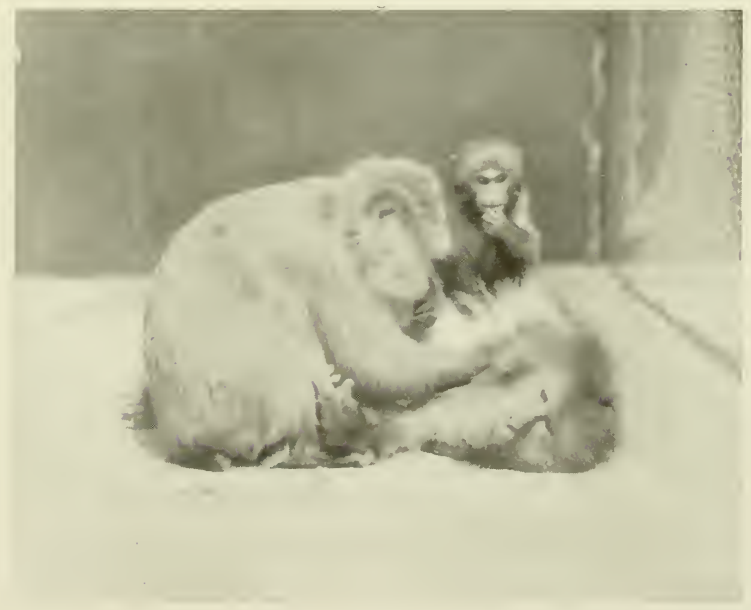

FIG. I 3O.-JAPANESE MACAQLES AND YOUNG 


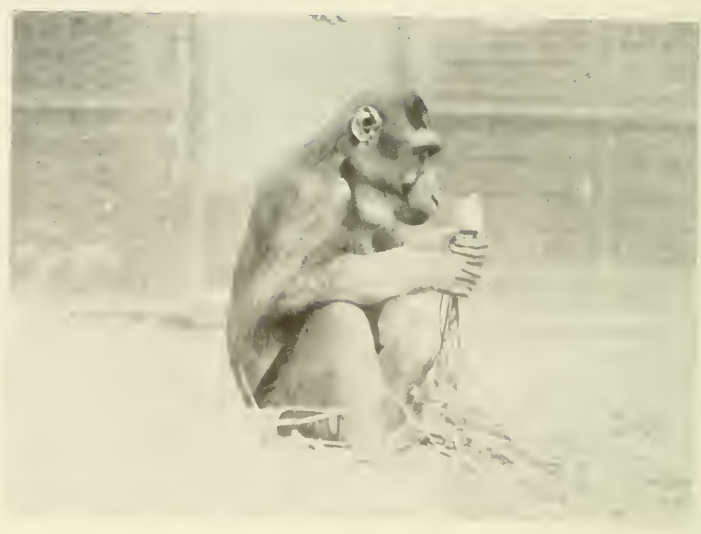

FIC. I3I. MOOR M.IC.IQLE

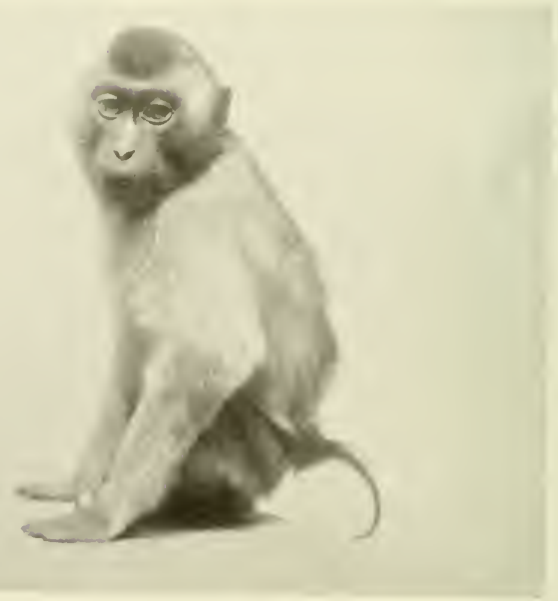

FJG. I.32. PIG-TAIIFI M.AC.IQLE 


\section{MONKEYS, APES AND THEIR KINDRED ${ }^{6} 67$}

for, after leaving the Bonnet Macaque, we come to the Bengal, or Rhesus, thence we follow on to the Pig-Tailed, already described, and eventually, after making acquaintance with the Brown StumpTailed Monkey, as representing the stump-tailed group of Macaques, we come, last of all, to the Magot, or Barbary, Macaque, in which the tail is totally absent.

DUSKY GELADA BABO0N.-Three kinds of Baboons are represented in the illustrations, namely, the Dusky Gelada (Fig. I33), the Guinea Baboon (Fig I34) and the Ibean Baboon (Fig. I35). Before treating of these specifically, a few notes may be given of the general characteristics of these curious members of the Monkey tribe.

Baboons are to be reckoned as the lowest of the Old World Monkeys; they are for the most part big, powerful beasts of a ferocious disposition; they are quite gregarious, and give vent to their feelings when alarmed or disturbed in no uncertain manner, uttering barks, screams, and other noises of a peculiar kind.

They possess Dog-like faces, with fore and hind limbs of almost equal length; long feet, and hair which is ringed or grizzled with different colours. They are wary beasts, and do an immense amount of damage not only in gardens and among growing crops, but also to Sheep. They also feed upon fruit, insects and Lizards. They chiefly resort to the ground, showing special preference for rocky and barren hills, not being well adapted for climbing trees, although sometimes frequenting the same.

Baboons are confined to Africa and Arabia, and Darwin has observed that they show their anger in two curious ways, namely, by striking the ground with one hand, "like an angry man striking the table with his fist," and "by opening their mouths widely as in the act of yawning." The Dusky Gelada (Fig. I33) and the Gelada Baboons are placed in a separate genus from the true Baboons because they have "the nostrils placed on the side of the snout, instead of being terminal and opening, Dog-like, on the blunt face of the truncated nose." The first-named species inhabits North-East Africa as well as "the eastern boundary of Abyssinia, near the sources of the Takazze river, on the confines of the Galla country," and has also been observed near Magdala. It is darker in colour than the Gelada Baboon, hence its name of Dusky, and has a ring of flesh-colour encircling the eyes, and two naked spots on the chest, surrounded by white hairs which extend to the inner side of 
the arm. The black, naked face; small, deep-set eyes; small ears; long mane, and bluish-grey callosities are also worthy of note. The beast measures over four and a half feet in length, excluding the tail, which extends to about twenty-six inches.

It is in the high Abyssinian mountain ranges that the Dusky Gelada makes its home. Here, among rocky fortresses, it is mostly secure from enemies, the large Vulture known as the Lämmergeir being one of its chief aggressors. If Man stalks it within striking distance, it is a dangerous animal to encounter, and the beast will resort to hurling stones at any one who dares to attack it. At nighttime it hides amid the shelter of the rocks, and before proceeding to take part in marauding expeditions in the fields, it comes forth from its hiding-place and suns its body after the night's repose.

GUINEA BABOON. - The Guinea Baboon (a small family party of which are shown in Fig. 134) is an inhabitant of West and East Africa. It has a tapering snout; naked black face, ears, palms, and soles of the feet; bushy whiskers; brownish-yellow head, back and limbs; fawn-coloured cheeks and whiskers; and is paler on the throat and under-side of body.

IBEAN BABOON. - This Baboon (Fig. I35) is a variety of the Chacma Baboon of South Africa, where it is found in large troops, and I do not think I am giving away a secret in stating that the beast has been accorded its name of IBEAN because the initial letters stand for Imperial British East Africa.

It resembles the Chacma in its general appearance and habits, this being the largest of all the Baboons. It resorts to rocky environments, often in the vicinity of the sea, and although both ferocious and dangerous, is stated to be very intelligent. It exhibits a remarkable sense of smell, "especially for hidden water-springs in dry and arid districts," and lives, like its relatives, in companies, which are often made up of a hundred animals. The Chacma is dark-brown or almost black in colour, with a green wash; the hairs are grey at the base, ringed alternately with green and black; the head, arms and legs are black, whilst the face, hands, feet and ears are dark-blue. The eye is surrounded with a ring of white; the upper eyelids are white, and the whiskers grey.

VARIEGATED SPIDER MONKEY.-This Monkey (Fig. I36) is very brilliantly coloured, and has a very wide distribution, "which extends from the upper reaches of the Amazon in Peru to the banks of the Rio Negro, flowing from Venezuela into the lower portion of the Amazon, and northwards into the Andes of Ecuador and Colombia." 


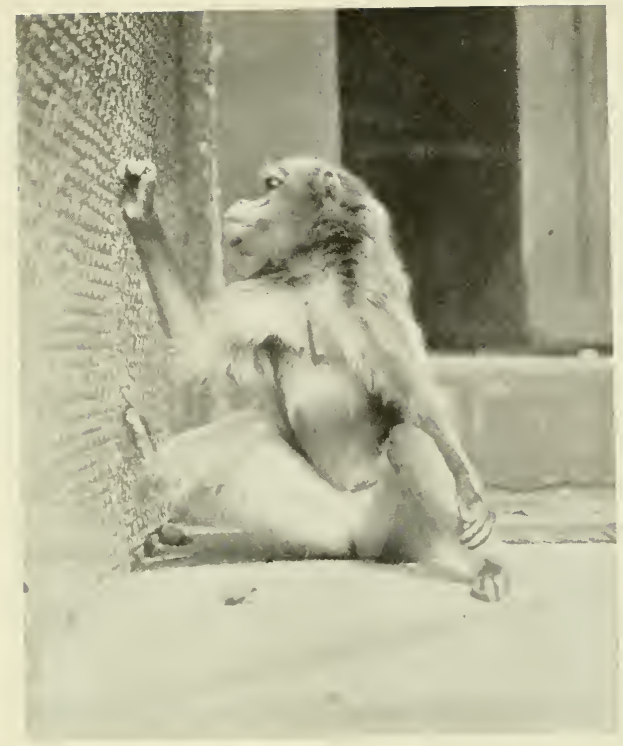

FIG. I 3.3 -DLSKY GELADA BABOON

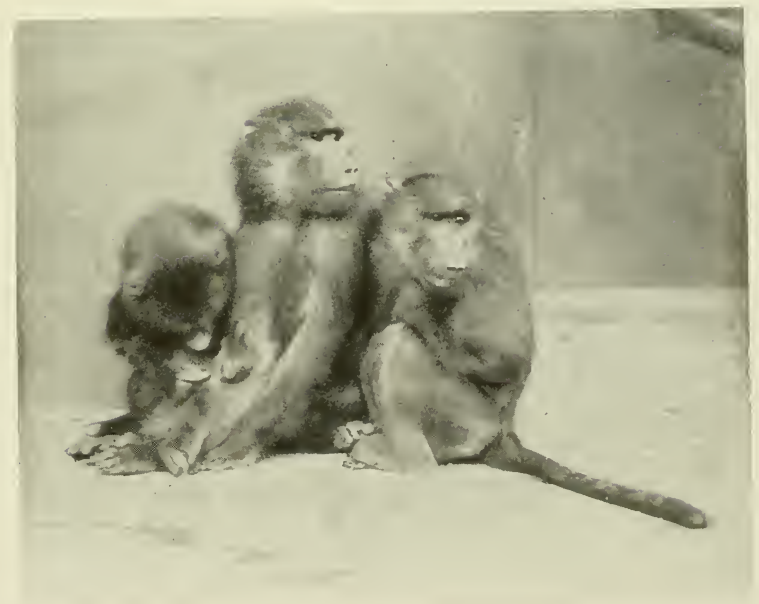

FIG. I34.-GUINEA BABOONS 


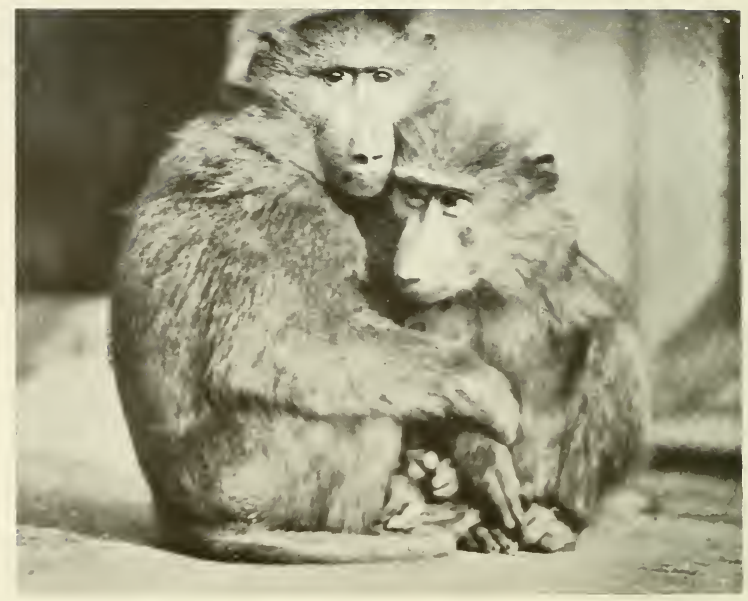

FIG. I35. -IBEAN BABOONS

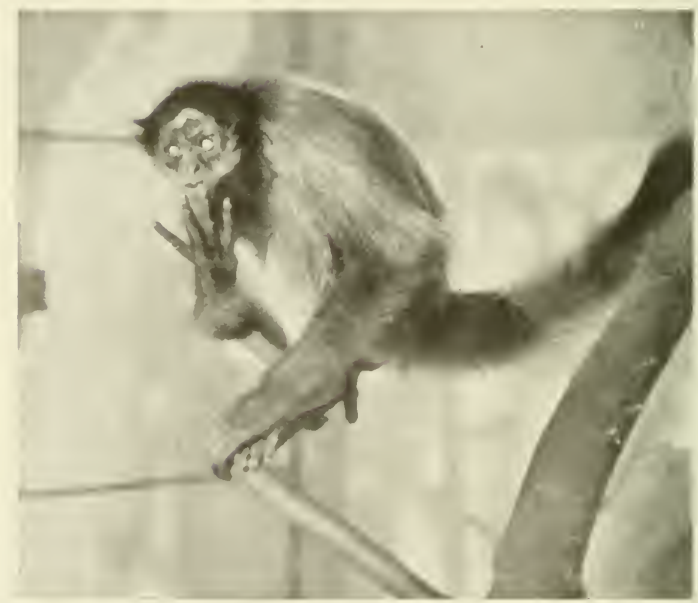

FIG. I 36. - VRIEC.ITEL SPIDER MONKEY 
It was first discovered on the Rio Negro, being described by Wagner, the German naturalist, but it was not until 1870 that the first living specimen reached England, and this only lived a month. It has long, thick black fur, which is very soft, and white cheeks. Across the forehead there is a bright reddish-yellow band; the underneath is greyish-yellow in the female and yellow in the male, and, as Fig. 136 clearly portrays, the eyes are very prominent, being pale blue in colour.

It is an inhabitant of the forest, travelling about in small companies. Active in disposition, it must be a fine sight to observe the male in his brilliant dress in his native wilds. The food consists of berries.

BLACK LEMUR.-The Lemurs are a most interesting family of Monkeys, divided into four sub-families, and of these we have representatives in the Black Lemur (Fig. 137), Dwarf Lemur (Fig. 138), Grey Slow Loris (Fig. 139), Slender Loris (Fig. 140) and Maholi Galago (Fig. I4r), whilst it is proposed to finish this section of our work by referring to the Douroucolis (Fig. I42), which are small animals somewhat Lemurine in appearance.

The distinguishing characteristics of the typical Lemurs are the thick woolly fur; the Dog-like snout and nostrils, and the structure and number of the teeth. The true Lemurs-to which the Black Lemurs shown in Fig. I37 belong-have small oval ears profusely clothed with long hair; the fore and hind limbs are of about the same length; and the tail is long and bushy. Among these true Lemurs may be found some of the most brilliantly coloured of living animals. They are of social habits, and although some kinds do not lead an arboreal life, the majority do so.

Unlike the other members of the Lemurinæ, these true Lemurs are not nocturnal, but feed at morning and evening, resting during the heat of the day and sleeping at nightfall, "with their long tails coiled about them." They progress on all-fours, and differ in this respect from most of their relatives, and feed upon fruit, birds and their eggs, and also insects. These true Lemurs all inhabit Madagascar and the Comoro Islands, lying in the west of the Indian Ocean.

Solicitous for the welfare of her young, the female carries her babies about with her, they being hidden among the thick hair of her breast; when, however, the youngsters are too big to be thus pampered, they adhere to the mother's back.

The Black Lemur is an inhabitant of the North-West coast of 


\section{I70 THE BOOK OF THE ANIMAL KINGDOM}

Madagascar, and whilst the young females possess the colour of the mother, the young males resemble their father. The colour of the male is quite black, as Fig. I 37 shows, the general colour of the female being rich ferruginous brown, with the arms, legs and neck reddish-yellow, and the throat and under-parts creamy-white.

DWARF LEMURS.-The Dwarf Lemur (Fig. ${ }^{1} 38$ ) is a tiny creature belonging to a different genus from the last-mentioned species, and these Dwarf Lemurs have the distinction of being the smallest of the Monkey tribe, to which, of course, they belong.

In size they are inferior to the common Brown Rat, as can be ascertained by a reference to the photograph, in which some grapes in the foreground will serve as a comparison.

Most nocturnal animals are characterized by the large size of the eyes, and in the case of these Dwarf Lemurs we find no exception to the general rule, for by means of these prominent bright organs of sight the little beasties are able to distinguish small objects in the dark. Their food consists principally of insects and fruit. The hind-limbs are longer than those in front; the snout is short, and the ears elongated.

There are five species of Dwarf Lemurs, known as the Small Dwarf Lemur, which is the smallest of all the Lemurs; the Dormouse Dwarf Lemur, which has a round, Cat-like head, and is redder in colour than the last-named; Smith's Dwarf Lemur, a rare species, which has apparently not been observed to any great extent; the Fork-Marked Dwarf Lemur, which is reddish-grey, and distinguished by "the black dorsal streak bifurcating on the forehead into two branches, extending on the inner side of the ears and terminating over each eye," and a fifth species known as Coquerel's Dwarf Lemur, or, as it is called by the natives, the "Sisiba," which resembles the Fork-Marked kind, but is somewhat smaller.

GREY SLOW LORIS.-The Slow Lemurs constitute a separate sub-family known as the Lorisinæ, one genus being represented in Asia and the second in Africa. These Slow Lemurs have soft woolly fur; a pointed face; large piercing eyes not far removed from one another; and fore and hind limbs of about equal proportions.

Their distribution in Africa is restricted to the western portions of the great continent, whilst the Asiatic species inhabit India, Malay and Indo-China. The Grey Slow Loris in Fig. I39 came from China. The Slow Loris is ashy-grey on the upper parts, paler underneath, with a silvery back and rufescent rump; there is a 


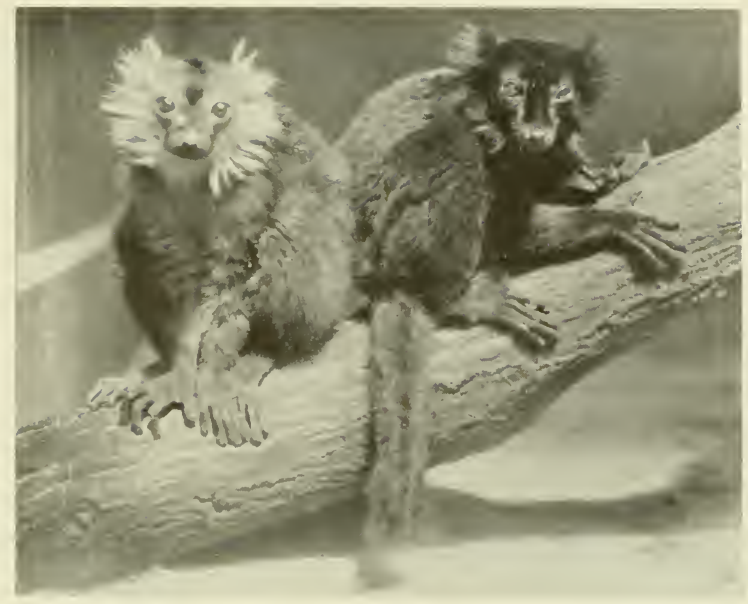

FIG. I37--BLACK LEMLRS (MALE AND FEMALE)

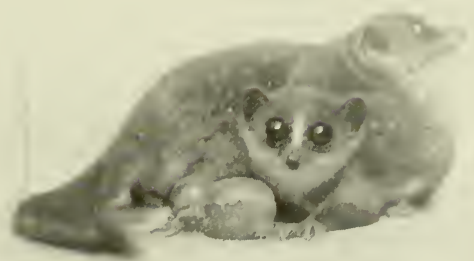

FIG. I 3 S. -DWARF LEMURS 


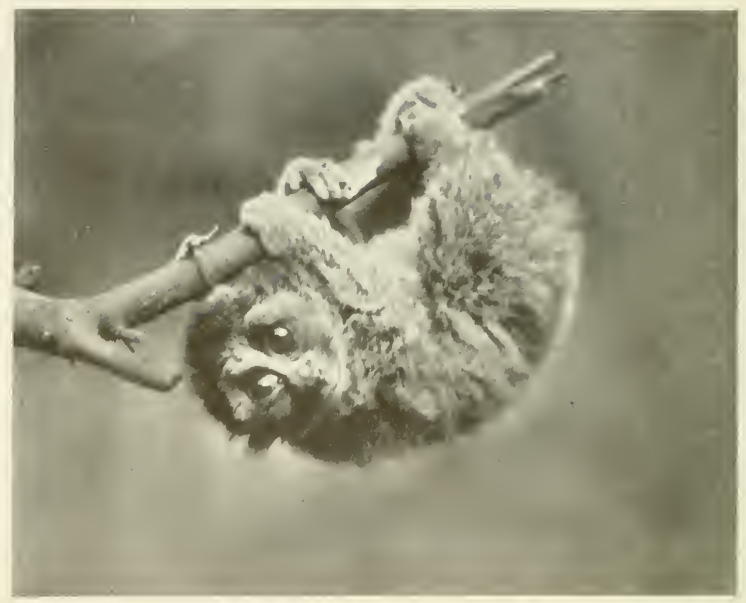

FIG. I 39. GREY SLOW LORIS

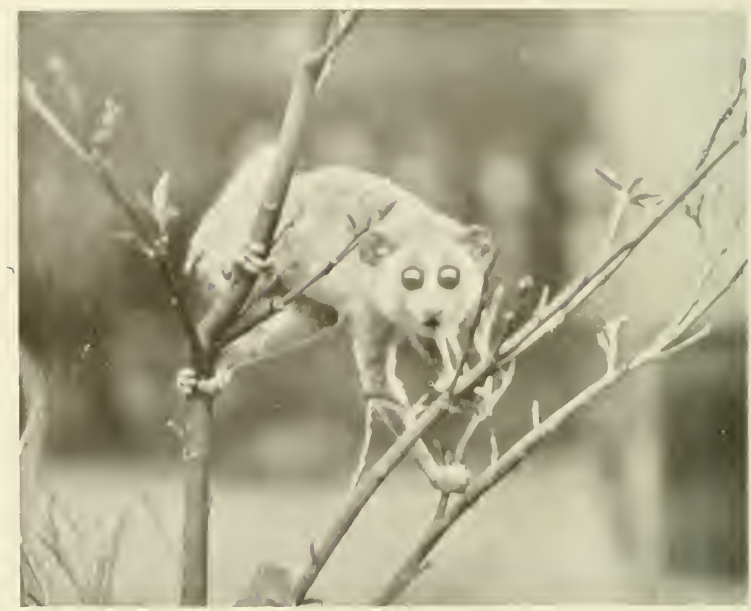

FIG. I HO. - SI.ENDER LORIS 
chestnut-brown dorsal stripe from the crown to the loins; a darkbrown circle round the eyes; and a prominent line of white down the nose and near the eyes. It varies a great deal, however, in both size and colour according to the district it frequents, and so great is the variety exhibited that some zoologists have accorded certain individuals specific distinction. This accounts for the name of Grey Slow Loris being given to the specimen depicted in Fig. I39, the silvery-grey fur of this animal entitling it, in the opinion of some naturalists, to be designated a distinct species.

It is a tree-loving animal of nocturnal habits, and resembles the Slender Loris in this respect. It is not gregarious, either being of a solitary disposition or living in pairs. As its name indicates, it is of slow movement, and differs in a marked manner from the true Lemurs in this respect.

SLENDER LORIS.-The Slender Loris (Fig. 140) is an inhabitant of Ceylon and Southern India, and has been referred to by Dr. Forbes-to whose work acknowledgment is due for a great deal of the information in the latter part of this chapter-as a "curious, emaciated-looking little creature" which "is nocturnal, living entirely in trees. It sleeps during the day rolled up in a ball, with its head between its legs, grasping its perch with its hands. According to Jerdon, these animals are occasionally brought in large numbers to the Madras market, their eyes being a favourite remedy of the Tamil doctors for ophthalmic diseases. In its movements it is slightly more active than the Slow Loris. Its food consists of succulent leaves, honey, insects, birds' eggs and small animals."

This species is so called because of its slender body and limbs, and these are clothed in soft, close woolly fur. The large eyes show up very prominently on the short, round head; the nose is pointed and narrow; and the ears small. In colour it is dingy-grey on the upper parts and greyish-white below. It is eight inches in length, and the young are more rust-coloured than the parents.

GALAGOS AND MOUSE LEMURS.-The Galagos are closely related to the two small animals last under review, and this sub-family of the Lemurs is split up into two groups, the one consisting of those kinds which are found on the African mainland, and the other of those only inhabiting Madagascar, known as the true African Galagos and Mouse Lemurs respectively.

The last-named are represented by the Maholi Galago in Fig. I4I. The Galagos have soft woolly fur; they vary in size; the ears 


\section{I72 THE BOOK OF THE ANIMAL KINGDOM}

are of large size, and the sense of hearing is very acute. The large eyes and elongated tail are also worthy of note. The species found in Madagascar, and known as the Mouse Lemurs, are usually of smaller size than their mainland relatives, and the snout protrudes beyond the lower jaw. Brief reference may be made to the species included under each genus. Among the first genus, namely, the Galagos, we have Garnett's Galago, which is found on the East African coast ; the Senegal Galago, which is a beautiful little Lemur, originally recorded from Senegal in West Africa, but now known to occur in other parts; Allen's Galago, named after Captain Allen, R.N., who first obtained it from Fernando Po in 1837; Demidoff's Galago, which occurs in Senegal, as well as in Central Africa; Monteiro's Galago, which was discovered by Mr. Monteiro in Cino Bay, West Africa; and the Great Galago of the South-East coast of Africa and some parts of the interior, and which the Portuguese call the "Rat of the Cocoanut Palm" because of its habits of "nestling by day among the palm fronds, its ears folded up like a Beetle's wing." A variety of the Great Galago known as Kirk's Galago occurs in the "maritime regions and mangrove forests of the East coast," and has the habit of imbibing too freely if it can obtain access to a pot of palm-wine, becoming intoxicated, and behaving in such a way that it may be easily captured. It thus pays the penalty for breaking the pledge!

There are four species of Mouse Lemurs, and these may be briefly mentioned before we pass on to the Douroucolis. Milius' Mouse Lemur is a rare species about the size of a Guinea Pig; the Black-Eared Mouse Lemur is a much rarer animal still, but closely resembling the last-named; the Hairy-Eared Mouse Lemur; and Crossley's Mouse Lemur, which is very nearly related to the lastmentioned species, and both of which are exceedingly rare, and of whose habits we are at present woefully ignorant.

DOUROUCOLIS.-The last members of the Monkey tribe with which we are here concerned are the Douroucolis, of which an illustration is given in Fig. 142 . These are small creatures, somewhat resembling the Lemurs in general appearance, with a short, thick body; a rounded head; and a short, round face encircled with a whitish ruff. The face is chiefly conspicuous because of the extraordinarily large yellowish eyes; the moderately long tail is bushy, but non-prehensile, and the body is clothed with soft, close woolly fur. 


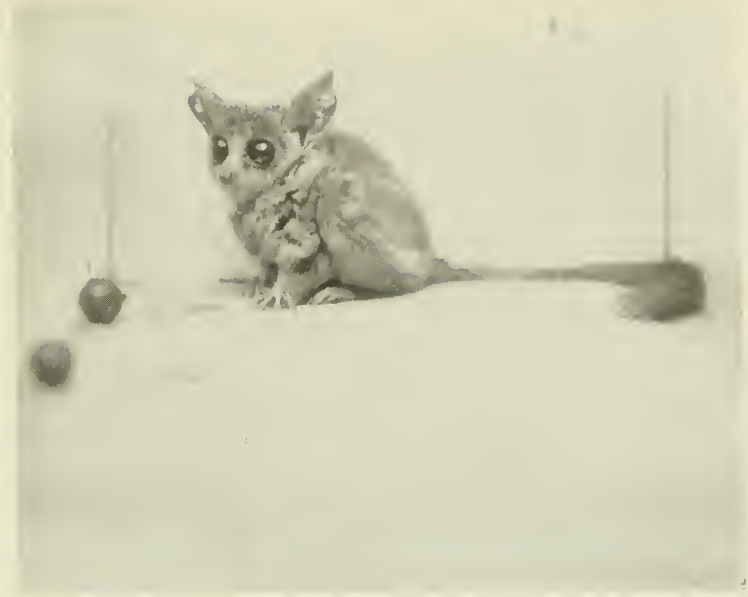

FIG. I 4 I - MAHOLI GALAGO

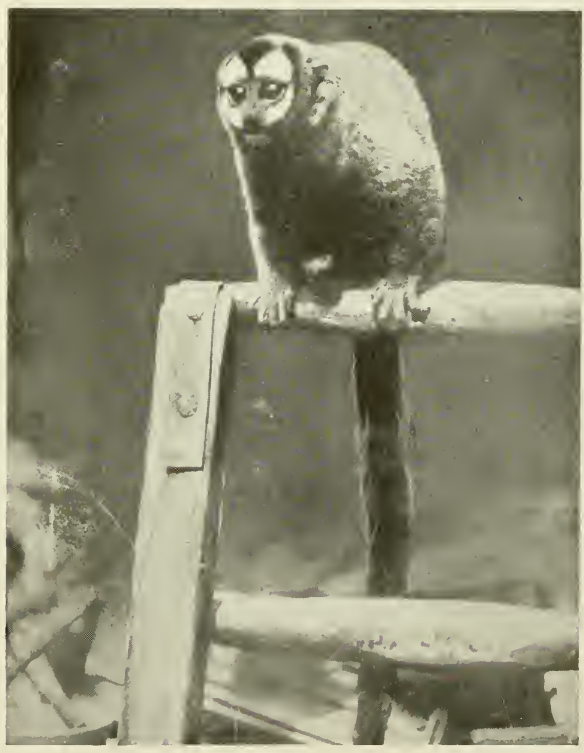

FIG. I 42. DOUROUCOLI 

Douroucolis are nocturnal and arboreal animals; they are eminently vociferous, uttering Cat-like cries or loud howls, and the food is made up of fruit, insects and small birds.

Their range extends "from Nicaragua to the Amazon and Eastern Peru," and the Indians call them "Devil Monkeys." They are difficult to keep in captivity, being of a delicate nature.

Reference may be made in concluding this chapter to the five species included in this genus, namely, the Three-Banded Douroucoli, which has a remarkably loud voice for an animal which is only about a foot in length; the Lemurine Douroucoli, which inhabits Colombia and Upper Amazonia and other parts of North-Western South America; the Red-Footed Douroucoli, whose distinguishing characteristic is sufficiently indicated by its name; Azara's Douroucoli, which is found in the North-East of the Argentine, "but not in Paraguay proper," and the Feline Douroucoli, which is a rare species closely related to the last-named, but to be distinguished by "the three facial streaks, irregular and combining together on the crown, the middle one broad and lozenge-shaped; the frontal spots short and white; fur longer and more woolly; neck, chest, under-surface of body, inner sides of the limbs and the base of the tail yellowish; tail round."

We next proceed to make acquaintance with the mammals of Australia, and in this section I give way to my good friend and brother naturalist, Charles Barrett, whose informative and entertaining sketches will, I am sure, prove of interest and value.

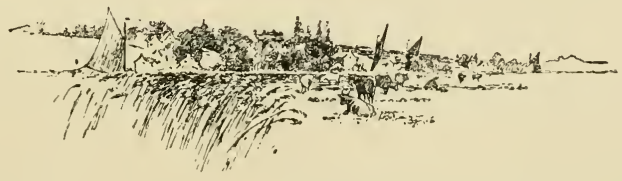




\section{CHAPTER $\mathrm{X}$ \\ MAMMALS OF AUSTRALIA

\author{
BY CHARLES BARRETT, M.A.O.U. \\ (MELBOURNE, VICTORIA) \\ CO-EDITOR OF "THE EMU"
}

INTRODUCTION.-The animals of Australia form a remarkable assemblage of strange types which are of absorbing interest to both the scientific zoologist and the field naturalist. Where else in the world will be found such a variety of forms which present problems for the biologist to solve, and possess curious habits for the consideration of field workers? Many great naturalists have visited Australia and spent more or less time in the island continent studying the fauna; and they have published books giving the results of their investigations. Now, these books often contain much valuable material, but they also contain a good deal of erroneous information - statements based on meagre observation or "facts" gleaned at second hand. To properly study the Australian fauna one must dwell in the land over which the Southern Cross beams in benediction. I have read in books compiled by hasty travellers that in Australia men hunt the Kangaroo with doormats hanging from their necks to defend their bodies from the terrible claws of the giant marsupials. Perhaps it is hardly necessary at the present time to give denial to such an absurd statement, yet others equally foolish and false have been published in books and magazines during recent years.

For readers who may desire to pursue the subject of Australian natural history beyond these pages no better work can be recommended than Lucas and Le Souëf's Animals of Australia. It contains a fund of reliable information, and I am indebted to the authors for some of the facts I am about to set out.

Of all the distinguished naturalists who have visited Australia 
one stands out as a most memorable figure in the pageant of science: Charles Darwin, whose name is associated for ever with the great theories of evolution and natural selection. In the nineteenth chapter of his fascinating book, The Voyage of the 'Beagle,' Darwin describes his journeys in New South Wales, and gives some fleeting impressions of man and beast as he found them there existing. Alfred Russell Wallace, whose name is as illustrious as that of Darwin, has written wisely and well of Australian natural history, and his passages on the marsupials and monotremes and other ancient types that still survive in these regions are too well known to be again quoted.

It will be necessary, before proceeding with a description of the fauna, to give some account of the geological history of the Australian region, and the relationship of the marsupial forms to the higher orders of mammals inhabiting other parts of the world. An imaginary line known as Wallace's line passes between two small Malayan islands, Bali and Lombok, and divides the Australian region from the rest of the world. As every reader of The Malay Archipelago will remember, the difference between the flora and fauna of Bali and Lombok is greater than that which exists between China and Peru. On the Asiatic side, Bali is linked with Java and Sumatra, the habitat of the Rhinoceros, Elephant, Tiger and Tapir, while Lombok's inclusion in the Australian zone is proved by the presence of marsupial forms restricted to that region. It is believed by geologists that æons ago Australia was connected with South America by means of an Antarctic continent; and there is also evidence that South America, Africa and Australia were probably united through a southern continent. It is fascinating to speculate on these vanished "land-bridges," to recreate continents which, if they ever had existence, disappeared in the sea long ere the advent of man on this ancient planet.

One of the most interesting evidences of the former land connection between South America and Australia is found in the distribution of a species of fresh-water fish, the Mountain Trout, or Minnow. This little fish is abundant in some Australian creeks and streams; the boys of the bush catch it on sunny half-holidays, little knowing its wonderful history. The Mountain Trout is also found in the lakes and rivers of Patagonia, and it has been captured in some of the islands which lie midway between the two Continents. Then, at Santa Cruz, on the coast of South America, fossil remains 


\section{I76 THE BOOK OF THE ANIMAL KINGDOM}

of an animal closely allied to the carnivorous marsupials of Australia have been discovered. It is all very wonderful. But "knowledge grows from more to more," and naturalists who flourish in the next century may find reason either to endorse or to modify or even to discard the theories we students of to-day have faith in and have built up with such care and labour.

With the knowledge at present possessed, it seems improbable that the primitive marsupials characteristic of Australia entered the continent from the north; they may have been cradled in Africa, and from thence spread to the two great Southern lands. The higher mammals were kept out of Australia by the Strait of Lombok-that deep, narrow channel of the sea has been a barrier to southern migration for a longer period of time than the mind can easily think upon.

In the introduction to his Marsupials and Monotremes, Mr. Lydekker gives a lucid summary of the peculiarities of Australian zoology.

"Differing widely from all other regions of the globe," he writes, "as regards both its fauna and flora, the great island continent of Australia, together with certain of the south-eastern Austro-Malayan islands, is especially characterized by being the home of the great majority of that group of lowly mammals commonly designated - marsupials or pouched animals. Indeed, with the exception of the few species of the still more remarkable monotremes, or egg-laying mammals, nearly the whole of the mammalian fauna of Australia consists of these marsupials, the only other indigenous mammals being certain Rodents and Bats, together with the native Dog, or Dingo, which may or may not have been introduced by man. All the other orders, such as the Ungulates, or Hoofed Mammals, the Apes and Lemurs, and the Carnivores are conspicuous by their absence from the Australian landscape, where their respective places are taken by the numerous representatives of the marsupial order, which have adapted themselves to all modes of life. IVe have, for instance, both terrestrial and arboreal types, while one form recently discovered passes an underground existence like the Mole. Sonie again are carnivorous and others herbivorous; while among the former certain kinds live on flesh and others on insects; an equal diversity obtaining among the vegetable feeders."

Australia has been isolated for countless ages, and its mammals have developed along their own lines. In this region survive the 
most primitive of all mammals, the Egg-Laying Monotremes, the Duck-Billed Platypus and the Spiny Ant-Eater. The Marsupials and Monotremes are most ancient types, and their intelligence is in an undeveloped state. In the marsupials the brain is small in proportion to the size of the head and body. There are other features in the structure of these animals which clearly indicate low organization.

"There is," states Mr. Lydekker, "one marked peculiarity in regard to the succession of the teeth of marsupials. Instead of the whole of the first set of teeth being replaced by a second set of permanent teeth, as in other mammals, one tooth only succeeds, and that not constantly. In fact, the mammals of Australia, from whatever point of view regarded, are of exceeding interest. Primarily, of course, the scientific naturalist and the biologist must deal with the Marsupialia, but in no part of the world is a finer field than Australia offered the outdoor naturalist for investigation. But there must be no delay; for Australia is no longer the wild land that Darwin found when he landed at Sydney over seventy years ago. Vast areas of 'bush' have been cleared, and the work of 'reclaiming' goes on unceasingly. Where once the Kangaroo fed peacefully, save when disturbed by the aboriginal hunters, flocks of Sheep now pasture, and the old-time haunt of the Emu is become a wheatfield. If something is not done to save them (other than the passing of ineffective game laws) the most interesting race of animals at present existing on our globe will become extinct. Nearly all species of marsupials are ruthlessly hunted down. In the early days of settlement the colonists formed Kangaroo 'drives.' Thousands of Kangaroos and Wallabies were rounded up by parties of men on horse and afoot, and when the unfortunate animals were hemmed in the slayers came among them and brutally did their work. This was termed 'sport' (?). And to-day the work of destruction still goes on. Marsupials are killed for their pelts, which are valuable. They are victims of the fur trade. Opossums, Kangaroos, Wallabies and native Bears (Koala) are all persecuted and being reduced in numbers. And they are gradually being driven back to the very wildest parts. No longer is it possible to see a Wallaby or Kangaroo on the outskirts of any of the capital cities of the Commonwealth. In fact, there are thousands of native-born Australians who have never seen a Kangaroo outside some Zoological Gardens.

"Some of the methods adopted by the pelt-hunter in Australia are barbarous. Opossums and Wallabies are caught in snares and gins $\mathrm{N}$ 


\section{I78 THE BOOK OF THE ANIMAL KINGDOM}

which must entail great suffering on the unfortunate victims ere death brings relief. The gun, of course, is largely used where the bigger mammals are concerned. But there is very little sport in Kangaroo hunting. The chasing of a timid, harmless creature is not sport. Unlike South Africa, for instance, Australia offers no attractions to the 'mighty hunter.' The man who finds Fox hunting a sport for weaklings and desires to face dangerous wild beasts should not come to the new Commonwealth. There is not a single creature, exclusive of the many poisonous Snakes, in the bush which it is really dangerous to meet unarmed. A ramble through an Indian jungle or an African or South American forest is fraught with danger to unarmed man. He may be surprised by a Tiger, a Lion or a Jaguar; but in the Australian bush nothing is to be feared in that respect. No fierce-fanged beasts lurk in the silent places ready to pounce on and rend the disturber of their peace. In most of the States, too, the wild man has become as a tale that is told. Only in the central deserts and in the far north-western portions of the continent does the savage aboriginal now roam; and his days are numbered on the scroll of fate."

Although it is proposed to deal here chiefly with the Pouched Mammals of Australia, it may be interesting to include the Eutheria and Reptiles in the census. The figures are from Animals of Australia.

Mammalia.-Monotremes 2, Marsupials 106, Eutheria 106.

Reptiles.-Crocodiles 2, Turtles and Tortoises 12, Snakes 105, Lizards 390.

Amphibia.-Frogs and Toads 62 .

Australia is peculiarly rich in Reptiles-but, as Kipling would say, that is another story.

In concluding these introductory remarks on the Mammals of Australia, I cannot do better than quote a sonnet composed in honour of the land of the Southern Cross by one of her most gifted sons, Mr. Bernard O'Dowd.

\section{"AUSTRALIA}

"Last sea-thing dredged by Sailor Time from space, Are you a drift Sargasso, where the West

In halcyon calm rebuilds her fatal nest?

Or Delos of a coming Sun-God's race?

Are you for Light, and trimmed with oil in place,

Or but a IVill-o'-Wisp on marshy quest?

A new demesne for Mammon to infest? 
Or lurks millennial Eden 'neath your face?

The cenotaphs of species dead elsewhere

That in your limits leap and swim and fly,

Or trail uncanny harp-strings from your trees,

Mix omens with the auguries that dare

To plant the Cross upon your forehead sky,

A Virgin helpmate Ocean at your knees."

That magnificent ninth line-

"The cenotaphs of species dead elsewhere"-

gives the natural history of Australia in a nutshell.

DING0.-The Dingo, or Wild Dog of Australia, (Fig. I43), presents an insoluble riddle to naturalists. How did it enter Australia, and from what "undiscovered country" did it migrate to the land of Marsupials? Ranging over the whole of the continent, the Dingo is the sole representative in Australia of the land carnivora. Authorities place the Dingo, on dental and skeletal evidence, in an intermediate position between the WVild Dogs of Southern America and the Dogs and Wolves of the Old World. A handsome animal, the Dingo is about the size of a Collie Dog, measuring five feet in length and over two feet in height. The head is Fox-like and the ears short and erect, giving the animal an alert appearance. The following admirable description of Australia's Wild Dog is given by Lucas and Le Souëf-

"The body is well covered with hair of two kinds, a grey underfur, and longer hairs which give the body colouring. The tail is of moderate length, bushy, but hardly with the brush of the Fox. The colour varies from yellow or brownish-red to even black, the IVestern Dogs being darker. The under-parts and inner surfaces of the limbs are lighter, and may be whitish. The feet and the tip of the tail are often white. Albinos occur, and these frequently breed true, so that a white race might be established. Females seem always to predominate."

The same authorities are of opinion that the Dingo reached Australia without the aid of man in Pliocene times. He did not come from the South, for Dingoes are not found in Tasmania. "It is probable," write our authors, "that he" (the Dingo) "is a descendant of some Miocene or early Pliocene Dog of South-Eastern Asia, who wandered into Australia when the land-bridge still existed where Torres Strait is now. The destruction of that bridge severed him from his kindred, and left him free to take possession of the new territory. At first he had to compete with the Marsupial ground N 2 
carnivores, but these he soon ousted, endowed as he was with far superior strength and intelligence."

The Dingo was known to the aborigines as the Warrigal, and they alone have succeeded in partly domesticating him. Reared from puppyhood in the black's camp, the Dingo is made a great pet of by its owner, and it helps him in his hunting.

Dingoes have inter-bred with settlers' dogs in the wilder parts, and the cross-breeds are sometimes very fierce and powerful animals. The Dingo is an outlaw with a price upon its head. For it is a Sheep-killer, and that, in Australia, as in other sheep countries, is an unforgivable crime. On most of the large stations or sheep-runs one or more Dingo trappers are employed to keep the Wild Dog in check. These men earn good wages, for their work of destruction is of vital importance to the sheep owners.

JERBOA RAT.-It is not the plan of this work to describe all the Australian mammals, the following pages dealing with the Marsupials and Monotremes; but the Rodents, of which Australia possesses her share, cannot be passed over altoget'ier. Many interesting species of Mice and Rats are found within the borders of the Commonwealth. Of the genus Mus twenty-eight species have been described. But the most interesting forms are those comprised in the genus Conilurus, which is confined to Australia. Fourteen species of Jerboa Rats are known. They are quaint-looking little animals with habits similar to those of the Jerboas of Northern Africa and Central Asia. The hind-limbs are much lengthened, and the mode of progression is by leaps or hops, after the manner of a İangaroo.

The Nest-Building Jerboa Rat ( $C$. conditor), which is the only species that can be described here, wears greyish-brown fur; the head and body are about six inches long, and the tail also measures the same. As the name implies, these animals construct nests; they live in "colonies," and the large domed nest is the result of combined labour. It is built about a bush, the branches of which are interlaced, various other sticks and twigs being added. The nest is divided into cells or compartments, which are warmly lined with grass bents. Each compartment is said to be sacred to the use of one family only; but the different "rooms" of this strange dwelling are connected by passage ways.

Fig. Ift depicts the Australian Desert Jerboa Rat. 


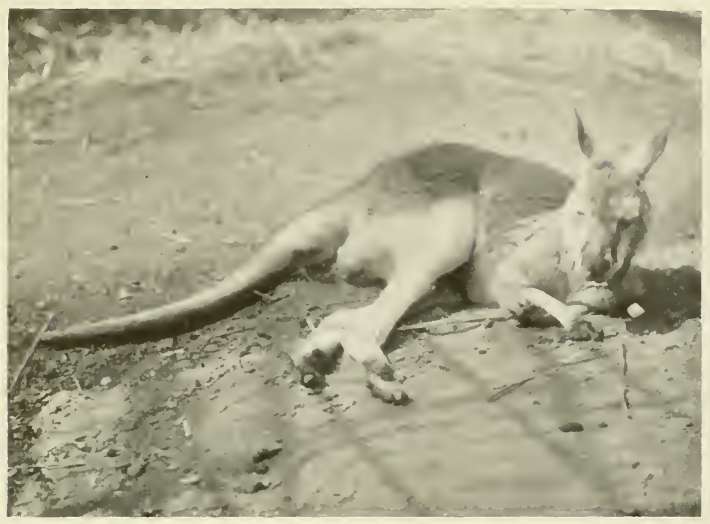

FIG. I 45. - GREAT RED KANGAROO

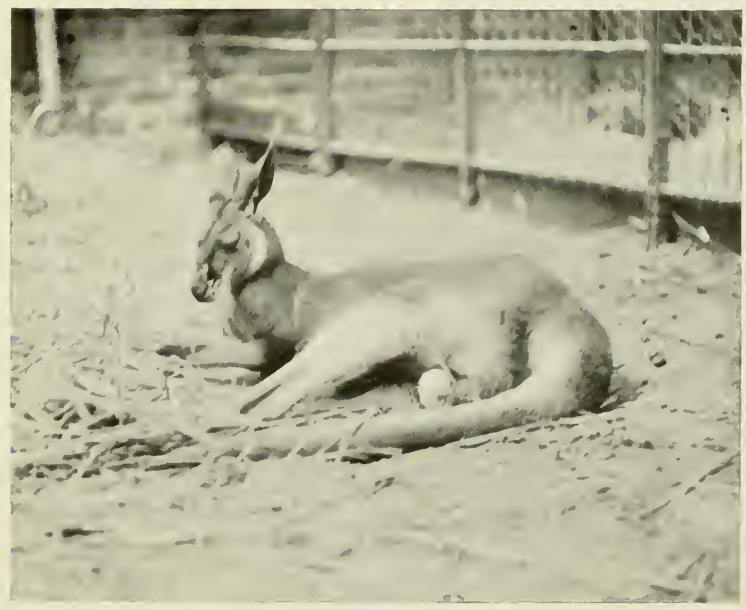

FIG. If6. GREAT GREY KANGAROO 


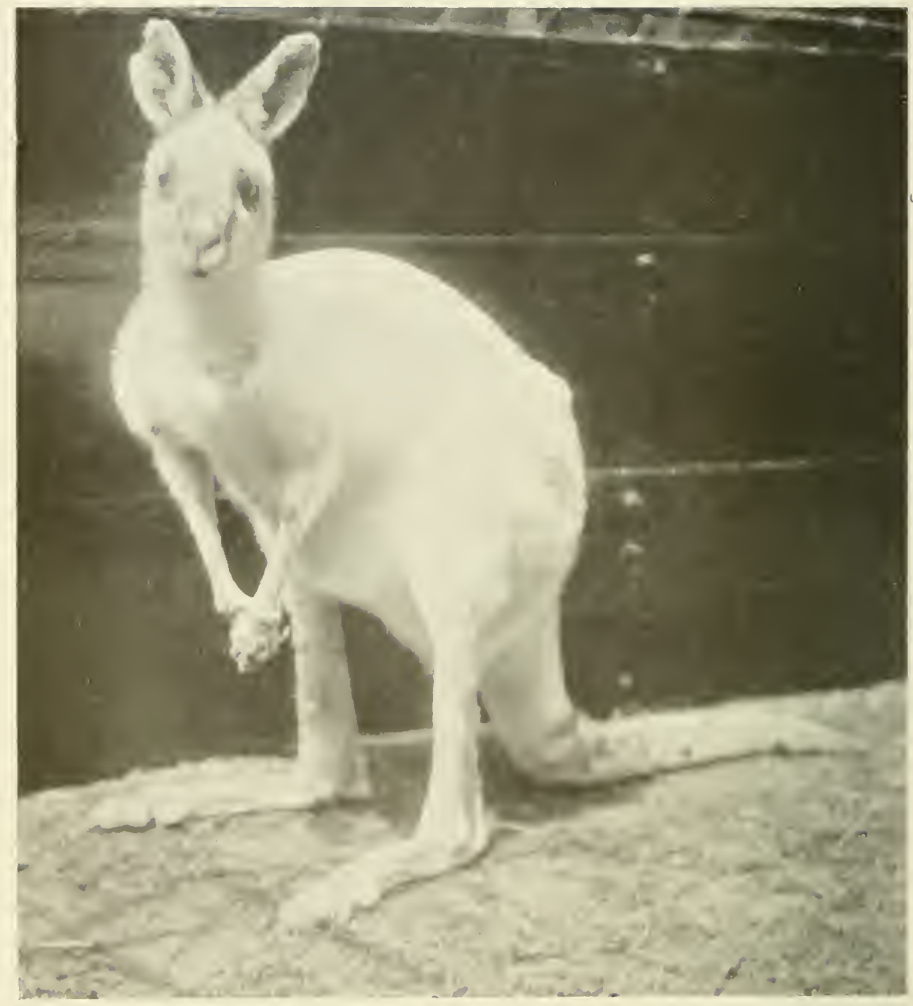

FIG. I 7 - - GREAT GREY KANGAROO (ALBINO) 


\section{Order Marsupialia}

As shown in the introduction, the Marsupials are of absorbing interest to scientific zoologists, and they have accordingly been exhaustively studied. Mr. Olfield Thomas, of the British Museum, has done much valuable work, and the results are published in the Catalogue issued by the great institution with which he is connected. It is, of course, highly technical, but Mr. Lydekker, in his monograph already referred to, has drawn upon the larger work and given a great deal of interesting information in more popular language. It is to his book that I am indebted for facts concerning structure, etc., which are mentioned hereafter.

What is a Marsupial? The name is derived from the word marsupium, or pouch, but this feature is not found in every species, so it will not serve as a definition. A general characteristic of the order is found, says Lydekker, in the imperfect state of development in which the young are born into the world. They are tiny helpless lumps of flesh, and display scarcely any movement. A new-born marsupial is a very ugly object, repelling, indeed, to human eyes, although doubtless the mother thinks it the sweetest little thing in the world. Immediately after birth the young are lifted from the ground by the mother and transferred to her teats. Opening the pouch with her fore-paws, a Kangaroo mother first places the mouth of the helpless babe on to the tip of the nipple, which is hardened and pointed. Of itself the tiny creature could hardly drink of the fount of life-giving liquid to which it is attached, so the doe gently causes the milk to flow into the quivering little body. The youngster clings to the nipple, which, swelling in its mouth, cannot slip out again. It is asserted by close observers that if the baby Kangaroo is removed from the teat by force it cannot be attached again, as the organ becomes soft, and the youngster inevitably dies. The lips, which almost form a circle, are provided with muscles specially modified for grasping. The teats in all Marsupials are situated in the abdomen and usually within the pouch. The infant Marsupials remain clinging to the nipples of their mothers until they are sufficiently well developed to perform the usual functions of life.

The Marsupials possess no placenta, and another feature of the group is the presence in all species, with the exception of the Tasmanian Wolf, where they are only rudimentary, of a pair of bones 


\section{I82 THE BOOK OF THE ANIMAL KINGDOM}

on the lower portion of the pelvis; these are known as the epipubic bones. The relatively small brain has already been mentioned as a characteristic of Marsupials, also the peculiarity in regard to the succession of the teeth, which Lydekker considers may be taken as characteristic of the order.

The Marsupials are placed in a sub-class by themselves. They differ greatly from the higher mammals, and in form and general appearance from one another ; structurally, however, they are closely connected. The order includes both carnivorous and herbivorous animals, and their habits are various. Some species are specially adapted for an arboreal life, while others are unable to climb; some dwell in caves of the rocks, others rear their young, like the Giant Kingfisher and the Ow1, in the hollow spouts of the forest gum-trees; but no Marsupial of aquatic habits has yet been discovered. Far more is known of the structural peculiarities of the Marsupials than of their habits. Many of them are extremely shy and difficult to observe in a wild state, and in captivity they change their ways more or less, like nearly all other animals. The bush naturalist tells some strange stories about the habits of Kangaroos and IVallabies, Wombats and Opossums, but the evidence of untrained observers is not always to be relied upon. There have been some fierce controversies carried on in the Australian newspapers, from time to time, regarding the mode of birth of Marsupials. Some bushmen are firmly convinced that the young of the Kangaroo are born in the pouch, and no amount of argument will shake their faith in such an absurd notion.

KANGAR00S.-Perhaps no other species of animal is so intimately associated with its native land as is the Kangaroo with Australia. Outside the Commonwealth, Australia is almost universally talked of as the "Land of the Kangaroo," and the long-legged, heavy-tailed animal figures in the national coat of arms. It is fitting that such a unique animal should be thus honoured; but it is to be feared that a century hence the Kangaroo will be only a memory, if the present rate of destruction is allowed to continue.

The Kangaroo not only symbolizes Australia, but it is the subject of myth and legend; in the folklore of many an Australian tribe you will find it enshrined. The Kangaroo totem is famous, and now that the blacks have nearly all passed away, the Boy Scouts of the different States are claiming the big grey animal as their own. On the troop-flags its form is seen to-day in the city streets in places 
where once the forest murmured and little creeks went sparkling between mossy banks, on their way to the rivers. Yes, there is something of romance clinging about the Kangaroo.

Captain James Cook, the great navigator, was the first to bring the Kangaroo under the notice of European naturalists. It was in the Summer of 1770 , when he was refitting his staunch little vessel, the Endeavour, at the mouth of the river in New South Wales which bears that name. The date was June 22. A party who had been sent ashore to shoot Pigeons for sick members of the crew returned to the Endeavour with a report that aroused great excitement. The men said that they had seen "an animal as large as a greyhound, of a slender make, of a mouse colour, and extremely swift." Two days later, as Lieutenant Cook was walking ashore at a little distance from the ship, he also saw the strange animal. Mr. Joseph Banks, the great naturalist, who was a member of the expedition, caught a glimpse of the swift, mouse-coloured animal and expressed the opinion that its species was unknown. On July I4 "Mr. Gore had the good fortune to kill one of the animals before mentioned, and which had been the subject of much speculation. It is called by the natives Kanguroo." And that was how the Kangaroo was discovered. The species referred to in Cook's Voyages is the Great Grey Kangaroo (Macropus giganteus). The Genus Macropus includes all the true Kangaroos and Wallabies. They form the first family of the first sub-order of the Marsupials, known to men of science as Diprotodontia. The Diprotodonts (two front teeth) include all the herbivorous members of the order, and their distribution is confined to Australia and the adjacent islands. The largest of the Marsupials are comprised in this sub-family. Some of their characteristics are powerful development of the hind-limbs in comparison with the fore-limbs, and the extremely large size of the tail. They possess small heads, and the ears are long and upright. Some of the dental characteristics have been already mentioned. The incisor teeth never exceed three pairs below and above. The innermost pair of incisors are very interesting, they are of large size and are furnished with sharp inner edges which are used by the animals almost after the manner of a pair of scissors. The molar teeth are characterized by broad square crowns, with either transverse ridges or blunted tubercles. There are about two score of living species of Kangaroos and Wallabies. They vary greatly in size. The species known to colonists as the "Boomer" and the 


\section{84 THE BOOK OF THE ANIMAL KINGDOM}

"Forester" stand as high as an average-sized man, while some of the Wallabies are no bigger than a Terrier Dog.

The true Kangaroos include the large forms, all of which are terrestrial. The colour of the fur is generally uniform and sombre. The mode of progression is by a series of leaps, and the animals can travel at a remarkable pace in this manner. The enormous tail is used as a kind of third limb when the animal is at rest, and when in motion acts as a balance to the fore-part of the body. The tail is not used as an organ of progression, as is often said; when the animal is travelling rapidly the tail does not come in contact with the ground. It is an inspiring sight to see a mob of Kangaroos travelling. The big grey animals make such astonishing leaps, and they stop for no ordinary obstacles; over rocks and bushes they go bounding away, as though springs were concealed in the powerful hind-limbs. When feeding, the daintily formed fore-limbs are used by Kangaroos to help them progress.

The long, sharp claw of the hind-foot is used by the Kangaroo as a weapon of offence, and hunters of the Marsupial take care to give it a wide berth when their Dogs have "cornered" an "Old Man." Many a fine dog has been killed when dashing at a big Kangaroo that has been brought to bay. One stroke of that strong claw on the hind-foot will rip a dog open. IThen close pressed by a pack of dogs a hunted Kangaroo will of ten make a stand with its back to the broad butt of a gum-tree and fight savagely for life. Woe to the dog that unwarily comes within reach of the desperate animal. It will instantly be seized by the fore-paws and held as in a vice while the Kangaroo raises one of its hind-limbs and rips its foe open with the big claw.

Kangaroos have been known to seize a pursuing dog and plunge into a creek or water-hole with it, and hold it under water until the unfortunate creature was drowned. This is a display of intelligence, although Marsupials generally are not credited, as previously stated, with a superabundance of brains. Yet they make delightful pets, become very attached to those who care for them, and are capable of learning tricks. Some years ago the "Boxing Kangaroo" was famous. It was shown in many countries besides Australia, and earned its owner fame and money. The "Boxing Kangaroo" wore gloves and displayed a good deal of science in the sparring matches with its trainer. And it generally "played the game" fairly, although sometimes the hind-foot was brought into action instinc- 
tively. More than one tame Kangaroo has learned the art of selfdefence. It is not uncommon to see pet Kangaroos and Wallabies about homesteads in the Australian bush, and some city folk are fond of having one on their premises.

When pursued by the fierce dogs used to hunt them, female Kangaroos are in the habit of thrusting the fore-paws into the pouch, pulling the young one out and throwing it into a bush or somewhere else. Some observers, who are loath to believe that Kangaroo mothers can so pervert the maternal instinct as to abandon their little ones, hold that when the young are cast from the pouch, as described, they are thus treated to ensure their safety. It may be so, but there is something to be said for the opposite view.

The colloquial term for a young Kangaroo, all over Australia, is "Joey." Few young animals are so charming and engaging as a "Joey." Soft furred and with large, dreamy brown eyes, the baby Kangaroo is irresistibly attractive. A quaint picture mother and child make when the "Joey" pops its head out of the pouch to take a brief survey of the outside world. And to see the female hopping along with her beloved burden is equally charming. The "Joey" stays in the pouch for some months, and even after it is sufficiently "grown up" to feed beside its mother, it looks upon its old cradle as a place of refuge in times of danger. It will take shelter in the pouch when alarmed, diving in precipitately.

The Kangaroos are exclusive vegetarians; they feed on grass and green herbage generally, so that it is not difficult to supply their wants in captivity. Dr. George Horne, of Melbourne, has a tame Wallaby which is very fond of fresh lettuce-leaves. At feeding time it comes bounding up to the wire-netting fence of its enclosure, and when a lettuce is dropped over by a kindly hand, takes it daintily between its front paws, sits up and munches away, as happy as a school-boy with a tart.

"Old Bushman," a sporting naturalist who camped in the Mordialloc district of Victoria, over half a century ago, when wild blacks still roamed where now is a thriving township, has some delightful passages on Kangaroos in a little volume long since out of print. He was a careful observer, and had opportunities which can never come again. Here is a quotation from his half-forgotten book of Bush Wanderings-

"Timid and shy, their" (the Kangaroos') "senses of sight, hearing and smell are most acute. Like the Hare, they appear to be unable 


\section{I86 THE BOOK OF THE ANIMAL KINGDOM}

to see an object directly in front of them when running-at least I have often stood still and shot one down as it came running up to me in the open forest. They are very gregarious, and are always to be met with in smaller or larger droves. I have often seen as many as one hundred and fifty in a drove, and our general ' mobs' used to average fifty or sixty. After the rutting season, the 'old men' will often draw away from the 'mobs' and retire by themselves to the thickest scrub. Each drove frequents a certain district, and has its own particular camping and feeding grounds. The 'mobs' do not appear to mix, and when the shooter once obtains a knowledge of the country, he has no difficulty in planting himself for a shot. Their camping grounds are generally on some open timbered rise, and they have well-trodden runs from one ground to another. They feed early in the morning and at twilight, and I think also much at night. [The Kangaroo's habits are diurnal-C.B.] The Kangaroo lies up by day, during the hot Summer weather, in damp, thicklyscrubbed gullies; in the IVinter, on dry, sandy rises. Here, unless disturbed, they will remain quiet for hours; and it is a pretty sight to watch a 'mob' camped up, some of them playing with each other, some quietly nibbling the young shrubs and grass, or basking in the sun half asleep on their sides. About Christmas [Summer-time at the Antipodes-C. B.] the young ones appear to leave their mothers' sides, and congregate in 'mobs' by themselves; I have seen as many as fifty running together, and very pretty they looked."

Such scenes as those pictured by "Old Bushman" are rarely seen now except in the country "out back." But the present writer has had the good fortune to see a certain species of VWallaby "at home." It was on an island in Bass Strait, which separates Tasmania from the mainland of Australia. The island is not large, but its hills, rock-strewn and clothed with dense scrub, abound in Wallaby. They are so rarely intruded upon and so little molested by the two human habitants of the isle that one may go among them and observe their ways. Sit quietly on a rock and watch the bushes around. Presently dark brown forms will be seen passing to and fro, and then, growing bolder, the IVallabies of the hills will come out into the light and hop about the lichened rocks in the most delightful manner. They will browse on the scanty herbage within a few yards of the watcher's feet. But a sudden movement will send them darting to cover. For they are not entirely ignorant of man and his evil ways. Where they are constantly trapped and hunted, 
Plate Xili.

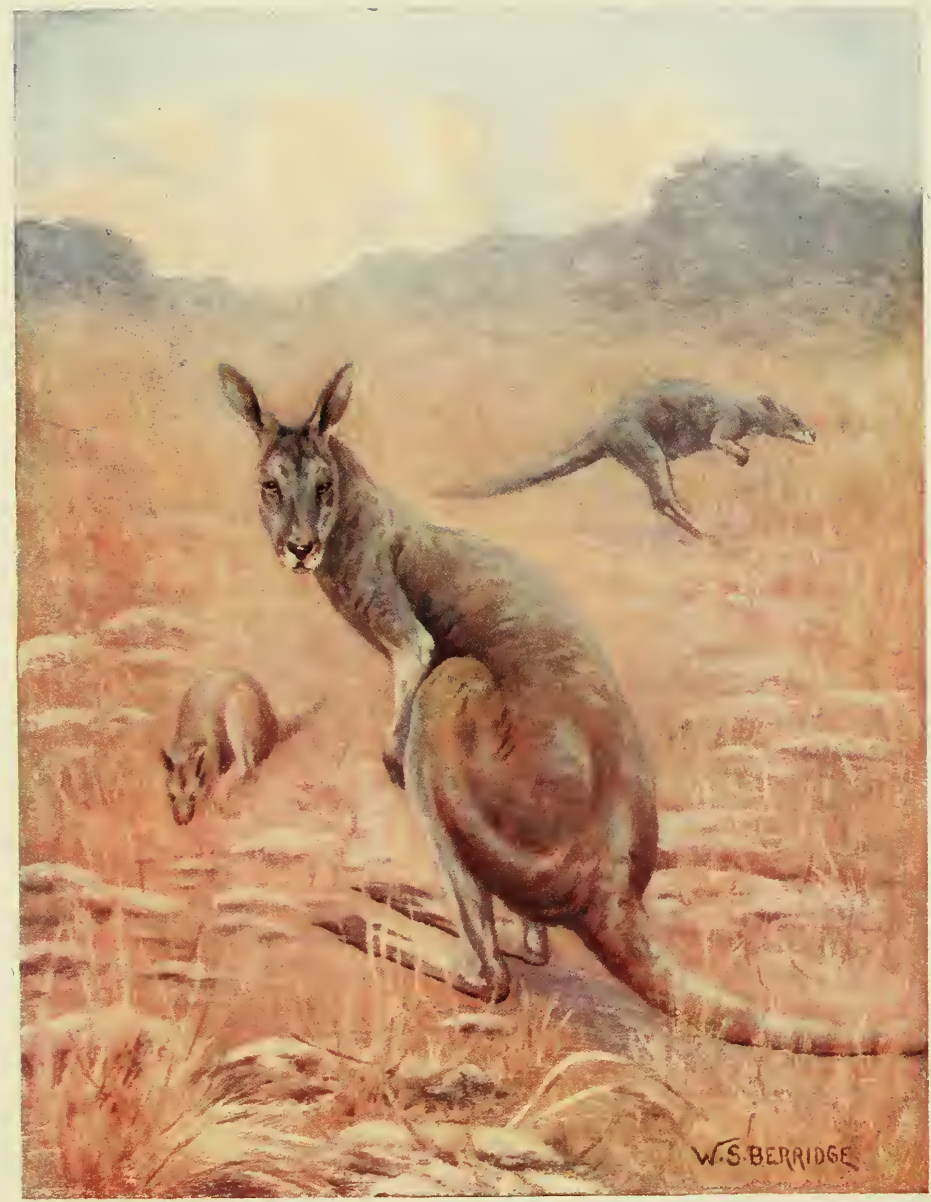

GREAT RED KANGAROO. 

as in most places where they are found on the mainland, Wallabies cannot be easily approached. They are too wary to come feeding about the feet of man the destroyer.

Having given a general account of the Kangaroos and Wallabies, it is necessary to consider some of the species in detail.

GREAT RED KANGAR00.-The Great Red Kangaroo (Fig. 145), which is now becoming rare, owing to various causes, is the largest living representative of its kind. The head and body of an adult measures about five feet five inches, and the tail forty-two inches. The fur is short and woolly; in the male the colour is bright rufous above, in the female slaty-grey; below the fur is coarser and straight, and of a pale-grey colour. The fur on the tail is also grey. The Red Kangaroo is found in Central Australia and on the plains inland in the Eastern and South-Eastern portions of the continent. This species moves about in small "mobs," generally composed of ten or at most a dozen individuals. It is very swift, the female at one time being known to the colonists as the "Flying Doe." The male Red Kangaroo is robust in form, but the female is rather slenderly built. From the nature of its fur it is sometimes called the Woolly Kangaroo. It has a preference for localities where there are "stony rises" covered with box-trees, and open plain country on which the pleasant sunlight falls. Professor Baldwin Spencer, F.R.S., writing of this species, says that during the Horn expedition to Central Australia it was seen feeding in parties of ten or twelve. "Amongst these would be two or three large rufous-coloured males, while the rest would be smaller blue-grey females and young ones. . . As this is the characteristic Kangaroo of this country, there can be no doubt whatever that it ranges into the inland parts of West Australia." The reddish fur of the males is said to harmonize with the hue of the desert and afford a certain amount of protection from discovery-another example of that "protective" coloration which is found in so many members of the animal kingdom.

GREAT GREY KANGAR00.-This species (Figs. I46 and 147 ) is so well known that it is often referred to as the "Common" Kangaroo. It is the species which Captain Cook discovered, as already recounted, and the one known to early colonists by such names as "Old Man," "Boomer" and "Forester." The scientific name, giganteus, is well bestowed, for the Great Grey Kangaroo, although lesser in size than its congener, the Red Kangaroo, measures when fully grown about sixty inches from nose-tip to the root of tail; the 


\section{88 THE BOOK OF THE ANIMAL KINGDOM}

tail itself measuring thirty-six inches. A well-developed male will turn the scale at $200 \mathrm{lb}$. What feasts the black fellows must have enjoyed when the hunters of the tribe brought in a "Forester"! Can you not picture them gathered around the wood fire gorging, as is their wont, on the half-cooked flesh of the victim? A circle of dark, savage faces, with the firelight playing upon them, and the "gins" in the background, eagerly snatching up such scraps as their lords and masters choose to throw to them. Unlike $M$. rufus, the Great Grey Kangaroo is slender in form, slender and graceful, a beautiful creature in motion and repose. The fur is short and woolly and of a greyish-brown colour. The tail is brown with a black tip. Dark "whisker marks" are present on the sides of the nose, which is hairy between the nostrils.

The Great Grey Kangaroo is distributed over the whole of the Australian continent, and a variety is also found in Tasmania, that pleasant island which is like a pendant jewel linked to the mainland by a necklet of islets strung across the sundering seaway known as Bass Straits. Known to the aborigines as the "Koora," the Great Grey Kangaroo roams over plains and through forests. But it is not now nearly so abundant as in the days of Captain Cook; the pelt-hunters often referred to have persecuted it mercilessly, and tens of thousands of skins are sent to market annually. And the tail is not despised as a delicacy for the "manufacture" of soup. Kangaroo flesh is not a favourite dish in Australia, although out in the wilds it is often put in the pot by hungry camping parties. Some species of Wallaby are more in favour for food, and the flesh of these, properly prepared by a bush cook, is most palatable. The writer has enjoyed more than one hearty meal of this kind on his natural history excursions in Australian wilds.

The Great Grey Kangaroo and other members of the family are strong swimmers. When the dogs are close upon them they will plunge unhesitatingly into any creek or river in the way of flight, and cross it with ease and rapidity. The leaps made by this Kangaroo are truly astonishing. Mr. Dudley Le Souëf, C.M.Z.S., director of the Melbourne Zoological Gardens, who is an authority on the Marsupials, mentions having once measured the distance covered by a female travelling at full speed down a gentle incline; the span proved to be twenty-five feet. It is said that a male of the species would clear an even longer space of ground in a single leap. In the "wild" country of South Australia the writer has seen "mobs" 


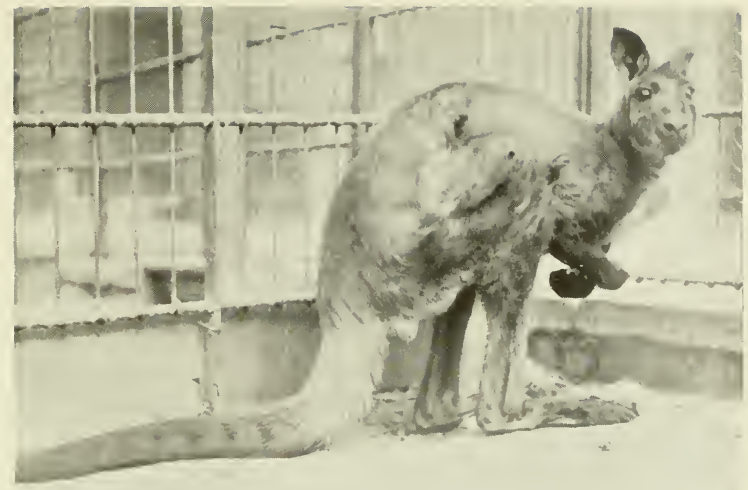

FIG. I 4 . GREAT WALLAROO

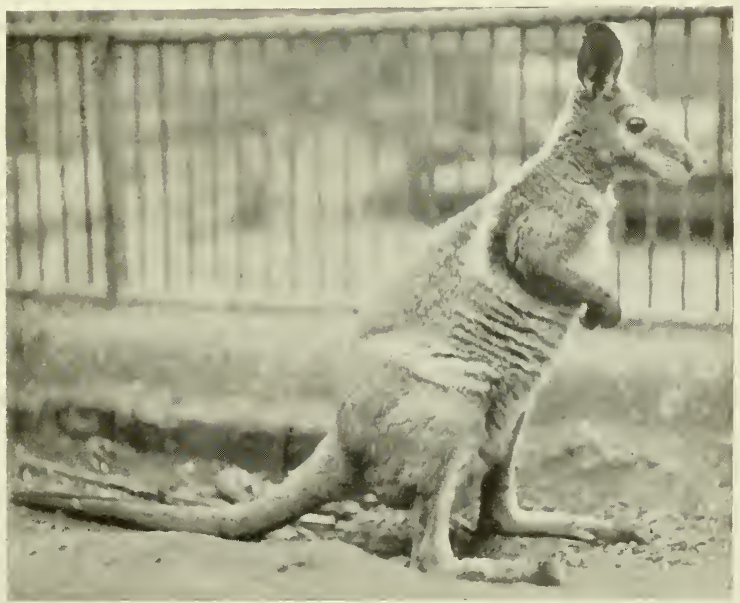

FIG. I49.--BRIDLED WALLABY 


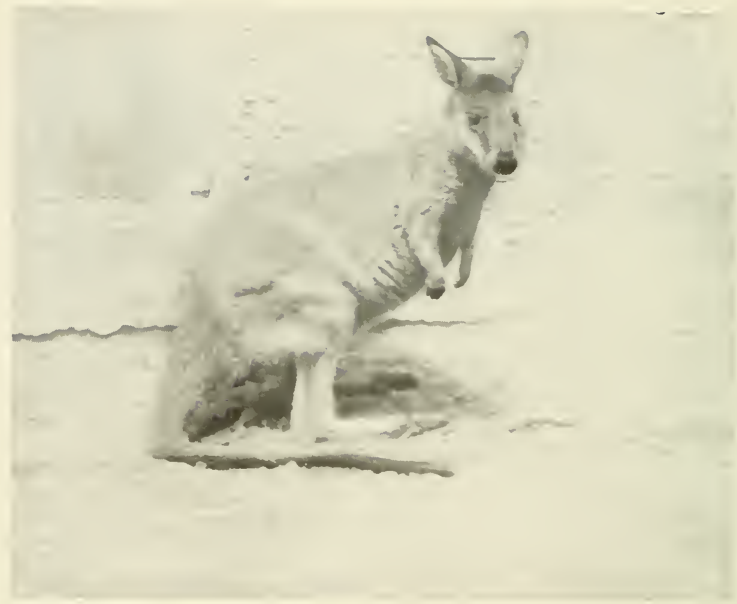

FIG. I5O. BLACK-GLOVED WALLABI

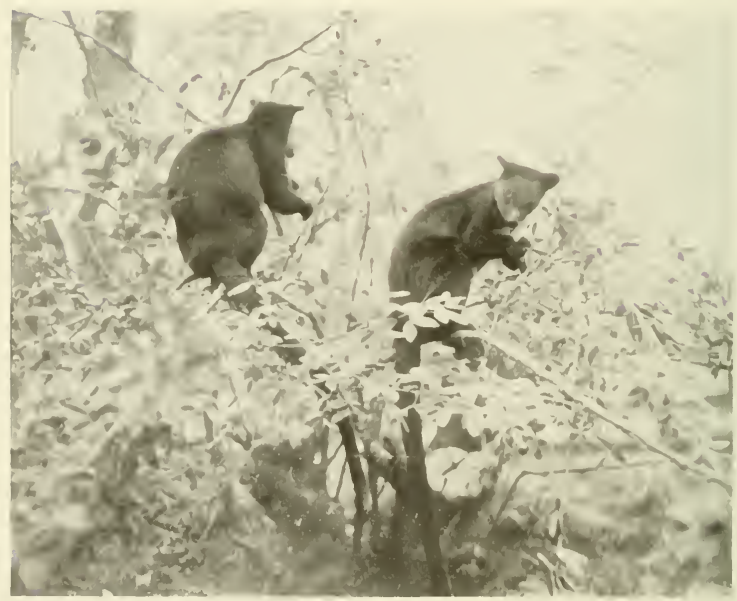

FIG. I51.—URSINE TREE KANGAROOS 
of the Great Grey Kangaroo bound across open spaces of considerable width. It is delightful to watch the big grey forms leap into view and then go thumping away through the brushwood. You think what splendid sport a Kangaroo race would make, if only the Marsupials could be trained to keep to a set course and not infringe racing rules.

WALLAR00.-It is not the purpose of this work to give descriptions of all the many species of Kangaroos and Wallabies; it would require too much space, and so the more familiar and typical representatives of the family have been selected for detailed description. Among the "chosen ones" the Wallaroo, or Rock Kangaroo, certainly deserves a place. The Wallaroo (Fig. 148) is a big animal, equal in size to the "Boomer," but differing from that form in being stout and heavy. The fur is thick and coarse, and dark-brown in colour, deepening into black at the extremities of the limbs and tail. The Wallaroo is a lover of the ranges; it dwells among the wild and lonely ridges where the bare rock-faces reflect the red beams of the Austral sun. It never descends to the plains, content with its haunt in the rocky hills where silence dwells. The Rock Kangaroo is found in Queensland, New South Wales, and the centre of Australia. It has a reputation for savageness, Lydekker stating that it will bite fiercely when attacked, and strike out with its powerful fore-limbs. John Gould, writing of this species, says-

"On one of the mountains near Turi, to the eastward of the Liverpool Plains, it was very numerous; and from the nature of this and other localities in which I observed it, must possess the power of existing for long periods without water, that element being rarely met with in such situations. The summits of the hills to which this species resorts soon became intersected by numerous roads and welltrodden tracks, caused by its repeatedly traversing from one part to the other; its food consists of grasses, and the shoots and leaves of the low scrubby trees which clothe the hills it frequents."

BRIDLED WALLABY. - The Bridled Wallaby (Fig. I49), which was first described by Gould in 1840 , is a small, slender animal with a sharp, woolly-haired nose and soft, thick fur on the body. The general "colour scheme" is grey, but the chest is white, and a portion of the back of the neck is black. A prominent white shoulder-stripe is present, and there is a faint stripe on the thigh. The tail is grey, with a black tip, and is furnished with a spur. The head and body measure about twenty-two inches, and the tail 


\section{I90 THE BOOK OF THE ANIMAL KINGDOM}

is eighteen inches long. Its short ears give the Bridled Wallaby a "smart" appearance. The Bridled Wallaby is very abundant; it is distributed over the interior of Northern Queensland, New South Wales and Victoria, and is generally admired for its elegant form. The male is much larger than the female, but both are charming in appearance. Their favourite haunt is in the low, stony ranges, and they love to be in company, being of gregarious habit. The spurtail of the Bridled Wallaby and the other members of the genus differentiate them from all other mammals, with the exception of the Lion.

Many are the theories which have been put forward to account for the peculiarity. Of what use is the spur?-that is the question which has puzzled generations of naturalists. No one has yet been able to give a satisfactory explanation, but the writer has some slight reason to think that the Spur-Tailed Wallabies make use of their spurs as aids to foothold among the rocks. Whatever its use may be, it gives its possessors great distinction in the matter of tails. The Bridled Wallaby has two relatives, who also possess spur-tails. All frequent rocky solitudes.

BLACK-GLOVED WALLABY. - The Black-Gloved Wallaby (Fig. 150) is of medium size, and slender and graceful in form. Its fur is soft and thick, colour on the upper parts of the body bluish-grey, on the under-parts grey, with a yellow tinge. The fingers and toes are black, the tail grey, with a clearly defined crest of black hairs above and underneath. The head and body of a full-grown specimen of $M$. irma will measure about thirty-two inches in length, and the tail about twenty-nine inches. The Black-Gloved Wallaby is found only in the southern portion of IVestern Australia, where it is the sole representative of its group. It is a very beautiful creature, and abundant in its habitats, but little is known regarding its habits. It is generally seen in the dense scrub jungles of the Western State.

PADEMELON WALLABY.-The Pademelon Wallaby is one of the best-known species in Victoria, New South Wales and Queensland, the three States of the Commonwealth through which it ranges. It is particularly abundant in New South IVales in the "big scrub" districts. It is a very graceful little creature, with long ears springing from a shapely head. The fur is thick and soft, grey on the upper portions of the body (rufous on the neck), and white on the under-parts. The length of the head and body 
is about twenty-five inches, and the tail measures about sixteen inches.

The Pademelon is hunted wherever it is found chiefly on account of its delicate flesh, which is grateful to the palate of many persons. It seems a pity that such a charming little animal should be so much persecuted. But Man has no thought for the creatures under his dominion when they have the misfortune to be in his way or to possess flesh, fur or feather which he desires for his own use. And so the Pademelon will continue to be hunted until its kind is exterminated.

It is called a pest, inasmuch as it frequents the crops in cultivated districts, and is alleged to do much damage.

The writer has met with this species both in New South Wales and in Queensland. It is weird at night in the tropical north to hear the Pademelon thumping through the scrub. In the sugarcane fields it is fond of spending moonlit evenings; you can hear it crashing through the thick-clustering stalks, whose sap is so sweet. The tropical scrubs which the Pademelon frequents are a veritable fairyland to the nature lover. It is here that the botanist can study that fierce struggle for existence which Darwin and Wallace and other great naturalists observed, and which helped to guide them to the golden keys which unlock dark portals guarding the secrets of Nature. In the "big scrub" the vegetation is luxuriant; plants great and small struggle fiercely for the light which means life. Giant fig-trees with far-spreading aerial roots tower above the graceful palms; the myriad trunks of all the forest trees are draped with green creepers, and linked together by weirdly twisted stems of the "Lawyer vine"; orchids with quaint and beautiful blooms cling to the branches. Does the little Pademelon take heed of all this wondrous beauty?

DAMA WALLABY.-The Dama Wallaby is a near ally of the Pademelon, but is distinguishable from it by the rufous fore-limbs and the different conformation of the upper incisor teeth. Its form is, like that of nearly all the Wallabies, very graceful. The fur is of a grey colour above, excepting on the shoulders, where it is rufous, and greyish-white on the under-parts of the body. The length of full-grown specimens from the tip of the nose to the root of the tail is from twenty-four inches to twenty-eight inches, according to locality; length of tail seventeen inches. The Dama Wallaby is confined to Western Australia and some islands lying 


\section{THE BOOK OF THE ANIMAL KINGDOM}

off the Western and Southern coasts. The smaller kind inhabit the mainland. Lydekker states that the Dama Wallaby owes its Latin name to the supposition that it was first obtained on Eugene Island, off the IVest coast, while Dama is said to be the name given to the species by the aborigines of the mainland. As with so many Marsupials, very little appears to be known about the habits of the Dama Wallaby.

TREE KANGAR00S.-The Tree Kangaroos (Fig. 15I) are most remarkable animals, and they are also very beautiful. There are five species; three inhabit New Guinea, and two are found in North Queensland. Few people associate Kangaroos with trees; their powerful hind-limbs and great tails seem to point to a purely terrestrial existence. Yet, as stated above, no fewer than five members of the family are adapted for an arboreal life. Perhaps some readers of this book have seen a Tree Kangaroo at some Zoological Society's Gardens, and been astonished at the agile manner in which the Marsupial moves about its leafy dwellingplace. Few naturalists even have seen more of the living Tree Kangaroo than this, for they are found in remote wilds, and are shy and difficult to approach. Tree Kangaroos are characterized by having both pairs of limbs normally proportioned to the body. There is but a slight difference in the length of the front and the hinder pair. The tail is very long and thick.

LUMHOLTZ'S TREE KANGAR00. - The best known of the four species of the genus Dendrolagus is that which inhabits the Herbert River district, Northern Queensland. Lumholtz's Tree Kangaroo (Dendrolagus lumholtzi) is named after its discoverer, the famous naturalist-traveller, Dr. Carl Lumholtz, who came to Australia in the year 1880 with the object of making collections for the zoological and zootomical museums of the University of Christiania. He spent fourteen months in constant travel and study in Northern Queensland, but he brought back to Europe no more remarkable specimen than the Tree Kangaroo which bears his name. The story of how the new mammal was discovered is related in Dr. Lumholtz's interesting book, Among Cannibals. The natives had told him of the existence of a tree-dwelling Kangaroo, and he knew no rest until they brought him a specimen of the strange creature known to them as "Boongary."

"I had just eaten my dinner," he writes, "and was enjoying the shade in my hut, while my men were lying about smoking their 


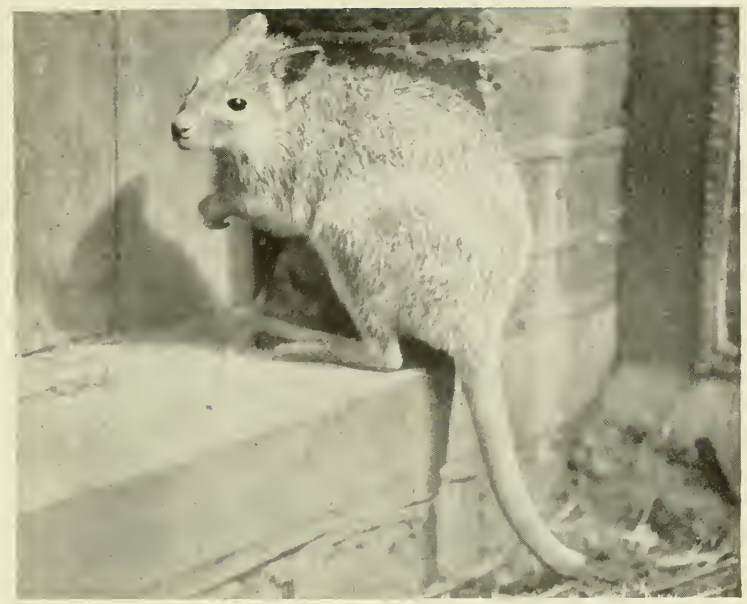

FIG. I52.-RUFOUS RAT KANGAROO

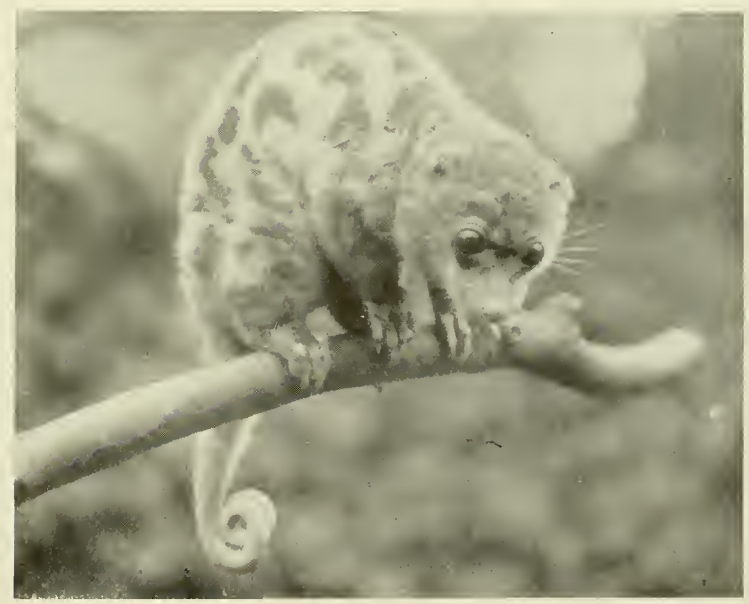

FIG. 153.-SPOTTED CUSCUS 


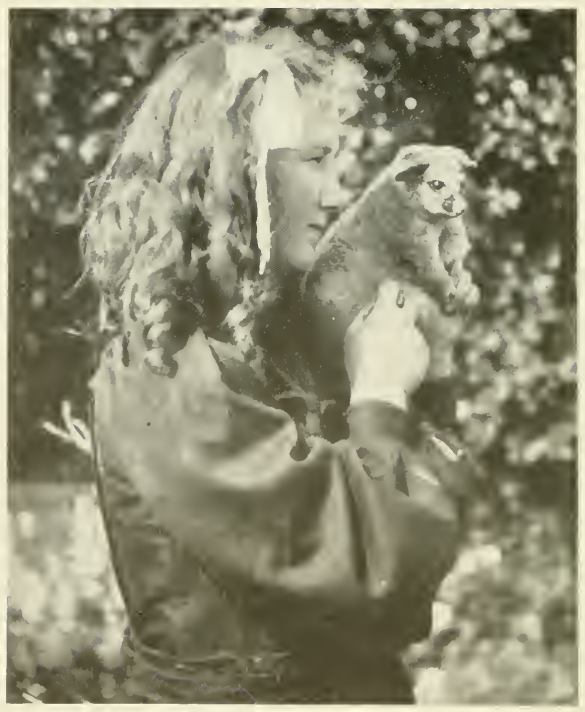

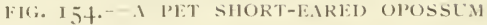

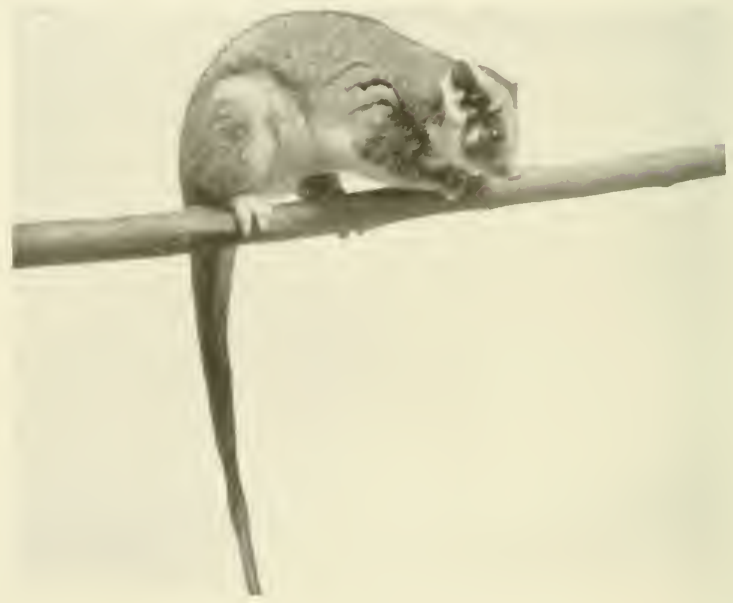

FIG. $15.5-R 1 N G-T .11 . E 1)$ OPOSSUM 
pipes, when there was suddenly heard a shout from the camp of the natives. My companions rose, turned their faces toward the mountain, and shouted, 'Boongary, Boongary!' A few black men were seen coming out of the woods and down the green slope as fast as their legs could carry them. One of them had a large dark animal on his back.

"Was it truly a 'Boongary'? I soon caught sight of the dog 'Balnglan' running in advance and followed by Nilgora, a tall, powerful man.

"The dark animal was thrown on the ground at my feet, but none of the blacks spoke a word. They simply stood waiting for presents from me.

"At last, then, I had a Boongary, which I had been seeking so long. It is not necessary to describe my joy at having this animal, hitherto a stranger to science, at my feet. Of course I did not forget the natives who had brought me so great a prize. To Nilgora I gave a shirt, to the man who had carried the Boongary a handkerchief, and to all food. Nor did I omit to distribute tobacco."

Dr. Lumholtz obtained some information regarding the Boongary from the natives, and also observed it himself.

"Upon the whole," he says, "the Boongary is the most beautiful mammal I have seen in Australia. It is a Marsupial, and goes out only at night. During the day it sleeps in the trees, and feeds on the leaves. It is able to jump down from a great height, and can run fast on the ground. So far as my observation goes, it seems to live exclusively in one very lofty kind of tree which is very common on the Coast Mountains, but of which I do not know the name. During rainy weather the Boongary prefers the young low trees, and always frequents the most rocky and inaccessible localities. It always stays near the summit of the mountains, and frequently far from water, and hence the natives assured me that it never went down to drink."

It is sad to learn that the first Boongary skin obtained by Dr. Lumholtz was stolen, when drying, by a Dingo, or Wild Dog, and mutilated. The Dingo ate the whole of the head and part of the tail and legs. The natives afterwards brought in other skins, and so the naturalist's sorrow was softened and his wrath turned away.

BENNETT'S TREE KANGAR00.-Bennett's Tree Kangaroo ( $D$. bennettianus) has been described as a distinct species, from o 


\section{THE BOOK OF THE ANIMAL KINGDOM}

osteological and other details. Its habitat is the Bloomfield River district, North Queensland.

Mr. D. Le Souëf, C.M.Z.S., relates in Animals of Australia how one of sixteen specimens of Bennett's Tree Kangaroo consigned to the "Zoo" escaped from its cage on board the steamer, and jumping at once into the rigging, climbed to the vicinity of the masthead with astonishing speed. "Up aloft" it seemed to be perfectly at its ease.

RAT KANGAR00S.-The Rat Kangaroos, generally known to the colonists as Kangaroo Rats, and of which there are several genera, are very quaint and interesting little animals. The head is Rat-like, the ears being short and rounded, and the tail hairy. All the Rat Kangaroos are of small size.

COMMON RAT KANGAR00.-The Common Rat Kangaroo (Potorous tridactylus) (Fig. 152) inhabits South Australia, New South Wales, Victoria and Tasmania. It is about the size of a Rabbit, the length of head and body being sixteen and a half inches, tail nine inches. The fur is greyish-brown above and greyish-white on the under-parts. The genus is characterized by the hind-limbs not being disproportionately longer than the front pair, and the hindfeet being shorter than the head. There are several other distinctive features. Gould states that these Rat Kangaroos run in a different way from other members of the sub-family, using the fore- and hind-legs in a galloping manner, and never kicking out with the hind-feet. They feed in the evening on roots and grasses, reclining during the hotter part of the day under bushes, where they form snug little nests of grass bents. The Rat Kangaroos are very abundant in some parts, and Lucas and Le Souëf state that "in the undisturbed economy of the bush they play much the same part as the Rabbit does in England, while the part of the Hare is taken by some of the smaller IVallabies."

PREHENSILE-TAILED RAT BANGAR00.-The Prehensile-Tailed Rat Kangaroos (Genus Bettongia) are most remarkable animals, distinguished among terrestrial mammals as being the only ones, so far as is known, which are provided with a prehensile tail. This tail is said to be used to carry the bunches of grasses of which the Bettongs make their nests. The tail is bent down over and round the grasses to be picked. The nest is a hollow in the ground, the entrance being shielded by grass bents. There are four known species of these curious Marsupials, closely similar externally. The 
head is Rat-like, and the ears are short and rounded. The colour of the fur in all the Bettongs is generally grey.

BRUSH-TAILED RAT KANGAR00.-The Brush-Tailed (B. penicillata) is the smallest and one of the most familiar species. The length of the head and body is about fourteen inches, tail twelve inches. This species is found all over Australia, except the far North.

LESUEUR'S RAT KANGAR00. - Lesueur's Rat Kangaroo ( $B$. lesueuri) inhabits South and Western Australia. The naturalist Krefft writes of it as follows-

"It is a truly nocturnal animal, which always leaves its burrow long after the sun is down, in fact, never before it is quite dark. I often watched near their holes, gun in hand, listening to their peculiar call; but I always had great difficulty in procuring specimens, as they were very shy, and hardly to be distinguished from the surrounding objects. The best plan is always to dig them out, an operation in which the black fellows are very expert, though it is rather tedious work, as the holes run into each other, and, being sometimes ten feet deep, several shafts have to be sunk before a couple of 'Boomings,' as the animals are called by the natives of the Murray district, can be secured."

PHALANGERS. - The Phalangers constitute the second family of the herbivorous Diprotodont Marsupials. There are over thirty species, comprising twelve genera. In this family are included the remarkable Flying Phalangers, or Squirrels, as the colonists erroneously call them, and the Koala, or "Native Bear." The geographical distribution of the Phalangeridæ is wide. They range over the whole of Australia and Tasmania, and are found in New Guinea and the Austro-Malayan islands.

Mr. Oldfield Thomas, in The British Museum Catalogue of Marsupials, observes that the Phalangers and their allies may be considered as the most generalized, and consequently, on presumption, the most ancient types of Diprotodont Marsupials now existing. They are of essentially arboreal habits; some species are provided with the useful prehensile tail, and others possess parachute-like expansions of the skin along the sides of the body.

K0ALA.-The Koala, or Native Bear, is one of the quaintest little creatures to be found in all wild Nature's realm. It is almost impossible to give a faithful description in words of this engaging "Australian native." It is the most inoffensive of animals, simple 


\section{I96 THE BOOK OF THE ANIMAL KINGDOM}

in disposition, and its broad face wears a droll expression of mingled astonishment and solemnity. These characteristics have led to the Koala being used as a model by Australian caricaturists; it figures frequently in the illustrated papers, and is pictured on the covers of magazines. A universal favourite with the nature lovers of Australia, the Native Bear is yet ruthlessly hunted for the sake of its pelt. Tens of thousands of skins are annually exported to London; and as a result of this persecution the Koala is becoming scarce. Some effort, fortunately, is now being made to afford the inoffensive animal protection; but it is difficult to prevent those wretched beings known as sportsmen from shooting the Koala. It is cold-blooded murder to shoot a Native Bear, and cruel in the extreme, for the Bear is entirely unsuspecting, and its enemies can encompass its destruction without difficulty. Dwelling in the treetops, it is sleepy during the daytime, clinging to a branch with its arms and claws, or resting in some hollow stem. Its disposition is so sluggish that even when alarmed it does not move very briskly. When wounded it will often remain clinging to a limb, and allow its body to be riddled with bullets without attempting to escape. It is most tenacious of life, and some wretches take advantage of this fact to have what they call sport! A shooting party will sometimes make an unfortunate Bear their target, and fire bullet after bullet into the suffering creature. The Koala clings so tightly to a branch sometimes when shot that after death the claws retain their hold of the bark, and the animal remains hanging there perhaps for days, or even weeks.

The form of the Koala is short and clumsy, and it does not possess a tail. The nose is short and broad, and of a black colour. The general colour of the fur is grey, under-parts white, or white tinged with yellow. The length of the head and body in a fullgrown specimen is about thirty-two inches. As regards distribution, it is confined to Eastern Australia. The food of the Koala consists chiefly of the tender shoots of the gum-trees; it pastures on young leafage, using its fore-paws in the quaintest manner to bring the food to its mouth.

The Native Bear makes a charming pet, but it is rather difficult to keep alive. A friend of the writer's owned a young Koala to which both he and his wife were much attached. It had been captured when an infant, and reared with infinite pains. It would follow the lady of the house about, and loved to be nursed 


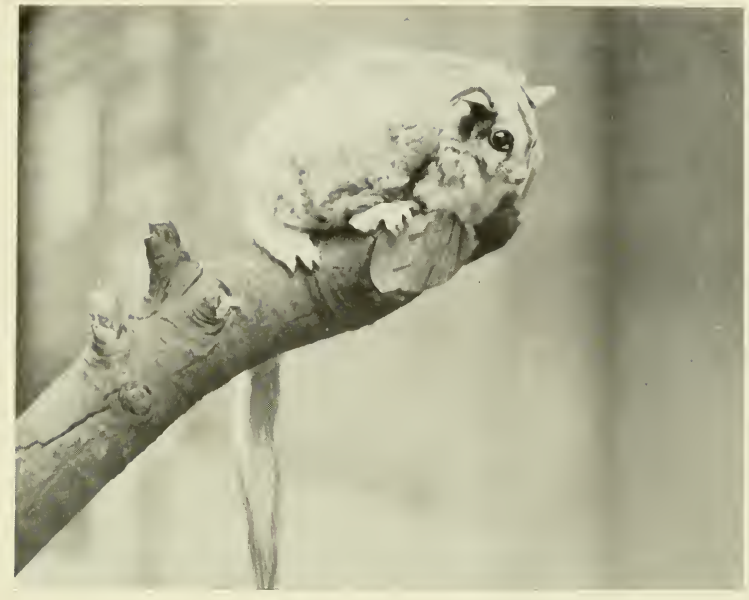

FIG. I 56.-SQUIRREL-LIKE FLYING OPOSSLM

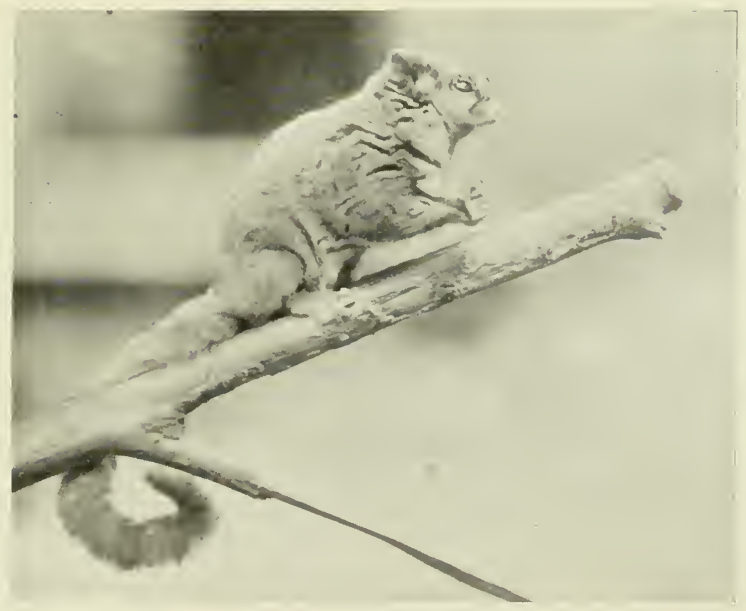

FIG. I 57--SHORT-HEADED FLYING OPOSSUM 


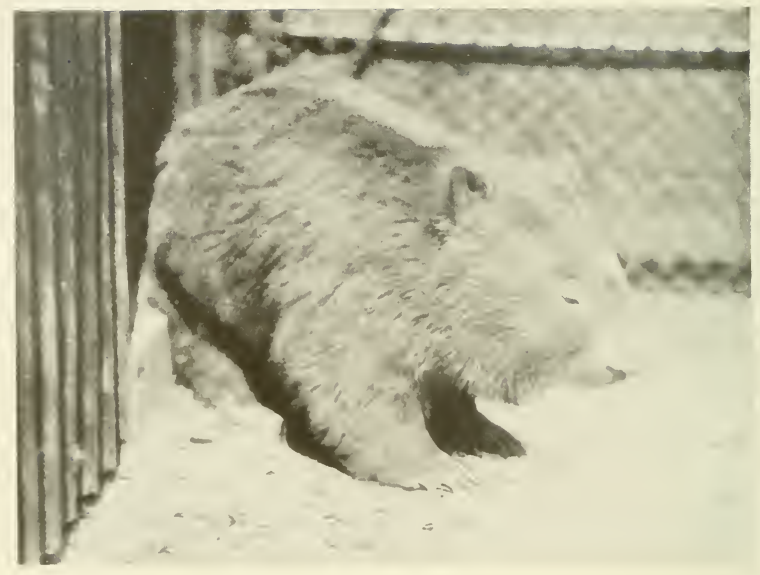

FIG. I $58 .-$ WOMB.IT

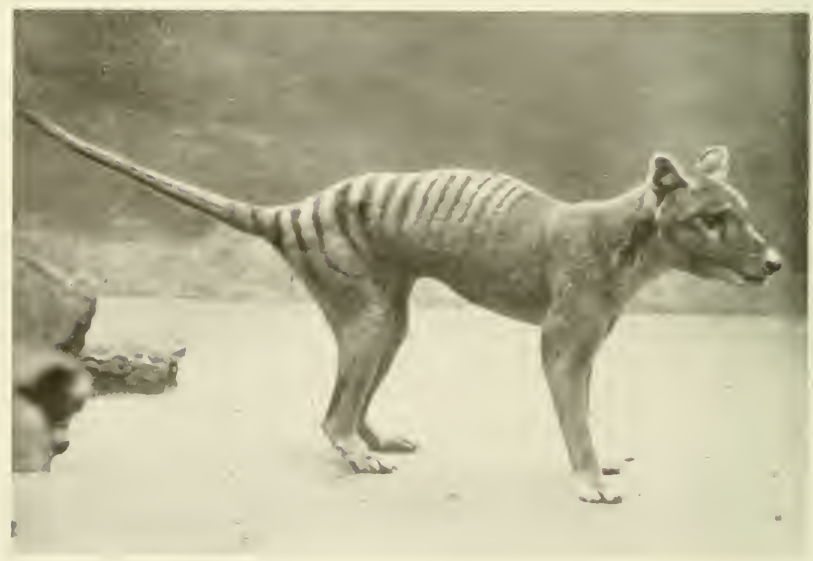

FIG. I 59. -TASMANIAN WOLF, OR TIGER 
by her; if she neglected to notice it, sometimes the Bear would grunt and groan in the most alarming manner until taken up and caressed. It came to an untimely end. One day the owner took his pet for an outing in a park near his city home, and gave it the freedom of the shrubs and trees; and the simple little mammal ate what proved his bane, the leaves of some plant which Nature had not ordained to be the food of Koalas. The Bear died in agony two days later, despite all the efforts made to save it.

Like many another Australian mammal, the Koala suffers greatly from parasites; its body is infested with hideous ticks which suck the blood of their unwilling host. The Bears frequently die from this cause, and their bodies may sometimes be found lying on the tracks through the bush.

CUSCUSES. - Five species of Cuscuses are known to naturalists; one kind is found in Northern Australia, as well as New Guinea and the Austro-Malayan islands, the remaining species being confined to the two last-named regions. They are nocturnal animals, and dwell in trees. Like the Koala, the Cuscuses are slow-moving and sleepy, but they are beautiful in appearance.

SPOTTED CUSCUS.-The best-known species is the Spotted Cuscus (Fig. I53) (Phalanger maculatus), which ranges over Northern Australia, Southern New Guinea, the Moluccas and Waigion. The Spotted Cuscus is curiously coloured. The upper surfaces of the body display various combinations of white, rufous and black, frequently spotted; under-parts white, tinged with rufous or yellow. The tail is of a deep yellow colour, and is about nineteen inches in length; the head and body measure about twenty-six inches. The fur of the body is soft, and the small ears are covered on both sides with soft woolly hair. The eyes are small, and red in colour. The Cuscus is credited with a bad temper; it is said that in captivity they are very quarrelsome, and will fight like cats if two are placed in the same cage. The Spotted Cuscus feeds on fruits and tender shoots, but the colonists bear it ill-will because they think that it raids the poultry-roost. Be that as it may, it is known that the species under consideration does not confine itself to an exclusive vegetable diet.

OPOSSUMS. - As mentioned in the introduction to the family Phalangeridæ, the name "Opossum" as applied to these Marsupials is erroneous, for both in structure and habits they differ markedly from the true Opossums, a carnivorous family confined to America. 


\section{I98 THE BOOK OF THE ANIMAL KINGDOM}

But, as Lucas and Le Souëf remark, the term "Opossum" is so firmly fixed in the minds of all Australians that it would be hopeless to attempt to bring any other for the Phalangers into general use. So in this work it is proposed to make concession to popular opinion, and call the Phalangers which are known in Australia as Opossums by that name.

COMMON OPOSSUM. - The Common Opossum (Trichosurus vulpecula) is distributed over the whole of Australia, with the exception of the Cape York district. It is a sprightly and engaging little animal, and a favourite with all nature lovers in the Commonwealth. As a pet it is highly prized, but, as is the fate of all Phalangers, it is persecuted by the pelt-hunters, many thousands being destroyed annually. The skins are extensively used in the manufacture of carriage and other rugs. The fur of the Common Opossum is thick and woolly, and of a grizzled-grey colour on the upper-surfaces of the body; the under-parts are white or yellowish. The tail is thick and bushy, measuring eleven inches, the length of the head and body of a full-grown Opossum of this species being about eighteen inches.

The Common Opossum is found in all sorts of queer situations, but it is chiefly a dweller in trees; it frequents the lofty gum-trees (Eucalyptus) of the bush, and during the day lies concealed in the hollow spouts. When the moon rises the Opossum wakes up, and its true life begins. It creeps softly about the branches and feeds on the buds and tender leaves of the tree in which its home is made. Rarely the animal comes down to the ground; it is so clearly "cut out" for an arboreal existence that it makes but an awkward figure on earth. The bush boys, when they desire to capture a full-grown Opossum alive, first of all wake it up if it be daylight when they go a-hunting, then, when the little creature has issued from its lair, they try to chase it into some tree of slender girth, whence it may be shaken to the ground. The capture is comparatively easy if this is accomplished. When the Opossum ventures to the ground it is frequently chased by a Fox or Wild Dog, and owing to its awkward gait is always in imminent danger of a violent death. At the base of a big gum-tree the bushman sometimes sees tufts of grey fur and the ground clawed up all about, telling of a tragedy enacted there.

'Possum shooting is a favourite sport with Australians; parties of young men sally forth on moonlit nights with Dogs and guns to 
encompass the destruction of the innocent little Marsupial. It is very cruel, but it is looked upon as "great fun " by the thoughtless sportsmen (?), and it is unlikely that while an Opossum remains in the bush "mooning" will cease.

The tail of the Opossum is highly prehensible, and of great service to the animal in its progress through the tree-tops. The 'Possum shooters are sometimes baulked of their prey; for the stricken creature in falling may twist its tail round a branch, and it will stiffen there in death, so that the animal remains hanging far out of reach. The Opossum is a most agile little creature, and it is delightful to watch them playing about the white boles of the gum-trees in the moonlight. At whiles they will pause on a bare branch, silhouetted against the moon's bright disc, and making a conspicuous mark for a gunner below. The methods adopted in trapping the Opossum are singularly cruel. The trapper searches for a "Possum tree," which is known by the marks of the claws on the trunk, the "blazed trail" of the Marsupial; a noose is fixed near the fork, so that the 'Possum coming down its accustomed track will poke its head into the fatal circle, and in attempting to escape tighten the noose and hang itself. When the noose is clumsily fixed the unfortunate captive may be only half strangled, and hang in agony all through the hours of darkness; its pain ends with the dawn, when the trapper comes and hits it on the head with a stick.

The Common Opossum is easily domesticated, and is not difficult to rear. But the intelligence of these Marsupials is not on a high scale, and although they become very tame and affectionate, it is rare to see a captive 'Possum that can perform any of those engaging tricks which animal-lovers are so fond of training their pets to perform.

But as half-tame pets the Opossums are delightful. In a country farmhouse once tenanted by the writer, the occupants obtained much pleasure and amusement from the Opossums which lived in the spreading branches of three old Moreton Bay fig-trees which shadowed the roof. At night the 'Possums would come down on to the roof and have fine revels in the moonlight. We could hear them thumping about, and those in the branches would drop the figs upon which they were feeding, the fruit pattering down like hailstones. On one occasion a too venturesome animal climbed the chimney-stack, and in poking its inquisitive pink-tipped nose into 
the yawning black cavity, overbalanced, and came tumbling down into the midst of the family. Fortunately for 'Possum it was a warm Summer night, and there was no fire on the hearth, or the consequences would have been much worse than they proved to be. Master 'Possum was captured after a wild scramble about the room, in which three chairs were upset and a valuable ornament or two on the mantelshelf broken. "Mr. Squeers," as the little captive was immediately named by one of the captors, who is a Dickens lover, lived happily in a big open-air cage for several years. Then one moonlit evening, the call of the wild being strong upon him, "Mr. Squeers" escaped from his cage and went to join his fellows in the fig-trees. Perchance to this day he lives among the broad green leaves, and enjoys arboreal gambols when the moon shines bright and the Southern Cross gleams on the dark blue mantle of night.

SHORT-EARED OPOSSUM. - The Short-Eared Opossum ( $T$. caninus) (Fig. 154) is closely allied to the Common species, but its distinguishing feature, the short ears, makes it easy to identify. The tail is thick and bushy, and the greater portion is black. The species has a fairly wide range over South-Eastern Australia. The writer met with it while on a recent trip among the islands of Bass Strait. In the romantic Kent group the lightkeeper's little daughter. Flora Robinson, had made a pet of a fine specimen of the Short-Eared Opossum. It was very tame, would perch on its mistress's shoulder, and follow her about the garden like a pet Dog. Strangers had to be cautious in approaching "Ruffles," for he would, in wayward mood, bite and scratch viciously, but the writer, with patience, succeeded in obtaining a charming photograph of the little maid and her pet, which has proved highly popular with audiences at lantern lectures delivered in Melbourne.

RING-TAILED OPOSSUM. - The Ring-Tailed Phalangers, or Opossums (Fig. 155), as we have decided to call these pleasing little creatures, are very abundant in many parts of Australia. There are several species, but it will suffice to deal here with one, the Common Ring-Tailed Opossum (Pseudochirus peregrinus), which has soft woolly fur, grey to rufous on the upper parts, and white or greyishwhite below. It is about the size of a small domestic Cat as to the body, and the tail measures a little over one foot in length. It is not a dweller in the eucalyptus forests so much as in the scrub-covered districts. In the coastal tea-tree scrub which grows near the writer's home on Port Philip Bay the Common Ring-Tail is abundant. 
One kept in a large aviary at the end of the bungalow verandah was closely observed. It was generally sleepy during the daytime, but uncoiled and came out of its snug bed in a tea-chest as the evening shadows commenced to deepen under the lilac bushes. "Chalgo" was fond of tender tea-tree shoots, but he also liked roses; it was a pretty picture when he sat nibbling the petals of a choice bud given him by the lady of the roses. After giving cage-life a fair trial, "Chalgo" decided in favour of the scrub, and one night went to join "his own people" outside the garden close.

The Ring-Tailed Opossum builds a big dome-shaped nest, which is said to resemble that of the English Squirrel; it is constructed of interlaced tea-tree twigs with the leaves upon them, and made very snug within. It is a favourite amusement of school-boys in Victoria to search out these nests, and shake the sleepy occupants out and chase them through the scrub. Many of the "Ring-Tails" are captured in this way, and taken to the boys' homes to become pets.

At the shops of the Melbourne bird-dealers, they are sometimes offered for sale at prices varying from five to ten shillings. They find a ready market, sailors from the ships in port being frequent customers; so that a good number must reach England and other countries overseas in the course of a year.

FLYING OPOSSUMS.- The Flying Opossums are among the most beautiful of all Australian mammals, and the curious parachute-like expansion of the skin along the sides of the body renders them of peculiar interest.

GREATER FLYING OPOSSUM.-One of the best-known species is the Greater Flying Opossum (Petauroides volans). It is of fairly large size, a full-grown specimen measuring seventeen inches from tip of nose to root of tail; tail twenty inches. The fur is as soft as silk and very long, the colour being dark-grey to black above, white or pale yellowish on the under-parts. The colour of the tail varies from ashy-grey to black. It will be realized from this description that the Greater Flying Opossum is a strikingly handsome creature; it is, indeed, fatally beautiful, the fur is coveted, but the skin is so tender that it is very difficult to remove it without tearing. The Greater Flying Opossum ranges over Eastern Australia, from Queensland to Victoria. The creature, despite its name, does not actually fly; the parachute-like expansions of the skin, mentioned above, aid in supporting the body when the animal makes its long leaps from one tall gum-tree to another. The 
writer has often seen these beautiful animals "flying" on moonlit nights, while seated outside his bush hut on the Olinda Creek, in the Dandenong Mountains (Victoria). First of all a dark form would be observed creeping along the bare branch of a giant gumtree, on the opposite side of the creek; on reaching the end of the limh the Flying Opossum would bunch itself up, and then, leaping lightly into space, go floating through the moonbeams like a shadow. The flight is in a downward direction, the Opossum always alighting on a bough or portion of a tree trunk much nearer the ground than its "leaping off" place. Sometimes when in flight these Phalangers scream piercingly, and they will make a similar outcry when alarmed.

YELLOW-BELLIED FLYING OPOSSUM.-The Yellow-Bellied Flying Opossum (Petaurus australis) is the largest species, the head and body of an adult measuring twelve inches in length and the tail thirteen inches. The fur on the upper parts of the body is brown, darkest along the backbone and over the parachute expansions of skin. The under-parts are deep orange. The long bushy tail is grey on the upper surface and orange below, darkening to black on the tip. This beautiful species inhabits the coastal ranges of Victoria and New South Wales.

SQUIRREL-LIKE FIYING OPOSSUM.-The Squirrel-Like Flying Opossum (Fig. I56) ( $P$. sciureus) is the intermediate species. It is of medium size and the fur is very beautiful, being silky and of a soft light-grey colour; there is a dark-brown or black stripe down the mid-line of the back. The colour of the fur on the under-parts is white, tinged with yellow. The parachute is dark-brown to greyish above, fringed with white or light yellow. The SquirrelLike Flying Phalanger is found in Eastern Australia, its range extending from Queensland to Victoria.

LESSER FLYING OPOSSUM.-The Lesser Flying Opossum ( $P$. breviceps) is the smaller of the three species which constitute the genus Petaurus. It is one of the dearest and prettiest little creatures imaginable. Clad in soft silky fur and with bright alert eyes, its every movement is full of grace. And it has most engaging ways. A young male of this species which the writer kept as a pet when liberated from its cage for a run in the study would climb about the furniture delightedly. And at times it would climb the stem of a small palm-tree growing in a bowl in a corner of the room; a charming picture the little animal made, clinging there and eyeing 
its master with mingled feelings, apparently of impudence and curiosity. Alas! my pet met with an accident and went untimely to the grave. This species is often referred to in the bush as the "Sugar Squirrel."

LONG-SNOUTED OPOSSUM.-In Western Australia is found the Long-Snouted Opossum (Tarsipes rostratus), which, differing widely from all others, has been placed in a sub-family by itself. Its form is small and slender and the head is long and narrow; the general coloration is grey. The Tarsipes, which is nocturnal in its habits, is a rare species, and very meagre information has been gathered regarding its mode of life in a wild state. It is provided with an extensile tongue, which it employs to glean honey from forest flowers; the tongue is thrust into the fragrant tubes after the manner of the big hawk moths, whose glimmering wings flutter about ivy-mantled walls at twilight.

Of a captive specimen of this species, Gould writes-

"It was strictly nocturnal, sleeping during the greater part of the day, and becoming exceedingly active at night. When intent upon catching flies, it would sit quietly in one corner of its cage, eagerly watching their movements, as, attracted by the sugar, they flew around; and when a fly was fairly within its reach, it bounded, as quick as lightning, and seized it with unerring aim, then retired to the bottom of the cage and devoured it at leisure, sitting tolerably erect and holding the fly between its fore-paws, and always rejecting the head, wings and legs. The artificial food given it was sopped bread, made very sweet with sugar, into which it inserted its long tongue, precisely in the way in which the Honey-Eaters among birds do theirs into the flower-cups for honey."

THE WOMBATS.-Differing widely from all other Marsupials, the Wombats are ungainly looking but most interesting animals. There are only three species, all included in the one genus.

COMMON WOMBAT. - The Common Wombat (P. mitchelli) (Fig. I58), which is distributed over New South Wales, Victoria and Tasmania, measures about forty-four inches in length. The fur is coarse and rough and varies much in coloration; it may be either yellow, grizzled-yellow and black or yellowish. The ears are short and rounded. This Wombat, like its congeners, is sturdily built and very strong, the muscles are powerful and the short stout legs are capable of much work; the hind-feet are provided with exceptionally strong claws adapted for digging, and the Wombats, as 


\section{THE BOOK OF THE ANIMAL KINGDOM}

a class, are digging and root-eating creatures. The tail is rudimentary, and there are distinctive dental features of interest chiefly to the systematists.

The Wombats, says Lydekker, may be regarded as filling in Australia the place occupied in the Northern Hemisphere by the Marmots and in South America by the Viscahas, both of which are members of the Rodentia.

The Common IVombat, which is known in some parts of Australia as the "Bush Pig," lives in burrows which it excavates in the hard ground in rocky country; sometimes natural clefts in the rocks-small caves or holes-are taken advantage of ; but it is very little trouble for the IVombat to make its own dwelling, for with its powerful claws it works rapidly, making the clods fly to some purpose. The Wombat is a perfectly inoffensive animal, and its nature is gentle; but it is said to be a very stupid animal, making no attempt to evade capture when hunted. Perhaps this statement needs some qualification. Its gait is an awkward shuffling in keeping with the animal's clumsy form.

The Wombat is hunted a good deal, but the skin only is of value, the fur being too coarse for any purpose, save, perhaps, to serve as portion of a door-mat; the writer has seen Wombat skins lying on the door-step of many a bush dwelling.

TASMANIAN WOMBAT.-The Tasmanian ITombat (P.ursinus), found in Tasmania and the islands of Bass Strait, is much smaller than the preceding species, in this respect departing from the general rule indicated by Mr. Oldfield Thomas, that Tasmanian mammals are of larger dimensions than their allies of the Australian mainland.

The writer recently had some interesting experiences in connection with this species. During a natural history expedition among the Bass Strait islands, at the request of the Curator of the Melbourne Museum, he endearoured to obtain skins of the Wombat known to exist on Flinders Island. Uncertainty existed as to the identity of this animal; it might be only a variety of the Tasmanian Wombat or identical with it, but, on the other hand, it might be an entirely distinct species. So the Museum authorities were naturally very anxious to obtain specimens for comparison with a series of $P$. ursinus from the larger island. Three dilapidated skins, almost useless for scientific or any other purposes, were found lying in the bush at the rear of a bark hut inhabited by 


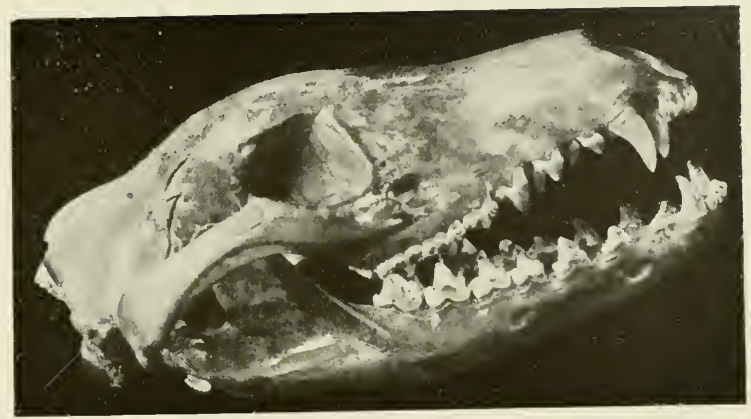

FIG. I60. -SKULL OF TASMANIAN WOLF

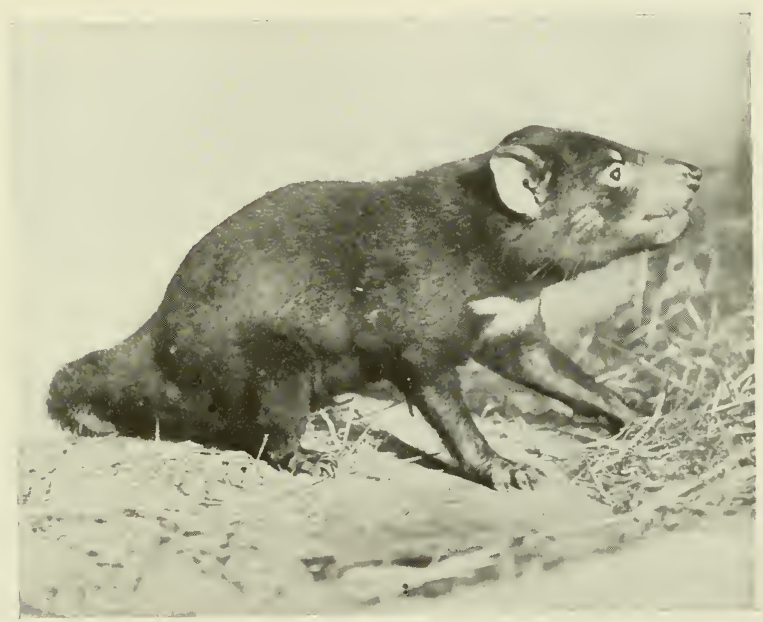

FIG. I6I.-TASMANIAN DEVIL 


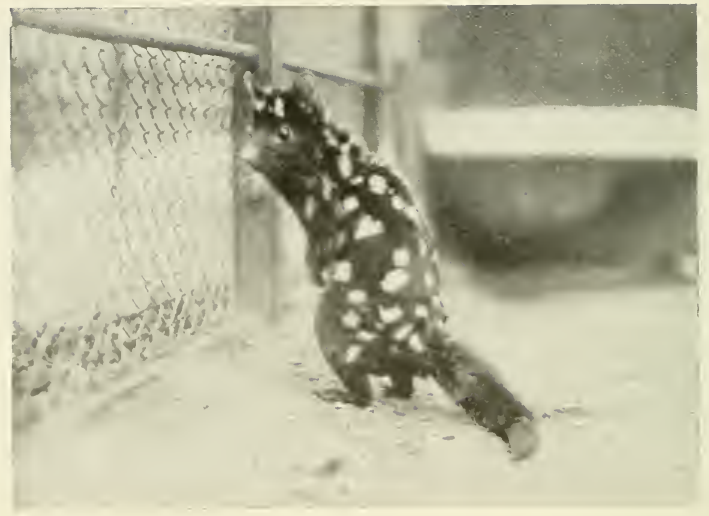

FIG. I62.-DASYURE, OR NATIVE CAT OF ALSTRALA

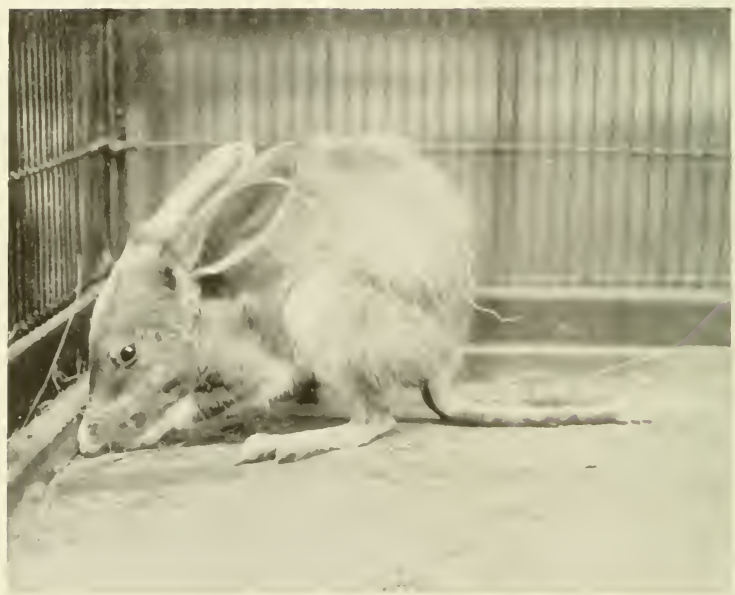

FIG. I63. R.ABIBIT-EARED B.INDICOOT 
some half-caste fishermen. The natives in response to eager questions, said that there were plenty of "Badgers," the name by which they know the Wombat on the island, and promised to procure specimens. But this they failed to do, although as much as ten shillings a-piece was offered for good skins.

A few months later the writer again visited Flinders Island, and renewed his quest for the mysterious Marsupial. Another mangy skin was discovered (it was in use as a door-mat), but the island fishermen had not succeeded in procuring fresh skins. It was very disappointing. Naturalists, however, are not easily discouraged, especially when on the trail of the unknown, and the quest in this instance was not forsaken. Landing, a day or two later, in a beautiful little bay, further round the coast, the writer rambled along the lonely shore for some distance, when suddenly he came upon the spoor of a large animal's foot-prints in the sands, and followed them up to the entrance of a cave in the rocks on the edge of the scrub. It was the home of the Wombat. All about were evidences of recent occupation. But the cave was deep and narrowed towards the end; it could not be fully explored.

It was a wild day; the rain fell in blinding sheets, and the wind moaned eerily about that desolate place, so full of interest and of possibilities. A rough pencil sketch was made of the locality and of the cave in the rocks. Then the signal of recall came from the little steamer in the bay, a signal that on these coasts of reefs and shoals and sudden squalls cannot be disobeyed, and the naturalist was compelled to hasten away from his "find." $\mathrm{He}$ has the satisfaction, however, of knowing that specimens of the Flinders Island Wombat have at length been secured, and are now being "worked out" by the zoologists of the Melbourne Museum.

HAIRY-NOSED WOMBAT.-The last species to be described is the Hairy-Nosed Wombat ( $P$. latifrons), which is characterized by having soft, silky fur, mottled-grey above and greyish on the underparts. It measures about forty inches, and is an inhabitant of South Australia.

MARSUPIAL MOLE.-The Marsupial Mole, which is found only in Central Australia and adjacent parts of the Western State, is a rare and very curious animal. Unlike the European Mole, it does not make a permanent run, but burrows under the loose sand of the surface in quest of food, going deeper into solid earth for the breeding season. Professor Baldwin Spencer, F.R.S., of the 


\section{THE BOOK OF THE ANIMAL KINGDOM}

Melbourne University, and Dr. Stirling are the principal authorities on this remarkable Marsupial and its habits. The eyes of the Notoryctes are atrophied and it has no external ears. The fur is long and silky, the colour varying from a light shade to a deep chestnut-brown; the tail is hard and distinctly "ringed," and is about one inch in length, while the head and body measure about six inches. The Marsupial Mole is a dweller among sand hills.

POUCHED MICE. - The animals belonging to this genus are widely distributed; they range over the whole of the Australian continent, New Guinea and adjacent islands. Shrew-like in appearance, they are very charming little creatures, arboreal in habits and live on insects. Thirteen species have been described, and all are of small size.

BRUSH-TAILED POUCHED MOUSE.-One of the most familiar forms is the Brush-Tailed Pouched Mouse ( $P$. penicillata), which is found all over Australia, except in the far North. It is about the size of the Common Rat (Rodent), stout in form and clad in short, coarse fur, grizzled pale-grey above and white or pale-grey on the under-parts. The length of the head and body is about ten inches, while the tail, which is covered from about midway to the tip with long black hairs forming a brush, measures six inches. The BrushTailed Mouse is a tree-dweller and nests in hollow spouts and holes in the branches. It is very graceful in its movements and makes a delightful pet. Strangely enough, just before the writer started to describe the Pouched Mice, a fine example of the species under consideration was brought to him for identification. It was mutilated, a domestic Cat having captured the little animal in the vicinity of a bush homestead.

NARROW-FOOTED POUCHED MICE.-The Narrow-Footed Pouched Mice of the genus Sminthopsis are distinguishable from the Phascologale by the characteristic form of the hind-feet, which their name implies. In the Phascologale the hind-feet are broad, with naked soles. In the Narrow-Footed Mice the soles of the hind-feet are granulated. There are six species of these dainty creatures. The Common Pouched Mouse ( $S$. murina) measures only three and a half inches from tip of nose to root of tail, and the tail is about the same length. The colour of the fur is much the same as that of the household Mouse, which indeed the animal closely resembles in other external aspects. 


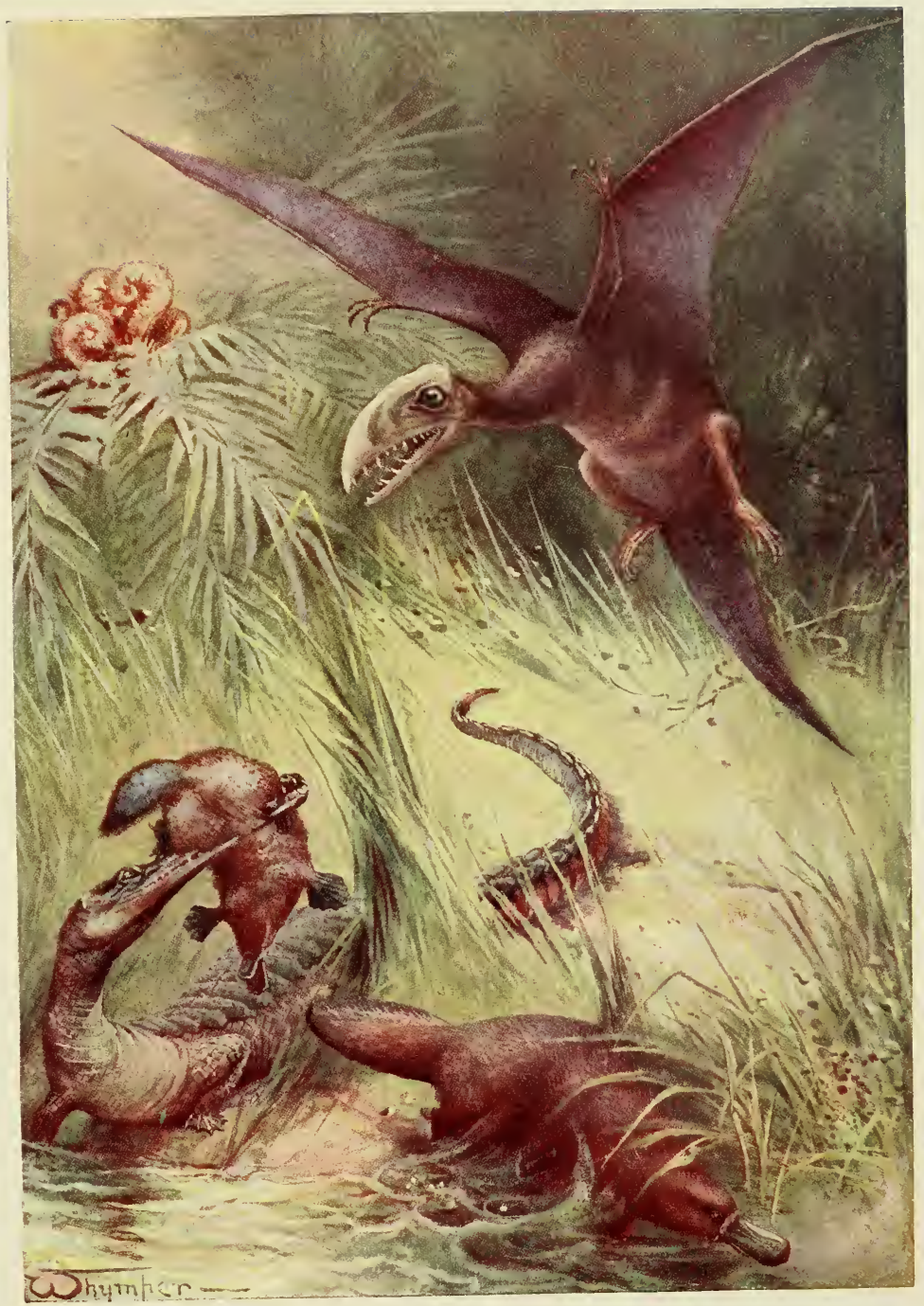

An extinct Pterodactyle as it appeared in flight, the extinct Teleosaurus (on left) and two examples of the Duck-Billed Platypus, the latter still existing in Australia and Tasmania. 

FAMILY DASYURID压. - The Family Dasyuridæ includes those remarkable carnivorous Marsupials, the Tasmanian Wolf and the Tasmanian Devil; it also embraces the so-called Native "Cats" or Dasyures.

TASMANIAN TIGER. - The animal known to the colonists as the Tasmanian "Wolf" (Fig. 159) or "Tiger," is confined to the Island from which its "front" name is derived. It has been so ruthlessly hunted down that it is now exceedingly rare, and perhaps within measurable distance of total extinction. Certainly it takes toll of the Island flocks, but Science demands that such an interesting animal as the Thylacine should not become a mere memory or be represented only by skulls and stuffed skins in the museums of the world.

Wolf-like in general appearance, the Thylacine has short close fur of a pale greyish-brown colour, with a tawny tint; the hinder portion of the back is transversely banded with blackish-brown stripes, sixteen in number; these are continued on the tail, which has a dark crested tip and measures twenty-one inches in length. The head and body are forty-four inches "over all." The Tasmanian Wolf is nocturnal in its habits, spending the hours of sunlight in a cave of the rocks or a hollow tree trunk. It inhabits only the wildest parts of the Island, and in the night-watches issues from its lair to raid the flocks. It is a lonely hunter, and its ferocity makes it a formidable adversary for the shepherd's faithful dogs. The cry of the Thylacine is a low guttural growl or cough rapidly repeated. Four young ones are produced at a birth.

TASMANIAN DEVIL.-The Tasmanian Devil (Fig. I6I), like the Thylacine, is no longer common as it was in the early days of settlement. The Devil is a great sheep-killer, and so its days on earth are numbered. It is nocturnal in habit and spends the day in its burrow. In general appearance the Tasmanian Devil resembles a Bear. The body is very powerfully built, and the head large and broad. The fur is thick and close and generally of a black or blackish-brown colour. White patches are sometimes present on neck, shoulders, rump and chest, the horse-shoe-shaped marks in the latter position being constant. The length of the head and body is about twenty-eight inches in a full-grown specimen, tail twelve inches. The animal is provided with very powerful canine teeth; it is of sluggish disposition, but so fierce when aroused that it becomes a foe which the sheep-dogs are loath to attack. Its 


\section{THE BOOK OF THE ANIMAL KINGDOM}

cry somewhat resembles the bark of a dog, but is hollow-sounding, and it occasionally grunts or snorts.

NATIVE CATS. - The Dasyures, which are universally known in Australia as "Native Cats," are Marten or Civet-like creatures, slender in form, and with long narrow ears and long hairy tails. In all species the body is spotted. Their range comprises Australia, Tasmania, New Guinea and the adjacent islands. The Native Cats are both flesh-eaters and insect-eaters, and, generally speaking, their mode of life is arboreal. They are not loved by owners of poultry; but despite their depredations in this direction, one cannot but sorrow for their rapidly decreasing numbers.

The Common Native Cat (Fig. 162) (D. viverrinus) is a slenderly formed animal of medium size, clad in pale-grey or black fur, thick and soft. The large white spots on the body enhance the beauty of the animal's appearance, and the unspotted bushy tail, with its white tip, does not lessen the effect. A fierce little beast, the Common Native Cat is not averse to the neighbourhood of man. It is said that they will haunt the vicinity of a homestead where there are hen-roosts and take toll during hours of darkness. It is with the Dasyures evidently a case of cupboard love. The Common Dasyure is found in Eastern New South IVales, Victoria, South Australia and Tasmania.

BANDICO0TS. - The Bandicoots (Fig. 163) are small burrowing and omnivorous animals, ranging over Australia and New Guinea. They are of quaint but delicate form, the ears being long and narrow and the nose short and slender. The hind-limbs are longer than the fore pair and the tail is long and not prehensile. Lydekker regards the Bandicoots as a highly specialized offshoot from the Dasyures.

The Bandicoots are all ground dwellers, and walking through the bush one frequently frightens the little animals from underneath bushes and logs. They are agile, and dart quickly into their burrows when disturbed while feeding. Of the many species of the True Bandicoots (Genus Peramcles) only one can be described here. The Short-Nosed Bandicoot ( $P$. obesula) is the most widely distributed species, being found in all parts of Australia south of the tropics and in Tasmania. The length of the head and body is about fourteen inches and of the tail five and a half inches. Rather stout in form and with coarse golden-brown fur, pencilled with 


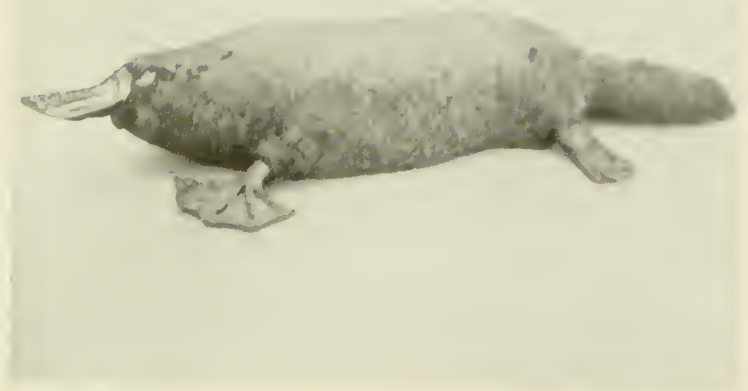

FIG. I6 4 - PLATYPUS

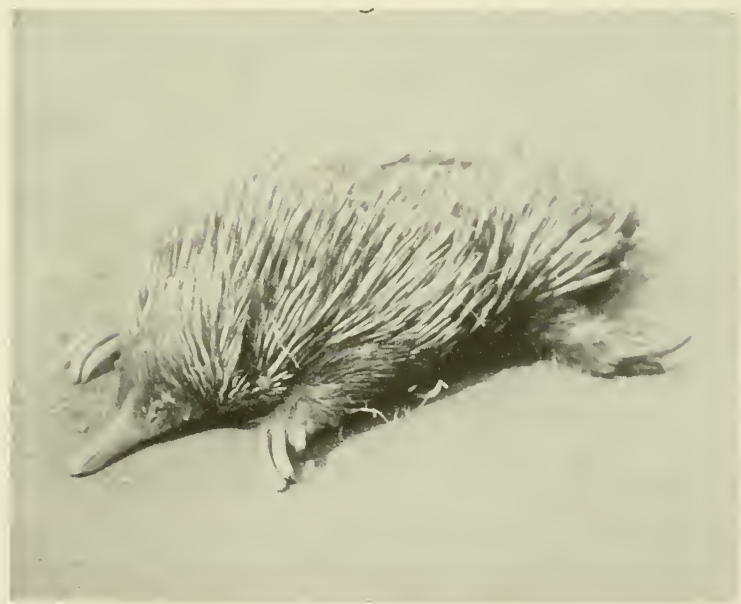

FIG. I65.-ECHIDNA 


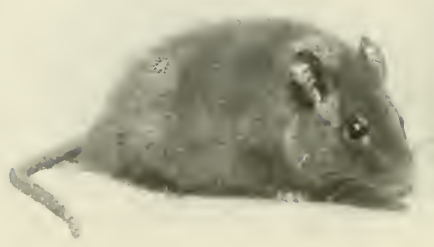

FIG. 166. - BLACK RAT

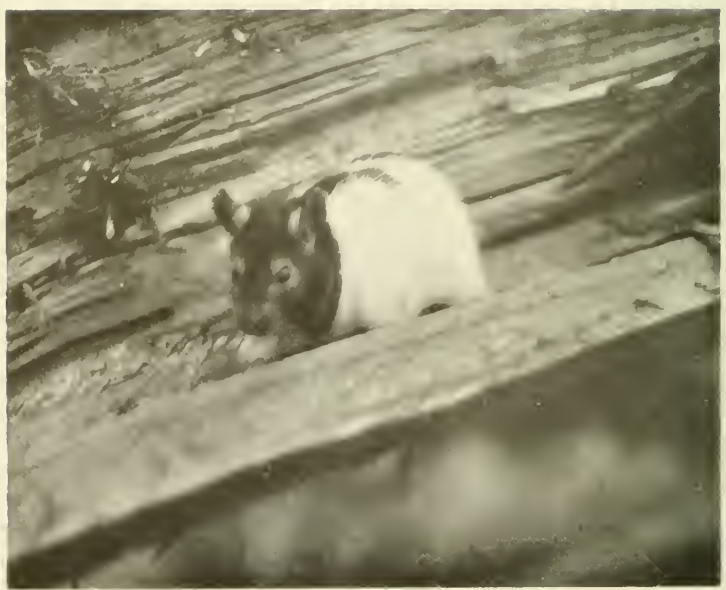

FIG. 167.-TAME RAT 
black, the Short-Nosed Bandicoot is a handsome animal. It is said to do much damage to root crops, and settlers bear it no goodwill. A very popular saying in Australia is, "Miserable as a Bandicoot"; it is applied to persons of lugubrious countenance and is supposed to denote that condition which is sometimes referred to as a "fit of the blues." Now the Bandicoot is a bright and pretty little animal, and does not deserve that its name should be associated with human misery. It is difficult to imagine how the saying in question originated.

MONOTREMES. - The Monotremes, or Egg-Laying Mammals of Australia, are perhaps the most interesting of all living animals. They constitute a distinct order (Monotremata) and also a separate sub-class (Prototheria), being radically distinguished from all other living representatives of the class Mammalia, which they connect with the lower classes of the Vertebrate sub-kingdom. The most primitive of living mammals, the Monotremes have been extensively studied by systematic zoologists and biologists, and there is difference of opinion as to their classification. But in a popular work on natural history it is not necessary to deal with such questions. For many years naturalists refused to believe the reports that came from Australia, stating that the Platypus (Ornithorhynchus) and the Porcupine Ant-Eaters (Echidna and Pro-Echidna) were mammals which nourished their young with milk after the mode of all other members of their class, yet laid eggs like a Bird or a Reptile. Anatomists and zoologists alike were sceptical until actual proof of the remarkable habits of the Monotremes was forthcoming. This cautious attitude was surely not unreasonable. Who, before the discovery of the Platypus and the Echidnas, ever heard of such an anomaly as an Egg-Laying Mammal? It would seem to those early naturalists a zoological nightmare. One is tempted to quote Hamlet-

"There are more things in heaven and earth, Horatio,

Than are dreamt of in your philosophy."

"The Monotremes," writes Lydekker, "derive their name from the circumstance that there is, as in Birds and Reptiles, but a single aperture at the hinder extremity of the body from which are discharged the whole of its waste products, together with the reproductive elements; the oviducts opening separately into the extremity of this passage, which is termed the cloaca. Reproduction is effected by means of eggs, which are laid and hatched by the female 


\section{IO THE BOOK OF THE ANIMAL KINGDOM}

parent; while after the extrusion from the egg, the young are nourished by milk secreted by special glands situated within a temporary pouch, into which the head of the young animal is inserted and retained. . . The milk-glands are of simpler structure than those of other mammals. . . . The skeleton differs from that of the Higher Mammals, and thereby corresponds with that of certain lower Vertebrates, in regard to the structure of the shouldergirdle, or that portion which serves for the support and attachment of the bones of the fore-limb."

The nearest allies of the Monotremes among the Vertebrates apparently are a group of Reptiles, whose fossil remains occur in the Secondary Rocks of South Africa. These Anomodonts, as the fossil Reptiles are termed, are, says Lydekker, "the only known vertebrates having a shoulder-girdle of the type characterizing the Monotremes." For many other interesting facts concerning the structure and affinities of the Monotremes, the student is advised to consult Mr. Lydekker's handbook, Marsupials and Monotremes.

PLATYPUS. - The Platypus, or "Duck-Bill" (Fig. 164), as it is often referred to in Australia, is a shy aquatic animal inhabiting rivers and streams of Queensland, New South Wales, Victoria, South Australia and Tasmania. It is not a large animal, the head and body of an adult male measuring eighteen inches, tail six inches. The female is of slightly smaller dimensions. The general colour of the fur on the upper parts of the body is umber or blackishbrown, and on the lower portions greyish-white. The broad, flat bill or beak is encased in sensitive skin, black in colour. The tail is broad and flattened and the feet are webbed. A large horny spine or spur is present on the hind-foot of the male. There has been a great deal of controversy regarding this curious organ, which is connected with a gland which is said to secrete poison. Old bushmen will relate stories of having been "stung" by a Platypus with this spur and suffering dire consequences. How much reliance is to be placed on such statements it is difficult to judge. No proof has yet been given that the Platypus is a "poisonous" animal, and the function of the spur cannot be said to be rightly understood at present. It has been suggested that the horny process is used by the male as a weapon when fighting for the possession of a mate.

The Platypus is of such a retiring disposition that it is very difficult to observe in a wild state. It spends a great part of its life in the water, and is a splendid swimmer and dives with ease 
and grace, disappearing when disturbed with astonishing celerity. Sometimes on a moonlit night these strange creatures may be seen disporting themselves in a river or stream. They do not love the sunlight, and rarely come ashore. The Platypus makes its home, a long narrow tunnel, in the banks of the stream wherein it obtains the aquatic insects and shell-fish on which it subsists. The burrow is excavated obliquely upwards from an entrance below the surface of the water. At the end it opens out into a domed chamber, which is snugly lined with dried grass bents, leaves, etc. The burrow is often over twenty feet in length. From one to four eggs are deposited by the female Platypus in the domed chamber described. The eggs are of an oval shape and the colour is dirty-white. The texture of the outer shell is leathery, as in the case of the Turtles and other Reptiles.

In Victoria, the State where the writer resides, the Government has wisely placed the Platypus on the "continuously protected" list. It would be a national, nay, a world calamity for such a wonderful animal to cease to exist.

ECHIDNA.-The Echidnas, or Porcupine Ant-Eaters (there are three varieties), form the second family of the Monotremes. They differ in external appearance from the Platypus and also in habits. They are burrowing animals, exclusively terrestrial, inhabiting forests and rocky localities. The typical variety, Echidna aculeata (Fig. 165), is known to the colonists variously as the AntEater, Native Porcupine and Australian Hedgehog. This variety is found all over Australia and Tasmania, also in South-Eastern New Guinea. The colour of the hair is black or dark-brown above, brown on the under-parts of the body. The long spines of the back usually conceal the fur; they are yellow with a black tip. The length of the head and body of a full-grown Echidna is about seventeen inches. The limbs are very strong, and the curved claws on the hind-feet are specially adapted for digging, which appears to be one of the Echidna's favourite occupations. Owing to their fossorial habits it is difficult to keep specimens of the Native Porcupine in captivity; they will burrow in the hardest ground, tunnel under the barriers of their prison, and so farewell.

As one of its popular vernacular names implies, the Echidna in a wild state subsists on ants and their eggs. The head is elongated into a slender cylindrical beak, destitute of teeth and provided with a small mouth. The tongue is long, slender and 


\section{THE BOOK OF THE ANIMAL KINGDOM}

extensile; it is the instrument with which the Echidna captures its tiny prey. The queer little animal digs into the nests of ants and termites ("White Ants"), and with its whip-lash tongue sweeps up the inmates by hundreds. Observers state that the tongue, which is coated with sticky saliva, is thrust into the breach in the nest and drawn back into the Echidna's mouth when covered with ants. The Echidna is a clumsy-looking creature and it moves over the ground at a ludicrous, shambling walk. But when it comes to burrowing the Echidna has no peer for celerity. When burrowing in soft soil it works so quickly and its powerful claws are such perfect fossorial appliances that the animal seems to sink into the ground as though it were in a quicksand. The Native Porcupine,

- which is nocturnal in habit, will, if attacked, roll itself up like a Hedgehog, the sharp spines forming a defensive armour, beneath which the vulnerable parts of the animal are secure.

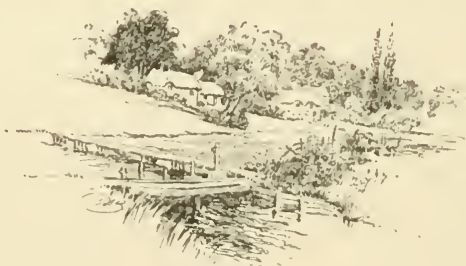




\section{CHAPTER XI}

\section{RATS AND MICE}

WE are concerned in this section with the Rats and Mice, animals belonging to the Rodentia which do not seem to appeal to many people, but whose life-histories are well worth examination. Having had some acquaintance with the detestable Brown Rat, which almost every one admits is a pest of which we might well be rid, the average individual appears to class all the rodents in the same category. This, however, gives quite a wrong impression, as many of these Rats and Mice, and also the Voles, are beautifully clean, well groomed and bright little beasts, feeding, many of them, upon a vegetable diet, and very unlike the Brown Rat in many respects. $\mathrm{He}$, of course, is sometimes a veritable scavenger, but, alas! he is also the disseminator of disease, the perpetrator of untold damage to grain and other things. Yet, in spite of almost everybody's hand being against it, it still flourishes like the cosmopolitan Sparrow. Probably the Rat and the Sparrow are the best-hated animals in the world from the point of view of the damage they are responsible for, and the general distaste with which they are held. And although war is constantly waged against both bird and mammal, they are still found in very considerable numbers. It is as well to make brief reference to the two, if for no other reason than because the bird has been referred to as the "Avian Rat." The title is somewhat misapplied, but we cannot enter into a controversy regarding it here.

BROWN RAT.-Although so well known, at any rate by sight and by the damage it does, the Brown Rat is worthy of consideration before we pass on to consider more desirable species. Its original home was China, but it now has an almost world-wide distribution. When it is remembered that it has become a citizen of the world within about the last two hundred years, some idea may be gained of the extraordinary rapidity with which its travels have been conducted. The rodent seems to have made its first appearance in England about the middle of the eighteenth century, and not only 


\section{I4 THE BOOK OF THE ANIMAL KINGDOM}

has this well-hated pest been carried to different parts of the world on board ship, but it is authentically recorded to have swum rivers and seas in immense numbers, and so set up a colony in another clime. Not content with thus establishing itself, the Brown Rat has waged incessant war with the Black species, and both in England and on the Continent has almost successfully exterminated it !

This voracious beast will eat almost anything. Nothing seems to come amiss to it, the veriest filth imaginable being greedily relished. It is only fair to notice that on occasions it is an animal scavenger, eating carrion, refuse, etc., but grain, eggs and young birds, young rabbits, fish and other creatures are also devoured. It is often found near and in water, and is stupidly referred to as the Water Rat, being confused with the dapper and innocent Water Vole, one of the cleanest and happiest little fellows under the sun. The misdeeds of the Brown Rat are, I venture to assert, often erroneously attributed to the herbivorous Water Vole, a delightful Beaver-like rodent whose antics in and around the water will amply repay observation.

One great reason why the Brown Rat multiplies and spreads so rapidly, when once it has become firmly established, is its extraordinary fecundity. It breeds from three to six times a year, the female first giving birth when she is only about three months old. As a rule the litter consists of about ten young ones, although this is only a fair average, and larger families are often reared. A simple calculation may be made to illustrate how rapidly this mammal can multiply its numbers, for if we calculate three litters of ten each being produced every year, a single pair, if left alone, would, in the short period of three years, have a progeny of ten generations, numbering no less than twenty million, one hundred and fifty-five thousand, three hundred and ninety-two. Whilst if the sum be carried a little further, we find that the eleventh generation, due at the beginning of the fourth year, would number over one hundred millions !

It is calculated that in France alone the Brown Rat is responsible for at least $\mathcal{E} 8,000,000$ worth of damage every year, for it not only eats two ounces of corn every day, but destroys quite as much as, if not more than, it eats. Both in the United States and in England efforts have been made to eradicate this, the worst of all mammalian pests, but the animal is still plentiful almost everywhere.

The greatest $\sin$ attributed to it-even if the enormous damage 


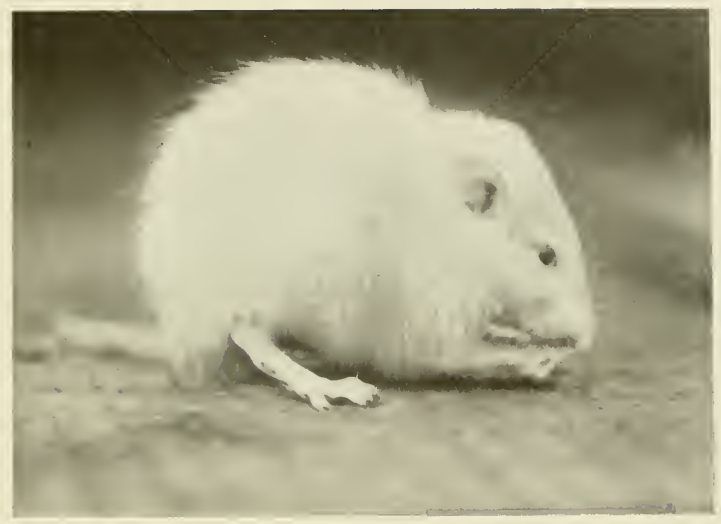

FIG. I68.-WHITE RAT

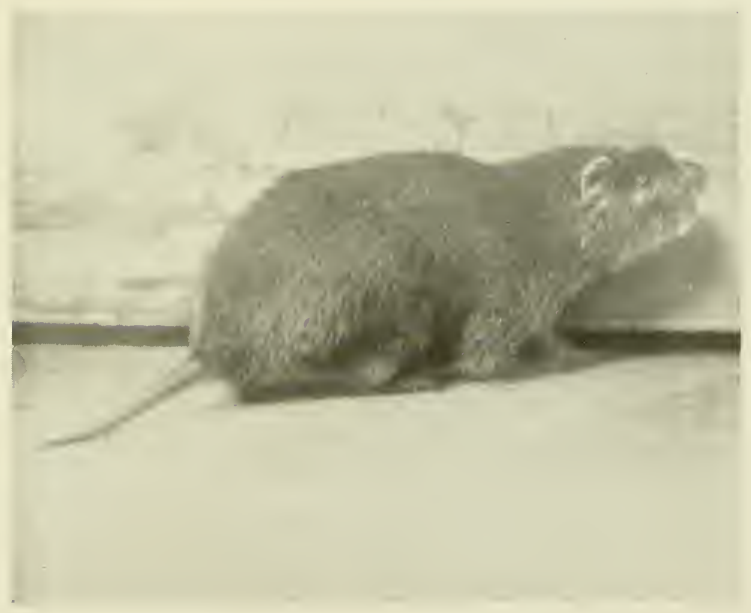

FIG. I69. CANE RAT 


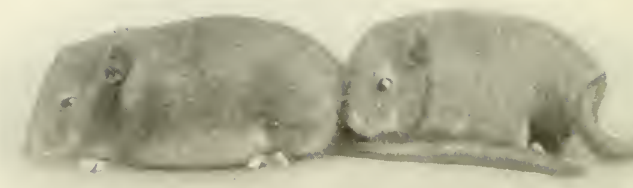

FIG. I TO. -DORMICE

FIG. ITI. CANADIAN JUMPING MOLSE 
it commits is overlooked-is the dissemination of disease, for, during the years 1906-08, it is computed that in India alone the ravages of this animal by spreading the deadly plague resulted in the deaths of considerably more than five million people! Disease is very prevalent among the Brown Rat, and when some of the food partaken of and the haunts frequented are borne in mind the reasons do not appear far to seek. The animal is infested with fleas, and these detestable parasites, having sucked the blood of a plaguestricken Rat, leave the dead body when there is no longer any blood to suck, and thereafter perchance alight upon a human being, to whom the fleas convey the plague bacillus.

In spite of all this we are told that in China this Brown Rat is fed up for the purpose of food. It then turns the scale at seven or eight pounds, and is not unlike a small sucking-pig! Buckland refers to these Rats which are used by the Chinese for food, and says that he saw "a dried Rat bought in the market of a Chinese town. It had been split down the centre, powdered with some white substance, and pressed under some heavy weight, as was evident from its shape, its appearance being very much like that of the common English haddock. These John Chinaman buys, soaks in water, and then dresses "more suo '-boils, roasts, or fries."

This animal is also a cannibal, for it will invariably prey upon a fellow Rat that is in trouble, and when hard put to it for a food supply the strong take advantage of the weak, and we have an apt example of the survival of the fittest.

Whenever it can do so, the Brown Rat will make good its escape from mankind, but if cornered it may prove an awkward customer to deal with, and a farmer in my own county relates an interesting incident which occurred to him, and which shows that when in a massed company of several individuals this fecund rodent possesses considerable courage and daring. The farmer referred to states that he was crossing a common when he came across a battalion of about one hundred Rats. Although he endeavoured to ward off their attention, the detestable beasts surrounded him, some running up his body to the shoulder and biting severely, "especially upon his hands." Other instances are forthcoming of fatal combats with this animal pest, although, true enough, savage attacks made upon mankind are few and far between.

BLACK RAT.-The Black Rat (Fig. I66) is still found in a few parts of England, but has been exterminated by its formidable rival 


\section{I6 THE BOOK OF THE ANIMAL KINGDOM}

the Brown species from many of its former haunts. Elsewhere it is widely distributed over the greater part of Europe, and is also found in many other parts of the world, whither it has been carried in vessels. Its introduction to the New IVorld dates from about 1554 .

The Black Rat varies a great deal, and in consequence of this we find a number of varieties known by such names as the Alexandrine Rat, which is distinguished by the softer reddish or greyish fur and the white under-parts; the Tree Rat from India, Ceylon and Burma, which resembles the last-named excepting that it is smaller; the Hill Rat from Nipal and Sikhim, which has a shorter tail; and the Andamanese Rat, which has, curious to relate, a number of spines among its fur.

The habits of the Black Rat mostly resemble those of its Brown relative, but we learn that some of the varieties found in other countries exhibit different characteristics, one kind found in India being said to be entirely arboreal, living among the cocoa-nut palms and never coming to the ground. Records show that when it was a prolific species in England, the Black Rat perpetrated considerable harm and was a pest to the farmer. Its fecundity is equal to that of the Brown Rat, and its disappearance is due simply to the presence of a keener and more formidable rival who kills and eats it whenever opportunity offers. There seems little doubt that although also known as the Old English Rat, this species was introduced from the East, and is not indigenous to Britain. It measures about seven inches, with a tail as long as, if not longer than, the body. It is deep iron-grey or almost black above, the under-parts being lighter: it has dirty, pale flesh-coloured feet, and the hind-feet are so formed that they can be turned round. By this means the claws are set in an opposite direction and the rodent can walk on an upright surface, or come down the same head first.

Attention need only be drawn to Figs. 167 and 168 , showing a tame Black-and- White Rat and a White $R$ at respectively. These make nice pets for children, as they do not seem to exhibit any savage tendency like their wild relations; but similar to the Black Rat when kept in captivity, they have a nasty habit of eating their own young ones just when they are becoming interesting. What is the reason of this extraordinary habit among some kinds of animals, such as Rats, Dogs, Pigs, Rabbits and others?

CANE RAT. - The Cane Rat (Fig. I69) is an African animal which belongs to a genus different from that of the species already described. It is a large animal, measuring some twenty-one inches 
including the tail, the latter attaining a length of from five and a half to eight and a half inches. It is distinctly Rat-like in general appearance, and has coarse fur and a sparsely-haired tail.

It is characterized by possessing three deep grooves on each of its broad red upper incisor teeth; these grooves giving the name to the genus of which this animal is the only representative. The fur is brown for the most part, the throat dirty-yellow, chin and upper lip whitish, and pale brownish-yellow below.

The Cane Rat is widely distributed throughout Africa, and two native names for it are those of "Ivondue" and "Yumba." The food seems to consist of ground-nuts and roots, and it not only burrows for these, but also makes an underground home, excepting in South-Eastern Africa, where, according to Mr. W. H. Drummond, this rodent does not excavate a burrow on its own account, but takes advantage of a hole or crevice among rocks or stones, or the uninhabited burrow of an Ant-Eater or Porcupine.

DORMOUSE.-This elegant-looking, but disappointing animal when kept as a pet (Fig. I 70) has for long been a favourite of mine, and before giving a description of it the following notes from my Nature Diary may perhaps afford interesting reading-

"It was Winter-time; the land all round was in the ice-firm grip of King Frost. At such season the thoughts of those who love and care for the wild animals naturally turn to the inhabitants of the woods, fields and hedgerows, for hard weather means hard hunting for both man and beast.

"Wild creatures, it should be noted in passing, do not suffer so much from cold as from hunger, but some tiny folk-wiser perchance in their time and generation than their brethren-make up their minds, so soon as the chill of Autumn is in the air, to retire to some secluded nook and there pass the Winter.

"There has been a keen hoar-frost overnight; let us put on our thick clothes and take a little journey into the country. At almost the first step we are wandering in Wonderland, for see how the trees, hedgerows and grasses by the wayside are literally festooned with ice-crystals which sparkle in the Winter sunshine like jewels in a King's crown.

"People often complain of the dulness and monotony of the country, but if they took intelligent interest in the wild tenants of the countryside, they would find themselves in a wonderland of beauty at all seasons of the year.

"The air is decidedly nippy, but the ground is clean and hard, 


\section{THE BOOK OF THE ANIMAL KINGDOM}

and as we tread upon a dead branch that has been torn from its moorings in the tree-top overhead, it cracks like a pistol-shot and frightens a courageous Rabbit which had been tempted to come from its underground home by the invigorating rays of the warm sunlight.

"The lane we are traversing is arched over with the naked and yet beautiful branches of some tall elm-trees, and on the summits of these numbers of noisy Starlings are perched, bathing their dark bodies in the sunshine, and uttering in chorus a perfect pandemonium of extraordinary music.

"As the feathered throng comes and goes-the birds evidently paying a round of visits this cold, frosty morning-they send down little showers of crisp hoar-frost, reminding us of the salt spray thrown up by some angry sea.

"And the little slumberer about whom I set myself out to write! Where and what is he? Peep into this bramble bush, and there you will espy a neat, round nest of dead grasses ingeniously knit together. Go quietly, for see, a company of Greenfinches-handsome fellows in green and gold-are engaged feeding upon a few dried-up blackberries which still remain, reminding us of the rich feast of the luscious fruit which the bramble gave us last Autumn.

"Do you hear the Greenfinch singing when upon the wing? This is one of the few British birds that perform this interesting feat. To-day, in the still wintry air, its singing has a most pleasant effect.

"Now the birds have disappeared from the bush, and we can approach it more closely. The little ball of dead grasses may now be plainly seen, and could we peep inside, a pretty sight would meet our gaze. IVe are tempted to do so, but a timorous Hedge Sparrow in brown and steel-grey uniform utters a note of warning, and we must leave the little slumberer in peace.

"It is the home of the Dormouse we have found, and it is here, during the rigours of King Winter, that he, brave little mammal, tucks himself up and slumbers until the Spring. Could we see him in his bed we should find that he is coiled right round, feet to feet, these latter being flesh-coloured and beautifully clean.

" His bright little eyes-like black diamonds--are tightly closed, his long tail is wrapped right round his warm brown body, and nought disturbs him until Fairy Spring comes forth with her wondrous wand and summons her wild children from slumber. 


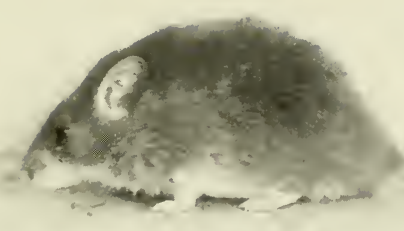

FIG. I $72 .-$ FAT MOUSE

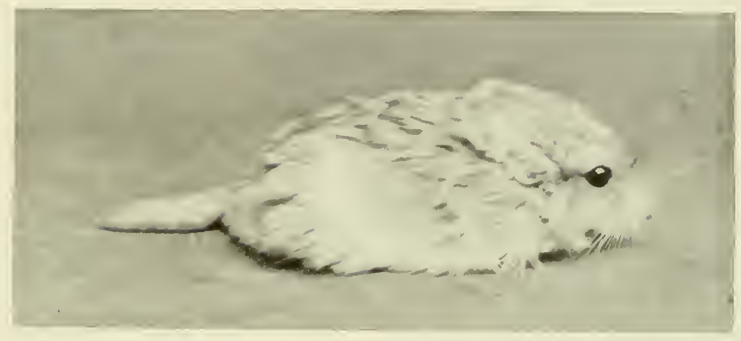

FIC. I73.-FAT-TAILED DESERT MOLSE

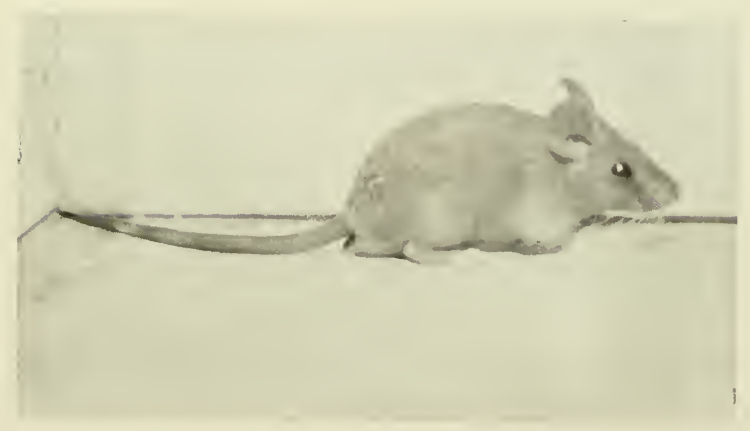

FIG. I74.-CAIRO SPINY MOUSE 


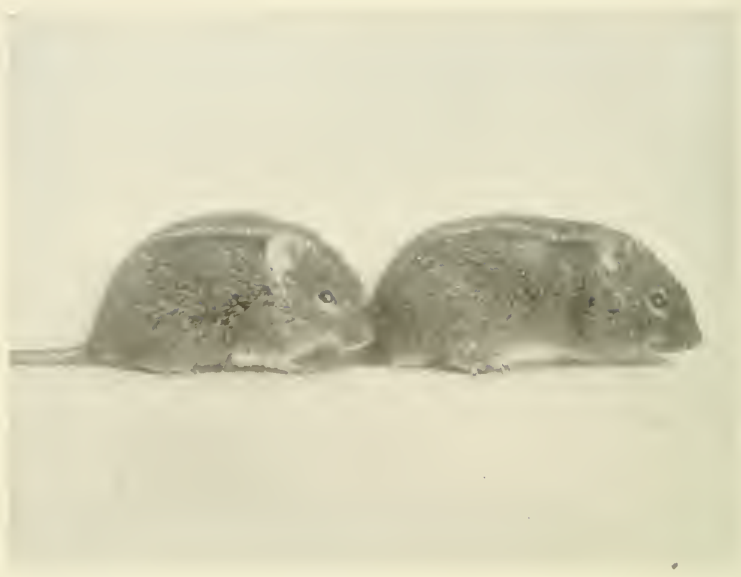

FIG. IT5.- STRIPED MICE

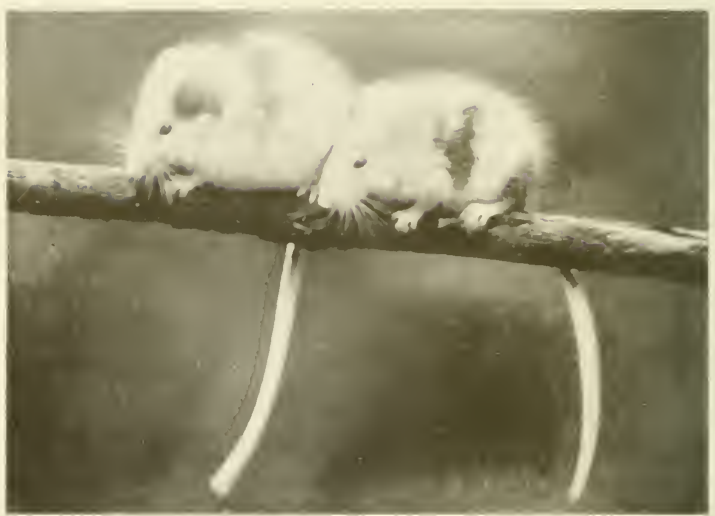

FIG. I 76 FANCY MCE 
"Sometimes I have found the Dormouse awake on a mild day; I have seen him peep outside his little citadel in the hedgerow-fastness, but withdraw inside the home in less time than it takes to tell the story. Such a rude awakening temporarily disturbed him, but, curiosity aroused and satisfied, back he went to the round grass cradle to slumber whilst yet keen Winter was upon the face of the land.

"How snug and warm the little homestead must be! How peaceful and secure the slumberer in his grassy home! Little cares he for the turmoil and strife of a wide and oftentimes unthinking world, for in the hedge I know he often sleeps for six months at a stretch.

"And who shall say that, as a result of an active and busy life during the Spring, Summer and Autumn, he does not deserve a wellearned repose?

"Bright, merry little Dormouse; wee mite, a ball of soft brown hair, we bode you no harm. Stay inside your homestead where nought may disturb you. There, among the naked branches of the hedgerow, may you dwell in safety. There, where the hungry Greenfinch comes to appease its frequent hunger; there where the Brown Wren flits hither and thither like a butterfly rather than a bird; there where the Yellow Bunting mounts the topmost twigs and sings his impetuous song so long as the sun casts a shadow on the dial; there where so many animal and vegetable treasures are hidden until a more favourable season; there, little slumberer, shall you be left securely until Winter is past and gone and the good Fairy Spring sounds the bugle-call to her wondrous children to rise from their long but necessary sleep."

The subject of this little sketch, the Dormouse, might be mistaken for a small kind of Squirrel, and I have before now had the animal brought to me as such. It has a long Squirrel-like tail, large ears and eyes, and short limbs, but, as so often happens among mammals, the teeth at once identify this gay little sprite, the presence of "a single pair of pre-molars in each jaw" and "all the cheek teeth being rooted and having their crowns inter-penetrated by transverse enamel-folds" serving to distinguish it from all the other British members of the order to which it belongs. There are internal differences also, but these need not be detailed.

Outside Britain, Dormice are found in various other parts of Europe, as well as Africa and some portions of Asia.

In colour the Common Dormouse is warm tawny on the upper- 


\section{THE BOOK OF THE ANIMAL KINGDOM}

parts, with yellowish below; there is an elongated patch of white on the throat and chest. The total length of body and tail is about five and a half inches. The usual habitats are hedges, woods and plantations. Green lanes-fast disappearing features of rural England-are, I find, favourite haunts, and I have during a few hours' ramble found quite a number of these trim and elegant little beasts snugly tucked up in a grassy ball-like nest in the hedgerow during early Spring.

It is a good plan to search for it where the nut-hazel flourishes, as the animal exhibits a partiality for the nuts and will often make its nest in the stump of a hazel-bush. It also partakes of grain, acorns, fruit and the seeds of various woodland trees. Beyond this dietary it has the habit of taking birds' eggs (like that woodland rover the Squirrel) as well as insects.

The lengthy sleep it undergoes during the IVinter is one of the most interesting phases connected with the life of this small creature, as it will often hibernate for six months at a stretch. A change in the temperature from cold to warmth will, however, tempt it from its snug Winter quarters, when it feeds upon the store it has wisely provided in case of emergency, but, having had a good fill, it retires again until the advent of brighter days. When it commences to undergo its long fast the Dormouse is fat and well calculated to go without food for some months, but at the conclusion of its sleep it has become considerably lessened in bulk and eagerly partakes of food. So securely tucked up is this animal, and so soundly does it slumber, that I have taken it from the nest, carried it home in my warm hand, and rolled it across a table without the slightest effect on the little slumberer. Continuous handling of the creature at such time, however, is bound to awaken it sooner or later, and the look of surprise and the bright black glistening eyes are a study worthy of an artist's brush.

The young are generally four in number and are produced during the Spring. They are blind at birth, but when a few days old acquire their sight and are soon able to forage for themselves. At first the young Dormice have a mouse-grey dress with the exception of the head and flanks, but by degrees the reddish-brown of the adult animal is assumed.

CANADIAN JUMPING MOUSE.-This interesting rodent (Fig. I 7 I) belongs to a family in which the Jerboas are included, and all the species lead a terrestrial life. They possess very long hind-limbs 
and tails, as may be seen by referring to the Canadian Jumping Mouse shown in the photograph. In their movements upon the ground these small mammals resemble the Kangaroos treated of in the last chapter. As a rule the Jumpers, as we may popularly designate them, are inhabitants of "open and dry districts, such as grassy steppes or sandy deserts," and are so coloured that their bodies resemble the environment frequented.

The species illustrated, which represents this interesting family of small rodents, has a wide distribution in North America, but this animal, according to Mr. Ingersoll, is a dweller in woods and fields, and not deserts. It is also non-gregarious.

In colour it is dark on the back, reddish-yellow on the flanks, and whitish on the under-parts. It attains a body length of about three inches, the almost naked tail being some five inches longer.

It is during late Summer that this Mouse constructs its home, and this consists of a globular ball of grass. This homestead is tenanted until the approach of WVinter, "when the pair find a deep cranny among rocks or dig a hole a little way into the ground, and there, in a snug bed of shredded bark, leaves, and so forth, go sound asleep with the first severe frost, and never wake up before May-day."

The sleep, therefore, is of long duration, and it is extremely sound. Probably no animal exhibits a deeper slumber-at any rate among American kinds.

The great majority of rodents are of nocturnal habits, but the species under review differs in this respect, as it may often be located during the day, and especially towards early evening.

Its movements are always well worth watching, for it possesses a wonderful knack of leaping, or jumping, a distance of several feet. It exhibits considerable ingenuity in these movements, as sometimes they take an irregular course, and the wary little beast will if closely pursued by an enemy, instantly squat upon terra firma-or, as Mrs. Brown has it, upon terra cotta-and so escape the attack of a Weasel, Hawk, Ow1, Snake or other predatory creature.

Like the Dormouse, it rolls itself into a ball when about to sleep, the feet being brought close together, the head snugly tucked near the hind-quarters, and the long tail wrapped right round the body.

JERBOA, OR KANGAROO RAT.-This interesting little rodent is also worthy of mention here. It has a somewhat wide distribution, being found in Central Asia, India and Ceylon, South-East Europe, 


\section{THE BOOK OF THE ANIMAL KINGDOM}

and "from Syria and Arabia it extends to Egypt and a great portion of Africa."

It measures from six to eight inches in length, and has a long tufted tail. The fur is as a rule sandy colour, but the most interesting feature of its structure is the difference in the length of the fore- and hind-legs. It has but three of the toes on the hind-foot well developed, but elastic pads on the sole aid the little beast in skipping over the ground in a remarkable way. It only uses the hind-limbs when making its wonderful bounding movements, and attains a great speed when thus engaged.

It is a gregarious animal, dwelling in underground burrows during the day, and coming out at night to feed.

Major A. E. Stanton, in a paper read before the Royal Colonial Institute on "Khartoom and the Sudan," says-

"One of the most remarkable proofs of instinct in animals is to be seen in these deserts. The Jerboa, or Kangaroo Rat, is found in considerable numbers in places miles and miles away from any water or even dew, and I was at a loss to understand how these little animals could exist through the ten months of drought. It appears, however, that after the scanty rains a small wild melon, of bitter taste but full of juice, flourishes in the desert. The Jerboa, as soon as the melon is ripe, bites off the stem and proceeds to dig away the sand under the melon, so that it gradually sinks below the level of the ground; the constant wind soon covers it over with six or eight inches of sand, which protects it from the scorching sun and from drying up. When all other moisture has evaporated, the Jerboa goes to his larder of melons and drinks the juice of these till the rains come on again. One Jerboa will bury as many as forty of these little melons to last him through the dry season."

FAT IMOUSE, AND FAT-TAILED DESERT MOUSE. - The Fat Mouse (Fig. I 72 ) and Fat-Tailed Desert Mouse (Fig. 173) are worthy of mention here. The first-named is a native of South Africa, and is so called because of its plump appearance. Little seems to be known of its habits, and it has only once been represented at the London Zoo. It is rather larger than the common House Mouse and mostly brown in colour. At one time a happy family of FatTailed Desert Mice lived in the old Squirrel-house at Regent's Park. Here they bred regularly and freely, but the stock has now quite died out, and the Zoological Society has been without any for five years or more. In size this Mouse is somewhat bigger than a 
large Dormouse, having most beautiful thick, soft, plushlike fur, and a remarkably fat tail from which it has acquired its name. This, as is well known by animal students, helps the little beast to store up fat in time of need, in the same way as the Camel with its hump, the Fat-Rumped Sheep, Dormouse, Bear and other animals which need not be detailed.

SPINY MICE.- The Spiny Mice are represented in our illustrations by the Cairo Spiny Mouse (Fig. 174). There are two genera; in the first we find the Malabar Spiny Mouse, which is an inhabitant of Southern India, and in the second there are several species characterized by the possession of thick, rigid, grooved spines on the hinder portion of the back in place of hair. They have been compared to small Hedgehogs, and it is to the genus containing the Hedgehogs that the Cairo Spiny Mouse belongs. These animals are dwellers in the desert, and range "from Syria to Eastern Africa, as far south as Mozambique, while a single example of one of the species has been found in Sind."

The Malabar Spiny Mouse resembles the Common Dormouse in both appearance and habits, being arboreal. The teeth are the distinguishing features, as well as the thickly haired tail. The pointed ears and broad flat spines which are intermixed with the hair on the upper parts are also worthy of note. The colour above is reddish-brown, and white underneath. It attains a length of about four and a half inches, the short tail being half an inch more.

It is a tree-loving species, and makes a suitable hollow in which to build its nest of moss and leaves.

The Striped Mice (Fig. 175) are at once identified by the stripe which runs along the top part of the back, whilst there are few boys who have not at some time or other kept Fancy Mice, as shown in Fig. 176.

Frank Buckland, in his own inimitable way, refers to the presence of Rats and Mice at the London Zoo, and attention may be drawn to this interesting habit of both animals, for to the observant visitor the Mice at any rate are sure to arrest attention, and their bravado in feeding within striking distance of a Lion or an Eagle has always struck me as very remarkable, and is apparently an apt illustration of the old adage that "familiarity breeds contempt."

Buckland writes that "as a curious way in which animals always find out the place best adapted for their habitation, I may adduce the fact that at the Zoological Gardens, although the Rats swarm 


\section{THE BOOK OF THE ANIMAL KINGDOM}

not ten yards away from the Parrot-house, yet they never come into this building. Here Mice take their place. How is this? The Rats have probably found out that it is no use going there; they would get nothing for their trouble, for they could not get through the bars of the birds' cages to get at the seed; the little Mice, on the contrary, who, as all well know, are great seed-eaters, with ease run in and out between the wide bars of the Parrots' cages, and help themselves to both seed and water. They have found out that, although the great Cockatoo has such an enormous and formidablelooking bill, it won't hurt them, and that Mr. Cockatoo is not a carnivorous bird. When, therefore, these gaudy denizens of the tropics have finished their day's screaming and 'pretty pollying,' out pop the little Mice, taking tithe of all the seed-boxes they can get at. Having finished their meal they retire behind the hot-water pipes which run round the room, and with full stomachs lie lazily in their warm and comfortable quarters alongside the pipes till they are hungry again. No wonder, therefore, they obey the law 'increase and multiply.'"

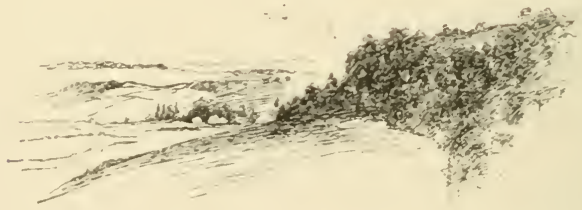




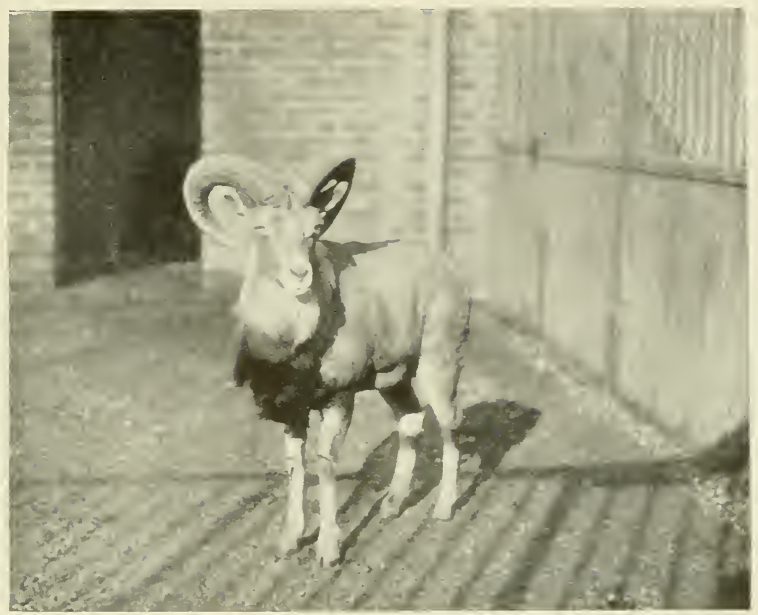

FIG. I77.- - URIAL, OR PUNJAB WILD SHEEP

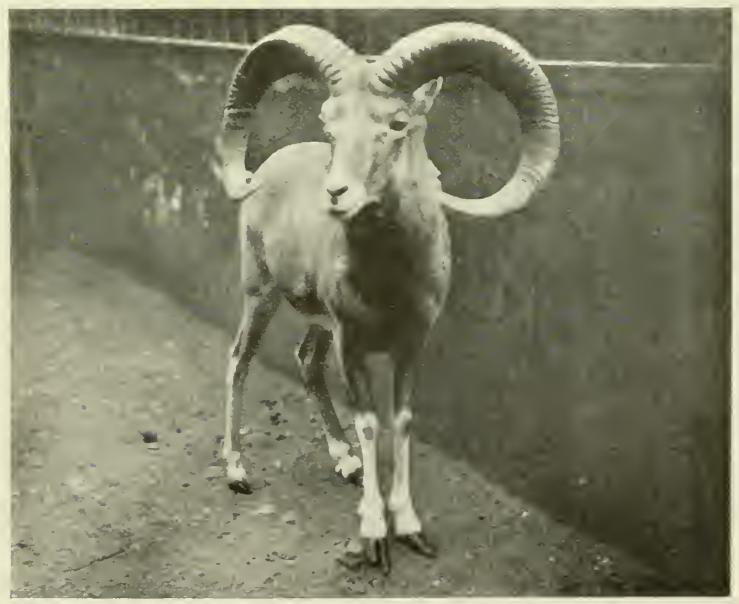

FIG. I $-8 .-$ BLANFORD'S SHEEP 


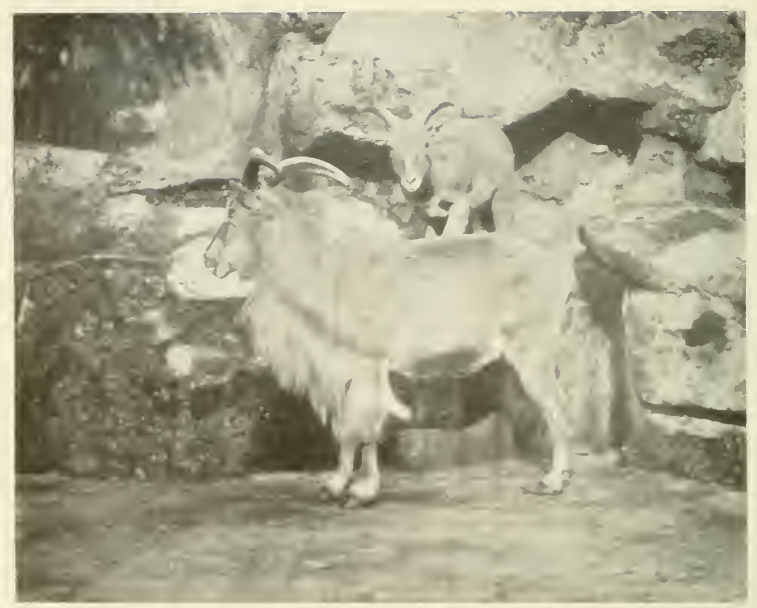

FIG. IT9. BARBARY SHEEP

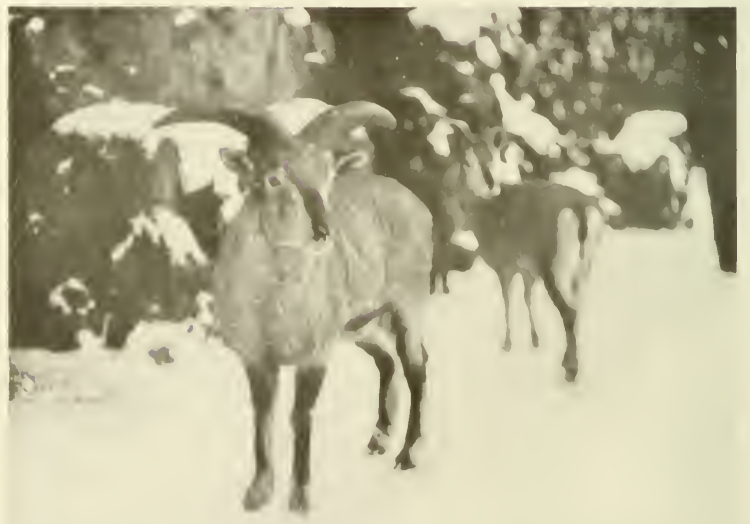

FIG. ISO, BLRRIIEI, WILI SHEEP 


\section{CHAPTER XII \\ WILD SHEEP AND GOATS}

URIAL, OR PUNJAB WILD SHEEP.-The first representative we have of the Wild Sheep, the Urial (Fig. 177), ranges from Bokhara in Asiatic Russia, through Persia, Afghanistan and the Ladak territories of Northern India to the Punjab. It is sandy-coloured, the ram having a black or black and white ruff, and is about equal in size to the common Sheep known to every one. Both sexes have horns, but those possessed by the female are much less significant than those of the ram shown in Fig. 177. Whilst known in the Punjab as the Urial, to the north of that territory, in Ladak, it is called the Sha, a name which would surely be more appropriate if applied to this animal in Persia!

The fine circular sweep of the horns both in this species and also in Blanford's Sheep (Fig. I78), which is merely a variety of the Urial, are well worth noting, and it should be stated that in the case of Blanford's Sheep the horns are larger and the spiral is greater. 'The short horns of the ewe are almost straight.

The Urial attains a height of about two and a half feet at the shoulder, but this applies to the animal inhabiting the Punjab, as the beast found in Ladak is its successful rival, attaining a height of at least three feet. This Ladak variety is distinguished also by the less developed ruff of the adult ram and the thicker horns at the base. Ewes and young rams differ from the rufous-grey or sandy of the adult male in being uniform greyish-brown.

This Sheep has a wide geographical distribution, for it is found inhabiting countries with cold or hot climates, and has a more extensive range than any other kind of Old World Sheep. In some districts it frequents grassy habitats, in others open valleys and hilly environments are resorted to, whilst in others, again, it is found on precipitous hills among bushes. It is of wary disposition, uttering a shrill sort of whistle when disturbed, as well as an ordinary bleat so characteristic of Sheep generally. 


\section{THE BOOK OF THE ANIMAL KINGDOM}

The breeding season varies in different localities, for whereas June sees the same in full swing in one district, it is not until September that it takes place in another. One or two lambs are produced, and not only will this species mix and feed with domestic Sheep, but it will also interbreed with them. Briefly, the Urial may be written of as a most interesting species because of its wide range, great variety, remarkable adaptability to different climates, active disposition, and the ease with which its traverses over rocky situations. The long legs are specially well displayed in Blanford's Sheep (Fig. I 78), this being a further characteristic worthy of note.

BARBARY SHEEP.-The next species on our list, the Barbary Sheep (Fig. I79), is exceedingly interesting if for no other reason because it is the sole representative of the group to which it belongs which is found in Africa. It is also known as the Maned Sheep, presumably on account of the lengthy hair situate on the throat, chest and fore-limbs. The thickly-haired tail is also of note.

It stands about three feet high, and in colour is almost pale rufous-yellow over the whole body. The ewe has shorter hair on the fore-quarters, but the horns of both sexes are almost the same size as Fig. I 79 displays. These horns attain a length of about two feet, and although those possessed by the lambs are of a wrinkled description, those of the adult animals are almost smooth.

Unlike the Urial last under review, the Barbary Sheep is not found in herds, being located either as a solitary animal, or at most two or three together. It loves to keep within the range of the desert, being found sparingly in regions of a precipitous character such as "the arid southern slopes of the Atlas range, from the Atlantic to Tunis." It presents an instance of protective coloration, as eye-witnesses inform us that its colour is harmonious with the limestone rocks which are found in mountainous districts. An instance of this protective coloration is given by Mr. E. N. Buxton, who says that when the Arabs frequent the haunts of this Sheep, the latter, finding escape difficult, resort to the habit of hiding their bodies successfully, and are evidently conscious of the protection which is afforded them by the environment. He states that on one occasion he was seated on a knoll which commanded a view of a small shallow hollow. Very little cover was available in which even so small an animal as a Rat could contrive to hide its body, but on rising from the position he occupied he found that a female Barbary Sheep and two lambs had been lying within a short 


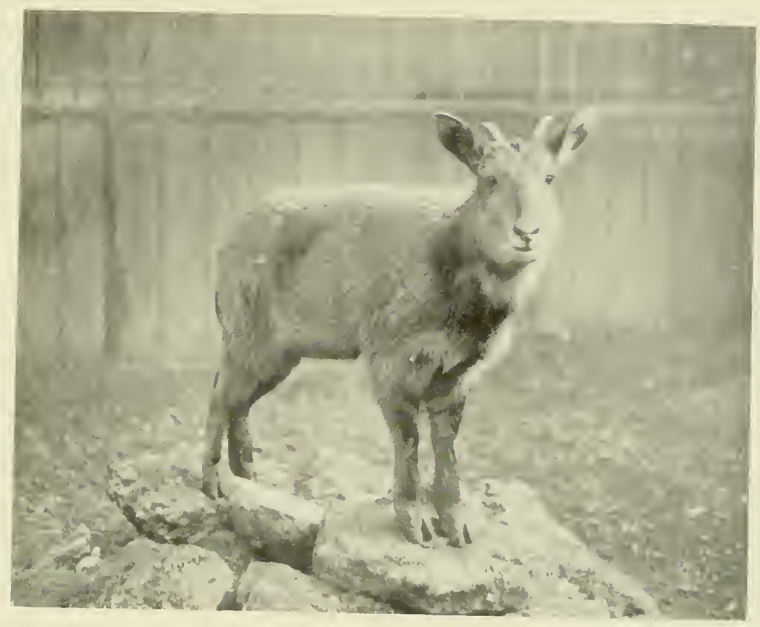

FIG. ISI.- HIMALAYAN GORAL

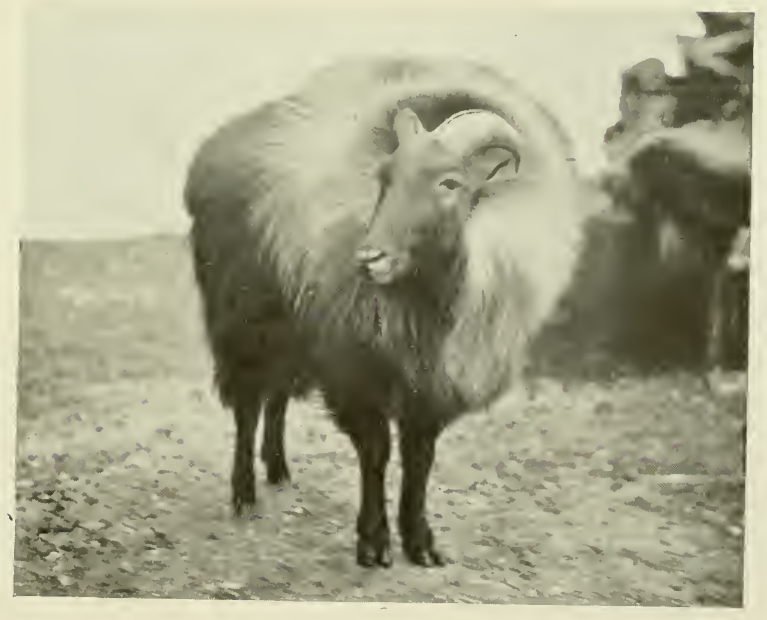

FIG. I 82.-TAHR 


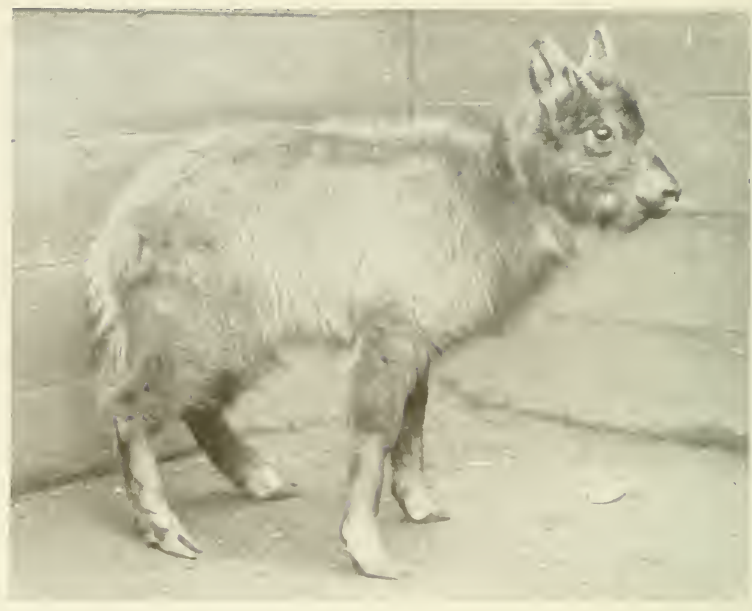

F1G. I $83 .-1.0 \times$ ( -T.MIIED GORA1

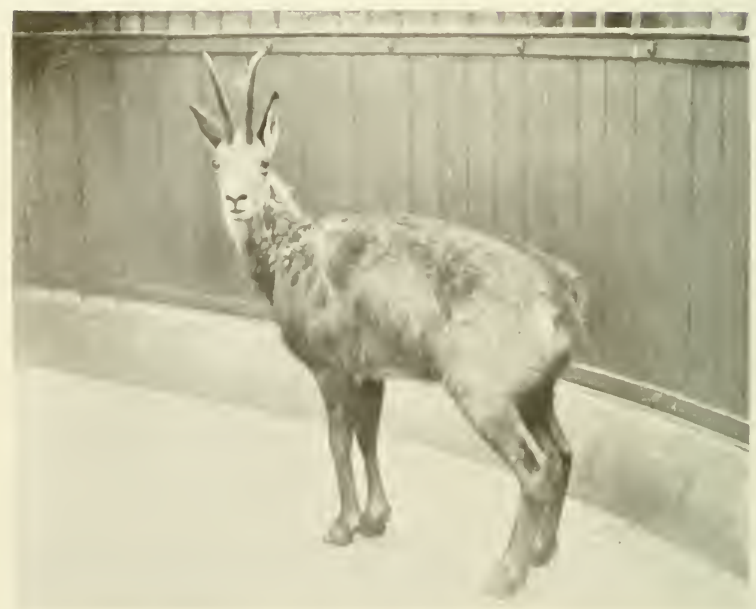

FIG. ISt. -CH.MOIS 
distance of him, and must have been aware of his presence the whole time he was in the vicinity. In this habit the Barbary Sheep resembles, states the same observer, the Pyrenean Ibex, which inhabits similar ground, and also trusts to concealment in preference to flight.

BURRHEL WILD SHEEP. - The Burrhel, Bharal, or Blue Sheep (Fig. 180) is an inhabitant of Tibet and those parts of the Himalayas bordering thereon. It is an interesting species and well worthy of inclusion here because, in a way, it is a sort of connecting-link between the Sheep and the Goats. Structurally it certainly is as much a Sheep as a Goat, but owing to the absence of a beard and the odour given off by the ram, it is best for it to occupy a place among the Sheep, and any one possessing a knowledge of this animal would not hesitate to accord it a position among the Wild Sheep. In general appearance it is most certainly like a Sheep and not a Goat, but, in spite of this, we are told that "it exhibits a marked difference from other species of the same general size in refusing to breed with domestic Sheep; and its relationship to the Goats is so strong that, were it not for convenience, there are considerable grounds for including both Sheep and Goats in a single genus."

It is in regard to the horns and skull that this animal resembles the Goat, the first-named being less spiral than those possessed by the more typical Sheep. These appendages are almost smooth and reach a length of two feet or more in the male, those of the ewe being short and curving upwards and outwards.

The smooth, compact fur is very distinctive, being brownishgrey on the upper parts in Summer, and stone-grey in Winter, with white underneath. The ram has a prominent black band on the sides of the body and down the front of the legs, and the same colour on the front of the face and chest and on the greater part of the tail. The ewe lacks the black markings on the face, chest and flanks. The last-named is a smaller beast than her mate, the ram standing about three feet high at the withers.

The Bharal inhabits craggy districts where the ground is undulating, and, like the Goat, it is a fine climber, picking its way over precipitous cliffs with consummate skill and ease. It is gregarious in its habits, herding together in companies of from a few to as many as a hundred individuals, and occupying high-lying situations often out of reach and secure from the hunter. The colour of the Q 2 


\section{THE BOOK OF THE ANIMAL KINGDOM}

fur ably protects this animal, especially when it is snugly ensconced near stones. Whilst both sexes may be observed together all through the year, during the Summer they are usually separated, and at this latter season they frequent high altitudes, ascending to as much as fourteen to sixteen thousand feet above sea level, and rarely, it is said, being found at any time at a lower elevation than ten thousand feet.

HIMALAYAN GORAL.-This animal (Fig 181 ) is a further interesting beast because it claims kinship with "an assemblage of Mountain-haunting Ruminants which to a great extent connect the Goats with the Antelopes." It is distinctly Goat-like in more ways than one, and there are three or four kinds, such as the Himalayan Goral, the Ashy Goral, the Grey Goral, the Long-Tailed Goral, and a further addition has recently been made of another form which appears to be distinct from the Grey Goral, and known by the Latin name of Nemorhadus bedfordianus.

The Goral has small cylindrical horns; a short tail (excepting the Long-Tailed species found in Formosa) (Fig. 183); Goat-like teeth, and does not possess a beard. It stands a little over two feet high at the shoulder, has coarse brown hair with a patch of white on the throat, a black tail and a naked muzzle. The hair is raised along the back part of the neck and forms a sort of crest.

It does not frequent the high altitudes mentioned in the case of the Bharal, selecting rocky forests or grassy slopes not more than eight thousand feet in height. It is not of a very gregarious disposition, for old bucks are, as a rule, found singly, but usually a male and female may be located, or even a few individuals numbering from four to eight.

The state of the weather controls the feeding habits of this species, for when the atmosphere is dull and overcast the Goral feeds during the day, but at other times partakes of its meals in the morning and evening, resting among rocks in the daytime. It sticks to the same feeding-ground, and although wary enough when real danger threatens, it does not exhibit much fear for mankind, and when one remembers that there is more preferable game not far away, such as the Chamois, the sportsman need not trouble this animal to any great extent.

TAHR. - The Tahr (Fig. 182) is a Himalayan Goat which is characterized by the absence of a beard, and has the end of the muzzle naked. The skull is longer and not so broad as in the case 


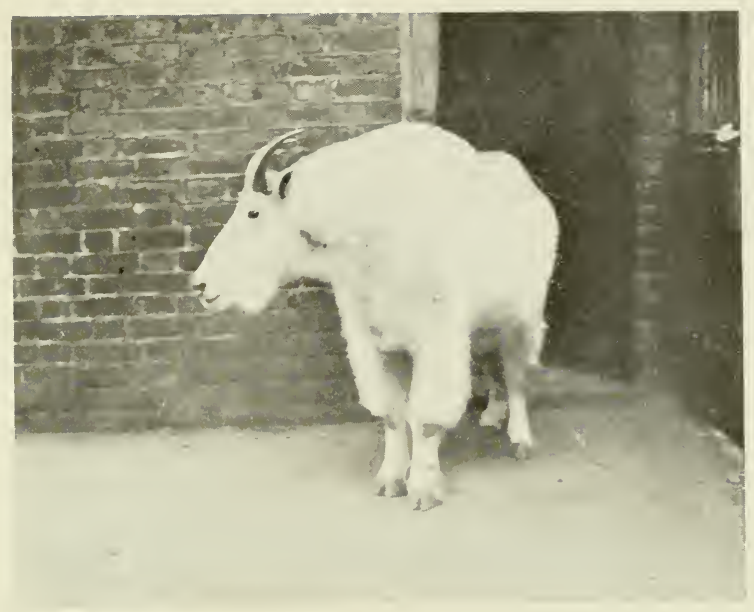

FIG. IS5.-ROCKI MOUNTAIN GOAT

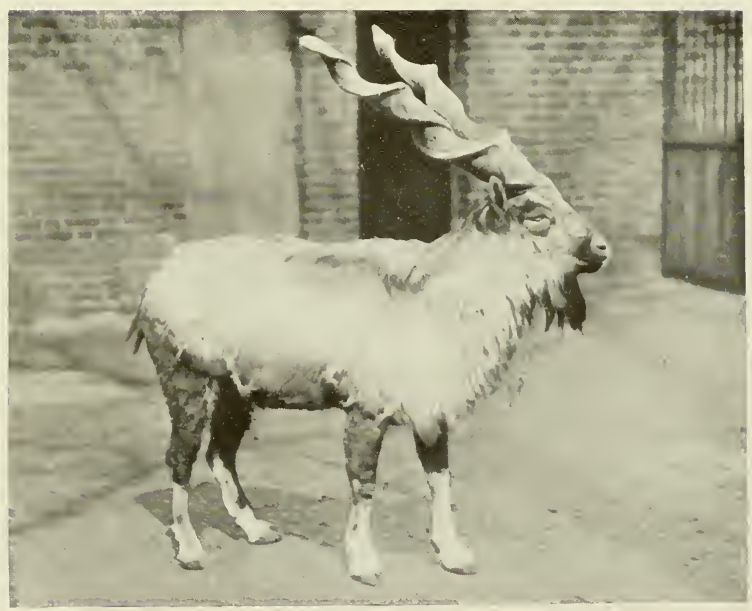

FIG. I86. -MARKHOR (MALE) 


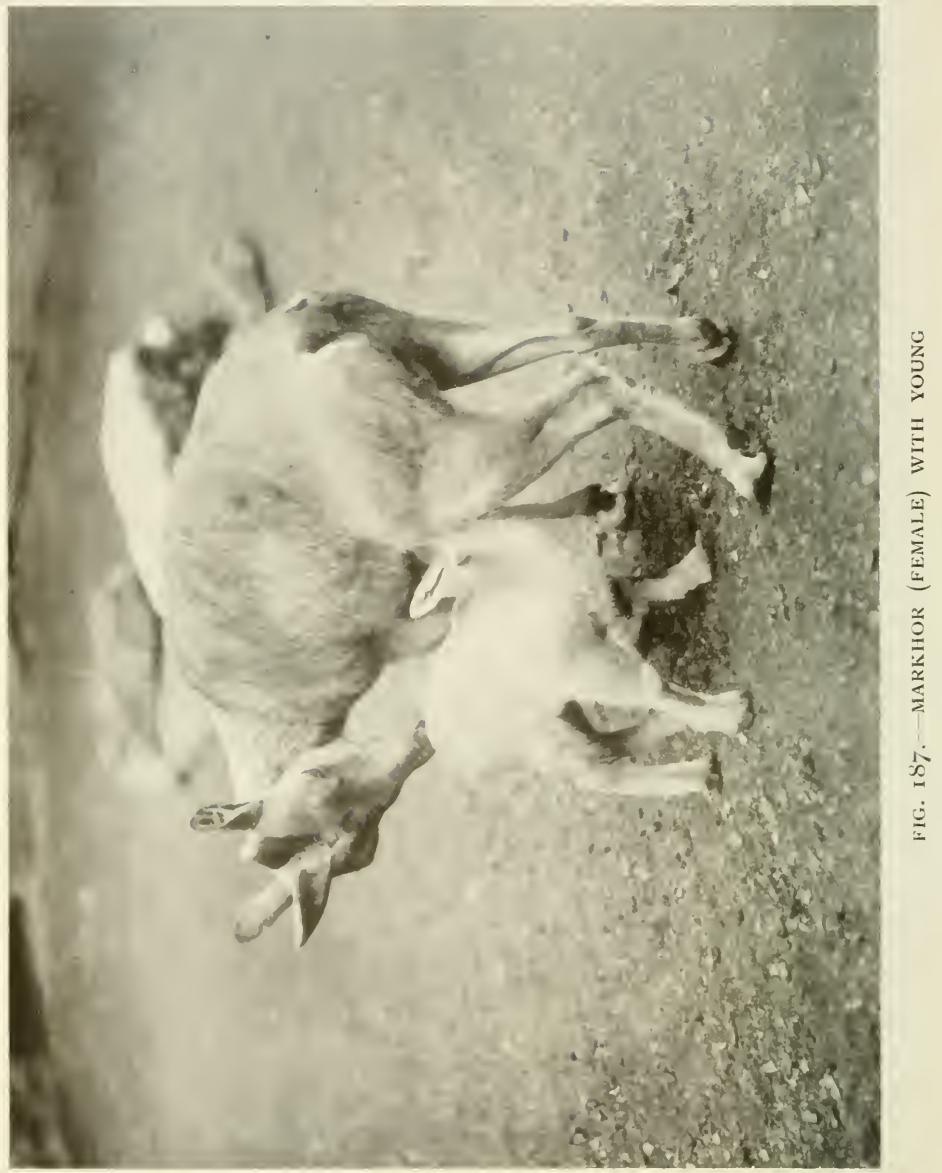


of the true Goats; the eye-sockets are not so pronounced, and the horns are comparatively short and about the same size in both sexes. What then, it may be asked, distinguishes a Sheep from a Goat? They certainly differ in form, clothing and habits, but the matter is not thus easily disposed of, for whilst domestic Sheep have a woolly coat known to every one, Wild Sheep, as we have already seen, do not possess one, and if domestic Sheep are given their unrestricted liberty in a hot country, and allowed to return to a wild state, in course of time the fleecy coat of wool is exchanged for one of hair, and thus the animal resembles a Goat. In some cases, of course, the horn is a distinguishing feature, but here again care is necessary before it is certain that a correct identification has been made.

Again, the absence or presence of a beard may prove useful as a means of identification, but whereas some Goats and Sheep possess beards and others do not, care must be exercised also on this score. True, some kinds of Sheep have only slight beards, but they are such as would do infinite credit to some members of the genus homo of my acquaintance! And so the matter may be summed up in the words of Mr. Protheroe, who writes that "while we place the Sheep in the genus Ovis and the Goats in the Capra, we may very well consider that the terms are almost interchangeable, trusting to the descriptions of the various selected animals to afford us the few safe means of identification."

To return to the Tahr, this animal is at once distinguished from any others by the structure of the black horns, "which have their lateral surfaces flattened and shelving regularly up to the sharp and beaded keel on the inner front border; they diverge regularly from their bases, at the same time curving sharply backwards, with a slight inward inclination at the tips." The general colour of the hair is dark or reddish-brown. It is short on the head, but more lengthy on the body; indeed in old bucks it becomes so long on the neck, chest and shoulders as to form a long shaggy mane reaching below the knees. The animal has a very dark face and is also dark on the front of the limbs; the young are a uniform greyishbrown, whilst kids are stated to be quite pale in colour. The female, it is most interesting to note, is quite different from every other kind of Goat or Sheep by possessing four teats instead of two, although another species of Tahr is now known which has the more usual number.

Standing somewhere about three feet high at the shoulder (the 


\section{THE BOOK OF THE ANIMAL KINGDOM}

female is not nearly so high), the male Tahr has a pair of horns which, measured along the curve, attain a length of from twelve to fifteen inches, those possessed by the doe being several inches less.

It is among the elevated forest regions of the Himalayas that this species makes its home, and it is in the habit of frequenting such precipitous spots that the sportsman, having shot his quarry, often has the mortification of seeing it fall down a precipice from which it is impossible to obtain it unless at very grave risk. It revels in steep hillsides clothed with trees, and traverses almost perpendicular slopes where it would seem no animal could possibly obtain a foothold. During the Summer the adult male keeps apart from the females as a general rule, but later in the year the breeding season brings the two sexes together, a single young one being born the following Summer.

CHAMOIS. - With the exception of the Saiga Antelope found in Russia, the Chamois (Fig. I84) is the only kind of Antelope which is an inhabitant of Europe, and as a sporting animal is much sought after by those who take pleasure in the chase. The Chamois is not found outside Europe, belonging to a group of Antelopes which frequent high mountain ranges where the stalker has to exercise considerable prowess before he obtains his quarry. In the Alps it is known as the Gems, whilst in the Pyrenees it goes under the name of Izard.

Both male and female possess horns, and both resemble one another in general appearance. The horns are black in colour and smooth in structure. They are straight for the most part, but towards the tip they curve abruptly backwards into a hook. It attains a height of about two feet at the shoulder, and the body is clothed underneath with thick wool, over this being a layer of hair which is brown in Summer and black in Winter. The coat is longer during the cold season than the hot weather, but whilst the Chamois appears to be quite impervious to the cold, it cannot tolerate heat a little bit.

Goat-like in many respects, and classed as such by some Zoologists, this interesting beast does not possess a beard, and when the hunter wishes to have a trophy "a tuft of the hair which grows along the back" is taken. It is undoubtedly due in a large measure to the excitement of the chase, the bravado it calls forth, and the high altitudes at which it is found that so much attention has been 


\section{WILD SHEEP AND GOATS}

bestowed upon this Antelope by those who go forth to hunt it, as its flesh does not offer any great attraction for the purpose of food, and excepting that a nicely mounted head may in after years be regarded as a well-won trophy, there is little more to recommend this animal to the hunter. It is splendidly adapted for frequenting high, precipitous situations among the mountains, and it is wonderfully sure-footed as well as of active disposition. A more sluggish animal would never be likely to be sought after to the same extent as this attractive species, and although it has acquired a reputation by reason of the so-called "Chamois" leather which is made from its skin, this is ill-deserved and erroneous, because this kind of leather is prepared for the most part from the skins of domestic beasts such as Deer, Sheep and Goats.

It travels about in companies consisting of several individuals, but these do not usually number more than about twenty. The old bucks, however, do not congregate with the herd, preferring to remain solitary. Although it will as far as possible restrict its haunts to the high mountain ranges on the snow line, or as near same as possible, when difficulty is experienced in obtaining an adequate food supply the Chamois must of necessity forsake the high altitudes and come down towards the valley to feed. The food is made up of various kinds of Alpine plants, the mere mention of which is sufficient to inspire with enthusiasm any one possessing a knowledge of the flowering plants of the Alps.

When the pairing season of the Chamois is in full swing during the Autumn, then it is that battles-royal may be witnessed between the bucks, the latter displaying savage tactics for the possession of a female. It is in the Spring that the mother gives birth to one, or at most two, kids, and the young follow her about very soon after birth.

This is, as may be supposed, a wary animal, and when a company of them are feeding on some lonely mountain-side precaution is taken to depute one of the herd to act the part of scout or sentry. This individual is posted on some prominent elevation from which a general view of the surrounding country may be obtained, and as soon as anything occurs which necessitates a signal being given to the beasts who are busily engaged feeding, the sentry sounds an alarm by making a loud hissing noise. This is quite sufficient to put the rest of the company on their guard, for feeding operations are immediately stopped, and the beasts gallop 


\section{THE BOOK OF THE ANIMAL KINGDOM}

off at breakneck speed, clearing awful-looking chasms, a fall down which would mean instant death, springing on to rocks upon which one would imagine no animal living could possibly obtain a foothold, and often leaping down a precipice and landing in perfect safety. Small wonder then that, in view of this, the Chamois should make such a strong appeal to the legitimate sportsman who is willing very often to risk his own life in pursuit of wild beasts such as this, for he must of necessity exhibit great skill, pluck and wonderful endurance.

ROCKY MOUNTAIN GOAT.-The Rocky Mountain Goat (Fig. I85), or White Buffalo, as the Indians called it, is another species about which Zoologists differ as to the place that should be accorded to it, for whereas it is called a Goat and is placed among this group by some naturalists, by others it is relegated to the Antelopes. It is certainly a difficult matter, in view of this divergence of opinion, for a popular writer to decide where to assign two such animals as the Chamois and the present species; thus some amount of licence must be allowed, and the critic must not be too hasty in condemning me for including the last-named and the present animal in this section. Mountain Antelopes both of them may be, and as such should perhaps have occupied a place in a previous chapter; but equally trustworthy authorities class them with the Goats, and here at any rate they have been accorded attention in the present volume.

The picture of this animal has a somewhat melancholy interest, for the specimen has died since its photograph was taken. It was a male which thrived well at the London Zoo for several years and was the only living specimen in Europe. It may be well imagined the great loss the Zoological Society sustained when this rare captive succumbed, and we are fortunate in having a photograph of it from life which adds interest to this sketch of its history. It is, as will be seen, a peculiar-looking beast, the oddest perhaps of all the ruminants. It has a white coat, all white and shaggy, the long hair hanging over the body in a way which has prompted one writer to compare it to the Polar Bear! The white coat, low-carried head, short legs, stout thick-set body and black nose, horns and hoofs are salient features worthy of note, and to these may be added the thick neck and legs. Indeed, the animal is thick all over, both in body and covering, and, this being so, the thin slightly-spread horns are more noticeable than if they were in keeping with the rest of the body. Although only about the size of a large Goat, this animal looks 
almost twice the size of any other living Goat, but it is the long, shaggy hair that makes the appearance deceptive. The pelage is only exceeded for softness and fineness by one other American hoofed mammal, namely, the Musk Ox, "but the hairs are coarser and stiffer along the spinal column. The wool was formerly formed into a sort of felted yarn by the Indians by teasing it and then rolling it under the palm on the bare thigh."

It inhabits the upper forest regions of the Rocky Mountains, and although it is an adept at climbing, it is quite unlike the last species under review so far as concerns its mobility and active disposition, for it neither bounds, leaps nor springs, relying largely on "sheer muscular power and flexibility of limb" to carry it to its high haunts in the mountain tops. It is found where the climate is damp and where the snow is abundant, but once the stalker gets over these difficulties, and those of circumventing dangerous mountain-sides and precipices, the Rocky Mountain Goat is said to fall an easy prey, being gentle and unsuspicious.

Although slow in its movements as compared with the Chamois, it is wonderfully sure-footed, and gets over the ground slowly but surely, mounting higher step by step. If the hunter can keep up with his quarry his first experience must be one of surprise, for we are told that when the White Goat knows you are after him, he will stop and turn back, "to peer around the corner and see what you are"! It has been aptly called a stately animal with a long white apron; it has straw-yellow eyes (those of the kids being black), and, according to Frederick Irland, really seems "too unsophisticated to shoot."

An interesting account of a climb after this North American animal was given by Mr. Grinnell in Scribner's Magazine, and with a quotation from this sketch the notes concerning it may be concluded. Mr. Grinnell says: "Although the (Rocky Mountain) Goat is nearly related to the Chamois it has little of the activity of that nimble species. The Bighorn is the runner and jumper of the Western Mountains, whilst the Goat is the plodder. He gets over the ground and climbs the loftiest peaks by main strength and awkwardness. The Bighorn rushes away along the mountain-side at a headlong pace; the alarmed Goat starts straight for the mountain-top at a rate which seems slow, often no more than a walk, but which is so steady and continuous that it soon carries the animal out of the way of danger. 


\section{THE BOOK OF THE ANIMAL KINGDOM}

"The Goat is marvellously sure-footed, and from the day of its birth is practised in climbing over the rocks, but it must not be imagined that it never falls from the insecure perches which it frequents. Such falls are not uncommon, but seem rarely to result in serious injury. Kids which have been captured when very young, and liept in captivity, have been observed to play at rolling down steep banks, repeating the tumble over and over again, as if practising for the falls which they might be obliged to take later in life."

MARKHOR. - The Markhor, of which a coloured representation is given in Plate $\mathrm{XV}^{\top}$., as well as photographs of a fine male (Fig. I86) and a female with her young one (Fig. 187), is a remarkable Goat, the horns of the male being very powerful, long, twisted appendages, and the hair on the chest and shoulders-a sort of extension of the beard-is also a very striking feature which cannot fail to arrest attention.

Markhor, being literally translated, means Snake-Eater, and this animal is also called the Spiral-Horned Goat. The horns vary in both size and form, for whilst one variety has them twisted somewhat like a corkscrew, another kind possesses horns in which three complete turns may be detected. At one time it was considered that the animals having these two forms of horns were distinct species, but Zoologists are now of opinion that they are merely varieties. In any case, it is important to recognize that the horns of the Markhor, which exhibit a corkscrew-like twist, are to be reckoned as the most remarkable appendages possessed by any species of living Goats.

The male, which with his remarkable horns makes such a striking figure that we have thought him worthy of inclusion among the coloured plates, attains a height of about three and a half feet at the withers, and the general form is enhanced in attraction by reason of the black and grey beard. The extension of this on to the crest and shoulders is confined to the male, the female (see Fig. 187) only possessing the beard upon the chin. The Markhor has a reddish-brown fur in Summer and grey in IVinter; the under-parts are paler, and there is a dark stripe on the bottom parts of the front of the legs. Old males, it should be stated, turn whitish during the Summer; the young ones are uniform greyish-brown, with the exception of a black stripe down the back.

This splendid Wild Goat is found, according to Mr. Finn, "in 


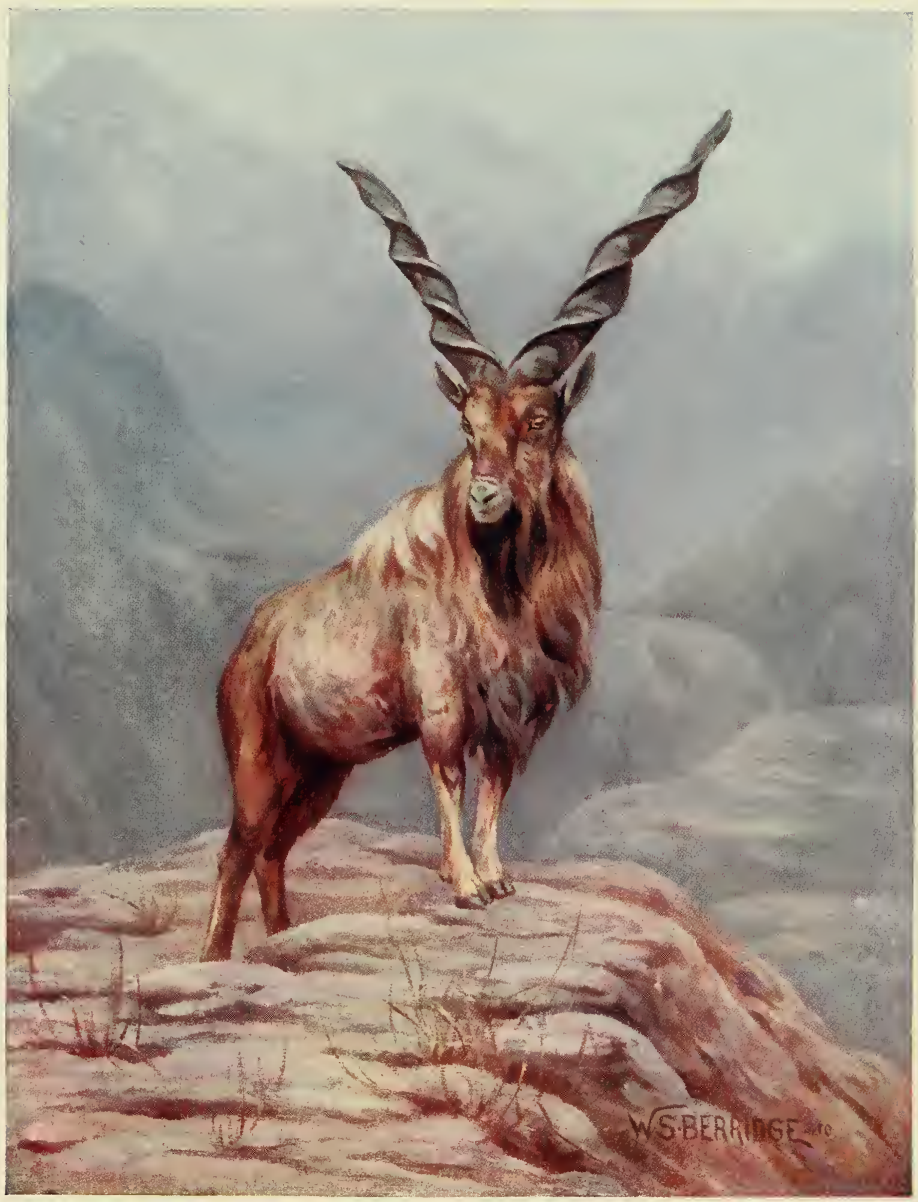

MARKHOR. 

the mountain ranges of the Indian North-West, the Pir Panjál to the south of Kashmir, and the Baltistan, Astor and Gilgit ranges to the north, as well as in many of the Afghanistan hills, including the Sulaiman range, where the poorest specimens, of comparatively small size, with straight screw horns are found, the splendid open spiralled specimens attaining their fullest development in the Astor and Baltistan ranges." There are at least four distinct varieties of this noble beast found inhabiting different localities, and these not only vary in size and in the character of the horns, but also in habits. One kind, for example, tenants high forest mountains near the snow, whilst another makes its home amid barren and rocky hills at a very much lower elevation.

The males and females usually keep in distinct flocks, and whilst comment has already been made as to the prowess and endurance that is necessary to successfully stalk the Chamois, in the Himalayas, we are told, there is hardly another animal "whose pursuit habitually entails so much difficult climbing" as the Markhor. It haunts environments where man dare not venture to tread, even if he could, and has the habit of keeping to the rocky forests which afford it concealment. It rarely comes out into open ground, but when a male is observed his massive form and noble bearing make a strong appeal to the sportsman who is fortunate enough to see him in his native wilds.

In spite of some varieties inhabiting high snow-clad mountains, the Markhor is very sensitive to the cold, and in Winter, although having a longer coat to withstand the change of temperature, has no under-fur like the Chamois, and invariably descends to protected areas.

Not only is this one of the most remarkable animals now living, but it possesses an ancient pedigree which stamps it as "one of the oldest types of Wild Goat, since a fossil species which cannot at present be satisfactorily distinguished from the living one, occurs in the Pliocene rocks of the Siwalik hills at the foot of the Himalaya."

The name of Markhor-or Snake-Eater-has resulted from the reports of natives as to its being fond of eating snakes, but this lacks authenticity and must be accepted with great reserve.

It may here be stated that naturalists seem to agree that the ancestor of the Domestic Goat is the Persian Ibex. It is very like the tame animal known to every one; it is light-brown during the 


\section{THE BOOK OF THE ANIMAL KINGDOM}

Summer and grey in Winter. It haunts craggy districts in SouthWestern Asia, and travels about in herds. Probably no domestic animal is so easily acclimatized as the Goat; cold and heat come alike to it, and it thrives well no matter in what part of the world it happens to be stationed.

HIMALAYAN SEROW, OR GOAT-ANTELOPE.-This is the last species which it is proposed to include in the present section, and Fig. I 88 will afford the reader a good general idea of the kind of beast it is with which we are now concerned. There is more than one species, and all have thick coats, short backward-curved horns, and are stoutly built. In size they have been compared to a Donkey, "and rather resembling one owing to their long ears."

The Serows vary a great deal in colour, and they range from the Himalayas to Sumatra and Tibet. The species illustrated is black for the most part, tan colour on the flanks, with white on the legs and belly. It is not a common animal by any means, being of a solitary disposition and inhabiting hillsides where forests and rocks afford it necessary cover.

Its looks belie its habits, for although "awkward and uncouth" at first sight and when seen in captivity, in its native haunts it is of active disposition, possesses indomitable pluck, and rather than make good its own escape will fight without hesitation if its mate happens to be wounded. It is an adept at going down steep hillsides, and although exhibiting an awkward gait it manages to overcome insuperable obstacles during its wanderings, and if only on account of the courage it displays when its partner is wounded, is a worthy beast with which this chapter may be brought to a close. 


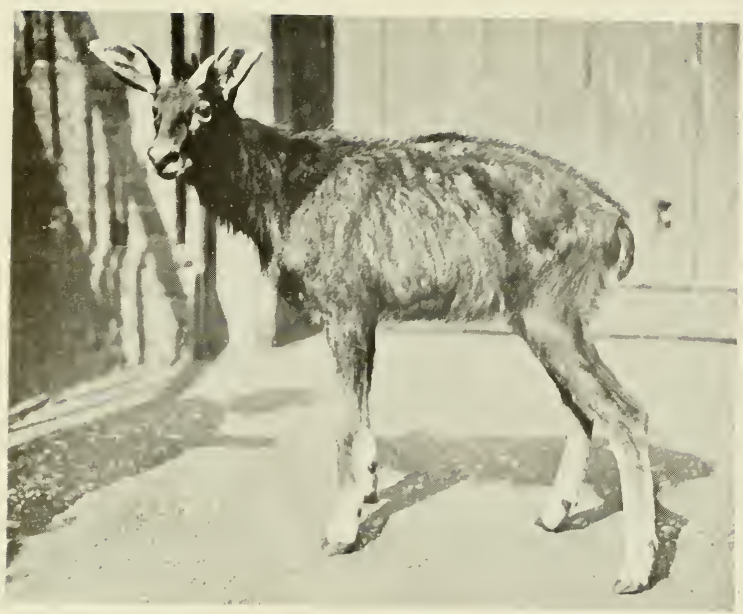

FIG. ISS. - HIMALAYAN SEROW, OR GOAT-ANTELOPE

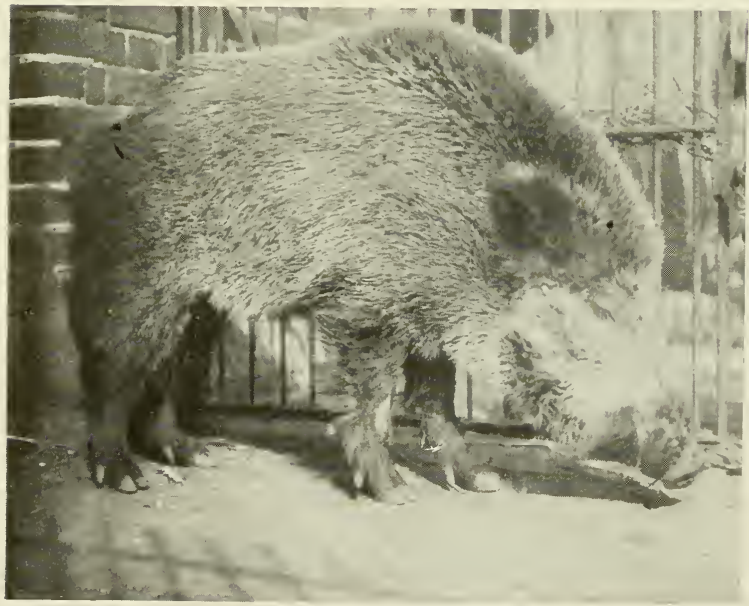

FIG. IS9.-ALBANIAN, OR EUROPEAN, WILD PIG 


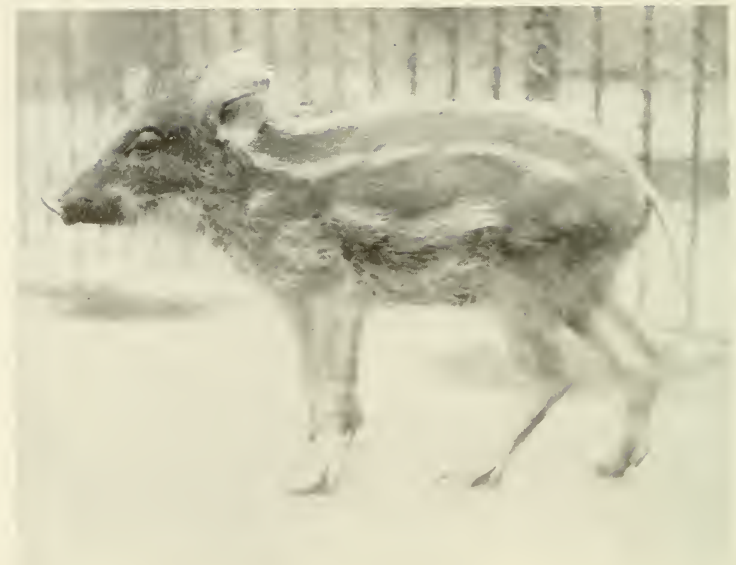

FIG. IGO. BABY INDIAN WILD PIG

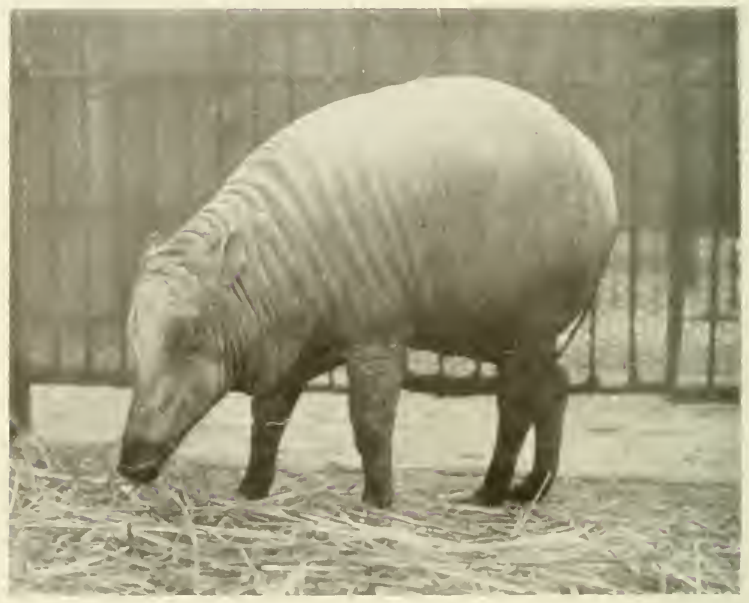

FIG. IGI. BABIRLSA 


\section{CHAPTER XIII}

\section{WILD PIGS}

Few people there are who appear to evince any real interest in Pigs. True enough the poor, the farmer and the large American packer do devote a good deal of attention to them because of the way in which they may be made to pay, but it is not from this point of view that it is desirable to approach the animals with which we are concerned in this section of our work.

Attention is to be devoted to a selection of Wild Pigs which are inhabitants of various parts of the world, but before dealing specifically with the subjects illustrated in Figs. 189 to 196 inclusive, it will be as well to point out many interesting features connected with these wild species. For this purpose I have made reference to Dr. Otto Schmeil's Textbook of Zoology, and wish, thus early, to acknowledge my indebtedness to the work in question for much of the information which follows.

Wild Pigs belong to the sub-order of Even-Toed Ungulates known as Non-Ruminants, the members of which have all three kinds of teeth developed in both jaws, with the canine teeth frequently appearing as strong tusks. They do not chew the cud or ruminate. They possess stout bodies; the skin is in many instances sparsely covered with hair or bristles; there is often a remarkable accumulation of fat under the thick skin (the fattened Domestic Pig sent to market is an apt example of this), and these animals do not possess either horns or antlers, although the remarkable tusks of the Babirussa, or Pig-Deer, are worthy of mention in this respect.

EUROPEAN WILD PIG, AND WILD PIGS GENERALLY - The European Wild Boar, or Albanian Wild Pig (Fig. 189), was at one time an inhabitant of Britain, for its remains are frequently being discovered, especially in those districts where, in mediæval days, Wild Boar hunting was one of the chief sports indulged in. An 


\section{THE BOOK OF THE ANIMAL KINGDOM}

instance came under my notice recently of how important it is to carefully examine the remains of animals before casting them on one side as useless and uninteresting. Excavations were being made near an old manor house whose history is mostly obscured in the mist of ages, for in its immediate vicinity a Roman Villa of great antiquity was discovered not long since, and beautiful examples of Roman pottery and other epitaphs of the Roman era have been unearthed close by. A biological friend of mine happened to be present during the time the excavations were taking place, and he was handed some bones of an animal which might or might not have been of interest. My friend pronounced the bones to be those of a IVild Boar, which assurance met with some amount of derision from certain so-called wiseacres who had assembled. They made fun of his pronouncement, ventured the opinion that the bones were probably those of a Domestic Pig, and the matter ended for the time being. Presently one of the men engaged in the work of excavation dug out the tusks of a Wild Boar, and my friend was at once heralded as a remarkable prophet. A little incident, it is true, but one which clearly illustrates how important it is to always be on the look-out for the remains of animals, for, as a result, an interesting link in a broken chain may often be supplied.

The Wild Boar, then, chooses as its habitat a swampy forestthicket, an uncommon environment which is little resorted to by many kinds of mammals. We thus find that the beast is particularly adapted for frequenting such a habitat, and can the better appreciate how it is that the domestic animal known to every one seems to revel in wallowing in slush amid the squalid surroundings of its pigsty home. The WVild Boar attains a height of about three feet up to the shoulders, a length of about six and a half feet, and weighs about four hundred pounds.

Dr. Schmeil considers this animal from five very interesting standpoints, namely, as an inhabitant of the forest, as an inhabitant of the marsh, as an omnivorous feeder, as a burrowing animal, and from its position in the economy of nature and in regard to man.

Briefly summarized, the results of Dr. Schmeil's investigations under these five heads may thus be given. As an inhabitant of the forest the Wild Boar is, like the Elephant, well adapted for forcing its way through the thickets and undergrowth by reason of the conical-shaped head which it pushes like a wedge through the bushes. 


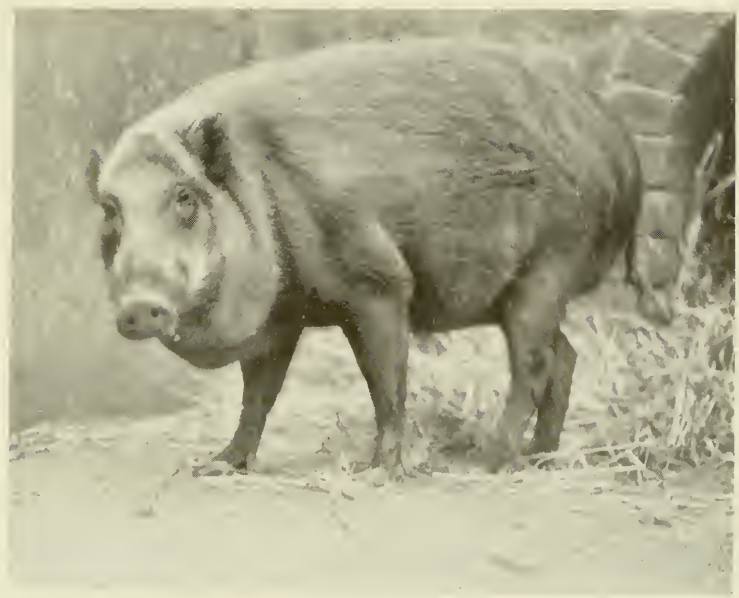

FIG. I92.-WHITE-WHISKERED SIVINE

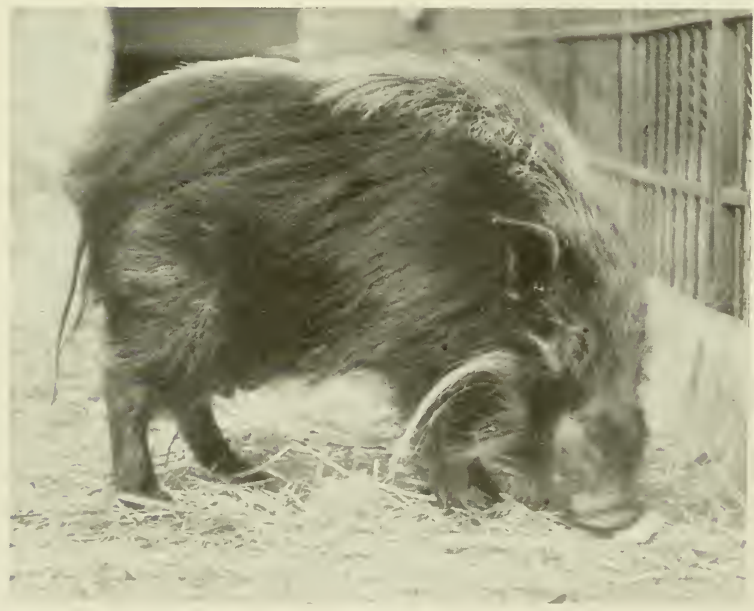

FIG. 193.-EAST AFRICAN RIVER HOG 


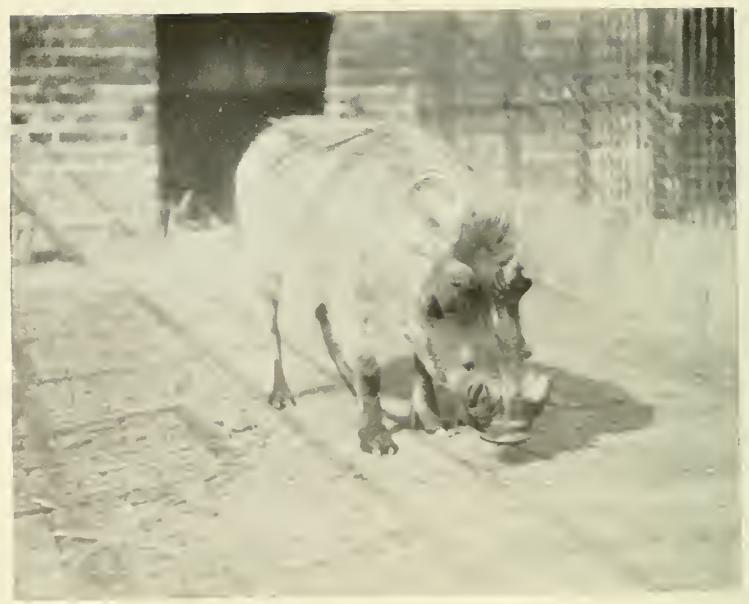

FIG. 194.-WART HOG

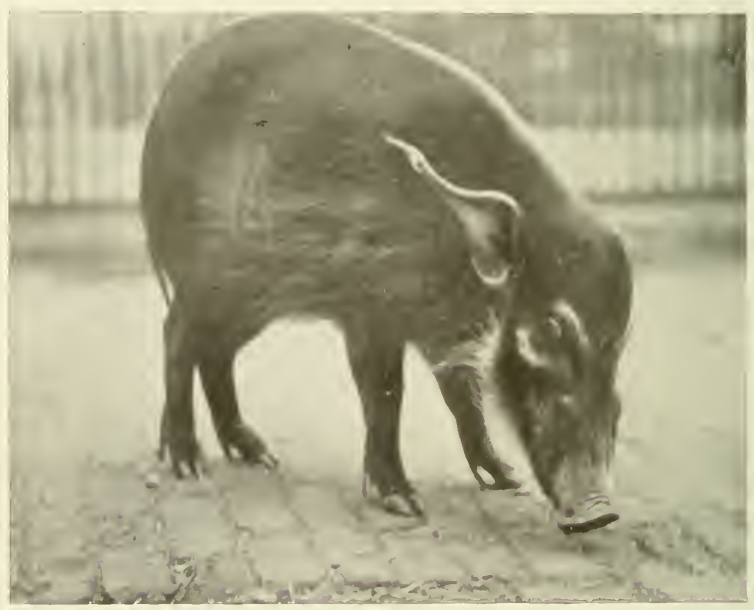

FIG. 195.- RED RIVER HOG 
Having effected an opening in the thicket by this means, the Boar has the way made clear for forcing its rigid body through the undergrowth, and, once having obtained an opening, we learn that its rate of progress is both swift and sure. It is also largely assisted in its movements by the short, powerful legs and the two central toes which are encased in strong hoofs. By means of these the animal is able to obtain a firm purchase upon the ground, and it is easy to understand that a beast possessing long legs and hoofless toes would be much less capable of doing this.

The skin being so tough acts as an admirable protection when the Wild Boar is making its way through the forest, the bristles with which the skin is coated do not hamper the animal's advance as would, for instance, the wool upon a Sheep, and the small, deepset and strong eyes are well protected by bristles and thus take no harm. Finally under this head, it is important to note that the thick impenetrable forest-thicket affords the Boar admirable protection both in regard to the adult animal, and also its defenceless young ones, against the attacks of enemies.

Being a lover of water and marshy surroundings, and exhibiting a keen delight in wallowing in mud and slush, we find that this animal, as an inhabitant of the marsh, is wonderfully well structurally adapted to undergo what is evidently a most enjoyable existence. It is excellently suited for pursuing such a life and is prevented from sinking in the mire "by the separation of the broad central toes, the area of the surface of support" being increased; "this happens even on hard ground, but still more on mud, because the latter penetrates between the toes. When these toes sink in further, the smaller hind-toes reach the ground and give further support." Then again, writes Dr. Schmeil, "by again bringing the toes together into their normal position, the animal, on sinking in a swamp, soon manages to liberate its feet. For a man this is a much more difficult performance, for on raising the foot a vacuum is formed below its surface. The two-toed Ox can also walk on swampy meadows, but not the one-toed Horse." Wonder may be expressed as to how it is possible for the Wild Boar to welter in swamps for a considerable time without inducing an excessive cooling of the body. What provision then is made against this? The thick layer of fat situate beneath the skin-and to which reference has already been made in passing-is of vital importance in this connection, as it has been proved to be a bad conductor of heat, 


\section{THE BOOK OF THE ANIMAL KINGDOM}

and beyond this the fat is of assistance to the animal when it is swimming, being of less specific weight than water. Added to these remarkable devices for assisting this animal to pursue its inhabitance among marshy surroundings, there is the fact of the bristles drying quickly and the colour of the skin well protects it from being espied.

As omnivorous feeders the Wild Boar and its domestic relation are well known, for whilst the latter does not appear to disdain anything in the eatable way, its wild cousin feeds on acorns, nuts, wild fruits, fungi, roots, potatoes, turnips, cereals, snails, insects, mice, worms and carrion. It is certainly not a vegetarian, partaking as it does of a large amount of animal food as well, and its teeth are adapted for procuring and masticating both.

The Wild Boar is largely a nocturnal animal, wallowing in the water during the heat of the day and coming out at night-time to appease its hunger. It is somewhat of a blunderbuss in its wanderings; that is to say, when feeding among crops it certainly destroys more than it eats, and when resorting to a district where farming operations are carried on, it undoubtedly perpetrates much damage. Being a night hunter it is essential that this beast should possess keen senses of smell and touch, and an acute sense of hearing. These are all prominently developed, the sense of sight being very weak. The sensitiveness of the snout is well known to those who have kept Domestic Pigs, and their habit of finding truffles (a kind of mushroom) need only be mentioned as illustrative of this.

We now pass on to consider the Wild Boar as a burrowing animal, for it has the habit of digging up roots, bulbs and insects found below the soil. In this, as may be supposed from what has already been written of its structure, the beast under review is well assisted by the pointed head, upon the end of which the nose is prolonged into a snout or proboscis. We find, too, that the nostrils are well protected when burrowing operations are taking place by being placed at the "anterior end on the terminal burrowing disc." Further, the canine teeth being developed into strong tusks and directed upward in both the upper and the lower jaws, serve the Boar well in its digging, for by means of them it is capable of tearing up the ground in search of delicacies, "and for lifting up roots as thick as a man's arm as easily as with a crowbar." The short, powerful neck, and the muscles at the nape, ably serve the Boar in its burrowing operations and otherwise, 
for whatever work the head is called upon to perform, it does not bend under the strain, no matter how violent the labour involved may be. It may be thought perhaps by the casual observer that too much stress has been laid upon the feeding habits of this and other kinds of animals treated of in this book, but an instance of how important it is to pay some amount of regard to these is well exemplified in the case of the Wild Pigs, for, as a matter of fact, the method of feeding accounts for their distribution. They inhabit Southern and Central Europe, Northern Africa and West and Central Asia, and thus it is obvious that in countries where any prolonged frosts are experienced the Wild Boar cannot find a congenial home; consequently it is not found there.

We may now briefly consider the animal under review from the position it occupies in the economy of nature and in regard to man. Has it any enemies, and if so, what are they? What damage does it perpetrate, and to what extent, and what are the animal's uses? The answer to the first question is that since the Wolf and the Lynx have disappeared from the haunts of the Boar, it has few, if any, enemies, with the exception of man himself. He likes it because of the sport which it affords, and probably he alone would regret its total abolition, though the Zoologist would also no doubt not agree to its extinction without dissent. It is stated that the Fox does attack young Wild Boars, and that in some regions the larger Wild Cats may be considered enemies of this beast, but it is pretty well calculated to take care of itself either when attacked by man or wild creatures, for by means of its powerful tusks it can direct ominous blows at its adversary. The blows are always directed upwards, the tusks "at every movement of the lower jaw are whetted against each other, and thus remain constantly sharp and pointed," and it is said that a single blow is sufficient to rip open the belly of a dog. The Domestic Pig, it will doubtless have been noticed, has not lost the blind rage of its wild cousin, and I have myself seen Pigs assume quite a threatening attitude, although in their case, of course, being minus the tusks, little harm is likely to be done.

Mention has already been made as to the amount of damage that Wild Swine are capable of doing when they frequent the vicinity of lands that bear crops, and it can be imagined how a herd can devastate whole areas when once they start on a foraging expedition. In consequence of this, few there are who are willing to say much in favour of this beast; it has been relentlessly persecuted in some 


\section{THE BOOK OF THE ANIMAL KINGDOM}

districts and become entirely exterminated as a result, and whilst it is also looked upon with disfavour by the forester, who recognizes the damage it does by ripping up the roots and trampling down plantations, it is as well to remember that "by incessant burrowing it destroys an immense quantity of injurious insect larvæ, and at the same time, by burying underground the fruits of the trees, it brings about involuntarily a sort of natural sowing of the forest."

The Domestic Pig has, of course, been utilized by man for a great number of years, and by judicious selection has been brought to a remarkable state of perfection, but even to the casual observer distinguishing differences will at once be apparent, for in the better known animals of the pigsty it will be noticed that the tusks are absent, the skull is shorter and higher, and the body is not clothed with hairs to the same extent. Yet we learn that when Domestic Pigs are given their freedom and allowed to return to a wild state, they "reassume the form and structure of their ancestral parents."

Beyond being in such request for the purpose of food, domesticated Swine are of use, for pig-skin makes a most serviceable leather and is particularly useful for saddles; from the bristles hair brushes are manufactured, and in many other ways these animals are of use, one writer facetiously remarking that everything in connection with them is useful with the exception of their "squeal."

The IVild Boar of Europe is dusky-brown or grey in colour, tending to black, whilst the young ones are white, and, as a rule, marked with yellow longitudinal stripes. In a wild state the old boar is found to be of a solitary disposition, and it is he who is such a dangerous adversary, as he has longer tusks than the sow and is of larger size. The sow and young keep together in small parties.

In Britain, where many of the forests in which it roamed are now no more, the Wild Boar was protected by William I. After the decease of that monarch the animal died out, but later on it was reintroduced by Charles I into the New Forest in Hampshire. The advent of the Civil War, however, soon put an end to its reintroduction and the animals were all destroyed. After this, so far as I am aware, no further effort was made to reintroduce them, but I remember some years ago seeing some at IVindsor which belonged to Queen Victoria, and which I believe were a present from some Indian Chief to "the Great White Queen." 


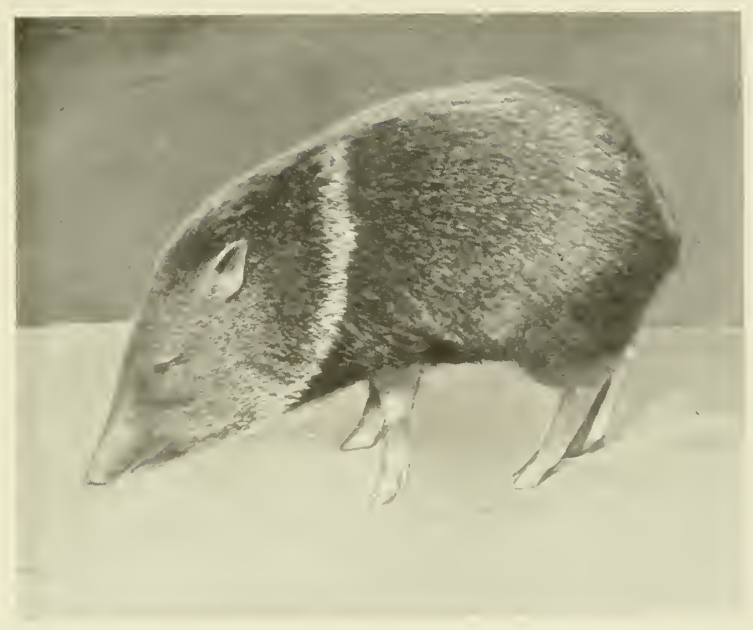

FIG. I96. COLLARED PECCARY

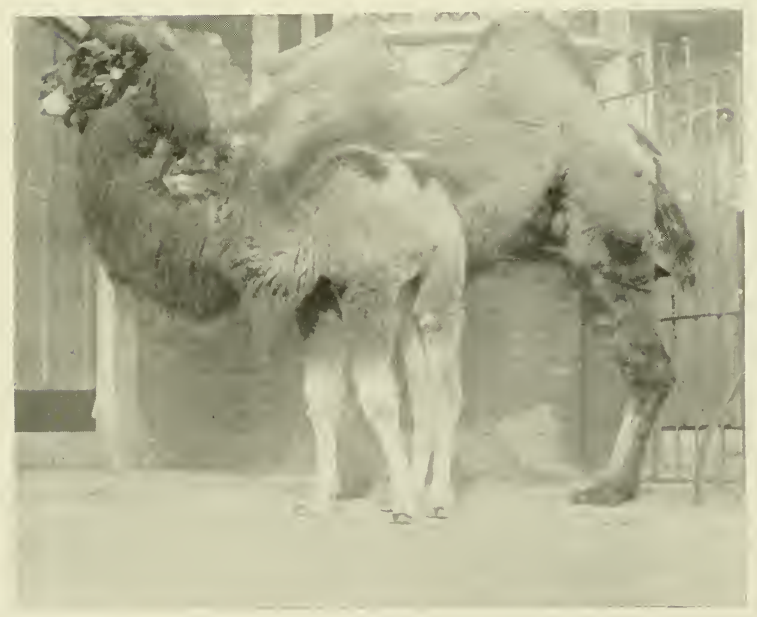

FIG. I97.-BACTRIAN CAMEL AND YOLNG 


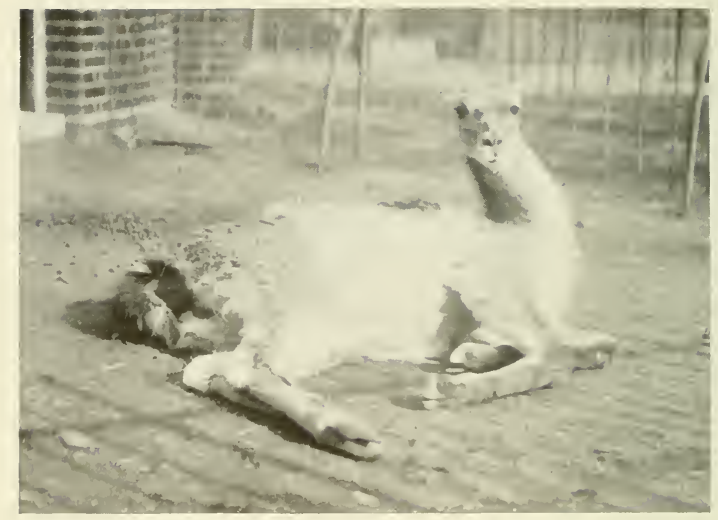

FIG. 198. HUANACO, OR GUANACO

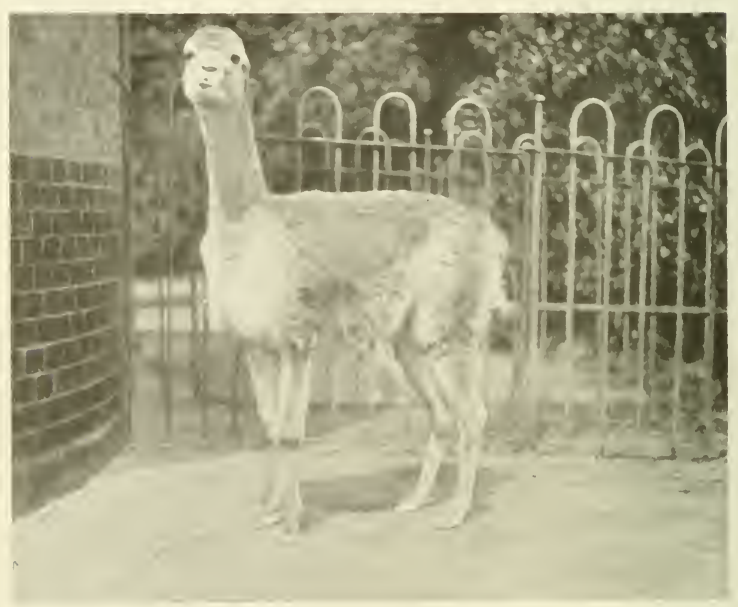

FIG. 199. - VICUNA 
Mr. Ernest Protheroe gives some interesting figures concerning how Pig rearing varies in different stock-raising countries, and remarks that "in the British Isles there are, roughly, four million Pigs to thirty million Sheep and eleven million Cattle. Australasia has but one million Pigs to a hundred million Sheep. The Argentine possesses only about three-quarters of a million Swine to seventy-four million Sheep and twenty-one million Cattle; but in the United States are forty million Pigs to about the same number of Sheep and Cattle. Austria, Russia and Germany are also big Swine raisers, the two former possessing about ten million each, while the last-named has half as many again. These figures show the immense importance of Swine in providing food for man. Pork is the most popular meat in France and many countries in Europe. In Chicago alone there are firms which each kill twenty-five thousand hogs a day; and in a single year the United States sends to the United Kingdom alone, bacon and hams to the value of EI I,000,000." (Vide The Handy Natural History.)

It is probable that the Domestic Swine found in various parts of the world are descended from either the European Wild Pig or the Indian kind, but frequent interbreeding and crossing have taken place to such an extent that it is difficult to arrive at a correct solution of this interesting problem.

What has already been written of the Wild Boar applies almost equally well to all the species that are illustrated, but a few further notes may be given as to some of these and other kinds. The various species are allocated to different genera; thus the European Wild Boar is accorded pride of place among the true Pigs in the genus Sus, and the same remark applies to its Indian cousin (Fig. 190).

INDIAN WILD PIG.-Many Zoologists are of opinion that the latter is not specifically distinct from its European relative, but it may be pointed out that it is a taller animal, has a thinner coat of hair and no under-fur, and is characterized by a crest or mane of long black bristles which run from the nape of the neck along the back, and there are distinguishing differences in regard to the teeth which need not be detailed.

OTHER WILD PIGS.-In the Andaman Islands there is a smaller species inhabiting the forests which has a shaggy coat and short tail; then there is the Pigmy Hog, which inhabits the forests "at the foot of the Himalayas in Bhutan, Sikhim and Nipal," this small species being no larger than a Hare. In the Malayan region, R 2 


\section{THE BOOK OF THE ANIMAL KINGDOM}

and also in Japan, there are other Wild Pigs which belong to the same genus as the European species, and we may now pass on to the Babirusa (Fig. I9I), which is placed in a genus of its own.

BABIRUSA. - This species has a naked skin of a dark ashy-grey colour, but is distinguished by the remarkable development of the tusks possessed by the male, there being two pairs of these, called the upper and lower tusks respectively. They curve upwards like those of the ordinary IVild Pig, but "instead of protruding from the margins of the jaws, arise close together near the middle line of the face, and thence, after being directed upwards for a short distance, sweep backwards, frequently coming into contact with the surface of the forehead, and are then finally directed forwards towards the tip." The lower tusks are somewhat similar, but are not often curved so strongly. The effect on first seeing these, and having no knowledge of the animal, is that it has a malformation. This species inhabits Celebes and Boru, and its name-Babirusagiven to it by the Malays, means Pig-Deer, and sufficiently indicates the extraordinary tusks which it bears.

WART HOGS.-The Wart Hogs (Fig. I9t) are African beasts, there being two closely allied species, and whilst the Red Bush-Pig (see Fig. 195) is stated to be the handsomest member of the Swine family, we are told that among the Wart Hogs there are forthcoming the most hideous-looking representatives not only of the group to which these beasts belong, but also of all the species included among the Ungulates.

These IVart Hogs are so called because of the large heads which, whilst flat and broad on the lower part of the face, have tremendous warty excrescences beneath each eye, and also two smaller ones between the eye and the tusk. Both sexes have enormous tusks, the muzzle of the head is very elongated and reminds one of the Hippopotamus, and the eyes in consequence are placed in a backward position.

GIANT BUSH-PIG.-Mr. Radclyffe Dugmore tells in his Camera Adventures in the African Wilds, how one day he came across, in a thickly-wooded region, an animal which he took to be a young Rhinoceros, but a second look proved it to be an animal which he had not met before. He says, "I was scarcely ready when it looked up, and as I pressed the shutter release I realized that the animal I was photographing was none other than the Forest IIog or Giant BushPig (Hylocharus meinertahageni), one of the rarest animals in East 
Africa. This huge creature, the largest of the Pigs, has only been known to science since I904, when it was discovered, I believe, by Captain R. Meinertzhagen, and since that time very few specimens have been secured. In general appearance it differs from the Wart Hog, not only in size, but in the enormous wart-like excrescences protruding immediately below the eyes, and by the inconspicuousness of the tusks, which in the one I saw were practically invisible. The colour of this one was a decidedly reddish-brown, but that may have been due to its having rolled in the dust, as it was of nearly the same tone as the sandy clay of the district. Needless to say, I was greatly delighted at such a stroke of good luck, for in my wildest dreams I had never expected to have an opportunity of photographing this rare and very shy animal."

PECCARIES.-The Peccaries, of which there are two recognized species, known as the Collared Peccary (Fig. I96) and the WhiteLipped, come between the Swine and the Hippopotami, and are, as a matter of fact, the American cousins of the animals with whom we have been so far concerned in this section. They have been deemed worthy of assignment to a separate family, and they constitute the only genus included in it.

A characteristic feature that will at once be apparent is in regard to the tusks, for, instead of being directed upwards as in the last group under review, the Peccaries have their tusks directed downwards. They exhibit differences, too, in their hind-limbs, for instead of having four toes, they have three only, whilst could we explore inside the animal's "little Mary" we should find that that part of the anatomy is not of simple construction as in the Old World Swine, but "a complex one approaching that of the Ruminants." In this, then, and other ways, the Peccaries are accorded a higher position in the scale of animal life than their Old World cousins, and they are "clearly one step in advance of their allies...." Further still, the Peccaries can at once be distinguished, at close quarters at any rate, by a beastly odorous oily substance which is exuded from a large gland situate in the middle of the back.

Note the slender limbs of the Peccary shown in Fig. 196, the absence of any visible tail; also the small, tapering ears; the bristles with which the body is thickly clothed, and which form a mane on the neck and a fringe on the throat; and the long snout.

The Collared Peccary is an inhabitant of America like its White- 


\section{THE BOOK OF THE ANIMAL KINGDOM}

Lipped relative, but is found further north than the last-named species, "its range extending from Arkansas and Texas to the Rio Negro in Patagonia." Both species haunt the dense forests, and in some districts of South America ascend to an altitude of several thousand feet. They make their homes among the cover afforded by the forest, or else take advantage of a burrow made by some other wild beast, or dwell in the snug retreat of a hollow tree. These Peccaries appear to be chiefly vegetarians, and hence differ from those animals treated of earlier, but it is stated that they vary their bill of fare by partaking of insects, worms or carrion.

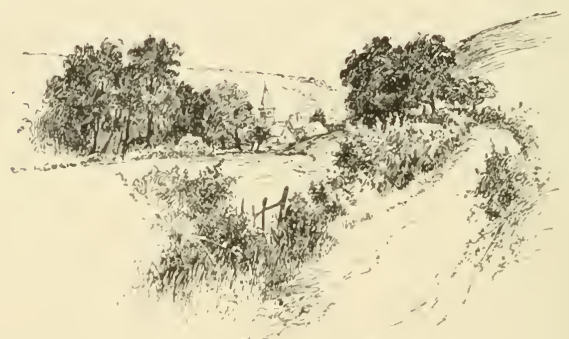




\section{CHAPTER XIV}

WOOL- AND FUR-BEARING ANIMALS

WE have now reached a very important section of our work, and shall make the acquaintance of quite a number of interesting and useful animals during the present expedition, among these being the Camels, Bears, Foxes, Skunks, Chinchilla, Marmots, Seals, Beavers and Otters. Although many of these animals are very valuable com. mercially. on account of the wool or fur which they produce, it is essential that first place should be assigned to the Camel, and it is not intended to treat at any length of the animals included from the standpoint of their commercial utility.

BACTRIAN AND ARABIAN CAMELS.-If only on account of its antiquity, the Camel is worthy of occupying a foremost position in this section, for authentic records prove that this "Ship of the Desert" was well known in Egypt over three thousand years ago. It is usually most highly regarded because of its usefulness as a beast of burden, traversing the desert regions and undergoing great trials of endurance which no other animal could withstand. But it is as well to recognize that it is not only on account of its use as a beast of burden the Camel makes a strong appeal, for the Arabs make a favourite dish with its milk by boiling it with a mixture of rice and flour, and even when the milk is sour it is mixed with flour and made into a kind of bread. The flesh, too, is of value, resembling veal, the hump being especially looked upon as a real delicacy. But this does not exhaust the usefulness of this animal, for the Arabs make harness and shoes from its skin, and clothing and tents from the hair with which its body is covered.

It seems remarkable, in spite of the fact that the Camel has been used for so long a time in the world's history, that it has never become reconciled as a beast of burden, preserving very largely its vicious temperament.

Beyond this, the beast under review has played at times an important part in history, for it is quoted in the book of Genesis 


\section{THE BOOK OF THE ANIMAL KINGDOM}

and elsewhere in the Bible, and there are many instances recorded showing how its use has had an important bearing concerning the decision of a battle. Mr. Harold J. Shepstone, in the course of a most interesting paper entitled "The Camel at Home," in The Animal World, writes-

"We are told that when Jacob fled across the wilds of Mesopotamia he 'rose up, and set his sons and his wives upon Camels.' These creatures are among the presents given to Abram by the King of Egypt, and by Jacob to his brother Esau. Joseph is drawn up from the pit, into which he had been cast by his jealous brethren, and sold to a passing caravan of Ishmaelites, who came by 'with their Camels bearing spices and balm and myrrh, going to carry it down to Egypt.' Later on, in the days of the Judges, there was an invasion of the land of Israel by the Midianites and the Amalekites, of whom we are told 'their Camels were without number, as the sand by the seaside for multitude.'

"Again, in what we may call a border raid by Amalekites in David's day, we find that warrior hero swooping down upon a party of plunderers while they were feasting and exulting over their spoils, not one of them escaping except 'four hundred young men who rode upon Camels.' The long, swinging stride of this desert steed must have carried many a defeated fighter safely out of the battle in ancient days. But where horses were used even his long legs were outmatched, as when, for instance, Zenobia, the warlike Queen of Palmyra, fled from the victorious Romans. Her city having been taken, she mounted her swift Camel and hurried off across the desert sands. But a troop of Roman cavalry espied her and gave chase, and the galloping horses easily came up with the Camel, and she was made captive.

"But history is replete with instances showing how the use of Camels has decided a battle. When Cyrus fought the rich Crosus he dreaded his enemy's cavalry, so he resorted to a stratagem. He collected his baggage Camels and replaced their loads with soldiers, whom he ordered to advance against the cavalry of Crosus. Behind the Camels Cyrus placed his foot-soldiers, and behind them his cavalry. The stratagem was successful, for when the horses of Crosus saw and smelt the Camels they at once turned tail and bolted. Thus Cyrus won the battle.

"Speaking of the part the Camel has played in early history, one writer says: "The Arabian conquest of North Africa, the rise of 
the Moorish kingdoms, the bringing of Moorish art and Moorish science to Western Europe, would never have taken place, or at all events would have been greatly delayed, were it not for the Camel.' But here one is naturally inclined to ask, who first tamed the Camel? Curiously enough, no one knows. Although it has been the subject of much research there is no satisfactory evidence of the existence of the Camel in an original wild state at any period whatever. True, some little time ago naturalists declared that they had found the true Wild Camel on the dry, wind-swept plain of Tsaidam, in Central Asia. The Camel there is certainly a healthy, hard-living beast and able to endure much that would kill his tame relatives in the sunnier lands of the south. But it is the opinion of Major Cumberland, an admitted authority on Camels, that these Wild Camels of Central Asia are the descendants of herds whose masters perished in a great sandstorm which swept over the district some two centuries ago."

There are two kinds of Camels, the Bactrian, or Two-Humped . Camel, shown in Fig. 197 with a young one, and the Arabian, or One-Humped Camel. People generally appear to regard the Camel as an animal inhabiting warm sandy deserts, and this is doubtless due to the animal's long association with Eastern countries; but the Bactrian Camel is an inhabitant of the desert regions of Central Asia, and the fine shaggy coat of the creature at once shows how well calculated it is to withstand the cold climate of such a country as Siberia.

The Bactrian is readily distinguished by its two humps; it is a heavier-looking beast than the Arabian, and has shorter legs but longer hair. It is interesting to compare the legs of these two species of Camels, for whereas those of the Bactrian are short and admirably adapted for traversing rocky districts, those possessed by the better known Arabian, or One-Humped Camel, are longer and well suited to carry the beast and its burden across vast wastes of desert.

In both disposition and habits the Bactrian resembles its relative, and in the countries it inhabits it is equally useful. It is, as in the days of old, still of service in war, or in preparations for war, for we learn that "the Persians use it for their celebrated Camel artillery, a light swivel-gun being mounted on the saddle and worked by the rider."

Leaving the Bactrian Camel, we may now consider in greater detail the Arabian species, stating straight away that the Dromedary 


\section{THE BOOK OF THE ANIMAL KINGDOM}

is merely a high-bred, fast-moving Camel, and the difference between the ordinary One-Humped Camel and this latter may be compared to the ordinary Horse and the Racehorse. A Dromedary can travel eight miles an hour with ease for several hours a day, and has been known to traverse a distance of six hundred and thirty miles in five successive days.

Besides being an inhabitant of Arabia, the species now under review is found in Asia Minor, Syria, Persia, Afghanistan, India, Egypt and Northern Africa generally. Mr. Protheroe says that "it has been introduced, among other places, into the South of Europe, United States and Australia. In the New World is was not a success, and the few animals in Italy are very inferior to those on the other side of the Mediterranean; but in Australia the Camel has proved invaluable in the desert regions, and the thorough exploration of the interior would have been practically impossible without it."

The Arabian Camel attains a length of almost seven feet and stands about the same in height at the shoulder, or two feet more to the top of the head. The latter is borne on a long curved neck, and the high arched back is also a characteristic feature. As a general rule the soft, woolly hair is reddish-grey, but there are many different breeds in Arabia, and these vary in the colour of their coats. On the chest and joints of the legs there are pads of hard skin admirably adapted for serving the beast when it wishes to lie down and rest. The small, rounded ears are worth noticing, and the prominent eyelids and eyebrows well protect the eyes from the sandstorms which are so often encountered upon the desert, and the nostrils can be opened and closed at will, and are thus similarly protected.

The feet are covered with hardened skin instead of bearing hoofs : there are two elongated toes which are furnished with soft pads, and these, when opened, enable the Camel to traverse the treacherous sandy desert with a firm tread and without sinking or slipping. The more the construction of this beast is considered the more interesting are its details revealed, for if we examine its inside, we find that is has a collection of water cells, or pockets, in which water may be stored, and upon which the animal can draw as it requires.

There are, as will be seen, many reasons which fit the Camel as an admirable beast of burden in regions where other animals would 
fail, not the least of which is the length of time it can go without food, and the remarkable habit it exhibits of scenting water at a distance often saves both the animal and its driver from suffering agony through thirst. The wide expanse of arid desert is its home, and whilst it is a mistake to suppose that the Arabian species cannot traverse rocky ground successfully in the same way as its Bactrian relative, it is a fact that on wet and slippery ground the beast is out of its element and quite unable to secure a foothold. The hind-legs "slide asunder on a treacherous surface, and the animal is unable to bring them back; and the result is that the weight of the body, to say nothing of a burden, forces the bones out of their sockets, and nothing can be done with the unfortunate creature but destroy it."

Beyond the water pockets already referred to, the Camel is well served by its hump, which is made up of fatty cells, and thus supplies a reserve of food in the same way as the fatty accumulation stored up in the bodies of animals which hibernate for a lengthy period, and to which attention has already been drawn in a previous chapter. When starting on a long journey and the animal has been well supplied with nourishment, the hump is in a fine condition, but should the food supply fail, the reserve of fat stored up in the hump is drawn upon, and as this takes place so surely enough the hump disappears, until at the end of the pilgrimage it is found to have shrunk to almost nothing.

The Camel is capable of carrying enormous burdens upon its back; its powers of endurance are very remarkable, and although used to some extent for agricultural purposes, it is because of its great service as a beast of burden that it is most highly regarded. To the Arab it is indispensable, for without it the burning tracts of the great Sahara desert could not be penetrated, whilst our knowledge of these vast regions would be very sparse had it not been for the services rendered to travellers by this wonderful beast.

And yet, although for so long a period it has been acquainted with mankind, serving him, as we have already seen, in so many directions, it is an unintelligent creature, ill-tempered, and does not, for example, learn to know its owner in the same way as a Horse. It has a great aversion to water-excepting when thirstyand rather than ford a river will permit its body to become immersed, to roll over and drown. Its movements are directed with great difficulty-if it is possible to direct them at all-for the beast goes just that way which best suits its purpose, and to ride it for the 


\section{THE BOOK OF THE ANIMAL KINGDOM}

first time is an experience not easily forgotten. Mr. Shepstone says-

"There is no doubt that Arabs can do more with Camels than Europeans. This is because they understand their ways and peculiarities. The animals are certainly stubborn and cannot be hurried. The proverb about the last straw breaking the Camel's back is no fiction'. Place a burden which is in the least degree too heavy upon a Camel's back and wild horses will not persuade it to get up, let alone start upon its journey. Then it is not a creature blessed with too much intelligence and is inclined to be stupid. Again, it must be left to fix its own pace while on the march. For these reasons the Government now, when they requisition the services of Camels for transport work in hot countries, use native drivers. In the Afghan War we lost, it is stated, 20,000 of these useful beasts because we did not understand how to manage them. In the more recent Somaliland campaign Somalis were put in charge of the Camels. They understood them, sang to them as they marched along, and the results were most gratifying."

HUANACO, OR GUANAC0.-The Huanaco (Fig. I98) belongs to the genus of New IVorld Camels which includes, in addition to the present species, the Llama, Alpaca and Vicuna (Fig. I99). None of these possess the hump of the Camels of the Old IVorld last under consideration, and Figs. 198 and 199 will at once show that they are of lighter build, smaller size, but in other respects akin. Their habits are, however, entirely different, for instead of inhabiting flat sandy deserts, they are natives of lofty mountainous regions. Having, unlike the Old World Camels, two sharp, hard hoofs instead of small nails, they are enabled to traverse precipitous regions where the Old World Camel would not dare to tread, even if it could obtain a foothold, and have been compared as little inferior to the Chamois in regard to their agility.

The Huanaco is the ancestor of the Llama and the Alpaca, the Perurians having domesticated the wild beast aforementioned, and producing from it the two animals referred to, the Llama serving as a beast of burden, and the Alpaca being domesticated for the purpose of providing the wool so well known as an article of commerce. Thus the Huanaco may be called the true IVild Llama, for it is a wild and wary animal with a rough, short coat of a brown colour. Its range extends through the Andes from the Equator to Cape Horn. 
VICUNA.-The Vicuna (Fig. 199) is very inferior in size to either the Llama or the Huanaco, standing about the height of an ordinary Donkey. It does not enjoy such a wide range as the Huanaco, being found in and around the region "of which Peru is the centre," but ascends to higher altitudes and, therefore, colder regions. It has a more or less light-brown coat, with white under-wool. The flesh of the Vicuna is much esteemed, whilst the wool is of very fine quality.

LLAMA.-It remains to be said that the Llama attains a height of at least four feet at the shoulder, and, like its Old World representatives, is capable of carrying a heavy load, and possesses great powers of endurance as a beast of burden. This "American Camel," as it may be designated, resembles those recently under review in disposition, progressing as and when it pleases, exhibiting a sulky temperament, and, beyond this, has a nasty habit of spitting in the face of a person with whom it is not on the best terms. Those visiting Zoological Gardens may have evidence of this if they approach too close to the beast and annoy it in any way, and I have myself seen visitors at the Gardens in Regent's Park who got more than they bargained for when looking at the animals there located. All the Llama family exhibit this curious habit.

ALPACA.-The Alpaca has a longer neck than the Llama, but it is a smaller animal and more often bears brown or black wool. It varies in colour like the Llama, and is sometimes wholly white, or white marked with brown or black. The Alpaca carries its head in an erect position, and although it thrives well in the country in which it makes its native home, it does not succeed outside, as although experiments have been made in Europe, and also in Australia, all have failed. The famous Alpaca wool is yellowishbrown, grey, white or black, and although it was used for many years for various purposes, its real value and use was not made manifest until machinery was invented by means of which the fibre constituting it could be properly dealt with. Since that time the demand for the wool has increased, until it is to-day responsible for a very large industry.

It is only during the important season of shearing that the Alpacas are allowed to temporarily quit the high mountain tablelands upon which they pasture. This process over, the animals leave the valleys and are taken back to their fastnesses for the greater part of the year. 


\section{THE BOOK OF THE ANIMAL KINGDOM}

POLAR BEAR.-The picture depicting a pair of Polar Bears (Fig. 200) at the London Zoo is of interest because it is one of the last taken showing these two animals in their old home. Sam and Barbara, as they are popularly known, have recently been transferred to much improved quarters, where they provide a fund of interest and amusement to visitors. Quite a number of incidents might be mentioned concerning these two well-known inmates of the Regent's Park collection, not the least exciting of which was the breaking of a padlock and their subsequent escape and recapture two or three years ago. Not long since Barbara gave birth to two cubs, but although Sam was temporarily removed and every precaution was taken, the young ones were not reared.

Reaching a length of as much as thirteen feet, and a weight of $1,600 \mathrm{lb}$; ; clad in a warm coat of yellowish-white, and with a mobility of body and a silent footfall, the Polar Bear is always a favourite beast in a Zoological Garden. But in its native home on the coasts and islands of the Arctic Ocean, it must present a fine sight to those who have the good fortune to observe it amid the splendours of ice-bound Polar Seas.

How well provisioned this fine beast is against the fierce Winter cold which it encounters in its own wild haunts! It has thick, shaggy fur, between the hairs of which there are large air-spaces. What purpose, then, do these serve? Air being a bad conductor of heat, the animal is thus well served by these air-spaces, and a thick layer of fat beneath the skin also affords protection, fat also being a bad heat conductor.

Its whitish coat assists the Polar Bear to secure food, for, by means of it, it is better able to creep towards its prey unobserved, being protected by its harmony with the surroundings of snow and ice; and the hairy covering on the soles of the feet ably assists it in securing a firm and silent foothold on even the most slippery ice. It is a good climber, feeding not only on the few kinds of mammals that inhabit its Arctic home, but also birds, their eggs and young. Beyond this it also partakes of a regetable diet, such things as grass, berries, lichens and mosses being consumed, "which, during the short Summer of the Arctic North, grow upon the thawed surface layers of the soil."

But in those desolate regions the Polar Bear often experiences considerable difficulty in supplying its bodily needs from the few other animals which eke out an existence in a land of perpetual 


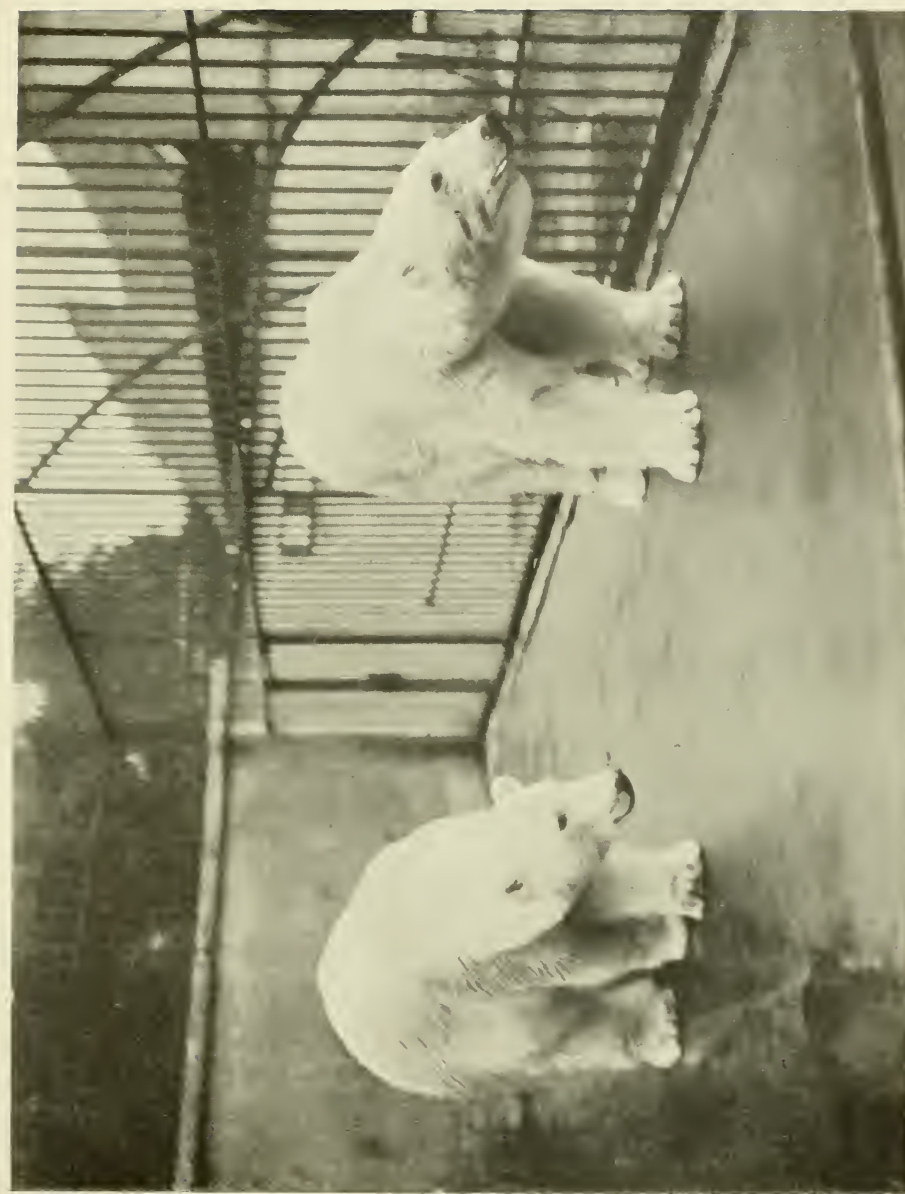

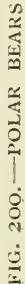




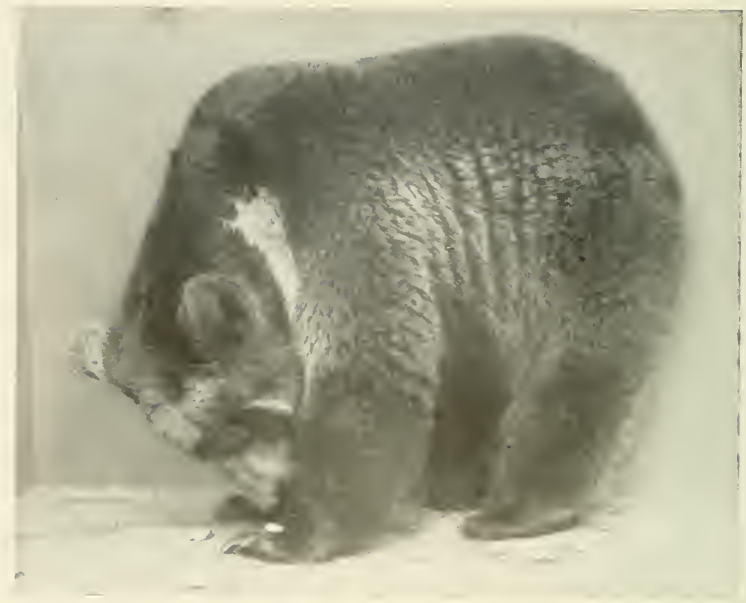

FIG. 2OI.—ISABELIINE BEAR

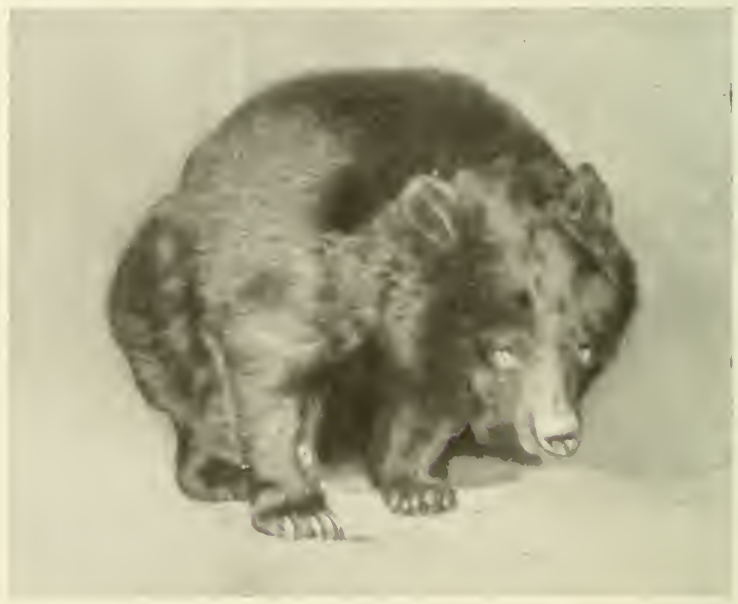

FIG. 202. J.PANESE BEIR 
snow and ice; thus we find that the food supply on land being restricted, the Bear makes the sea its chief hunting ground. It is as much at home in the water as on land, a fact which may be verified by visiting the new Polar Bear enclosure at the London Zoo, for the splendid creature swims easily and with great powers of endurance. Not only is the body ably protected "from the fatal effects of cooling in the icy water by the large air-spaces between the hairs of its fur," but also "by the thick and adipose layer under the skin ... and by the copious secretion of fat from the glands of the skin by means of which the furry coat is kept constantly lubricated, and thus never allowed to get wet." Then again, as Dr. Schmeil states, swimming is "facilitated by the large airspaces between the hairs of the shaggy coat and the fat accumulations within the body; for air as well as fat, being lighter than water, helps to diminish the specific weight of the body."

It has enormous strength, and this, together with the wide paws and the cutaneous webs between the toes, assist it greatly and enable it to swim both rapidly and with endurance.

It can catch fish with much cleverness, and in stalking Seals, Walruses and other marine creatures exhibits a strategy which shows the born hunter, the animal diving noiselessly and swimming cautiously until well within striking distance of its prey.

As it can so well secure animal or vegetable food, both on the land and in the sea, it is not necessary that this Bear should undertake any migration movements, or enter into a Winter sleep, whilst its thick coat and other provisions already alluded to ably protect it throughout the rigours of the Arctic Winter.

When hunted, it is a dangerous foe to encounter, and the very fact that it is able to successfully attack such large prey as the Walrus-which is comparable in bulk to that of a small Elephantis sufficient indication of its enormous strength and clever stalking. It does not hug the hunter like its relatives next to be dealt with, but bites and claws in no half-hearted manner whenever opportunity presents itself.

Although regarded as a solicitous and devoted mother when in a wild condition, the experience of the Zoo authorities in London with Barbara in 1908, and again in I9ro, tells a different story, for in I 908 Barbara cared no more about her young one than to pick it up soon after it was born and drop it heavily on the concrete floor! Again in Igro two cubs were born, one of which was, I under 


\section{THE BOOK OF THE ANIMAL KINGDOM}

stand, eaten by the mother, and the remaining one did not long survive.

BROWN BEAR.-All the members of the Bear family present a striking resemblance to one another if exception be made of the handsome Polar Bear last under review. The fur is coarse and long, thick and shaggy in those beasts which inhabit the colder regions. Those kinds which resort to hot countries have shorter and thinner fur, a thick coat not being so essential as in the case of the Bears which inhabit cold climates.

Brown or black is the prevailing colour of all the Bears, but in some a white collar is present on the throat. The black coloration is most interesting for the reason that it "is a feature unknown in any other group of Carnivores, and is, indeed, rare among mammals in general."

Passing by the Isabelline Bear (Fig. 20I) with the remark that it is closely related to the Brown Bear and a resident of the Himalayas, we may, before dealing with the Japanese, Malayan and Sloth Bears, devote attention to the Brown Bear, which deserves recognition in view of the fact that it is most typical of the whole family, and the commonest of them all.

The Brown Bear varies a great deal in colour, various shades of brown being forthcoming in different races. This has resulted in several so-called species being established, but these are, at best, simply local races of the species now under consideration.

The Brown Bear has a wide distribution, for "its range extends throughout almost the whole of Europe, particularly Russia, Scandinavia, Central Europe, the Pyrenees and the Balkan Peninsula; in Asia it is found throughout Siberia to the shores of the Pacific; and it also inhabits the colder regions of North America."

It is interesting to notice that evidence has been collected which proves that the Brown Bear was an inhabitant of the British Isles in the eighth century, and, before this, when the Romans held undisputed sway in this country, this species was used by them wherewith to fight in the arena. The extinct Cave Bear (Ursus spelcus) was a different species, for it was a gigantic beast whose remains have been found "in such profusion in the caverns of Europe, and less commonly in the brick-earths and other superficial deposits." In the olden days this huge creature was, we are informed, "a contemporary of the Mammoth and early human inhabitants of Europe," and one wonders at this time of day how 
it was possible for rude, uncouth savages to fight such a formidable wild beast. Armed only with flint hatchets and spears, what a contrast these rude hunting implements are to the modern firearms. It is obvious that these ancient Britons must have possessed remarkable powers of both offence and defence to successfully overcome such a powerful adversary which tenanted the forests of Britain in the remote past, and at a period in the history of our land which is largely obscured by the mist of ages.

Even in the days of Queen Elizabeth the Brown Bear was used for Bear-baiting, but in that remarkable reign, which produced such men as Shakespeare, Bacon, Drake and Raleigh, it is obvious that the animals were imported, the species having become exterminated as a native some considerable time previously.

Of the European Carnivora, the Brown Bear is the largest representative, the Polar Bear, of course, being excepted. It attains a height of about three and a half feet at the shoulder, and a length of from five to seven feet. It has a long, shaggy dark-brown coat, what has been well described by Mr. Protheroe as a "shambling gait," and, what is not quite so accurate in my opinion, it is said to be "an uncouth-looking brute." I have often been criticized with regard to my innate love for the brute creation, and, in spite of this, I cannot bring myself to describe any living thing as "hideous," "distasteful" or "an uncouth-looking brute." I believe strongly that man is far too prone to ill-judge some of the less appealing and attractive-looking animals, and although I know full well that Sir Herbert Maxwell, among others, has expressed the opinion that he cannot follow me in my principle of laissez-faire with regard to birds, I would, if I had my way, give a fair chance of existence to every living creature. My knowledge of animals leads me to the conclusion that few are inimical to mankind, and those of my friends who have travelled extensively in foreign countries where innumerable wild beasts populate the air, the earth and the fresh and salt waters, have convinced me that there are not a great number of the brute creation whom man, in his wisdom, need dread as mortal enemies. I certainly regard no living thing as "hideous" or "an uncouth-looking brute," for all forms of life have an interest for me, and whilst we do not all see or think or reason alike (and I admit it is a real blessing we do not), I do not think that any one interested in the outdoor world should apply unnecessary epithets towards any wildling, no matter how distasteful its form or habits may be. I 


\section{THE BOOK OF THE ANIMAL KINGDOM}

often hear people venture their opinions concerning both animals and plants. Most people love Roses and Violets, but few have a kind word to say for the humble Dandelion and Daisy. Bird-lovers who are friends of mine are in the seventh heaven of delight if they chance to stalk an uncommon feathered creature, but pay little or no attention to our common resident birds, whose constant presence does so much to make the countryside and our gardens such pleasant places in which to pass our daily lives.

The reader must pardon this digression from the Brown Bear, but an opportunity presented itself of writing as I have done, and, with a promise not to return to the subject again, we may now pass on.

Like the Polar Bear, our Brown friend loves water, and is an expert swimmer. Beyond this it is also a good climber, as all visitors to the Bear Pit at the London Zoo can testify, and when coming down a tree or elsewhere, it takes the precaution of descending backwards after the manner of a human being.

Its diet is made up mainly of various kinds of vegetable matter, such things as roots, leaves, corn, berries and fruit being eaten. Sometimes the diet is varied with the grubs of wasps and bees, and, on occasions, it takes to killing cattle.

When attacking, the Brown Bear exhibits a quickness of movement which is very remarkable, and the power it possesses is not less striking. It exhibits an uncertain temper, although, when obtained young, it is not difficult to tame, but cannot always be trusted.

In America there are, of course, the Grizzly Bear of the Rocky Mountains-which is not only the most formidable animal of the North American continent, but the most ferocious of the Bear family-and the American Brown Bear. This latter is quite distinct from the Grizzly, or "Old Ephraim," as it is also known, and in Alaska attains a very large size, exceeding even the Russian Bears, which have magnificent coats and possess a stature of great dimensions.

JAPANESE BEAR. - Little need be written of this species (Fig. 202) excepting that it is closely allied to the Himalayan Bear, and is regarded by many Zoologists as only a variety, the chief distinguishing feature being the less prominent white mark around the throat. It is a common inhabitant of Northern Japan.

MALAY BEAR.-The Malay, or Malayan, Bear (Fig. 203) is a resident, as its name implies, of the Malay Peninsula and the 


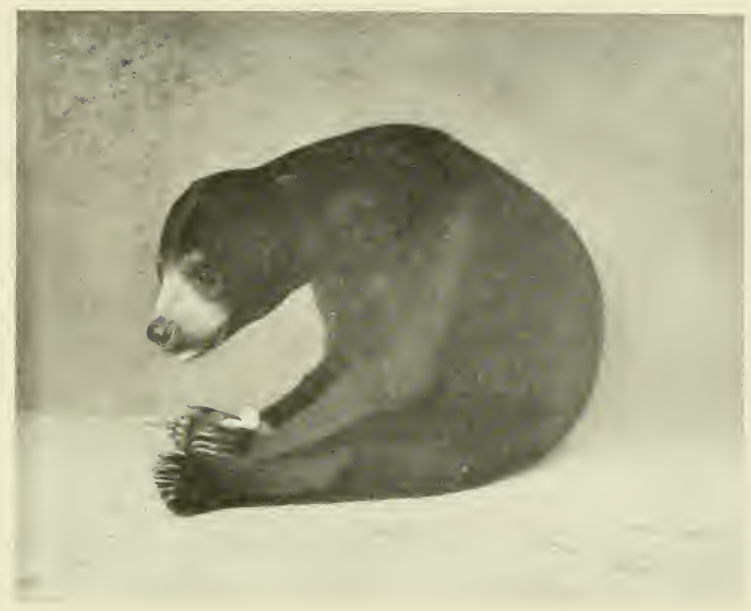

FIG. 2O3. MALAY BEAR

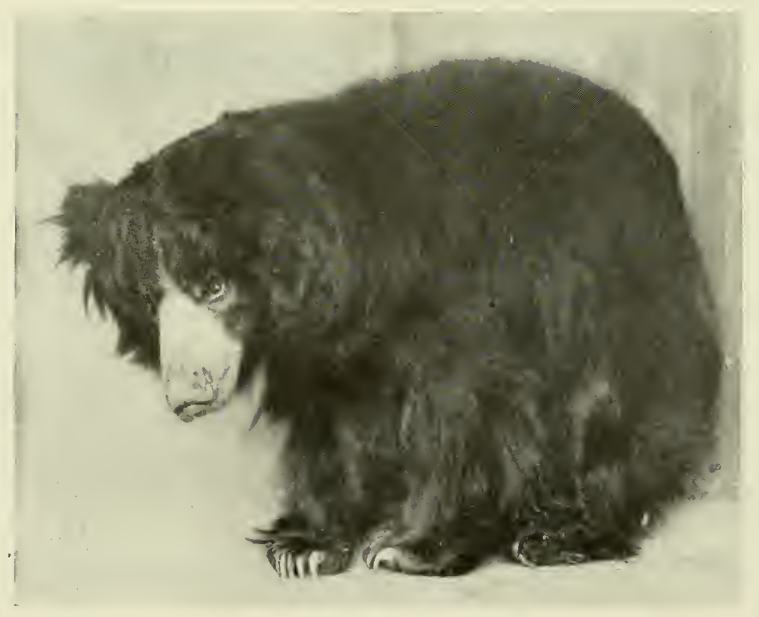

FIG. 2O4. SLOTH BEAR 


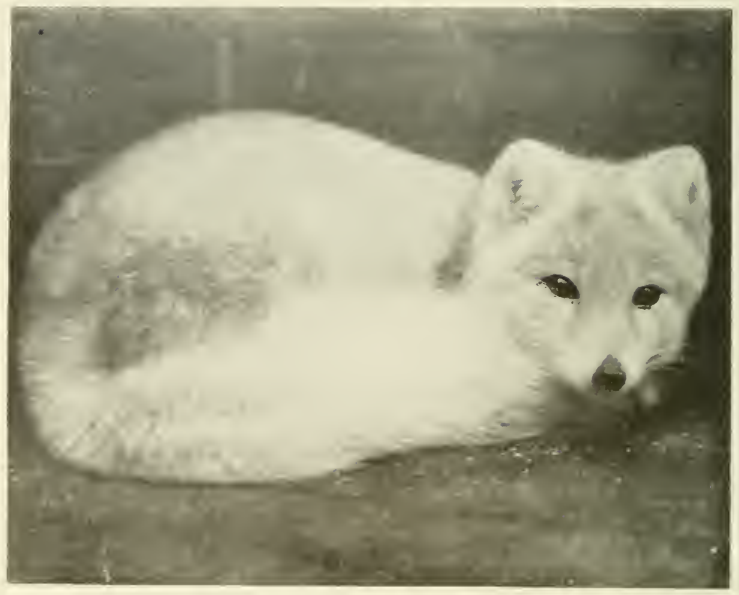

FIG. 205. ARCTIC FOX IN WINTER COAT

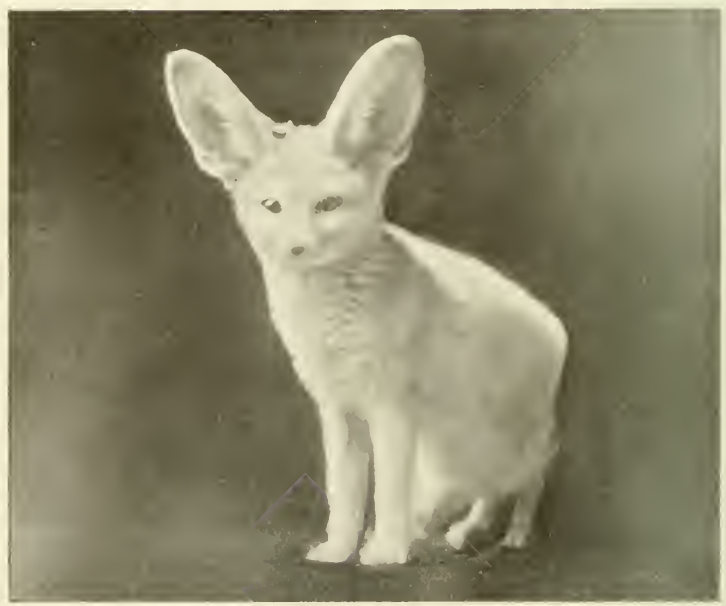

FIG. 2O0.- FENNEC F(): 
adjacent islands. It is an interesting species and makes a good pet, the one shown in the photograph having served a well-known regiment in that capacity. There is also, at the time of writing, a young Bear of this species at the London Zoo with which I have the honour of being on intimate terms of acquaintance. True enough the little beast is too fond of a desire to hug one's leg, but it appears to be more in play than otherwise, and I have seen it allow quite young children to fondle it without any harm accruing. To see the baby Bear walk on its hind legs in a sedate sort of way, and in a bolt-upright position, is a delightful experience, and I hope that some day Mr. Berridge may be prevailed upon to snapshot the animal in the act. In a wild state the Malayan Bear exhibits a great preference for honey, whilst it is also said to perpetrate a great deal of damage in cocoa plantations. I have noticed with interest that when feeding in captivity both the young and adult animals lie on their backs whilst thus engaged, taking the food in the front paws and enjoying their meals in this way. I cannot account for this strange proceeding, and imagine that it can be only a habit that has been acquired in captivity.

SLOTH BEAR.-The last of the Bears with which we are at present concerned is the shaggy-coated individual shown in Fig. 204. This is an Indian species which is commonly known in its own country as the Bhalu, and by the Mahrattas as the Aswal.

It is an important animal which should not be overlooked, as it differs so much from its relatives that it has been placed in a separate genus of its own. We need not enter into the reasons for this generic distinction excepting to state that the structure and number of the teeth are mainly responsible, and that the large and powerful claws, the elongated and mobile snout and lower lip are salient characteristics.

It has been described as being "at best but an ugly-looking animal," and although I am desirous of adhering to my promise, I cannot refrain from stating that there is something quite distinct which makes a strong appeal to me in this rough, shaggy-coated warrior. Its very presence denotes in a way the wilds which it frequents, and one is able to conjure up in the mind the place it occupies in the fauna of the Indian Empire, difficult as that may be when the beast is surveyed behind iron bars.

It is not such a large beast as might be supposed from an examination of Fig. 204, but it makes up for its comparative 


\section{THE BOOK OF THE ANIMAL. KINGDOM}

diminuty of stature by being a very formidable beast to tackle. Indeed it has been described by an eye-witness in its native haunts as "a perfect fiend, rushing about hither and thither, clawing and biting anything he comes against, yelling and roaring all the time."

The food of this Bear is made up of flowers, fruits and honey, whilst the long muzzle and mobile lips admirably assist it to procure white ants, beetles and grubs. The power of suction is very remarkable in this animal, as well as the propelling of wind from its mouth, and it is by this means that it is able to procure the white ants or termites from their strongholds. The sugar-cane is another delicacy of which the Sloth Bear takes heavy toll, and whilst the diet mentioned is mainly partaken of, instances have been forthcoming of flesh also being eaten.

Most kinds of Bears usually produce two cubs, and there is no exception to the general rule in the case of the species under review. In some instances three cubs are born, but this is an uncommon occurrence. One well-known observer has recorded that the cubs are carried on the back of the parent until they are several months old. It is also well to recognize that such "an ugly-looking animal" is exceedingly affectionate among its own kith and kin, and capable of being well tamed when taken young. Of timid disposition as a general rule, the Sloth Bear has nevertheless been known to attack a human being without its first having been interfered with, but it is only fair to state that competent observers have remarked that these attacks are probably more due to timidity than ferocity. When once the attack is made, however, the fight is bound to be a stiff one, for the Sloth, by means of its teeth and claws, is one of the most dangerous animals to encounter at close quarters.

COMMON RED FOX.-Among the wool- and fur-bearing animals so far considered we have only made acquaintance with the Old and New World Camels and the Bears. In such a section as this the Foxes must occupy a prominent place, and whilst attention may be drawn to the various animals shown in Figs. 205 to 209 inclusive, a great deal cannot be written of all the species illustrated, and a general account of the Common Red Fox will be sufficient to indicate their general life and habits. A few notes may be given of the others at a later stage before concluding our acquaintance with them.

As regards the Common Fox, few people in Britain at any rate have such fine opportunities of studying it to advantage as gamekeepers, and I am indebted very largely to Mr. Thos. Bamford, head 
keeper to the Earl of Clarendon, for valuable notes supplied by him in regard to this sagacious beast.

Naturally enough, Reynard, as he is generally known, is not sought after by sportsmen for the sake of the fur, but on account of the "sport" he affords, and it is because of this that in England he is accorded so much protection. Outside the British Isles this Fox, however, is sought after by trappers, and the beast is killed in large numbers for its valuable skin.

The period of gestation of the Fox is, roughly speaking, eight weeks. Cubs may be expected any time between February I $_{5}$ and March I5, although I know two instances of cubs having been born as early as the first week in January. This may, however, be considered exceptionally early, and a friend of mine once dug out a vixen with a litter of five cubs not more than two or three days old as late as April 17. The majority of cubs, no doubt, arrive during March.

Litters of five and six are the usual number, although I have known as many as nine in one lot, and as few as three in several others. They, like nearly all carnivorous animals, are born blind and remain so for about eight days. The vixen is a very poor navvy, and, this being so, she has to depend to a great extent upon the exertions of the Badger and the Rabbit for the making of a home for herself and family. She never starts an "earth" on her own account, no matter how easy digging the soil may be, but always takes possession of one made by a Badger, or, in a neighbourhood where this animal does not exist, takes to a Rabbit burrow, which she enlarges by following up and clearing out the passages. In some localities where there are no Badgers, and the soil is too heavy and wet for the Rabbit to make strong burrows, vixens do not attempt to breed underground, but lay up their cubs in a stub root of a tree, or in any dry, suitable place.

Some years ago a keeper had occasion to visit some men who were cutting undergrowth in a big wood in the Woodland Pytchley country. At the time of his visit the men were sitting round a big fire eating their dinner. While speaking to them, he noticed a slight movement in the dry leaves in a big Ash stub about five yards distant from where the men were sitting. He stepped forward to see what the stub contained, and there found six cubs only a few hours old. The poles had been removed that morning from the stub without the men noticing anything there. I may add this was on February 5, 


\section{THE BOOK OF THE ANIMAL KINGDOM}

and frozen snow three inches deep was on the ground at the time. My friend was very anxious as to the safety of this young family, as Foxes were strictly preserved in the district. He therefore at once had the fire put out and the woodcutting operations stopped in that part of the wood. He was curious to know what steps the mother would take as a result of this disturbed state of her home, and in consequence sent for his field-glasses and kept watch, for he felt sure she would not be absent long if she had any regard for her youngsters, especially during such severe weather. He had not long to wait when he saw her come to the edge of the uncut wood, take a general survey round, and, finding all quiet, she very cautiously took half-a-dozen circles round the stub, finally entering, curling herself up, and suckling her cubs in the same way as a bitch would treat her puppies. The following morning he again went to the spot and found the youngsters gone. No doubt the vixen had removed them to a more quiet part of the wood.

It has been said that the offspring of stub-bred Foxes will always breed above ground, but I have had many instances brought to my notice of this not being so, for, after removing stub-bred Foxes into a country where there are plenty of earths, my keeper friends tell me, the animals go to ground and breed there as freely as the natives do. I think this is proof that stub-bred Foxes are so only by compulsion and not from choice.

There is no doubt about Foxes pairing off during the breeding season, for this is often shown by the fact that where hounds find a vixen in the early Spring months a Dog Fox is there too. If not actually with her, he is almost sure to be "viewed away" from the same covert. That the pair both take an active part in preparing a home for the expected family is also plainly to be seen by the two sizes of pads on the fresh-drawn soil at the entrance to the earth.

From observations made over a series of years, I am of opinion that the Dog Fox does the greater part of the work of clearing out and making ready the earth. After the cubs are born he still continues to be a helpmate to the vixen by providing her with food. Some keepers say he will bring up the family by himself should the mother get killed. This may be so in some cases, but Mr. Bamford tells me that he has never known a single instance where this has taken place, although he has seen many litters left motherless at various ages. Of course, there is no question as to the result if the vixen loses her life during the time the cubs are entirely dependent 
on the support they get from her body. For at least ten weeks they are quite incapable of getting their own living, and are supported by both parents.

The Dog Fox does the greater part towards getting food, but in the event of the vixen being killed he has no further interest in the family, and leaves them to starve to death. This is not so if death overtakes the dog, for the mother will keep the family going singlehanded. While watching the Dog Fox bring food, he has been seen to leave it on the earth, but more often he meets the vixen some distance away with it.

One evening a friend of mine was going to visit a Fox earth two miles distant where there were cubs. On his way, and not more than one hundred yards from his house, a white Pheasant was sitting on her eggs in a hedge-bottom. He gave a glance and saw her there as he passed. He had not been in sight of the earth more than two minutes when he saw the vixen come out and trot down the woodride in the direction he had come from. To his surprise and annoyance in less than five minutes she returned with his white Pheasant in her mouth. This clearly shows that the Dog Fox killed the bird immediately after the keeper had left her on the nest, and met the vixen with it.

Upon my friend's return, he not only found the bird gone, but the eggs too! The Fox, no doubt, had "champed" these up, and would probably disgorge them for the vixen when delivering up the bird.

It is very curious that a vixen with cubs nearly always gets the food supply from a distance, although there may be easy means of getting it near the earth. Mr. Bamford tells me that he has many times seen Pheasants and Partridges sitting on their eggs within a hundred yards of an earth without being molested, while in a neighbourhood a mile or two away every bird has been taken as soon as they started sitting! Rabbits, too, in plenty were occupying burrows within a few yards from the earth, yet these were not interfered with. Why this is so appears difficult to explain, unless it is that there shall be a good supply of food close at home when the cubs are first learning to catch the same on their own account. One good authority on Foxes says he is of opinion the vixen does not kill her prey near home to avoid causing any disturbance which might act as an advertisement to disclose the situation of her earth, and perhaps lead to her own destruction. There may be something in this; if so, 


\section{THE BOOK OF THE ANIMAL KINGDOM}

she quite forgets the advertising business when bringing birds from a distance, for feathers are strewn freely around, which makes nothing more easy to be seen than an earth where cubs are present.

The slightest interference with a litter of cubs will often be the means of causing the vixen to shift them. Sometimes this happens as a result of a person merely walking over the earth! Another earth is generally in readiness not far away in the event of anything turning up of a disturbing nature. Some vixens are constantly shifting their cubs for no apparent reason, while others are reared where they are born.

I once knew of a vixen drawing an earth ready for cubs near the boundary of an estate, the owner of which did not look on Foxes as desirable visitors, much less as residents. For this reason the keeper was anxious to shift her into an earth in the same wood which had previously been occupied by Foxes as a breeding earth and on more welcome ground. He took a Terrier and bolted her. The keeper took the precaution to taint the earth thoroughly inside and out with renardine, an offensive preparation which, the manufacturers say, no Fox will approach! He also well stopped the earth, but upon his return the next morning he found she had torn it open and was working freely. He tainted and stopped it up again, and this was repeated every day for ten days, but eventually it had to be given up, for, in spite of his efforts, she would persist in opening and working the earth each night even after the cubs were born and she had the chance to move them. This, of course, was a very exceptional case, and proof of how far sometimes one vixen may deviate from the general rule.

Vixens do not often move their cubs during the first month of their existence unless they are disturbed in some way. The means the mother employs for their removal is by carrying them in her mouth one at a time, just in the same way as a Cat would carry her kitten. She can do this up to the time they are six weeks old. After this they are able to follow her any reasonable distance. When cubs are a month or six weeks old it is not unusual for the vixen to distribute them into two or three different earths, probably two or three in each, and sometimes these earths may be as far as a mile apart, but more often quite close. Much depends on what there is available.

Vixens prove themselves very devoted mothers when the lives of their youngsters are at stake, although there is little fear beyond 


\section{WOOL- AND FUR-BEARING ANIMALS 265}

man and dogs. It is curious, but nevertheless a fact, that few Terriers will face and fight a vixen with cubs. A Terrier used for bolting Foxes, and perhaps good enough to kill one at other times, will seldom tackle a vixen with cubs; in fact, it is she who becomes the attacking party, and not the attacked, as was the case before the cares of a family rested upon her.

Once, while out ferreting, a keeper came across a big sand-earth, which a Terrier seemed very keen to enter. Thinking it had probably been worked by a Badger, the dog was let go, but before he had got a yard in he pushed himself out backwards in a great hurry, followed by a vixen who had only just laid up her cubs there. So determined did her ladyship seem to drive him quite off the premises that she followed him for thirty yards out. This same Terrier had previously, and has since, bolted many Foxes.

Another curious matter is the Fox and the Badger living on such neighbourly terms as they do together (often bringing up their families in the same earth), especially when one considers how totally different the two animals are in their habits. The Fox is, perhaps, not dirty in person, but is naturally very untidy in and about his home, for he will leave the decaying remains of his prey about the earth in the most filthy manner, whereas the Badger is particularly clean both in person and home.

Nothing seems to come amiss to the Fox in his bill of fare. Among some of the most common of his prey are fowls of every variety from the farmyard, Pheasants, Partridges, Hares, Rabbits, Rats, Field-Mice, Moles, young Rooks, Pigeons, small Birds, Cockroaches, Wild Cherries and Berries (especially Blackberries).

It will be seen that he, like most other animals, has his good and bad points. Looking at him from a gamekeeper's point of view, it must be said his bad qualities far overbalance his good ones. At the same time he is an excellent vermin killer, and it may not be generally known, even by those who know him best and often paint him blackest, that he is a deadly enemy both to the Stoat and Weasel. He has a bad reputation as a fowl stealer, some part of which is well earned, for there is nothing he seems to enjoy more than a chicken, but in this respect he needs a broad back to bear all the charges brought against him, especially in a hunting district where a substantial poultry fund exists for damage done by stray Dogs, Cats and vermin.

It must be admitted he does seem to take a delight in slaughter, 


\section{THE BOOK OF THE ANIMAL KINGDOM}

for I have known a Dog Fox kill more Pheasants and Fowls in one night than he and his family could eat in a fortnight. However, after one of these big hauls he is always thrifty enough to bury as much of it for future use as he can.

It is really wonderful how the Fox holds his own as he does, considering the many enemies he makes for himself by his raids on the poultry yard and game preserve. I have known many neatly laid plans for his destruction, but it is seldom he can be brought to book, owing to his keen sense of smell, observation and wary ways. Of course he may be poisoned, and unfortunately often is by those selfish enough to think of nobody else's interests and pleasures but their own. To lay down poison is, besides being illegal, one of the most cowardly actions imaginable, suspicion and punishment often resting on the wrong person as a result.

A poisoned Fox will often die some distance from where the poison was picked up, and perhaps on another's land. To trap in hopes of having revenge for some paltry loss of Poultry or Pheasants, which most hunts are willing to compensate for, is bad enough, but in this case Reynard has a hundred-to-one chance, for it is rarely that he is going to be caught by the ordinary methods of vermin trapping.

A keeper well known to me has been trapping vermin and Rabbits for over thirty years in many parts of the country where Foxes have been plentiful, and he tells me that he has never had the misfortune to catch a Fox. His vermin traps have been baited, too, with all kinds of birds and other animals, many of which are considered delicacies by Reynard. He never allows such traps to remain too long set in one place, and renews the bait of ten enough, hence the secret of trapping where Foxes are preserved. To catch a Fox in a freshly baited trap is very improbable, if not impossible. Rabbit traps left unattended for weeks are liable to do harm in this way. Run traps may catch cubs if set anywhere near the earth.

A friend of mine once caught a cub in a drain-pipe where he always kept a trap set for Stoats. The little chap got his pad rather badly crushed, but after a few dressings he soon got well. Through being constantly handled he also became tame to a certain extent, but never wholly so, He became a great pet and was kept tied up to a small box-kennel in the corner of a yard. When he was about a year old he took to killing poultry, and got so bad at this that it 
was sudden death to any fowl that went within reach of his chain! One day some one on the estate was passing through the yard when his Terrier (who was very keen on Cats) hustled one of the farm Cats near Reynard's kennel. It proved too near, for he sprang out, seizing her across the shoulders and killing her instantly. My friend told me he had lost five or six Cats in the same way, and I have heard since that this Fox got so bad at this kind of thing that his kennel had to be enclosed with wire. Although he was well and regularly fed his love of slaughter seemed as if it could not be resisted when the opportunity came.

Tame, or so-called tame, Foxes are by no means rare. There is always a demand for them in most of the Midland hunts, not only for litters of cubs, to turn down in the Summer for the IVinter's hunting, but also for old Foxes to release late in the hunting season, where the supply has become exhausted through too many being killed by hounds, or more likely still, where some shooting man, who has kept his coverts closed to hounds until the end of the shooting season, and who never keeps a good wild Fox if he can help it, through fear of losing some of his game, does not like to have the reputation of being drawn blank when his coverts are open to hounds.

Such a Fox as he turns down has probably been shut up ever since it was a small cub and not released until hounds are perhaps in the neighbourhood. Should an animal like this be lucky enough to escape being killed by hounds his future is not likely to be a very happy one, for he will be anything but favourably situated. In the first place, he has never had the chance of learning the ways and means of getting his own living; and, secondly, he is thrown on his own resources at a time of year when the food supply is at its lowest. Consequently, he is driven by hunger to pick up all sorts of filth, and there is no wonder, under such circumstances, that we hear so much of mangy Foxes in these days. Litters of cubs turned down in the Summer, and artificially fed, are nevertheless also sources of mange.

Outside the British Islands, the Common Fox is found, with slight variations in colour, size and strength, throughout Europe, Northern and Western Asia, and Northern Africa, whilst in India and North America allied species are forthcoming. It is mainly reddish-brown in colour, with white underneath and on the tip of the tail; the outer parts of the ears and some parts of the limbs are frequently black. The fine bushy tail gives the animal an imposing 


\section{THE BOOK OF THE ANIMAL KINGDOM}

appearance, and the frill on the chest is also very characteristic in a good specimen.

ARCTIC FOX.-The Arctic Fox (Fig. 205) is a beautiful creature at all times, but especially when it is wearing its IVinter coat, as shown in the photograph. It is not such a large beast as the Common Red Fox last described, and is a resident of colder regions, living within the Arctic Circle. It has a grey or bluish coat during Summer, but this turns to pure white in Winter. During the Autumn months large numbers of these Foxes collect together and migrate southwards. There they stay until the Spring-time, and are much sought after by trappers on account of the value of their skins.

FENNEC FOX. - The Fennec Fox (Fig. 206) will at once arrest attention because of its large ears and tail. This species is an inhabitant of Northern Africa. It is pale fawn colour, a pretty creature of nocturnal habits, and only attains a length of about one foot, excluding the bushy tail.

INDIAN FOX.-The Indian Fox (Fig. 207) is another pretty little species deserving of mention. It is almost the smallest member of the true Foxes, and is known in India by the name of Lumri. It utters a short yelping bark, is not at all shy in disposition, but as it does not possess the strong scent of its European cousin it is not hunted to any extent with hounds. It is easily tamed, and this, together with the absence of any distasteful smell, makes it an agreeable animal to keep in captivity.

In colour it varies like most of the Foxes, but the general colour of the fur is grey, with a reddish tinge.

SILVER FOX.-The Silver Fox is a native of North America, and is also known as the Black Fox. It is a rare beast, and the fur is stated to be the most valuable in the world. It is deep black in colour, with white tips to the hair, which gives the animal a beautiful silvery effect.

Mr. Protheroe states that "the imperial pelisse of the Czar of Russia, made of the black necks of the Silver Fox, was exhibited at Hyde Park in 1851 . It was valued at $\&_{3}, 500 . "$

Attention need only be drawn to the Silver-Backed Fox (Fig. 208) of South Africa, and the Virginian or Silver-Grey Fox (Fig. 209) of Central America, and we may now pass on to consider the claims of some other animals who are deserving of a place in this important section of our work.

COYPU RAT.-This aquatic animal (Fig. 2 Io) is an inhabitant 


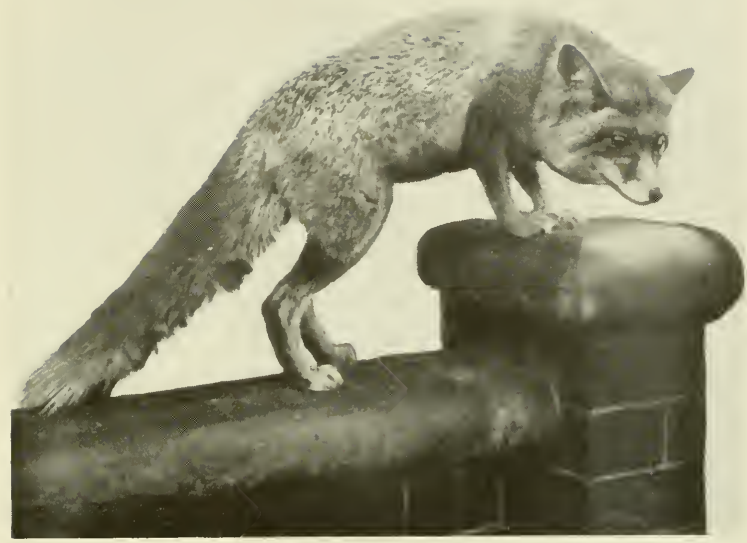

FIG. 207.-INDIAN FOX

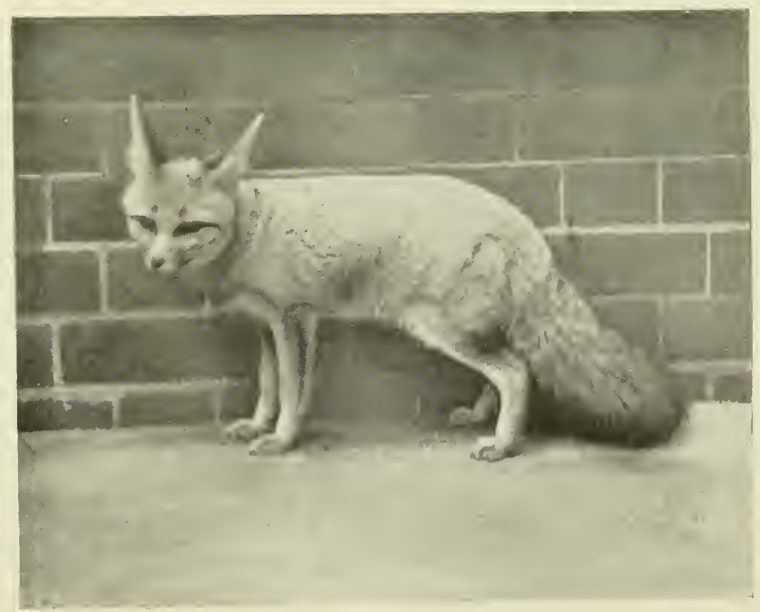

FIG. 208. - SILVER-BACKED FOX 


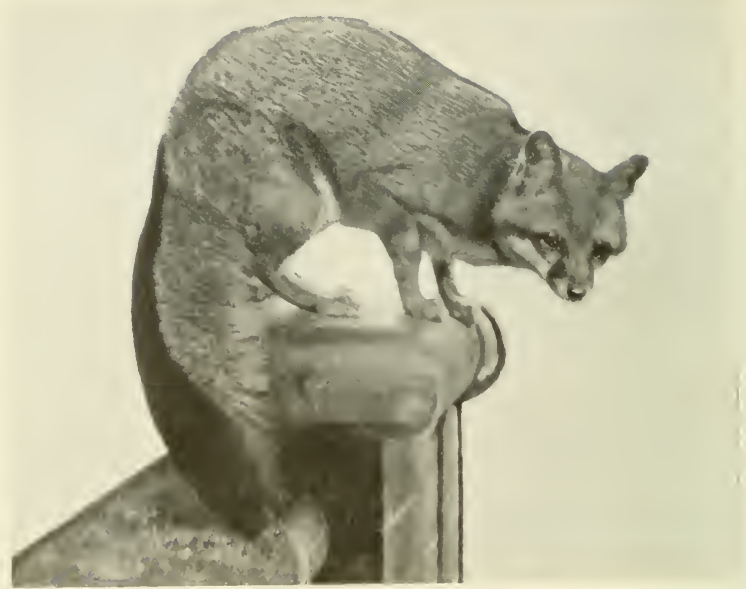

FIG. 2O9. - VIRGINIAX OR SHLER-GREY FOX

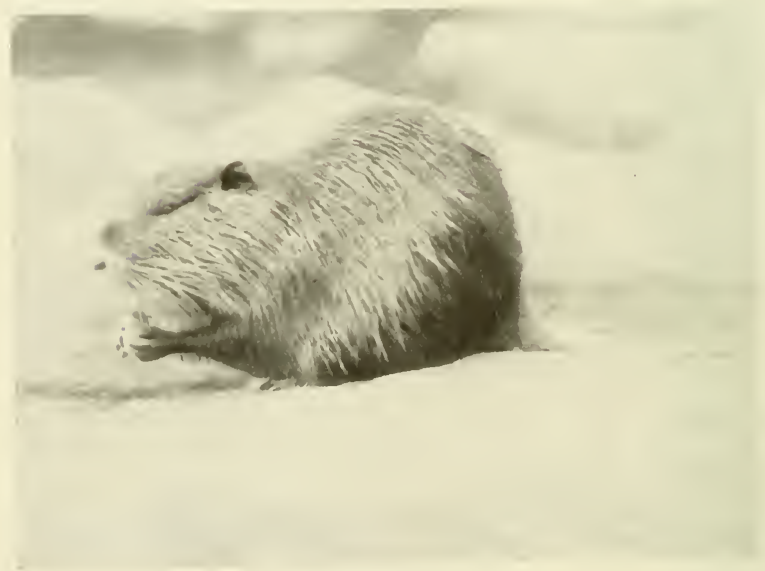

FIG. 210.-COYPU RAT 
of South America, and, in addition to the long tail, attains a length of nearly two feet. It has a harsh covering which is known as Nutria fur, Nutria being the Spanish for an Otter. In former times its skin, like that of the Otter, was largely used in hat-making.

Rivers and lakes are the habitats of this species, a burrow being made in the banks of same, or, when this is not possible, a nest is constructed among aquatic herbage. It is a capital swimmer, but on land exhibits an awkward gait. The food is made up of various parts of plants which flourish near its environment, but in some districts the Coypu leads a more terrestrial life than in others, the burrow being constructed in forests away from the shore. When, some time since, this valuable animal was threatened with extinction and became protected by law, its numbers increased enormously. Thereupon its aquatic habits were temporarily abandoned, and $\mathrm{Mr}$. Hudson says that it "became terrestrial and migratory, and swarmed everywhere in search of food. Suddenly a mysterious malady fell on them, from which they quickly perished and became almost extinct."

CHINCHILLA.-The Chinchilla (Fig. 2i I) is a delightful little beast measuring about ten inches in length, excluding the prominent tail, which is well shown in the photograph. It has been described as something like a Rabbit with a Squirrel's tail. It is an inhabitant of the Andes of South America, congregating in burrows like the prolific Rabbit.

It is highly regarded on account of its beautiful soft grey and greyish-white fur, and there is a great demand for its skin. It is interesting to notice that when this agile and fast-moving animal is being hunted in its burrows a somewhat similar method is adopted for bolting it as with the Rabbit at home, but instead of a Ferret being used, the South Americans utilize a species of Weasel. The Chinchilla is an exceedingly clean little beast, and in this respect resembles other wild creatures which possess a covering of fine texture.

SKUNKS.-The remarkable North American animal commonly known as the Canadian Skunk (Fig. 2 I2) is chiefly noticeable for two things. It has the power of emitting a vile odour from two teats situate under the tail, and also "when hunters are camping out it is apt to gnaw their hands while they sleep, in most cases causing death by hydrophobia." There are several species of Skunks, but all of them are exclusively American, and whilst they 


\section{THE BOOK OF THE ANIMAL KINGDOM}

inhabit districts which vary in climate, their habits are practically identical. The fur in the nine species which have been discovered may be described as long, thick and glossy black, or dark-brown, variegated with stripes and patches of pure white. The Canadian Skunk is about eighteen inches long, exclusive of the bushy tail, and in spite of the abominable acrid liquor which is emitted from the anal glands, the fur is used in commerce, the smell being got rid of as a result of great heat being applied to the skin.

These animals are largely insectivorous in diet, but mice, rabbits and reptiles are preyed upon, and in Texas there is a species which subsists largely on insects, cacti, fruits and berries. In spite of their offensiveness, Skunks are stated to perform much good in ridding the land of insects, mice, etc., but these beasts, like many other useful creatures, are not always regarded as they should be.

The young of the Skunk number from six to ten, and these are born in a deep burrow, hollow stump, cave, stone wall, beneath a house or barn and other places. The animal is fearless of mankind, but when taken young may be easily tamed, and is declared to be a desirable pet, being "attractive in appearance, gentle, cleanly, playful, and sometimes really affectionate."

MARMOTS. - I have seen a company of Prairie Marmots (Fig. 213) holding high revel in an English Park, their burrows being made in the soft loam of a hillside, but they looked strangely out of place, possessing a foreign appearance which contrasted strangely with the native inhabitants, $i$. e. Rabbits and Red and Fallow Deer, hard by. The Prairie Marmot is a small North American species which inhabits the prairies of that vast continent, but one of the largest kinds is the Hoary Marmot, which is found in the North-West of British North America.

Still another, the Bobac, lives in Eastern Russia and elsewhere, whilst the Alpine Marmot (Fig. 214) resides upon the higher altitudes of the Alps, Pyrenees and Carpathian Mountains. It is twice the size, or more, of the Prairie Marmot, and may be compared to the well-known Rabbit in this respect.

Marmots have strong claws wherewith to carry out their underground burrowings; they are stoutly built and have short tails. The burrows are ingenious arrangements, consisting of several chambers which are approached by means of narrow tunnels. The food is made up of various kinds of herbage, and when feeding the wary 


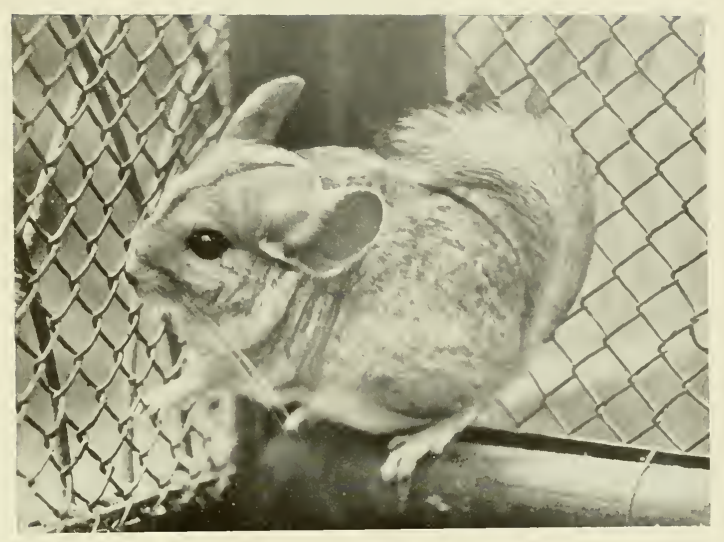

FIG. 2 II.-CHINCHILLA

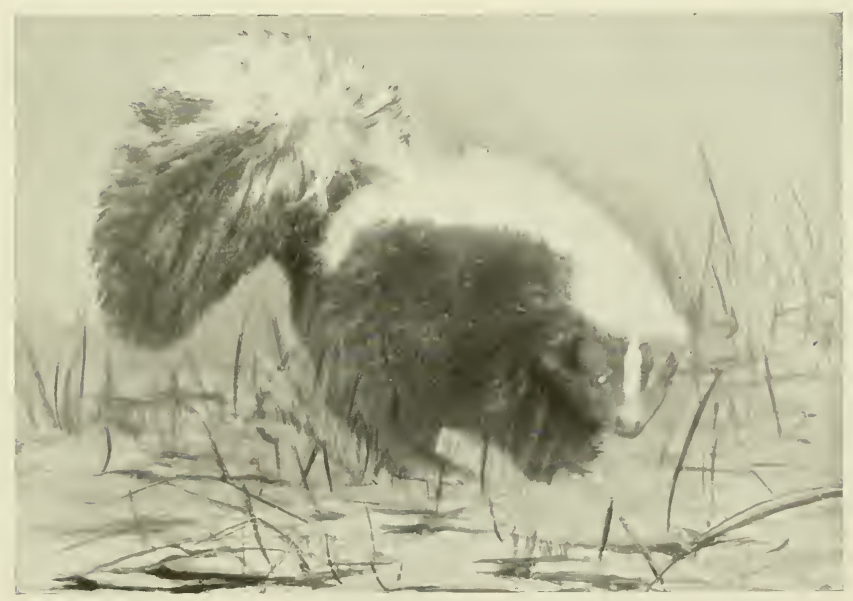

FIG. 212.- CANADIAN SKUNK 


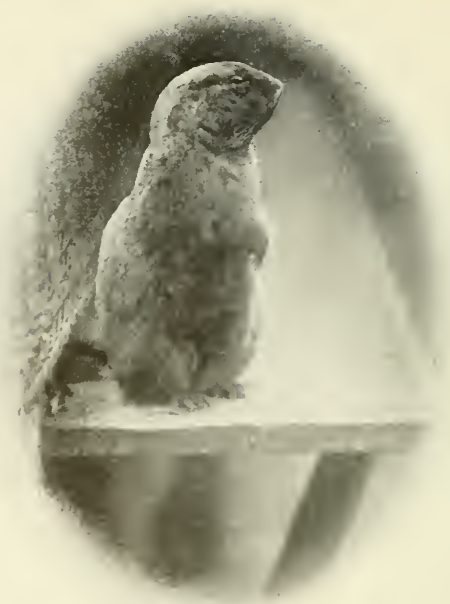

FIG. 2I3.-PRAIRIE MARMOT

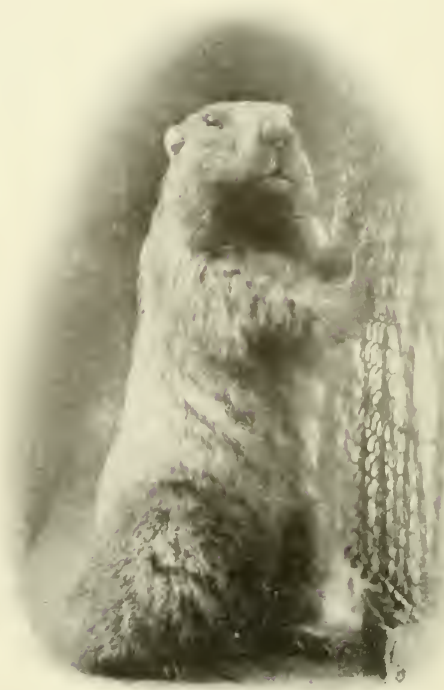

FIG. 2 I 4. -ALPINE MARMOT 
little creatures are always worth watching. They take cover at the slightest alarm, one of the number being told off as a sort of scout. As soon as danger is ahead the scout gives the alarm, and the animals scuttle into their burrows in double-quick time, stopping temporarily at the entrances to ascertain if it is only a false alarm. It may be that after only once being disturbed the Marmots will soon make their appearance again, but if further disturbance takes place they go to cover a second time, and rarely show themselves any more for several hours.

During the Winter the Marmot closes up the entrances to its burrows, and remains underground until it is time to be out and about again. A supply of food is stored up, and the animal feeds until it is fat enough to retire for a lengthy sleep of some months' duration. It is at this time that the fur is in best condition, and, in consequence of this, the Marmot is then sought after by the hunter.

SEALS.-Although the Californian Sea Lion (Fig. 215 and Coloured Plate XVI) is not one of the Fur-Bearing Seals, it represents the type, and as such may be accorded a place in this part of our work. This is a prominent carnivorous animal of the sea, and belongs to the Pinnipedia, from the Latin pinna, a fin, and pes, pedis, a foot. Among the Pinnipedia acquaintance may be made with the various species known as Seals, also the Sea Leopard, Sea Elephant, Sea Lion, Sea Bear, or Northern Fur Seal, and the IValrus.

Important, useful and highly interesting as these fin-footed animals are, it is not possible to treat of all the species here, for they are split up into different sections which would demand lengthy descriptions and technical details outside the scope of this book. Shortly stated, there are three main groups, consisting of the true or Earless Seals, the Eared Seals and the Walrus, or, as the fur-trader adopts, the Hair Seals, Fur Seals and the Walrus, the latter being probably the only member of the Trichechida (see also reference on p. 59).

Admirably adapted for an aquatic life, but ungainly and awkward in their movements upon land, Seals dive and swim with amazing cleverness, and visitors to Zoological Gardens where any of these beasts are on view may see for themselves the remarkable evolutions they undergo at feeding-time.

If a Seal be examined at close quarters, the short limbs, arranged after the manner of the pectoral fins and tail of a fish; close, rounded 


\section{THE BOOK OF THE ANIMAL KINGDOM}

body; strong muscles; structure of the nostrils and nature of the coat, cannot fail to convey to the observer an idea of how excellently adapted the animal is for pursuing an aquatic existence.

The Common Seal-which we have already met with in Chapter III-belongs to the Earless, or True Seals, and is widely distributed, whilst other species belonging to the same group, and which can only be mentioned by name, are the Grey Seal of the North Atlantic, the Bladder Nose or Crested Seal, and the Greenland Seal.

The Sea Leopard is a Hair Seal which inhabits Southern Seas and attains a length of as much as twelve feet; the Sea Elephant is a larger cousin, being, with the exception of the large Whales, the biggest marine mammal in existence, attaining a length of from twenty to thirty feet.

Steller's Sea Lion belongs to the Eared Seals, and is the largest member of the genus to which it belongs; the Californian Sea Lion (Fig. 215) claims kinship with the same genus, but is not restricted to the country from which it has acquired its name, being found on both sides of the North Pacific; the Sea Bear, or Northern Fur Seal, represents the Fur Seals (of which there are also four or five rare Southern species), and which resorts to the islands in the Behring Sea, and the last species which can be mentioned is the IValrus (see Fig. 236). This latter is also known as the Morse, or Sea Horse, and a full-grown adult weighs at least a ton. It is not often found outside the Arctic Circle, and, in addition to its immense size and weight, is chiefly distinguished by means of two enormous canine teeth, or ivory tusks as they may be called. The uses of these lengthy teeth are many, for by means of them and its tough hide the Walrus is well protected against the Polar Bear, and they also assist the huge monarch in hauling its body out of the water on to the ice, and in searching for marine creatures hidden in the sand and mud.

Among the valuable kinds of Seals ceaseless hunting has resulted in many thousands of these animals being killed every year. In consequence, several species have been reduced to a minimum, but it must not be overlooked that to the Eskimo and other residents near the haunts of these mammals of the sea, Seals are of the greatest use, indeed among the very necessities of life. Thus, whilst we must deplore the depopulation of our seas as a result of Seal-hunting expeditions for commercial greed, and, above all, the senseless slaying of those kinds of no economic value, we must not judge too harshly the primitive races of mankind whose only chance of exist- 


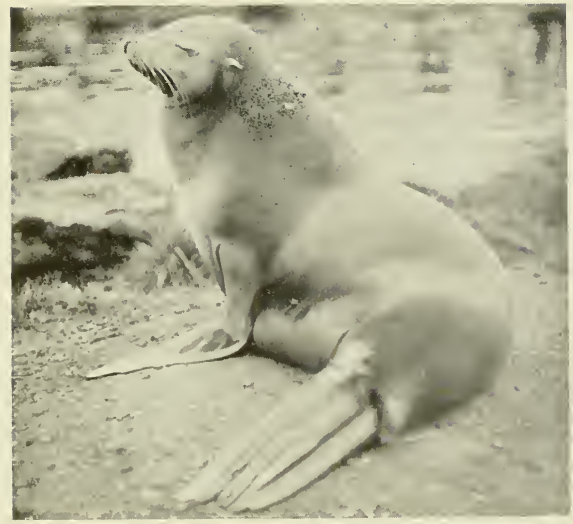

FIG. 215 -CALIFORNIAN SEA-LION

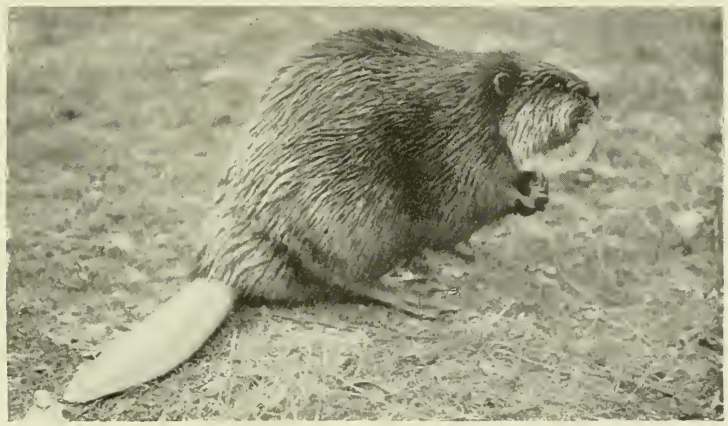

FIG. 216. - CANADIAN BEAVER

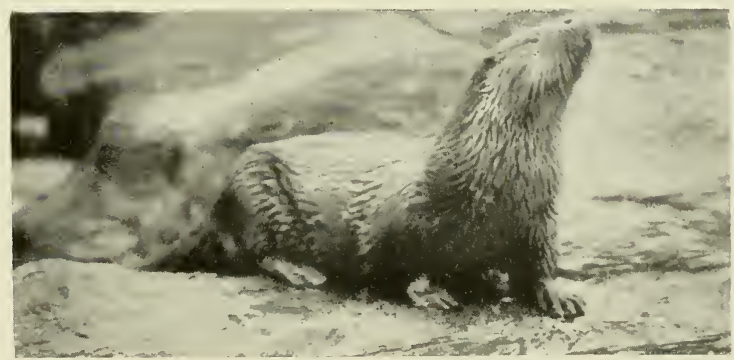

FIG. 217 - COMMON OTTER 


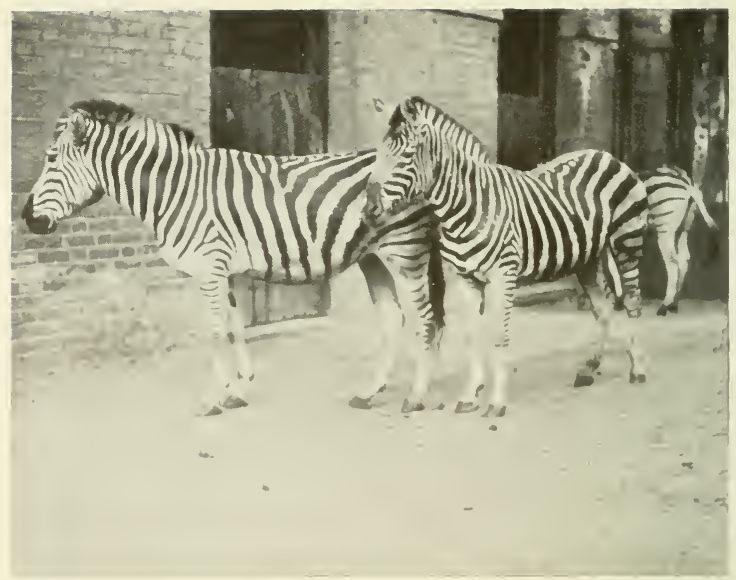

FIG. 2IS. - BLRCHELL'S ZEBRAS

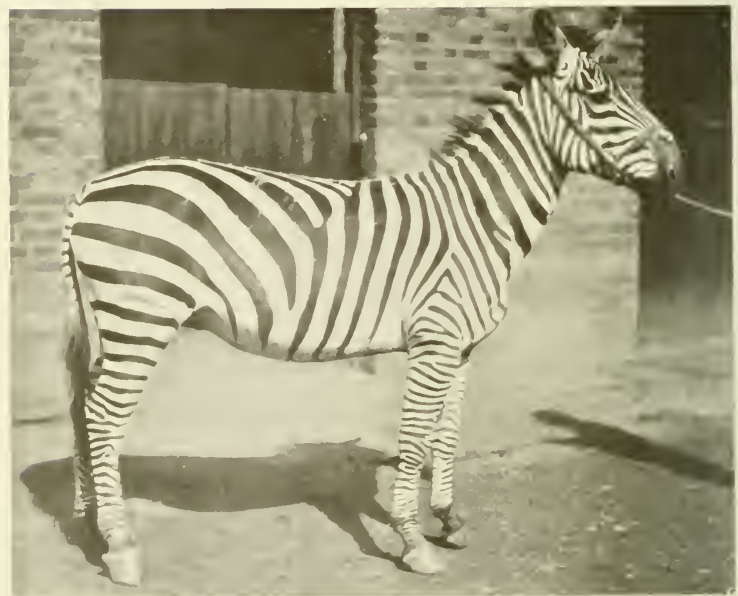

FIG. 2I9.-GRANT'S ZEBRA 
ence is to take toll from the wild creatures among whom they pass their oftentimes dreary lives.

BEAVER.-This large rodent has had an interesting history, for hundreds of years ago it was a common inhabitant of most parts of Europe, including Britain and Northern Asia. Now-a-days the animal has, of course, long since disappeared from Britain, and even across the water there are few districts in which it still exists, and then because it is rigorously preserved. In America a somewhat similar tale has to be told, for, owing to the ceaseless persecution of the valuable beast on account of its pelage, and an odoriferous substance known as castoreum, its numbers have been alarmingly reduced, until to-day it is chiefly in the West and in Canada that a few animals remain. The photograph (Fig. 216) depicts the Canadian Beaver, admirably displaying it in a characteristic attitude and showing to advantage the flat tail.

The last Beaver appears to have disappeared from Great Britain during the twelfth century, and from a valuable paper read by my friend Mr. Hugh Boyd Watt, M.B.O.U., before the Glasgow Natural History Society, I learn that Mr. John Smith has found its remains in the Ardrossan Shell-mound and in Cleaves Cove, Dalry, N.B., whilst in 1874 a small colony was established at Mount Stuart, Bute, by the then Marquess of Bute, but by 1890 the animals had all died out.

As Fig. 216 shows, this is a stoutly built animal, with short, strong legs bearing sharp claws; only the hind-feet are webbed. The large head has short ears, whilst the broad, flat tail is very distinct, being scaly and furrowed. The thick, soft coat worn by the Beaver has mostly been accountable for its downfall, for we are told that about one hundred and sixty years ago no less than 127,000 skins were exported from Quebec alone, whereas to-day its numbers have been so reduced that probably not more than one-twentieth of this number of animals are trapped over the whole of America and Canada.

In colour the coat is chestnut-brown above and greyer underneath, and it is interesting to note that the further North the Beaver inhabits the darker its fur becomes.

It is not only on account of its valuable fur that this rodent has attracted attention, for it is a wonderfully industrious creature, and has been well described as "the most methodical engineer and builder of all animals." 


\section{THE BOOK OF THE ANIMAL KINGDOM}

Of sociable disposition, and resorting, as might be supposed, to water and its immediate vicinity, Beavers construct dwelling-places with remarkable cleverness, such streams, ponds, lakes, etc., being frequented near which timber may be procured. Strong teeth enable the four-footed builders to bite through and collect wood wherewith to build their homes, and little logs having been prepared by them of a suitable length, the animals, with the aid of mud, stones and other material, construct a dam which has been known on occasions to measure two hundred yards in length and several feet in thickness. This having been accomplished, and a quiet sequestered pool having been walled in, as it were, the Beavers set about the construction of various dome-shaped residences, each dwellingplace being capable of housing five or six of their number. From the houses which constitute the little colony there are burrows connected with the bank, the entrances to these being placed underwater so that enemies are placed at a discount, and to provide a means for securing food when the river is frozen.

The roof of each house is built of mud, and when the time for Spring-cleaning arrives there is great activity among the inhabitants of the Beaver "village," each tenement being repaired and made ready for family affairs. The fore-feet ably assist the animal in becoming an expert plasterer; the hind-legs are used for swimming, whilst the tail acts as a sort of rudder. In Winter the Beaver is less active than at any other time, keeping secure inside one of the well-constructed habitations, which, during frost and snow, becomes frozen hard, and thus shelters the beast from its enemies, chief among which is the Wolverine.

The food consists of various kinds of vegetable matter during Summer, but in Winter bark from stored-up logs is partaken of exclusively.

OTTERS.-The Common Otter (Fig. 2I7) is first cousin to the larger beast known as the Sea Otter, the latter at no time a very numerous species, being restricted to the East and West portions of the North Pacific.

Belonging to the Weasel family, there are several other kinds of Otters besides the two mentioned, such as the North American Otter, which has a much larger "naked area at the tip of the muzzle" than the European animal; the Brazilian and Feline Otters of South America, the former being the largest of all living kinds and the latter one of the smallest; the Smooth Indian Otter, Hairy-Nosed 


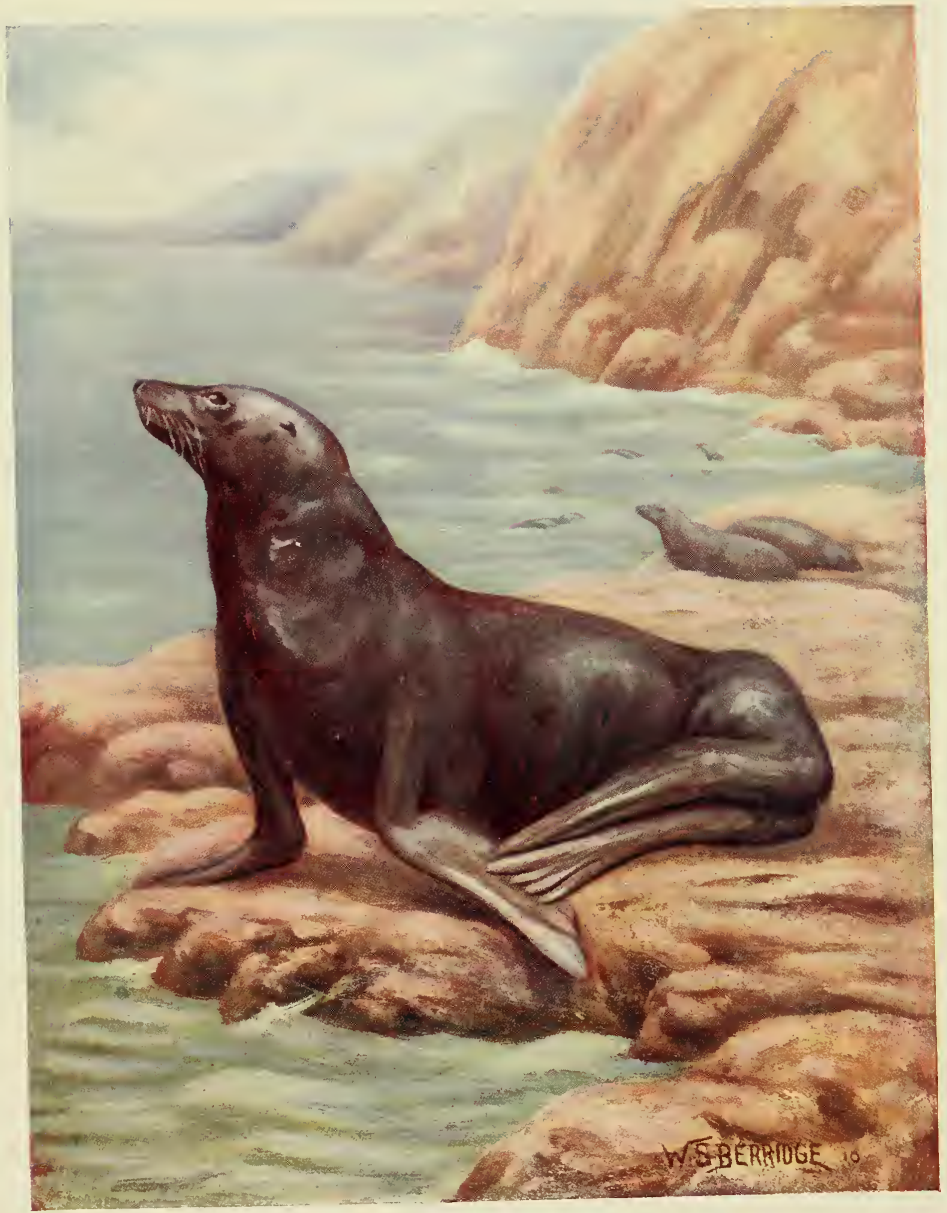

CALIFORNIAN SEA.LION. 

Otter, Clawless Otter, and two African species, known as the African Clawless Otter and Spotted-Necked Otter respectively.

The Common Otter is an inhabitant of many parts of Europe and Asia, and is a good representative of this highly interesting genus. A few notes concerning the life and habits of this species will serve equally well for the other members.

Active both on land and in the water, the Otter has long been held in high estimation for the sport it presumably affords, for in the water it is thoroughly at home, the webbed toes, short, flat head and flattened tail assisting the little beast to carry out remarkable manœuvres which, thankful to relate, often baffle the huntsman and his dogs. Being largely nocturnal, the Common Otter is rarely seen excepting by those who are frequently near its haunts, and it is so quick of movement that when fishing I have only had momentary glances of the wary creature as it has suddenly appeared close by, and then slipped away in less time than it takes to tell the story. Accused, no doubt often unduly, of feeding largely upon the angler's precious trout and salmon, the Otter has not many friends, but, as I have written elsewhere on more than one occasion, I have known many anglers who have, by taking a number of undersized fish, done more harm in a few excursions by the river than an Otter will do in a season. Why grudge an animal its natural food supply? Does not the beast in question frequent water where fish are abundant and can best be spared, and is it not a sufficiently attractive inhabitant of our streams and seas to warrant protection? My angling days are over, but I always look back with more satisfaction upon the wild creatures I was privileged to see during my fishing exploits than on heavy bags secured. Blank days occur ta me when not a single fish fell to my rod, but at such times many other delightful interviews took place between myself and wild folk which more than repaid me for lack of success with rod and line. Therefore may I make a humble plea for the preservation of the Otter as a British animal, for only recently in my own neighbourhood there have been killed two beasts-a bitch and a dog-which frequented a stream containing to-day as many trout and other fish as ever it did!

The last representative in this section of fur-bearing animals, the Otter, has a coat of short close fur which is light grey in colour on the under-parts, and long, silky fur of a rich brown colour above. It attains a length of about three feet, including the tail. 


\section{THE BOOK OF THE ANIMAL KINGDOM}

Although possessed of indomitable courage, and exhibiting a fierce, wild and shy disposition, which gives to the animal the greater part of its charm when in the full enjoyment of its liberty, it makes a tame and docile pet when kept in captivity, but, as such, looks strangely out of place to those who have watched it by some sylvan stream where the wind sighs through the tall rushes, and Nature is seen unadorned through non-interference by mankind.

A burrow close to the edge of the water is usually the retreat of this animal, the burrow extending some way under the bank and being nicely hidden by the surrounding herbage.

Otters do not restrict their attention to a diet of fish when hunger presses and food is scarce, for birds' eggs, frogs, fresh and salt water crustaceans, water-fowl and poultry are preyed upon, and, it is said, even young lambs and pigs. The worst accusation that can be brought against these animals is that-like the Fox-they kill more food than they can eat, and one can understand how galling it must be to the owners or tenants of angling waters to find a partly eaten salmon or trout left by an Otter on the prowl. If such a habit as this were not possessed by the Otter, surely any other misdeeds might be overlooked, and the abominable practice of hounding the creature to death put a stop to.

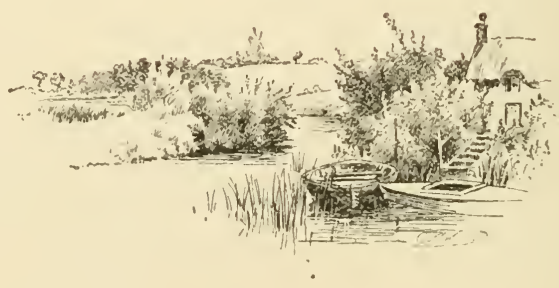




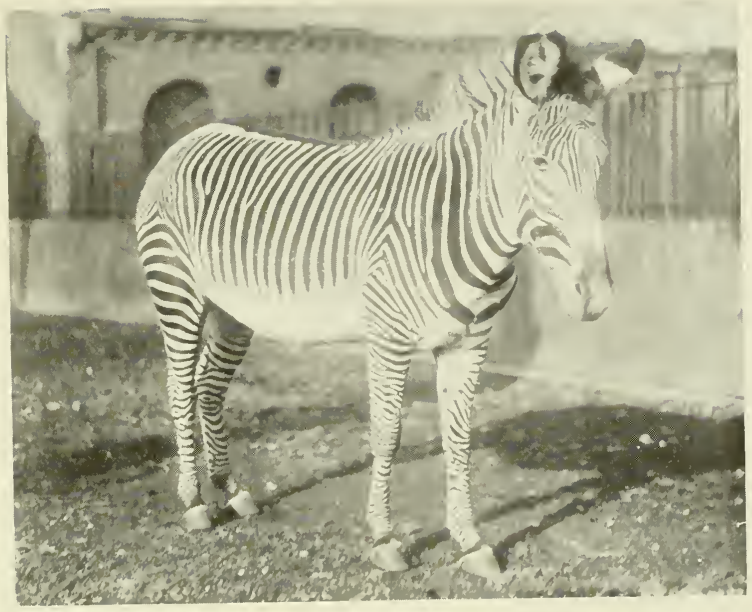

FIG. 220.-GRÉVY'S ZEBRA

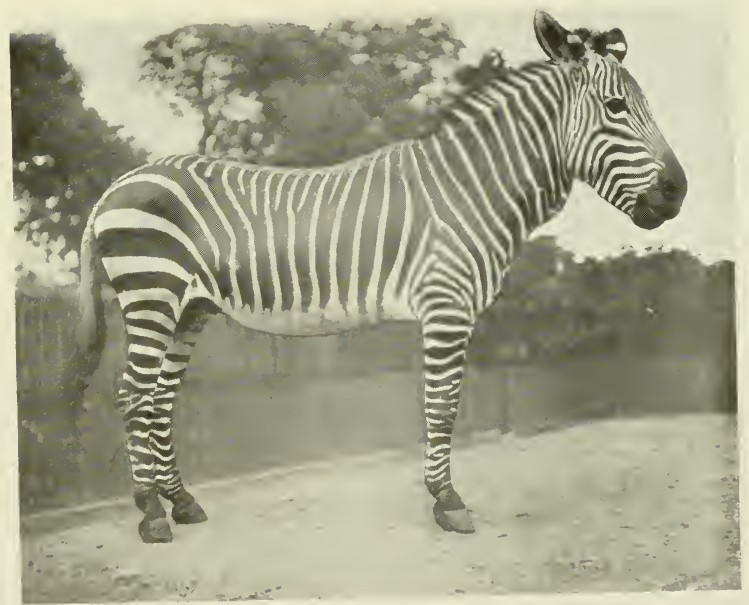

FIG. 22 I.-MOUNTAN ZEBRA 


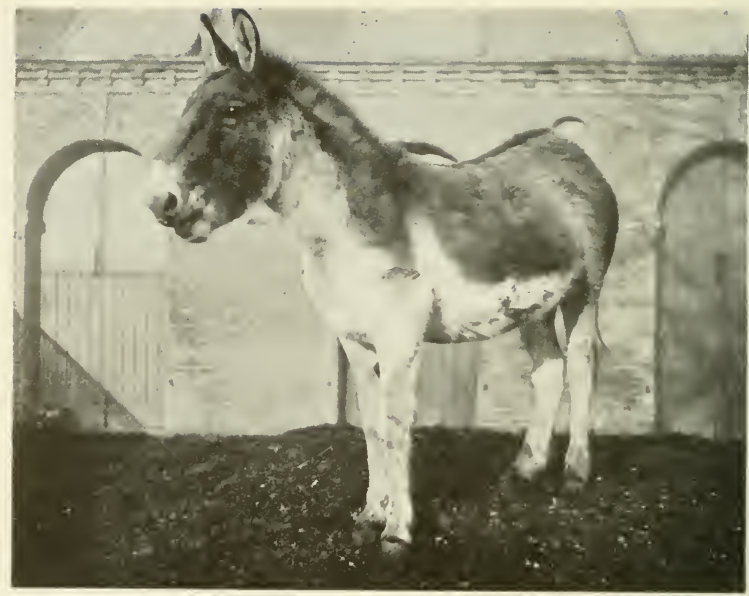

FIG. 222.-KIANG

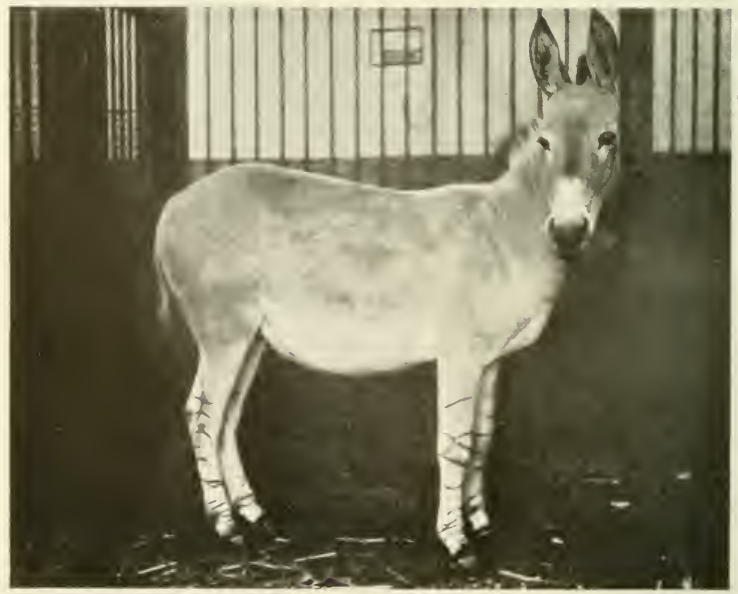

FIG. 223. AFRICAN WILD ASS 


\section{CHAPTER XV \\ ZEBRAS AND ASSES}

OF four-footed beasts the Zebras may be reckoned among the most beautiful, the remarkably striped bodies invariably attracting attention and eliciting admiration. There are three distinct species of these animals, known as Burchell's Zebra, Grévy's Zebra and the so-called Common, or Mountain, Zebra, whilst a fourth animal that may be mentioned before we reach the Asses is the Quagga, which is a connecting link between the true Zebras and the Asses.

Our illustrations depict the three species of Zebras mentioned, and also Grant's Zebra (Fig. 2I9), but this latter is probably a variety of Burchell's Zebra, most authorities agreeing that it is not specifically distinct from the beast in question.

In many ways the Asses resemble the Zebras, but the last-named are to be at once distinguished by the heads and bodies being mostly striped, whilst in the case of the Quagga we have an animal that is only partially striped, and to this reference will be made later on.

Whilst the Common, or Mountain, Zebra is the most typical representative of this handsome family of beasts, to facilitate easy reference, and to follow out the plan which has been more or less adopted with most of the animals to which attention has been directed in this work, the species may here be considered in alphabetical order. This brings us in the first instance to Burchell's Zebra.

BURCHELL'S ZEBRA.-This species (known to the Boers as the Quagga, but being, of course, distinct from that animal as known to Science) is shown in Fig. 2r8. It is often exhibited in Zoological collections, and the photograph depicts two of these beasts at the London Zoo. At the time of writing, a further addition of some animals belonging to this species has been made to the Regent's Park collection, and these were heralded by a certain London paper, which shall be nameless, as beasts new to Science! It is true that Burchell's Zebra has disappeared from many of its former strong. 


\section{THE BOOK OF THE ANIMAL KINGDOM}

holds in South Africa-especially in the Transvaal-but it is still a common inhabitant "on the plains of the Chobi and Zambesi, as well as in East Africa," and is to be met with in far from scanty numbers elsewhere on the great continent. But it is certainly not new to Science !

Burchell's Zebra attains a height of about four feet to four feet six inches, and is both taller and stouter than the much rarer Mountain species shortly to be described. The ears, too, are shorter, but the mane is heavier, the tail is more profusely haired, and the gridiron marks on the back of the Mountain Zebra are not possessed by this species.

Although in both animals shown in Fig. $2 \mathrm{I} 8$ the legs are striped for almost the entire length, in the typical form of this beast there are no markings on this part of the bodv. Burchell's Zebra is any colour from white to yellowish-brown, the stripes being either black or dark-brown.

There seems little doubt that Zebras are well protected when tenanting certain environments, more especially, it is recorded, "when standing on sandy ground in full moonlight," but at other times the grand picture presented by a herd of these fine creatures quietly browsing, and heedless of the approach of an observer, has been commented upon by some of those who have had the good fortune to see them in their own native homes.

Grant's Zebra (Fig. 219), as has already been mentioned, is considered by many authorities as a variety of the last-named, and it does not call for special mention, excepting to direct attention to the way in which the legs are marked right down to the hoofs.

GRÉVY'S ZEBRA.-This species (Fig. 220), it is true, has not been discovered many years, and is an inhabitant of certain mountainous parts of Africa, outside which continent, of course, no Zebra is found. Gréry's Zebra is not so stoutly built as the other kinds, but, like the animal next to be described, it has the legs well striped all the way down, as well as prominent ears, and an absence of markings underneath the body, as the photograph clearly indicates. This species has a long mane and a well-haired tail, whilst the stripes upon the body are very profuse, and easily outvie those possessed by both Burchell's and the Mountain species. The stripes and streaks, moreover, are not so broad, and the first-named are deep black in colour. A still further distinguishing feature that is worthy of note is the make-up of the stripes, for an examination 
of Figs. 2I8, 2I9, 220 and 22I will at once show that in Grévy's Zebra the stripes which run transversely across the sides of the body are much more numerous than in the other beasts, and "the obliquely longitudinal ones on the haunches are proportionately shortened." Whilst Burchell's Zebra is a dweller upon the plains, Grévy's Zebra (which was first discovered by the two well-known explorers, Colonel J. A. Grant and Speke in the mountainous country north of the Victoria Nyanza) is a lover of the forest and is rarely found away from it, in the neighbourhood of water and hills. The noise made by Burchell's Zebra has been compared to the subdued whining bark of a Dog, but Colonel Grant says that the first time he heard the neighing of Grévy's Z Zebra he "mistook it for that of a bird, and could scarcely be persuaded till I heard the decided Donkey-notes following the shriller sounds." This Zebra travels about in small companies consisting of only a few individuals, and it is stated, by the same capable explorer already referred to, that probably the largest male of the little troop takes general charge.

MOUNTAIN ZEBRA.-At one time a common species deserving of being known as such, the Mountain Zebra (Fig. 22I and Coloured Plate XVII), has now almost entirely disappeared from the mountains of Cape Colony, only a few herds still remaining on the higher ranges, where, it is pleasant to relate, they are rigorously protected. This is a lover of high altitudes, resorting to hilly districts, and is the smallest of the few species known to us. It does not attain a much greater height than about four feet at the withers, and it is as well to emphasize that, although the ears are long, the mane is short, and the tail is not very well haired. Generally, the Mountain Zebra is white on the greater part of the body, with bright brown on the lower part of the face, and black stripes. These stripes are well distributed, as Fig. 22 I displays, only the belly and inner sides of the thigh being devoid of these highly ornamental markings. The short gridiron-like stripes along the back have already been mentioned earlier in this chapter, but should not be overlooked.

QUAGGA.-The Quagga, or Cougga, as it is also called, because of the shrill nature of its voice, may well be mentioned here before passing on to the IVild Asses, as it is a connecting link between the Zebras and the last-named as recently referred to.

Its general colour is a sort of combination between the two kinds of animals mentioned, but in other respects-as, for instance, the 


\section{THE BOOK OF THE ANIMAL KINGDOM}

shortness of the ears and the hair on the tail-is more nearly akin to the Horse.

The Quagga stands about four feet high, and whilst the head, neck and front part of the body are all marked with stripes of a chocolate-brown colour, the remaining parts of the body do not bear the well-known stripes of the true Zebras. There is, it should be mentioned, a dark stripe which runs along the back as far as the upper part of the tail. The upper parts are light reddish-brown, whilst the animal is white underneath.

At one time this species was found in very large numbers in South Africa south of the Vaal River, but its valuable hide and flesh have proved a source of great attraction, and, in consequence, the beast has become entirely extinct. Although some seventy years or less ago the Quagga was found in large herds, it seems to have kept to its own kith and kin and did not associate with the Zebras, although it is recorded that it was not averse to making friends with the Gnu, Ostrich and Domestic Ass. Man has taken advantage of the Zebras and the Quagga and domesticated them as beasts of burden and for other purposes, but many of these experiments have not proved altogether satisfactory, the Asses being much more amenable in this respect. It is said, however, that the Quagga, although a fierce beast to encounter in its native wilds, becomes docile in captivity, and evidence is forthcoming of a pair having been driven through the streets of London. Man alone has not been responsible for the snapping of this interesting link in the chain of animal life, for its flesh was greatly relished by the King of Wild Beasts, and the Lion has much to answer for in helping to exterminate the immense herds which once roamed about on the plains of South Africa, where, it is now reasonable to suppose, this animal will never be seen again.

ASIATIC WILD ASS. - The Kiang (Fig. 222) belongs to the Asiatic WVild Asses, whilst the African Wild Ass (Fig. 223) belongs, of course, to Africa. There are three varieties of Asiatic IVild Asses, and of these the Kiang is a worthy representative. It is an inhabitant of Tibet and Mongolia, and, as Fig. 222 displays, it is a large beast and has a massive head which gives it a very distinct appearance. In colour it is dark-reddish, with a narrow stripe along the back. Then there is the Ghorkhar, or Onager, which is a resident of WVestern India and Baluchistan. This is a smaller beast than the Kiang; it is not nearly so dark-coloured as the last 
mentioned, and has a broad dorsal stripe instead of a narrow one. The third variety of Asiatic Wild Ass is found in Persia and Syria. It much resembles the two preceding kinds, and although for some time it was considered that there were at least two distinct species of these animals, it now seems agreed that the three beasts referred to are connected with the same species.

In the arid regions of Asia these Wild Asses find a congenial home; they are possessed of wonderful powers for traversing rough ground, and travel about at a great speed. They are mostly gregarious, keeping together in moderately sized companies, although, on occasions, these have been known to number as many as one thousand animals.

In some parts these Wild Asses are of a shy and retiring disposition, but the Kiang is a notable exception, as this is a most inquisitive animal, and has been known to walk into camp without demur, evidently attracted by a curious desire to ascertain what was going on.

One would imagine that, in view of the arid habitats in which these Wild Asses are found, difficulty would be experienced in finding a suitable and abundant food supply, and there is no doubt that during the Summer, when the pools of water and herbage become parched, the beasts find it a hard task to make ends meet. It is then that the Asses must of necessity search for fresh feeding-grounds, and they migrate to the hills for the purpose of securing both drink and food. Various kinds of grasses are partaken of, as well as woody plants which only grow in many of the arid regions inhabited. The Ghorkhar especially is fleet-footed, and attains a wonderful speed. It requires a good Horse to successfully overtake it, but, when hunting these IVild Asses, attention is chiefly devoted to the foals which, being reared, realize good prices when "sold to the native princes (of India), by whom high prices are given for these animals."

The Asiatic species attains a length of six or seven feet, and stands about four feet high at the shoulders.

The skin is of considerable value, and is made into shagreen, this being a kind of leather or parchment, which is prepared, without having to undergo the process of tanning, from the skins of Horses and Camels, as well as these and other Asses. The method adopted seems to be that "the strips, having been softened by steeping in water, and cleared of the hair, are spread on the floor 
and covered with the seeds of the Goose-foot (Chenopodium album). A covering of felt is laid on, and the seeds are pressed into the skin by trampling or mechanical means, thus producing the peculiar granular appearance of shagreen. It is dyed green with salammoniac and copper filings, red with cochineal, etc. Shagreen is also made of the skins of Otters, Seals, Sharks, etc. It was formerly much used for cases for spectacles, instruments, watches, etc.," and who knows but that the covering of the very desk upon which these notes were written did not at one time help to clothe one of these Wild Asses of a foreign land?

AFRICAN WILD ASS.--Fig. 223 represents a specimen of the African Wild Ass from Somaliland, and it will be at once seen, on comparing it with the form of the Kiang, that there is a very considerable difference between the two animals. The African IVild Ass, for example, possesses much longer ears, a shorter mane and a less profusely haired tail. There is, too, a noticeable divergence in regard to the colour of the coat, for the present species has creamy or bluish-grey hair, with dark bars on the limbs and a prominent dark stripe on the shoulder. The lower part of the head, the throat and underneath portions are white, and, as a rule, there is a good deal of white upon the limbs. On occasions the leg stripes shown in Fig. 223 are absent, whilst there are other variations exhibited in different animals which need not be detailed.

This IVild Ass attains a height of about four and a half feet or more at the withers, and has a wide distribution in the desert regions of the North-Eastern parts of Africa. Nore than one observer has drawn attention to the remarkable colour protection afforded to this beast, and amid the desert surroundings frequented it is essential that the creature should be protected from enemies. Although, as with its Asiatic cousin, food is often at a discount and at no time plentiful, the African Wild Ass invariably seems to be in good condition, and the Arabs consider its flesh very excellent eating.

Mention has already been made in Chapter II. of various features of interest concerning the relationship which exists between the African Wild Ass and our various breeds of domestic beasts, for there seems little doubt, as has been already pointed out, that the Domestic Donkey is the tamed African Ass.

I have already drawn attention to certain traits in the character 


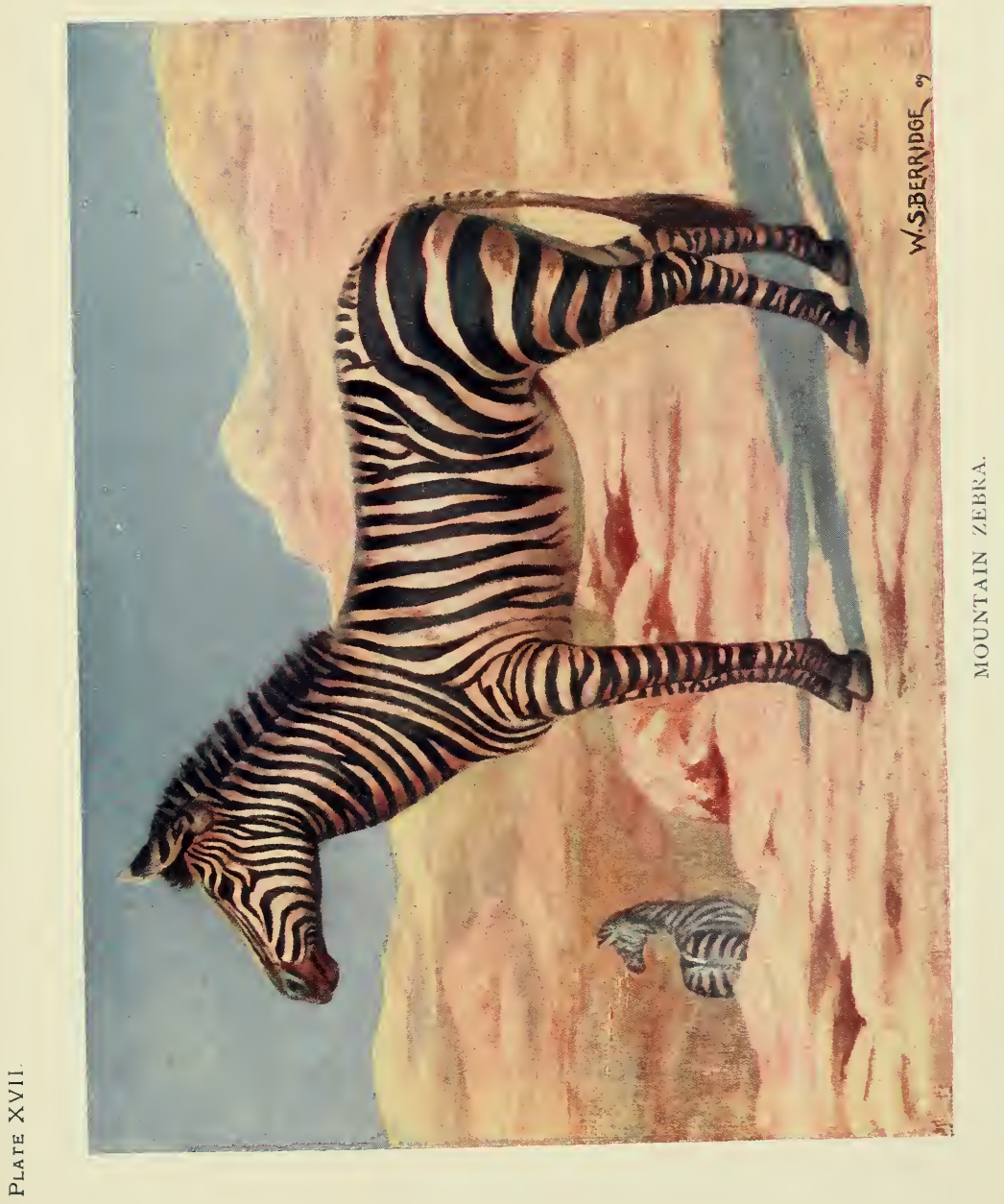



of this beast as a domestic animal, and it is not necessary to write more here.

Before bringing this section to a close, however, a few instances may be given of the legends that have been handed down to us with regard to the humble and useful Donkey. A writer in The Animal World says-

“At Killeedy, Co. Limerick, close to 'St. Ita's Well,' there is a stone supposed to show the print of the hoof of the favourite Donkey of St. Ita- ' the Mary of Munster.' Day by day the animal brought milk from St. Ita's farm, four miles to the westward, to her convent close to the holy well, coming and going without a guide, though the caretaker at the farm milked the cows and placed the milk in two pails, which hung at either side of the animal. One day two robbers made a raid on the dairy farm and found the Donkey ready to start home with two pails full of new milk. Angry at having found no treasure at the farm, they overturned the pails and let the milk run down the hill, but God showed His anger by turning the milk into blood, and the place is still called 'Turna-fulla,' or 'Plenty of blood,' to this day, and the angry Donkey kicked and left the print of its hoof on a stone. Another story tells how the beast once stood on a strong thorn, which pierced the frog ${ }^{1}$ of its foot, laming it badly and causing it severe pain. St. Ida pulled out the thorn, which she stuck in the ground, commanding it not to lame the Donkey for ever more. It grew into a large whitethorn tree, whose thorns all pointed downwards! It is said that this tree flourished till quite recently, and was an object of veneration till some one dug around it, when 'St. Ida's thorn' withered away.

"St. Patrick is said to have once wandered wearily along the road, exhausted and footsore, when he met a mule and tried to mount it and ride on his way, but the stubborn animal kicked him off, and would not allow him to ride, and the Saint went on sadly. Then he met a little Donkey, and the kindly beast gladly permitted him to mount it, and bore him on his journey, and St. Patrick cursed the mule, saying: 'May you be always ill-tempered and stubborn and may your race be few in the land '; but to the Donkey he said: 'May you be as plentiful as the ferns!' and ever since Donkeys abound in Ireland.

"When this Saint was about to build his cathedral at Armagh

${ }^{1}$ A kind of tender horny substance growing in the middle of the foot, dividing into two branches, which run like a fork towards the heel. 


\section{THE BOOK OF THE ANIMAL KINGDOM}

he could not decide upon a site for a long while, but went to and fro, as if he were seeking for some sign, till suddenly a doe and her fawn rushed from the thicket, and as the warriors who accompanied the Saint were about to kill them with their spears, both animals ran fearlessly to St. Patrick, who took up the fawn in his arms, and, followed by the doe and the assembled company, he traced the boundary of the future cathedral of 'Ardmacha' (High Field).

"It is not only Irish Saints who are associated with the humble, useful Donkey. St. Isidro, or Isidore, a Spanish peasant, who loved all animals and birds, had a favourite Donkey on which he rode through the country, and which he once left outside a church to graze while he went in to pray. Meanwhile a hungry IVolf tried to devour the poor beast, but was suddenly struck dead. The birds sang their sweetest as Isidro went by, because when the Saint, who was a farm servant, went out to sow he scattered seeds for the birds, saying: 'Eat, little birds, for when Our Lord looks forth at dawn He looks upon us all!' As he dropped the barley in the furrows he said: "This for God, this for us, this for the birds, and this for the ants!' His companions mocked him, crying, 'For the ants!' 'For the ants, too,' said Isidro, 'since they are God's ants, and His royal bounty is for all His household!' And God took his fields under His protection, and though Isidro spent much time praying in the churches or under the trees, his crops were abundant, and rain and sunshine never failed to come in due season.

"Once as he bore a sack of corn to the mill on a Winter day, when the ground was covered with snow, he untied the sack and strewed the contents on the ground for some hungry pigeons, but when he reached the mill, lo! the sack was full again."

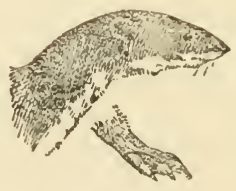




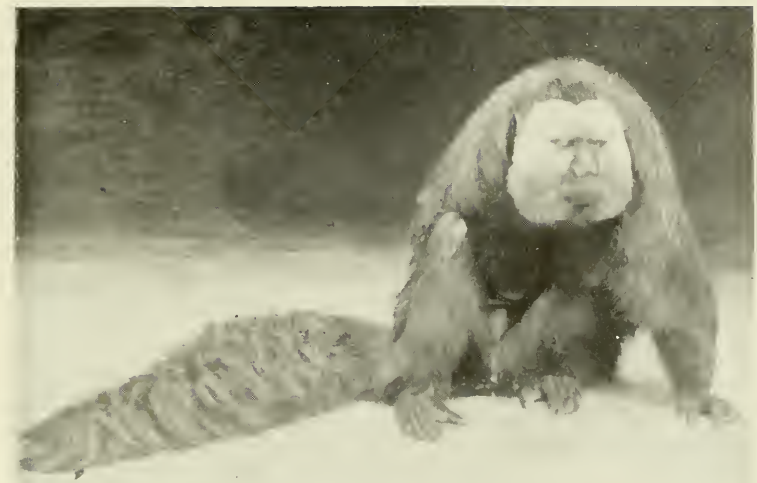

FIG. 224.-WHITE-HEADED SAKI

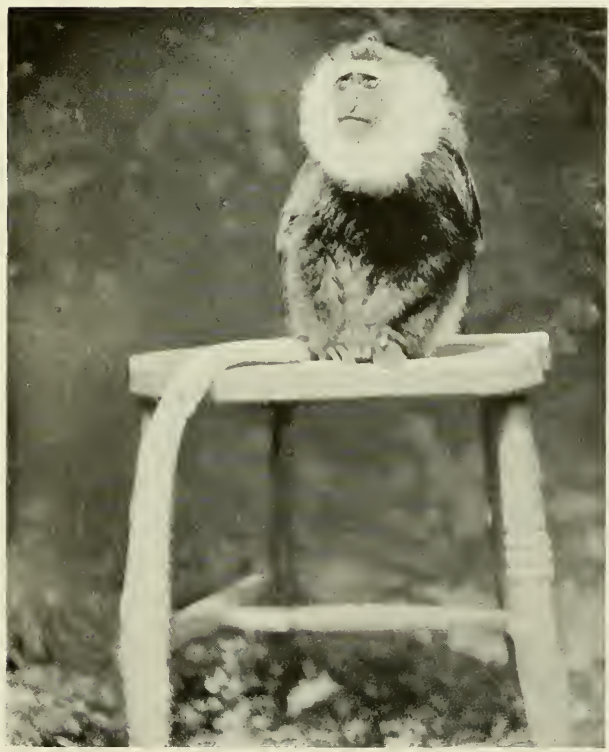

FIG. 225. -WHITE-THIGHED GUEREZA 


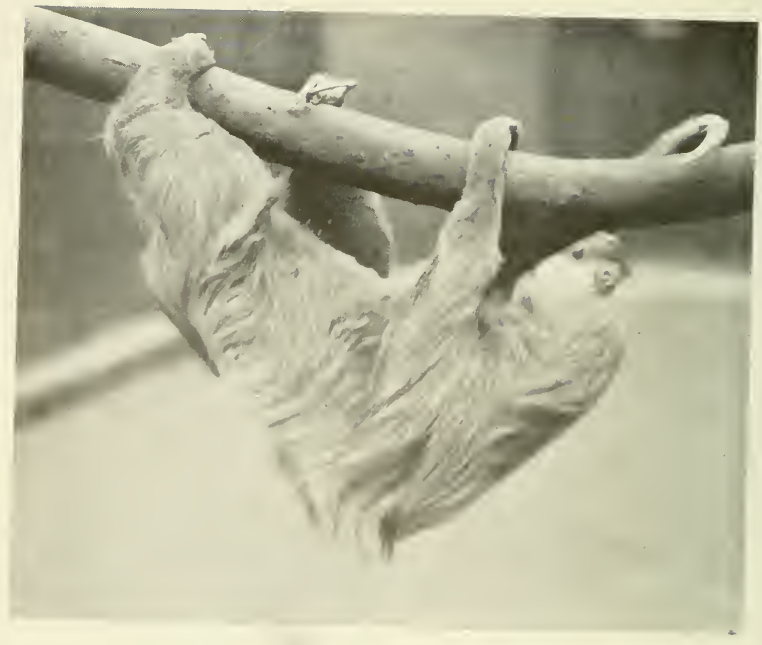

FHG. 226. HOFFMANX'S SLOTH

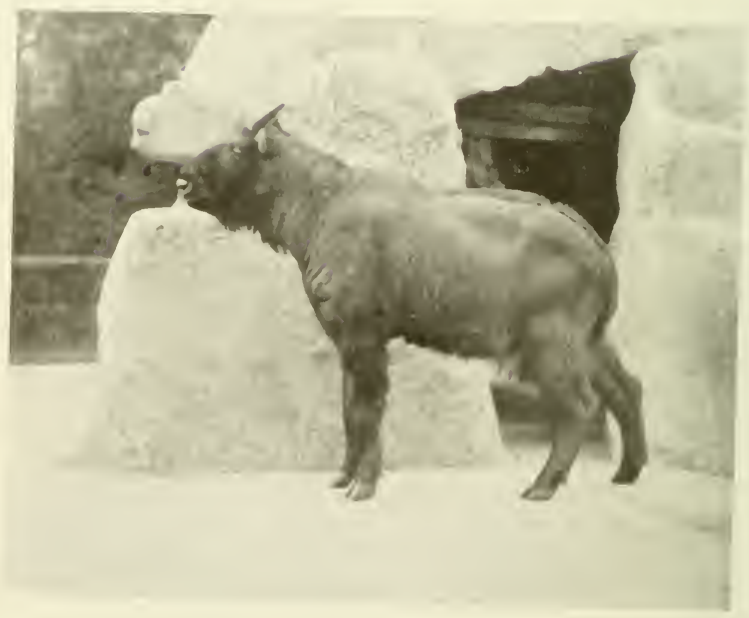

FIG. 227.․ BHUTAN TAKIN 


\section{CHAPTER XVI}

\section{RARE AND UNFAMILIAR ANIMALS}

EVEN if in the preceding sections of this work we have made the acquaintance of many well-known animals, there have no doubt been several unfamiliar ones which the reader knew very little about, and in this chapter there are quite a number of rare and unfamiliar beasts which may engage attention before we pass on to deal with some Mammals of the Sea and Air.

These could, of course, have been accorded a place among some of the other sections of which this volume consists, but the result would have been certain unwieldy chapters, and in their present position they may best be considered. There are more than thirty different kinds of animals included in this sixteenth section, and, this being so, it will not be possible to give very elaborate accounts of any of them, the salient and characteristic features alone being dealt with.

Some of the remarkable creatures here depicted are exceedingly rare, and it is unlikely that any opportunity will be forthcoming of securing fresh photographs of several of them for many a long day, and in this respect may be specially mentioned the White-Headed Saki, White-Thighed Guereza, Bhutan Takin, Walrus, etc. Probably the White-Headed Saki is easily the most extraordinary-looking animal of any included in the representative selection here gathered together, and a few notes concerning it will doubtless be read with interest.

WHITE-HEADED SAKI.-As may be assumed from an examination of Fig. 224, this is a Monkey, but it is a rare and curious member of that interesting family of wild beasts and hails from Central America. The specimen shown in the photograph arrived at the London Zoo during the Autumn of I909, and caused sensational interest among zoologists. Unfortunately, however, the wonderful animal only survived for a few days at the Zoo, but not long afterwards another of the rare South American Saki Monkeys reached the famous Gardens in the person of Humboldt's Saki. 


\section{THE BOOK OF THE ANIMAL KINGDOM}

It was thought at one time that the first Saki referred to was Humboldt's, but it proved after further examination to be the WhiteHeaded, the name of which, as Mr. Finn says, "is not at all a happy one, for the hair on the face is straw-yellow-very probably, however, fading to white in stuffed specimens-and the back of the head, at all events, is black, the long hair forming a hood." Humboldt's Saki "is a grizzly-grey animal, with the face not differing strikingly in the colour of its scanty hair from the long coat which covers the body. Though less striking in appearance than the other, it is a prettier animal, and being very tame, is an ideal Monkey for a pet. It has a soft twittering voice very much like that of the Marmosets."

If such an epithet as "hideous-looking" can be applied to any beast, then surely the IVhite-Headed Saki deserves mention in this respect, for certainly its features repel rather than attract, and although of extreme value and interest to zoologists, I am not at all sure that the specimen which was so short-lived would have attracted much attention from the general public, much less endeared itself as a popular animal at the London Zoo. The curious facial expression is very remarkable and is the least attractive part of the Saki's body, for it is otherwise a finely-built Monkey, and clothed with long furry hair. The Saki appears to feed very largely upon the honeycomb of IVild Bees, and it has been suggested that the thick body-covering protects it from the stings of the Bees when it is engaged raiding their citadels.

WHITE-THIGHED GUEREZA.-Coming from an entirely different part of the world to the Sakis, the IVhite-Thighed Guereza (Fig. 225) is a resident of West $\mathrm{Africa}$, and presents with its whiskered face a grandfatherly look deserving of notice. It is interesting to observe, too, the long white tail, which, as seen in the present photograph, is apt to be overlooked owing to the fact that it is resting in a line with the left-hand leg of the stool upon which the Guereza is seated.

This, of course, is still another Monkey, and the last one we are likely to encounter during our present pilgrimage. It belongs to the genus Colobus, or Thumbless Nonkeys. These are African beasts, and about twelve species have so far been described by scientists.

The White-Thighed Guereza may be distinguished by the long appendage which has already been referred to, as also the white whiskers all round the dark face, and the jet-black head, body and limbs. The contrast between the black and white in this animal is 
very remarkable, and one well-known naturalist has stated that it is "without exact parallel among other mammals, although the coloration of the Skunk is somewhat suggestive of it." It should also be stated that on each side of the back, or thighs, of this animal there is a profusion of pure white hairs which hang down like a mantle over the flanks and give the adult beast a fine appearance. This White-Thighed Guereza is, it appears, merely a variety of the ordinary animal, as in the commoner kind the tail is black and shorthaired for at least a foot or more, the white tufts of hair being present only on the last few inches.

The Guereza feeds upon leaves, wild fruits and insects in its native state, but it is rarely seen in captivity as it is difficult to get it to successfully overcome a long journey across the sea, even if it could be reared when it had safely arrived at its destination. It is said to be a restless and silent animal in its native wilds, and to be capable of leaping from tree to tree in a most remarkable way.

SLOTHS.-The Sloths are animals possessing an ancient origin, for Hoffmann's species (Fig. 226) is a descendant of the Giant Ground Sloths which have long since become extinct. And here attention may be drawn to the plates of extinct animals included in this volume, namely, Plates II, VII, VIII, XI, XIV and XVIII. At this juncture the last-named plate, showing the extinct Giant Sloth and two Armadillos, need only be referred to specifically, but it is highly desirable that the remaining plates should not be overlooked, and the relationship of the animals depicted with living representatives of to-day should be closely studied.

At one time the Giant Sloth, a terrestrial and not an arboreal animal like the living species, was a common inhabitant of South America, and it is most essential that it and others should be represented in this book, as it is largely because of the remains which have been discovered of these extinct monsters that we are able to piece together the fascinating story of animal life, and obtain some conception of the huge creatures which populated the earth and sea before the advent of man. One species of Giant Sloth now no more has been compared to the Elephant in size. There was no need for it to climb trees like the small Sloths of to-day, even if the trees could bear its weight, for it could easily reach the tree-tops, as Plate XVIII shows. These Giant Sloths were not distantly related to the Ant-Eaters, they were herbivorous and heavy beasts, and 


\section{THE BOOK OF THE ANIMAL KINGDOM}

whilst most of them were restricted to South America, one large species was an inhabitant of North America, and a near relative belonging to another genus was, it is believed, exclusively North American.

The living Sloths are divided into two genera, popularly known as Three-Toed and Two-Toed, and to the former Hoffmann's Sloth belongs. The Three-Toed Sloth, or Ai, as it is called, on account of the curious cry it emits, is a resident of Brazil, and although possessing a shaggy coat is not a very large beast, attaining a length of not more than a couple of feet. The specimen shown in Fig. 226 is portrayed in a very characteristic attitude, as the animal walks upside down in this way, clinging to branches by means of the strong toes, and when progressing in its primeval forest home it is able to turn its head completely round by means of nine vertebræ instead of the usual seven bones in the neck. The value of this will be apparent, as by being able to twist the head right round without having to move the partly anchored body the Sloth can see where it is going, and be on the look-out for enemies such as snakes and man, the latter being its remorseless enemy.

The coarse fur is brownish-grey in colour, but the male has a black patch of hair between the shoulders, the hairs having a fringe of yellow and giving a very curious effect. This is, like its congeners, a vegetarian in the matter of diet, and the succulent fruits, leaves, etc., upon which it feeds are sufficient to satisfy its thirst, for it does not, so far as is known, need to drink.

The Two-Toed Sloths are characterized by the possession of two toes on the fore-foot, but on the hind-foot the three toes are present. There are at least two well-defined species of these two-toed animals; they are larger than their three-toed relatives, but, with this exception, and the loss of one toe on the fore-foot, there are no other features of great divergence to which attention need be directed.

BHUTAN TAKIN.-This brings us to the Bhutan Takin (Fig. 227), and it is interesting to note that this is the first specimen of this animal ever imported alive to Europe. It is still more pleasant to record that this specimen has already become a general favourite at the London Zoo, and is thriving splendidly. The beast, by persuasive coaxing, will allow visitors to stroke it, and dearly relishes a scratch of the head. Care should, of course, be exercised in thrusting one's hand through the bars of its commodious apartment, but otherwise little need be feared. 


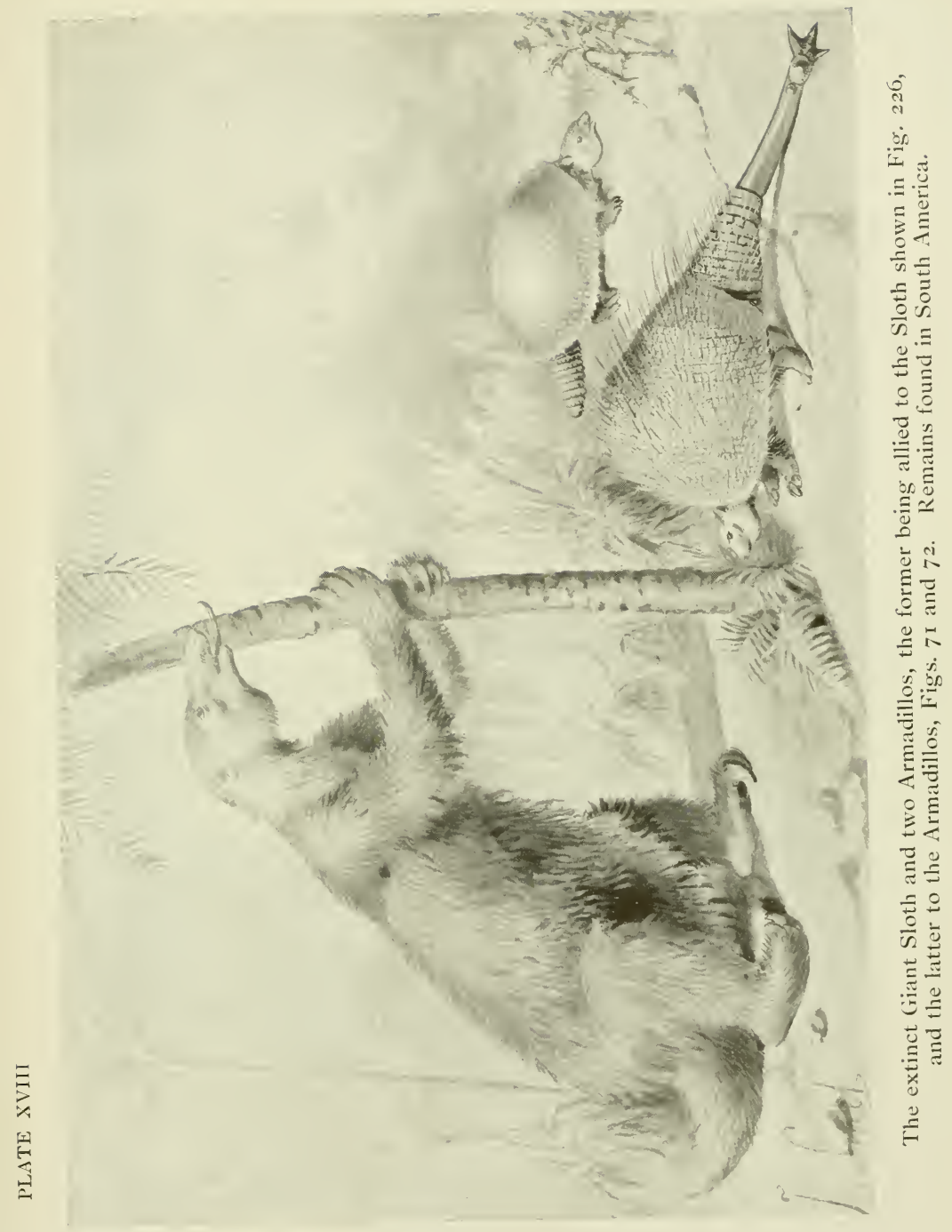




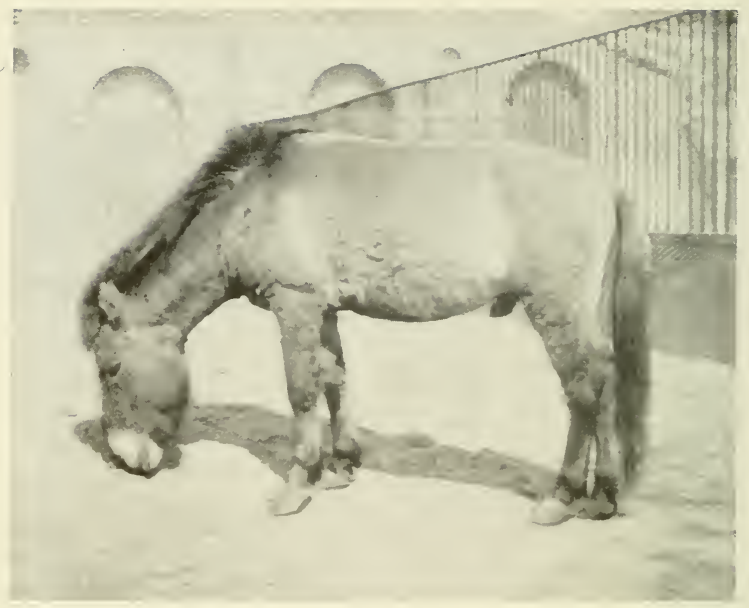

FIG. 228. PREJEVALSKI'S WILD HORSE

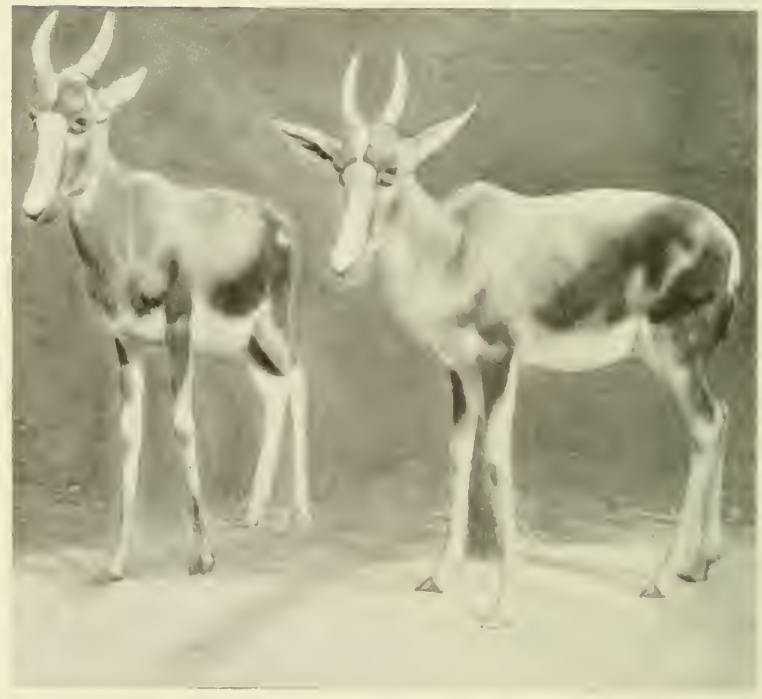

FIG. 229. BONTEBOKS 
The Zoo specimen referred to was presented to the Society by the Maharaja of Sikkim and Mr. Claude White, late British Commissioner in Sikkim. It is a young bull, and was procured from Bhutan in Northern India.

There are two species of Takin, and these are small Ruminants which are not very distantly related to the Serows or Goat-Antelopes (see Fig. I 88 and Chapter XII). The Takin, however, is neither a Goat nor an Antelope, and can best be described as occupying an intermediate position between the two kinds of animals named.

A writer in the Scientific Monthly says that "it is also possible that Takin are related to the Musk Ox, now restricted to Arctic and sub-Arctic America and Greenland, but formerly having a geographical range extending over the North of Asia and Europe. A certain similarity of the horns and the large lateral hoofs, together with the shortness of the tail in both animals, lends colour to this assumption. It may also be remembered that both Takin and Musk Oxen inhabit cold and snow-covered regions, and are adapted to life in high altitudes. It is not improbable that Takin, Serows, Musk Oxen and the extinct Bucapra of the Himalayas have a common origin."

The adult Takin measures about six feet, and stands about three and a half feet high at the shoulder. The stout limbs are covered with shaggy hair in Winter and short hair in Summer; both sexes possess horns. The general colour of the coat is reddish-brown, with the face black, and there is a dark stripe along the neck and the centre of the back.

PREJEVALSKI'S WILD HORSE - Little opportunity has been presented thus far to pay any tribute to the Horse, but an occasion now arises when some amount of attention may be devoted to it. I am under obligation to Mr. Edward G. Fairholme, the indefatigable Secretary of the Royal Society for the Prevention of Cruelty to Animals, for permission to incorporate in these notes extracts from two articles which appeared in the Society's excellent magazine, The Animal World.

In the first instance preference may be given to a most informative and highly interesting sketch of the Horse by Mr. Fairholme himself. He writes-

"Huxley in his Letters on Evolution says: "The Horse is in many ways a remarkable animal; not least so in the fact that it presents us with an example of one of the most perfect pieces of 


\section{THE BOOK OF THE ANIMAL KINGDOM}

machinery in the living world. In truth, among the works of human ingenuity it cannot be said that there is any locomotive so perfectly adapted to its purpose, doing so much work with so small a quantity of fuel, as this machine of Nature's manufacture-the Horse. And, as a necessary consequence of any sort of perfection, of mechanical perfection as of others, you find that the Horse is a beautiful creature, one of the most beautiful of all land animals.'

"The Horse has been the hero of every nation, and to have been able to make the Horse not only his friend, but also his constant companion was the aim of every knight of old, who was wont to consider the comfort of his steed before that of his own. The Horse is, as it were, a symbol of chivalry, and it is interesting to mention that in the time of Edward VI it was a capital offence to steal a Horse, and that such an offender could not, before going to execution, have 'the benefits of the clergy.' We need not now consider how the Horse was treated in those long-ago days, but it should be remembered that the Horse was never subjected to any cruel sports, such as were the Dog, the Bull, the Cock, etc., and this shows us how far above other animals this one stood in the estimation of people who were not too refined to enjoy cruel sights. As was written in the Koran, Horses were created for man's use, but they were also 'to be an ornament unto him,' and this idea seems to have existed all through history ever since the Horse was domesticated and became the faithful friend and servant of human beings. The man who was a perfect horseman and rode as though his steed were part and parcel of himself was looked upon as a leader of men. Indeed, it is said that Cardinal Wolsey first secured the royal favour of Henry VIII by his superb horsemanship.

"Homer of old, in many stirring passages, testified to the veneration and admiration with which the warriors regarded their horses. Xanthus, the Horse of Achilles, is rendered famous by the great poet, and is endowed with a wonderful prophetic power, which warned Achilles of his approaching death. The name of Alexander the Great at once suggests that of his Horse, Bucephalus, and one recalls the story of how this royal Horse, when wearing his regal trappings, would allow no one but his master to mount him. In later times the great soldiers possessed heroic horses, whose names have been linked with the deeds of their great masters. Marengo, a wonderful, pure white Arab, whose skeleton and hoofs are preserved in our own Royal United Service Museum in London, is almost as famous as is the great Napoleon, and Copenhagen, who bore 


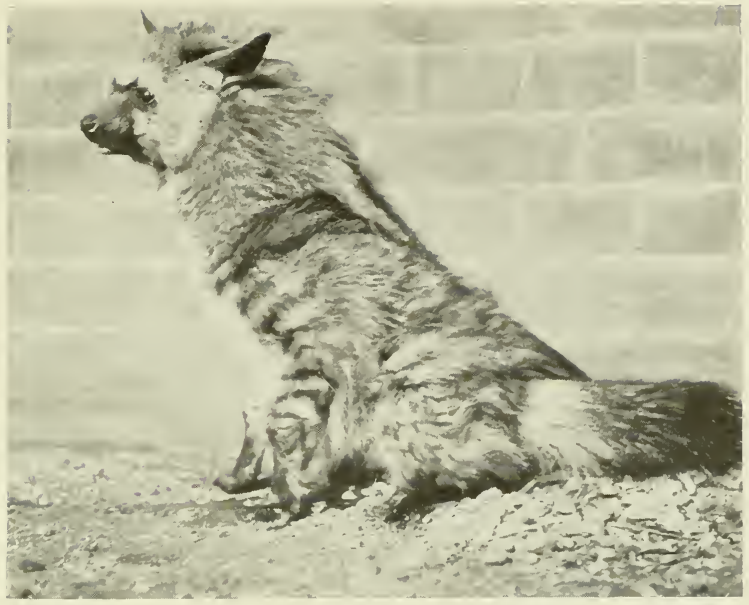

FIG. $230-A A R D$ WOLF

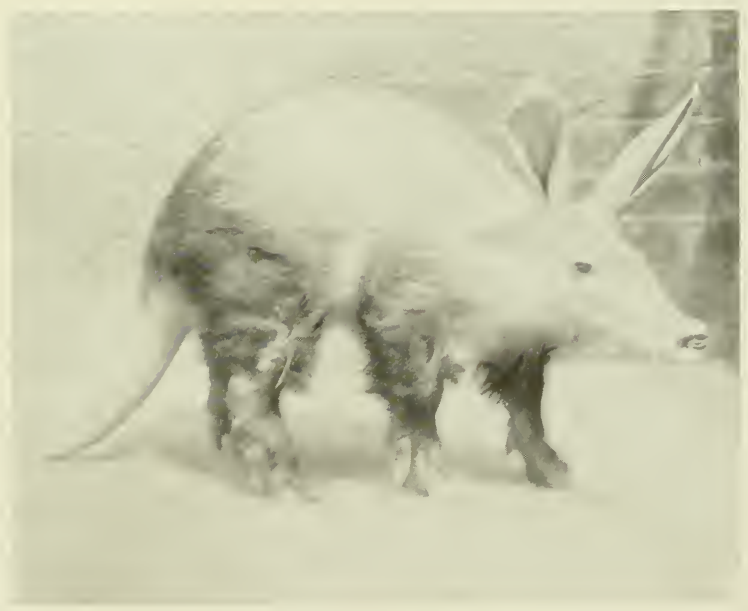

FIG. 231.- CAPE ANT BEAR, OR AARD VARK 


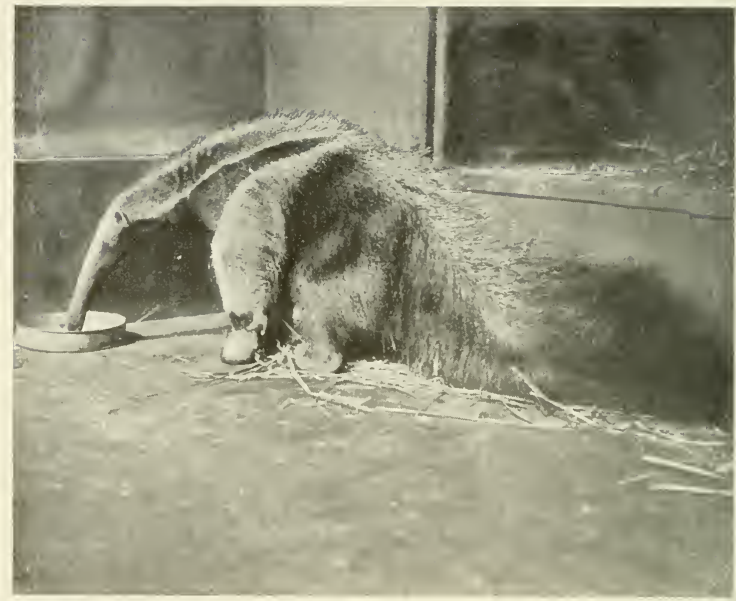

FIG. 232.-GREAT ANT-EATER

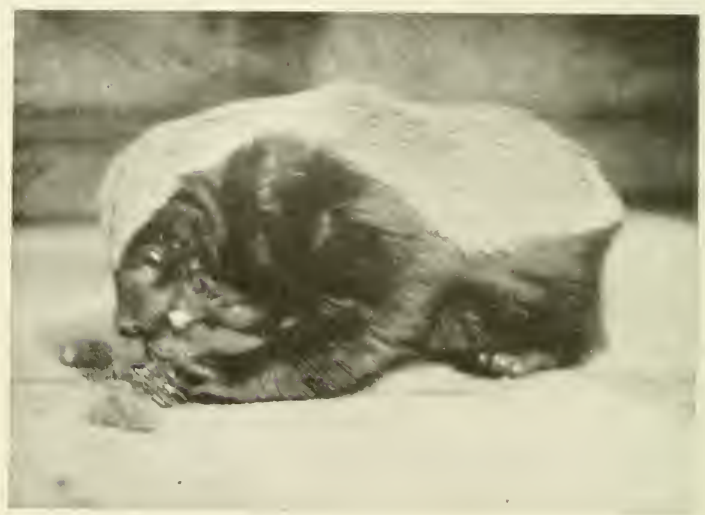

FIG. 233.-RATEL, OR HONEY BADGER 
Wellington to victory at Waterloo, has become a character in history.

"Horses were sent in ancient, as well as in modern, times as presents of the highest value to neighbouring kings or mighty rulers with whom it was desirable to be on terms of peace, and the breeding of Horses in England, first mentioned by Cæsar, has been considered worthy of the greatest consideration through all ages, so much so indeed that it was in early times protected by special laws.

"The Arab steed has always been regarded as the most perfect animal for speed, lasting, and sagacity, and it has therefore been the most sought after and, as many travellers have narrated, the most difficult to obtain. The Eastern blood was first introduced into England by Charles II, who sent his Master of the Horse to Asia to buy horses for his own stable. These beautiful animals were known as 'Royal Horses,' and it is from that time that the custom arose for the reigning monarch to use cream-coloured Arabians on State occasions. The French General Daumas asked the Amir Abd el Kadir what was the origin of the Arabian horse. The Amir, in his poetic way, informed him that Allah created the Horse out of the wind as he created Adam out of the mud. This terse description of the creation explains the relative position in the mind of the Arabs of the horse and of the man. That the horse has been the object of admiration and veneration from the very earliest time is shown by the prehistoric sketch of horses discovered in cave dwellings, for the artists of those days mostly depicted their Gods or the animals they feared or venerated."

It is not possible to set out at this juncture a detailed account of the evolution of the Horse, or of the many real and so-called wild kinds which are still found in various parts of the world (including, for instance, Exmoor and the New Forest in England, to mention two places at home), but a few particulars concerning Prejevalski's, or Mongolian, Wild Horse (Fig. 228) may be quoted from the same source as recently mentioned before passing on to the next animal on our list.

"A yellow or dun colour has always been considered the primitive colour of the Horse tribe, and Prejevalski Horses do not disappoint us in the hue of their livery. They are yellow dun, a colour which must blend with the sandy desert region in which these animals make their home and render them comparatively inconspicuous. The muzzle is cream, and the mane, tail and legs

U 2 


\section{THE BOOK OF THE ANIMAL KINGDOM}

blackish. Now, it is often held-and we have no reason to doubt the truth of the assertion-that the younger a domesticated animal is the more closely it resembles the wild ancestor of the species. If we admit the truth of this proposition, then we see at once why the majority of foals are light bay or dun in their 'baby' coat. No matter whether they are going to be grey, rich bay, or light brown in later life their foal coat is usually a dun colour, and their mane and tail shade to black-brown, like those of Prejevalski's Horse. In two important points, however, no resemblance can be drawn between the Wild Horse and the foal, and those are in the carriage of the mane and in the colour of the legs. The mane of every foal is erect like that of a Zebra or Ass, and, as one might be led from analogy to surmise, presumably like that of its wild ancestor also. There is no forelock. In the Prejevalski's Horse, however, it will be seen that the mane is too long to remain erect like that of a foal, and that it falls between the ears into a decided forelock like the 'bad' mane of many British Hill Ponies. The legs of most foals are creamy white, like those of the Onager, and without the darkness in the knee and hock regions and down the canon bones shown by Prejevalski's Horse, which only comes with the second coat. These differences incidentally afford somewhat strong proof in favour of a feral origin of these ugly desert Horses.

"It always used to be supposed that the wild ancestor of domestic horses was ornamented with a black dorsal stripe, some horizontal stripes about the knees and hocks, and perhaps one or more shoulder bars on an otherwise yellow coat. This opinion was arrived at by the facts that so-called reversionary dun-coloured individuals produced by a process of mongrelization were generally so marked; that breeds of dun Ponies which exist in various parts of the world are usually so adorned; and that the dorsal band persists occasionally in Horses of other colours than dun. In the Central Asian Horse the markings are either entirely absent or are much fainter and less well defined than they usually are in dun-coloured British Horses. This fact again suggests that the IVild Horses are not entitled to be raised to the dignity of specific rank as they lack uniformity in a well-defined particular. Were they the descendants of an ordinary unstriped domesticated Horse it is not difficult to understand how a point of practical unimportance like the one under consideration might have failed to be reproduced in all the individuals of a feral race. 
“The one point in which Prejevalski's Horse differs markedly from most other known Equidæ, and to which those naturalists anxious to raise it to specific rank attach great importance, is in the tail, which although long and coarse like the tails of all common Horses, is singular in that it is sparsely covered with short hair near the root. In ordinary Horses the hair growing on the upper part of the dock reaches a considerable length-down to about the hocks, in fact; in the Wild Horse long hairs only grow from the lower half of the dock, so that if the animals were docked short there would be very little hair on the remaining bone at all."

BONTEBOK.-This animal (Fig. 229) is now extinct in a wild state, and we owe its preservation to one or two privately owned nerds. It is-or rather was-a South African Antelope, closely related to the Blessbok, the Bontebok being distinguished by the white marking on the face being continued as far as the base of the horns, and also by the patch of white on the buttocks and the white legs. The Bontebok is the larger animal of the two, attaining a height of from three to four feet at the withers. Both the species referred to are at once recognized by the rich purple-red of the coat, and the white marking, or blaze, as it is called, on the face, and in days gone by these beasts must have presented a fine sight to South Africans, although they are wary creatures and difficult to approach. As showing the effect produced by a sight of them, and the numbers that existed at one time on the great African Continent, one writer states that "on my right and left the plain exhibited one purple mass of graceful Blessboks, which extended without a break as far as my eye could strain. The depth of their vast regions covered a breadth of about six hundred yards."

AARD WOLF.-Another African animal is depicted in Fig. 230. The Aard IVolf is somewhat of a puzzle to zoologists, for in some instances we find that it is placed among the Hyænas and in others with the Civets. Strictly speaking, the best place for it to occupy is between the two, the beast being relegated to a distinct family known as the Proteleidæ.

The Aard, or Earth, Wolf measures about three feet six inches in length, is yellowish-grey in colour, with prominent dark stripes and a long, thickly-haired tail. As its name indicates, it is a burrowing animal, indeed it is to be reckoned among the most remarkable beasts who resort to an underground dwelling-place, several individuals occupying the same abode. It is nocturnal in its habits- 


\section{THE BOOK OF THE ANIMAL KINGDOM}

like the Fox and the Badger-of a cowardly nature, slinking away when observed above ground in double-quick time. In its general carriage it is certainly Hyæna-like, and whilst its food consists of somewhat the same kind, $i$. e. carrion, it also has a liking for termites, which it is able to unearth from their strongholds by means of its strong claws.

CAPE ANT BEAR, OR AARD VARK.-Before leaving Africa acquaintance may be made with still another remarkable beast found there in the person of the Aard Vark (Fig. 23I). This curiouslooking animal is in no way related to the species last under review, being, as a matter of fact, first cousin to the Great Ant-Eater next to be described. The large pointed ears, tapering snout and tail, and stumpy legs will at once arrest attention, and in several ways, particularly in regard to the long viscid tongue, the Aard Vark strikingly displays its relationship to the Ant-Eaters. The body, however, is quite unlike that of the last-named, for instead of being profusely clothed it is scantily covered with hair. Small wonder then that the Boers call this creature the Earth Pig, for Pig-like it most certainly is at a casual glance, and even on further investigation there is a kinship deserving of notice. It is, for example, very fond of both grubbing and burrowing, in which it is largely aided by the pointed snout, and Mr. Protheroe says that "to complete the appropriateness of the name, it may be mentioned that the hindquarters of the animal are cured in the same manner as hams, and are almost, if not quite, equally esteemed."

Unlike Pigs, however, this African beast possesses much greater burrowing powers, and experiences little, if any, difficulty in hiding its whole body below ground. During the heat of the day the Aard Vark remains concealed in its burrows, and being nocturnal in habits, as well as of a shy disposition, it is only observed with great difficulty. It feeds upon termites. Only one young is born, and this keeps company with the parents until its babyhood is well advanced and the youngster is able to secure provender on its own account.

GREAT ANT-EATER.-In South America, whither we have gone in search of a number of interesting animals, the Great Ant-Eater (Fig. 232) is found, but opportunities are sometimes presented of seeing this beast in Zoological Gardens, where its massive and remarkable body is sure to elicit admiration. A fine, bulky fellow this, with tapering snout, long tongue, strong legs, well-haired body 


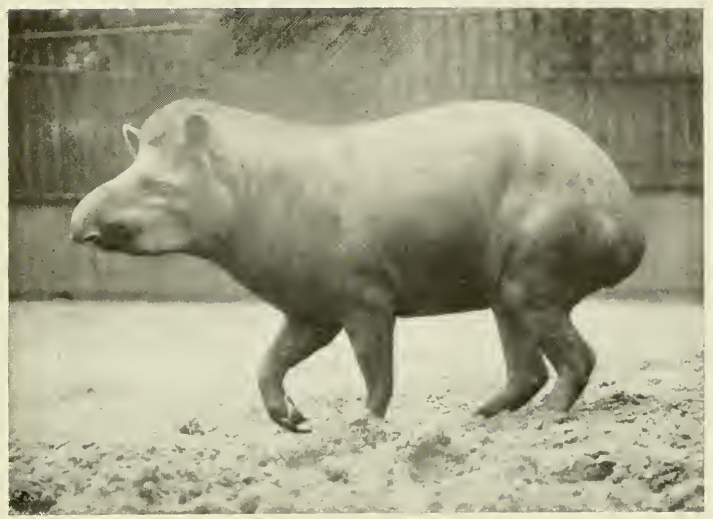

FIG. 234.-BRAZILIAN TAPIR

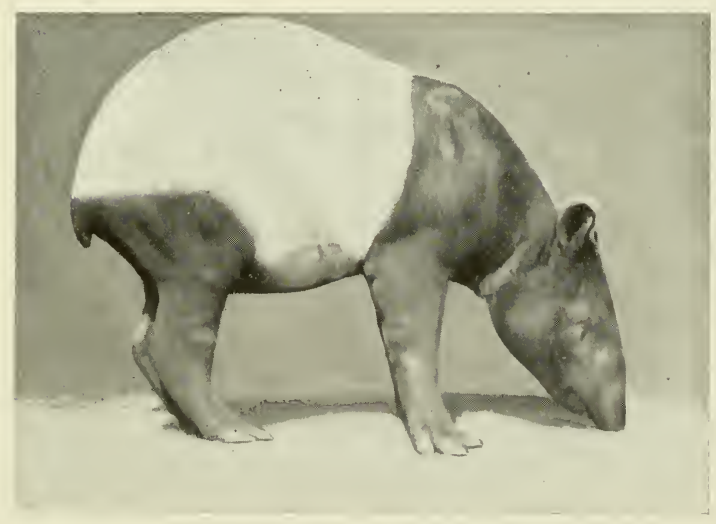

FIG. 235.-MALAYAN TAPIR 


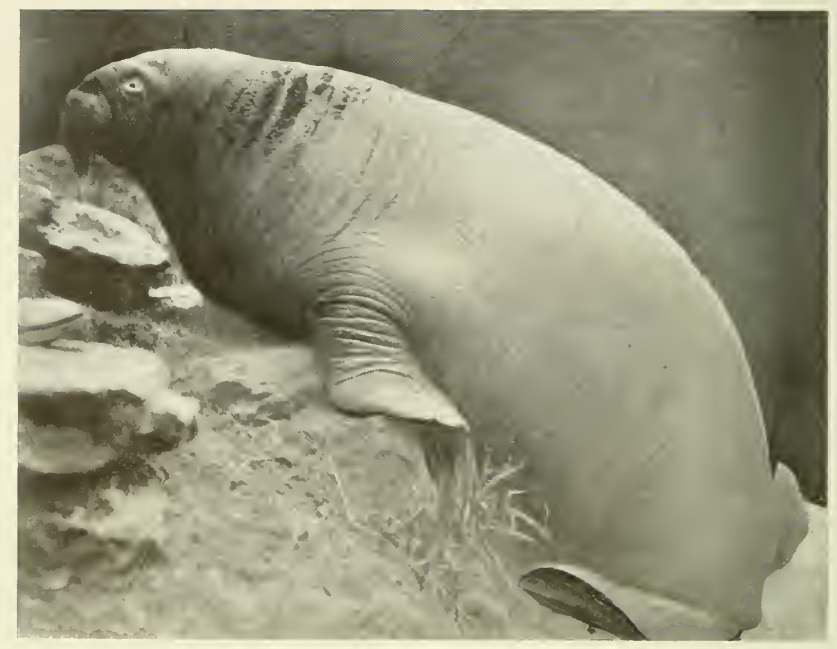

FIG. 236. W WARLS

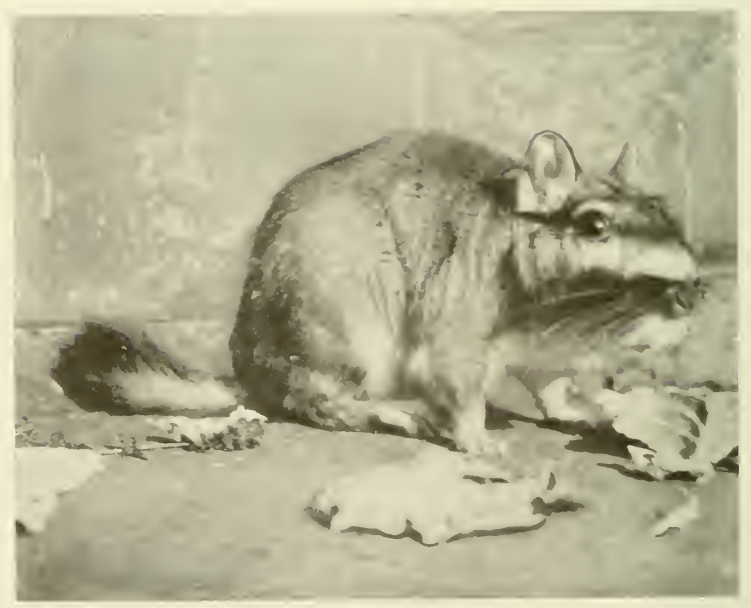

FIG. 237.-VISCACHA 
and bushy tail. It is a large beast, attaining a length of four feet exclusive of the tail.

The coloration is ash-grey to black, whilst, as Fig. 232 well shows, there is a distinct black stripe across the shoulders edged with white. Visitors to the Zoo and elsewhere should note, when one of these animals is on view, the curious manner in which it walks, the movements being very cumbersome as the beast is unable to tread on the soles of the fore-feet.

Feeding as it does almost exclusively upon termites, the AntEater must perform a great deal of good, as these insects are very injurious, possessing strong jaws which are capable of much destruction. The animal under review, however, is well calculated to make short work of a termite's nest, even although these remarkable citadels are strongly built and often of huge dimensions. Having laid bare the homestead, the Ant-Eater gets to work by means of its long tongue and soon licks up the inhabitants of the stronghold.

Like the Badger, this beast is quite inoffensive, and unless attacked will not deign to interfere with any one. If occasion does arise for it to defend its body, then the strong arms come into use for holding its adversary, and the claws do the rest.

Possessed of remarkable tenacity, this creature is not easily despatched, for in addition to the stiff and bristly hairs which clothe the body, there is a tough skin underneath which it is not easy to penetrate.

It is distinctly a rare animal, and well entitled to inclusion in this section of our work. Nocturnal in habits, it minds its own business, as it were, like our old friend Brock already dealt with in a previous chapter, and during the daytime remains concealed among herbage. The mother Ant-Eater is very solicitous for the welfare of her one baby. This little one she carries about with her on her back, and that she is fond of it, and parts with it in regret, is proved by the fact that it is not until another arrival is almost due that she leaves her reared youngster to look after itself.

RATEL, OR HONEY BADGER.-Although relegated to a different genus, the Ratels, or Honey Badgers, as they are also known (Fig. 233), are closely allied to the Common Badger which we met with on a previous expedition. The particular specimen figured in the illustration is famous in the zig-zag at the London Zoo as "These animals bite!" As Fig. 233 clearly portrays, the Honey Badger is 


\section{THE BOOK OF THE ANIMAL KINGDOM}

distinctly Badger-like in general appearance, although it has been compared also to a small Bear. There are two kinds, one being found in Africa and the other in India.

Light above and dark below, with short tails, no external ears, short, strong limbs with tremendous claws on the fore-feet, may be given as briefly descriptive of these animals, whilst in size they are nearly akin to the Common Badger, attaining a length of from twenty-six to thirty-two inches, excluding the tail.

We appear to have struck quite a number of nocturnal animals on our present pilgrimage, and it is interesting to note that the Ratels are also rovers during the darkness, concealing themselves in burrows in the daytime, these being excavated in all probability by the animals themselves.

It is the African species which seems to have the most partiality for honey, whilst Bee grubs are also relished, the beast being able to extract both from the insect's homestead in a hollow tree by means of the enormous claws on the front pair of legs. This African Ratel enjoys a fairly wide range over the great Continent, but exhibits a preference for the Southern and Western portions.

Some authorities do not consider that the two animals referred to are entitled to specific distinction, but, on comparison being made, it is obvious that the African Ratel can at once be distinguished from its Indian cousin by means of the prominent line of white along the sides of the body which divides the black underparts from the whitish-grey above. Besides the food mentioned, Ratels feed upon such creatures as frogs, birds, insects and rats, and it is stated that in districts where poultry are kept a good deal of damage is perpetrated.

BRAZILIAN TAPIR.-There are four species of South American Tapirs, and of these the Brazilian Tapir (Fig. 234) is a worthy representative. It is an inhabitant of the forests of Brazil, Paraguay and Northern Argentina. Curiously enough, outside South America only one species of Tapir is found, $i . e$. the Malayan Tapir next to be described.

The eminent Swedish naturalist Carl Von Linné, or Linnæus, to whose remarkable classification of animals and plants the scientific world owes such a debt of gratitude, originally described the Tapir "as a terrestrial species of Hippopotamus," and whilst it is true that in our classification of animals to-day the Tapir is not far removed from the bulky beast with whom Linnæus associated it, it is placed 
in a separate family, and comes between the Hippopotami and the Rhinoceroses.

The Brazilian, or Common, Tapir attains a length of some five feet. It possesses a strongly built body, a powerful thick neck, short legs, and a curious proboscis on the upper part of the snout. It is uniform dark-brown or blackish in colour, but the young, it is interesting to note, are spotted and striped like the Malayan species. The South American animal has a short, rigid mane, and the ears are margined with white. The small eyes, short tail, smooth, thick skin, and erect oval ears are further features worth recording.

One would have thought that the four species found in Central and Southern America would all be closely related, but this is not so, as although two are quite distinct and nearly akin, the remaining two species are first cousins to the Malayan Tapir, and fossil remains which have been discovered in Europe, China, the United States and Brazil go to prove that these forest dwellers of bygone days closely resembled the living species, and are thus to be numbered among the most ancient patriarchs of the mammal world.

All the five Tapirs may be written of as shy, retiring and inoffensive beasts of nocturnal habits, and all are fond of frequenting the neighbourhood of water, in which they are constantly immersing their bodies. They feed exclusively upon a vegetable diet, such delicacies as leaves, buds and shoots being greatly relished.

They possess keen powers of both smell and hearing, carrying the head close to the ground when walking. When disturbed, the beasts rush headlong away, paying little regard to any obstacles that may cross their path, and, when coming to water, plunging in without the slightest hesitation and swimming with ease and facility.

Tapir hunting, although not affording particularly good sport, is indulged in to a large extent in South America, the flesh of the animal being very nice eating, and the tough hide is, after proper treatment, made into reins and bridles. Whilst man is an enemy to be reckoned with, there are other foes which have to be overcome, chief among which is the Jaguar in South America, whilst the Tiger is an inveterate enemy of the Malayan species.

MALAYAN TAPIR.-This Tapir (Fig. 235) differs in both size and colour from the animals last under review, as it attains a length over all of some eight feet and stands from three to three and a half feet in height at the withers. Constant reference to the latter makes it necessary to explain that the withers is the junction of the shoulder- 


\section{THE BOOK OF THE ANIMAL KINGDOM}

bones, forming an elevation at the bottom of the neck and mane. In colour the Malayan Tapir is black or dark-brown on the head and front part of the body, as well as on the limbs, but on the rest it is greyish-white. The young, however, differ from their parents until some few months old, as they are brownish or black, spotted and streaked with brownish-yellow on the sides of the body and white on the under parts.

As might be assumed, the Tapir now being dealt with resides in the Malay Peninsula, its range extending "northwards to Tenasserim, and it also occurs in the Island of Sumatra, and perhaps in Borneo."

WALRUS. - The IValrus (Fig. 236) has already been referred to in Chapters III and XIV, and it is not necessary to do more than draw attention here to the photograph of this animal, which, rare and unfamiliar as it is, is deserving of inclusion in this section. It is an uncommon animal in captivity, and the pair which the Zoo authorities had at Regent's Park (of which the photograph shows one) came to an untimely end, one of the animals being drowned through getting under some tarpaulin which was placed in the water, and the remaining one dying of pneumonia, which it is suggested may have been brought on by the bad fogs that are so characteristic of London in the fall of the year.

VISCACHA. - This brings us to the Viscacha (Fig. 23j), and takes us back again to the Argentine Republic, in which country we have already made the acquaintance of quite a number of interesting mammals aptly entitled to inclusion in this book. One would hardly imagine that this curious-looking beast is a near relative of the Chinchilla (see Fig. 2II), but such is the case, as the Viscacha belongs to the same family.

This animal resides on the wide areas of the open pampas, whereas its near relatives, the Chinchillas, inhabit the higher Andes. It is a burrowing species, has a long, bushy tail, a stoutly built body nearly two feet in length excluding the tail, and in general appearance is quite different from the pleasing form of the Chinchilla. In colour the Viscacha is grey, mottled with dusky and black; the under parts, however, are white or yellowish-white, whilst there is a band of blackish across each cheek surmounted by a broad stripe of white.

On the open plains of the pampas this South American rodent forms its burrows, and, being a special species, numbers of them 


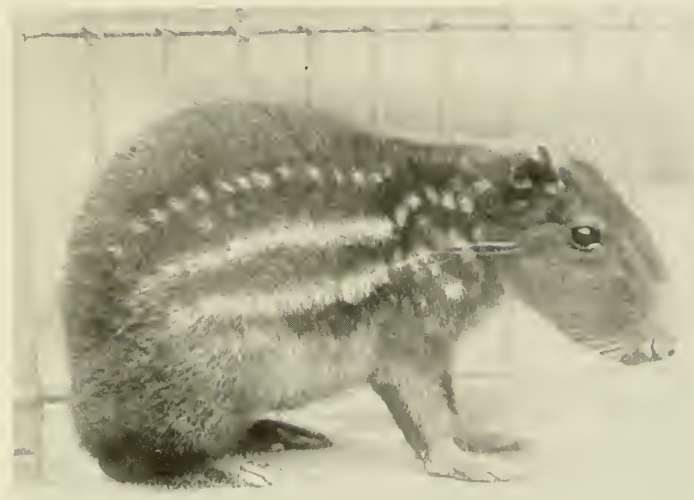

FIG. 238 . - PACA

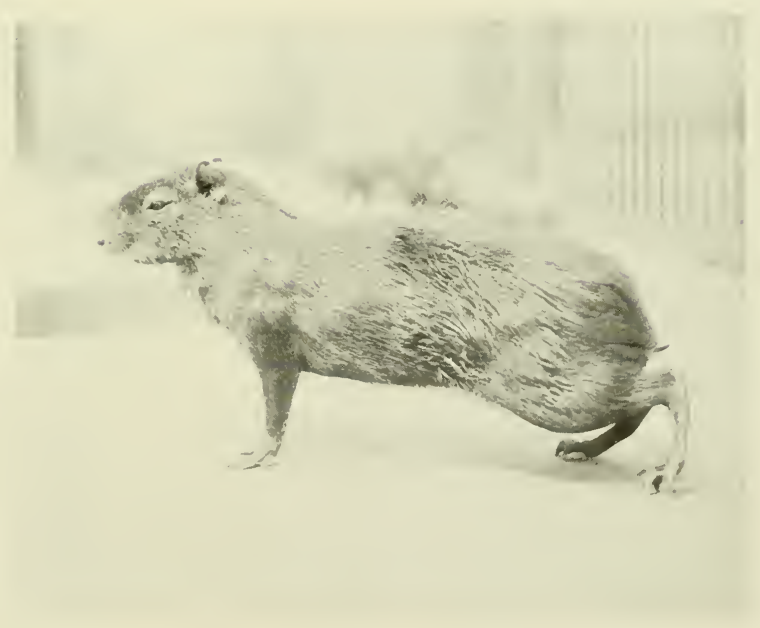

FIG. 239.-WEST INDIAN AGUTI 


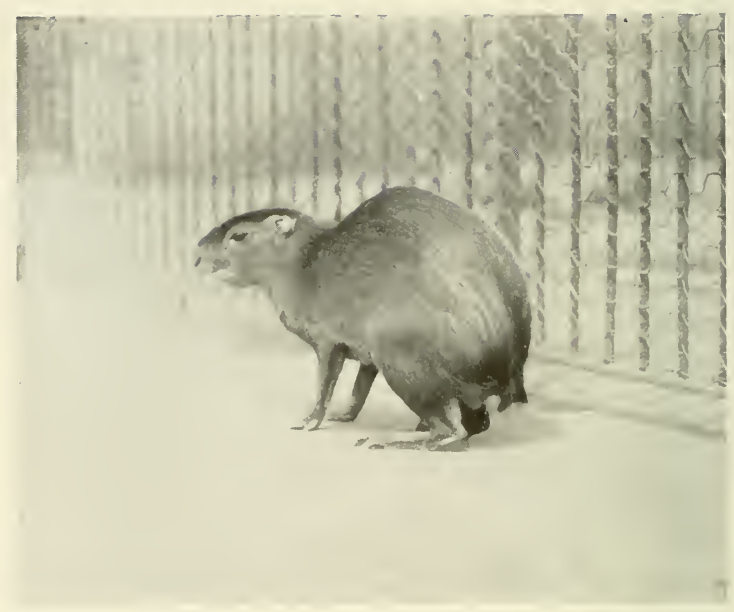

FIG. $240 .-$ PUNCTATED AGUTI

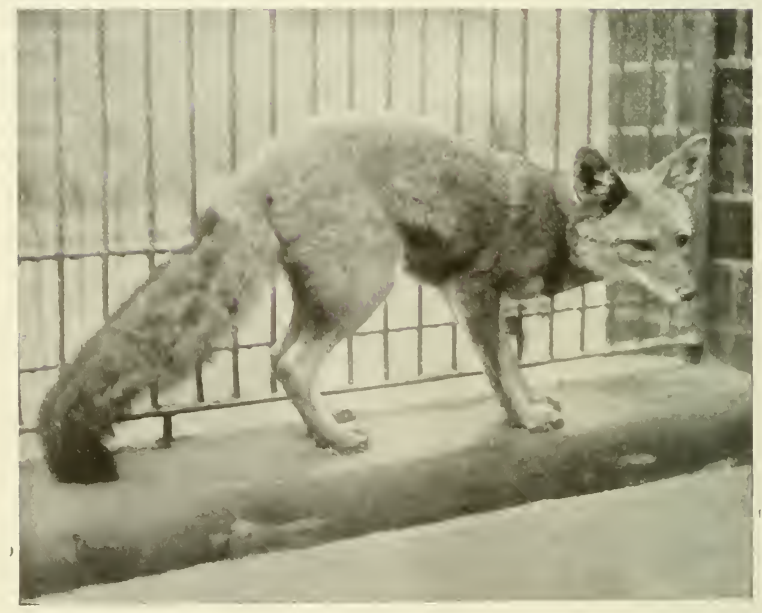

FIG. $241 .-$ CRAB-EATING DOG 
live together, making warrens which are known as viscachera. Earth brought to the surface as a result of excavations made below ground results in raised mounds being formed, and it is interesting to notice that the burrow generally assumes the shape of the letter Y. These burrows are taken advantage of by other animals after evacuation, much after the manner of some of our British birds which place their eggs in holes made by rodents in peaty soil, in the north of our island home; for at least three kinds of birds, including the Burrowing Owl, take possession of the deserted Viscacha burrows. The Viscacha feeds upon herbage, including grass, seeds and roots.

It is a nocturnal animal, and when observed on the open pampas at or about sunset must present a fine sight to any one interested in the wild life there found. From two to three young ones are born in the early Autumn, and, in spite of the fact that it takes some two years before the young attain the adult state, we learn that previous to the advent of the agriculturist-whose hand is against it because of the harm done to growing crops-this animal was found in numbers so enormous as to be hardly credible to-day, when its ranks have been so greatly reduced.

PACA.-There seem to be a large proportion of South American animals among the rare and unfamiliar beasts with which we are now concerned, and it is in that part of the world that the curious-looking Paca (Fig. 238) resides. It belongs to the same family as the Agutis next to be described, but is easily distinguished from them by means of the longitudinal rows of light spots which are admirably shown in the illustration, and there are structural differences that need not detain us.

The Paca is a stouter and more clumsily built animal than the Aguti; it has shorter limbs; the head, as will be noticed by a comparison of Figs. 238, 239 and 240, is much broader, and this is due to the arches of the cheeks being "greatly expanded from above downwards, so as to form huge bony capsules on the sides of the face, each of which encloses a large cavity communicating by a narrow aperture with the mouth."

The coarse fur varies in colour from fawn to blackish, and the rows of spots which greatly relieve the coat also vary in number.

The Paca enjoys a wide distribution throughout South America, for although it is a rare beast in Peru and a few other parts, it is a common inhabitant of other portions of the Southern Continent.

We have here again both a nocturnal and a burrowing animal, 


\section{THE BOOK OF THE ANIMAL KINGDOM}

and it is interesting to note, as we have done before concerning animals of a similar nature, that it is a shy, retiring beast. When disturbed the Paca hies away to the nearest water, for there, being a good quick swimmer, it is secure from its enemies. It is hunted on account of the general excellence of the flesh-especially in the early part of the year, when it is found to be very fat-and also because there are so few South American mammals which can really be considered good eating.

AGUTIS.-The Agutis, like the Paca, are South American rodents of which there are several different kinds inhabiting Central and South America, whilst one species, the West Indian Aguti (Fig. 239), is found in the West Indies. A second beast is shown in Fig. 240, this being known as the Punctated Aguti, and is merely a variety of the West Indian species which is more typical of this interesting family of beasts. I do not know exactly why the Punctated Aguti is so called, unless it is that the coat is smoother than that of its IVest Indian cousin, and dotted or coloured with very small round spots. The Agutis possess long, slender limbs; they have only three toes on the hind feet, instead of five like the Paca, and all of them are lovers of forest regions, where, during the silent watches of the night, they carry out their exploits, remaining hidden during the day in hollow trees or burrows.

When seen in the open during the daytime, away from the thick growth of the luxuriant forest home, the Aguti is said to present an attractive appearance, exhibiting quick and graceful movements pleasant to watch. And it is not only on land that this South American animal attracts attention, for it readily takes to the water, and, although unable to dive, is a really expert swimmer.

The food is made up of plants and wild fruits, but in districts which are cultivated it is stated that much harm is perpetrated in plantations, especially among sugar-canes.

Like the Chaffinch among British birds, the Agutis separate after the breeding season is over, the two sexes keeping apart from one another until the pairing time again brings them together. The mother Aguti is most solicitous for the welfare of her progeny (which may number one, two or more), and prepares a snug home in which to rear them. She jealously guards her babies, and it is not until they have been born some little time that she permits the father to inspect the new arrivals.

CRAB-EATING DOG,-Another South American animal that claims 


\section{RARE AND UNFAMILIAR ANIMALS}

attention here is the Crab-Eating Dog (Fig. 24r). There are several different kinds of IVild Dogs un the great continent with which we have been so much associated in this section, including the solitudeloving and so-called Maned Wolf, the small Fox-like Azara's Dog, the handsome Colpeo (which is an inhabitant of Tierra del Fuego and Chili), the Short-Eared Dog (of which only one solitary specimen seems to have been obtained so far), and others. The CrabEating Dog, or Carasissi, as it is also known, is a dweller in the forest or jungle, and has acquired the first-mentioned name from its habit of feeding upon various kinds of crustaceous creatures, as well as rodents and birds. In colour it varies a good deal, but may be described generally as brownish-grey on the upper parts, with rufous on the top of the head, as well as on the sides of the body and the outside of the limbs. There is black on the back and on the upper portion of the tail, whilst the tip of the caudal appendage is invariably black. The ears and tail are both prominent, as Fig. 24I displays, and the first mentioned are reddish-brown in colour.

As this is the last member of the Dog tribe with which we are concerned in this work, a famous legend of the taming of the "Wolf of Agobis," associated with that great lover of animals, St. Francis of Assisi, may here be told. Says Farm and Home-

"That Wolf was a quadruped without morals; not only had he eaten kids, but also men. All attempts to kill him failed, and the townsfolk were afraid of venturing outside the walls even in broad daylight. One day St. Francis, against the advice of all, went out to have a serious talk with the Wolf. He soon found him, and, 'Brother Wolf,' he said, 'you have eaten not only animals, but men made in the image of God, and certainly you deserve the gallows; nevertheless, I wish to make peace between you and these people, brother Wolf, so that you may offend them no more, and neither they nor their dogs shall attack you.' The Wolf seemed to agree, but the Saint wished to have a distinct proof of his solemn engagement to fulfil his part in the peace, whereupon the Wolf stood upon his hind legs and laid his paw on the Saint's hand. Francis then promised the Wolf should be properly fed for the rest of his days, 'for well I know,' he said kindly, 'that all your evil deeds were caused by hunger'-upon which text several sermons might be preached, for truly many a sinner may be reformed by a good dinner and by nothing else. The contract was kept on both 


\section{THE BOOK OF THE ANIMAL KINGDOM}

sides, and the Wolf lived happily for some years-fed by the people -at the end of which he died of old age, mourned by all the inhabitants."

We have already in an earlier section-Cats, Great and Smallmade acquaintance with a goodly array of members of the Cat tribe, but before concluding our task attention may be directed to a few rare and unfamiliar kinds deserving notice.

BLACK-FOOTED CAT. - The Black-Footed Cat (Fig. 242) is one of the smallest Cats and is a very rare African beast, the specimen depicted hailing from the Zambesi.

CIVET CAT.-The Civet Cat (Fig. 243) is also an African species, possessing a strongly marked and long body; a narrow elongated head; short legs; small, rounded feet, and a large tail. Strictly speaking, neither the African Civet nor its Indian cousin should be designated Cats, as the Civets (both real and so called), the Genets, the Linsangs, the Palm Civets, and other genera, which need not be specifically referred to, are in themselves not altogether easy to define in a popular way. The African and the Indian Civets belong to the true Civet genus, the Fossa of Madagascar being the culprit which has caused zoologists a good deal of trouble as to the exact position it should occupy in the classification of animals.

MALACCAN CIVET, OR RASSE-There are six different kinds of true Civets, and of these we have a further representative in the Malaccan Civet, or Rasse, depicted in Fig 244. This is quite a small beast-indeed the smallest of the six species included in this genus-and may soon be identified from its relatives "by the absence of erectile hairs along the middle of the back." The Rasse has a sharply-pointed head, and measures some thirty-six to forty inches, including the long, ringed tail.

PALLAS'S CAT. - Pallas's Cat (Fig. 245), it is interesting to note, is closely related to the IVild Cat already treated of in Chapter VIII (see also Fig. I14), but is a resident of Siberia, Mongolia and Tibet, the specimen in the photograph having been procured from the lastnamed country. It is further known as the Manul Cat, or, in Latin, Felis manul, but is more frequently called Pallas's Cat, after Pallas who first described it; but this handsome creature has disappeared from many of the haunts in which its discoverer found it.

It may be compared in size to our own familiar Pussy, but, as an examination of Fig. 245 will reveal, it possesses a long, thick, furry coat and a prominent tail. The breadth of the head is also worth 


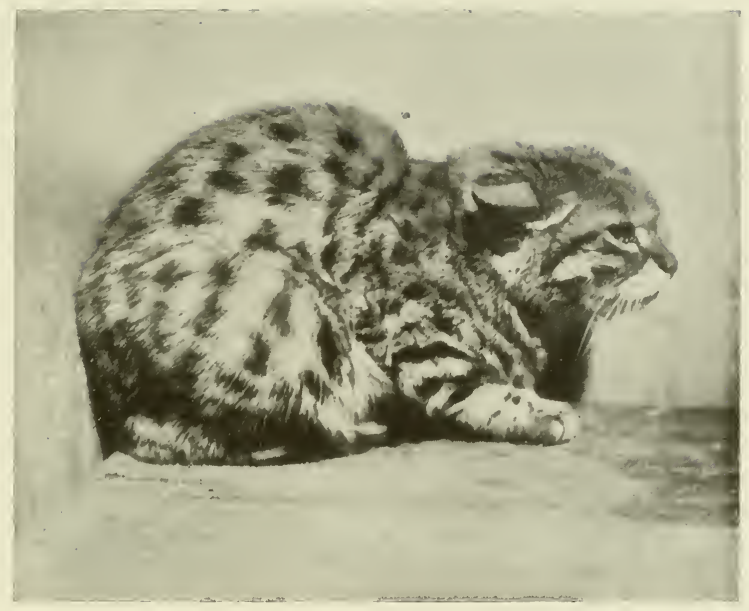

FIG. 2+2.-BLACK-FOOTED CAT

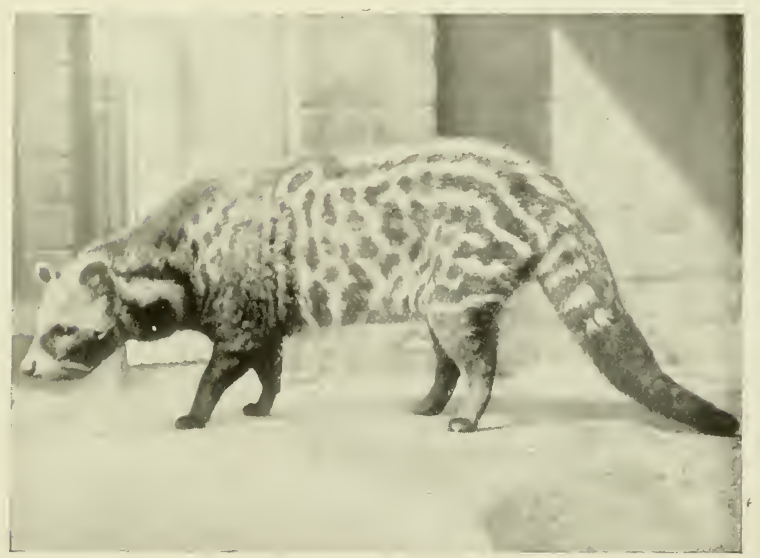

FIG. 243. CIVET CAT 


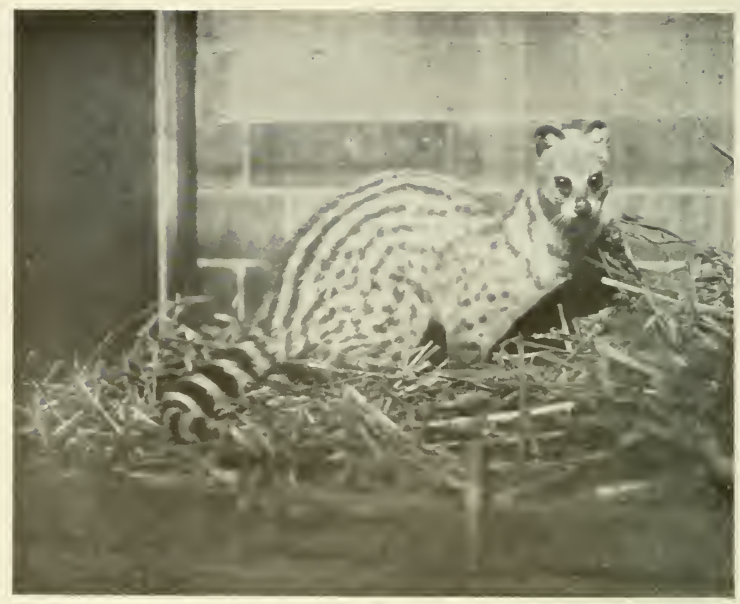

FIG. $2+4$ - MALACCAN CIVET, OR RASSE

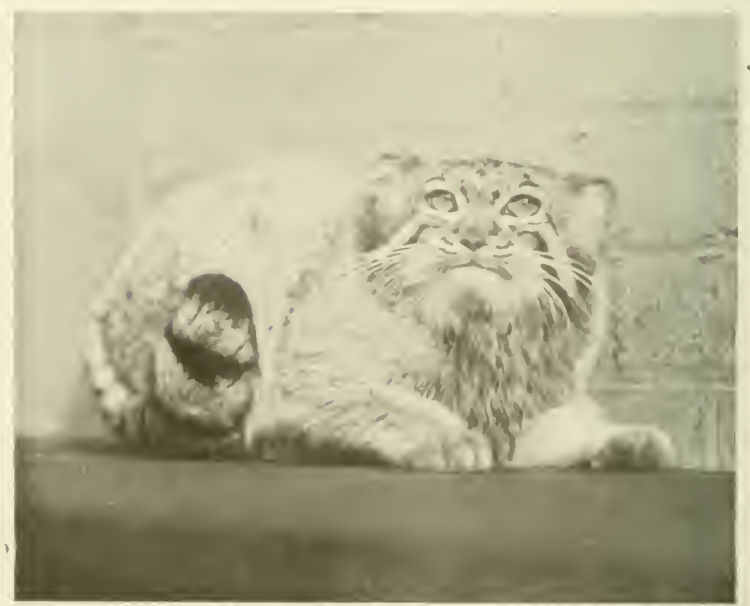

FIG. 245 - PALLAS'S CAT 
drawing attention to, as well as the moustaches and the piercing eyes. In colour Pallas's Cat may be described as varying from silver-grey to yellowish-buff, with lighter or darker on different parts of the body, some stripes on the loins, perhaps a few bands on the limbs, a dark ringed tail, and, of course, a pair of transverse streaks on the cheeks, these being easily distinguished in the picture of this Cat.

PALM CIVETS.-The Palm Civets-represented in the illustrations by the one solitary African species (Fig. 246) - are known also as Tree Cats or Toddy Cats. With the exception of the African Palm Civet all the species are restricted to Asia, and they are practically devoted to an arboreal life. They are also nocturnal beasts, feeding both on animal and vegetable food, for procuring which their teeth are admirably suited. The tails of these Palm Civets are long appendages, measuring in the majority of species more than half the length of the head and body. The name of Toddy Cats has been applied to these animals because, like the Fox-Bats, they display a strong liking for palm-juice, or toddy as it is popularly called, which the natives collect by means of vessels hung on the trees. Palm Civets have the curious habit of emitting a distasteful odour when they are irritated, presumably for protective purposes.

GENETS.-The Rusty-Spotted Cat of India-the smallest member of the Cat tribe-must not be confused with the Rusty-Spotted Genet (Fig. 247), or vice versa, as the case may be. The Genets are close relatives of the Civets, but are to be distinguished by the still more slender bodies, shorter legs, longer tails, etc.

The Rusty-Spotted Genet illustrated in Fig. 247 came from Northern Rhodesia, but there are many species which reside in other parts of Africa. There are four species found in the continent which do not occur elsewhere, indeed only the Common Genet occurs outside Africa. Genets have close-cropped and soft fur, the general coloration being either greyish or brownish-yellow. There is a black line along the centre of the back; there are also brown or black spots on the sides, light and dark markings on the head, and black rings on the tail.

CAPE HYRAX, OR KLIP-DAS.- Very few people on being asked what kind of animal the Cape Hyrax (Fig. 248) was would be able to give a correct answer. Most of them would probably call it "a kind of Rabbit or Rat," but it may be known by means of its feet. It is a delightfully entertaining little beast, and is first cousin, if 


\section{THE BOOK OF THE ANIMAL KINGDOM}

you please, to the Elephant! True enough it belongs to a different family, known as the Hyracidæ, occupying a position in the scale of animal life between the Hares and Rabbits (Family Leporidæ) and the Elephants (Family Elephantidæ).

Being so much like a Rodent in general appearance, it is small wonder that, on learning of its relationship with the Elephant, the observer should express surprise, but a glance at the toes of the Hyrax will reveal small hoofs which are joined by skin to the nails, thus resembling those of both the Elephant and Rhinoceros. Yet again, the teeth are best compared to those of the Hippopotamus, and the distinguished French naturalist, Baron Cuvier, referred to the Hyrax as being, if the horns of the Rhino are excepted, "a Rhinoceros in miniature." The reader will thus gain some idea of the curious build of this little beast which has greatly puzzled zoologists for a long time past.

There are quite a number of these small relatives of the largest terrestrial animal now living, and whilst some are exclusively ground dwellers, there are others whose habits are entirely arboreal, the name of Tree Hyraces having been conferred upon these. They are residents of East and West Africa.

The Cape Hyrax is, as its name implies, an inhabitant of South Africa, where it is also known as the Klip-Das, or Rock Badger.

Other species inhabit Arabia and Syria, the Syrian Hyrax being the "Coney" referred to in the Bible. The Cape Hyrax (Fig. 248) is clothed with soft, fine hair of a dark-brown colour, with specks of pale-yellow or white, and a black spot on the back. It haunts rocky places (hence the name of Rock Badger), and may be observed playing about its environs in a delightful way, similar to the prolific Rabbit, which it also resembles in exhibiting a preference for feeding during the morning and evening.

COMMON POLECAT.-This animal (Fig. 249) is a rare British species to-day, for, being an inveterate enemy of game birds, the hand of every keeper in the country is against it, and in most districts it has been entirely stamped out. Reference has already been made to this savage beast on pages $40-42$, to which the attention of the reader is directed, but before dealing with the Zorilla, or Cape Polecat, it may be stated that outside Britain the Common Polecat is found in most other countries of Europe. It is a handsome creature, having a coat dark above and paler below, with a black 


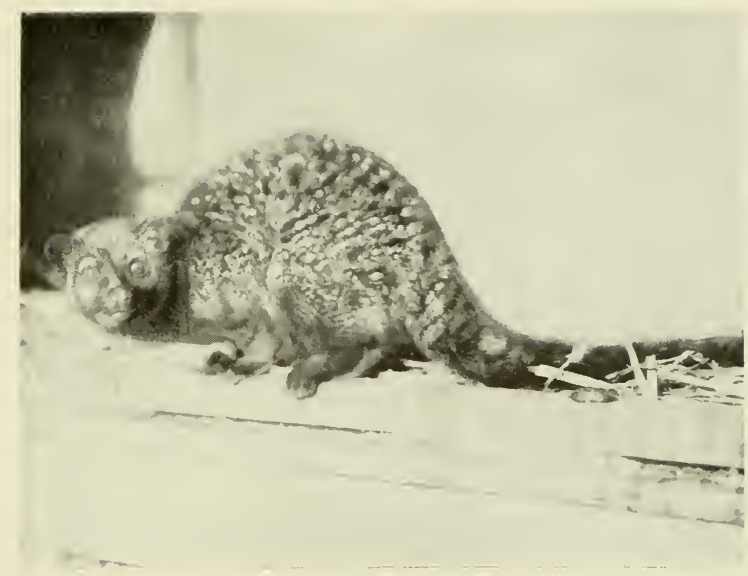

FIG. 246 - AFRICAN PALM CIVET

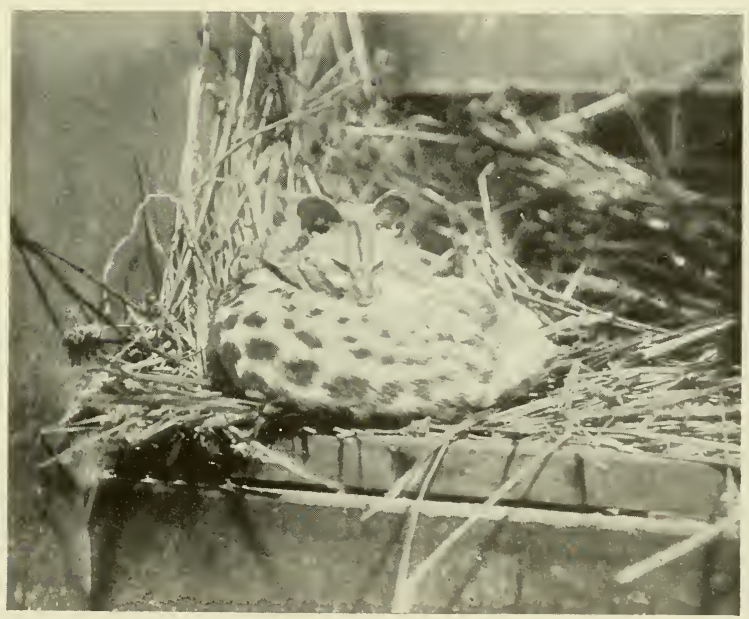

FIG. 247.-RUSTY-SPOTTED GENET 


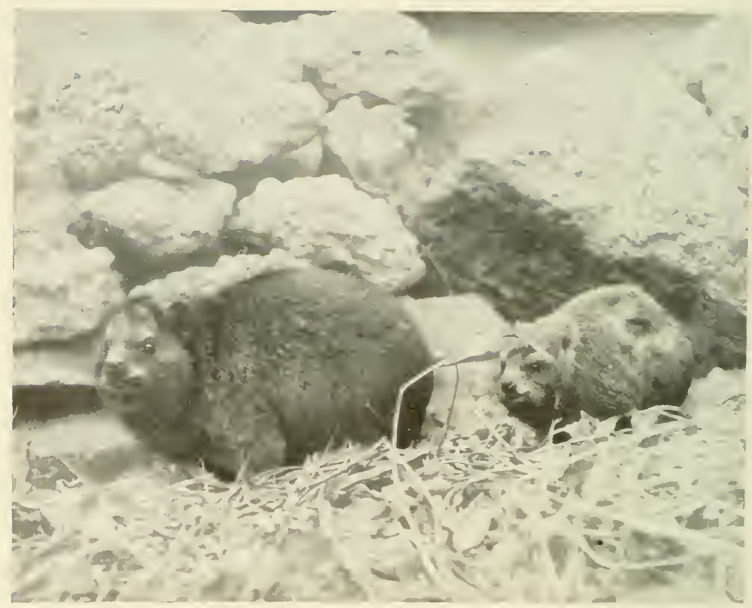

FIG. 2 f. C CAPE HYRAX, OR KLIP-DAS

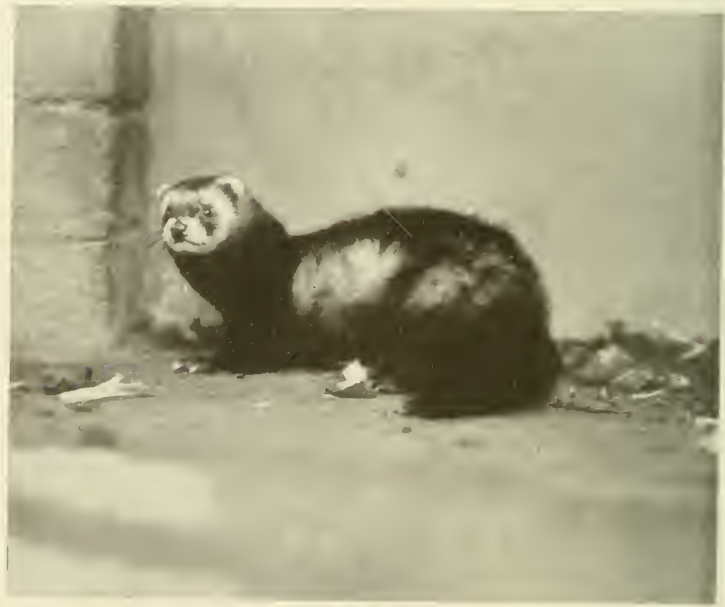

FIC. 2fG. - COMMON POLECAT 
and white head. It attains a length of sixteen or seventeen inches excluding the tail, but the female is some few inches less.

Like its relatives, the Stoat, Marten and Weasel, the Polecat is a ferocious animal; it is a great enemy of Rabbits and other kinds of mammals, a splendid swimmer and a lover of fish. Its powers of hunting and killing are remarkable, and one beast has been known to account for a large number of Rabbits as the result of a single visit to a favourite warren. When it was commoner in our own land than it is to-day, poultry-keepers suffered a great deal from its ravages, as it has a lust for killing and is to be regarded as one of those wild hunters which have the habit of slaying far more food than they can possibly eat.

As a means of protection it is not only a ferocious beast to encounter, but can at will emit a most distasteful odour calculated to repel any one excepting the gamekeeper, who thinks lightly of such things. The fur, too, is saturated with this unpleasant smell, but when the skin is prepared for commercial purposes the odour is got rid of.

ZORILLA, OR CAPE POLECAT.-The Zorilla (Fig. 250) is another evil-smelling animal. It is not at all unlike a small member of the Skunks, both in colour and general appearance, but belongs to a genus of its own. The teeth are different in size from those of the Skunk, and more nearly resemble those possessed by the true Polecat.

A comparison of Figs. 249 and 250 will, failing observation of the living animals, reveal a great similarity, as both kinds of beasts have short limbs, and the shape of the body is also akin. The long bushy tail of the Zorilla is well displayed in the illustration, as also the light and dark markings upon the back and sides of the body, and on the top part of the head. The distribution of this animal is "from the Cape to Senegal," but in Northern Africa and Asia Minor a further species is found of close relationship.

A lover of rocky situations, the Zorilla also frequents bushes and trees, and is nocturnal in habits. It preys upon various kinds of small mammals, also birds and their eggs, as well as frogs and lizards.

This African animal cannot climb like the true Polecat, neither does it exhibit such a preference for water. It can swim, but does not possess the same powers as the species last under notice. The Cape Polecat is tamed and used in the same way as the Ferret, but 


\section{THE BOOK OF THE ANIMAL KINGDOM}

instead of Rabbits, the Dutch Boers utilize the beast for the purpose of keeping down Rats and Mice.

ORKNEY VOLE.-This interesting Vole (Fig. 25I) was first noticed by the well-known naturalist, Mr. J. G. Millais, son of the famous artist, in the Orkneys in August I886. It was a most unexpected discovery in British mammalogy, and only goes to prove how important it is to pay intelligent attention to any animal that is encountered which presents any divergence from the recognized type. Mr. Millais was first attracted to the Orkney Vole by reason of its dark appearance and its large size, and a comparison between it and its common mainland relative will reveal the broad,-blunt and heavily furred head of the Orcadian species, while the incisor teeth are different in size, and the molar teeth are of a different pattern. It seems curious that whilst a boreal Vole is found in the Orkney Islands the same is absent from the Shetlands, and a further point of interest to which notice may be drawn is, that in the case of this newly discovered British mammal the general rule of island forms being smaller animals than those found on the mainland is reversed, for instead of the Orkney animal being smaller than its mainland cousin, it is decidedly larger over the whole of the body, with the sole exception of the tail, which is about the same size. The Orkney Vole is almost twice the size of the Common Field Vole, and the general colour is dull sandy-brown.

There can be no doubt that if more attention were devoted to insular faunas and floras much valuable data would result. This has been carried out in Ireland by enthusiastic naturalists there with great success during recent years, and their excellent work might well be followed up by other naturalists in all parts of the world where it is possible to carry out similar undertakings.

GERBILS.-The Gerbils are small Rodents which are at once distinguished by having long hind-limbs and long, hairy tails, and they remind one in appearance and habits of the Jerboas. They are, however, distinct from the last-mentioned animals in regard to the muzzle, eyes, toes on the hind-feet, and teeth.

There are a large number of different species of Gerbils found in both Africa and Asia, and the illustration (Fig. 252) shows the Cape Gerbil. This species is not so well known as its Indian cousin, and it is the latter that had best be described. This may be compared in size to the Brown Rat. It is brownish-rufous on the upper parts and white below; it has large, bright eyes, a long, tufted tail, and, 
like its many relatives, is an inhabitant of wide sandy districts, and of graceful habits. It is a social little animal, living happily enough in company with its fellows, and constructing burrows in which a large number of young ones are produced. The Indian Gerbil, for example, has from twelve to fifteen or more babies at one time, and thus resembles in fecundity many of its better-known cousins which belong to the Rodentia.

Gerbils feed for the most part upon roots and grass, but when tenanting cultivated districts they perpetrate much damage among growing crops. The long hind-legs enable the interesting little beasts to take prodigious leaps, the Indian Gerbil being capable of leaping a distance, it is said, of from twelve to fifteen feet.

CRAB-EATING OPOSSUM.-The Crab-Eating Opossum (Fig. 253) brings us to the completion of our present expedition among some of the rarer mammals of the world. A recent popular work on animal life issued in London states that the mammal chosen as worthy of concluding this chapter is the only kind of Marsupial that exists outside the great Australian Continent. This, however, is incorrect, as there are certainly other Marsupials outside Australia beyond the Crab-Eating Opossum, although it is no doubt true that they are little known except by the zoologist.

The species with which we are now concerned is of arboreal habits, although, curiously enough, it procures its living on the ground, and often resorts to the seashore when its hunger requires appeasing. When on terra-firma its movements are ungainly, but in the treetops it finds a congenial habitat, the long prehensile tail enabling it to perform remarkable feats among the pliant branches. It has acquired its name by reason of its partiality for various kinds of small crustaceans, but also eats small mammals, birds and insects.

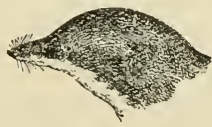




\section{H A P TER X VII}

\section{GIANTS OF THE DEEP}

Whilst pictorially the Whales, Porpoises, Dolphins and Bats are unrepresented in this work, it would ill become us to conclude The Book of the Animal Kingdom without deroting attention to these Giants of the Deep and Mammals of the Air (Bats), for, of course, all the animals mentioned are mammals, and justly entitled to inclusion here.

GREENLAND WHALE AND WHALES IN GENERAL.-Before proceeding to describe a few of the more remarkable species of Whales and their relatives, the Porpoises and Dolphins, it will be as well to consider the structure and mode of life of one of these mammalian monarchs of the sea, and for this purpose we cannot do better than choose the Greenland Whale, and follow its story as recorded by Dr. Schmeil in his Textbook of Zoology.

Whales are hairless, fish-like mammals which resort to an aquatic life, and although regarded by many, if not most, people as fishes, it will soon be apparent to the reader that the marine beasts we are now about to deal with are mammals of great usefulness and immense interest. They do not possess any hind-legs, whilst the fore-limbs are fin-like and the tail fin is horizontal, a feature of importance that we shall find out at a later stage.

The Greenland Whale inhabits the most northern portions of both the Atlantic and the Pacific Oceans, and its structure and mode of life admirably suit it for an aquatic existence. Although not the largest WWhale-the giant Rorqual being its successful rival-the species under review attains a length of from sixty to eighty feet,

- and a weight of from 220,000 to 330,000 pounds, which Dr. Schmeil compares to that of 150 to 200 strong oxen!

Among the members of this genus there exist not only the largest of living mammals, but, with the exception of some of the enormous land reptiles of the Secondary period, also of pre-existing times, the terrestrial giants treated of in Chapter I sink into insignificance when compared with the huge monsters now being considered. 
A creature possessed of such enormous bulk must of necessity live in the water, and, moreover, in the sea. But, it may be asked, why should this be so? The answer is, that most mammals which are found on land have the body supported by two pairs of limbs, and this body may well be compared to a bridge supported by pillars. If the pillars of a land bridge are not constructed in such. a way that the main portion is well supported, and its arches built strong and rigid, a sudden collapse is assuredly threatened; but if the bridge is laid on the water (i.e. a boat-bridge), it is not necessary that the structure should be of such great strength and solidity, "since it is supported on the water at all points." Thus the strength of the larger land animals and the immense size of the Whale will be understood from this apt comparison, for, as has already been noted, the Whale exceeds in size any terrestrial animal. We not only find this divergence of size and firmness in the animal worldthat is, as between land and aquatic beasts-but even among plants interesting analogies are forthcoming with regard to the size and strength of water plants as compared with their neighbours, which anchor themselves on land, and often have to take advantage of the surrounding vegetable life, being too weak and fragile to successfully fight the great battle of existence without resorting to climbing, straggling, twining, creeping, or throttling.

The Whale is a superb diver, and in the mazy depths of the ocean is as much at home as the Squirrel gambolling in the pliant tree-tops or the Rabbit secure inside its burrow. But how, it may be asked, is it possible for an animal of such gigantic proportions to successfully overcome the enormous pressure of water consequent upon the Whale's habit of passing the greater part of its existence far beneath the surface of the sea? At first sight the conundrum seems impossible of solution, but close acquaintance leads us to an awakening. For example, "most of the bones of the body remain cartilaginous ${ }^{1}$ at their points of union, the two halves of the mandible ${ }^{2}$ are only united by ligaments, ${ }^{3}$ and only the first pair of ribs is directly united with the sternum $;^{4}$ all these arrangements tend to prevent fracture of the bones, and impart great elasticity to the body."

We have already seen during some of our previous expeditions

1 Gristly, the bones containing little or no calcareous or limy matter.

2 The lower jaw. ${ }^{3}$ Short bands of strong white glistening fibres, by which the bones are bound together, 4 The breast bone, 


\section{IO THE BOOK OF THE ANIMAL KINGDOM}

how many kinds of land animals are protected by a thick upper skin, $e . g$. Elephant and Rhinoceros, but in the IVhale the skin is exceedingly thin and soft, and thus resembles that possessed by many other aquatic mammals. The IVhale's body, then, is covered with this thin skin; it has no hairy coat such as is worn by land or amphibious animals, and it will at once be recognized by the merest tyro that such a covering would prove of no service whatever to the Cetacean. And beneath the thin skin what do we find? There is a layer of fat, or blubber, from eight to sixteen inches in thickness, and it is through the agency of this complete envelopment of the body that this giant of the deep is able to preserve heat, and thus be permitted to inhabit even the ice-cold waters of the Arctic Seas.

It is wonderful to notice that, in spite of its enormous bulk, the Whale's movements in the water are both nimble and rapid. It simply revels in the water, for it tumbles about in it as if in play, much after the manner of a good swimmer who has perfect control over his movements, and will actually lift its body above the surface of the waves, or stand on its head and lash the water with its tail! How is it possible for this huge beast to carry out such extraordinary evolutions? Briefly they may be described as under. The body is shaped like a boat, or fish, and hence the animal is still known in some parts as Whale-Fish, and as a Fish to many people. There is no visible neck, the vertebræ forming only narrow rings, or discs, which are partially joined together.

It is by means of the large tail that the Whale is able to propel its huge body through the water, this appendage having powerful muscles, and, writes Dr. Schmeil, "by its rotatory movements it acts just like the screw of a steamer in driving the animal forwards, while by its upward or downward strokes it enables it to sink below or ascend above the surface. The force located in the tail may be estimated from the fact that one stroke of it can shatter a stout boat."

The fin-like fore-limbs are the steering gear of the Whale, and as all the parts of these fore-limbs are strongly united, there being no joints excepting at the shoulder, the limb. works like a piece of wonderful machinery, and the pliancy of the whole body admirably assists the action of the fore-limbs and the tail.

The fat in which the body is enveloped naturally lightens the weight of the body in the water, as well as the oil which permeates 
the porous bones. Then again, when we come to examine the inside of the enormous creature, we find that the very large lung extends further back than in land animals, and thus the centre of gravity is shifted further forwards.

Friction in the water is obviated, or at any rate largely diminished, by the smoothness of the skin, and as the Whale does not possess any external ears progress is unimpeded, as it would not be if outside ears were present. It must not be assumed, however, that this animal giant of the deep is devoid of the sense of hearing, as it is stated to exhibit most acute powers in this respect when below the surface. The eyes are placed close to the angles of the mouth, and are comparatively small, being about the same size as those of a Domestic Cow. How does the Whale breathe? Fishes, as we know, breathe by means of gills, and in their case they take in air dissolved in water. The IWhale, however, inhales free atmospheric air, and to obtain this life-giving product it rises to the surface every few minutes, whereupon it expels the used air through the nostrils, making, as it does so, a loud noise that may be heard some distance away.

Being an inhabitant of cold latitudes "the water-vapour with which this air is saturated becomes visible (like the vapour of our breath in Winter), and appears in the form of two huge jets of steam ejected from the head of the animal. It is this phenomenon which is spoken of as the 'blowing' or 'spouting' of the Whale."

It will thus be seen it is an absolute essential that this mammal should be able to come to the surface of the water to take in a fresh supply of air, and the powerful tail-fin is the wonderful mechanism which drives the beast upwards. This is the reason why the tail-fin occupies a horizontal position. The large lungs are capable of taking up an abundant supply of air, whence it comes about that it is not necessary for the animal to take in a fresh store of the necessary of life in less than from ten to fifteen minutes, although, curious to relate, a wounded beast has the power of remaining in the depths beneath for an hour or more, surely a wonderful provision of Nature whereby the giant may be secure from enemies above-board. Look at a Whale's head if ever an opportunity occurs, and it will then be seen that the nostrils are well placed, and that they take the form of narrow slits. They occupy a position on the summit of a roundish protuberance on the top of the head, and after a fresh supply of air has been inhaled the openings close as the monarch dives below again, and thus water is prevented from entering them. 


\section{I 2 THE BOOK OF THE ANIMAL KINGDOM}

We may now consider the food of Whales, and we shall then learn something of the peculiar structure of the mouth, and shall be able to ascertain the difference between the toothed and the toothless species. The Greenland Whale belongs to the last-named, which is, in itself, probably sufficient to occasion some amount of surprise, but few people appear to be aware of the fact that, although carnivorous, or flesh-feeders, many of the Whales feed upon very small animals which inhabit the sea. This "whale food," as it may be called, consists mostly of a transparent mollusc known as Clio borealis, which only measures about one and a quarter inches in length. These molluscs, as well as a creature smaller still which is allied to the common Fresh-water Shrimp, are found in immense numbers at or near the surface of the IVhale's native seas, "especially at the border of the drift ice," and it is among the inhabitants of these innumerable shoals of small marine animals that the Whale makes havoc. The abundance of food which it is necessary for such a gigantic beast to partake of may well be imagined, and here we have another reason why it is only possible for it to inhabit the sea, the latter, "with its superabundance of animal life," being the only place which can supply its demands.

One would hardly credit the statement that most kinds of Whales are unable to swallow a fish larger than a herring-and thus we may at once conclude that some animal other than a Whale was the one chosen by Jonah in which to spend three days and three nights as recorded in the Holy Word-but such is the case owing to "the remarkably small calibre of the oesophagus." It must not be overlooked, however, that the Whale under review has a gigantic toothless mouth. So large is it that the beast could take in a small boat with comparative ease, but the smallness of its "swallow" would bar any further progress, so that Jonah could not, if he had wished, have safely located himself in the Whale's belly, even if he had successfully accommodated his person in the animal's mouth !

These small creatures, then, upon which some kinds of Whales feed, must of necessity be collected in countless numbers, and to enable them to be scooped up the animal is provided with a remarkable apparatus, which may be compared to a sieve or a fisherman's net. This apparatus consists of a row of triangular-shaped horny plates, which are suspended from each side of the palate, and may be likened to skins hanging from a roof. These horny plates are 
known as "baleen," and from them the "whalebone" of commerce is furnished. They are from two to three hundred in number, and the central ones sometimes attain a length of seventeen feet. The inside edges of these plates are found to be the longest, and if these are carefully examined it will be observed that they are "frayed out, as it were, into a close fringe of detached fibres of whalebone. As the Whale shoots through the water with the large mouth widely open, a large quantity of the marine molluscs and crustaceans before mentioned are taken in. When the mouth is now closed, the tongue, which resembles a lump of fat, and is firmly united to the floor of the mouth, is applied to the central part of the palate, which is devoid of baleen, and to the fringes of the baleen plates. In this way the water is forced out of the mouth, while the minute molluscs, crustaceans, etc., which have been caught in the fringes of the baleen are forced into the œsophagus. Anything left behind in this sieve is washed back by the next inflowing current of water."

We thus see that the mouth of this giant of the deep may be compared to a sort of huge bucket arrangement, and this accounts for the enormous size of the head and the length of the jaws. Indeed, the head is responsible for a quarter to one-third of the entire length of the body.

The reader has no doubt noticed the saliva which issues from the mouth of a Cow, or some other animal, but this is not present in the Whale, as the food being itself extremely slimy, salivary glands are unnecessary; and another feature of interest which may be referred to before passing on, is that "whilst in all other mammals the food passes above the larynx" (which on that account is provided with a lid), "in the Whale it passes around it, the larynx being firmly wedged into the lower nasal aperture" (in the throat). "This arrangement enables the Whale to breathe and swallow food simultaneously."

It is as well to recognize that little doubt exists as to the evolution of these giant beasts. They are in no way closely related to fishes, for they breathe, as we have seen, atmospheric air, and have no trace whatever of gills. Again, careful examination reveals traces of a one-time hairy covering-which is so characteristic a coat worn by mammals-and whilst it is difficult to accurately determine the terrestrial mammals most closely related to the Whales, it seems agreed by zoologists that they have derived their 


\section{I4 THE BOOK OF THE ANIMAL KINGDOM}

origin from terrestrial mammals, and are to be regarded as some of the most specialized of the creatures dealt with in this Book of the Animal Kingdom. It has been suggested by one eminent scientist that the Whales are most closely related to the Ungulates, "but," writes Mr. Lydekker, "the teeth of the earliest forms are quite unlike those of any Ungulates, and approximate much more closely to those of Carnivores. It may, therefore, be suggested that the alliance between Cetaceans and Carnivores may prove to be closer than is often considered to be the case." There are more species possessing teeth than there are without them, and these teeth are "of a simply conical or compressed form; and in many of the Dolphins they are much more numerous than in any other mammals." In the toothless species-as the Greenland so far under consideration - the place of the teeth is occupied by the horny plates called "baleen," as already described, but when young, even these toothless IVhales are found to possess rudiments of teeth situate low down in the gums.

It will be readily conceded that great difficulty must be experienced in studying the habits of these giants of the deep, for, excepting when coming to the surface to take in a fresh supply of air, or gambolling in the water as previously referred to, no amount of continuous observation is possible, and were it not for the experiences of those who have been engaged in the whaling trade, our knowledge-poor as it undoubtedly is-would be far less than at present. When we come to consider the build of the mammalian monarch, then it is that we are able to ascertain how it is possible for it to live, but to find out some of the many hidden secrets of its home life is the intense wish of those who take an intelligent interest and delight in the world's animals and their ways.

Occasional glimpses are, it is true, obtained by seafarers of the Cetacean during some of its more interesting movements, especially when it has young. The mother Whale is, we are told, a most solicitous parent, and shelters her young in a most pathetic way. She is neither a coward nor a giant brute devoid of maternal cares, and her solicitude for her young one has been touchingly described by the few reliable persons who have had the good fortune to watch her when she has had a baby under her care.

When one of these mighty denizens of the deep does happen to lose its bearings, as it were, and become stranded, the huge form of the animal is sure to arrest attention, but is a matter of much 
concern for the public authorities upon whose land the Whale is cast. For example, a large Whale of the Rorqual species became stranded at Cloughton Wyke, six miles north of the fashionable watering-place of Scarborough, Yorkshire, as recently as March of the present year (I9I0). When first discovered it was still alive, but soon succumbed. It measured, I am told, fifty feet in length, seven feet in depth and nine feet across. It was estimated to turn the scale at not less than seventy tons, but as it was not a fullgrown individual it will be seen that an adult beast would measure and weigh a great deal more. In September I 900 another large Rorqual Whale was towed into Scarborough Bay, and this specimen measured seventy-three feet in length, and within recent years among other kinds which have been noted there are the Killer, or Grampus, and the Beluga, or White Whale, the latter being a very rare species in those waters.

A Whale, having become stranded on some sea-shore near any inhabited place, will very soon proclaim its presence in no uncertain way by the stench which its decaying hody will create, and hence the Board of Trade accepted the offer of a Cloughton farmer to cut up the carcass of the beast already referred to and bury it ten feet below the surface for the sum of $£_{2} 28$. Probably this farmer made something out of the deal when it is borne in mind that it would, when buried on his agricultural land, enrich the soil by way of manure; but a Bournemouth doctor who, in an unguarded moment, once purchased a stranded giant of the deep, bitterly repented his bargain, for he narrowly escaped prosecution by the sanitary authorities, and was eventually much out of pocket as a result of his ill-considered purchase.

It should be stated that all the members of the order Cetacea (Whales, Porpoises, and Dolphins) are carnivorous, with one single exception, and that is a kind of Dolphin which inhabits the large rivers of West Africa. The food of this animal is believed to be vegetable matter. Then again, it is important to point out that, whilst the small creatures mentioned earlier in this chapter constitute the food of several kinds of Cetaceans, and they are unable to swallow any large object, there is one species, i.e. the Killer, or Grampus, which preys upon Seals, but this is the "only member of the order which subsists on warm-blooded animals." It is the Greenland Whale which is unable to swallow even as small a fish as a herring. 


\section{THE BOOK OF THE ANIMAL KINGDOM}

Generally speaking, Whales are not ferocious creatures, although perhaps exception should be made in the case of the Killer, which exhibits a fierce disposition. They travel about for the most part in "schools," and among the smaller members (Porpoises and Dolphins) we find that, on occasions, a "school" will be comprised of several thousands of individuals.

It will be observed from what has already been written, there are two distinct groups of these marine animals, one consisting of the true, or Whalebone IVhales, in which there are no teeth, and the second comprising the Toothed Whales, which possess teeth, at any rate in the lower jaw. Beyond these distinguishing features there are others which are of such a distinct character that it is considered by one of our greatest authorities on this subject reasonable to suppose that "the IVhalebone and the Toothed IWhales have originated independently of one another from totally distinct groups of terrestrial mammals."

We may now consider the chief features of interest in regard to a few selected species of these animals, and having given a sketch of the life history and general structure of the Greenland Whale as a typical example of these monsters, it will not be necessary to repeat the points to which attention has already been directed when dealing individually with the different species hereafter.

Among the Right Whales the Greenland holds an honoured place, and having recently considered the claims of this species in some detail, we can, after pointing out that it occupies the foremost position among the members of the order Cetacea, and the genus Balæna, pass on to remark that although the Whale which inhabits the South Atlantic has been considered a distinct species from the one inhabiting the North Atlantic, a remark which also applies to the beasts found in the North and South Pacific, it is considered by competent authorities that all these forms are only local races of one widely distributed species. All these forms claim kinship with the Right IWhales, and it is also interesting to notice that fossil remains of some members of this genus have been discovered in England and also on the Continent.

PIGMY WHALE. - The Pigmy Whale-so called because it does not attain a length of more than twenty feet-need not detain us, as it is a rare species which is found in the seas round New Zealand, Australia and South America. This brings us to the Grev Whale. 
GREY WHALE.-This is the only species included in the genus to which it belongs, and it has acquired its name from the greyishblue colour of the skin. The female is the larger of the two sexes, attaining a length of from forty to forty-four feet, the male being several feet less. This species is not found away from the North Pacific, but from fossil remains that have been discovered it is considered probable it may in by-gone days have also been an inhabitant of the Atlantic Ocean. Perhaps more than any other Whale this species exhibits wonderful affection for its young, sheltering its offspring in a most solicitous and delightful way and defending the same with immense zeal. One often hears people who know little about such things talk of the migration of birds, for it is well known that during the Summer the fields, lanes and woods of England are tenanted by a feathered population which largely seeks more congenial climes when Autumn's lease has almost run out, and in a few instances (i.e. Cuckoo and Swift) even before the lease has commenced to lapse. Few seem to realize, however, that other animals besides birds undertake migration movements, but this is a mistake, as instances of this wonderful spirit of unrest are forthcoming among Mammals (including Whales), Fishes, Reptiles, Batrachians, Insects, etc. Thus the Grey Whale is found in southern latitudes when breeding, but, after rearing its young, it proceeds northwards to within the Arctic Circle, the progeny accompanying the parents.

HUMPBACK WHALE.-This species is called Humpback because of "the prominence on the back which carries the fin," but individuals vary as to this prominence, and it is not always a safe guide to follow for identification purposes. It has a large head, a short, deep body, and long flippers which attain a length of from ten to fourteen feet. The beast measures up to fifty feet, and is black on the upper parts, marbled with white underneath.

The Humpback enjoys a wide distribution, and although some amount of variation is exhibited in different individuals, these are all believed to be local races of one species. It appears to be both gregarious and solitary, enjoying life equally well under either condition, and is fond of carrying out its frolics "near extensive coasts or about the shores of islands, in all latitudes between the equator and the frozen oceans, both north and south."

The yield of oil from the Humpback is also subject to variation, for, whilst in some instances as much as seventy-five barrels has 


\section{I8 THE BOOK OF THE ANIMAL KINGDOM}

been forthcoming, in others eight or ten barrels, or even less, may be considered a good average.

FIN-WHALES, OR RORQUALS.-We are still among the Whalebone, or Toothless, Whales, but the last representatives of these species brings us to the Fin-Whales, or Rorquals. They are also known as Fin-Backs, or Razor-Backs, and there are four well-known kinds. All these are distinguished from the last species with which we made acquaintance by having a more elongated and slender form and smaller heads. The flippers, too, are shorter, and are narrow and pointed. These Rorquals are the commonest IVhales we have, and this is not difficult to account for when it is remembered that, in addition to being possessed of great speed and activity, the oil which they yield is comparatively small and the quality of their whalebone very inferior. As a consequence of this, the Rorquals have not been so relentlessly persecuted as some of their more valuable cousins. The incessant warfare waged against good oil and whalebone-producing species has, however, told its own tale, and of recent years both these Rorquals and the Humpback have been more sought after than heretofore.

Brief reference may be made to the four species included in this genus.

LESSER FIN-WHALE.-The smallest of the four is known as the Lesser Fin-Whale. It rarely attains a greater length than some thirty feet, and the general colour is greyish-black above and white below. This species may, however, be readily identified by means of the prominent broad white band on the upper outside surface of the flippers. It is a rare species in British waters, and appears to be most common on the shores of Norway. All the Fin-Whales, however, are of wide distribution, and "are found in nearly all seas except those of the Antarctic regions."

EDEN'S AND RUDOLPHI'S FIN-WHALES.-Eden's Fin-Whale is a rare species restricted to the seas of India, and need only be mentioned in passing, and Rudolphi's Fin- IThale is rarer still. This latter attains a length of about forty feet, or even more, and is bluish-black on the upper parts and white below. There are oblong spots of white above. Whilst the whalebone of the Lesser Fin-IVhale is white, that of this species is black. It is believed that Rudolphi's Whale feeds exclusively on small crustaceans and does not eat fish. It is a quick swimmer, and does not have to come to the surface to take in a fresh supply of air so frequently as some of its relatives, 
being able to remain in the vast recesses of the mighty deep for several hours at a stretch.

COMMON FIN-WHALE, OR RORQUAL.-The Common Fin-Whale, or Rorqual, is a much larger animal, as it grows to a length of sixty to seventy feet. It has an elongated body, fairly lengthy jaws, and long flippers. It is slate-grey on the upper parts and white beneath.

This is a common Cetacean, occurring in numbers "throughout the more northern seas of Europe, ranging as far as the 7 oth or 75 th parallels of latitude. It is likewise widely distributed in American waters, where it is commonly known as the Fin-Back ; and it appears that the so-called Southern Fin-Whale of New Zealand is not specifically separable."

SIBBALD'S FIN-WHALE.-The largest Rorqual of all is Sibbald's Fin-Whale, for this species attains a length of from seventy to eighty odd feet. Indeed, Mr. Lydekker says it enjoys the distinction of being the largest of living animals. In colour it is dark-greyishblue, spotted with white on the chest. The American whalers call this animal the "Sulphur Bottom," by reason of the "more or less marked yellowish tinge on the under surface of the body, which has given origin to the popular name."

Sibbald's Fin-Whale passes the Winter amid the storms of the wide open sea, a typical oceanic species during that season; but when the cares of parentage come upon it in the Spring, it migrates northwards and clings near the coast. The food is made up of crustaceans and fish, and although not exhibiting the daring of the Common Rorqual, it will follow a ship for several days at a stretch, and "is considered to be the fastest of all the larger Cetaceans.”

SPERM WHALE.-We now come to the Toothed Whales, and of these the Sperm Whale is the first representative. From none of the remaining species on our list is whalebone to be obtained, and beyond this these Toothed Whales are characterized by the possession of permanent teeth, at any rate in the bottom jaw. There are several other structural distinctions, but these need not detain us.

The Sperm Whale is a large beast which attains a length of from fifty to sixty feet, although the female is not much more than half the proportions of her mate. The Cachalot, as it is also called, has a tremendous head, and has from twenty to twenty-five teeth on each side of the lower jaw. It is difficult to accurately determine, 


\section{THE BOOK OF THE ANIMAL KINGDOM}

unless closely acquainted with this species, its exact form, for the head is characterized by "the great height and abrupt truncation of the enormous muzzle," giving the animal the appearance of having been chopped off, so to speak. The mouth is situated some way from the tip of the muzzle, and it is of large dimensions. The general colour is black or blackish-brown above, and silver-grey on the chest.

This Sperm Whale must be a remarkable ocean wanderer. It loves the warm open sea, but has been hunted so persistently that it has disappeared from many of its former haunts. As showing the great distance this species can travel, an instance is recorded of a specimen being killed in the Atlantic Ocean which it was ascertained had been harpooned in the Pacific.

Gregarious in habits the Sperm Whale not only displays much solicitude for the welfare of its own young, but this kinship is also apparent among the adult beasts. This solicitude is, it appears, restricted to the females, for we learn that young males are "far less chivalrous in disposition, and will at once leave a wounded companion to its fate." When the young Sperm Whale is born (there is usually only one, but two are sometimes produced), it measures, it is stated, from eleven to fourteen feet.

It is not intended to enter into an account of Whale-hunting in this book, for exhaustive descriptions of this industry may be found elsewhere, and it is not in keeping with the plan already adopted to set out in any lengthened manner the commercial uses of these mammals of the world. It is necessary to state, however, that of all the Cetaceans the Sperm Whale is the most sought after, as the sperm oil yielded by the thick layer of blubber with which the body is enveloped, and "the spermaceti contained in the cavity of the head," are of high commercial value, and, in addition, the product known as ambergris also comes from this animal. This ambergris is found floating in the sea, or waslied upon some shore, as the Sperm Whale casts it up when an accumulation of it has gathered in its intestines. It consists of the indigestible parts of various marine creatures that have been swallowed, and although in days gone by it was in request for medicinal purposes, it is used now only in the preparation of perfumes.

BOTTLENOSE-WHALE.-This Whale is, like the species last under notice, an inhabitant of the open sea, but, in spite of this, it is of no uncommon occurrence for it to be found stranded. It differs 


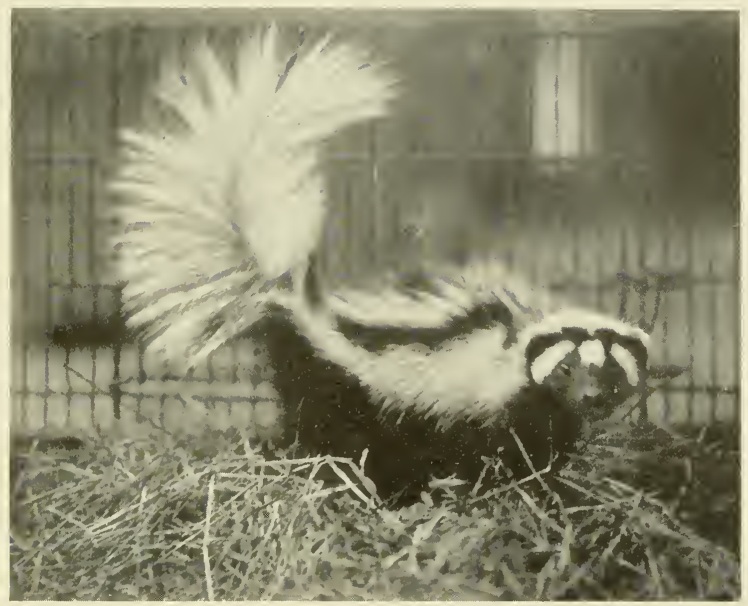

FIG. 250.-ZORILLA, OR CAPE POLECAT

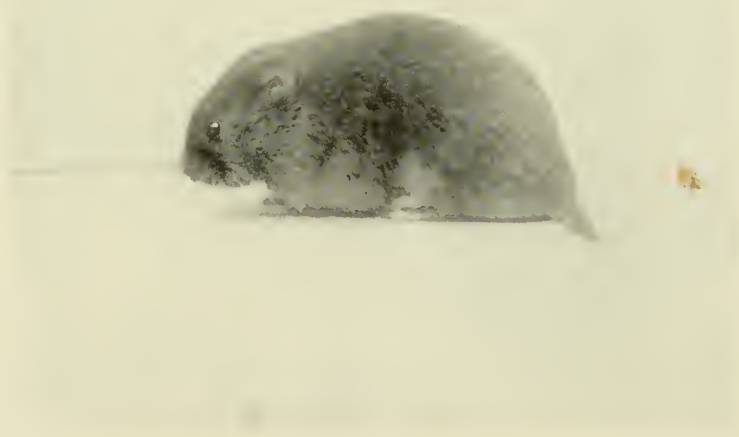

FIG. 25I.-ORKNEY VOLE 


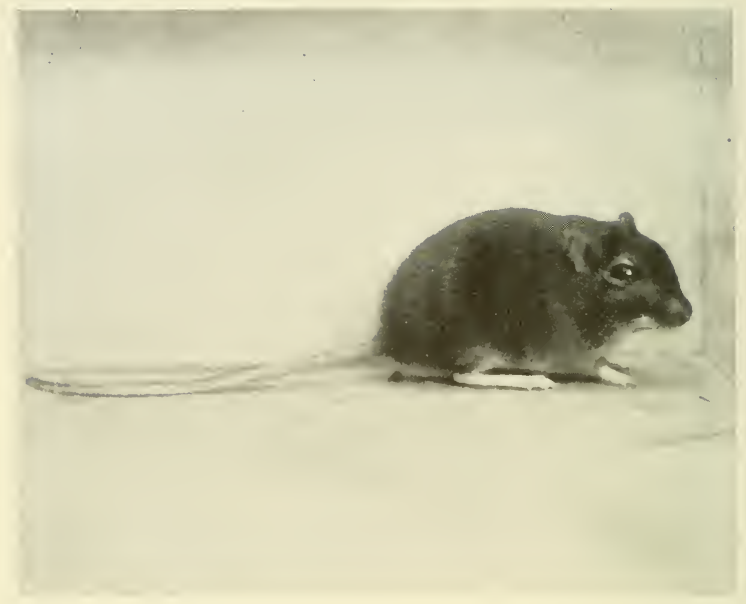

FIG. 252.-CAPE GERIBIL.

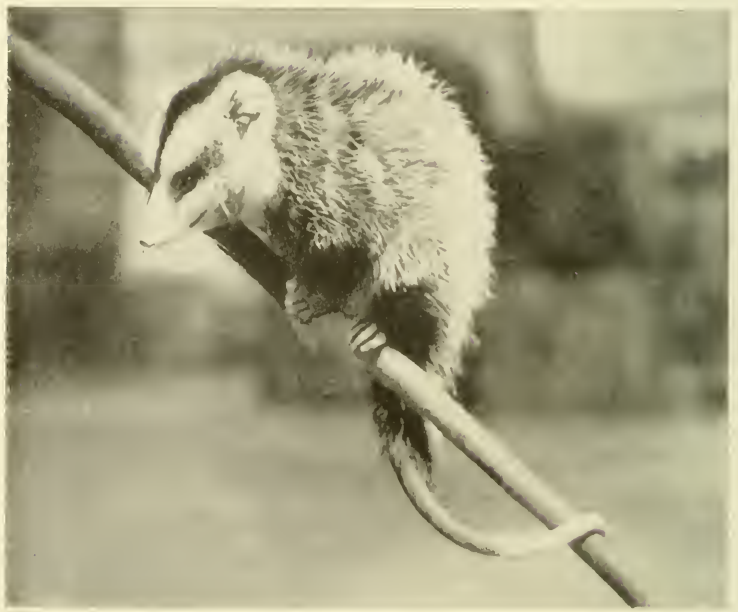

FIG. 253. CRAB-EATING OPOSSUM 
from the Sperm Whales in regard to the teeth, as in the Bottlenose there are only a single pair, and these are of large size. One species belonging to this genus, however, possesses two pairs of teeth. In front of the blowhole there is a prominent elevation caused by a sort of fatty cushion, and this accounts for the popular name accorded.

Squids and Cuttlefish are the common food of this Whale, and it inhabits the North Atlantic Ocean. Although it sometimes exhibits a solitary disposition, or travels about in pairs, at others "schools" of many individuals may be located. The female is the smaller of the two sexes, for whereas she attains a length of only some twenty to twenty-four feet, the male grows several feet longer. The adult is light-brown to yellow above and greyishwhite underneath, but the young are black on the upper parts.

Very tenacious, and exhibiting little fear of mankind, the Bottlenose is an active Whale, and has the power of leaping several feet out of the water. As they do this the head is turned round so that the giants may take their bearings, as it were, and, when descending, the water is re-entered head-first, "instead of falling helplessly on their sides like the larger Whales."

From this species oil similar to that obtained from the Sperm Whale is procured, as well as spermaceti, and it is stated that an adult male will yield two tons of oil, and some two hundredweight of spermaceti.

Cuvier's Whale-named after the great French naturalist-is a rare beast which need only be mentioned by name, and of the Beaked Whales we may select Sowerby's as the first representative.

SOWERBY'S WHALE. - The members of this genus (the Beaked Whales) have been accorded their English name by reason of the presence of long and narrow solid and ivory-like bone which is found on the skull and resembles a beak, whilst the scientific name has been acquired from a pair of teeth which are usually present not far from the centre of either side of the lower jaw. The ivory-like bones are of great density, and it is stated that they are probably the most substantial bones found among the Vertebrates.

This Whale was first discovered by Sowerby. off the Elgin coast in 1800 . It is not a large species, as it grows to only a length of about fifteen feet, and in colour appears to vary from bluish-slate to blackish-blue on the upper parts and light slate below. It resorts to northern seas, and, although the genus is represented in southern 
oceans, the species under review has not at present been found there.

LAYARD'S WHALE. - This Whale is a typical southerner, being found in the seas of the Southern Hemisphere, and is characterized by the possession of two large teeth which "become lengthened by continuous growth of the fangs into long curved tusks. These arch over the upper jaw or beak, and crossing one another above it at their tips, form a ring round it, and lock the lower jaw, so that the animal can only open its mouth for a very short distance indeed. The tusks are seen always to be worn away in front by the grating of the confined upper jaw against them. How the animal manages to feed itself under these conditions is a mystery."

It is stated by competent authorities that these remarkable teeth hamper rather than help Layard's Whale, and afford an instance of one of those curious developments in an animal which it is difficult to understand the meaning of. This is a very rare species, but is worth mention by reason of the growth of the teeth just alluded to.

ARMUX'S WHALE.--Before coming to the Porpoises and Dolphins brief reference may be made to Armux's Whale, which is an inhabitant of the seas round New Zealand. It is a larger beast than the last mentioned, attaining a length of some thirty feet, and is distinguished from its relatives by having two pairs of teeth which are situated close to the front part of the jaw.

FRESH-WATER DOLPHINS.-There are three species of these animals, and they are closely related to the true Dolphin to be considered towards the end of this section. They are small beasts, and whilst two are restricted to fresh water, the third is a tenant of estuaries. The best known of the three species is the Susu, or Gangetic Dolphin, which inhabits the Indus, Ganges, and Bramaputra Rivers of India. It attains a length of some seven or eight feet, perhaps more, and the female is larger than her mate. Curious to relate, this Dolphin is quite blind, and it has been suggested that in view of the turbid nature of the waters it frequents sight would be of little, if any, use to it. It is not particularly gregarious, although, on occasions, several individuals may be seen together, and those who are acquainted with the habits of these interesting creatures are able to locate them by means of the blowing noise they make when engaged in rising to breathe. This detection, however, is only possible when the water frequented is comparatively quiet in the cold 
weather, for when the rainy season comes on, and the rush of water is considerably increased, it is not possible to detect any sound.

The Gangetic Dolphin has a long snout, and with the aid of this it is able to probe among mud for food, this consisting of various kinds of fish and prawns. Only one young one is as a rule produced at a birth, and this takes place from Spring to Mid-Summer.

In the Amazon River of Brazil there is another species of FreshWater Dolphin which may be called the Amazonian Dolphin, but is known in South America as the Bonto, or Inia. Although the male grows to a length of some seven feet the female is about only half that size. The general colour is blackish above and reddish beneath.

Another species found tenanting the Amazon is known as the Tucuxi, and there is still a further one which is pale flesh-colour. Bates writes that "in the broader parts of the Amazon, from its mouth to a distance of fifteen hundred miles in the interior, one or other of the three kinds here mentioned are always heard rolling, blowing and snorting, especially at night, and these impressions contribute much to the impression of sea-wide vastness and desolation which haunts the traveller."

NARWHAL. - This remarkable species is at once recognized by the tremendous spirally-twisted tusk which projects from one side of the upper jaw of the male. It has been ascertained that this tusk is almost invariably situated on the left side, that on the right attaining a length of only a few inches. Those possessed by the female are quite rudimentary and are entirely hidden within the jawbone. The tusk of the male Narwhal is composed of ivory, and may attain a length of seven or eight feet.

This Dolphin, for such it is, has a blunt, rounded head; it has not a back fin, and has short, broad and rounded flippers. It is darkgrey on the upper parts and white below, whilst the back and sides have irregular mottlings of grey of various shades. With the tusk, the male measures some twelve to sixteen feet. The Narwhal is an inhabitant of cold seas, and, similar to the Greenland Whale, "is circumpolar in its distribution." It has been subjected to considerable persecution, and, in consequence, has been much reduced in numbers. In spite of this, large "schools" are sometimes located by those who visit its haunts, the species being generally gregarious. From it oil and ivory are obtained, and the former is of excellent quality.

WHITE WHALE, OR BELUGA.-This animal is first cousin to the 


\section{THE BOOK OF THE ANIMAL KINGDOM}

Narwhal, and like it is an inhabitant of the cold seas of the Arctic regions. It does not possess a back fin, a ridge alone indicating the position such would occupy were it present. It grows to a length of about sixteen feet, and is of a bright white colour; the young, however, are brownish-grey.

The Beluga is fond of ascending rivers, and when it is located is found in considerable numbers. It is a timorous beast of the sea, for on the slightest alarm it will take the precaution to dive below, where, under shelter of the mighty deep, it is secure from enemies. It is quick of movement, and when fishing exhibits an adroitness delightful to notice. The prey appears to consist chiefly of flounders, halibut, cuttles and crustaceans.

Not only is the Beluga prized for the oil yielded by the blubber, for its flesh is much relished, and its glistening white unmarked hide serves as a fine trophy for the huntsman. The inhabitants of the North (the Eskimos) value its flesh not only for their own use, but also wherewith to feed their indispensable dogs.

COMMON PORPOISE-Excepting when seen stranded, or on exhibition, few people have had the good fortune to observe a living Cetacean, unless, indeed, it be the species now under consideration. In European seas the Common Porpoise may often be seen, and the appearance of a shoal of the marine beasts, or the capture of one by some local fishermen, is sure to arrest attention. The fisherman detests this creature, as it has a nasty habit of tearing his nets, and is regarded by him in no respectful manner. After capture, the Porpoise will perhaps be brought ashore with the rest of the catch, and exhibited to visitors for the purpose of bringing in a few stray pennies, but beyond this the carcass is considered of little service.

The small, barrel-shaped body of the Porpoise is well known, and, like nearly all the animals described in this section, it has two distinct colours on the upper and under parts, the coloration above being dark-slate or blackish and silvery-white below. The beach boys call it the "Porpus-Pig," and, anxious to make hay whilst the sun shines, pester visitors with continual entreaties to have a penny peep at the dead beast.

Shoals of these animals may often be observed from the shore, and, when gambolling in the water, the sight is a very pleasant one, for, with the exception of observing the inevitable Gulls and prying into rock-pools-where such abound-few visitors to the 
seaside appear to take any intelligent interest in the wild life that may be observed for the searching. I have long made a practice of seeing as much as I possibly can during my pilgrimages by the sea, and it adds a zest to one's holiday to gather as much information as possible of the fauna and flora of a strange neighbourhood. Lists may be made of the different kinds of animals and plants that come under observation, and in after years it is useful and interesting to compare these local lists, and, moreover, one is able, as a result of compiling them, to answer queries respecting some portion of our island home, and perchance put a kindred spirit on the track of some animal or plant with which he or she desires to make acquaintance.

To return to the Common Porpoise after this digression; it attains a length of some five feet, and frequents the North Atlantic and North Pacific Oceans, the North Sea and the coasts of Europe. It is an active, and, indeed, elegantly mobile beast when seen pursuing its movements in the water, turning and twisting in a most engaging way, showing as it does so now the dark upper parts and now the pure white belly. It simply revels in the sea, and when a company are engaged at play their antics cannot fail to arrest attention. It feeds entirely upon fish, and the fishermen also fall foul of this animal because of this, such fish as herrings, mackerel and pilchards being much sought after by this Cetacean.

Only one young is born, and this happens some time during the Summer months.

It must not be supposed that because the fisherman discards the body of the Porpoise that it is of no commercial value, as oil is obtained from it and the skin is also of service. In days gone by the flesh also of the animal was esteemed in England. The body of one individual yields about three gallons of oil, but it is necessary to capture a great many of them before it is worth while making raids upon them.

INDIAN PORPOISE, AND OTHERS.-The Indian Porpoise is distinguished from the Common species by the absence of the backfin, and it does not possess so many teeth. It is also a smaller animal, measuring only some four feet and is black all over. It is an inhabitant of shallow water, and is said to be of a sluggish disposition.

Passing by Heaviside's Dolphin, which resides in the sea near the Cape of Good Hope, and the Irawadi Dolphin, which is a large 


\section{THE BOOK OF THE ANIMAL KINGDOM}

species frequenting the river of that name, we come to the largest and most ferocious of all the Dolphin family.

KILLER, OR GRAMPUS.-This large species is black above and whitish beneath, and attains a length of as much as twenty feet or more. Above and behind the eye there is a prominent streak of white. The Killer has a remarkable distribution, "ranging from Greenland in the north to the coasts of Australia in the south." It is an inhabitant for the most part of open seas, but is not averse to ascending tidal rivers, for not many years ago three of these Dolphins were seen in the Thames, almost within a stone's throw of the very heart of the greatest city in the world.

Fish, Seals, and even relatives of their own order, constitute the food, and in procuring the same the Killer-by name and nature it is such-exhibits a great daring, as befits its "carnivorous propensities." They travel about in little companies, or squads, and have been compared to a small regiment of soldiers disporting in the water, for their movements are stated to present "a pleasing and somewhat military aspect."

The Killer is possessed of great power of movement and has no difficulty in catching up with and overtaking its prey, swallowing the smaller Dolphins alive without even taking the trouble to kill them. As showing what a ravenous beast this is, an instance is recorded of one animal being known to swallow four Porpoises one after the other, and "from the stomach of another individual, whose length did not exceed sixteen feet, were taken fourteen Seals."

Union being strength, the Killer will, when assisted by its fellows, even attack the Greenland Whale, of which a full account has already been given at the commencement of this chapter, and, wonderful to relate, the largest mammalian monarch of the deep, and, indeed, in the world, seems powerless to defend itself against the attacks of these military pirates of the sea. It has been described as a ITolf of the ocean, and its attacks "may be likened in some respects to a pack of Hounds holding a stricken Deer at bay."

There is a smaller species belonging to a different genus, known as the Lesser Killer, which also enjoys a cosmopolitan range. It grows to a length of some fourteen feet, and its habits are believed to be similar to those of the remarkable beast just described.

As this book does not pretend to be scientific or to treat of every known mammal, but merely to give a bird's-eye view of a selection 
of them, many species of Cetaceans as well as other mammals must of necessity be passed by, and if the reader is desirous of following up the subject further, some standard work should be consulted. Before bringing this chapter to a close, however, it may be stated that there are various kinds of Short and Long Beaked Dolphins, Bottlenosed Dolphins, and Rough-Toothed Dolphins. With these it is not intended, nor is it possible, to deal, but before passing on to consider the claims of some mammals of the air reference may be made to the Common Dolphin (Delphinus delphis) which represents the true Dolphins belonging to the genus Delphinus.

COMMON DOLPHIN.-This species inhabits both cold and warm seas. It has a long narrow beak-as indeed have all the forms included in the genus - a number of sharply-pointed teeth, a small head and slender body. The flippers are long and pointed, and the usual colour of the body is dark-grey, with white or whitish underneath. The Common Dolphin measures up to seven or seven and a half feet in length. It is a sociable beast like so many of its relatives, and is full of activity and playfulness. It appears to delight in following a ship, and affords considerable pleasure to passengers who are glad of having the monotony of a long voyage relieved by watching the manœuvres of these children of the sea.

The food is made up of various kinds of fish, but some of the other species of the true Dolphins partake also of both crustaceans and molluscs.

Only one young is born, but this single offspring is, it is pleasant to notice, tended with loving solicitude, and thus this creature resembles some of its larger relatives described at an earlier stage in this section of our work.

True enough, this chapter deals for the most part with the animals whose claims for inclusion among "Giants of the Deep" could not be disputed, but other members of the same great order of mammals are included whose claims to be designated "Giants" are not worthy of consideration. Yet it has been thought best not to ostracize these from the rest, and, as has been remarked elsewhere, some amount of latitude must be allowed in a book which purports to set out in a popular way a general survey of some of the more interesting mammals of land and sea. 


\section{CHAPTER XVIII \\ MAMMALS OF THE AIR}

CHIEF FEATURES OF BATS.-The mammals which we now have to consider are not only difficult to observe in their home life-and thus somewhat resemble the beasts under review in the last sectionbut very peculiar notions exist as to their construction, their life and habits, and the place they occupy in the economy of Nature. Thus, before proceeding to describe a few of the more noteworthy species, it will be as well to pay attention to several general features of interest concerning them.

These mammals of the air, as we may call them, are either insect or fruit eaters, and day or night fliers. Some of them are both diurnal and nocturnal, for the commonest British species-the Pipistrelle-may often be seen out and about at midday as well as at night.

The lives of these remarkable creatures are spent either in flight, resting or hibernation, and when we come to examine them we find that they are perfectly adapted to their mode of life and habits. They differ from all other mammals in being able to fly, and hence it comes about that their bodies are constructed in many ways quite differently from those of all the animals already treated of in this book. The Bat possesses a flying membrane which extends between the lengthy fore-limbs and the short hind-limbs, and by means of this and the tail, flight is made possible. When not in flight this membrane is closed up something like the folds of an umbrella, but when unfolded the animal rests in the air upon a very large surface. This, however, is not sufficient in itself to enable the body to be propelled through the air, and the Bat has to resort to a continuous downward movement of the fore-limbs, "each depression of these limbs bringing in its train a condensation of the atmosphere. The larger the flying membrane, the more easily will the animal be able to support itself in the air, and the more rapidly will it be able to progress. Hence the strikingly large size of the flying membrane." Then again, the bones of the arm act after the manner of the ribs 
of an umbrella by keeping stretched out during flight that portion of the membrane which projects beyond the lower arm. The thumbs and feet are not enclosed within the membrane, and consequently are not increased in length. The reason for this will be ascertained later on.

A further important part of the anatomy is a bony process known as the spur which is found from the heel backwards, and this spur, it is interesting to notice, does not occur in any other mammal. It serves as a support for that part of the flying membrane situate between the legs and the tail. The membrane is of great elasticity, and as it is highly important for a man-made machine to be well and regularly oiled in order that it may run smoothly, so it is essential that the Bat should be able to maintain the membrane in an elastic condition. Such being the case, the animal is able, by means of fat which is secreted in special glands situated between the nose and eyes, to lubricate the membrane on each occasion a flight is about to be taken.

Having to undergo much endurance upon the wing in order that at any rate the insectivorous species may procure the necessaries of life, it is essential that the muscles of the Bat should be of great strength, and this we find to be the case, for it has "very powerful thoracic muscles which are attached to remarkably large shoulderblades and to a high bony crest developed along the median line of the sternum, which thus presents arrangements very similar to those which obtain in birds." There is, however, this distinguishing characteristic: whilst the bones of birds are hollow, or, as one might say, pneumatic, like the tyres of the modern bicycle, those of the Bat are not hollow, but, excepting the bones of the shoulderblades and clavicles, are very thin and yet quite rigid. There are no air-sacs within the body cavity as in birds, so that the Bat has to rely upon other means whereby the weight of the body is diminished, whilst the surface which goes to support the body is much larger in the winged mammal than in the case of the bird. The supporting surface in a bird is formed by the wings and the feathers borne upon them, but in a Bat it extends beyond the legs to the tail.

Whilst, as is well known, the Bat possesses a remarkable flight, it is not able to carry out the same wonderful evolutions in the air as its companionable rivals just referred to. The flight of the mammal is mostly jerky. It cannot poise or soar like the Skylark, 
for example, yet it can dip down and swoop in an uncertain, hesitating way, as those who have watched it can well testify. The Bat must of necessity be continually using its flying membrane when engaged in flight, as it is only by this means that it prevents itself from falling, and if it does happen to come to ground it is not easy for it to rise again, and reminds one of the Swift among birds in this respect.

Yet the mammal we have under review is possessed of wonderful powers of endurance upon the wing; indeed, it is because it has to constantly keep its flight organs in full working order that its endurance is so marked. It cannot temporarily check its progress through the air like the Kingfisher, for instance, which, when dashing like a feathered meteor down stream, can pull itself up suddenly and, without any apparent discomfiture, hover over the surface of the water more like a large tropical Butterfly than a bird.

Neither can the Bat free-wheel in the air with the amazing cleverness and great delicacy of movement exhibited by the Ring Dove, nor sweep along and upwards with the dexterity of the Swallow. The tail of the mammal, however, ably assists it and acts as a rudder. By means of it the animal is able to execute rapid turns when flying, and in many ways exhibit when in the air active and nimble movements which cannot fail to be noticed.

In the construction of the limbs, however, it will be found upon examination that the Bat is well adapted for executing other movements that its mode of life demands. By means of them it can both creep and climb, and the claw-shaped thumb enables it to hook itself on to the ground or other solid object. When upon the ground the Bat shambles along and reminds one of a decrepit old man more than anything else, the body being pushed forward with its feet. This, it will be recognized, would not be possible if the thumb and feet were included in the flying membrane. The claw-like thumb and feet enable the creature to climb up trees, posts, walls, or other objects, and then, having ascended, it is able, by flinging its body into the air, to pursue its aerial movements. It is for this reason, too, that a Bat, when resting, is always found suspended head downwards, for, if it drops, it can immediately expand the flying membrane. The feet are very slender, but, in spite of this, the animal is able to secure a firm hold of the support to which it becomes attached, so much so that during the period of hibernation it is able to keep its position for some months at a stretch. 
During the daytime most Bats at any rate devote their time to slumber, resting so that at the gloaming hour they may come forth from their hiding-places in a fresh condition ready to pursue their prey during the silent watches of the night. The insectivorous species prey upon such creatures as moths, beetles, flies, gnats and other insects, and I have observed with interest that the Long-Eared Bat has a partiality for the Stag Beetle and of partaking of its meals in a favourite habitat. One individual over which I kept careful watch resorted at nightfall to the porch of a house for feeding purposes, and every morning the ground was strewn with the discarded wings of moths which had been captured during the night.

The eyes are not developed to any appreciable extent, and consequently the sight powers are not great, but the senses of touch and hearing are very remarkable. It is said that so acute is the sense of touch that even the vibrations of the air generated by the strokes of their flying membranes and reflected by surrounding objects is responsible for the instance which has often been alluded to of a Bat having been known to fly in a room from which threads were extended without ever coming into contact with one of them. And this in spite of the fact that the animal's eyes had been covered over with sticking-plaster! Dr. Schmeil says that "the fineness of the threads in the above experiment itself shows how faint such vibrations must be. In the same way the animal becomes sensible of the faint air vibrations generated by a flying insect. It feels its prey, as it were, from afar." It differs entirely from insect-eating birds in this respect, for the Spotted Flycatcher, adept as he is, must first see his prey before catching it.

Has the reader ever heard a Bat utter any sound? The probability is that the reply is in the negative, and this leads one to observe that the sense of hearing in the Bat is wonderfully acute, for the voice is so fine and high-pitched that many, if not most, people are unable to hear it at all. Yet the Bat itself must be well able to distinguish quiet sounds, and we are told that "the large pinnæ, which are movable and capable of being laid back, in fact, represent ear-trumpets. At the commencement of the aerial voyage they are erected, and probably enable the animal to hear sounds inaudible to human ears, such as the flight of a moth, more especially as the animal itself moves without sound." This reminds one of the keen powers of hearing exhibited by the Cat and the Owl, yet the mammal and bird named are themselves 
capable of moving without creating any sound audible to a human being.

As it catches its food upon the wing it is necessary that the Bat should have a wide-cleft mouth. Such it possesses, and thus reminds us of the wide aperture of the Nightjar (which feeds upon very similar creatures to the Bat, and is a nocturnal bird), and also the more familiar Swallow.

The sharp, needle-like teeth of the Bat enable it to bore through the outer covering of its prey, and it uses its teeth only for biting and boring, gnawing and grinding being unnecessary. The short neck is in keeping with the other structure of the body, as a long neck would be of no service in view of the fact that when upon the wing it is an easy matter for the head and body to be turned together in any desired direction.

Unlike birds, the Bat is unable to undertake a perilous journey over land and sea, hence at the approach of Winter it does not migrate to a warmer climate where an abundant food supply would also be procurable, although it is stated that one species in North America does migrate to warmer climes. Thus, when the chill of Autumn is Lpon us, the Bat adopts the habit of hibernating, and for this purpose it selects a hiding-place where it may be secure for the Winter. In such a snug retreat as a cave, roof of a house or barn, chimney, hollow tree, quarry, cellar or among ruins, this mammal seeks out a congenial spot where it may rest during the cold weather, and large numbers of them may very often be found hibernating together, hanging up by their feet, unconscious, stiff and motionless. Dr. Schmeil states that when in this condition the pulse only beats about once every three minutes, and the respirations are rare and hardly perceptible.

It is essential, of course, that while in this comatose state the Bat should be guarded against sinking below a certain minimum of body heat, and this is provided against by means of the uncommonly thick, heavy covering of the body, and also the flying membrane, which, by enfolding the body similar to a mantle, "likewise forms a protection against an excessive loss of body heat, since the air enclosed within it acts as a bad conductor of heat."

During the time it is out and about the Bat stores up within its body a supply of fat which stands it in good stead when it is necessary for it to go into temporary retirement, for "although during its Winter sleep the Bat is suspended like a corpse, life is by no means 
extinct in the interior of the body. The lungs, the heart and the other organs continue their work slowly but uninterruptedly." Thus it is essential that, even with this small amount of work, the combustion of food material must take place. Hence the superabundance of its food during the mild seasons is stored up, and "this fat by degrees enters the circulation, and is conducted thence to all the organs in which it undergoes combustion. In this manner the needful quantities of heat and force are continually produced afresh, so that, though the animal machine works slowly, it is not brought to a standstill."

Bats, being insect or fruit eaters, are naturally enough found only in those countries where an abundant food supply is forthcoming. Consequently their distribution in the world is rendered explicable from their mode of life. In a very cold country, where insect life is at a discount, it is obvious that this flying mammal would, if it inhabited it, have a sorry time, for, in view of the long Winter and the extreme cold, it would undoubtedly perish from want of food or loss of heat-would, in fact, either starve or freeze. In spite of this we are told that at least one species is found within the Arctic Circle.

These creatures have for long been regarded with superstition and, indeed, dread by many country people. These latter call them Flitter Mice, and having done that their practical acquaintance with them begins and ends. Owing to their noiseless flight and nocturnal exploits, these harmless beasts were, once upon a time, looked upon as evil spirits, and two stupid notions which are hardly worth giving further publicity to, are that they eat up the bacon in the larder and sometimes entwine themselves in the hair of people.

That Bats are beneficial animals goes without saying. They perform useful work in the economy of Nature, and the insectivorous species take up at nightfall the good deeds carried out by insecteating birds during the day. It has been conclusively proved that Bats in feeding, for instance, upon a certain kind of moth, known as the Processional Moth, do inestimable good, for in Germany at the beginning of the nineteenth century "a large number of oaktrees were cut down in the neighbourhood of Hanau, in the hollow trunks and branches of which thousands of Bats were found in the hibernating condition. In sawing and splitting up these trees many of the animals perished from the cold, many were killed 
wantonly. The result was a marked and rapid increase in the larvæ of the Processional Moth, which latter had been hitherto for the most part destroyed by the Bats. From that time onwards these insect pests increased to such a degree, that in the course of the following years first all the oaks, and afterwards also many other trees, for miles around, were exterminated."

And what enemies has the Bat? It does not appear to possess many, because of its being nocturnal and continually on the wing when away from its hiding-place, and also by reason of the inaccessibility of its retreat. Another member of the nocturnal police force, the Owl, will pounce upon a Bat when on the wing, and it is stated that the Marten, Polecat, Weasel, and Cat will do so while it is at rest. A Dog, however, does not care to touch it. In addition to their usefulness as insect-eaters, Bats are of service to man and bring him considerable wealth where they congregate in any large numbers, for, when such is the case, guano or excrement is found in great quantity.

This is especially so in the guano caves of San Antonio in Texas, but the valuable excretion has also been located in other countries such as Italy, France and the Pyrenees. It will naturally be concluded that to be found in a marketable quantity a tremendous number of Bats must be congregated in the cave frequented, and we are told that the number of animals in the largest cave is enormous. Mr. Protheroe says that "when evening comes it is a wonderful sight to see them issue forth from the mouth of the cave in a dark stream, like a moving cloud, for quite two hours, with a noise of whirring wings which sounds like a gale of wind. The sight is wonderfully interesting, but the stench from the creatures is almost unbearable. The supply of guano is naturally not inexhaustible. When the guano has been taken from a cave it is closed for a period of four years, by which time there is another deposit well worth removal."

There are more than four hundred and fifty different species of Bats known to science, and probably many more remain to be discovered. One, or at most two, young are produced during the Summer. It would serve no good purpose in a popular work of this description to set out reiterated details of a large number of species, as they are more or less alike in their general characteristics, and a few typical kinds need only be mentioned. Before coming to these, however, it will be as well to state that, except in cold 
countries, Bats are found. They have a wide distribution, but are most numerous and attain their greatest size in the Eastern tropics.

They are divided into two groups, Insect-Eaters and FruitEaters. Those coming under the first named are the species found in Europe, "and most of those of America, as well as portions of Asia and Africa," and the fruitarians are mostly inhabitants of the south-east of Asia.

KALONG. - Among the Fruit Bats we find the largest members of the order Chiroptera, meaning "hand-winged" animals, and these are generally known to many people as Flying Foxes. The Kalong of Java is an immense Bat, for its wings when spread out measure almost five feet across, and it has been compared for size of body with that of the Common Rook. In spite of its size this species has a perfectly noiseless flight, and as Mr. Protheroe has well said, "it is a wise arrangement of the Creator that gives muffled wings to all night-flying creatures, whether Birds, Moths, or Bats."

These Fruit Bats-indeed, most kinds of these flying mammals - are of gregarious disposition, living in large companies, and when a horde of these beasts of the air come forth from their hiding-places and commence feeding upon soft fruits, such as figs and bananas, it may well be imagined that it does not take long for considerable damage to be perpetrated. So that against the real good deeds of the insectivorous species, we have to place the misdeeds of the frugivorous kinds. It must be remembered, however, that the Kalong at any rate does not disdain lizards and small birds, and helps by partaking of these to preserve the balance of Nature.

With a long pointed muzzle and large full eyes (for a Bat), the Kalong has a somewhat Fox or Dog-like appearance about the head. It belongs to those kinds of Bats which, unlike the majority of their fellows, are not distasteful of light, for we find that, instead of hiding their bodies in dark places, like the species known by sight to most people, these Fruit Bats suspend their bodies from the summits of tall trees. When sleeping an anchorage is obtained by hanging on to a bough with one foot only, the second one being tucked away underneath the wing. It seems curious why this should be, for although, as has been well stated, "the Goose sleeps upon one leg lest upon some frosty night it may get frozen hard and fast to the ice," it seems difficult to account for any kind of Bat carrying out such a practice when a double anchorage would make it more secure in the dizzy heights it frequents. 


\section{THE BOOK OF THE ANIMAL KINGDOM}

VAMPIRE BAT.-Short reference may be made to the Vampire Bat, for in olden days this and other species were the objects of superstitious dread. This Vampire Bat belongs to the Leaf-Mouth or Spectre Bats, and when seen flying about silently it is perhaps small wonder that these Vampires of the air should have become associated with evil designs and foul deeds. We do not now live in such a superstitious age-although it is remarkable to notice how old customs and habits are still observed in remote country districts -and seem more concerned in seeking for the truth and endeavouring to learn about the real home life of these creatures of the wild, whether of air, land or sea.

The Vampire Bat is not so large as the Kalong, as the wingstretch does not exceed some two and a half feet. Yet it is the largest of its family, and by no means a small species when compared with some of the common kinds known to us. It has no tail, and thus resembles its other fruit-eating relatives, for, as insects are not captured, it is not so essential that the powers of flight should be so rapid or exact, and whilst it seems agreed that it is for the most part a fruitarian, there is every reason to believe that it has some first cousins who are not so easily satisfied with a fruit diet, but who "are in the habit of sucking the blood from the bodies of the larger mammals, not excluding man, while the victim is asleep."

That the Vampire Bat is well calculated to be able to do this is proved by an examination of its teeth, for these are very sharppointed and "so placed as to make a triple puncture like the bite of a leech."

LONG-EARED BAT.-This well-named species represents, with the Pipistrelle next to be described, the Insect-Eaters among these mammals of the air. It is sometimes called the Rabbit-Eared Bat, the large ears being somewhat like a miniature edition of those possessed by the well-known rodent. When a large Bat is seen in England it is usually this species, for it is fairly well distributed in our country, and outside it is found in various other parts of Europe as well as Northern Africa and Central and Western Asia. Compared with the one or two Fruit-Eaters with which we have already made brief acquaintance, the Long-Eared Bat is quite a pigmy, for it only measures about four inches if the tail be included, whilst the wing-structure is a little more than one foot. The large ears form the most characteristic feature of this species, and as the 
mammal pursues its airy course it will be seen, if carefully watched, to move its ears backwards and forwards as if the beast were eagerly trying to catch the slightest sound. And when flight is over and rest is needed, the Bat retires to its chosen habitat and hangs head downwards at peace with all the world, but before it passes into slumberland it takes the precaution to fold up its ears, and displays, when doing so, a care which one exhibits when putting away a dress suit!

Catch the Long-Eared Bat asleep and you will probably be surprised to find that it looks a different animal when thus seen. Look at its head! The long ears are gracefully folded up, but what is that small appendage? That is the inner lobe, or tragus as it is called, and you may well be excused if you imagine that this species is possessed of two pairs of ears, an outer and an inner pair.

These insect-eating Bats are very voracious feeders, and in a season when we are threatened with a plague of insect denizens they perform an immense amount of good, and blessed be their appetites at such times.

Brief reference may be made to the Greater and Lesser Horseshoe Bats, which are so called because they have what is known as a nose-leaf in the form of a horseshoe, and to the fact that whilst British Bats are dull coloured there are species which inhabit other climes whose fur is beautifully coloured, and those examples of the large Fruit Bat that I have seen in collections have been most attractive by reason of the brilliant orange-yellow upon the belly. These captive Bats are seen to little advantage, for they rarely take to flight, stretching a wing occasionally and giving one an idea of their immense wing-stretch, but that is all. Anchored towards the top of their cage, there they remain day in and day out and look strangely out of place when it is known that flight to them at any rate has been made impossible.

PIPISTRELLE.-Last among the few kinds of Bats that it has been found possible to notice is the Pipistrelle, and this little species deserves inclusion because it is the commonest British Bat and the smallest we possess, being comparable in size to the Common House Mouse, and resembling that little rodent in more ways than one.

It is not so fond of sleep nor of the hours of darkness as some of its relatives, as it hibernates for only some three months out 


\section{$33^{8}$ THE BOOK OF THE ANIMAL KINGDOM}

of the twelve, and may often be seen flying about during the daytime. Then is a good opportunity to carefully watch its fly-catching manœuvres, and a good idea may at such time be gained of its remarkable powers to which attention has already been drawn earlier in this chapter.

The colour of the fur and the ears of the Pipistrelle resemble those of a Mouse, and the old country people who still persist in calling this little Bat the "Flitter Mouse," may well be excused for confusing it with a flying edition of the cheeky rodent which has such a nasty habit of nibbling at the cheese or finding out where the bacon is kept in the larder !

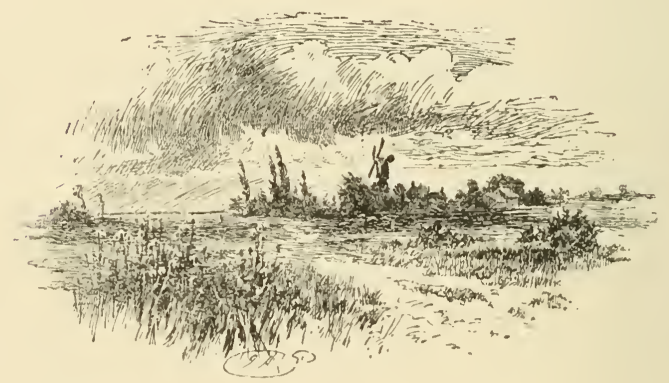




\section{CHAPTER XIX}

\section{ANIMALS OF LONG AGO}

THE STORY OF THE EARTH.--Extinct animals, of whose appearance and general characters we learn from fossil remains preserved in the strata of the earth, are no less interesting than existing species; indeed, they are a most fascinating subject of investigation and study. Unfortunately the vicissitudes of time and accident have completely destroyed myriads of life-forms which existed in past ages, but the remains which have been preserved in the various stratified rocks of the world are sufficiently numerous and varied to enable us to understand that for vast ages the earth has been populated by teeming multitudes of curious creatures. Some kinds of creatures have persisted through long ages of geological time, and we still have their living descendants with us; many of these have preserved the characteristics of their kind from a very remote period, while others have undergone various modifications in order to meet changed circumstances, and to secure victory in the ceaseless struggle for existence.

In this chapter an attempt is made to give the reader some description of a few out of the many extinct animals of which remains have been found in such quantity and state of preservation to enable skilful anatomists to reconstruct their skeletons and give a very fair idea of their original appearance and habits. It is not the writer's intention, nor is it within the scope of this volume to present an elaborate and detailed thesis on the subject. In fact it is hoped that these altogether inadequate lines will stimulate the reader to investigate the subject for himself by a careful perusal of such books as Extinct Monsters and Creatures of Other Days, by the Rev. H. N. Hutchinson; Extinct Animals, by Sir E. Ray Lankester, as well as numerous other books of a more technical character. The knowledge and pleasure gained from such a study will amply repay the effort involved.

Extinct animals, of course, are such as do not exist to-day; they 


\section{THE BOOK OF THE ANIMAL KINGDOM}

are kinds of life-forms which, in the procession of life, have fallen out by the way and perished. Their remains, as found in the earth's strata, are known as fossils (literally, something dug up). The study of these remains, or fossils, is called Palæontology, which means the science of ancient life.

It must be borne in mind that our earth is very old and has been inhabited by living creatures of various kinds for æoons. Man is quite a recent arrival, and has been fittingly called "the crown of creation." The first living forms were characterized by simplicity of organization, and as the world has grown older there has been a remarkable succession of life-forms, exhibiting more and more elaborate developments. The simplest life-forms are found in the oldest sedimentary rocks, and as strata have succeeded strata so have the creatures peculiar to them betrayed variations and greater complexity.

Generally speaking, there are two kinds of rocks which enter into the composition of the earth as we know it to-day-the igneous, or fire-formed rocks, and the sedimentary or deposited rocks. The sedimentary rocks are made up in their first origin of the wear and tear of igneous rocks, and have been deposited in the form of mud and sand; they also consist of limestones which in some instances have been chemically precipitated, but in most cases are made up of the calcareous remains of occupants of seas and lakes. Naturally, we do not look for fossil remains in the igneous rocks; it is to sedimentary deposits, or stratified rocks, that we must turn if we would find vestiges of ancient life-forms. The oldest strata are, of course, the lowest and most interior of the sedimentary deposits, and had the succession of strata laid above them been evenly deposited, and left undisturbed, we should know little or nothing of them; indeed, they would be many thousands of feet below the present surface and beyond our reach. Fortunately, many forces have been at work by which even the oldest strata have been exposed. Later deposits have been washed away; streams of water have cut through strata and made their succession and content's evident, and there have been earth movements, causing faulting by which recent deposits are lowered and older ones raised. In many instances strata have been turned on edge, and as one walks over the ground where this phenomenon has taken place, one progresses across the upturned edges of stratifications which are the work of ages upon ages. There are numerous cases in which rocks have actually been folded by earth movement, 
and instances are observable where older rocks have been thrust above newer ones. Needless to say, such phenomena greatly complicate geological problems.

THE FOUR GREAT EPOCHS.-For convenience of study, the stratified rocks of the earth have been classified. The geologist speaks of four epochs-

I. The Primary or Palæozoic (ancient-life) Epoch.

2. The Secondary or Mesozoic (middle-life) Epoch.

3. The Tertiary or Cainozoic (modern-life) Epoch.

4. The Quaternary or Recent Epoch.

The rocks of the Primary Epoch contain fossils of the oldest lifeforms, whilst the Quaternary deposits are quite recent. The Epochs are divided into Systems, and the Systems into Strata.

The Primary Epoch includes the strata of the following systemsArchæan, Cambrian, Ordovician, Silurian, Devonian, Carboniferous and Permian. Each system is remarkable for the peculiar fossils which predominate in its strata.

The ARCHEAN system includes strata estimated to be some 50,000 feet in thickness. This system is often called Eozoic (Greek, eos= dawn, $z o e=$ life) because its rocks betray evidence of the beginning of life; but the organic remains they contain have been so changed by the vicissitudes of time and the exigencies of change that their nature cannot be definitely determined.

The Cambrian rocks, consisting of coarse sediments which were evidently laid down as shore deposits in shallow seas, contain fossils known as Trilobites, or three-lobed creatures, thought by some authorities to be akin to wood-lice, or shrimps. Sir E. Ray Lankester, however, considers it probable that they were a primitive marine group allied to the scorpions, spiders and king-crabs. ${ }^{1}$ These Trilobites were fairly well organized creatures, and it is remarkable that they are among the earliest life-forms discoverable in a fossil state. We can hardly expect to find perfectly preserved fossils of lower forms, as such would not lend themselves to preservation. There can be no doubt, however, that in Archæan times much lowlier forms of life existed. The Cambrian rocks are estimated to be about 12,000 feet thick.

The Ordovician system gets its name from the Ordovices, a tribe

${ }^{1}$ See Extinct Animals, 1909 Edition, p. 274. 


\section{THE BOOK OF THE ANIMAL KINGDOM}

anciently occupying territory in Shropshire, bordering on Wales. The Ordovician rocks are noted for their curious fossil remains known as Graptolites, which are creatures allied to the modern seafirs, discoverable on our coasts. Trilobites and some molluscs and worms also thrived in Ordovician times. The thickness of these rocks is calculated to be about 15,000 feet, and the system includes grits, shales, slates, limestones and sandstones. The rocks are especially well developed in Shropshire and Eastern Wales.

In the Silurian rocks, estimated at a thickness of some 7,ooo feet, we find, in addition to many of the fossils peculiar to the Cambrian and Ordovician, remains of fishes and marine scorpions. These rocks consist of sandstones, conglomerates, limestones, shales, mudstones and flagstones. Here are discovered traces of land-plants. The fish appear towards the top of the series, and they are the earliest vertebrate or backboned animals of which we have found fossil remains. The name Silurian is associated with the tribe of the Silures who, in Roman times, occupied ground in Shropshire and Central and South IVales, where the rocks of this system are typically developed.

Next in order to the Silurian rocks come those of the Devonian system, attaining a thickness of about 5,00o feet, and found in Devonshire, Cornwall, WVales and Scotland. The rocks called Devonian are principally marine in origin, but the Old Red Sandstone was laid down at the same time, though under different conditions. Remains of fish are so numerous in Devonian rocks that the period during which they were deposited is commonly known as "The age of fish." The fish of Devonian age are called ganoids on account of the coat of armour with which nature had provided them as a protection against their enemies. This armour was made up of a series of bony plates which can be easily recognized in wellpreserved specimens.

The CARboniferous system succeeds the Devonian, and its rocks attain an approximate thickness of 12,000 feet. They are usually rich it: fossil remains, and they include the coal measures. The remains of this system give evidence of great developments in life-forms and an increasing variety thereof. Its limestones contain corals, sea-lilies and shells of various species. In Carboniferous times there were huge club-mosses and horsetail plants which must often have reached a height of thirty or forty feet; tree-ferns were also numerous. Some of the club-mosses and horsetails at present extant are 
probably the dwarfed descendants of gigantic Carboniferous ancestors; and our valuable coal seams have been formed from the vegetation of this period. A fact of the greatest interest is the appearance of remains of Amphibians in the Carboniferous rocks. To this class belong Toads, Salamanders and Frogs, but the Amphibians of Carboniferous times were rather different from their modern representatives, and much more numerous in species. They are termed Labyrinthodonts, a name given to their kind on account of their peculiar teeth, which have a curiously complicated structure somewhat after the nature of a labyrinth. Labyrinthodont means "labyrinthtoothed." The Amphibia originating in Carboniferous times persisted into later periods, the Permian and Triassic; they varied in size from an inch or two to seven or eight feet. They tenanted the coal-forests of America and Europe and must have spent a large part of their existence in the extensive marshes of their time.

The PERMian rocks succeed the Carboniferous, and are of the comparatively moderate thickness of about I,500 feet. They get their name from the province of Perm in Russia, where they are well developed; indeed, they appear over the greater part of European Russia. They are also developed in India, Southern Africa, New South Wales, Texas and Kansas. The Trilobites, first found in Cambrian rocks, persisted up till Permian times and then disappeared. Great amphibia abounded in the marshes and ganoid fish still existed. With the Permian rocks the Primary or Palæozoic Epoch is terminated.

The Secondary or Mesozoic Epoch comprises the Triassic, Jurassic and Cretaceous Systems.

The Triassic system covers rocks of about 3,000 feet in thickness, including the New Red Sandstone. The remains of Labyrinthodonts still occur, even the impressions of their footprints being in some instances preserved. The chief interest of the Triassic rocks to the student of extinct animals, however, is the existence in them of remains of what are known as Theromorphic Reptiles, so named because in some characteristics of their jaws and skulls they resemble the Theria or Mammals; indeed, they seem to be an approach to that point in the development of backboned animals from which Amphibians, Reptiles and Mammals have branched off. Their remains have been discovered in Triassic rocks in Scotland, India, South Africa and Russia. One of these Theromorphs known as the Pareiasaurus (Greek, "surpassing a reptile") is represented by a reconstructed 


\section{THE BOOK OF THE ANIMAL KINGDOM}

skeleton from Cape Colony, and exhibited in the Natural History Museum in London. It has the appearance of a huge pug-dog, its length being about nine feet. Its teeth are quite small and indicate a herbivorous habit.

The JURASsic rocks, taking their name from the Jura Mountains and attaining a thickness of some 5,000 feet, are noted for their fossil remains of Great Reptiles as well as for the large number of Ammonites and Belemnites they contain.

The Cretaceous system, so called on account of its chalk (Latin, creta), includes rocks of 2,500 feet in thickness. Its fossils indicate land occupied by forests of trees akin to ferns and known as Cycads. These forests provided home and food for huge Reptiles called Deinosaurs (Greek, deinos, terrible; sauros, reptile).

The Tertiary or Carnozoic Epoch includes the Eocene, Oligocene, Miocene and Pliocene rocks.

The Eocene rocks, some 800 feet thick, are so named because therein we find fossils of living species of shells to the extent of about three per cent. The name is derived from the Greek eos, dawn, and kainos (cene), recent, and it therefore indicates the dawn of recent species.

The Oligocene (Greek, oligos, few, and kainos, recent) rocks contain a larger number of living species of shells, although they are still comparatively few. These strata are estimated at a thickness of about 600 feet.

The MIOcene (Greek, meion, less, and kainos, recent) strata bear remains of even more living species of shells, but they are less numerous than the extinct species. The Miocene formations are said to be about $\mathrm{I}, \mathrm{000}$ feet in thickness.

Pliocene rocks are so called because they contain a large proportion of fossil remains of shells that still exist. The derivation of the term is from the Greek pleion, more, and kainos, recent. Pliocene strata are the highest and most recent series of rocks of the Tertiary Epoch. They approximate a depth of some 250 feet.

The Tertiary or Cainozoic rocks bear fossil remains of absorbing interest, remains which indicate the preponderance of mammals during the epoch which they represent. The higher strata of the Primary rocks yield remains of great amphibia; the Secondary or Mesozoic rocks bear fossils of great reptiles, and the Tertiary formations are noted for the remains of great mammals which they preserve. The reader will note the ascending scale of life-forms as 
preserved in the deposits of the world; the merest traces of lowly organisms in the Archæan; the invertebrates, crustaceans and worms of the Cambrian, Ordovician and lower Silurian; the armoured fishes of the Devonian; the amphibia of the later Carboniferous, Permian and Triassic; the reptiles of the Secondary Epoch, and the mammals of Tertiary age and more recent times. The mammal is a late arrival upon the arena of existence, but it has the elements of victory in its composition, and has come to stay.

The Quaternary Epoch, succeeding the Tertiary, is also called Pleistocene, meaning most recent, and obviously its rocks and deposits bear fossil remains of a comparatively recent flora and fauna. The strata are said to be some 200 feet thick.

CREATURES OF THE PAST.-Having presented the reader with a cursory survey of the world's sedimentary deposits and given a general idea of their extent and typical fossil remains, an attempt will now be made to describe in greater detail some of the creatures of long ago. A beginning will be made with the Amphibians, and to do this we must go back in imagination to the period in Palæozoic time when the coal deposits were in process of formation. The seams of coal, often buried hundreds of feet below the surface of the earth, are evidences of old land surfaces which have gradually subsided, and their vegetation has been covered with mud and sand ultimately transformed into shale and sandstone. Seams of coal lie in succession one above another with intervals of shale and sandstone. As the Carboniferous land-surfaces subsided and were covered with mud and sand, there were halts in the process of subsidence, and during these halts fresh vegetation sprang up, flourished and perished, in course of time to sink below the level of surrounding land and to be covered with sediment at the bottom of a marsh or lake. Ultimately the vegetable remains, mingled perhaps with those of fish, scorpions, etc., were converted through pressure and other agencies into coal. The coal measure land-surface bore curious plant life. There were forests of giant horsetails, club-mosses and tree-ferns growing in a humid, warm atmosphere in damp ground beside shallow seas and lakes. The land was intersected by rivers carrying in suspension the débris of older rocks broken up by water, chemical action and other denuding agencies. This material was deposited in banks, in lakes and seas, and in course of time silted them up, making new land-surfaces to be invaded by vegetation. Animal life must have been abundant, although much of it has left 


\section{THE BOOK OF THE ANIMAL KINGDOM}

no trace of itself. We know from fossils that have been identified that there were large Scorpions and Spiders as well as Dragon-Flies. Beetles were in evidence, Cockroaches and Walking-Stick Insects. The plants produced spores, but no seeds; they bore no flowers in the ordinary sense of the term, and so provided no nectar for bees, wasps and honey-feeding insects. The ancient Trilobites were becoming rare, and among the shell-animals the lower molluscs, known as Brachiopods, were giving way to more fully developed Lamellibranchs, bivalves like the Oyster, Cockle and Mussel; and to the Gasteropods, which are univalves, and of which our modern Snails may be taken as types. There were Fishes in the Carboniferous waters, chiefly Ganoids, especially in the lagoons. Sharks existed and preyed upon smaller fry.

In such an environment the earlier Amphibia known as Labyrinthodonts, to which some reference has already been made, were the probable monarchs. They are certainly the most highlydeveloped animals of which the Carboniferous rocks yield remains. They may be likened to our modern Newts and Salamanders. Several kinds have been found varying in size from an inch or two to seven or eight feet; the larger ones were the lagoon monsters. It has been surmised that the amphibian known as Archegosaurus was among the first of the vertebrate air-breathers; its remains suggest a likeness to the Mud-fish, which in the wet season lives in water, but in dry times buries itself in mud and breathes by the agency of an air-sac, which is a primitive lung. Some of the Carboniferous amphibians dispensed with legs, although the majority possessed them; their tails were well developed and strong, enabling them to swim with a powerful movement.

The amphibians reached the height of their development in the Permian period, when many new forms appeared. It is in Permian strata that remains of true Reptiles are found, and they indicate a marked forward movement in the development of life-forms. But it is in the Secondary strata that they reach their finest growth. The Ichthyosaurs (Fish Reptiles) attained large dimensions. The head of one possessed by the Geological Society, and preserved in its rooms in London, is some five and a half feet long, and the animals must often have been upwards of forty feet from tail to snout. They had thick bodies, and possessed a pair of big paddles to the fore and a smaller pair behind. Their tails were fishlike. They could swim easily in the sea, which was their farourite element, but on 
occasion they could crawl on the shores. Being air-breathers, possessing lungs, they would need to appear often on the water's surface. Their large eyes indicated sharp vision, and their jaws, armed with sharp teeth, a predatory habit. The eyes were protected by circular bony plates. The probability is that they were viviparous, giving birth to their young in an active condition, not laying eggs. They would present an appearance somewhat similar to that of a Grampus.

PLESIOSAURS. - Mention must also be made of the Plesiosaurs (literally, near to reptiles)-small-headed, small-brained, longnecked Sea-Lizards. They attained a size equal to that of the Ichthyosaurs. The body of the Plesiosaurus has been likened to the hull of a submarine. The creature had four paddles with a leg-like structure; it had strong jaws in which many pointed teeth were set. It revelled in the sea, probably not venturing to great depths, but haunting the shores; its long neck would enable it to reach out to small animals on the shore and secure them for food without leaving the water. It would propel itself through the water principally by means of its paddles, for its tail was comparatively short, and nothing like so powerful as that of the Ichthyosaurus. The paddles, on the other hand, were well developed and reached out from the body like great oars.

TELEOSAURUS AND PTERODACTYLE.-Plate XIV represents two curious creatures of Mesozoic age, the Teleosaurus and the Pterodactyle. The Teleosaurus (meaning complete reptile) was similar to the modern Crocodile; some species were at least thirty-three feet long, the head being no less than three feet in length. The species known as Teleosaurus cadomensis was armoured with two cuirasslike arrangements, one on the back and the other beneath its belly. It had terrible jaws, opening to the extent of six feet, and could provide doubtful hospitality for animals of considerable proportions. The Pterodactyles (Greek, pteron, wing; dactylos, finger) were, as the illustration suggests, winged reptiles, and had we lived in their day, the larger species might well have inspired us with terror. It takes a little time to get our minds accustomed to the idea of flying reptiles, as such creatures are foreign to our experience. How these reptiles acquired the power of flight is a difficult story to relate, or rather, riddle to interpret. The struggle for the means of existence must have been very keen among the reptiles of Mesozoic times; certain species may have taken to trees and cliffs to secure 


\section{THE BOOK OF THE ANIMAL KINGDOM}

food and have gradually developed their limbs in adaptation to their surroundings. In the course of time the wing-like membrane would become more and more extensive, until a creature originally of the land became a beast of the air. But such a development would involve the activity of the law of natural selection through very many generations. Certain it is that winged reptiles were actually in existence "once upon a time." They had not the wings of a bird, but a loose thin membrane such as our modern Bats possess. Many of the Pterodactyles were quite small, perhaps not so large as the Common Bat, but some species attained great size, their flying apparatus extending between twenty and thirty feet. Their remains indicate big heads, strong, toothed jaws, large eyes, giving good vision, and the power to perch on trees and hang on cliffs. These reptiles must have fulfilled the rôlc of the fiend as given in the lines-

\section{"The fiend}

O'er bog or steep, through strait, rough, dense, or rare,

With head, hands, wings, or feet, pursues his way,

And sinks, or swims, or wades, or creeps, or flies."

They could fly with ease, stand erect upon the ground and crawl by the aid of their four limbs, the wings being neatly tucked up for the occasion. It is not unlikely that they sometimes swooped upon fish as they rose in the water, and they may also have consumed the insects common in their time. Perhaps it was these creatures, aptly termed the "Flying Dragons," that in some way yet to be explained gave rise to the idea of the mythical dragons of the fables.

DEINOSAURS.-The Deinosaurs (Greek, deinos, terrible; sauros, reptile) appeared in Triassic time, but reached a greater state of development in the Jurassic period. These were the greatest of Land Reptiles. One of their number, the Megalosaurus (large reptile) is figured on Plate VIII. It is correctly represented as a carnivorous beast, for its teeth were like those of a Tiger. Doubtless it had no compunction in killing and eating its herbivorous cousins. It will be noticed that it had a Kangaroo-like build. It walked mainly upon its massive hind-legs, although it may sometimes have gone on all-fours. Its fore-legs were used for grasping prey. It would occupy shallow waters on occasion, but would generally move along the margins of lakes and marshes in search of food. The appearance of this creature could not have been particularly inviting, but it was not so huge as some of its relatives, 
although it may have attained the considerable length of twentyfive feet.

STEGOSAURUS.-Another of the Deinosaurs is named the Stegosaurus, and is represented on Plate VII. This is the Plated Lizard, protected, as the illustration shows, by spines and plates of bone along its back. A skeleton of a Stegosaur found in Jurassic strata in the neighbourhood of the Rocky Mountains shows a length of twenty-five feet. The fore-legs are shorter than the hind limbs: the former, however, were strong, although the remarkable size and power of the hind-leg bones indicate their more extensive use. The animal may have used these hind limbs and its tail as a kind of tripod upon which to rest or support itself. Some of the plates, already referred to, are two to three feet in diameter. These remains are fully described and explained by the Rev. H. N. Hutchinson in his Extinct Monsters and Creatures of Other Days.

BRONTOSAURUS. - The Brontosaurus was another of the Deinosaurs. It was a huge beast which may have weighed anything from twenty to thirty or more tons. Its remains have been discovered in the Jurassic rocks of North America; they indicate an animal from fifty to sixty feet long with a shortish, thick body, a short, small-brained head on a long neck, and a long tail. Its feet were of great size; they have left impressions nearly a yard square in area. It had no bony plates as a protection to its body, such as the Stegosaurus possessed, and it must have used its powerful tail for aggressive or defensive purposes. It was a vegetarian. Its remains are usually found where it had become bogged. We can quite understand that an animal so bulky and heavy would have difficulty in negotiating bogs. Mr. Henry R. Knipe, in his Nebula to Man, speaks of the Brontosaurs in these terms-

"But forms surpassing Stegosaurs are seen,

In point of size, and of as weird a mien.

Some here there are that look like Plesiosaurs

With elephantine legs, as on all fours

They creep along. And some among the band

From nose to tail-end eighty feet command.

Some twenty tons a monster maybe weighs,

And woe to him if into bogs he strays,

For going there, for ever there he stays.

Small headed are these Brontosaurs, since named,

Although in trunk and limb they huge are framed.

Quite simple are their tastes. The trees and plants

Afford them all they need for sustenance."

OTHER DEINOSAURS.-Other Deinosaurs were the Diplodocus, one 


\section{$35^{\circ}$ THE BOOK OF THE ANIMAL KINGDOM}

of the biggest of its kind, attaining a length of about eighty feet; the Atlantosaurus, possessing a thigh-bone bigger than a man, and perhaps thirty feet high; the Cetiosaurus, not less than sixty feet in length, and the Iguanodon, so named because its teeth resemble those of a West Indian land-lizard called the Iguana.

But the king of the Deinosaurs was the Tyrannosaurus. Although shorter than the Brontosaurus, he was quite superior to that animal. The total length of a specimen in the American Museum of Natural History in New York is thirty-nine feet. His anatomy suggests brain power and agility. The specimen is remarkable for the immense size of the feet, which are no less than four feet long by three feet wide. Some of the teeth measured six inches. He is thus described by a writer in Knowledge: "We have every reason for congratulating ourselves that Tyrannosaurus Rex is not our contemporary. He was practically a biped, with an agile, bird-like manner of progression, the immense feet possessing three enormous toes projecting forward, and one extending backward-all furnished with huge tearing claws. The head is much larger than that of the Brontosaur, and the great teeth are serrated and sharp-edged. Tyrannosaurus seems to have come in about the time that Brontosaurus went out-perhaps he materially hastened the departure of the latter." This animal is declared to be "the largest carnivorous land animal yet discovered, and the most ferocious monster of the Reptile Age." The remains were found at a place called Hell Creek in Montana.

THE FIRST BIRDS. - It will be borne in mind that the Pterodactyles already described were not birds, but Bat-like flying reptiles. The first birds seem to have appeared in Jurassic times, but they differed greatly from any birds that exist in the present age. They bore indications of a reptile origin. Their jaws were armed with teeth; they had long tails similar to those of lizards, and each of the tail vertebre bore a pair of feathers. Their bones were solid and their flight must have been clumsy. The Archæopteryx (Greek, arche, a beginning; ptcron, a wing) was discovered in Bavaria, in the quarries of Solenhofen. The stone containing the fossil is in the Natural IIistory Museum; it was purchased for

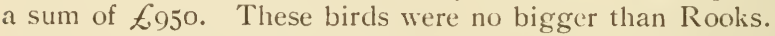

In the Cretaceous rocks of North America, in the neighbourhood of the Rocky Mountains, remains of a bird, to which the name of Hesperonis regalis has been given, were found by Professor 
Marsh. The reconstructed skeleton shows the bird to have been a diver, in size about five feet from bill to toe. Like the Archæopteryx its jaws were furnished with teeth, and it was probably addicted to fishing. To some extent it was like the modern Penguin, but it had not the same wing development. It would depend mainly upon its tail for propulsion through the water. The wings, indeed, were quite rudimentary. Another Cretaceous bird was the Ichthyornis, which differed from Hesperonis in having its wings well grown. It was of the aquatic type, its jaws were toothed, but it was no bigger than a Rook. Quite a score of species of Cretaceous birds have been found in fossil state.

THE DODO.-While the subject of extinct birds is before us, it may be well for us to give some attention to the famous Dodo (Didus ineptus). This bird, now extinct, but which was found alive in the island of Mauritius so late as the seventeenth century, was allied to the Pigeons, but was larger than a Swan. Owing to generations of laziness, probably caused by absence of necessity to fly far afield in search of food, the wings of this bird degenerated to such an extent that they were useless for flight. The Dodo seems to have settled down to a life of ease and the development of adipose tissue. It was fat and heavy, but managed to maintain a tolerable existence until man arrived in Mauritius and introduced Pigs there. The Pigs occupied the island and devoured the eggs and young of the Dodo, and the seamen and colonists killed the old birds, defenceless and flightless, in great numbers. The Mauritius was uninhabited by man until 1598, when some Dutch seamen were wrecked there; it was colonized in 1644, and in 1693 not a single Dodo was in existence. A live Dodo was exhibited in London in $16_{3} 8$. This bulky and defenceless bird could exist so long as the environment to which it had adapted itself remained undisturbed, but its extinction was inevitable when man arrived upon the scene. Extinction was the price it had to pay for generations of indolence and the consequent atrophy of the power of flight. It is a law of Nature that organs not used degenerate, and in course of time disappear.

THE MOA.-The Moa is another bird which is said to have become extinct through the incursions of man. The Moas inhabited New Zealand and must have been common there. About fifteen species were once in existence. They were land-running birds, after the nature of the Ostrich; they varied in size, the dwarf species 
being only three feet high, but the Giant Moa (Dinornis maximus) attained a height of some eleven feet. These birds were quite flightless and appear to have been extinguished by the Maoris, who settled in New Zealand about the fourteenth century.

It is claimed by evolutionists that birds have been derived from a reptilian ancestry and have developed their characteristics by natural selection. Sir E. Ray Lankester says: "It is now certain that Reptiles similar to the Iguanodon were the stock from which birds have been derived, the front limb having become probably first a swimming flipper or paddle, and then later an organ for beating the air and raising the creature out of the water for a brief flight. From such a beginning came the feather-bearing wing of modern birds." 1 The testimony of the rocks favours this declaration. The Archæopteryx already described bears many reptilian features, and seems to be a link between a reptilian ancestry and more fully developed birds.

THE AGE OF MAMMALS.-IVe now turn to the Tertiary or Cainozoic Epoch, which was conspicuously the Age of Mammals. Sir Archibald Geikie, in his Class Book of Geology (page 366, edition 1903), gives an excellent conception of the earth in Tertiary time which I cannot do better than set down in his own words. "The importance of this part of the geological chronicle may be inferred from the following facts: During Tertiary time the seabed was ridged up into land to such an extent as to give the continents nearly their existing area and contour. The crust of the earth was upturned into great mountain ranges, and notably into that long band of lofty ground stretching from the Pyrenees right through the heart of Europe and Asia to Japan. Some portions of the Tertiary sea-bed now form mountain peaks 16 , ooo feet or more above the sea. The generally warm climate of the globe, indicated by the world-wide diffusion of the same species of shells in Palæozoic, and less conspicuously in Mesozoic times, now slowly passed into the modern phase of graduated temperatures, from great heat at the equator to extreme cold around the poles. At the beginning of the Tertiary or Cainozoic periods, the climate was mild even far within the Arctic Circle, but at their close, it became so cold that snow and ice spread far southward over Europe and North America.

"The plants and animals of Tertiary time are strikingly modern

1 Extinct Animals, p. 202, 1909 Edition. 
in their general aspect. The vegetation consists, for the most part, of genera that are still familiar in the meadows, woodlands and forests of the present day. The assemblage of animals, too, becomes increasingly like that of our own time, as we follow the upward succession of strata in which the remains are preserved. ... As the manifold reptilian types died out, the mammals, in ever-increasing complexity of organization, took their place in the animal world. By the end of the Tertiary periods they had reached a variety of type and a magnitude of size altogether astonishing, and far surpassing what they now present. The great variety of pachyderms" (thick-skinned animals) "is an especially marked feature among them."

THE PALAOTHERIUM.-In the lowest Tertiary strata (Eocene) remains have been found of an early mammal which has received the name Palæotherium (literally, ancient wild beast). It is thus described in a volume called The Primeval World, published in 1876 : "Its body was short, thick and ungainly; it had short but very robust legs; the feet were supported by three toes enclosed in a hoof; the head was immensely large, with a nose terminating in a muscular fleshy trunk, or rather snout, like a Tapir's; eyes small, dull and displaying little intelligence; the general size that of a large Horse. Its remains have been found in such quantities as to show that it must have lived in great herds in the valleys round the Paris basin, the lacustrine districts of Orleans and Argenton, the Tertiary formations of Rome, and the limestone plains of the Isle of Wight. In each jaw it had six incisors and two canine teeth; its molar teeth resembled those of the Rhinoceros; the upper were square, with projecting ridges of diverse configuration; the lower, shaped like crescents. Their feet were divided into three toes; in the Tapirs, the two fore-feet have four."

The Palæotherium lived at the same time as the Anoplotherium (literally, a beast without arms, or defenceless). Cuvier suggested that this creature had an aquatic habit, but this is by no means demonstrated. It was about the size of a Deer; it had divided hoofs, a long tail, and may have been a ruminant; its build was much lighter than that of the Palæotherium.

ANIMALS OF EOCENE DAYS. In Eocene times hornless Deer and Antelopes as well as herds of hog-like animals occupied the land, and in the woodlands were the primitive ancestors of our Lemurs, Hedgehogs, Squirrels and Bats. The Uintatherium (literally, the wild beast of the Uinta Mountains) equalled the A A 


\section{THE BOOK OF THE ANIMAL KINGDOM}

Elephants in size and the Rhinoceroses in form. The skull, however, bore three pairs of horns, or horn-like projections, one pair on the forehead, one on the snout and one on the cheeks. This animal was one of the earliest of the Dinocerata, a name descriptive of a group of horned monsters; more highly developed members of the same ground were Dinoceras ingens, which would weigh nearly three tons, and Dinoccras mirabile. The brains of these animals were very small; but what they lacked in intelligence was compensated for by brute strength. Massive bodies are often associated with scanty brains, and the brain is generally developed at the expense of the body. But intelligence can accomplish more than brute force, as the study of the history of life-forms amply reveals. The amphibians, reptiles and early mammals had small brains, and it is no wonder that they were outwitted by their more intelligent successors. Physically, man is a weakling in comparison with an Elephant, but his intelligence enables him to subjugate the huge brute and make him serve his ends.

BRONTOPS- The Eocene Dinoceras were succeeded in Miocene times by another remarkable family of animals, of which Brontops robustus may be taken as a type. Brontops was a four-footed beast with an Elephant-like body and tail, but with limbs rather shorter than those of that animal. It had a big skull of curious shape, indented above the eyes and terminating at the snout with two hornlike projections. It stood some eight feet high and twelve feet long. The stull alone was a yard in length, but it was shallow and allowed small space for brains. The Miocene fauna also included Hogs as big as Rhinoceroses, Lions, Wolves, Bears, Camels and Stags.

THE EVOLUTION OF THE HORSE.-Among the many interesting remains of Tertiary age are those which throw considerable light upon the life-story-especially the past history-of the Horse. No more remarkable or complete record has been discovered. The Horse appears to have evolved from a small five-toed ancestor, which probably existed in Eocene times. There are European remains which exhibit a line of development varying in some details from that indicated by American fossils. The American remains are the most complete. The story begins with the Eohippus (Greek, eos, dawn; hippos, horse), the remains of which were found by Professor Marsh in the lowest strata of the Eocene rocks. This animal was about as big as a small Fox, Pony-like in appearance. It had four well-developed toes on the front foot, three on the hind foot 
and, in addition, the remains of another, or fifth toe on the fore feet. Higher in the strata was found the Orohippus (literally, the mountain horse, so named on account of being found near the Rocky Mountains). This animal (also called the Hyracotherium) was larger than the Eohippus-about the size of a Fox-it had the same number of complete toes, but no remnant of a fifth. Passing from the Eocene to the higher Miocene rocks a somewhat larger animal was discovered and called the Mesohippus (Middle Horse); it had three toes to the fore, in addition to a large splint of bone, and three toes behind. This corresponds with the European Anchitherium, although there are points of divergence. Next in order, and found in the lower strata of the Pliocene rocks, was unearthed the Protohippus (First Horse). In this animal the centre toe, or digit, of each foot was large and evidently got the work to do, while there were two digits, quite small, with their tips above the level of the big central digit: a European specimen presenting similar features has been called the Hipparion. The Protohippus was larger than its Miocene ancestor. It was the size of a Donkey. In the higher Pliocene strata discovery was made of another link in the chain of development, in the remains of the Pliohippus (Pliocene Horse). The foot of this animal differed from that of the modern Horse in some small details. At the top of the Tertiary rocks remains of the true Horse are found.

In order to give the reader a clearer view of these remarkable facts it may be well to present them in tabular form.

Name.

1. Eohippus

2. Orohippus, or
Hyracotherium

3. Mesohippus

4. Protohippus

5. Pliohippus

Pliocene

Pliocene

\section{Description.}

Four toes on front feet, three on the back. Traces of a fifth digit on the fore feet. Size of a small Fox.

Higher Eocene As above, but minus remains of fifth digit. Size of ordinary Fox.

Lower Miocene Three toes on all four limbs. A large splint of bone on front limbs. Similar to European Anchitherium.

One large digit and two small ones. The small ones not touching the ground. Corresponds to European Hipparion. Size of a Donkey.

Bigger than Protohippus, feet much the same as modern Horse.

6. The Modern Horse

A A 2 


\section{THE BOOK OF THE ANIMAL KINGDOM}

The interpretation of these facts is not difficult. The Eohippus is the descendant of a five-toed ancestor, the progeny of which had no use for all its toes. That ancestor may have been the five-toed Eocene Phenacodus, which some claim to have been the original parent of all hoofed animals : but the claim is disputed. According to the laws of natural development, the used limb becomes stronger, the disused ones atrophy. So in the history of the Horse. Out of the five toes of the Horse's original ancestor, the Eohippus had lost two from its hind feet, and one was disappearing from the front feet. The middle toe of each foot was being used most extensively, and becoming stronger and bigger. This does not mean that these missing toes suddenly disappeared : the atrophy was a very gradual process, and must have been due to the operation of natural selection through very many generations. The five-toed originals must have been handicapped in the struggle for existence; the progeny that used fewer toes became swifter and were favoured in that respect. The slower ancestors perished, while the swifter progeny bred and produced young with tendency to use fewer toes. The toes that were used remained in the Eohippus, those that had not been used for many generations had disappeared. Some day remains may be found of intermediate developments of this gradual process. The Orohippus represents another stage in the evolution of the Horse-the entire loss of the fifth digit and an increase in size. The Mesohippus exhibits a stronger growth of the central toe due to much usage; it had lost completely two toes from each limb, and other two were showing signs of disuse, and the promise of decay. In the larger Protohippus the process was greatly accentuated; the central toe was still increasing in power and usefulness; the two smaller digits no longer touched the ground and had fallen into desuetude. That same desuetude doomed them to atrophy, the promise of which is fulfilled in our noble, swift, useful and intelligent one-toed Horse.

This developmental story is rendered clearer by knowledge of some elementary facts concerning the Horse. The hoof of this animal is really a big nail of a highly developed middle digit. Quadrupeds usually have two distinct bones, known as the ulna and radius, in their fore limbs. An examination of the fore limb of a Horse would seem, at first glance, to show but one bone where two are naturally expected. A closer scrutiny, however, discloses the fact that two bones have been blended into one. The knee of the 
Horse is really its wrist. The "canon bone" corresponds to the middle one of the five metacarpal bones which support the palms of our hands. The remaining bones, commonly called "pastern," "coronary" and "coffin," are the joints of the central digit greatly strengthened. They correspond to the joints of our middle fingers. The second and fourth digits are represented by thin bones like splints. At the base of these splints small bony knots are occasionally found, and these may be taken as representing the missing first and fifth digits. Thus we see the Horse actually bears traces of its five-toed ancestor! Students of embryology (the science of pre-natal developments) assure us that an embryonic foal at an early stage of its growth actually has five toes. This is not surprising in the light of the facts we have already considered. It is a recognized principle in embryology that an embryo epitomizes the life history of its ancestors. But the fact noted is further confirmation of the testimony of the rocks. It is also interesting to note that horses are occasionally born in these modern days with two extra hoofed toes depending from the splint bones which have their place on either side of the big toe, now looked upon as a hoofed foot. Julius Cæsar, it was declared by Suetonius in his life of that individual, rode a Horse with almost human feet, with hoofs cleft like toes. Professor Marsh describes a Horse from Cuba, which had two well-grown toes on each foot.

Remains of the horse's curious ancestors may be seen in the American Museum of Natural History in New York. There is a set of casts of skulls and bones in the London Natural History Museum. It is curious that when America, so conspicuously the home of the Horse's ancestors, was discovered, it yielded no traces of the modern Horse. The wild Horses of the Pampas are the descendants of Horses introduced by Spanish colonists at least three centuries ago.

SABRE-TOOTHED TIGER. - The extinct Sabre-Toothed Tiger, called the Macharodus (Greek, machaira, a sabre), figured on Plate XI, roamed the earth in Pliocene times, and a terrible enemy it must have been to its herbivorous contemporaries, which included in their number ancestors of our Camels, Deer, Antelopes and Apes. It was the monarch of the Pliocene forests. Its canine teeth resembled the blade of a poignard, and by their instrumentality the animal could easily and effectively rip the hides even of the Pachyderms. The teeth blades were some twelve inches long. In 


\section{$35^{8}$ THE BOOK OF THE ANIMAL KINGDOM}

South America remains have been found indicating a beast larger than the modern Lion, possessing fore limbs of great power and armed with large claws, which could be drawn back when not in use, in the same manner as those of a Cat. Remains of this Tiger have also been found in parts of France, Hungary and Italy. It probably glutted itself on the blood of its victims, for the reason suggested in these words written by Mr. Henry R. Knipe-

"Brutes tusked and tiger-like still wend their way, Seeking by means more sly than brave their prey. And some with little ease can eat their food,

So long and thick their 'sabre' teeth protrude."

It does not require a great stretch of the imagination to see in this sabre-toothed carnivore the ancestor of the modern Tiger.

GIANT SLOTH, OR MEGATHERIUM,-Plate XVIII figures the Giant Sloth of Pleistocene times, the remains of which have been found in the alluvial deposits of Paraguay. It has been dignified by the name Megatherium (Greek, megas, great; therion, animal) and fully justifies the appellation. Living Sloths are quite dwarfs in comparison with this monster, which was almost the size of an Elephant. In the Natural History Museum, London, there is a cast of its skeleton, which gives a good idea of what the animal must have been like in a living state. The length is eighteen feet. The hinder parts of the skeleton exhibit a combination of weight and strength; the bones are bigger than those of an Elephant, the thigh bone being especially massive. To the fore, the skeleton is more slender, but not to the sacrifice of power. The living Sloth, as was pointed out in Chapter XVI, is arboreal in habit; that is to say it lives in trees, suspending itself by its feet from the branches, and it feeds on fruits, leaves and young herbage. The extinct Megatherium, on the contrary, had no need to climb trees; he was tall enough to reach all the food he required. His was a case of the mountain coming to Mahomet. He took the vantage-point of the ground beneath a tree, making his powerful hind legs and tail a tripod upon which his body rested. The weight of the hinder parts made the upright position easy. Stretching out his fore-legs, or arms, and extending his claws, he firmly grasped the trunk of a tree and bent it downwards so that he could get the leaves; or mayhap he snapped the trunk and brought the foliage to the ground. He was certainly powerful enough to accomplish 
almost anything in the way of bending or breaking even good-sized trees. The jaws of the Megatherium suggest the possession of a long tongue, which would be useful to its possessor for stripping branches. It has been thought that living species of little Sloths are descendants of these extinct giants; but the notion is open to question on several grounds.

THE MYLODON.-The Megatherium was not the only big Sloth of Pleistocene times. The Mylodon was contemporaneous with it, but was not so huge; its length being some eleven feet. It was similar in build in nearly all respects to its bigger cousin, and like it was a vegetable feeder. Sir E. Ray Lankester in his Extinct Animals relates facts which go to prove that the Mylodon was actually in existence at the same time as man. He tells us that some years ago a Dr. Nordenskjöld discovered a cavern at the end of a fiord near the Chilian coast, and in this cavern some white settlers had found and removed thence a big piece of skin covered with greenish-brown hair and studded on the inner side with little knobs of bone. This turned out to be a portion of the skin of a Mylodon. Dr. Moreno, of the La Plata Museum, explored the cave and gathered an immense quantity of bones as well as more pieces of hairy skin. The cavern had probably been inhabited a long time ago by Indians, for a number of the bones had been cut or broken by human agency in order that the marrow might be extracted for food. The same writer continues to tell us that Mylodons had evidently lived in the cave, for big balls of dung made up of the refuse of masticated grass were found; and the discovery of a large quantity of cut grass suggested the idea that the Indians had actually kept the Mylodons alive in the cavern and fed them with hay. If this last surmise is true, it would seem that Mylodons were amenable to human discipline and could be to some extent domesticated. However that might be, the animals are now extinct, and their extinction, like that of the Dodo and the Moa, has been hastened by man. It seems a pity that so interesting a creature has not been preserved so that its habits might be observed in a living state. It should be added that the bones of at least twenty Mylodons were found in the cavern referred to.

SCELIDOTHERIUM.-Among the extinct Sloths mention should also be made of the Scelidotherium, literally, the limb beast, so called on account of its conspicuously long limbs. It was the size of a Polar Bear. Charles Darwin, in his South American travels, 


\section{THE BOOK OF THE ANIMAL KINGDOM}

secured a nearly complete skeleton. In regard to the remains of this beast the great investigator says in his Journal of Researches: "The number of the remains of these quadrupeds embedded in the vast estuary deposits which form the Pampas and cover the granitic rocks of Banda Oriental must be extraordinarily great. I believe a straight line drawn in any direction through the country would cut through some skeleton or bones. As far as I am aware, not one of these animals perished, as was formerly supposed, in the marshes or muddy river-beds of the present land, but their bones have been exposed by the streams intersecting the sub-aqueous deposit in which they were originally imbedded. We may conclude that the whole area of the Pampas is one wide sepulchre of these extinct gigantic quadrupeds."

ARMADILLOS.- It is suggested that there was a relationship between the extinct Sloths and Armadillos, although they were very different in appearance. Their bones present striking resemblances and they certainly both belonged to the Edentata (literally, the toothless animals), a name which rather misrepresents the facts: the animals did have teeth, but possessed none in the front of their mouths. Two extinct Armadillos are figured on Plate XVIII. Their modern representatives do not attain more than three feet in length; they are protected by scales which may number from three to thirteen, and these scales are so arranged that the animals can roll themselves up somewhat after the manner of a Hedgehog. The fore feet are very strong and are used for burrowing, which the animal can accomplish at an astounding rate. The extinct Armadillos were built on a larger scale, and their protective armour was all of a piece, not divided into separate scales as in living species. Their remains are found in the Pleistocene beds of the Argentine in South America; they were contemporary with the Giant Sloths. These animals have been named Glyptodons (carved tooth) on account of a carved appearance of the surface of their teeth. They would be as large as an Ox. Their carapace being solid, they could not roll themselves up as modern Armadillos can, and their fore feet do not seem to have been used for burrowing.

ANCESTORS OF THE ELEPHANT.-A chapter on extinct animals would not be complete without some reference to the extinct ancestors of the modern Elephant. The evolution of this monster mammal has been practically traced, although the chain of evidence is perhaps not quite so complete as in the case of the Horse. An examination of 
the skull of a full-grown Elephant shows a remarkable straightness of face and absence of snout; in fact the skull shows no sign of a snout. A new-born Elephant's skull, however, shows indications of a snout. Now it is quite usual for young beasts to epitomize the peculiarities of their ancestry, and the young Elephant is no exception in this respect. The indications of a snout exhibited in skulls of new-born Elephants disappear as the animal grows in years and stature, but they are sufficiently marked to connect the race with a long-snouted ancestry. To what extinct animal of elephantine characteristics must we go in order to find the snout which is betrayed in the young of the modern Elephant? The remains of the animal we are looking for have been found amongst deposits of Miocene age in Egypt. They are of Tetrabelodon augustidens-a long-jawed Mastodon. This Mastodon resembled the modern Elephant in many important particulars; it was nearly the same size, but its trunk was somewhat shorter, and it had a long lower jaw armed with two short tusis meeting together; there were two long upper tusks spreading outwards and a snouty prominence was in evidence. But Tetrabelodon was probably the descendant of the Palæomastodon, a much smaller animal about five feet high. The remains of this beast have been found in the later Eocene beds of Egypt. The skull is some three feet long, the snout is better developed than in Tetrabelodon, but there are signs of a much shorter trunk, which would rest upon the lower jaw, and would not be flexible. The tusks of both jaws are comparatively short, the neck more in evidence. In Egyptian Eocene beds remains of the Mcritherium have been discovered, and it is conjectured, with great probability, that this animal, which was small in comparison with our present-day Elephants, being only three feet high at the shoulder, was the original of those creatures. The skull of the Mœritherium indicates an animal the size of a Tapir; its length is about sixteen inches and the snout is distinctly prominent. The tusks in both jaws are small and the trunk must have been quite short. The leading facts relating to these extinct animals and the chain of development will be better comprehended if the story is presented in tabular form.

Name.

Moritherium

Palaomastodon
Period.

Eocene

Later Eocene
Leading Details.

Skull sixteen inches long, short tusks and trunk. Prominent snout.

Skull three feet long. Longer tusks and trunk. Less prominent snout. 


\section{THE BOOK OF THE ANIMAL KINGDOM}

$\begin{array}{ccc}\text { Name. } & \text { Period. } & \text { Leading Details. } \\ \text { Tetrabelodon } & \text { Miocene } & \text { Elongated lower jaw. Trunk and tusks } \\ & & \text { still longer. Snout still less prominent. } \\ \text { The Elephant } & \text { Recent } & \text { Long trunk and tusks Short neck. } \\ \text { (Elephas Africanus) } & & \text { Snouty prominence absent in skulls of } \\ & & \text { adults, but detected in infants. }\end{array}$

The Elephant's tusks have evidently been developed from prominent teeth of a remote ancestor, and its trunk or proboscis is the result of a gradual extension of the face and upper lip. The lower jaw seems to have shortened as the trunk has developed, until it presented no obstacle to its falling over and hanging freely in the regulation way. Fuller facts and evidences of the Elephant's history and ancestry will be found in Sir Ray Lankester's Extinct Animals, to which I have already had occasion to refer several times. Dr. A. Smith Woodward, F.R.S., thus concisely sums up the changes involved: "They gradually increased in size without essentially altering their limbs and body; but as their legs lengthened and their neck shortened, their face and chin gradually became elongated to reach the ground for browsing. When this strange adaptation had reached its maximum degree, the chin suddenly shrivelled, leaving the flexible toothless face without any support. Thus arose the unique proboscis of the Elephants, which has become prehensile by stages which cannot be traced, because soft parts are not preserved in ordinary geological formations." 1 It will be noticed, if the theories presented are correct, that both the Elephant and the Horse have evolved from quite small ancestors. This finding, of course, is quite contrary to the superstitious imaginings of those who people the old world with monsters and fail to realize that we have monsters in the world of to-day bigger than any of which the fossilized remains have been discovered.

THE MAMMOTH.-(See Plate II.) No extinct animal has been the subject of greater interest than the Mammoth (Elephas primigenius). The Plate referred to gives a fair idea of its appearance. In height it was from fifteen to eighteen feet; its skin was clothed with wool of a reddish-brown hue, and it had what might be termed a mane of black hairs along its back. It possessed enormous tusks. This shaggy-hided Elephant is said to be akin to the existing Indian Elephant. Quite possibly the Mammoth and the Indian Elephant may have been derived from a common ancestor; the former having adapted itself to a cooler climate and the latter to a tropical. Remains

${ }^{1}$ Quoted by Rev. H. N. Hutchinson in his Extinct Monsters and Creatures of Other Days. 
of the Mammoth are widely distributed in the Northern Hemisphere; they have been found in Britain, Central Europe, Germany, Russia, Spain, Italy, Greece; also in Asia, Africa and North America. The range of the animal must have been between the fortieth and the sixtieth degree of latitude, and it may have penetrated as far north as the seventieth degree. To understand its movements we must bear in mind that it thrived in Pleistocene times and lived during the great Glacial Period. It might not be correct to say that it haunted cold regions, but it was certainly equipped to endure a greater degree of cold than its Indian relation, and it did not suffer any great discomfort when cold descended upon it. During the Glacial Period great ice sheets reached from the far north into the very heart of Europe and stretched over North America well into the United States. These ice-sheets did not remain set and motionless, but flowed glacier-like from the heights into the lowlands and finally to the sea, carrying along with them débris from the hills and remains of any living creatures that became imbedded in them. The sheets were often of enormous thickness; perhaps no less than six thousand feet thick in the region of Scandinavia; upwards of five thousand in Scotland; but they thinned as they approached the less arctic temperature of the south. In this period of intense cold Northern Europe would be as cold, ice-bound and desolate as North Greenland is now. The temperature was not regular, however. There were alternations of arctic cold and moderate temperature in those southerly regions upon which the ice had descended. The ice receded to the north during the warmer periods, but gained on the south again as the colder temperature returned. When warm times drove the ice northwards, the country it had covered, instead of providing a habitat for hardy, arctic fauna and vegetation, became hospitable to animals and plants delighting in a temperate climate; while the arctic forms receded northwards with the ice. The Mammoth, along with its contemporary the Woolly Rhinoceros, roamed in search of food over a vast territory, and seems not to have been above seeking "fresh fields and pastures new." It followed the retreating ice in interglacial intervals, browsing upon such vegetation as it could find. Its teeth were able to crush, and help in the mastication of, quite tough vegetable fibre such as is developed in the hardy trees of northern regions. If, therefore, the Mammoth found itself bewintered near the glaciers it could maintain itself upon fir-trees which its teeth could easily grind down to pulp; and 


\section{THE BOOK OF THE ANIMAL KINGDOM}

the shaggy coat provided fair protection from the cold. Probably the Mammoth often roved too near to the edge of the glaciers and was entrapped in an avalanche, with the inevitable consequence-death; its remains being discovered centuries later, to the astonishment of curious humanity. The territory of the Mammoth would be restricted in glacial times, but its extent would be greatly increased. during a warm interval, and perhaps even more so when the glacial period came to a close.

The Mammoth, we must remember, was in existence when the earliest men roamed the earth in search of food and clothing. The requirements of primitive man were simple, but he often had to go far afield to secure them. A water-worn cave or overhanging ledge of rock was accepted for shelter, the skins of animals served for clothing and their flesh for food. Failing flesh food, or fish or fowl, fruits, nuts and roots, and even grubs and worms might be made to minister to his appetite. Our Palæolithic (old stone age) ancestors must have been mighty hunters. They pursued with success the Bison, Horse, Cave-Bear, Rhinoceros and Reindeer. But the Manmoth was probably their most exciting quarry. We can imagine them eagerly looking for signs of their presence, tracking them by their spoor to their haunts, making traps for them and when caught killing them with flint-tipped arrows and spears, afterwards flaying them with their rudely-shaped flint knives and scrapers. After spending many weary days in their hunt, we can understand these primitive men, tired and hungry, gorging themselves with their victim's carcass, breaking their bones to secure the coveted marrow, and storing hide and sinews, splints of bone and tusks for use in their daily avocations. Perhaps it was primitive man who drove the Mammoth northwards, pressing him ever closer and closer to the ice, making his existence a constant terror. The extinction of our shaggy subject is not difficult to understand. The brains of man were too quick and subtle for him. Man interfered with his breeding, captured the young when they happened to come to the birth, and literally hunted him to extinction. The experience of the Mammoth in the Northern Hemisphere was probably akin to that of the Mylodons of South America.

The cave men of La Madelaine, in France, must have had some artistic feeling. At least one of their number was an artist, for he has left us a memorial of his ability in the form of a Mammoth well engraved upon Mammoth ivory. This is an interesting, tell-tale 
relic. It shows that man hunted the Mammoth, that indeed the Mammoth existed not so very long ago, when we consider how recently man appeared, and what ages passed before his coming.

All doubt as to the actual proportions and appearance of the Mammoth has been dispelled by the finding of a frozen body in Siberia. The story is an interesting one, and will bear re-telling. A Tungusian fisherman, yclept Schumachoff, in the year 1799 , descried at Tamut, near the mouth of the Lena, amongst blocks of ice, a shapeless fragment, the import of which he did not then discover. A year after he saw the same fragment in a somewhat altered condition, but still failed to divine its nature. Again in 1801 he visited the spot, and to his astonishment saw one side and one tusk of a Mammoth freed from ice. By $\mathrm{I}_{80}$ the ice had cleared away so that the frozen animal fell on to a bank of sand. The fisherman visited the place again in 1804 , secured the tusks and disposed of them to a merchant. In $1806 \mathrm{Mr}$. Adams, a Moscow professor and member of the Russian Academy of Sciences, visited the frozen Mammoth, but found it greatly mutilated. Wild beasts had fed on the flesh, and some of it had been given to dogs. One leg was missing, otherwise the skeleton was complete. The length of the animal from forefront of skull to end of tail was sixteen feet four inches; in height it was nine feet four inches. Measured along the curve the tusks extended to nine feet, six inches; from point to base in a straight line they were three feet, seven inches. Mr. Adams got together what was left of the interesting discovery and dispatched it to St. Petersburg-a distance of more than seven thousand miles. In one account it is said that no less than sixty pounds weight of the reddish-brown wool and black, bristly hairs were collected and preserved; another account, however, states the weight to be "more than thirty-six pounds." The skeleton of this Mammoth is to be seen in the Museum of the St. Petersburg Academy.

It is related that in 1800 one Gabriel Saryschew saw an entire Mammoth embedded in ice, standing erect on the banks of the Alaseia.

Many Mammoth remains have been found in Great Britain. It probably made its way there in the wake of retreating ice, under the pursuit of its human enemies at a time when what are now the British Isles were attached to the European mainland. Then the North Sea, the Irish Sea and the English Channel were not in existence; where their waters now ebb and flow there were great 


\section{THE BOOK OF THE ANIMAL KINGDOM}

plains, which were, probably, fens, and continental animals and men could come and go as their requirements demanded.

CONCLUDING REMARKS.-For a more complete account of the animals of long ago the reader must be referred to volumes specially devoted to the subject. But even from such a general review as has here been made, some idea may be formed of the moving panorama of life, and of the strange, and even romantic, drama that has been enacted. There has been much shifting of scenery, many entrances and exits have been effected; altogether it has been "a strange coming and going of feet." Nothing but the Eternal Law is fixed. All living creatures are subject to variations, no physical form is settled for eternity. The posterity of an animal may preserve the ancestral type for a million years, and exhibit promise of generations upon generations to follow. But a new factor introduced into the environment may bring about its extinction in less than a century. When we consider the arrival of such creatures as the Sabre-Toothed Tiger we can easily understand the extinction of multitudes of beasts which had few, if any, means of protecting themselves against its sly, subtle, but ferocious and destructive incursions. If we are asked why animals have become extinct, the answer is that they have not been capable of adapting themselves to changed circumstances. That creature survives that can readily adapt itself to changes in temperature, change of food and habitat, and defend itself against the attacks of invaders. The advent of carnivorous mammals wrought mighty changes, and determined numerous extinctions. In considering causes of extinction we have to remember that even the geography of the world is not settled. The continents of to-day did not always have their present configuration. The waters of the restless sea cover ancient land surfaces, and old sea bottoms have been upheaved into continents and mountain chains. Geological changes have been accompanied by changes in both flora and fauna. Earth movements may affect sea-currents and modify the winds, and these in turn may make great differences in climate. Although geological developments are usually gradual, creatures may not necessarily modify themselves to meet even a gradual change. Failure in such modification leads to inevitable extinction. Perhaps man has done more to bring about the rapid extinction of animals, and even 
plants, than any other factor introduced into the arena of Nature. If what we have surmised be true, the Mylodon and Mammoth have disappeared under his dominion. He has extinguished the Wild Boar in Britain, the Dodo in Mauritius, the Moa in New Zealand. Man has probably also been the chief agent in the extinction of the famous Irish Elk, or Great-Antlered Stag (Cervas megaceros). The remains of this beautiful animal have been found in Ireland in great abundance, particularly in the mosses and peat-bogs. The position of the remains as found in bogs indicates that the animals had ventured on the treacherous ground and been engulfed, perishing miserably. The head was thrown upwards, with stretched neck and horns backwardly inclined, in the final, desperate attempt to secure air as the body sank in the spongy moss. The horns of the Irish Elk were from nine to eleven feet from point to point, and the skeleton shows that the animal was not only bigger than the modern Stag, but equally as beautiful and graceful. It is conjectured that both males and females were horned, no specimens having been found without horns; and in this respect they were similar to the Reindeer-a creature that once inhabited Britain, but for various reasons retired to more northerly regions. Remains of the Irish Elk are not confined to Ireland, where it is likely it made its last stand; they have been found in the Isle of Man, France, Poland, Germany and Italy. It lived at the same time as the Cave-Bear and Cave-Tiger.

The Brown Bear is no longer to be found in Scotland, although it lived among the mountains there so late as 1707. The British Wild Cat has been driven to Argyllshire fastnesses, where an occasional specimen is got; but its extinction is assured. So ferocious an animal will not be endured by civilized men. The Red Deer would have disappeared long ere this had it not been carefully preserved. In some cases it has been introduced at places where it had become extinct. A number of British Game Birds would not have survived in the struggle for existence had not man lent them his aid-for his own special reasons. Man has waged unceasing warfare against animal pests, and will continue to do so; he has also hunted beasts that he considered good for food until none of them were left. Other animals have survived because they have been domesticated; many of them would stand a sorry chance if they were left to the tender mercies of Nature. IVe may have strong feelings about a few wealthy individuals holding up 


\section{THE BOOK OF THE ANIMAL KINGDOM}

large tracts of land for Deer-forests and game preserves; but the naturalist must admit that these gentlemen have been the means of preserving a number of animals that otherwise would have become extinct. Their preserves are sanctuaries of wild life, both animal and vegetable. Their keepers sometimes commit the indiscretion of shooting rare birds which might with advantage be permitted to increase, and their Deer and Pheasants are not beloved of the farmers who suffer their depredations. For the sake of sport, the Fox is kept in existence, much to the annoyance of the chickenraiser; but the general tendency of man's dominion in Nature is undoubtedly in the direction of the survival of the useful and the extinction of pests. Man may have that in him which in a certain sense raises him above Nature, but as to his physical life and in his physical requirements he is a part of Nature-a member of the animal kingdom. His arrival has changed the countenance of things in a more marked and speedy fashion than the arrival of any of his predecessors; but he is the supreme factor in Nature's ever-changing panorama; an aider and abettor of the process of natural selection. Through him a mighty work is being accomplished-the elimination of the foul and vicious, and the perpetuation and supremacy of the harmless, clean and useful.

But in spite of the changes wrought by man, the great struggle for existence has not been arrested; indeed, he has been compelled to take part in that struggle, not only with lower nature, but also with his own kind. The struggle of man with man for the necessities of life has been long and keen; but we are slowly learning better ways. Co-operation, mutual aid and the solidarity of the race enter into our visions and dreams. However, the ground of competition is only shifting, the spirit of it is taking new and harmless forms, but will never perish. In sub-human realms the struggle is as keen as ever, the race is still to the swift and the battle to the strong. The strange drama goes on and develops in its own wonderful way. The fauna of a thousand, nay, a hundred years ago was not that of to-day; what is common now may be extinct a few centuries hence, perhaps much sooner.

The original ancestors of man are extinct. His remains have been discovered, and they show that there is as much difference between him and highest man, as there was between him and highest ape. Primeval man had to disappear; he could not compete with his bigger-brained progeny. 
Nature, quite unintentionally, has been kind in preserving memorials of the past. More have perished than have been preserved, but the investigator is thankful for what he is able to find. From what has been discovered we are able to form some conception of the history of this world of ours and, in imagination, reconstruct the past. It is remarkable that we have so much evidence to work upon, that remains ages old have not utterly perished. As Emerson wrote: "Nature will be reported. All things are engaged in writing their history. The planet, the pebble goes attended by its shadow. The rolling rock leaves its scratches on the mountain; the river, its channel in the soil; the animal, its bones in the stratum; the fern and leaf, their modest epitaph in the coal. The falling drop makes its sculpture in the sand or stone. Not a foot steps into the snow, or along the ground, but prints, in characters more or less lasting, a map of its march ... the ground is all memoranda and signatures; and every object covered over with hints, which speak to the intelligent."

Ripple marks made by the waves of the sea on shore sands millions of years ago are sometimes observable on sandstones; even the processes of solidification of the sand into rock, and a superimposed weight of millions of tons of strata, have not been sufficient to remove the evidence of the action of those ancient waves. The footprints of birds and reptiles have made impressions so lasting that they still remain, and are a testimony in stone of the life-forms that existed in the period the rocks they are associated with represent. Even raindrop impressions on mud, and sun-cracks made untold ages ago may be detected by the practised eye of the geologist. Pieces of the huge horsetail plants and club-mosses of Carboniferous times fell into streams and were carried by them into lakes where they were covered by mud and sand washed from the land: to-day we find them fossilized in our sandstone quarries, can recognize them, tell what they were, and imagine their story. The preservation of animal remains in sedimentary deposits is easily accounted for. Carcasses of animals are often drifted by rivers in flood into estuaries, seas and lakes, where their flesh gradually disappears, but the harder bones are preserved in sedimentary matter which gradually accumulates about and above them. Bodies of ancient beasts were carried into lakes and seas in a similar manner. The sediment with which they were covered has now become rock. Such sediment is often deposited in great quantities at a remarkable 
speed, and we know that what happens to-day in this regard happened also in past ages. Skeletons left on dry land soon disappear; they are at the mercy of living animals and the disintegrating power of the atmosphere; but skeletons protected by sediments under water escape the attentions of both animals and atmosphere, and readily become fossilized. It is related by the editor of Dean Buckland's work on Geology, that when the river wall of the waterworks at Kingston-on-Thames was being built, the skeleton of a man was found embedded in the mud, at a level above the ordinary height of the water. Nothing like clothes were found upon him; but close to the bones of the heels were two portions of iron which had been nailed on to his boots. This was probably some poor labourer who had been drowned many years ago, and whose body had been subsequently washed by a flood into the place where it was found. What happened to this unfortunate drowned man in our own times, happened also to the carcasses of the ancient beasts that lived long before the appearance of man upon this earth.

An animal, perhaps, came to an untimely end in Tertiary times. It may have perished in a lake or its carcass was carried into one by a river in high flood. The same river gave the body decent burial under the sediment it was constantly depositing, and made unconscious provision for the preservation of the bones for indefinite time. The sediment, in course of time, became rock. To-day a quarryman splits the rock and finds the fossilized remains of the animal. If he be a sensible man he will notify a local expert concerning his find, and perhaps be the means of adding to the sum of human knowledge. It is not improbable that he will think it is no business of his and will throw the fossils on a refuse heap, no one being the wiser. Thoughtless folk take the easy course, the line of least resistance; it is less trouble not to bother; calling in experts requires some effort.

The writer cannot close this chapter without exhorting his readers to pay attention to the claims of Geology and the possibilities of Palæontology; and he will feel that he has altogether failed in his purpose if some of his readers do not beget some enthusiasm and zeal in the pursuit of these studies. Practical workers are needed in all branches of Nature Study; workers who will go out into the fields, through the woods, over the mountains and by the sea in order to get first-hand knowledge of natural objects. The absorbing interest that is awakened by the study of living things 
should not detract from what will be discovered to be the equally fascinating study of the life-forms of long ago. The ordinary amateur naturalist who loves birds, beasts and flowers, and goes out alone, or in company with companions like-minded with himself, to study them in their natural haunts, will be wise, in the interests of his own pleasure and of knowledge generally, if he carries with him a geological hammer and chisel, and gives some of his attention to stone quarries, clay beds and sand-pits. Wherever rocks are exposed they should be examined, especially if they are of a sedimentary nature. Sandstones, shales, limestones and chalk cliffs should be carefully worked for fossils; the alluvium of ancient streams should receive particular attention.

While rapid strides have been made in geological knowledge during the last half-century, the subject has not been exhausted; great discoveries await the earnest investigator. The amateur naturalist might chance to find links in the chain of ancient life equally as readily as the learned specialist. Even if the remains of gigantic reptiles are not found by the amateur, he cannot fail to be rewarded for his efforts by the collection of scores of curious relics of by-gone days; and he will have interest and delight in finding out their names, imagining the manner of their life, and arranging them in their proper order and classification. Such workers are needed all over the world, workers who, although they may not have time and opportunity to go far afield, will thoroughly investigate the deposits of their own districts. There are many books which can be consulted when difficulties arise in the pursuit of investigations, and experts are always willing to do what they can to help earnest amateurs.

A little boy of nine years of age known to the writer has, during a few months' diligent searching, found quite a number of most interesting mementoes of the past, and, as a result, takes an intelligent interest in creatures whose fossilized remains cannot fail to arrest attention.

Belemnites-or, as they are commonly called, "Thunderbolts" - may be found in some districts very commonly, and the boy in question has collected quite a large number of them. Many country people still believe that these are "Thunderbolts" hurled from the clouds during a storm, and a good deal of persuasion is often necessary to convince them that such is not the case, and that no such thing as a "Thunderbolt" has ever been discovered!

B B 2 


\section{THE BOOK OF THE ANIMAL KINGDOM}

Few people, at any rate, would associate these "Thunderbolts" with the Cuttlefish of our seas, and yet all are willing to admit the likeness of the fossil Gryphæa to the well-known Oyster.

Curious-shaped stones should never on any account be passed by, but may be added to a collection, and little by little the young geologist will gather together an interesting series of specimens, which, when submitted to an expert, may perchance contain some valuable data worth noting. In any case, the young collector will have his powers of observation quickened and interest stimulated and a foundation laid for the cultivation early in life of a sensible hobby. This is bound in after years to help him to appreciate more fully, and to the best advantage, the story of the earth whose very stones, as Shakespeare reminds us, preach eloquent sermons to those who are willing to listen.

Every boy who has a penchant for Nature study-and especially Geology-would do well to read the life of the eminent Scottish geologist, Hugh Miller, which is an admirable instance of how a man rose in the world from being a working stone-mason to one of the most noted geologists of his time.

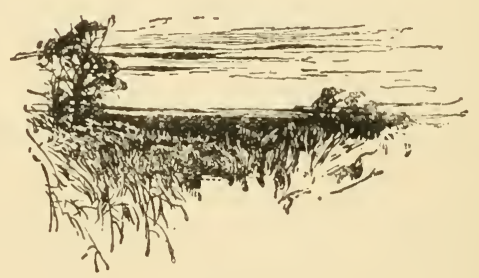




\section{INDEX}

A

Aard Vark, 294

Aard Wolf, 293

African Buffalo, 17

Aguti, Punctated, 300

, , IVest Indian, 300

Agutis, 300

Alpaca, 253

Altai, I3 I

American Bison, I9

Animal Giants, I

$$
\text { ,' Pets, } 43
$$

Animals of Long Ago, 339 ", with Armour, 92

Ant-Eater, Great, 294

Antelope, Addax, 108

$$
\begin{aligned}
& \text {,", Beatrix, } 108 \\
& \text { ", , Dik-Dik, } 109 \\
& \text { ", Four-Horned, } 120 \\
& \text { ", Indian, } 120 \\
& \text { ", , Nagor, } 109 \\
& \text { ", , Nilgai, } 109 \\
& \text { ", Prong-Horned, I Io } \\
& \text { ", Sable, I13 } \\
& \text { ", , Saiga, } 230
\end{aligned}
$$

Antelopes and Deer, 108

Armadillo, Giant, 94

, , Hairy, 93

, , Tatouay, 94

" , Pink Fairy, 95

Armenian Wild Sheep, 29

Asiatic Wild Ass, 280

Ass, African Wild, 25, 282

,, , Asiatic Wild, 280

", Hybrid, Somali and Domestic, 25

", Hybrid Zebra and Pony, 25

", Spanish and English Domestic, 25

, , Spanish Domestic, 25

Asses, 24, 280

Aurochs, 32

Azara's Dog, 301
B

Babirusa, 244

Baboon, Dusky Gelada, 167

, , Guinea, 168

, , Ibean, 168

Badger, Common, 77

,, , Honey, 295

", , Rock, 304

", , Sand, 8o

Bandicoot, Short-Nosed, 208

Bandicoots, 208

Banting, 37

Barasingha, I30

Barbary Sheep, 29, 226

Bat, Fruit, 335

," , Greater Horseshoe, 337

,, , Kalong, 335

", , Lesser Horseshoe, 337

,, , Long-Eared, 336

,, , Pipistrelle, 337

, , Rabbit-Eared, 336

, , Vampire, 336

Bats, 328

Bear, American Brown, $25^{8}$

", , Brown, 256

,, , Grizzly, 258

,, , Isabelline, 256

", , Japanese, $25^{8}$

", Malay, $25^{8}$

", , Polar, 254

", Sloth, 259

Beaver, 273

Beluga, 323

Bharal, 227

Bhutan Takin, 288

Black Buck, 120

Blanford's Sheep, 225, 226

Blessbok, 293

Blue Sheep, 227

Bontebok, 293

Bonto, 323 
British Park Cattle, 34

Burrhel Wild Sheep, 227

\section{C}

Californian Sea-Lion, 59

Camel, Arabian, 247

, , Bactrian, 247

", , One-Humped, 249

", , Two-Humped, 249

Cape Ant-Bear, 294

, Hunting Dog, 72

" Hyrax, 303

Caracal, 147

Carpincho, $5^{8}$

Cat, Australian Native, 208

, , Black-Footed, 302

", Caffre, Egyptian, or Fettered, 90

,, , Leopard, I53

", Manul, 302

,, Pallas's, 302

,, , Rusty-Spotted, 303

", , Servaline, 154

,, , Wild, 149

Cats, Great and Small, 134

Cavies, 40

Cavy, Cutler's, $5^{8}$

,, Restless, 58

,, , Spix's, $5^{8}$

Cawquaw, roo

Cetaceans, 308

Ceylonese Langur, 89

Chamois, 230, 233

Chimpanzee, $45,{ }_{5} 8$

Chinchilla, 269, 298

Chousingha, 120

Civet Cat, 302

Civet, African, 302

, , African Palm, 303

", , Indian, 302

, , Indian Palm, 303

", Malaccan, 302

,, , Palm, 303

Coati, Ring-Tailed, 49

Coatis, 49

Colpeo, 301

Coney, 304

Cougga, 279

Coyote, 70

Coypu Rat, 268

Crab-Eating Dog, 300

Cuscus, Spotted, 197

Cuscuses, 197
Dasyures, 208

Deer, Altai, 13I

, , Axis, Chital, or Spotted, 129

", Barking, or Muntjac, 130

", Eld's, or Panolia, I30

, , Fallow, 12 I

,, Japanese, or Sika, I3 I

, , Mouse, 132

, , Musk, 131

, , Red, 12 I, 127

, , Red Brocket, 132

", Sambar, 130

," , Swamp, I30

Dhole, 74

Dingo Dog, 60, 179

Dog, Crab-Eating, 300

,", Indian Wild, 74

", , Short-Eared, 301

,, , Siberian IVild, 74

Dolphin, Amazonian, 323

," , Common, 327

," Gangetic, 322

," Heaviside's, 325

," , Irawadi, 325

, , Narwhal, 323

Dolphins, Fresh-Water, 322

Domestic and Semi-Domestic Animals, 24

,, Cattle, 34, 83

, Dog, 6I

" Donkey, 25, 282

,, Horse, 24, 289, 354

, Oxen, 32, 83

, Rabbits, 38

, Sheep, 27

Dormouse, 2 I 7

Douroucolis, 172

$$
\begin{array}{ll}
\text { ", } & \text {, Feline, 173 } \\
\text { ", } & \text {, Lemurine, 173 } \\
\text { ", } & \text {, Red-Footed, I73 } \\
\text {, Three-Banded, } 173
\end{array}
$$

Dromedary, 249

Duiker, Abyssinian, 115

,, , Banded, I15

,, Common, II5

", Jentink's, I15

", Yellow-Backed, I $_{5}$

Duikers, I I5

Dumba Sheep, 27

Dwarf Buffalo, 17 
E

Earth, the story of the, 339

Echidna, 2 I I

Eland, 20

Elephant, African, I

", , Ancestors of the, 360

Elk, 22

," Indian, I

English Wild Bull, 32

Extinct Animals, 339

Ancestors of the Elephant, 360

Animals of Eocene Days, 353

Archæopteryx, 350

Armadillos, 360

Atlantosaurus, $35^{\circ}$

Brontops, 354

Brontosaurus, 349

Cetiosaurus, $35^{\circ}$

Cycads, 344

Deinosaurs, 348

Dinocerata, 354

Diplodocus, 349

Dodo, $35^{1}$

Eohippus, 354

Glyptodons, 360

Hesperonis, $35^{\circ}$

Hyracotherium, 355

Ichthyornis, $35^{1}$

Ichthyosaurs, $34^{6}$

Iguanodon, $35^{\circ}$

Machærodus, 357

Mammals, $35^{2}$

Mammoth, 362

Mastodon, 36 I

Megatherium, $35^{8}$

Mesohippus, 355

Moa, 35I

Mœritherium, 36I

Mylodon, 359

Orohippus, 355

Palæomastodon, 36I

Palæotherium, 353

Phenacodus, $35^{6}$

Plesiosaurs, 347

Pliohippus, 355

Protohippus, 355

Pterodactyle, 347

Sabre-Toothed Tiger, 357

Scelidotherium, 359

Stegosaurus, 349

Teleosaurus, 347

Tetrabelodon, 362

Tyrannosaurus, 350

Uintatherium, 353
F

Fat-Rumped Sheep, 27

Ferret, 40

Fin-IWhales, 318

Flying Foxes, 335

Fossa, 302

Fox, Arctic, 268

,, , Black, 268

,", Common Red, 268

", , Fennec, 268

", Indian, 268

", , Silver, 268

", , Silver-Backed, 268

", Silver-Grey, or Virginian, 268

\section{G}

Galago, Allen's, I 72

," , Demidoff's, 172

,, , Garnett's, I72

, , Great, I72

,, Kirk's, I72

, , Senegal, 172

Galagos, I7 I

Galla $\mathrm{Ox}, 88$

Gayal, 35

Genet, Common, 303

,, , Rusty-Spotted, 303

Genets, 303

Geological Epochs, 34 I

Gerbil, Cape, 306

,, , Indian, 306

Gerbils, 306

Ghorkhar, 25, 280

Giant Bush-Pig, 244

Giants of the Deep, 308

Gibbon, Hoolock, I6I

Gibbons, I6 I

Giraffe, I5

Gnu, Brindled, I I9

," , White-Tailed, I 19

Goat-Antelope, 236

Goat, Rocky Mountain, 232

,, , Spiral-Horned, 234

Goral, Ashy, 228

," , Grey, 228

,, Himalayan, 228

, , Long-Tailed, 228

Gorilla, I 57

Grampus, 326

Guanaco, 252

Guenons, 162

Guereza, White-Thighed, 286 
Guinea Pigs, 40

", Abyssinian, 40
", Bolivian, 40
" $\quad$ ", English, 40
", Long-Haired, 40
", Peruvian, 40
", , Short-Haired, 40

\section{$\mathrm{H}$}

Hare, Common, 62

Haussa Sheep, 27

Hedgehog, Common, 102

Hedgehog-Tenrec, I07

Himalayan Goral, 228

Hippopotamus, 8

Serow, 236

Horse, Prejevalski's Wild, 24, 289

Horse, the evolution of the, 354

Huanaco, $25^{2}$

Humped Cattle, 82

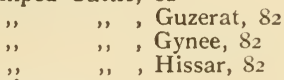

Hunia, 27

Hyæna, Brown, 75

$$
\text { , , Spotted, } 76
$$

", , Striped, 76

Hyrax, Cape, 303

,, , Syrian, 304

\section{I}

Indian Chevrotain, 132

Inia, 323

Domestic Sheep, 27

\section{J}

Jackal, Black-Backed, 71

Jackals, 71

Javan Ox, 37

Jerboa, Egyptian, 64

Jerboa Rat, I8o

Jerboas, 64,22 I

K

Kalong, 335

Kangaroo Rat, 22 I
Kangaroo, Bennett's Tree, 193

", , Brush-Tailed Rat, I95

", , Common Rat, 194

, , Great Grey, 187

", , Great Red, 187

, , Lesueur's Rat, 195

, , Lumholtz's Tree, I92

,, , Prehensile-Tailed Rat, 194

, , Rat, 194

, , Tree, 192

Kangaroos, 182

Kiang, 25, 280

Killer, 326

Kinkajou, 48

Klip-Das, 303

Koala, 195

Langurs, 89

Lemur, Black, 169

,, , Coquerel's Dwarf, 170

, , Dormouse Dwarf, I7o

", , Dwarf, I7o

,, , Fork-Marked Dwarf, I7o

,. , Ring-Tailed, 47

", , Ruffled, 48

, , Small Dwarf, I7o

,, , Sinith's Dwarf, I70

Lemurs, 47, 170

Leopard, 143

Lesser Killer, 326

Lion, 134

Llama, 253

Loris, Grey Slow, I7o

,, , Slender, I7 I

Lovers of the Chase, 66

Lynx, Canadian, I49

, , European, 148

," , Northern, 148

\section{M}

Macaque, Barbary, 166

", Crab-Eating, 166

," Japanese, 164

,, , Magot, 166

, , Moor, $16_{5}$

., , Pig-Tailed, I66

Maholi Galago, I69

Mammals of Australia, 174

Mammals of the Air, 328

Mammoth, 2, 362

Mandrill, 155

Maned Sheep, 226 
Maned Wolf, zor

Mangabey, Grey-Cheeked, 164

$$
\begin{aligned}
& \text {, Hamlyn's, } 164 \\
& \text { ", Jamrach's, } 164 \\
& \text { ", Sooty, 164 } \\
& \text { ", White-Collared, } 164 \\
& \text {, White-Crowned, I64 }
\end{aligned}
$$

Mangabeys, 164

\section{Margay, 153}

Markhor, 234

Marmoset, Black-Eared, $5 \mathrm{I}$

$$
\text { ", , Lion, } 5^{\mathrm{I}}
$$

Marmosets, 50

Marmot, Alpine, 270

$$
\text { , , Bobac, } 270
$$

Marmots, 270

Marsh Buck, II 5

Meerkat," 52

$$
\text { ," Congo, Ir5 }
$$

Mice, Pouched, 206

" ," , Brush-Tailed, 206

Mithan, 36

, Narrow-Footed, 206

Mole, Marsupial, 205

Mongoose, 52, 53

$$
\text { ", , Grey Indian, } 53
$$

Monkey, Bengal or Rhesus, 166

$$
\begin{aligned}
& \text {," , Bonnet, } 166 \\
& \text { ", , Brazza's, } 162 \\
& \text {," Brown Stump-Tailed, I66 } \\
& \text {,, , Diana, } 16_{3} \\
& \text { ", Hanuman, } 89 \\
& \text { ", , Lion-Tailed, } 166 \\
& \text {, , Moustache, 162 } \\
& \text { ", Patas, } 162 \\
& \text { ", , Red-Eared, 163 } \\
& \text { ", , Roloway, 163 } \\
& \text { ", , Schmidt's, } 163 \\
& \text {,, , Variegated Spider, } 168 \\
& \text { ", , Vervet, } 162
\end{aligned}
$$

Monkeys, Apes, etc., I55

Monotremes, 209

Mouflon, 29

Mountain Lion, 145

Mouse Lemurs, $17 \mathrm{I}$

$$
\begin{aligned}
& \text { ", , Black-Eared, I72 } \\
& \text { ", , Crossley's, 172 } \\
& \text { ", , Hairy-Eared, 172 }
\end{aligned}
$$$$
\text { Mouse, Cäro 'Spiny, } 223
$$

$$
\text { ", , Cancy, } 223
$$

Mouse, Fat, 222

, , Fat-Tailed Desert, 222

", Malabar Spiny, 223

Musk Ox, 289

$$
\text { Striped, } 223
$$

Narbada Ox, 89

Narwhal, 323

$$
\text { O }
$$

Ocelot, I 47

Onager, 25, 280

One-Horned Indian Domestic Sheep, 27

Opossum, Common, 198

$$
\begin{aligned}
& \text { ", Crab-Eating, } 307 \\
& \text { ", Flying, 201 } \\
& \text { ", Greater Flying, 201 } \\
& \text { ", Lesser Flying, } 202 \\
& \text {, Long-Snouted, } 203 \\
& \text {, Ring-Tailed, 200 } \\
& \text {, Short-Eared, 200 } \\
& \text {, Squirrel-Like Flying, } 202 \\
& \text {, Yellow-Bellied Flying, } 202
\end{aligned}
$$

Opossums, 197

Orang-Utan, 45, I59

Otter, African Clawless, 275

,, , Brazilian, 274

,, Clawless, 275

,, , Common, 274

", Feline, 274

", Hairy-Nosed, 274

,, , North American, 274

", Sea, 274

,, , Smooth Indian, 274

,, , Spotted-Necked, 275

Oxen, $8_{3}$

$$
\mathrm{P}
$$

Paca, 299

Pangolin, 95

Peccary, Collared, 245

Persian 'Ibex, 235

Phalangers, 195

Phatagin, 96

Pichiciago, 95

Pig, European WVild, 237

,, , Indian WVild, 243 
Pigmy Hog, 243

Pigs, Wild, 237

Platypus, 2 Io

Polar Bear, 254

Polecat, 4I

" , Cape, 305

, Common, 304

Porcupine, Brush-Tailed, Ioo

," , Canadian, ıоo

," , Common, 97

Porpoise, Common, 324

"' , Indian, 325

Prejevalski's Wild Horse, 24, 289

Puma, I45

Punjab Wild Sheep, 225

Pyrenean Ibex, 227

\section{Q}

Quagga, 279

$\mathrm{R}$

Rabbit, Angora, 38, 39

$$
\begin{aligned}
& \text {, Belgian Hare, } 3^{8} \\
& \text {, Black and Tan, } 39 \\
& \text {, Blue and Tan, } 39 \\
& \text {, Dutch, } 38,39 \\
& \text { " English, } 38,39 \\
& \text {, Flemish Giant, } 38 \\
& \text {, Himalayan, } 38,39 \\
& \text {, Japanese, } 39 \\
& \text {, Lop, } 38,39 \\
& \text {, Patagonian, } 39 \\
& \text {, Siberian, } 39 \\
& \text {, Silver, } 38 \\
& \text {, Wild, 39, } 62,64
\end{aligned}
$$

Raccoon, 54

$$
\text { , , Crab-Eating, } 55
$$

Rare and Unfamiliar Animals, 285

Rasse, 302

Rat, Black, 215

", Brown, 213

1, , Cane, 216

,, , Coypu, 268

", , Jerboa, I8o

Ratel, 295

,, , African, 296

, , Indian, 296

Rats and Mice, 213

Red Bush-Pig, 244

Rhinoceros, African, 12

, Indian, 12

" , Javan, 12

", Sumatran, 12

Rorquals, 318

\section{S}

Sacred Animals, 82

Saki, Humboldt's, 285

, , White-Headed, 285

Sea Bear, $27^{2}$

", Horse, 272

", Leopard, 272

"Lion, Californian, 271

„. Lion, Steller's, 272

Seal, Common, 59, 272

", Northern Fur, 272

Seals, 59, 271

Serows, 236

Sha, 225

Sharp-Fronted $\mathrm{Ox}, 89$

Sheep, Cheviot, 30, 3 I

," , Domestic, 27

", Dorset, 30, 3I

", Heath, 30, $3 \mathrm{I}$

", , Irish, 30

, , Irish Wicklow, 31

,, , Kerry, 31

", Long-Woolled, $30,31,32$

", Merino, 30

," , Moor, 30

, , Norfolk, 30, 3 I

", , Orkney, 30

", Scotch, 30

," Shetland, 30

", Southdown, 30, 31

," Welsh, 30

Sing Sing Water Buck, I16

Sitatunga, 115

Skunk, Canadian, 269

Skunks, 269

Sloth, Giant Ground, 287, $35^{8}$

, , Hoffmann's, 288

", , Three-Toed, 288

, , Two-Toed, 288

Sloths, 287

Springbok, I 16

Squirrel, American Grey, 56

Sunga, 88

, , British, 56

Suricate, $5^{2}$

Susu, 322

\section{$\mathrm{T}$}

Tahr, 228

Takin, Bhutan, 288

Tapir, Brazilian, 296

, , Malayan, 297 
Tapirs, 297

Tasmanian Devil, 207

Tenrec, Common, 106

," , Long-Tailed, I07

,, , Rice, 107

,, , Streaked, I07

Tenrecs, 106

Tiger, 140

," , Sabre-Toothed, 357

", Tasmanian, 207

Toddy Cats, 303

Tree Cats, 303

", Hyraces, 304

Turkestan Wapiti Stag, 2 I

U

Urial, 29, 225

Urson, 100

Vicuna, 253

Viscacha, 298

Vole, Common Field, 306

," , Orkney, 306

\section{W}

Wallaby, Black-Gloved, I9o

," , Bridled, 189

, , Dama, 19ı

,, , Pademelon, 190

Wallaroo, 189

Walrus, $59,272,298$

Wapiti Stag, 21

Wart Hogs, 244

Water Bucks, 116

Whale, Armux's, 322
Whale, Bottlenose, 320

, , Fin, $3 \mathrm{IS}$

,", ,, Common, 319

", , ,", Eden's, 318

", , , , , Lesser, 318

," , , , Rudolphi's, 318

", , , , Sibbald's, 319

", , Greenland, 308

:, , Grey, 317

," , Humpback, 317

," , Layard's, 322

,, , Pigmy, 316

", , Sowerby's, 32 I

, , Sperm, 319

," , White, 323

Whales, 308

White Buffalo, 232

IVild Ass, 25

", Ox, 32,83

, Pigs, 237

, Sheep, 225

, Sheep and Goats, 225

Wolf, Common, 66, 70, 301

, , Great Grey, 68

," , Prairie, 70

, , Tasmanian, 207

,, , Timber, 68

Wombat, Common, 203

", , Hairy-Nosed, 205

," Tasmanian, 204

Wool- and Fur-Bearing Animals, 247

Z

Zebra, Burchell's, 277

, , Grévy's, 278

,, , Mountain, 279

Zebras and Asses, 277

Zebu, 82

Zorilla, 305 
Richard Clat \& SONs, Linited, PIEAT STREET HTL, E.C, AND ETNGAY, S. FFOLK. 

3 


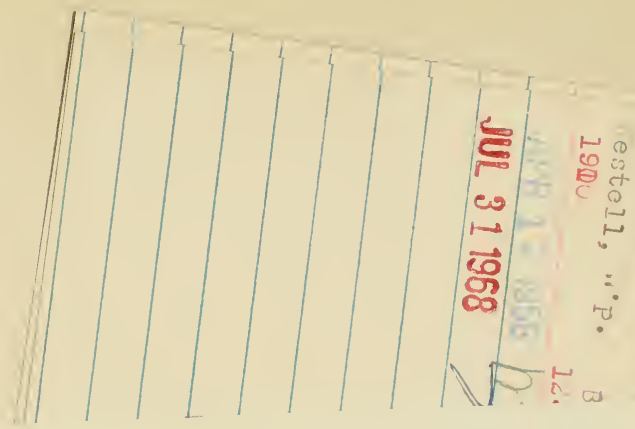


AMNH

|

In⿴囗十)

100114189 